Non-Compliance Procedures and Mechanisms AND THE EFFECTIVENESS OF

InTERnAtional ENVIRONMENTAL AgreEMENTS 
1 


\title{
Non-Compliance Procedures AND MECHANISMS AND THE EFFECTIVENESS OF INTERNATIONAL Environmental Agreements
}

\author{
Editors \\ Tullio Treves, Laura Pineschi, Attila Tanzi, \\ Cesare Pitea, Chiara Ragni, Francesca Romanin Jacur
}

A project of the Universities of Milan, Bologna and Parma co-financed by the Italian Ministry of University and Research 
Published by T.M.C. AsSER PRESS

P.O. Box 16163, 2500 BD The Hague, The Netherlands

$<$ www.asserpress.nl>

T.M.C. ASSER PRESS' English language books are distributed exclusively by

Cambridge University Press, The Edinburgh Building, Shaftesbury Road, Cambridge CB2 2RU, UK,

or,

for customers in the USA, Canada and Mexico:

Cambridge University Press, 100 Brook Hill Drive, West Nyack, NY 10994-2133, USA

$<$ www.cambridge.org $>$

The publication of this book was supported by the financial contribution of the Italian Ministry of University and Research (MIUR) and of the Universities of Milano, Bologna and Parma, within the framework of a research project of national interest (PRIN 2005, n. 2005124407).

ISBN 978-90-6704-273-4

All rights reserved.

(C) 2009, T.M.C. Asser Press, The Hague, The Netherlands, and the Authors

This publication is protected by international copyright law. All rights reserved. No part of this publication may be reproduced, stored in a retrieval system, or transmitted in any form or by any means, electronic, mechanical, photocopying, recording or otherwise without the prior written permission of the copyright owners. 


\section{Summary of Contents}

Table of Contents

Contributors and Editors $\quad$ XXIX

Abbreviations $\quad$ XXXI

Journals XXXIII

List of Treaties $\quad$ XXXVII

List and Websites of Non-Compliance Mechanisms XLI

$\begin{array}{ll}\text { Selected General Bibliography XLV } & \text { XLV }\end{array}$

Introduction $\quad 1$

Tullio Treves

SeCTION I

Non-Compliance Procedures and Mechanisms in Environmental Agreements

Universal Treaties

Chapter 1 - The Non-Compliance Procedure of the 1987 Montreal Protocol to the 1985 Vienna Convention on Substances that Deplete the Ozone Layer

Francesca Romanin Jacur

Chapter 2 - Mechanism for Promoting Implementation and Compliance with the 1989 Basel Convention on the Transboundary Movements of Hazardous Wastes and Their Disposal

Alessandro Fodella

Chapter 3 - The Compliance Procedures and Mechanism of the 1996 Protocol to the 1972 London Convention on the Prevention of Marine Pollution by Dumping of Wastes and other Matter

Seline Trevisanut

Chapter 4 - Procedures and Mechanisms Relating to Compliance under the 1997 Kyoto Protocol to the 1992 United Nations Framework Convention on Climate Change

Sabrina Urbinati

Chapter 5 - Draft Procedures and Mechanisms on Compliance with the 1998 Rotterdam Convention on the Prior Informed Consent Procedure for Certain Hazardous Chemicals and Pesticides in International Trade Stefano Brugnatelli 
Chapter 6 - Procedures and Mechanisms on Compliance under the 2000 Cartagena Protocol on Biosafety to the 1992 Convention on Biological Diversity

Chiara Ragni

Chapter 7 - Draft Non-Compliance Procedure under the 2001 Stockholm Convention on Persistent Organic Pollutants

Giulia Bigi

Chapter 8 - Draft Procedures and Operational Mechanisms to Promote Compliance and to Address Issues of Non-Compliance under the 2001 International Treaty on Plant and Genetic Resources for Food and Agriculture

Luigi Crema

\section{Regional Treaties}

Chapter 9 - Procedures and Mechanisms on Compliance under the 1976/1995 Barcelona Convention on the Protection of the Mediterranean Sea and its Protocols

Irini Papanicolopulu

Chapter 10 - Procedures and Mechanisms for Review of Compliance under the 1979 Long-Range Transboundary Air Pollution Convention and its Protocols

Enrico Milano

Chapter 11 - Procedures and Mechanisms for Review of Compliance under the 1991 Espoo Convention on Environmental Impact Assessment in a Transboundary Context and its 2003 Protocol on Strategic Environmental Assessment

Elena Fasoli

Chapter 12 - The Compliance Mechanism of the 1991 Convention on the Protection of the Alps and its Protocols

Laura Pineschi

Chapter 13 - Procedures and Mechanisms for Review of Compliance under the 1998 Aarhus Convention on Access to Information, Public Participation and Access to Justice in Environmental Matters

Cesare Pitea

Chapter 14 - Procedures and Mechanisms for Review of Compliance under the 1999 Protocol on Water and Health to the 1992 Convention on the Protection and Use of Transboundary Watercourses and International Lakes

Cesare Pitea 
Chapter 15 - Procedures and Mechanisms for Review of Compliance under the 2003 Protocol on Pollutant Release and Transfer Registers to the 1998 Aarhus Convention

Cesare Pitea

\section{Section II}

Selected Studies on Practice

Chapter 16 - The Compliance Mechanisms of the Aarhus Convention and the Cartagena Protocol on Biosafety: A Comparative Analysis of the Negotiation Histories and their Outcomes

Veit Koester

Chapter 17 - The Practice of the Compliance Committee under the Kyoto Protocol to the United Nations Framework Convention on Climate Change (2006-2007)

René Lefeber

Chapter 18 - Practice and Relevant Cases that Emerged in the Context of the Espoo Convention Implementation Committee

Jerzy Jendrośka

Chapter 19 - In Search of New Ways to Ensure Effective Compliance with Environmental Procedures and Policies: The Experience of the European Bank for Reconstruction and Development with its Internal Recourse Mechanism

Francesco Seatzu

\section{SECTION III}

Institutional and Procedural Aspects

Chapter 20 - Structural and Institutional Aspects of Non-Compliance Mechanisms

Alessandro Fodella

Chapter 21 - Triggering Non-Compliance Procedures

Francesca Romanin Jacur

Chapter 22 - Procedural Guarantees in Non-Compliance Mechanisms

Chapter 23 - The Outcomes of the Procedure and their Legal Effects

Enrico Milano

Chapter 24 - Controlling and Assisting Compliance: Financial Aspects 
Chapter 25 - Multiplication and Overlap of Non-Compliance Procedures and Mechanisms: Towards Better Coordination?

Cesare Pitea

\section{SeCtion IV}

Non-Compliance Mechanisms and International Law

Chapter 26 - Non-Compliance Procedures and the Law of Treaties

Chapter 27 - Non-Compliance Procedures and the Law of State

Responsibility

Laura Pineschi

Chapter 28 - The Settlement of Disputes and Non-Compliance Procedures

Tullio Treves

\section{SECTION V}

Non-Compliance Mechanisms and European Union Law

Chapter 29 - Non-Compliance Procedures in Multilateral Environmental Agreements: The Interaction between International Law and European Union Law

Antonino Ali

Chapter 30 - The Policy and Practice of the European Union on Compliance Mechanisms under Multilateral Environmental Agreements Nicola Notaro

Chapter 31 - Obligations of the European Community and its Member States under the Kyoto Protocol

Leonardo Massai

\section{Section VI}

CONCLUSIONS

Chapter 32 - Non-Compliance Mechanisms: Lessons Learned and the Way Forward

Attila Tanzi and Cesare Pitea 


\section{Table of Contents}

Summary of Contents

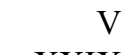

Contributors and Editors

XXIX

Abbreviations

XXXI

Journals

XXXIII

XXXVII

XLI

List and Websites of Non-Compliance Mechanisms

XLV

Introduction

Tullio Treves

1. Non-Compliance Mechanisms in Environmental Agreements: The Research Method Adopted

2. Common Features and Differences in Non-Compliance Mechanisms of Multilateral Environmental Agreements

3. Non-Compliance Mechanisms: An Imperfect Means to Reach Certain Ends

\section{SECTION I}

Non-Compliance Procedures and Mechanisms in Environmental Agreements

Universal Treaties

Chapter 1 - The Non-Compliance Procedure of the 1987 Montreal Protocol to the 1985 Vienna Convention on Substances that Deplete the Ozone Layer

Francesca Romanin Jacur

1. Brief Introduction to the Montreal Protocol

2. Legal Basis of the Mechanism and Negotiating History 12

3. The Text Establishing the Mechanism

4. The Principles Governing the Mechanism and the Procedure

5.

Institutional Aspects

5.1 The Secretariat

5.2 The Implementation Committee

5.3 The Meeting of the Parties

6. Functions of the Committee

7. Trigger Mechanism 
8. The Procedure before the Implementation Committee and Procedural Safeguards $\quad 21$

9. Sources of Information 23

9.1 Information from the Parties 23

9.2 Information from Other Sources 23

10. Decision-Making 24

11. Outcomes 26

12. Coordination with Dispute Settlement Procedures and Other Non-Compliance Procedures $\quad 27$

13. Participation of the European Community 29

14. Financial Aspects 30

15. Survey of Practice 30

15.1 General Overview 30

15.2 The Case of the Russian Federation's Non-Compliance 31

Bibliography $\quad 32$

Chapter 2 - Mechanism for Promoting Implementation and Compliance with the 1989 Basel Convention on the Transboundary Movements of Hazardous Wastes and Their Disposal Alessandro Fodella

1. Brief Introduction to the Basel Convention 33

2. Legal Basis of the Mechanism and Negotiating History 34

3. The Text Establishing the Mechanism 35

4. The Principles Governing the Mechanism and the Procedure 36

5. Institutional Aspects 36

5.1 The Compliance Committee 36

$\begin{array}{lll}5.2 & \text { The Secretariat and the COP } & 37\end{array}$

$\begin{array}{lll}5.3 \text { Observers } & 38\end{array}$

6. Functions of the Committee 38

7. Trigger Mechanism 39

8. The Procedure before the Compliance Committee and Procedural Safeguards $\quad 40$

8.1 General Procedural Issues: Sources 40

8.2 Participation and Transparency 40

8.3 The Procedure for Specific Submissions: the Preliminary Stage 41

8.4 The Role of the Party under Consideration 42

8.5 The Committee 42

9. Sources of Information 43

10. Decision-Making 43

11. Outcomes 44

12. Coordination with Dispute Settlement Procedures and Other

13. Financial Aspects 46

14. Survey of Practice 46 
15. Conclusions 47

Bibliography

Chapter 3 - The Compliance Procedures and Mechanism of the 1996 Protocol to the 1972 London Convention on the Prevention of Marine Pollution by Dumping of Wastes and other Matter

Seline Trevisanut

1. Brief Introduction to the 1972 London Convention and the 1996 Protocol Thereto

2. Legal Basis of the Mechanism and Negotiating History

3. The Text Establishing the Mechanism

4. The Principles Governing the Mechanism and the Procedure

5. Institutional Aspects

5.1 The Compliance Group

5.2 The London Protocol Scientific Group

5.3 The Meeting of the Contracting Parties to the 1996 Protocol (MCPP)

5.4 The Secretariat

5.5 The International Atomic Energy Agency (IAEA) 55

6. Functions of the Compliance Group 55

7. Trigger Mechanism 56

8. The Procedure before the Compliance Group and Procedural Safeguards

8.1 Procedure of Initiating Submissions of Non-Compliance 56

8.2 Consideration by the Compliance Group 57

$\begin{array}{ll}8.3 \text { Monitoring } & 57\end{array}$

$\begin{array}{lll}8.4 & \text { Procedural Safeguards } & 57\end{array}$

9. Sources of Information $\quad 58$

10. Decision-Making 58

11. Outcomes 59

12. Coordination with Dispute Settlement Procedures and Other

13. Participation of the European Community 60

14. Financial Aspects 61

Bibliography

Chapter 4 - Procedures and Mechanisms Relating to Compliance under the 1997 Kyoto Protocol to the 1992 United Nations Framework Convention on Climate Change Sabrina Urbinati

1. Brief Introduction to the United Nations Framework Convention on Climate Change and the Kyoto Protocol 63

2. Legal Basis of the Mechanism and Negotiating History 65

3. The Text Establishing the Mechanism 
4. The Principles Governing the Mechanism and the Procedure 67

5. Institutional Aspects 68

$\begin{array}{lll}5.1 & \text { The Compliance Committee } & 68\end{array}$

$\begin{array}{lll}5.2 & \text { The COP/MOP } & 69\end{array}$

$\begin{array}{lll}5.3 & \text { The Secretariat } & 70\end{array}$

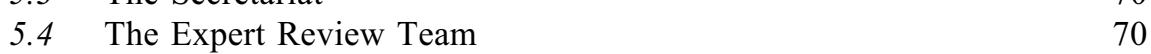

6. Functions of the Committee 71

6.1 The Plenary of the Committee 71

$\begin{array}{lll}6.2 & \text { The Facilitative Branch } & 71\end{array}$

6.3 The Enforcement Branch 72

7. Trigger Mechanism 72

8. The Procedure before the Compliance Committee and $\begin{array}{ll}\text { Procedural Safeguards } & 73\end{array}$

$\begin{array}{lll}8.1 & \text { The Procedure } & 73\end{array}$

8.2 The Procedural Safeguards 76

9. Sources of Information 77

10. Decision-Making $\quad 78$

11. Outcomes 78

12. Coordination with Dispute Settlement Procedures and Other

$\begin{array}{ll}\text { Non-Compliance Procedures } & 81\end{array}$

13. Participation of the European Community 81

14. Financial Aspects $\quad 82$

15. Survey of Practice $\quad 83$

Bibliography $\quad 84$

Chapter 5 - Draft Procedures and Mechanisms on Compliance with the 1998 Rotterdam Convention on the Prior Informed Consent Procedure for Certain Hazardous Chemicals and Pesticides in International Trade 85 Stefano Brugnatelli

1. Brief Introduction to the Rotterdam Convention 85

2. Legal Basis of the Mechanism and Negotiating History 88

3. The Text Establishing the Mechanism 89

4. The Principles Governing the Mechanism 89

5. Institutional Aspects 90

5.1 The Compliance Committee 90

$\begin{array}{lll}5.2 & \text { The Secretariat } & 91\end{array}$

5.3 The Conference of the Parties 91

6. Functions of the Committee 92

7. Trigger Mechanism 92

$\begin{array}{lll}7.1 & \text { Self Trigger } & 92\end{array}$

7.2 Party-to-Party Trigger 93

7.3 Submission by the Secretariat 93

8. The Procedure Before the Compliance Committee and
Procedural Safeguards

8.1 Sources of Procedural Rules and General Remarks 93 
8.2 Procedure for Handling Cases 94

8.3 Consideration by the Committee 94

8.4 Deliberation by the Committee 94

8.5 Procedural Safeguards 95

9. Sources of Information 96

9.1 Procedure Relating to Compliance by an Individual Party 96

9.2 Consideration of Systemic Issues of General Compliance 97

10. Decision-Making 97

11. Outcomes 97

11.1 Facilitation Measures by the Committee 97

11.2 Possible Measures to Address Compliance Issues by the COP 98

$\begin{array}{lll}11.3 & \text { Follow-up } & 98\end{array}$

12. Coordination with Dispute Settlement Procedures and Other Non-Compliance Procedures 98

12.1 The Relationship with Dispute Settlement under the Convention 98

12.2 The Relationship with Other Compliance Procedures or Dispute
Settlement Mechanisms

13. Participation of the European Community 99

14. Financial Aspects 100

Chapter 6 - Procedures and Mechanisms on Compliance under the 2000 Cartagena Protocol on Biosafety to the 1992 Convention on Biological Diversity

Chiara Ragni

1. Brief Introduction to the Cartagena Protocol on Biosafety to the Convention on Biological Diversity

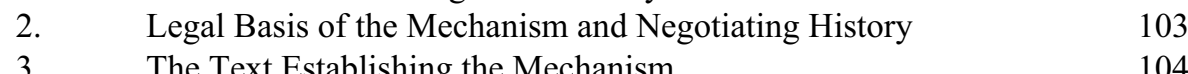

$\begin{array}{lll}\text { 3. The Text Establishing the Mechanism } & 104 \\ \text { 4. } & \text { The Principles Governing the Mechanism and the Procedure } & 105\end{array}$

5. Institutional Aspects 106

$\begin{array}{lll}5.1 & \text { The Compliance Committee } & 106\end{array}$

$\begin{array}{lll}5.2 & \text { The Secretariat } & 107\end{array}$

$\begin{array}{ll}5.3 \text { The COP/MOP } & 107\end{array}$

$\begin{array}{ll}5.4 & 107\end{array}$

6. Functions of the Committee 108

7. Trigger Mechanism 110

8. The Procedure before the Compliance Committee and Procedural $\begin{array}{ll}\text { Safeguards } & 110\end{array}$

$\begin{array}{ll}8.1 & \text { The Procedure } \\ 8.2 & 110\end{array}$

$\begin{array}{ll}\text { 8.2 Procedural Safeguards } & 111\end{array}$

$\begin{array}{ll}\text { 9. } & 112\end{array}$

$\begin{array}{ll}\text { 10. Decision-Making } & 113\end{array}$

11. Outcomes 113

12. Coordination with Dispute Settlement Procedures and other
Non-Compliance Procedures 
13. Participation of the European Community 116

14. Financial Aspects 117

15. Survey of Practice 118

16. Conclusions 119

Bibliography 119

Chapter 7 - Draft Non-Compliance Procedure under the 2001 Stockholm Convention on Persistent Organic Pollutants

Giulia Bigi

1. Brief Introduction to the Stockholm Convention 121

2. Legal Basis of the Mechanism and Negotiating History 123

3. The Text Establishing the Mechanism 125

4. The Principles Governing the Mechanism and the Procedure 125

5. Institutional Aspects 126

5.1 The Compliance Committee 126

$\begin{array}{ll}5.2 \text { The Secretariat } & 126\end{array}$

$\begin{array}{lll}5.3 & \text { The Conference of the Parties } & 127\end{array}$

6. The Functions of the Committee 127

$\begin{array}{ll}\text { 7. Trigger Mechanism } & 127\end{array}$

$\begin{array}{lll}7.1 & \text { Submission by a Party } & 128\end{array}$

7.2 Submission by the Secretariat and Initiation by the Committee $\begin{array}{ll}\text { Proprio Motu } & 128\end{array}$

$\begin{array}{lll}7.3 & \text { Form of Submissions } & 128\end{array}$

$\begin{array}{lll}7.4 & \text { Admissibility Criteria } & 128\end{array}$

8. The Procedure before the Compliance Committee and Procedural $\begin{array}{ll}\text { Safeguards } & 129\end{array}$

8.1 The Sources of Procedural Rules 129

8.2 Procedure for Handling Cases 129

8.3 Consideration by the Committee of the Submissions 129

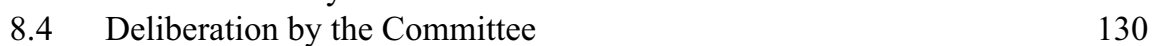

$\begin{array}{ll}\text { 8.5 Procedural Safeguards } & 130\end{array}$

9. Sources of Information 132

10. Decision-Making 132

11. Outcomes 133

11.1 The Notion of Non-Compliance 133

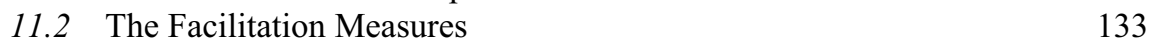

$\begin{array}{lll}11.3 & \text { Follow-up } & 133\end{array}$

12. Coordination with Dispute Settlement Procedures and Other $\begin{array}{ll}\text { Non-Compliance Procedures } & 134\end{array}$

12.1 The Relationship with the Dispute Settlement under the Convention 134

12.2 The Relationship with other Compliance Procedures or Dispute Settlement Mechanisms 134

13. Participation of the European Community 134

14. Financial Aspects 135 
Chapter 8 - Draft Procedures and Operational Mechanisms to Promote Compliance and to Address Issues of Non-Compliance under the 2001 International Treaty on Plant and Genetic Resources for Food and Agriculture

Luigi Crema

1. Brief Introduction to the ITPGRFA 137

$\begin{array}{lll}1.1 & 138\end{array}$

$\begin{array}{lll}1.2 & \text { The Treaty } & 138\end{array}$

2. Legal Basis of the Mechanism and Negotiating History 141

3. The Text Establishing the Mechanism 143

4. The Principles Governing the Mechanism and the Procedure 143

5. Institutional Aspects 143

$\begin{array}{lll}5.1 & \text { The Compliance Committee } & 143\end{array}$

5.2 The Role of the Governing Body 145

$\begin{array}{lll}5.3 \text { The Secretariat } & 145\end{array}$

5.4 Civil Society and Other Organizations 145

6. Functions of the Committee 146

7. Trigger Mechanism 147

8. The Procedure before the Compliance Committee and Procedural Safeguards 147

9. Sources of Information 148

$\begin{array}{ll}10 . & 149\end{array}$

11. Outcomes 149

12. Coordination with Dispute Settlement Procedures and Other

$\begin{array}{ll}\text { Non-Compliance Procedures } & 149\end{array}$

13. Participation of the European Community 150

14. Financial Aspects 152

Bibliography $\quad 152$

Regional Treaties

Chapter 9 - Procedures and Mechanisms on Compliance under the 1976/1995 Barcelona Convention on the Protection of the Mediterranean Sea and its Protocols

Irini Papanicolopulu

1. Brief Introduction to the Barcelona Convention and its Protocols 155

2. Legal Basis of the Mechanism and Negotiating History 156

3. The Text Establishing the Mechanism 158

4. The Principles Governing the Mechanism and the Procedure 158

5. Institutional Aspects 159

5.1 The Compliance Committee 159

5.2 The Meeting of Contracting Parties 160

$\begin{array}{ll}5.3 \text { The Secretariat } & 160\end{array}$

6. Functions of the Compliance Committee 161 
7. Trigger Mechanism 161

7.1 Submissions by a Party 161

7.2 Referrals by the Secretariat 162

8. The Procedure before the Compliance Committee and Procedural Safeguards 162

8.1 The Procedure before the Committee 162

8.2 Procedural Safeguards 163

9. Sources of Information 164

10. Decision-Making 165

11. Outcomes 165

11.1 Measures by the Committee 165

11.2 Measures by the Meeting of Parties 166

12. Coordination with Dispute Settlement Procedures and Other Non-Compliance Procedures 166

13. Participation of the European Community 167

14. Financial Aspects 167

15. Conclusions 167

Chapter 10 - Procedures and Mechanisms for Review of Compliance under the 1979 Long-Range Transboundary Air Pollution Convention and its Protocols

Enrico Milano

1. Brief Introduction to the 1979 LRTAP Convention 169

2. Legal Basis of the Mechanism and Negotiating History 171

3. The Text Establishing the Mechanisms 172

4. The Principles Governing the Mechanism and the Procedure 172

5. Institutional Aspects 173

6. Functions of the Committee 173

7. Trigger Mechanism 174

8. The Procedure before the Implementation Committee and Procedural Safeguards 174

9. Sources of Information 175

10. Decision-Making 176

11. Outcomes 176

12. Coordination with Dispute Settlement Procedures and Other Non-Compliance Procedures 177

13. Participation of the European Community 177

14. Financial Aspects 178

15. Survey of Practice 179

Bibliography 180 
Chapter 11 - Procedures and Mechanisms for Review of Compliance under the 1991 Espoo Convention on Environmental Impact Assessment in a Transboundary Context and its 2003 Protocol on Strategic Environmental Assessment Elena Fasoli

1. Brief Introduction to the Espoo Convention

2. Legal Basis of the Mechanism and Negotiating History

3. The Text Establishing the Mechanism

4. The Principles Governing the Mechanism and the Procedure

5. Institutional Aspects

6. Functions of the Committee

7. Trigger Mechanism

8. The Procedure before the Implementation Committee and Procedural Safeguards

9. Sources of Information 196

11. Outcomes 197

12. Coordination with Dispute Settlement Procedures and Other Non-Compliance Procedures $\quad 197$

13. Participation of the European Community 200

14. Financial Aspects 201

15. Survey of Practice 202

Bibliography 203

Chapter 12 - The Compliance Mechanism of the 1991 Convention on the Protection of the Alps and its Protocols

Laura Pineschi

1. Brief Introduction to the Alpine Convention 205

2. Legal Basis of the Mechanism and Negotiating History 208

3. The Text Establishing the Mechanism 209

4. The Principles Governing the Mechanism and the Procedure 209

5. Institutional Aspects 209

5.1 The Reviewing Committee 209

$\begin{array}{ll}5.2 \text { The Secretariat } & 211\end{array}$

$\begin{array}{ll}5.3 \text { The Standing Committee } & 211\end{array}$

$\begin{array}{ll}5.4 & \text { The Alpine Conference } \\ \end{array}$

6. Functions of the Committee 212

7. Trigger Mechanism 212

$\begin{array}{lll}\text { 7.1 Submissions by Parties and Observers } & 212\end{array}$

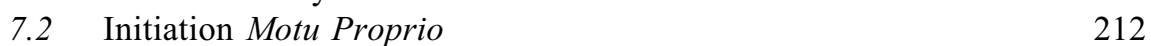

$\begin{array}{lll}7.3 & \text { Referrals by the Secretariat } & 212\end{array}$

7.4 Communications by Territorial Entities and the Public 212

8. The Procedure before the Reviewing Committee and Procedural $\begin{array}{ll}\text { Safeguards } & 213\end{array}$

$\begin{array}{lll}\text { 8.1 General Procedural Issues } & 213\end{array}$ 


\begin{tabular}{llr}
\multicolumn{1}{l}{8.2} & Procedural Safeguards & 213 \\
9. & Sources of Information & 214 \\
10. & Decision-Making & 214 \\
11. & Outcomes & 215 \\
12. & Coordination with Dispute Settlement Procedures and Other \\
& Compliance Procedures & 216 \\
13. & Participation of the European Community & 216 \\
14. & Financial Aspects & 217 \\
15. & Survey of Practice & 217 \\
16. & Conclusions & 218 \\
Bibliography & 219
\end{tabular}

Chapter 13 - Procedures and Mechanisms for Review of Compliance under the 1998 Aarhus Convention on Access to Information, Public Participation and Access to Justice in Environmental Matters

Cesare Pitea

1. Brief Introduction to the Aarhus Convention 221

2. Legal Basis of the Mechanism and Negotiating History 223

3. The Text Establishing the Mechanism 224

4. The Principles Governing the Mechanism and the Procedure 224

5. Institutional Aspects 225

5.1 The Compliance Committee 225

$\begin{array}{ll}5.2 & \text { The Secretariat } \\ 5.326\end{array}$

5.3 The Meeting of the Parties 226

6. Functions of the Committee 227

6.1 General Tasks in Relation to Compliance Issues 227

6.2 Individual Cases of Non-Compliance 227

7. Trigger Mechanism 228

7.1 Submission by a Party (Party-to-Party Trigger and Self-Trigger) 228

$\begin{array}{lll}7.2 & \text { Referrals by the Secretariat } & 228\end{array}$

$\begin{array}{ll}7.3 \text { Communications from the Public } & 228\end{array}$

$\begin{array}{ll}7.4 & \text { Initiation Proprio Motu } \\ & 230\end{array}$

8. The Procedure before the Compliance Committee and
Procedural Safeguards

8.1 Sources of Procedural Rules and General Remarks 230

8.2 Procedure for Handling Cases 231

8.3 Consideration by the Committee of Submissions, Referrals and Communications

\begin{tabular}{ll}
8.4 & Deliberation by the Committee \\
\hline
\end{tabular}

$\begin{array}{ll}\text { 8.5 Procedural Safeguards } & 234\end{array}$

9. Sources of Information 237

10. Decision-Making 238

11. Outcomes 238

11.1 The Notion of Non-Compliance 239

11.2 Consideration of Response Measures by the MOP 240 
11.3 Consideration of Response Measures by the Committee

11.4 Follow-up

12. Coordination with Dispute Settlement Procedures and Other Non-Compliance Procedures

12.1 The Relationship with Dispute Settlement under the Convention

12.2 The Relationship with other Compliance Procedures or Dispute Settlement Mechanisms

13. Participation of the European Community

13.1 The Participation to, and Implementation of, the Convention by the European Community

13.2 The Participation of the EC and the Functioning of the Compliance Mechanism

14. Financial Aspects

15. Survey of practice 248

16. Conclusions 249

Bibliography

Chapter 14 - Procedures and Mechanisms for Review of Compliance under the 1999 Protocol on Water and Health to the 1992 Convention on the Protection and Use of Transboundary Watercourses and International Lakes

Cesare Pitea

1. Brief Introduction to the Protocol on Water and Health

2. Legal Basis of the Mechanism and Negotiating History

3. The Text Establishing the Mechanism

4. The Principles Governing the Mechanism and the Procedure

Institutional Aspects

5.1 The Compliance Committee 254

5.2 The Secretariat 255

5.3 The Meeting of the Parties 256

6. Functions of the Committee 256

7. Trigger Mechanism 256

7.1 Submission by a Party (Party-to-Party Trigger and Self Trigger) 256

$\begin{array}{lll}7.2 & \text { Referrals by the Secretariat } & 257\end{array}$

$\begin{array}{ll}\text { 7.3 Communications from the Public } & 257\end{array}$

7.4 Initiation Proprio Motu 257

8. The Procedure before the Compliance Committee and $\begin{array}{ll}\text { Procedural Safeguards } & 257\end{array}$

8.1 Sources of Procedural Rules and General Remarks 257

$\begin{array}{lll}8.2 & \text { Procedural Safeguards } & 258\end{array}$

9. Sources of Information $\quad 259$

10. Decision-Making 259

11. Outcomes 259 
12. Coordination with Dispute Settlement Procedures and Other Non-Compliance Procedures

13. Participation of the European Community 261

14. Financial Aspects 262

15. Survey of practice 262

16. Conclusions 262

Bibliography $\quad 262$

Chapter 15 - Procedures and Mechanisms for Review of Compliance under the 2003 Protocol on Pollutant Release and Transfer Registers to the 1998 Aarhus Convention

Cesare Pitea

1. Brief Introduction to the Protocol on Pollutant Release and Transfer Registers to the Aarhus Convention 263

2. Legal Basis of the Mechanism and Negotiating History 265

3. The Text Establishing the Mechanism 266

4. The Principles Governing the Mechanism and the Procedure 266

5. Institutional Aspects 267

$\begin{array}{lll}5.1 & \text { The Compliance Committee } & 267\end{array}$

$\begin{array}{lll}5.2 & \text { The Secretariat } & 268\end{array}$

5.3 The Meeting of the Parties 268

6. Functions of the Committee 268

7. Trigger Mechanism 268

7.1 Submission by a Party (Party-to-Party Trigger and Self-Trigger) 268

$\begin{array}{lll}7.2 & \text { Referrals by the Secretariat } & 269\end{array}$

$\begin{array}{lll}7.3 & \text { Communications from the Public } & 269\end{array}$

7.4 Initiation Proprio Motu 269

8. The Procedure before the Compliance Committee and Procedural Safeguards $\quad 269$

8.1 Sources of Procedural Rules and General Remarks 269

$\begin{array}{ll}8.2 & \text { Procedural Safeguards } \\ & 270\end{array}$

9. Sources of Information 271

10. Decision-Making 271

11. Outcomes 272

12. Coordination with Dispute Settlement Procedures and other Non-Compliance Procedures $\quad 272$

13. Participation of the European Community 273

$\begin{array}{ll}\text { 14. Financial Aspects } & 274\end{array}$ 


\section{SECTION II}

Selected Studies on Practice

Chapter 16 - The Compliance Mechanisms of the Aarhus Convention and the Cartagena Protocol on Biosafety: A Comparative Analysis of the Negotiation Histories and their Outcomes

Veit Koester

1. Introduction

2. The Aarhus Convention and the Cartagena Protocol and the Legal Basis of their Compliance Mechanisms

2.1 The Nature of the Aarhus Convention and the Cartagena Protocol

2.2 Legal Basis of the Compliance Mechanisms of the Aarhus Convention and the Cartagena Biosafety Protocol

3. Some Introductory Remarks on the Negotiation Processes in respect of the Compliance Mechanisms of the Aarhus Convention and the Cartagena Protocol on Biosafety

4. Development of the Compliance Mechanism of the Aarhus Convention

4.1 The Meeting of the Signatories to the Convention and the Meetings of the Task Force on Compliance (1999 and 2000)

4.2 The First Meeting of the Working Group for the Preparation of the First Meeting of the Parties and the Meetings of the Working Group on Compliance and Rules of Procedure (2001 and 2002)

4.3 The Second and the Third Meeting of the Working Group for the Preparation of the first Meeting of the Parties (2002)

4.4 The First Meeting of the Parties (2002)

5. Development of the Compliance Mechanism of the Cartagena Protocol

5.1 First Meeting of the Intergovernmental Committee for the Cartagena Protocol (2000)

5.2 Second Meeting of the Intergovernmental Committee (2001)

5.4 First Conference of the Parties to the Convention on Biodiversity Serving as the Meeting of the Parties to the Cartagena Protocol (2004)

6. Similarities and Differences between the two Negotiation Processes

7. Subject and Scope of the Analysis of the Outcomes of the two Negotiation Processes

8. A Comparison of the Compliance Mechanisms of the Aarhus Convention and the Cartagena Protocol on Biosafety 
8.3 Functions of the Compliance Bodies 295

8.4 Trigger Mechanisms 296

8.5 Procedural Safeguards and Some Other Procedural Aspects 297

8.6 Sources of Information 299

8.7 Non-Compliance Response Measures 300

9. Some Concluding Remarks 301

Chapter 17 - The Practice of the Compliance Committee under the Kyoto Protocol to the United Nations Framework Convention on Climate Change (2006-2007)

René Lefeber

1. Introduction 303

2. The Organisation of Work in the Committee 304

2.1 The Structure of the Committee 304

2.2 Transparency in the Committee 305

3. The Members of the Committee 306

3.1 The Participatory Rights of Members 306

3.2 The Personal Capacity of Members 306

4. The Powers of the Committee 309

4.1 The Mandates of the Organs of the Committee 309

4.2 The Application of Powers by the Organs of the Committee 314

5. Conclusions 316

Chapter 18 - Practice and Relevant Cases that Emerged in the Context of the Espoo Convention Implementation Committee

Jerzy Jendrośka

1. Introduction 319

2. Legal Basis 319

2.1 Origins 319

2.2 Towards a Proper Legal Basis 321

2.3 "Implementation" or "Compliance" Committee 322

3. Modus Operandi 322

3.1 "Structure and Functions ..." 322

3.2 Operating Rules 323

3.3 Working Language 324

4. Structure 326

4.1 Membership 326

4.2 Requirements 327

4.3 Officers 328

5. Public Involvement and Transparency 328

5.1 Legal Basis and Approach 328

5.2 Openness and Public Access to Documents 329

5.3 Public Trigger 330

6. Bystroe Canal Case - Romania v. Ukraine 331 
6.1 The Case and Its Procedural History 331

6.2 Facts and Legal Basis 332

6.3 Main Legal Issues 333

7. Conclusions 335

Chapter 19 - In Search of New Ways to Ensure Effective Compliance with Environmental Procedures and Policies: The Experience of the European Bank for Reconstruction and Development with its Internal Recourse Mechanism

Francesco Seatzu

1. Introduction

2. The Environmental Policies and Procedures as the Applicable

Law to EBDR Loan Development Activities

3. The IRM's Mandate and its General Functioning 342

3.1 IRM Independence and Membership 342

3.2 Some General Remarks on the Functioning of the IRM 344

4. $\begin{array}{ll}\text { The IRM Procedure } & 346\end{array}$

4.1 The Jurisdiction of the IRM 346

4.2 The Consequences of IRM's Investigations and Recommendations 348

5. Assessment and Final Remarks $\quad 349$

5.1 An Assessment of the IRM 349

5.2 Some Modest Proposals for Reform 350

6. Final Remarks 351

\section{SECTION III}

Institutional and Procedural Aspects

Chapter 20 - Structural and Institutional Aspects of Non-Compliance Mechanisms

Alessandro Fodella

1. Introduction

2. The Legal Basis for the Creation of Non-Compliance

Mechanisms: Structures Built on "Unstable Foundations"? 356

3. The Nature and Role of "Compliance Bodies" 359

3.1 Independence vs. Political Control? 359

3.2 Other Issues of Efficient Institutional Design 362

4. Effectiveness of non-compliance mechanisms and Participation by Other "Actors" in the System 365

4.1 Participation by Treaty Bodies 365

4.2 Participation by States Parties 366

$\begin{array}{lll}4.3 & \text { Participation by Civil Society } & 368\end{array}$

5. Inter-institutional Coordination 370

$\begin{array}{ll}\text { 6. Conclusions } & 372\end{array}$ 
Chapter 21 - Triggering Non-Compliance Procedures

Francesca Romanin Jacur

1. Introduction 373

2. Subjects Entitled to Set in Motion Non-Compliance Procedures 374

$\begin{array}{lll}2.1 & \text { Self Trigger } & 374\end{array}$

$\begin{array}{lll}2.2 & \text { Party-to-Party Trigger } & 375\end{array}$

$\begin{array}{lll}2.3 & \text { Trigger by organs of the MEA } & 377\end{array}$

$\begin{array}{lll}2.4 & \text { Trigger by Non-State Actors } & 380\end{array}$

3. Procedural Aspects Related to the Triggering Phase 381

4. Admissibility Criteria 383

$\begin{array}{lll}4.1 & \text { Formal requirements } & 384\end{array}$

$\begin{array}{lll}4.2 & \text { Substantive requirements } & 385\end{array}$

5. Conclusion 386

Chapter 22 - Procedural Guarantees in Non-Compliance Mechanisms 389

Massimiliano Montini

1. Introduction 389

2. The Principles of the Non-Compliance Procedure 390

3. The Procedural Guarantees 392

3.1 Procedural Guarantees under MEAs 392

3.2 Due Process 394

3.3 The Compliance Committee: Composition, Impartiality and
Equitable Geographical Representation

4. The Outcomes of the Procedures 402

5. Conclusion 404

Chapter 23 - The Outcomes of the Procedure and their Legal Effects 407

Enrico Milano

1. Introduction 407

2. Decision-making and Types of Measures 408

3. Outcomes and Legal Effects 411

4. Concluding Remarks 417

Chapter 24 - Controlling and Assisting Compliance: Financial Aspects $\quad 419$

Francesca Romanin Jacur

1. Introduction 419

2. Financing Non-Compliance Mechanisms 420

2.1 The General Budget as the Source of Financing for Compliance Committees under MEAs $\quad 421$

2.2 Responses to the Lack of Adequate Funding 425

3. Financial Means to Assist Countries in Complying with Their

$3.1 \quad$ Funds for Developing Countries $\quad 427$

3.2 Flexibility Mechanisms for Industrialized Countries 433 
4. The Control Exercised by Non-Compliance Mechanisms on Financial Matters

5. Conclusions

Chapter 25 - Multiplication and Overlap of Non-Compliance Procedures and Mechanisms: Towards Better Coordination?

Cesare Pitea

1. Overlap of Multiple Non-Compliance Procedures: Examples, Reasons and Risks

2. A Single Non-Compliance Mechanism? An Unrealistic and Unsuitable Perspective

3. Information-Sharing Clauses in Existing and Perspective NonCompliance Mechanisms 442

4. The Practice of Synergy Enhancement 444

4.1 Institutional Synergies: The Role of Secretariats 444

4.2 Procedural Synergies: Taking into Account Procedures under other Compliance Mechanisms and Ensuring Harmonious Jurisprudential Developments

5. The Way Forward

\section{Section IV}

Non-Compliance Mechanisms and International Law

Chapter 26 - Non-Compliance Procedures and the Law of Treaties Malgosia Fitzmaurice

1. Introduction

1.2 New Treaty Structures and Treaty Regimes 454

1.3 The Setting up of Non-Compliance Procedures 455

1.4 Novelty, Innovation and the Law of Treaties 455

2. The Issue in Relation to Modification of Treaty Obligations 455

2.1 Introduction $\quad 455$

2.2 Amendment or Adjustment Procedures 456

2.3 Analysis of the Legal Nature of the Adjustment Procedure 460

2.4 Enabling Clauses 462

2.5 Theories as to the Legal Character of COP/MOP Decisions 463

2.6 Interim Conclusions

3. The Relationship of the Actions under Non-Compliance Procedures in Response to Non-Compliance with Provisions of Article 60 of the Vienna Convention 467

3.1 The Nature of the Problem 467

3.2 Provisions as to Suspension of Treaty Rights under NonCompliance Procedures

3.3 Relationship with Article 60 of the Vienna Convention 469 
3.4 Some General Comments 470

4. The Issue of Suspension of Rights (or Imposition of Trade Restrictions) by the Montreal Protocol Non-Compliance Procedure in Relation to the Non-Compliance of Certain Former Soviet Block States

4.1 How the Issue Arose 472

4.2 Subsequent Position of the Parties 473

4.3 Conclusions 473

5. The Special Problems Relating to the Kyoto Protocol 474

5.1 Introduction 474

5.2 The Legal Character of the COP/MOP Decisions under the Kyoto Enabling Clauses

5.3 The Legal Character of the Consequences Applicable under the Kyoto Protocol Non-Compliance Procedure

6. Conclusions

Chapter 27 - Non-Compliance Procedures and the Law of State Responsibility

Laura Pineschi

1. Introduction 483

2. The Non-Compliance Procedures: Special Regimes of State Responsibility?

3. Coordination with General Rules on State Responsibility 491

4. Concluding Remarks 497

Chapter 28 - The Settlement of Disputes and Non-Compliance Procedures 499 Tullio Treves

1. Introduction

2. Dispute-Settlement Provisions of Environmental Agreements Providing for Non-Compliance Mechanisms

2.1 The Model Followed and the Variants Set Out in the Different Agreements

2.2 "Negotiation" and other Peaceful Means of the Parties' Choice

500

2.3 Optional Compulsory Adjudication: ICJ and Arbitration 501

2.4 Compulsory Conciliation 503

3. The Relationship between Dispute-Settlement and NonCompliance Procedures under Environmental Agreements 505

3.1 The "Without Prejudice" Clauses

3.2 The Relationship between Dispute-Settlement and Non-Compliance Procedures from the Point of View of the Dispute-Settlement Bodies

3.3 The Relationship between the Dispute-Settlement and the Non-Compliance Procedures from the Point of View of the Non-Compliance Bodies 
3.4 Diplomatic and Binding Dispute-Settlement Procedures and Non-Compliance Procedures

4 "Disputes" under the Environmental Agreements 512

4.1 The Relevance of the Notion of Dispute 512

4.2 Different Kinds of Obligations and Possible Disputes

4.3 The Limited Availability of Dispute-Settlement Mechanisms in the Environmental Agreements

5. Concluding Remarks

\section{Section V \\ Non-Compliance Mechanisms and European Union Law}

Chapter 29 - Non-Compliance Procedures in Multilateral Environmental Agreements: The Interaction between International Law and European Union Law Antonino Ali

1. Introduction: Multilateral Environmental Agreements as Mixed Agreements

2. The Reasons for Concluding Mixed Agreements

3. Competences and Responsibility

4. The Participation of the European Community in MEAs:

The Declarations of Competences

5. MEAs and the European Community: the Case of the Aarhus Convention

6. The Practice and the Relevant Cases Concerning the EC that Have Emerged in the Context of the Non-Compliance Mechanism in MEAs

7. On the interaction of the European Commission and the Non-Compliance Mechanism in MEAs

Chapter 30 - The Policy and Practice of the European Union on Compliance Mechanisms under Multilateral Environmental Agreements Nicola Notaro

1. Introduction

2. The International Dimension of European Community

Environment Policy

3. Shared Competence in MEAs

4.

EU Position on Compliance: Where Is It and What Is in It?

4.1 Enabling Clauses

4.2 Objectives-Size and Composition-Functions 539

4.3 Triggering

4.4 Transparency and Openness 541

4.5 Procedural Safeguards 541

4.6 Compliance Measures and Decision-Making 541

4.7 Capacity Building and Financial Mechanisms 542 
4.8 Compliance v. Dispute Settlement - Review Clauses 542

5. EU Position on Compliance and Third Parties

6. Non-Compliance of Member States and Consequences for the $\mathrm{EC}$

Chapter 31 - Obligations of the European Community and its Member States under the Kyoto Protocol

Leonardo Massai

1. Introduction

2. The Participation of the EC and its Member States in the International Climate Regime

2.1 Article 4 of the Kyoto Protocol

2.2 EU Burden Sharing Agreement

549

551

2.3 EU Enlargement

3. EC and Member States Compliance with the Kyoto Protocol Obligations

3.1 Methodological and Reporting Obligations

3.2 Eligibility Criteria and Flexible Mechanisms

3.3 Reduction Obligations

4. Consequences for Non-Compliance with the Kyoto Protocol Obligations

5. EC and Member States Compliance with the Kyoto Protocol Obligations

6. Conclusions

\section{Section VI}

Conclusions

Chapter 32 - Non-Compliance Mechanisms: Lessons Learned and the Way Forward

Attila Tanzi and Cesare Pitea

1. Introductory Remarks

2. The Purpose of Non-Compliance Mechanisms and the Factors Enhancing Their Effective Functioning

2.1 A Means to Enhance the Effectiveness of International Environmental Law

2.2 Mandate. Between the Political and Legal Dimensions

2.3 Composition and the Issue of Independence

2.5 Transparency and the Role of non-State Actors

3. Beyond Claims of State Responsibility through Inter-State Dispute Settlement: the Legal Nature of Non-Compliance Mechanisms 


\section{Contributors and Editors}

Antonino Alì

Giulia BIGI

Stefano BRUGNATELLI

Luigi CREMA

Elena FAsoli

Malgosia FitzMAurice

Alessandro FodelLA

Jerzy JENDROŚKA

Veit Koester

René LEFEBER

Leonardo MASSAI
Ph.D. (Palermo); Associate Professor of International Law, Faculty of Law, University of Trento (Italy) Doctoral candidate in International Law, University of Milan (Italy)

Doctoral candidate in International Law, University of Milan (Italy)

Doctoral candidate in International Law, Universities of Milan (Italy) and Geneva (Switzerland)

Doctoral candidate in International Law, University of Milan (Italy)

Professor of Public International Law, Department of Law, Queen Mary, University of London (United Kingdom)

LL.M (London), Ph.D. (Milan); Associate Professor of International Law, Faculty of Law, University of Trento (Italy)

LL.M (Wrocław), Ph.D. (Warsaw); Chair of European and Public International Law, Opole University (Poland); Member of the Aarhus Convention Compliance Committee; Representative of Poland to the Espoo Convention Implementation Committee

Chairperson of the Compliance Committee of the Aarhus Convention on Access to Information, Public Participation in Decision-Making and Access to Justice in Environmental Matters; Chairperson of the Compliance Committee of the Cartagena Protocol on Biosafety.

Professor of International Environmental Law, Faculty of Law, University of Amsterdam (the Netherlands); Member of the Enforcement Branch of the Compliance Committee of the Kyoto Protocol; Legal Counsel, International Law Division, Netherlands Ministry of Foreign Affairs

Doctoral candidate in International and European Environmental Law, University of Frankfurt (Germany); Researcher in EU Environmental Law, T.M.C. Asser Institute, The Hague (the Netherlands) 
Enrico Milano

Massimiliano MonTINI

Nicola NOTARO

Irini PAPANICOLOPULU

Laura PINESCHI

Cesare PItEA

Chiara RAGNI

Francesca Romanin JACUR

Francesco SeAtzu

Attila TANZI

Tullio TREves

Seline Trevisanut

Sabrina URBINATI
LL.M (Nottingham), Ph.D. (London); Aggregate Professor of International Law, Faculty of Law, University of Verona (Italy)

LL.M (London); Associate Professor of European Union Law, Faculty of Economics, University of Siena (Italy)

LL.M (Bruges), Ph.D. (London); Legal Adviser MEAs in the Directorate General for Environment, European Commission; Alternate Member of the Facilitative Branch of the Compliance Committee of the Kyoto Protocol

Ph.D. (Milan); Senior Researcher in International Law, University of Milan-Bicocca (Italy)

Professor of International Law, Faculty of Law, University of Parma (Italy)

LL.M (London), Ph.D. (Milan); Aggregate Professor of International and European Law, Faculty of Law, University of Parma (Italy)

Ph.D. (Milan); Senior Researcher in International Law, Faculty of Law, University of Milan (Italy)

DESUP (Paris), Ph.D. (Milan); Post-doc Researcher in International Law, University of Milan (Italy); Legal Adviser to the Italian Ministry of the Environment, Land and Sea within a project of the University of Siena (Italy)

Ph.D. (Nottingham); Associate Professor of International Law, Faculty of Law, University of Cagliari (Italy) Professor of International Law, Faculty of Law, University of Bologna (Italy); Chairperson of the Compliance Committee of the Protocol on Water and Health

Professor of International Law, Faculty of Law, University of Milan (Italy); Judge at the International Tribunal for the Law of the Sea

Ph.D. (Milan); Post-doc Researcher in International Law, Lecturer of International Law, University of Trento (Italy)

Master Degree (Paris), Ph.D. (Paris-Milan); Lawyer (Bologna) 


\section{Abbreviations}

\begin{tabular}{|c|c|}
\hline AAU & Assigned Amount Unit \\
\hline AIA & Autonomous Institutional Arrangement \\
\hline BAN & Basel Action Network \\
\hline $\mathrm{BCH}$ & Biosafety Clearing-House \\
\hline CER & Certified Emission Reduction \\
\hline CDM & Clean Development Mechanism \\
\hline CIS & Commonwealth of Independent States \\
\hline CITES & $\begin{array}{l}\text { Convention on International Trade in Endangered Species of } \\
\text { wild Fauna and Flora }\end{array}$ \\
\hline CMP & $\begin{array}{l}\text { Conference of the Parties serving as the meeting of Parties to } \\
\text { the Kyoto Protocol }\end{array}$ \\
\hline COP & Conference of the Parties \\
\hline EBRD & European Bank for Reconstruction and Development \\
\hline EC & European Community \\
\hline ECJ & European Court of Justice \\
\hline EEC & European Economic Community \\
\hline EIA & Environmental Impact Assessment \\
\hline EMEP & $\begin{array}{l}\text { Cooperative Programme for Monitoring and Evaluation of the } \\
\text { Long-Range Transmission of Air Pollutants in Europe }\end{array}$ \\
\hline ERT & Expert Review Team \\
\hline ERU & Emission Reduction Unit \\
\hline EU & European Union \\
\hline GEF & Global Environment Facility \\
\hline GHG & Greenhouse Gas \\
\hline GMO & Genetically modified organism \\
\hline IAEA & International Atomic Energy Agency \\
\hline IBRD & International Bank for Reconstruction and Development \\
\hline $\mathrm{IC}$ & Implementation Committee \\
\hline ICAO & International Civil Aviation Organisation \\
\hline ICCP & Intergovernmental Committee for the Cartagena Protocol \\
\hline ICJ & International Court of Justice \\
\hline IET & International Emission Trading \\
\hline IFI & International Financial Institution \\
\hline IGO & Inter-Governmental Organization \\
\hline ILC & International Law Commission \\
\hline IMO & International Maritime Organization \\
\hline IPPC & Integrated Pollution Prevention and Control \\
\hline
\end{tabular}


IRM

ITLOS

ITPGRFA

JI

LMO

LRTAP

LULUCF

MEA

MOP

MSC

$\mathrm{NCP}$

NGO

ODS

OSCE

PCIJ

PIC

POP

PRTR

QELRC

REIO

RMU

SEA

UN

UNCED

UNDP

UNECE

UNEP

UNESCO

UNFCCC

UNIDO

VOC

WG

WMO

WTO
Independent Recourse Mechanism

International Tribunal for the Law of the Sea

International Treaty on Plant Genetic Resources for Food and

Agriculture

Joint Implementation

Living Modified Organism

Long-Range Transboundary Air Pollution

Land-Use, Land-Use Change and Forestry

Multilateral Environmental Agreement

Meeting of the Parties

Maritime Safety Committee

Non-Compliance Procedure

Non-Governmental Organization

Ozone Depleting Substance

Organization for Security and Cooperation in Europe

Permanent Court of International Justice

Prior Informed Consent

Persistent Organic Pollutant

Pollutant Release and Transfer Register

Quantified Emission Limitation and Reduction Commitment

Regional Economic Integration Organization

Removal Unit

Strategic Environmental Assessment

United Nations

UN Conference on Environment and Development

UN Development Programme

UN Economic Commission for Europe

UN Environmental Programme

UN Educational, Scientific and Cultural Organization

UN Framework Convention on Climate Change

UN Industrial Development Organization

Volatile Organic Compounds

Working Group

World Meteorological Organization

World Trade Organization 


\section{Journals}

Am. J. Int'l L.

Am. U. J. Int'l L. \& Pol'y

Ann. Français Dr. Int.

Austrian Rev. Int'l Eur. L

Baltic YB Int'l L.

Boston College Int'l \& Comp. L. Rev.

British YB Int'l L.

Canadian YB Int'l L.

Colo. J. Envt'l L. \& Pol'y

Colo. J. Int'l Envt'l L. \& Pol'y YB

Com. Int.

Common Market L. Rev.

Cornell Int'l L.J.

Dir. Com. Sc. Int.

Duke Envt'l Pol'y \& L. Forum

Ecol. L. Q.

Env'l Liab

Envt'l Pol'y \& L.

Eur. Envt'l L. Rev.

Eur. J. Int'l L.

Finnish YB Int'l $L$.

Fordham Envt'l L. J.

Fordham Int'l L. J.

Georgetown Int'l Envt'l L. Rev.

Ger. YB Int'l L.

Hague YB Int'l L.

Harvard Int'l L. J.

Hum. Rts. Q.

IDI Annuaire

Int'l \& Comp. L. Q.

ILM
American Journal of International Law

American University Journal of International

Law and Policy

Annuaire français de droit international

Austrian Review of International and European

Law

Baltic Yearbook of International Law

Boston College International and Comparative

Law Review

British Yearbook of International Law

Canadian Yearbook of International Law

Colorado Journal of Environmental Law and Policy

Colorado Journal of International Environmental Law and Policy Yearbook

La Comunità Internazionale

Common Market Law Review

Cornell International Law Journal

Diritto Comunitario e degli Scambi Internazionali

Duke Environmental Law and Policy Forum Ecology Law Quarterly

Environmental Liability

Environmental Policy and Law

European Environmental Law Review

European Journal of International Law

Finnish Yearbook of International Law

Fordham Environmental Law Journal

Fordham International Law Journal

Georgetown International Environmental Law Review

German Yearbook of International Law

Hague Yearbook of International Law

Harvard International Law Journal

Human Rights Quarterly

Annuaire de l'institut de droit international International \& Comparative Law Quarterly International Legal Materials 
Int. Comm. L. Rev.

Int'l Envt'l Agreements

Int'l J. Mar. \& Coast. L.

Int'l L. Forum

International Organization

Italian YB Int'l L.

J. Eur. Envt'l Plan. L.

J. Int'l Econ. L.

J. W. Intell'l Prop.

$J$. Eur. Integration

JWT

Leiden J. Int'l L.

Max Planck YB UN L.

Melbourne J. Int'l L.

Michigan J. Int'l L.,

Mod. L. Rev.

Netherlands Int'l L. Rev.

Netherlands YB Int'l L.

New Zealand J. Envt'l L.

Non-State Actors \& Int'l L.

Nordic J. Int'l L.

NYU J. Int'l L. \& Pol.

$O J$

$R d C$

\section{RECIEL}

Rev. Bel. Dr. Int.

Rev. Jur. Env.

Rev. Gén. Dr. Int. Pub.

Riv. Dir. Int.

Riv. Giur. Amb.

Singapore YB Int'l L.

Syracuse J. Int'l L. \& Commerce

Tul. Envt'l L. J.

Tul. J. Int'l \& Comp. L.

UNTS

YB Eur. Envt'l L.

YB Int'l Envt'l L.
International Community Law Review

International Environmental Agreements

International Journal of Maritime and Coastal Law

International Law Forum

International Organization

Italian Yearbook of International Law

Journal for European Environmental and Planning

Law

Journal of International Economic Law

Journal of World Intellectual Property

Journal of European Integration

Journal of World Trade

Leiden Journal of International Law

Max Planck Year Book of United Nations

Law

Melbourne Journal of International Law

Michigan Journal of International Law

Modern Law Review

Netherlands International Law Review

Netherlands Yearbook of International Law

New Zealand Journal of Environmental Law

Non-State Actors and International Law

Nordic Journal of International Law

New York University Journal of International Law and Politics

Official Journal of the European Union

Recueil des Cours de l'Académie de Droit International de La Haye

Review of European Community and International Environmental Law

Revue belge de droit international

Revue juridique de l'environnement

Revue générale de droit international public

Rivista di diritto internazionale

Rivista giuridica dell'ambiente

Singapore Yearbook of International Law

Syracuse Journal of International Law and

Commerce

Tulane Environmental Law Journal

Tulane Journal of International and Comparative

Law

United Nations Treaty Series

Yearbook of European Environmental Law

Yearbook of International Environmental Law 
YB Int'l L. Comm.

ZaöRV
Yearbook of the International Law Commission

Zeitschrift für ausländisches öffentliches Recht und Völkerrecht 
1 


\section{List of Treaties}

Aarhus Convention

Acidification LRTAP Protocol

Alpine Convention

Barcelona Convention

Barcelona Dumping

Protocol

Basel Convention

Bern Convention

Cartagena Protocol

CITES
Convention on Access to Information, Public Participation in Decision-making and Access to Justice in Environmental Matters (Aarhus, Denmark, 25 June 1998), ILM 38 (1999) 517, in force 30 October 2001

Protocol to the 1979 Convention on Long-Range Transboundary Air Pollution to Abate Acidification, Eutrophication and Ground-level Ozone (Gothenburg, Sweden, 13 November 1999), <http:/www.unece.org/ env/lrtap/multi_h1.htm>, in force 17 May 2005

Convention on the Protection of the Alps (Salzburg, Austria, 7 November 1991), ILM 31 (1992) 767, in force 6 March 1995

Convention for the Protection of the Marine Environment and the Coastal Region of the Mediterranean (Barcelona, Spain, 10 June 1995), <http://195.97.36.231/dbases/ webdocs/BCP/bc95_Eng_p.pdf>, in force 9 July 2004, amending and renaming the Convention for the Protection of the Mediterranean Sea Against Pollution (Barcelona, Spain, 16 February 1976), ILM 15 (1976) 290, in force 12 February 1978

Protocol for the Prevention of Pollution by Dumping from Ships and Aircraft (Barcelona, Spain, 16 February 1976), in force 12 February 1978 (revised in Barcelona, Spain, in force 10 June 1995)

Basel Convention on the Transboundary Movement of Hazardous Wastes and Their Disposal (Basel, Switzerland 22 March 1989), ILM 28 (1989) 649, in force 5 May 1992

Convention on the Conservation of European Wildlife and Natural Habitats (Bern, Switzerland, 19 September 1979), CETS 104, in force 1 June 1982

Cartagena Protocol on Biosafety to the Convention on Biological Diversity (Montreal, Canada 29 January 2000), ILM 39 (2000) 1027, in force 11 September 2003

Convention on International Trade in Endangered Species of Wild Fauna and Flora (Washington, United States, 3 March 1973), 993 UNTS 243, in force 1 July 1975 
Convention on Biological Convention on Biological Diversity (Rio de Janeiro, Diversity Brazil, 5 June 1992), ILM 31 (1992) 822, in force 29 December 1993

Convention on UN Convention on the Privileges and Immunities of the Privileges and Immunities United Nations (New York, United States of America, 13 February 1946), 1 UNTS 15, in force 17 September 1946

Desertification Convention Convention to Combat Desertification in those Countries Experiencing Serious Drought and/or Desertification, particularly in Africa (Paris, France, 17 June 1994), ILM 33 (1994) 1328, in force 26 December 1996

EPER LRATP Protocol Protocol to the 1979 Convention on Long-Range Transboundary Air Pollution on Long-term Financing of the Cooperative Programme for Monitoring and Evaluation of the Long-range Transmission of Air Pollutants in Europe (EMEP), (Geneva, Switzerland, 28 September 1984), ILM 27 (1988) 701, in force 28 January 1988

Espoo Convention Convention on Environmental Impact Assessment in a Transboundary Context (Espoo, Finland, 25 February 1991), ILM 30 (1991) 802, in force 10 September 1997

European Convention on Human Rights

Convention for the Protection of Human Rights and Fundamental Freedoms (Rome, Italy, 4 November 1950), CETS 005, in force 3 September 1953, as amended by Protocol No. 11 to the Convention for the Protection of Human Rights and Fundamental Freedoms, restructuring the control machinery established thereby (Strasbourg, France, 11 May 1994), CETS 155, in force 1 November 1998

First Sulphur LRTAP

Protocol to the 1979 Convention on Long-Range Transboundary Air Pollution on the Reduction of Sulphur Emissions or their Transboundary Fluxes by at least 30 per cent (Helsinki, Finland, 8 July 1985), ILM 27 (1988) 707, in force 2 September 1987

Heavy Metals LRTAP Protocol to the 1979 Convention on Long-Range Transboundary Air Pollution on Heavy Metals (Aarhus, Denmark, 24 June 1998), <http://www.unece.org/env/ lrtap/hm h1.htm $>$, in force 29 December 2003

Helsinki Convention Convention on the Protection and Use of Transboundary Watercourses and International Lakes (Helsinki, Finland, 17 March 1992), ILM 31 (1992) 1312, in force 6 October 1996

ITPGRFA

International Treaty on Plant and Genetic Resources for Food and Agriculture (Rome, Italy, 3 November 2001), <ftp://ftp.fao.org/ag/cgrfa/it/ITPGRe.pdf>, in force 29 June 2004 
Kyoto Protocol

Kyoto Protocol to the United Nations Framework Convention on Climate Change (Kyoto, Japan, 16 March 1998), ILM 37 (1998) 22, in force 15 February 2005

Law of the Sea Convention United Nations Convention on the Law of the Sea (Montego Bay, Jamaica, 10 December 1982), ILM 21 (1982) 1261, in force 16 November 1994

London Dumping

Convention

Convention on the Prevention of Marine Pollution by Dumping of Wastes and Other Matter (London, United Kingdom, 29 December 1972), ILM 11 (1972) 1294, in force 30 August 1975

London Dumping Protocol London Protocol to the Convention on the Prevention 1996 of Marine Pollution by Dumping of Wastes and Other Matter (London, United Kingdom, 7 November 1996), ILM 36 (1997) 1, in force 24 March 2006

LRTAP Convention Convention on Long-Range Transboundary Air Pollution (Geneva, Switzerland, 13 November 1979), ILM 18 (1979) 1442, in force 16 March 1983

Montreal Protocol Montreal Protocol on Substances that Deplete the Ozone Layer (Montreal, Canada, 16 September 1987), ILM 26 (1987) 1541, in force 22 September 1989

NOx LRATP Protocol Protocol to the 1979 Convention on Long-Range Transboundary Air Pollution Concerning the Control of Nitrogen Oxides or their Transboundary Fluxes (Sofia, Bulgaria, 31 October 1988), ILM 28 (1989) 212, in force 14 February 1991

Optional Protocol to the ICCPR

Optional Protocol to the International Covenant on Civil and Political Rights (New York, United States of America, 16 December 1966), 999 UNTS 17, in force 23 March 1976

OSCE Convention Convention on Conciliation and Arbitration within the on Conciliation and Arbitration

OSPAR Convention

POPs LRATP Protocol OSCE (Stockholm, Sweden, 15 December 1992), ILM 32 (1993) 551, in force 5 December 1994

Convention for the Protection of the Marine Environment of the North-East Atlantic (Paris, France, 22 September 1992), ILM 32 (1993) 1068, in force 25 March 1998

Protocol to the 1979 Convention on Long-Range Transboundary Air Pollution on Persistent Organic Pollutants (POPs) (Aarhus, Denmark, 24 June 1998), $37 \operatorname{ILM}$ (1998) 505, in force 23 October 2003

Protocol on Water and Health Protocol on Water and Health to the Convention on the Protection and Use of Transboundary Watercourses and International Lakes (London, United Kingdom, 17 June 1999), ILM 38 (1999) 1708, in force 4 August 2005

PRTRs Protocol Protocol on Pollutant Release and Transfer Registers (Kiev, Ukraine, 21 May 2003), <http://www.unece. org/env/pp/prtrtext.htm>, not yet in force. 
Ramsar Convention

SEA Protocol

Second Sulphur LRTAP Protocol

SOLAS Convention

Stockholm POPs

Convention

UNFCCC

Vienna Convention

Vienna Ozone Convention Vienna Convention for the Protection of the Ozone Layer

VOC LRTAP Protocol (Vienna, Austria, 22 March 1985, ILM 26 (1987) 1529,

in force 22 September 1988

Convention on Wetlands of International Importance especially as Waterfowl Habitat (Ramsar, Iran, 2 February 1971), 996 UNTS 245, in force 21 December 1975

Procedure for Certain Hazardous Chemicals and Pesticides in International Trade (Rotterdam, the Netherlands, 10 September 1998), ILM 38 (1999) 1, in force 24 February 2004

Protocol on Strategic Environmental Assessment to the Convention on Environmental Impact Assessment in a Transboundary Context (Kiev, Ukraine, 21 May 2003), $<$ http://www.unece.org/env/eia/sea_protocol.htm $>$, not yet in force

Protocol to the 1979 Convention on Long-Range Transboundary Air Pollution on Further Reduction of Sulphur Emissions (Oslo, Norway 14 June 1994), ILM 33 (1994) 1542; entered into force 5 August 1998

Convention for the Safety of Life at Sea (London, United Kingdom, 1 November 1974), 1184 UNTS 2, in force 25 May 1980

Stockholm Convention on Persistent Organic Pollutants (Stockholm, Sweden, 23 May 2001), ILM 40 (2001) 532 , in force 17 May 2004

United Nations Framework Convention on Climate Change (Rio de Janeiro, Brazil, 9 May 1992), ILM 31 (1992) 851, in force 21 March 1994

Vienna Convention on the Law of Treaties, (Vienna, Austria, 23 May 1969), ILM 8 (1969) 679, in force 27 January 1980

Protocol to the 1979 Convention on Long-Range Transboundary Air Pollution Concerning the Control of Emissions of Volatile Organic Compounds or their Transboundary Fluxes (Geneva, Switzerland, 18 November 1991), ILM 31 (1992) 568, in force 29 September 1997 


\section{List and Websites of Non-Compliance Mechanisms}

1. The Non-Compliance Procedure of the 1987 Montreal Protocol to the 1985 Vienna Convention on Substances that Deplete the Ozone Layer: Decision IV/5 on Non-Compliance Procedure, doc. UNEP/OzL.Pro.4/15 (25 November 1992), at 13 and Annex IV at 44, subsequently amended by Decision X/10 on Review of the Non-Compliance Procedure, doc. UNEP/OzL.Pro.10/9 (3 December 1998), at 23 and consolidated text in Annex II, at 47.

$<$ http://ozone.unep.org/Meeting_Documents/impcom/>

2. Mechanism for Promoting Implementation and Compliance with the 1989 Basel Convention on the Transboundary Movements of Hazardous Wastes and Their Disposal: Decision VI/12 on Establishment of a Mechanism for Promoting Implementation and Compliance, Appendix, doc. UNEP/CHW.6/40 (10 February 2003), at 45.

$<$ http://www.basel.int/legalmatters/compcommitee/index.html $>$

3. The Compliance Procedures and Mechanism of the 1996 Protocol to the 1972 London Convention on the Prevention of Marine Pollution by Dumping of Wastes and other Matter: Procedures and Mechanisms Pursuant to Article 11 of the 1996 Protocol to the London Convention 1992, doc. LC 29/17(14 December 2007), Annex 7.

$<$ http://www.imo.org/home.asp?topic_id=1488>

4. Procedures and Mechanisms Relating to Compliance under the 1997 Kyoto Protocol to the 1992 United Nations Framework Convention on Climate Change: Decision 27/CMP.1 on Procedures and Mechanisms Relating to Compliance under the Kyoto Protocol, doc. FCCC/KP/CMP/2005/8/Add.3 (30 March 2006), at 92.

$<$ http://unfccc.int/kyoto_protocol/compliance/items/2875.php>

5. Draft Procedures and Mechanisms on Compliance with the 1998 Rotterdam Convention on the Prior Informed Consent Procedure for Certain Hazardous Chemicals and Pesticides in International Trade: Decision RC-3/4 Draft text of the Procedures and Mechanisms on Compliance with the Rotterdam Convention, doc. UNEP/FAO/RC/COP.3/26 (10 November 2006), Annex, at 27.

$<$ http://www.pic.int/home.php?type=b\&id=27\&sid=27\&tid=41>

6. Procedures and Mechanisms on Compliance under the 2000 Cartagena Protocol on Biosafety to the 1992 Convention on Biological Diversity: Decision BS-I/7 on Establishment of Procedures and Mechanisms on Compliance under the Cartagena Protocol on Biosafety, doc. UNEP/CBD/BS/COP-MOP/1/15 (27 February 2004), Annex I, at 98.

$<$ http://www.cbd.int/biosafety/issues/compliance.shtml $>$ 
7. Draft Non-Compliance Procedure under the 2001 Stockholm Convention on Persistent Organic Pollutants: Decision SC-3/20 on Non-Compliance, doc. UNEP/POPS/COP.3/30 (4 May 2007), Annex, at 57.

$<$ http://chm.pops.int/Convention/Compliance/tabid/61/language/en-US/ Default.aspx $>$

8. Draft Procedures and Operational Mechanisms to Promote Compliance and to Address Issues of Non-Compliance under the 2001 International Treaty on Plant and Genetic Resources for Food and Agriculture: Draft Procedures and Operational Mechanisms to Promote Compliance and to Address Issues of Non-Compliance, doc. IT/GB-2/07/14 (2 November 2007). The Governing Body has also decided an interim procedure for addressing compliance, see Resolution 3/2006 on Compliance, doc. IT/gb-1/06/report (16 June 2006), at 7. $<$ http://www.fao.org/ag/cgrfa/compliance.htm $>$

9. Procedures and Mechanisms on Compliance under the 1976/1995 Barcelona Convention on the Protection of the Mediterranean Sea and its Protocols: Decision IG 17/2 on Procedures and Mechanisms on Compliance under the Barcelona Convention and its Protocols, doc. UNEP(DEC)/MED IG. 17/10 (18 January 2008) (the Almeria Report), Annex 5, at 21.

$<$ http://www.unepmap.org/>

10. Procedures and Mechanisms for Review of Compliance under the 1979 LongRange Transboundary Air Pollution Convention and its Protocols: Decision 1997/2 Concerning the Implementation Committee, its Structure and Functions and Procedures for Review of Compliance, doc. ECE/EB.AIR/53 (7 January 1998), Annex III, at 28, subsequently amended. Consolidated text in Decision 2006/2 on Implementation Committee, its Structure and Functions and Procedures for Review, doc. ECE/EB.AIR/89/Add.1 (5 February 2007), at 4.

$<$ http://www.unece.org/env/lrtap/ic/welcome.htm>

11. Procedures and Mechanisms for Review of Compliance under the 1991 Espoo Convention on Environmental Impact Assessment in a Transboundary Context and its 2003 Protocol on Strategic Environmental Assessment: Decision II/4 on Review of Compliance, doc. ECE/MP.EIA/4 (7 August 2001), Annex IV, at 72 revised by Decision III/2 on Review of Compliance, doc. ECE/MP.EIA/6 (13 September 2004), Annex II (consolidated text).

$<$ http://www.unece.org/env/eia/implementation_committee.htm>

12. The Compliance Mechanism of the 1991 Convention on the Protection of the Alps and its Protocols: Decision VII/4 Mécanisme de verification du respect de la Convention alpine et de ses protocols d'application (in Italian) (Seventh Alpine Conference, 2002), reprinted in 33 Envt'l Pol'y \& L. (2003) 179. $<$ http://www.convenzionedellealpi.org/page4_fr.htm $>$

13. Procedures and Mechanisms for Review of Compliance under the 1998 Aarhus Convention on Access to Information, Public Participation and Access to Justice in Environmental Matters: Decision I/7 on Review of Compliance, doc. ECE/ MP.PP/2/Add.8 (2002, subsequently issued on 2 April 2004), as amended by Decision II/5 on General Issues of Compliance, doc. ECE/MP.PP/2005/2/Add.6 (13 June 2005), para. 12.

$<$ http://www.unece.org/env/pp/compliance.htm> 
14. Procedures and Mechanisms for Review of Compliance under the 1999 Protocol on Water and Health to the 1992 Convention on the Protection and Use of Transboundary Watercourses and International Lakes: Decision I/2 on Review of Compliance, doc. ECE/MP.WH/2/Add.3 - EUR/06/5069385/1/Add.3 (3 July 2007).

$<$ http://www.unece.org/env/water/meetings/documents_CC.htm>

15. Procedures and Mechanisms for Review of Compliance under 2003 Protocol on Pollutant Release and Transfer Registers to the Aarhus Convention: Draft Decision on Review of Compliance, doc. ECE/MP.PP/AC.1/2007/L.10 (18 July 2007).

$<\mathrm{http}: / /$ www.unece.org/env/pp/prtr.htm> 
1 


\section{Selected General Bibliography}

For further references see Bibliographies of Chapters 1 to 15 and footnotes.

H. Adsett, A. Daniel, M. Husain and T.L. McDorman, "Compliance Committees and Recent Multilateral Environmental Agreements: the Canadian Experience with Their Negotiation and Operation", Canadian YB Int'l L., 42 (2004) 91-142.

U. Beyerlin, P.-T. Stoll and R. Wolfrum (eds.), Ensuring Compliance with Multilateral Environmental Agreements (Leiden: Martinus Nijhoff, 2006).

U. Beyerlin, "State Community Interests and Institution-Building in International Environmental Law", ZaöRV, 56 (1996) 602-627.

U. Beyerlin, "The Role of NGOs in International Environmental Litigation", ZaöRV, 61 (2001) 357-378.

D. Bodansky, "The Role of Reporting in International Environmental Treaties: Lessons for Human Rights Supervision", in P. Alston, J. Crawford (eds.), The Future of UN Human Rights Treaty Monitoring (Cambridge [etc.]: Cambridge University Press, 2000) 361-378.

L. Boisson de Chazournes, "La mise en œuvre du droit international dans le domaine de la protection de l'environnement: enjeux et défis", Rev. Gén. Dr. Int. Pub., 90 (1995) 37-76.

L. Boisson de Chazournes, "Technical and Financial Assistance and Compliance: the Interplay", in U. Beyerlin, P.-T. Stoll and R. Wolfrum (eds.), Ensuring Compliance with Multilateral Environmental Agreements (Leiden: Martinus Nijhoff, 2006) 273-300.

L. Boisson de Chazournes and M.M. Mbengue, "À propos du caractère juridictionnel de la procedure de non-respect du Protocole de Kyoto”, in S. Maljean-Dubois (ed.), Changements climatiques, les enjeux du contrôle international (Paris: La Documentation Française, 2007) 73-109.

M. Bothe, "Compliance Control beyond Diplomacy - the Role of Non-Governmental Actors", Envt'l Pol'y \& L., 27 (1997) 293-297.

M. Bothe, "Ensuring Compliance with Multilateral Environmental Agreements Systems of Inspection and External Monitoring", in U. Beyerlin, P.-T. Stoll and R. Wolfrum (eds.), Ensuring Compliance with Multilateral Environmental Agreements (Leiden: Martinus Nijhoff, 2006) 247-257.

J. Brunnée, “The Kyoto Protocol: Testing Ground for Compliance Theories?”, ZaöRV, 63 (2003) 255-280.

J. Brunnée, "Enforcement Mechanisms in International Law and International Environmental Law", in U. Beyerlin, P.-T. Stoll and R. Wolfrum (eds.), Ensuring Compliance with Multilateral Environmental Agreements (Leiden: Martinus Nijhoff, 2006) 1-23.

W. Burhenne, "The Role of NGOs", in W. Lang (ed.), Sustainable Development and International Law (London: Graham and Trotman, 1995) 207-211. 
R. Churchill and G. Ulfstein, "Autonomous Institutional Arrangements in Multilateral Environmental Agreements: a Little Noticed Phenomenon in International Law", Am. J. Int'l L., 94 (2000) 623-659.

M. Ehrmann, "Procedures of Compliance Control in International Environmental Treaties”, Colo. J. Int. Envt'l L. \& Pol'y, 13 (2002) 377-443.

A. Epiney, "The Role of NGOs in the Process of Ensuring Compliance with MEAs", in U. Beyerlin, P.-T. Stoll and R. Wolfrum (eds.), Ensuring Compliance with Multilateral Environmental Agreements (Leiden: Martinus Nijhoff, 2006) 319352.

M. Fitzmaurice, "Compliance with Multilateral Environmental Agreements", Hague YB Int'l L., 20 (2008) 19-51.

M. A. Fitzmaurice and C. Redgwell, "Environmental Non-Compliance Procedures and International Law", Netherlands YB Int'l L., 31 (2000) 35-65.

M. Goote, "Non-Compliance Procedures in International Environmental Law: the Middle Way between Diplomacy and Law”, Int'l L. Forum, 1 (1999) 82-89.

G. Handl, "Compliance Control Mechanisms and International Environmental Obligations”, Tul. J. Int'l \& Comp. L., 5 (1997) 29-49.

G. Handl, "Controlling Implementation of and Compliance with International Environmental Commitments: the Rocky Road from Rio", Colo. J. Int. Envt'l L. \& Pol'y, 5 (1994) 305-331.

A. Handler Chayes, A. Chayes and R.B. Mitchell, "Active Compliance Management in Environmental Treaties", in W. Lang (ed.), Sustainable Development and International Law (London: Graham and Trotman, 1995) 75-89.

A. Kiss, "Reporting Obligations and Assessment of Reports", in U. Beyerlin, P.-T. Stoll and R. Wolfrum (eds.), Ensuring Compliance with Multilateral Environmental Agreements (Leiden: Martinus Nijhoff, 2006) 229-245.

J. Klabbers, "Compliance Procedures", in D. Bodansky, J. Brunnée and E. Hey (eds.), The Oxford Handbook of International Environmental Law (Oxford: Oxford University Press, 2007) 996-1009.

T. Kolari, "Constructing Non-Compliance Systems into International Environmental Agreements - a Rise of Enforcement Doctrine with Credible Sanctions Needed?", Finnish YB Int'l L., 14 (2003) 205-231.

M. Koskienniemi, "Breach of Treaty or Non-Compliance? Reflections on the Enforcement of the Montreal Protocol", YB Int'l Envt'l L., 3 (1992) 123-162.

M. Koskienniemi, "Comment on the Paper by Antonia Handler Chayes, Abram Chayes and Ronald B. Mitchell”, in W. Lang (ed.), Sustainable Development and International Law (London: Graham and Trotman, 1995) 91-96.

W. Lang, "Compliance Control in International Environmental Law: Institutional Necessities", ZaöRV, 56 (1996) 685-695.

G. Loibl, "Comment on the Paper by Andronico Adede", in W. Lang (ed.), Sustainable Development and International Law (London: Graham and Trotman, 1995) 125129.

G. Loibl, "Environmental Law and Non-Compliance Procedures: Issues of State Responsibility”, M. Fitzmaurice and D. Sarooshi (eds.), Issues of State Responsibility before International Judicial Institutions (Oxford [etc.]: Hart, 2004) 201-217. 
G. Loibl, "International Environmental Agreements: 'Compliance Mechanisms and Procedures at the Crossroads'?", A. Reinisch and U. Kriebaum (eds.), The Law of International Relations: liber amicorum Hanspeter Neuhold (Utrecht: Eleven International Publishing, 2007) 191-209.

G. Loibl, "Rechtseinhaltungsregime ('Compliance procedures and mechanisms') im internationalen Umweltrecht", in K. Schmalenbach and W. Benedik (eds.), Von Terrorismusbekämpfung bis Klimaschutz: Beiträge zum 32. Österreichischen Völkerrechtstag 2007 in Altaussee (Frankfurt am Main [etc.]: Lang, 2008) 99-112.

T. Marauhn, "Towards a Procedural Law of Compliance Control in International Environmental Relations", ZaöRV, 56 (1996) 696-731.

E. Maruma Mrema, "Cross-Cutting Issues Related to Ensuring Compliance with MEAs", in U. Beyerlin, P.-T. Stoll and R. Wolfrum (eds.), Ensuring Compliance with Multilateral Environmental Agreements (Leiden: Martinus Nijhoff, 2006) 201-227.

N. Matz, "Financial and Other Incentives for Complying with MEA Obligations", in U. Beyerlin, P.-T. Stoll and R. Wolfrum(eds.), Ensuring Compliance with Multilateral Environmental Agreements (Leiden: Martinus Nijhoff, 2006) 301-318.

R. B. Mitchell, "Comment on the Paper by Patrick Széll”, in W. Lang (ed.), Sustainable Development and International Law (London: Graham and Trotman, 1995) 111124.

R. B. Mitchell, "Compliance Theory: an Overview", in J. Cameron, J. Werksman and P. Roderick (eds.), Improving Compliance with International Environmental Law, (London: Earthscan, 1996) 3-28.

R.B. Mitchell, "Compliance Theory. Compliance, Effectiveness, and Behaviour Change in International Environmental Law", in D. Bodansky, J. Brunnée and E. Hey (eds.), The Oxford Handbook of International Environmental Law (Oxford: Oxford University Press, 2007) 893-921.

C. Pitea, "NGOs in Non-Compliance Mechanisms under Multilateral Environmental Agreements. From Tolerance to Recognition?", in T. Treves, M. Frigessi di Rattalma, A. Tanzi, A. Fodella, C. Pitea, C. Ragni (eds.), Civil Society, International Courts and Compliance Bodies (The Hague: T.M.C. Asser Press, 2005) 205-224.

V. Röben, "Institutional Developments under Modern International Environmental Agreements", Max Planck YB UN L., 4 (2000) 363-443.

P. H. Sand, "Sanctions in Case of Non-Compliance and State Responsibility: pacta sunt servanda - Or Else?", in U. Beyerlin, P.-T. Stoll and R. Wolfrum (eds.), Ensuring Compliance with Multilateral Environmental Agreements (Leiden: Martinus Nijhoff, 2006) 259-272.

P. Sands, "Non-Compliance and Dispute Settlement", in U. Beyerlin, P.-T. Stoll and R. Wolfrum (eds.), Ensuring Compliance with Multilateral Environmental Agreements (Leiden: Martinus Nijhoff, 2006) 353-358.

P. Sands, "The Role of Non-Governmental Organizations in Enforcing International Environmental Law", in W.E. Butler (ed.), Control over Compliance with International Law (Dordrecht: Kluwer Academic Publishers, 1991) 61-68.

D. Sarooshi, "The Legal Framework Governing United Nations Subsidiary Organs", British YB Int'l L., 67 (1996) 413-478. 
J. Sommer, "Environmental Law-Making by International Organisations", ZaöRV, 56 (1996) 628-667.

P. Széll, “Compliance Regimes for Multilateral Environmental Agreements - a Progress Report”, Envt'l Pol'y \& L., 27 (1997) 304-307.

P. Széll, "The Development of Multilateral Mechanisms for Monitoring Compliance", in W. Lang (ed.), Sustainable Development and International Law (London: Graham and Trotman, 1995) 97-109.

G. Ulfstein, "Dispute Resolution, Compliance Control and Enforcement in International Environmental Law", in G. Ulfstein (ed.), Making Treaties Work: Human Rights, Environment and Arms Control (Cambridge [etc.]: Cambridge University Press, 2007) 115-133.

J. Voïnov Kohler, Le mécanisme de contrôle du respect du Protocole de Kyoto sur les changements climatiques: entre diplomatie et droit (Genève [etc.]: Schulthess, 2006).

M.G. Wiser, Compliance Systems under Multilateral Agreements - a Survey for the Benefit of Kyoto Protocol Policy Makers (Center for International Environmental Law, October 1999).

R. Wolfrum, "Means of Ensuring Compliance with and Enforcement of International Environmental Law", RdC, 272 (1999) 9-154.

O. Yoshida, "Soft Enforcement of Treaties: the Montreal Protocol's Noncompliance Procedure and the Functions of Internal International Institutions", Colo. J. Int. Envt'l L. \& Pol'y, 10 (1999) 95-141. 


\title{
Introduction
}

\author{
Tullio Treves
}

\section{Non-Compliance Mechanisms in Environmental Agreements: The Research Method Adopted}

In the last quarter of a century multilateral environmental agreements have started to be completed by an institutional framework: the Conference or Meeting of State Parties (COP/MOP). The main tasks of the COP/MOPs are to review the implementation of the agreements and to provide for their up-dating, in particular in the light of the evolution of scientific knowledge. Within this institutional framework mechanisms have been set up whose task is to consider compliance in general and, especially, cases of alleged non-compliance by given State Parties. These are the Compliance, or Non-compliance, Mechanisms of the Multilateral Environmental Agreements. ${ }^{1}$

The present book starts with the observation that, while certain non-compliance mechanisms such as, especially, those contained in the Montreal and Kyoto Protocols, have attracted a lot of attention, much less attention has been devoted to non-compliance mechanisms as a general category. This is the approach adopted by this book. It sets out the results of a cooperative research project, financed in part by the Italian Ministry of Universities and Research, of the Universities of Milano, Bologna and Parma, involving senior and junior researchers, as well as personalities active in practice.

\footnotetext{
${ }^{1}$ The literature is huge. Among the most interesting and recent contributions are U. Beyerlin, P.-T. Stoll and R. Wolfrum (eds.), Ensuring Compliance with Multilateral Environmental Treaties (Leiden/Boston: Martinus Nijhoff, 2006); H. Adsett, A. Daniel, M. Husain and T.L. Mc Dorman, "Compliance Committees and Recent Multilateral Agreements: the Canadian Experience with their Negotiation and Operation", Canadian YB Int'l L., 42 (2004) 91-142; J. Klabbers, "Compliance Procedures", in D. Bodansky, J. Brunée and E. Hey (eds.), The Oxford Handbook of International Environmental Law (Oxford: Oxford University Press, 2007) 996-1009. Among less recent general studies seem particularly interesting those of M. Koskienniemi, "Breach of Treaty or Non-Compliance? Reflections on the Enforcement of the Montreal Protocol", YB Int'l Envt'l L., 3 (1992) 123-162; G. Handl, "Compliance Control Mechanisms and International Environmental Obligations", Tul. J. Int'l \& Comp. L., 5 (1997) 29-49; M.A. Fitzmaurice and C. Redgwell, "Environmental Non-Compliance Procedures and International Law", Netherlands YB Int'l L., 31 (2000) 35-65. Important contributions are also set out in studies on specific mechanisms that cannot be quoted here for limitations of space.

T. Treves et al., eds., Non-Compliance Procedures and Mechanisms and the Effectiveness of International Environmental Agreements

(C) 2009, T.M.C. ASSER PRESS, The Hague, The Netherlands, and the Authors
} 
An initial survey of the various mechanisms led to the working hypothesis that, while the non-compliance mechanisms follow a common pattern, the differences are significant. A further working hypothesis reached was that the differences concern different ways of overcoming problems that emerge in all mechanisms and do not have to do only with the differences between the basic substantive obligations set out in the agreements as they depend also on the political and geographical (universal versus regional) context.

The method followed in the research project was developed on the basis of these preliminary findings. The first phase would consist of drawing up a common scheme for the examination of each of the mechanisms existing and under negotiation and in making such examination the subject of specific studies: a revised and up-dated version of these studies is included in section I of this book. The second phase would examine - in a "transversal" way - common problems and different solutions emerging from the practice of the various mechanisms. These transversal studies would not be limited to questions emerging within the different mechanisms. They would also focus on the relationships between the mechanisms and general international law, in particular the law of treaties, of State responsibility and of the settlement of disputes; as well as on the relationships between the different mechanisms. The peculiar aspects concerning the role of the European Union and Community, practically ignored by scholars, were considered from the outset as of particular interest. These studies are set out in sections III, IV and V. Section II contains - without any attempt to be complete - papers submitted by specialist personalities involved in the practice of noncompliance mechanisms. Their contribution was not limited to these papers, as these personalities were generous in providing helpful indications to the authors of the various studies during a Symposium held in Milan on 9-10 November 2007 and in previous and subsequent correspondence.

\section{Common Features and Differences in Non-Compliance Mechanisms of Multilateral Environmental Agreements}

An element common to all mechanisms is that they are aimed at furthering the implementation of the relevant agreement and that the nature of the procedures is non-confrontational. These concepts are not always explicitly set out in the agreements or in the decisions establishing the mechanisms, and, when they are, different formulations are used. So it is, for example, that the Aarhus Convention ${ }^{2}$ states that the mechanism to be established shall be of a "non-confrontational, non-judicial and consultative nature" (Article 15); in more detail the Basel Convention's non-compliance mechanism provides that: "The mechanism shall be non-confrontational, transparent, costeffective and preventive in nature, simple, flexible, non-binding and oriented in the

\footnotetext{
2 Treaties will be quoted throughout the book with short names. For a list of abbreviations used and full references see supra at XXXVII. For the Aarhus Convention NCP, see Decision I/7 on Review of Compliance, doc. ECE/MP.PP/2/Add.8 (2001, subsequently issued on 2 April 2004).
} 
direction of helping Parties to implement the provisions of the Basel Convention." ${ }^{3}$ The differences in formulation do not seem to have substantial importance, as what counts are the contents of the procedures.

As regards the legal basis of the non-compliance mechanisms, in most cases their institution is provided for in an "enabling clause" set out in the main agreement as a task to be performed by the COP/MOP. The establishment of the mechanism is then obtained through a decision of the COP/MOP. In some cases the institution of the non-compliance mechanism is not explicitly mentioned in the main agreement, and it has been effected directly by the COP/MOP invoking general provisions of the agreement. This is, for instance, the case of the non-compliance mechanism of the Basel Convention, set up on the basis of general powers to establish subsidiary organs to assess the implementation of the convention, and of the non-compliance mechanism concerning the LRTAP Convention based on similar general clauses of the main Convention and on a more specific clause of one of the Protocols. ${ }^{4}$ In the case of the Espoo Convention the Parties established the non-compliance mechanism on the basis of a very general provision of the Convention and then sought give to it a sounder legal basis through a proposal for adding a specific provision to the main agreement. ${ }^{5}$ However, while the proposed amendment has not entered into force, the MOP-created compliance mechanism functions in a way not different from those established in the framework of agreements explicitly providing for such establishment.

When the main agreement provides explicitly for the establishment of a non-compliance mechanism, in most cases the indications as to its nature and functions are very short, although in other cases a certain amount of detail is introduced. Article 8 of the Montreal Protocol ${ }^{6}$ is a clear example of the first category ("The Parties [...] shall consider and approve procedures and institutional mechanisms for determining non-compliance with the provisions of this Protocol and for the treatment of parties

\footnotetext{
${ }^{3}$ Basel Convention NCP (Decision VI/12 on Establishment of a Mechanism for Promoting Implementation and Compliance, Appendix doc. UNEP/CHW.6/40 (10 February 2003), at 45), para. 2.

${ }^{4}$ See, LRTAP Convention NCP (Decision 1997/2 Concerning the Implementation Committee, its Structure and Functions and Procedures for Review of Compliance, doc. ECE/EB.AIR/53 (7 January 1998), Annex III, at 28, subsequently amended. Consolidated text in Decision 2006/2 on Implementation Committee, its Structure and Functions and Procedures for Review, doc. ECE/EB.AIR/89/Add.1 (5 February 2007), at 4.

5 See, Espoo Convention NCP (Decision II/4 on Review of Compliance, doc. ECE/MP.EIA/4 (7 August 2001), Annex IV, at 72 revised by Decision III/2 on Review of Compliance, doc. ECE/MP.EIA/6 (13 September 2004), Annex II (consolidated text)). See also the proposal for introducing a new Article 14 bis to the Convention, Decision III/7 on Second Amendment to the Espoo Convention, doc. ECE/MP.EIA/6 (13 September 2004), Annex VII, at 93.

${ }^{6}$ For the Montreal Protocol NCP see Decision IV/5 on Non-Compliance Procedure, doc. UNEP/OzL. Pro.4/15 (25 November 1992), at 13 and Annex IV at 44, subsequently amended by Decision X/10 on Review of the Non-Compliance Procedure, doc. UNEP/OzL.Pro.10/9 (3 December 1998), at 23 and consolidated text in Annex II, at 47. The provision of the Barcelona Convention is even shorter: "The Contracting Parties undertake to cooperate in the developing of procedures enabling them to control the application of this Convention and the Protocols" (Art. 21). See also the Barcelona Convention NCP (Decision IG 17/2 on Procedures and Mechanisms on Compliance under the Barcelona Convention and its Protocols, doc. UNEP(DEC)/MED IG. 17/10 (18 January 2008) (the Almeria Report), Annex 5, at 21).
} 
found to be in non-compliance"). Article 18 of the Kyoto Protocol ${ }^{7}$ is an example of the second category. According to this provision, the COP/MOP shall establish "appropriate and effective procedures and mechanisms to determine and to address cases of non-compliance with the provisions of this Protocol, including through the development of an indicative list of consequences, taking into account the cause, type, degree and frequency of non-compliance." The provision adds a much-discussed provision, according to which: "Any procedures and mechanisms under this Article entailing binding consequences shall be adopted by means of an amendment to this Protocol." Another example of detailed indications can be found in the Aarhus Convention's Article 15, which, after giving the already quoted indications as to the nature of the mechanism, adds that: "These arrangements shall allow for appropriate public involvement and may include the option of considering communications from members of the public on matters related to this Convention."

Provision for these kinds of details indicates that the Contracting Parties want to make the task simpler for the COP/MOP by making certain choices before the latter discusses the matter. It may, nonetheless, also create some difficulties during the discussion or the implementation of the non-compliance mechanism. So it is that the political impossibility of adopting the amendment mentioned in Article 18 has made the conclusions adopted by the Kyoto Protocol non-compliance mechanism (including the Enforcement Branch) by definition non-binding, even though they bind, within the Kyoto system, States that want to obtain certain results.

Looking at the institutional aspects, a common pattern recognizable in all systems is that a specialized restricted body is established (the Compliance Committee or Body) which works within the framework of the COP/MOP. There are, however, important differences between the various mechanisms. Firstly, while in the majority of mechanisms the conclusions reached by the compliance body are set out in a report to the COP/MOP and the final decision (whose effects may vary) is taken by the latter, in the Kyoto Protocol mechanism the decision is directly taken by the Compliance Committee and the COP/MOP has only a limited power to decide on appeals against a decision of the Compliance Committee for denial of due process. ${ }^{8}$ The Aarhus Convention mechanism may be seen as something in-between. While the final decision is taken by the MOP, the Committee may directly adopt measures of a facilitative nature in consultation with, or with the agreement of, the non-complying party, or, lacking such agreement, in the form of advice. ${ }^{9}$

Secondly, an important difference concerns the composition of the compliance bodies. In some cases the required fields of expertise of the members are indicated, while in others they are not. More importantly, in most cases the members are representatives of States, even though, as in the Basel Convention mechanism, they may be bound to "serve objectively and in the best interest of the Convention". ${ }^{10}$ However, in a few but important cases they are independent experts serving in their personal

7 For the Kyoto Protocol NCP see Decision 27/CMP.1 on Procedures and Mechanisms Relating to Compliance under the Kyoto Protocol, doc. FCCC/KP/CMP/2005/8/Add.3 (30 March 2006), at 92.

${ }^{8}$ See Kyoto Protocol NCP, section XI.

9 Aarhus Convention NCP, para. 36.

${ }_{10}$ Basel Convention NCP, para. 5. 
capacity (this is the case of the members of the committees established under the Aarhus Convention, the Kyoto Protocol, the Cartagena Protocol ${ }^{11}$ and the Barcelona Convention).

Thirdly, in a limited number of cases, experts nominated as candidates by NGOs may become members of the compliance body, as provided in the Aarhus Convention mechanism. In the Alpine Convention ${ }^{12}$ Verification Committee, which is composed of State representatives, NGOs having observer status in the COP/MOP participate as observers. Thus, their status is not as full as that in the Aarhus mechanism which, as mentioned, is composed of experts serving in their personal capacity.

The fact that the final decision is entrusted to the compliance body and that the compliance body is composed of experts acting in their personal capacity are elements that tend to ensure that the political aspect of the proceeding is minimized, while the technical characteristics are enhanced. Minimization of the political aspects may protect States from politically motivated decisions against them; it may also, however, protect them, for political reasons, from findings and decisions which would be in the interest of the implementation of the convention. It may be wondered, in this connection, whether, had the Montreal Protocol Implementation Committee been composed of experts acting in their personal capacity, it would have been so bold as to qualify, as it did, the request for a grace period submitted by the Russian Federation as a "submission" to the non-compliance procedure. ${ }^{13}$

In the majority of mechanisms decisions are entrusted to the political body and the compliance body is composed of State representatives. In some cases, such as in the Basel Convention mechanism, a compliance body may directly take measures of facilitation and assistance, while more incisive action is reserved to the governing body. Composition by experts serving in a personal capacity while final decisions are entrusted to the Compliance body is found only in the Kyoto Protocol mechanism. In some cases, such as the mechanisms established under the Cartagena Protocol, the Protocol on Water and Health ${ }^{14}$ and the Barcelona Convention, the competence of the compliance body to take measures directly is limited to those of a facilitative nature. The mechanism of the Aarhus Convention, in which a body composed of experts serving in a personal capacity is combined with entrusting the final decision to the political body, is somewhere in the middle. Nevertheless, practice under the Aarhus mechanism seems to indicate that efficiently conducted proceedings and well

${ }^{11}$ See Cartagena Protocol NCP (Decision BS-I/7 on Establishment of Procedures and Mechanisms on Compliance under the Cartagena Protocol on Biosafety, doc. UNEP/CBD/BS/COP-MOP/1/15 (27 February 2004), Annex I, at 98).

12 See the Alpine Convention NCP (Decision VII/4 Mécanisme de verification du respect de la Convention alpine et de ses protocols d'application (Seventh Alpine Conference, 2002)), reprinted in Envt'l Pol'y \& L., 33 (2003) 179 and in T. Treves, L. Pineschi, A. Fodella (eds.), Sustainable Development of Mountain Areas (Milan: Giuffré, 2004) 327.

13 See Report of the Eleventh Meeting of the Implementation Committee, UNEP/OzL.Pro/ImpCom/11/1 (14 September 1995), Annex II; Decision VII/18 on Compliance with the Montreal Protocol by the Russian Federation, doc. UNEP/OzL.Pro.7/12 (27 December 1995), at 34, para. 1; and J. Werksman, "Compliance and Transition: Russia's Non-Compliance Tests the Ozone Regime”, ZaöRV, 56 (1996) 750-773.

${ }_{14}$ See the Protocol on Water and Health NCP (Decision I/2 on Review of Compliance, doc. ECE/ MP.WH/2/Add.3 - EUR/06/5069385/1/Add.3 (3 July 2007)). 
reasoned reports enhance the status before the political body of the conclusions reached by the Compliance body composed of experts serving in their personal capacity.

As regards the way the non-compliance procedures are set in motion, the so-called "triggering" mechanisms, the constant pattern is that the States Parties to the Convention are among the subjects entitled to set in motion the procedure. These include the State whose compliance is to be considered. "Self trigger" is a constant characteristic and - also in light of its relatively frequent use in practice - is a fundamental element to confirm the non-judicial, cooperative character of the proceedings in general. Submissions by the Secretariat are also often (but not always: see, in particular, the Cartagena and the Alpine Conventions' mechanisms) provided for. Submissions from the public are the exception, found in the mechanisms of the Aarhus Convention, of the Protocol on Water and Health and of the PRTRs Protocol. The Alpine Convention's mechanism provides for triggering by observers, which, as mentioned, in that framework are NGO representatives. In the framework of the Espoo Convention mechanism, after a long discussion and contrary to an initial interpretation, it was established that the Implementation Committee would be allowed to trigger the procedure proprio motu on the basis of information provided by NGOs.

Triggering by States Parties different from the non-complying State is a very rare occurrence. As happens for requests by States Parties to human rights conventions against human rights violations by another State Party, States are usually reluctant to take this initiative. This is why the most active non-compliance mechanisms are those where triggering by NGOs or by the Secretariat is admitted.

As regards the procedural guarantees afforded to the States involved in the proceedings, the rights provided to the States under scrutiny are rather extensive, as in all procedures they are entitled to access documents, to comment on submissions, and to be present at the meetings of the Compliance body, with the exception of the deliberative phase. The same cannot be said as regards the State Party that, outside the hypothesis of self-trigger, has made the submission. In most cases the rights granted do not go beyond those granted to any other party to the Agreement. Even though this lack of specific rights for the submitting State may be seen as an element stressing the non-confrontational character of the procedure, it seems unsatisfactory, especially in a context like that of the Basel mechanism, in which the State Party making the submission is an "affected" State. ${ }^{15}$ The Alpine Convention mechanism provides for stricter guarantees, as: "every interested contracting Party is entitled to participate in the entire procedure, to access all relevant documents in their integrity and to take a position on the proceedings" (Section II, paragraph 3.1.1, translation by the present author). An equivalent provision is found in the Aarhus mechanism. A broad reference to "due process" is set out in the Barcelona mechanism (paragraph 28).

The possible outcomes of the non-compliance procedure are often indicated by the relevant instruments. An important aspect is that the purpose of maintaining pressure on the non-complying State, even while specific measures have not - or have not yet been - adopted, is pursued by the various mechanisms. A clear example is the

15 Admittedly, under para. 16 of the Basel Convention NCP, the triggering State may be admitted to the meeting dealing with its submission if the Committee and the Party whose compliance is in question agree. 
progression from the reports that "express disappointment", to those that "note with concern", to further reports that "remain concerned", and to those that "urge" or "strongly urge" of the LRTAP Convention's mechanism. ${ }^{16}$

The contents of the measures depend in part on the nature of the obligations compliance with which is discussed. It may be said that the various instruments insist on cooperative assistance-oriented measures, while in most cases they do not exclude more severe measures that could be seen as sanctions but which it may be preferable to consider as incentives and disincentives. ${ }^{17}$ These include, in particular under the Montreal Protocol and the Kyoto Protocol mechanisms, suspension from certain privileges.

One element which logically precedes the measures taken, be they of a soft-cooperative nature, or of the more severe incentive/disincentive kind, is the determination of non-compliance. ${ }^{18}$ This is the aspect in which the outcomes of non-compliance proceedings come closest to the outcome of a judicial or arbitral proceeding, as the distinction between non-compliance and breach of an international obligation - that a judge or arbitrator could find in its decision - is difficult to draw. The differences are, nonetheless, relevant. The determination of non-compliance by a non-compliance body is functional to the specific proceedings within which it is made and to their possible outcomes, which consist of measures that normally are not binding. When, in cases such as that of the Kyoto mechanism, the measures can be considered as binding, they are so only within the system of the relevant agreement, and, as will be illustrated, there is no implication that the determination of non-compliance is res judicata.

\section{Non-Compliance Mechanisms: An Imperfect Means to Reach Certain ENDS}

Non-compliance mechanisms are established by States in order to deal with the particular needs of multilateral environmental agreements in case compliance by one or more States Parties is questioned. These needs do not consist of the possibility of determining, through a binding procedure, that a breach has been committed, that responsibility has been incurred, that reparation is due. The latter needs, although not excluded by the relevant agreements, are seen as not as important as that of obtaining

16 J. Slingers and W. Kakebeeke (eds.), Cleaning the Air: 25 Years of the Convention on Long-Range Transboundary Air Pollution (Geneva: UN Publications, 2004), 124.

${ }^{17}$ L. Pineschi, "Responsabilità internazionale e procedure di non-compliance", in P. Fois (ed.), Il principio dello sviluppo sostenibile nel diritto internazionale ed europeo dell'ambiente (Napoli: Editoriale Scientifica, 2007) 425-462, at 443.

18 This determination may, however, not be always necessary, as in some cases the procedure may be started when non-compliance is foreseeable: see Findings and Recommendations with Regard to Compliance by Belgium with its Obligations under the Aarhus Convention in Relation to the Rights of Environmental Organizations to Have Access to Justice (Communication ACCC/C/2005/11 by Bond Beter Leefmilieu Vlaanderen VZW (Belgium)), adopted on 16 June 2006, doc. ECE/MP.PP/C.1/2006/4/Add.2 (28 July 2006), and C. Pitea, "The Non-compliance Procedure of the Aarhus Convention: Between Environmental and Human Rights Control Mechanisms", Italian YB Int'l L., 16 (2006) 85-116, at 103-104. 
that the non-complying State is brought, or brought back, to compliance. What counts is that all Parties act in conformity with the agreements and comply with their obligations. This is particularly evident as regards those environmental agreements, for which non-compliance mechanisms have been established, that set out obligations to be continuously complied with over the years, and aim at avoiding risks of a cumulative nature in which each instance of non-compliance has to be seen in conjunction with all other such instances past and future and not looking exclusively at its immediate direct effects.

The non-compliance mechanisms as they exist in practice are imperfect means for achieving these ends. States, justifiably distrusting, although not eliminating, the traditional means of settling disputes and the legal techniques, involving the law of responsibility and the law of treaties, these means are based upon, have preferred to set up mechanisms based on combinations of good will, cooperation, political handling of matters, technical expertise and the prudent recourse to incentives and disincentives which include the possibility of declaring non-compliance. Experience has shown, however, that questions of a legal nature cannot be eliminated and that interpretation of legal texts is one of the most important aspects of the work of compliance bodies. Whether the combination of all these elements, legal and not, succeeds in obtaining the result desired has to be assessed on a case-by-case basis. The right combination of good will, political finesse, legal and technical expertise, whatever the provisions to be applied, depends on the political situation of the moment and on the quality of the men and women engaged in the proceedings.

The fact that a number of new non-compliance mechanisms is currently being negotiated testifies that States Parties to multilateral environmental agreements consider that the setting up of such mechanisms is a necessary, or at least a useful, complement to the obligations set out in the agreement they have adopted. However, in all these negotiations the same difficulties emerge: will the members of the compliance body be acting in a personal capacity or will they be State representatives? Will triggering by the Secretariat or by the Compliance body itself be admitted? Will the outcomes be directly adopted by the Compliance body, or by the COP/MOP? Will NGOs or the public at large have a role in triggering the proceedings or in the election of members? Is the submitting party to be given a specific role and guarantees in the proceedings? Answers to these questions are not to be taken for granted. Each negotiation sees them discussed again. This shows that, notwithstanding agreement on the importance of non-compliance mechanisms and on the limited common pattern of such mechanisms, States are far from agreeing on a common model. With results that can vary in different contexts, they remain engaged in debates whose ultimate object concerns striking what each of them considers the right balance between objective assessment by experts and the measure of control they wish to exercise on the procedure, as members of the compliance bodies, of COP/MOPs or as Parties whose compliance is in question. 
Section I

Non-Compliance Procedures and Mechanisms

in Environmental Agreements

Universal Treaties 
1 


\title{
Chapter 1
}

\section{The Non-Compliance Procedure of the 1987 Montreal Protocol to the 1985 Vienna Convention on Substances that Deplete the Ozone Layer}

\author{
Francesca Romanin Jacur
}

1. Brief Introduction to the Montreal Protocol

The Convention for the Protection of the Ozone Layer (Ozone Convention) ${ }^{1}$ intends combat the harmful effects on human health and the environment caused by modifications of the ozone layer due to human activities.

The Convention establishes a plenary organ, the Conference of the Parties (COP) which meets on a regular basis and reviews the effectiveness of the Convention. The COP is entitled to adopt Protocols ${ }^{2}$ and it made use of this competence in 1987, when it adopted the Protocol on Substances that Deplete the Ozone Layer (Montreal Protocol or the Protocol), ${ }^{3}$ which provides for the progressive elimination of substances that deplete the ozone layer (ODS).

The Ozone Convention and the Montreal Protocol share the same institutional structure: the COP, acting as Meeting of the Parties (MOP), although with a different composition because not all Parties to the two treaties coincide, serves also the Proto$\mathrm{col}$; and the Secretariat, provided by UNEP, functions as the administrative body for both treaties. ${ }^{4}$

The Montreal Protocol requires Parties to reduce and phase out production and consumption of certain ODS by specified percentages in accordance with defined timetables. In order to achieve these aims and to stimulate participation in the Protocol, restrictions are also imposed on Parties with regard to the trade of ODS with nonParties. ${ }^{5}$

The Protocol was adjusted and amended by the MOP on several occasions in order to strengthen the commitments of the Parties: new substances to be reduced and phased out were added, and new timetables for these reductions were established. ${ }^{6}$

\footnotetext{
1 Vienna, Austria, 22 March 1985, entered into force on 22 September 1989, ILM, 26 (1987) 1529.

2 See Art. 8 of the Convention.

${ }^{3}$ Montreal, Canada, 16 September 1987, entered into force on 1 January 1989, ILM, 26 (1987) 1550

${ }^{4}$ On the role of the Secretariat with regard to compliance matters, see infra para. 5.1.

5 See Art. 4 of the Montreal Protocol.

6 The Protocol was adjusted and amended by the second Meeting of the Parties (London, 27-29 June 1990), entered into force on 10 August 1992; by the fourth Meeting of the Parties (Copenhagen, 23-25

T. Treves et al., eds., Non-Compliance Procedures and Mechanisms and the Effectiveness of International Environmental Agreements

(C) 2009, T.M.C. Asser PRESS, The Hague, The Netherlands, and the Authors
} 
The practice of frequently updating the commitments under the Protocol has contributed to the success of the Montreal Protocol, which is generally considered one of the most effective multilateral environmental treaties.

For a better implementation of the Protocol, the MOP has created the following subsidiary bodies: the Bureau, ${ }^{7}$ four Assessment Panels, ${ }^{8}$ the Open-Ended Working Group, which reviews the reports of the Assessment Panels and prepares draft proposals for amendments to the Protocol. ${ }^{9}$ The recommendations of the Open-ended Working Group, although without legal value, constitute a negotiated compromise among all the Parties on certain issues and have therefore great influence in the adoption of final decisions by the MOP.

Another subsidiary body which has been established to facilitate the transfer of financial resources and technology to developing countries is the Executive Committee of the Multilateral Fund. This Committee monitors policies and guidelines relating to the Protocol's implementation and develops plans for the allocation of financial resources of the Multilateral Fund among the Implementing Agencies (UNDP, UNEP, UNIDO and the World Bank).

In order to deal with matters concerning compliance with the Protocol, the MOP has established an Implementation Committee and has approved a procedure for determining situations of non-compliance.

\section{Legal Basis of the Mechanism and Negotiating History}

Article 8 of the Montreal Protocol provides that:

"The Parties, at their first meeting, shall consider and approve procedures and institutional mechanisms for determining non-compliance with the provisions of this Protocol and for treatment of Parties found to be in non-compliance."

At the first MOP the Parties decided to establish an Open-ended ad hoc Working Group to develop proposals on procedures and institutional mechanisms for determining

November 1992), entered into force on 14 June 1994; by the ninth Meeting of the Parties (Montreal, 15-17 September 1997), entered into force on 10 November 1999; by the eleventh Meeting of the Parties (Beijing, 29 November-3 December 1999), entered into force on 25 February 2002.

7 The Bureau is comprised of the President, three Vice Presidents and the Rapporteur, elected by each MOP. It has a facilitative role by assisting the MOP in reviewing the activities developed by the working groups.

8 These technical bodies (Panel for Scientific Assessment, Panel for Environmental Assessment, Panel for Technical Assessment and the Panel for Economic Assessment), were established by the first MOP, see Report of the First Meeting of the Parties, doc. UNEP/OzL.Pro.1/5 (6 May 1989), at 14. They evaluate the control measures on the production and consumption of ODS on the basis of available scientific, environmental, technical and economic information and have strongly influenced the adoption by the MOP of the amendments and adjustments mentioned above.

9 The Open-ended Working Group was established by the first MOP, see Report of the First Meeting of the Parties, supra n. 8, at 15. It is composed of representatives of all the Member States and may discuss all the issues on the agenda of the MOP, except for compliance matters which are handled by the Implementation Committee. 
non-compliance and submit them to the Ozone Secretariat. ${ }^{10}$ Parties and signatories to the Protocol were invited to participate in the activity of the Working Group by submitting comments and proposals on the procedure and on the possible action to take with regard to Parties found to be in non-compliance.

The second MOP went further in the consideration of the topic and adopted the non-compliance procedure on a temporary basis. ${ }^{11}$ The Parties gave mandate to the Working Group to further elaborate the non-compliance procedure and set the terms of reference for the Implementation Committee. At the following third MOP, the Working Group was requested to identify possible situations of non-compliance, to develop an indicative list of advisory and conciliatory measures to encourage compliance and to frame the advisory and conciliatory role of the Implementation Committee. $^{12}$

While some of the debated issues, such as the indicative list of measures, ${ }^{13}$ were included in the final version, on others, such as the identification of situations to be classified as non-compliance, no agreement was reached and they were omitted.

The non-compliance procedure was established by Decision IV/5 of the fourth MOP. ${ }^{14}$ The preamble of this Decision recognises Article 8 as the appropriate legal tool for providing the MOP with the competence to establish the non-compliance procedure $^{15}$ and recalls that:

"There is no need to expedite the amendment procedure under Article 9 of the Vienna Convention for the Protection of the Ozone Layer."

Not all the Parties to the Protocol participated in the elaboration of the non-compliance procedure: Australia, Austria, Norway, the Netherlands and the United Kingdom have been particularly active while only few developing countries were involved; the latter were concerned about their ability to comply and tended to avoid a stringent compliance mechanism. This is one of the reasons why a "softer" procedure was ultimately adopted. ${ }^{16}$

10 See Report of the First Meeting of the Parties, supra n. 8, at 15-16.

11 Decision II/5 on Non-compliance, Annex III, doc. UNEP/OzL.Pro.2/3 (20 June 1990), at 11. In this interim non-compliance procedure the Implementation Committee was composed of five members.

${ }_{12}$ Decision III/2 on Non-Compliance Procedure, doc. UNEP/OzL.Pro.3/11 (21 June 1991), at 18-19.

${ }^{13}$ See infra para. 3.

14 Decision IV/5 on Non-Compliance Procedure, doc. UNEP/OzL.Pro.4/5 (25 November 1992), at 13 and Annex IV at 44 (Non-compliance procedure).

15 Non-compliance procedure, Preamble: "The following procedure has been formulated pursuant Article 8 of the Montreal Protocol."

${ }^{16}$ For further details on the elaboration of the procedure and on participation of other States, see D.G. Victor, The Early Operation and Effectiveness of the Montreal Protocol's Non-Compliance Procedure, IIASA Paper ER-96-2 (1996), at 5. 


\section{The Text Establishing the Mechanism}

Decision IV/5 of the fourth MOP established the non-compliance procedure and adopted the following indicative list of measures that might be taken by the MOP in cases of non-compliance:

“a) appropriate assistance, including assistance for the collection and reporting of data, technical assistance, technology transfer and financial assistance, information transfer and training; b) issuing cautions; c) suspension, in accordance with the applicable rules of international law concerning suspension of the operation of the treaty, of specific rights and privileges under the Protocol, whether or not subject to time limits, including those concerned with industrial rationalization, production, consumption, trade, transfer of technology, financial mechanism and institutional arrangements." 17

After several years of operation of the non-compliance procedure, the ninth MOP recognised the importance of a regular review of the procedure in order to guarantee its effective and efficient activity and established an ad hoc Working Group of legal and technical experts on non-compliance, ${ }^{18}$ with the specific mandate of reviewing the non-compliance procedure and considering modalities to strengthen it. After considering the Working Group's Report, the tenth MOP acknowledged that the non-compliance procedure was functioning satisfactorily and adopted only marginal amendments aimed at clarifying some aspects of the procedure. ${ }^{19}$ The amendments introduced the provision for a reminder to be sent by the Secretariat to Parties in potential non-compliance and introduced new rules for the election of the Implementation Committee's members.

Furthermore, the issue of persistent non-compliance was considered and the Implementation Committee was requested, consistent with its practice, to make the appropriate recommendations to the MOP "with a view to ensuring the integrity of the Montreal Protocol, taking into account the circumstances surrounding the Party's persistent pattern of non-compliance." ${ }^{20}$ On this occasion it was also decided to review the procedure no later than 2003 but no decision was adopted regarding the introduction of an automatic review of non-compliance, although a proposal for an automatic review of compliance every four years had been envisaged. ${ }^{21}$

17 The List of measures is contained in the Report of the Fourth Meeting of the Parties, Annex V, doc. UNEP/OzL.Pro.4/5 (25 November 1992).

${ }^{18}$ The Working Group, composed of fourteen members representing equally both developed and developing countries, was established by Decision IX/35 on Review of the Non-Compliance Procedure, doc. UNEP/OzL.Pro.9/12 (25 September 1997), at 41.

${ }_{19}$ The amended non-compliance procedure is set out in Decision X/10 on Review of the Non-Compliance Procedure, Annex II, doc. UNEP/OzL.Pro.10/9 (3 December 1998) at 23 and consolidated text in Annex II, at 47.

${ }^{20}$ Ibid., para. 3.

${ }^{21}$ Report of the Ad-Hoc Working Group of Legal and Technical Experts on Non-Compliance with the Montreal Protocol, doc. UNEP/OzL.Pro/WG.4/1/3 (18 November 1998), para. 55: "With regard to automatic review of non-compliance, there was general support for a further review in principle but views differed on whether it should be undertaken only if difficulties emerged in the operation of the current procedure.[...]" 
In 2002 the United States proposed some amendments to the procedure that aimed, in the first place, to increase continuity in participation in the Implementation Committee by allowing outgoing members to participate as observers, with an advisory capacity and, secondly, to shorten the terms for submission of data by the Parties to the Secretariat. This draft, considered as a package deal, was withdrawn due to the lack of agreement on all the proposed elements. ${ }^{22}$

\section{The Principles Governing the Mechanism and the Procedure}

The procedure is conceived as cooperative, non-confrontational and conciliatory. This approach emerges clearly from the wording of Article 8 of the Protocol, which states:

"The Implementation Committee shall consider the submissions, information and observations referred to in paragraph 7 with a view to securing an amicable solution of the matter on the basis of respect for the provisions of the Protocol."

The facilitative approach of the non-compliance procedure is shown by the fact that, rather than adopting sanctions against States in non-compliance, the Implementation Committee has used strong measures only as a last remedy against Parties that did not show good will and effective action to return to compliance or that, although in good faith, are in persistent non-compliance.

To date there have been no cases of a developing country being deprived of assistance or being suspended from its rights and privileges under the Protocol. However, as will be further analysed, in the case of the Russian Federation's non-compliance the MOP limited the right of the country to export depleting substances to some Parties to the Protocol. ${ }^{23}$

The non-compliance procedure aims at being transparent by providing that:

"The report [of the Implementation Committee], which shall not contain any information received in confidence, shall be made available to any person upon request. All information exchanged by or with the Committee that is related to any recommendation by the Committee to the Meeting of the Parties shall be made available by the Secretariat to any Party upon its request $[\ldots] .{ }^{24}$

Furthermore, the non-compliance procedure retains the main elements of due process such as notification, right to a fair hearing, impartiality. ${ }^{25}$

${ }^{22}$ Report of the Fourteenth Meeting of the Parties, doc. UNEP/OzL.Pro.14/9 (5 December 2002), para. 39

${ }^{23}$ Decision VII/18 on Compliance with the Montreal Protocol by the Russian Federation, doc. UNEP/ OzL.Pro.7/12 (27 December 1995), at 33-35. See also K. Madhava Sarma, "Compliance with the Multilateral Environmental Agreements to Protect the Ozone Layer", in U. Beyerlin, P.-T. Stoll and R. Wolfrum (eds.), Ensuring Compliance with Multilateral Environmental Agreements. A Dialogue between Practitioners and Academia (Leiden: Martinus Nijhoff, 2006) 25-38, at 25.

${ }^{24}$ Non-compliance procedure, para. 16.

25 See infra, para. 8 


\section{INSTITUTIONAL ASPECTS}

The non-compliance procedure of the Montreal Protocol is enacted mainly by three organs: the Secretariat, the Implementation Committee and the MOP.

\subsection{The Secretariat}

The Secretariat arranges the meetings of the Implementation Committee and provides advice for the accomplishment of its functions.

The main duties of the Secretariat are to receive communications and reports from Parties on their status of compliance and submissions of Parties asserting that another Party may not be in compliance and if necessary request them to add further information.

The Secretariat is also the depositary of all information related to compliance.

When a possible case of non-compliance occurs, the Secretariat reports the matter, in the first place, to the Implementation Committee, ${ }^{26}$ and subsequently to the MOP. The Secretariat has an important mediatory role between the Parties and the Implementation Committee because all relevant information must go through its prior supervision before being submitted to the Committee. Moreover, the Secretariat is the link between the Implementation Committee and the Executive Committee of the Multilateral Fund.

\subsection{The Implementation Committee}

\section{a) Composition}

The Implementation Committee is composed of ten representatives of the Parties, elected by the MOP for a term of two years, on an equitable geographical representation basis. ${ }^{27}$ There was extensive discussion on whether members of the Implementation Committee should be elected as representatives of Parties or as experts serving in their personal capacity, but it was impossible to reach an agreement on the latter position. ${ }^{28}$

Each Party shall endeavour to ensure that the same individual remains its representative throughout the entire term of office. Outgoing Parties may be re-elected for one consecutive term, and after this the member shall be eligible again only after an absence of one year. ${ }^{29}$ In order to ensure a certain degree of institutional continuity,

${ }^{26}$ Non-compliance procedure, paras. 1, 2, 4.

${ }^{27}$ Ibid., para. 5. In practice, equitable geographic distribution is assured by the selection of two representatives for each of the five United Nations regional groups (Western Europe and others; Africa; Asia and the Pacific; Latin America and the Caribbean; Eastern Europe).

${ }^{28}$ G. Bankobeza, Ozone Protection: the International Legal Regime (Utrecht: Eleven International Publishing, 2005), at 261: "Parties were concerned that too much independence of individual members may cause the Meeting of the Parties to lose the Committee's control and the Meeting's decision-making power over matters of non-compliance."

${ }^{29}$ These provisions were included on the occasion of the revision of the Non-compliance procedure. See Decision X/10, supra n. 19. 
every year new members replace half of the membership of the Implementation Committee.

With regard to the requested expertise of members it was decided that, once their expert credentials had been ascertained, each Party has the right to decide on the qualifications of its representative. It may be observed that leaving the discretionary power to each Party may cause lacunae in the competence of the Implementation Committee and that it would then be necessary to coordinate Member States when choosing their representatives in order to ensure a differentiated composition that guarantees the technical competences necessary for an efficient functioning of the Committee.

The Implementation Committee elects its own President and Vice-President every year, and the latter has also the function of Rapporteur.

\section{b) Observers}

The Implementation Committee may invite to its meetings representatives of the Multilateral Fund Secretariat and of the Implementing Agencies who play a fundamental role in granting financial assistance to developing countries. ${ }^{30}$ These organizations provide useful information to the Implementation Committee on projects to phase out ODS that are developed with their financial assistance.

When States with economies in transition expressed their difficulties in respecting their Protocol's obligations, the Implementation Committee invited representatives of the Secretariat of the Global Environmental Facility (GEF) and of the Technology and Economic Assessment Panel to participate in its meeting.

On the one hand the GEF provides financial assistance to countries with economies in transition which, as they are not developing countries, are not eligible for funding under the Multilateral Fund. On the other hand the Technology and Economic Assessment Panel was requested to analyse the particular situation of countries with economies in transition who were in non-compliance for the current year despite the efforts taken and to report on possible solutions for tackling their non-compliance. ${ }^{31}$

The participation of the GEF, although not envisaged in the text of the non-compliance procedure, has become a customary practice of the Implementation Committee when the compliance of a State receiving its assistance is under consideration. ${ }^{32}$

Recently, on the basis of a recommendation of the Implementation Committee, the

${ }^{30}$ Representatives of the Fund Secretariat and of the Implementing Agencies participated in an Implementation Committee meeting for the first time in September 1992. See Report of the Fourth Meeting of the Implementation Committee, doc. UNEP/OzL.Pro/ImpCom/4/2 (25 November 1992), para. 2.

${ }_{31}$ Technology and Economic Assessment Panel Ad Hoc Working Group on CEIT Aspects, Assessment of the Basic Problems Confronting Countries with Economies in Transition in Complying with the Montreal Protocol, 9 (1995).

${ }^{32}$ See the regret expressed at the thirty-ninth Meeting of the Implementation Committee (12-14 September 2007) about the absence of a representative of the GEF. The Committee expressed the view that the presence of a GEF representative was important whenever the potential non-compliance of a Party receiving assistance from the GEF was under consideration (Report of the Implementation Committee under the NonCompliance Procedure for the Montreal Protocol on the Work of its Thirty-ninth Meeting, doc. UNEP/OzL. Pro/ImpCom/39/7 (11 November 2007), 2). 
MOP decided that the President and Vice-President of the Implementation Committee and the Chair and Vice-Chair of the Executive Committee of the Multilateral Fund should attend each other's meetings in order to facilitate the exchange of information between them. ${ }^{33}$ This decision is due to the need to increase the exchange of information on the situations of developing countries which, after the expiry of the grace period, i.e., after 1999, must implement the obligations relating to the control and phase out of ODS.

During the negotiation of the non-compliance procedure the possibility was envisaged that the Implementation Committee may consider information from non-governmental sources, such as non-governmental organisations, private entities, mass media, individuals, but this proposal met with some objections. ${ }^{34}$ These actors can, however, address their submissions to the Secretariat.

\subsection{The Meeting of the Parties}

The MOP as the political body, representing the full membership of the Parties, considers the report of the Implementation Committee and adopts the draft decisions approved by the Implementation Committee.

Only the MOP is entitled to take measures of assistance and, as a last resort, sanctions in order to ensure full compliance with the Protocol, ${ }^{35}$ while the Implementation Committee's mandate is limited to the adoption of recommendations to Parties. To date, the practice shows that all draft decisions proposed by the Implementation Committee have been adopted by the MOP. ${ }^{36}$

There are dissenting opinions as to whether the MOP has a discretionary power in indicating the measures of the List or if it should follow an ascending order that starts from the more amicable steps, such as financial and technical assistance, ending with the more severe ones, which may be taken in cases of persistent non-compliance. ${ }^{37}$

NGOs may participate in the MOP as observers, unless one third of the Parties object $^{38}$ and in these cases they may provide information on compliance and raise concerns and pressure on governments to comply.

${ }_{33}$ Decision XIV/37 on Interaction between the Executive Committee and the Implementation Committee, doc. UNEP/OzL.Pro.14/9 (5 December 2002), 60. See also Report of the Twenty-Sixth Meeting of the Implementation Committee, doc. UNEP/OzL.Pro./ImpCom/26/5 (23 July 2001), para. 51.

${ }^{34}$ Report of the Third Meeting of the Ad-Hoc Working Group of Legal and Technical Experts on NonCompliance with the Montreal Protocol, doc. UNEP/OzL.Pro/WG.3/3/3 (9 November 1991), para. 23.

35 Non-compliance procedure, para. 9.

${ }^{36}$ See the document prepared by the Ozone Secretariat for the Implementation Committee's members: Implementation Committee under the Non-Compliance Procedure of the Montreal Protocol on Substances that deplete the Ozone Layer, Primer for Members, October 2007, available at $<$ http://ozone.unep.org/Publications $>$ (Implementation Committee Primer), at 20.

${ }^{37}$ See the case of non-compliance of the Russian Federation, infra para. 15.2.

${ }^{38}$ Rule 7 of the Rules of Procedure of the Meeting of the Parties to the Montreal Protocol (Decision I/1 on Rules of procedure for Meetings of the Parties, doc. UNEP/OzL.Pro.1/5 (6 May 1989), Annex I). 


\section{Functions of THE COMMitTEe}

The Implementation Committee serves as an advisory and conciliatory body. It meets twice a year, reviews the reports and recommends action to the MOP.

The Implementation Committee is required to consider submissions forwarded to it by the Secretariat relating to the implementation of both procedural obligations, such as reporting on relevant data and baselines, ${ }^{39}$ research and public awareness activities, ${ }^{40}$ and substantive commitments: the phase-out of the production and consumption of ODS, the limitations on trade in controlled substances with non-Parties to the Protocol, ${ }^{41}$ the establishment of systems for licensing the import of new, used, recycled ODS. ${ }^{42}$

When necessary to achieve a complete opinion on the matter, it may ask the Secretariat for further information or, with the consent of the Party under scrutiny, it may decide to undertake on site inspections to ascertain specific facts.

The original non-compliance procedure was amended with a new paragraph introducing a specific function according to which the Implementation Committee shall

"[i]dentify the facts and possible causes relating to individual cases of non-compliance referred to the Committee and make appropriate recommendations to the Meeting of the Parties". ${ }^{43}$

In light of this provision, it may be observed that the Implementation Committee is charged not only with taking into account the information provided by the Parties but it should also investigate in order to find out the reasons at the basis of the non-compliance situation.

After having identified the facts and causes of non-compliance, the Implementation Committee submits its report, with appropriate recommendations, to the MOP.

Although, in general, the Committee addresses cases of individual non-compliance, it may not be excluded that it may be concerned with more general issues on compliance, possibly arising from an individual case of non-compliance. ${ }^{44}$

An issue which would need further attention is the one concerning how persistent patterns of non-compliance may be treated either by the Implementation Committee or by the MOP, in particular with regard to a definition of the concept, or by the development of criteria on the subject. ${ }^{45}$

39 Obligations deriving from Arts. 5 and 7 of the Montreal Protocol.

${ }^{40}$ Obligations deriving from Art. 9 of the Montreal Protocol.

${ }^{41}$ See Montreal Protocol, Art. 4.

${ }^{42}$ See ibid., Art. 4B.

${ }^{43}$ Non-compliance procedure, para. 7(d).

${ }^{44}$ Ibid., para. 7(b): "The functions of the Implementation Committee shall be [...] to receive, consider and report on any information or observations forwarded by the Secretariat in connection with the preparation of the reports referred to in Article 12(c) of the Protocol and on any other information received and forwarded by the Secretariat concerning compliance with the provisions of the Protocol."

${ }^{45}$ This matter was taken into consideration by the Working Group in charge of reviewing the noncompliance procedure, see supra para. 3 . 


\section{TRIGGER MECHANISM}

The non-compliance procedure may be initiated either by the Secretariat or by another Party or even, through a self-trigger, by the same Party which is unable to comply.

a) Submission by One or More Parties

Paragraph 1 of the non-compliance procedure states that:

"If one or more Parties have reservations regarding another Party's implementation of its obligations under the Protocol, those concerns may be addressed in writing to the Secretariat. Such a submission shall be supported by corroborating information."

The Secretariat, having received a submission on a possible case of non-compliance, shall within two weeks inform the Party concerned by transmitting a copy of the submission. The Party whose compliance is at issue may in reply, within three months or a longer period, submit information to the Secretariat and other Parties concerned. Once this documentation has been received, the Secretariat shall submit all the data to the Implementation Committee, which shall consider the matter as soon as practicable. ${ }^{46}$

\section{b) Submission through the Secretariat's Report}

The Protocol provides the obligation for Parties to report on an annual basis data on their production, consumption, import and export of controlled substances. ${ }^{47}$ Through these reports the Secretariat may become aware of a potential situation of non-compliance. In such a case, the Secretariat may request the Party concerned to furnish the necessary information about the matter. The procedure continues as in the abovementioned situation: the Party concerned has three months of time to reply to the Secretariat's request and after the expiry of this period the Secretariat shall report the matter both to the Implementation Committee and to the MOP. In practice, the report is considered first by the Implementation Committee, ${ }^{48}$ which makes recommendations to the MOP for decisions.

It has been noted that the triggering power of the Secretariat may not be considered as a strict obligation to report the possible situation of non-compliance to the Implementation Committee because the first step the Secretariat may undertake to activate the procedure is the request for information from the Party in possible non-compliance and from the wording of the text, only after this request, does the Secretariat have the obligation to include the matter in its report. ${ }^{49}$

${ }^{46}$ Non-compliance procedure, para. 2.

47 Montreal Protocol, Art. 7.

48 The submission to the Implementation Committee should be made at least four weeks before its meeting. See Report of the Implementation Committee on the Work of its Second Meeting, doc. UNEP/OzL.Pro/ ImpCom/2/3 (12 April 1991).

49 Victor, supra n. 16, at 5: "The Secretariat has an ambiguous obligation to inform the Implementation Committee if it becomes aware of possible non-compliance." 
c) Self Trigger

The procedure of "self-incrimination" occurs

"When a Party concludes that, despite having made its best, bona fide efforts, it is unable to comply fully with its obligations under the Protocol, it may address to the Secretariat a submission in writing, explaining, in particular, the specific circumstances that it considers to be the cause of its non-compliance." ${ }^{50}$

There have been many cases of self-incrimination, the first of which was the submission by the Russian Federation and by other countries with economies in transition that will be discussed in para. 15.2.

\section{d) Other Triggering Methods Envisaged during the Negotiations of the Non-Compliance Procedure}

In the course of the 1998 review of the non-compliance procedure there was a proposal to allow the Secretariat of the Multilateral Fund, the Implementing Agencies and other actors, who are in a strategic position to achieve relevant information, to bring non-compliance cases to the attention of the Implementation Committee. However, differing views were expressed on the issue and it was preferred to resort to these sources only to provide complementary information to the Secretariat while preparing its report. ${ }^{51}$

Another proposal envisaged in 1998 was about granting to the Implementation Committee the additional function of initiating reports and recommendations for consideration by the MOP, but after considering the proposal, the Working Group concluded that:

"The system had not shown any lacunae that warranted giving such authority to the Committee. Consequently, it decided not to pursue the proposal." ${ }_{52}$

\section{The Procedure Before the Implementation Committee And Procedural SAFEguards}

As noted above, although the Montreal Protocol Non-compliance procedure is based on facilitative and amicable principles, it also envisages principles of due process, such as notification, right to a fair hearing and impartiality, which are usually found in traditional dispute settlement mechanisms.

50 Non-compliance procedure, para. 4

${ }^{51}$ Report of the Ad Hoc Working Group of Legal and Technical Experts on Non-Compliance with the Montreal Protocol, supra n. 21. For a detailed description of the role of these organizations in the Noncompliance procedure, see the Implementation Committee Primer, supra n. 36, at 12.

${ }_{52}$ Report of the Ad Hoc Working Group of Legal and Technical Experts on Non-Compliance with the Montreal Protocol, supra n. 21 
As far as notification is concerned, the procedure provides that when the Secretariat becomes aware of a possible situation of non-compliance it notifies the Party concerned of its possible non-compliance within two weeks and the latter has three months, or such longer period as the circumstances of the matter may require, to respond to the alleged facts. An amendment to the procedure was introduced stating that if the Secretariat does not receive a reply from the Party concerned within three months, it shall send a reminder to urge a response and to ascertain whether the Party is encountering difficulties in submitting information. ${ }^{53}$

With regard to the right to a fair hearing, the procedure grants the Party that is potentially in non-compliance the opportunity to express its position on the non-compliance issues at stake. ${ }^{54}$ Where a Party under scrutiny is not a member of the Implementation Committee, it shall be entitled to participate in the meetings where its submission is considered. However, the Party in potential non-compliance is not allowed to participate in the elaboration and adoption of the recommendation concerning its compliance case. ${ }^{55}$

The possibility of appeal against decisions of the MOP was envisaged on the occasion of the first review of the non-compliance procedure, ${ }^{56}$ but no support was expressed for this proposal which, at least at that time, was perceived as premature and it has not been subsequently reconsidered.

With regard to the meetings of the Implementation Committee, the necessity to make Parties feel free to provide as much data and information on their situation as possible, without worrying about the disclosure of sensitive data, has been the major reason for the exclusion of observers from the meetings. Hence, confidentiality is considered as a basic element of the non-compliance procedure that transmits trust to the participants and has to be preserved and therefore the Implementation Committee and the Parties involved in the deliberations are required not to communicate information they receive in confidence..$^{57}$

Furthermore, in as much as access to documents is concerned, the Parties can consult, upon request, communications or recommendations exchanged between the Implementation Committee and the MOP, but they must guarantee the protection of confidential information. ${ }^{58}$

In relation to transparency, on the other hand, the report of the Implementation Committee, which shall not contain any information received in confidence, is available to any person upon request. ${ }^{59}$

${ }_{53}^{53}$ Non-compliance procedure, as amended, paras. 2 and 3.

${ }^{54}$ Ibid., para. 10.

${ }_{55}$ Ibid., para. 11.

${ }^{56}$ Report of the Ad Hoc Working Group of Legal and Technical Experts on Non-Compliance with the Montreal Protocol, supra n. 21.

${ }^{57}$ Non-compliance procedure, para. 15.

${ }_{58}^{58}$ Ibid., para. 16.

${ }^{59}$ Ibid. 


\section{SOURCES OF INFORMATION}

\subsection{Information from the Parties}

The Implementation Committee may ask for and receive information only through the Secretariat ${ }^{60}$ and if necessary it may undertake, upon invitation of the Party concerned, information gathering in the territory of the Party. ${ }^{61}$

Once the procedure has been established, the Party concerned is entitled to participate in the consideration by the Implementation Committee of its submission, and therefore it may directly address the Implementation Committee with relevant information. ${ }^{62}$

When the Secretariat becomes aware of a case of potential non-compliance, it may request the Party concerned to furnish the necessary information on the matter. The Secretariat may also ask for further clarification from Parties when needed, in particular when discrepancies emerge with other data provided, for example, by the Executive Committee of the Multilateral Fund. However, it has no right to reject the submitted data and in the case inconsistencies remain, the data provided by the Party should be used. ${ }^{63}$

\subsection{Information from Other Sources}

Although no role is expressly envisaged for civil society, the Secretariat may obtain relevant information from NGOs or other non-state actors; in fact, from the wording of para. 3 of the non-compliance procedure stating that:

"Where the Secretariat, during the course of preparing its report, becomes aware of possible non-compliance by any Party with its obligation under the Protocol [...]",

it seems that the Secretariat may also rely on informal sources of information and that therefore, although in an indirect way, NGOs may play an important role by informing the Secretariat of possible situations of non-compliance.

In the course of the review of the procedure it was proposed that the Implementation Committee could seek information directly from the Implementing Agencies and other intergovernmental organisations. However, concerns were expressed with

${ }^{60}$ Ibid., para. 7(c)

${ }^{61}$ Ibid., para. 7(e)

${ }^{62}$ Ibid., para. 10.

${ }^{63}$ On discrepancies between data provided by the Party to different organs, see Decision VII/20 on Discrepancy between the Data Reported by a Party to the Ozone Secretariat and the Data Presented by that Party to the Executive Committee of the Multilateral Fund, doc. UNEP/OzL.Pro.7/12 (27 December 1995). On discrepancies between data provided by a Party and data coming from a different source, see ibid., para. 38: "Regarding potential discrepancies between data submitted by a Party and data available elsewhere, as was the case concerning the population figures for Lebanon, the Committee had agreed that the best available data should be used whenever possible and supported consultations by the Secretariat to that end. The Committee had also agreed, as the matter concerned sovereign States, that data submitted and supported by an individual country might be respected." 
regard to potential conflicts between information originating from the Parties and other sources and consequently the proposal failed. ${ }^{64}$

Although a formal amendment to the procedure was rejected,${ }^{65}$ in practice representatives of the Executive Committee, of the Secretariat of the Multilateral Fund and of relevant Implementing Agencies regularly attend meetings of the Implementation Committee and provide important information about the technical and financial aspects of the Parties' compliance. ${ }^{66}$

With regard to physical data relating to the ozone layer, the Global Ozone Observing System ${ }^{67}$ provides additional information on the atmospheric concentration of ozone through the use of remote sensing by satellites, ${ }^{68}$ without the need to access the territories of Member States. This source of information constitutes "a very rough and indirect check of the information produced by the parties themselves" ${ }^{\prime 69}$ but nonetheless it could be considered as a soft form of evidence of the data reported in the national reports by the Parties.

\section{DECISION-MAKING}

The procedure does not provide for specific rules on how the Implementation Committee shall adopt its decisions. In the 1998 review of the non-compliance procedure, there was a proposal to introduce majority voting, but the proposal was withdrawn "as the rules of procedure dealt satisfactorily with the decision-making rules for adoption

${ }^{64}$ Report of the Ad Hoc Working Group of Legal and Technical Experts on Non-Compliance with the Montreal Protocol, supra n. 21.

${ }^{65}$ Ibid., para. 24: "The proposal to amend subparagraph 7(e) to include exchange of information with the GEF Council, the implementing agencies of the Multilateral Fund and the Technology and Economic Assessment Panel, as well as the Secretariat of the Multilateral Fund, was supported by some experts as a reflection of what already happened in practice. There was, however, opposition by some experts to the inclusion of certain of those bodies. Regarding this latter point, it was noted that adding the names of just some of the bodies would be limitative and that subparagraph 7(c) covered information-gathering in a nonlimitative manner. The proposal was consequently not accepted by the Group."

${ }^{66}$ On the participation as observers of these agencies, see supra para. 5.2(b). The Implementation Committee Primer (supra n. 36, at 13) describes the practice of gathering information from the Implementing Agencies: "At the request of the Ozone Secretariat, the implementing agencies provide information both before and during the meetings of the Committee on the status of the technical and financial assistance which they are providing to Article 5 Parties and non-Article 5 countries with economies in transition that are under consideration by the Committee. The implementing agencies provide information during meetings through their representatives, while information made available before meetings is presented in meeting documents that are distributed to the members of the Committee in advance of Committee meetings."

${ }^{67}$ This system was established by the World Meteorological Organization (WMO), under the umbrella of the UNEP Global Environmental Monitoring System and has approximately 140 monitoring stations worldwide, which are supplemented by remote sensing by satellites.

${ }^{68}$ Remote sensing is the measurement or acquisition of information of an environmental phenomenon or an object by a recording device that is not in physical or intimate contact with the object being monitored.

${ }^{69} \mathrm{~J}$. Wettestad, "Enhancing Climate Compliance - What are the Lessons to Learn from Environmental Regimes and the EU?", in O. Stokke, J. Hovi and G. Ulfstein (eds.), Implementing the Climate Regime. International Compliance (London: Earthscan, 2005) 209-231, at 215. 
of recommendations."70 Therefore, the decision-making takes place in accordance with the Rules of Procedure of the MOP, which apply mutatis mutandis to subsidiary bodies when it is not provided otherwise.

Rule 26.6 indeed provides:

"Unless otherwise decided by the meeting, these rules apply mutatis mutandis to the proceedings of committees and working groups, except that:

(a) The chairman of a committee or working group may exercise the right to vote; and

(b) Decisions of committees or working groups shall be taken by a majority of the Parties present and voting, except that the reconsideration of a proposal or of an amendment to a proposal shall require the majority established by rule $38 . "$

The fact that the Committee is not provided with its own Rules of Procedure has been considered an "important omission", ${ }^{71}$ particularly because of the absence of a cross-reference provision to the rule providing that the Committee shall be governed by the rules of the MOP.

As noted above, the Party whose compliance is at issue shall be entitled to participate in the consideration by the Implementation Committee of that submission, but it may not take part in the elaboration and adoption of recommendations on that matter. ${ }^{72}$ On the other hand, a practice has developed, according to which representatives of the Multilateral Fund and of the Implementing Agencies are present at the deliberation of recommendations and, although they do not participate directly in its adoption, they may be asked to answer questions regarding the matter discussed..$^{73}$

There are matters that do not require specific consideration and additional information and are therefore subject to a more straightforward procedure called "blanket approval" because they are similar to issues addressed on a regular basis by the Implementation Committee. In such a case, the draft recommendation prepared by the Secretariat is based on a text previously approved by the Committee and is generally approved without a complete deliberation. ${ }^{74}$ The adoption of these standardized recommendations contributes to the equal treatment of the Parties and, at the same time, facilitates the work for the Implementation Committee by making it easier and more efficient.

${ }^{70}$ Report on the Work of the Ad Hoc Working Group of Legal and Technical Experts on Non-Compliance with the Montreal Protocol, supra n. 21.

71 Bankobeza, supra n. 28, at 275 notes that: "Although this lacuna in the non-compliance procedure has never become an issue in the proceedings of the Implementation Committee, it shows how the procedure is not self-contained and is vulnerable. [...] There is a need for the Parties to the Montreal Protocol to make a cross-reference within the Non-compliance procedure regarding the application of the rules of procedure for the meetings of the Parties to the decision-making process of the Implementation Committee. Alternatively, it may be helpful for the Parties to make an express provision on decision-making within the non-compliance procedure itself, as is the case under the Basel Convention and the Kyoto Protocol, so that this important aspect of the procedure is made clear."

72 Non-compliance procedure, para. 5.

73 See Implementation Committee Primer, supra n. 36, at 26.

${ }^{74}$ This practice is described in details in the Implementation Committee Primer, supra n. 36, at 14. 


\section{Outcomes}

The Implementation Committee has only advisory powers. Interim and final decisions are left to the MOP and the Implementation Committee does not have the power to take any compulsory measure against a Party in non-compliance..$^{75}$

The Committee issues recommendations on a variety of matters: from its own working procedures, to data reporting, to the classification criteria of developing countries, to the recommended decisions for the MOP.

It is worth mentioning the recommendations on continuity of membership in the Committe $^{76}$ and the ones, already noted, that concern the strengthening of the relations between the Implementation Committee and the Executive Committee of the Multilateral Fund. ${ }^{77}$

Furthermore, the Committee considered the cases of Parties that were initially classified as developing countries but did not meet the criteria stated by Article 5 of the Protocol. ${ }^{78}$ These countries were therefore treated as developed countries until they reduced their levels of consumption of controlled substances: only then did the Committee recommend their reclassification to the MOP. ${ }^{79}$ The Committee also considered the case of Slovenia which vice versa wanted to be reclassified as developed country in view of its accession to the European Union. ${ }^{80}$

It has already been mentioned that, although the Committee is not entitled to issue binding decisions directly to the Parties, its recommendations to the MOP are normally adopted without debate ${ }^{81}$ This shows that the Committee de facto contributes indirectly to law-making under the Protocol.

Most of the decisions on non-compliance adopted by the MOP invite the Parties to submit action plans with time-specific benchmarks that demonstrate their path to return to compliance and provide for monitoring by the Implementation Committee; ${ }^{82}$

75 The Implementation Committee Primer, supra n. 36, at 18, reports that: "Feedback from Parties subject to the non-compliance procedure of the Protocol has indicated that, as decisions of the Parties are perceived to have a higher public profile than recommendations of the Committee, Parties are often likely to respond more promptly to decisions rather than recommendations on compliance."

${ }^{76}$ Report of the Implementation Committee on the Work of its Fifth Meeting, doc. UNEP/OzL.Pro/ ImpCom/5/3 (9 March 1993). The Committee recommended that Governments of the Parties represented in the Committee should maintain continuity in their representation. This recommendation was incorporated in para. 5 of the revised procedure in 1998.

77 Report of the Implementation Committee on the Work of its Eighth Meeting, doc. UNEP/OzL.Pro/ ImpCom/8/3 (4 July 1994). The MOP formally endorsed this recommendation in Decision XIV/37 on Interaction between the Executive Committee and the Implementation Committee, supra $\mathrm{n} .33$.

78 Art. 5 requires a Party to report a consumption of controlled substances below 0,3 kilograms per capita in order to be classified as a developing country.

79 This has been the case of Bahrain, Malta, Singapore and the United Arab Emirates. See Decision III/3 on Implementation Committee, doc. UNEP/OzL.Pro.3/11 (21 June 1991), at 19-20.

${ }^{80}$ Decision XII/12 on Request by Slovenia to be Removed from the List of Developing Countries under the Montreal Protocol, doc. UNEP/OzL.Pro.12/9 (10 January 2001), at 28.

${ }^{81}$ See, for example, the thirty-three recommendations on non-compliance submitted by the Committee in November 2003 to the MOP which were all adopted as presented. Report of the Implementation Committee, doc. UNEP/OzL.Pro/ImpCom/31/3 (13 November 2003), Annex I. See also supra para. 5.3.

82 Bankobeza, supra n. 28, at 274 notes that: “[...] The procedure for the presentation of action plans to enable defaulting Parties to return to compliance has developed through practice by the Implementation 
at the same time, typical of the "carrot-stick" approach adopted to encourage compliance, it is normally decided that the non-complying State, which has demonstrated good will in working to return to compliance, should continue to receive financial assistance from the Multilateral Fund or from the GEF. However, the Party concerned is cautioned that, in the event it fails to return to compliance in a timely manner, the MOP may consider the issuing of sanctions under paragraph $\mathrm{C}$ ) of the List of Measures. $^{83}$

\section{Coordination with Dispute Settlement Procedures and Other Non-Compliance Procedures}

Article 11 of the Ozone Convention illustrates the different means Parties may resort to in the case a dispute "concerning the interpretation or application of this Convention" arises and states that this provision applies to any Protocol to the Convention unless otherwise provided by the Protocol itself. ${ }^{84}$

The parallel existence of the traditional dispute settlement procedures on the one hand, and of the non-compliance procedure on the other, has been repeatedly confirmed during the negotiation of the non-compliance procedure. Some delegations expressed the need to clarify that the non-compliance procedure should be without prejudice to the operation of the settlement of disputes procedure laid down in Article 11 of the Ozone Convention ${ }^{85}$ and this resolution was endorsed in the chapeau of the non-compliance procedure.

It follows that both procedures may function simultaneously and, under this hypothesis, safeguards have been envisaged in order to coordinate their operation. According to the non-compliance procedure the Parties involved in it shall:

"Inform through the Secretariat, the MOP of the results of proceedings taken under Art.11 of the Convention regarding possible non compliance, about implementation of those results and about implementation of any decision of the Parties pursuant to paragraph 9." ${ }^{\prime 86}$

Committee under the Montreal Protocol and is not specifically provided in the Non-compliance procedure itself. However, the same practice has recently been fully institutionalised under other multilateral environmental agreements as an integral part of the mechanisms and procedures for compliance."

83 See, for instance, the Decision XIV/18 on Non-compliance with the Montreal Protocol by Albania, doc. UNEP/OzL.Pro.14/9 (5 December 2002), at 49-50.

${ }^{84}$ According to Ozone Convention, Art. 11 disputes between Parties concerning the interpretation or application of this Convention may be settled through negotiation, good offices, mediation, conciliation, arbitration or by submitting the matter to the International Court of Justice.

${ }^{85}$ For this purpose the MOP decided to: "Endorse the conclusion of the Ad Hoc Working Group of Legal Experts that the judicial and arbitral settlement of disputes provided for in Article 11 of the Ozone Convention and the Non-compliance Procedure pursuant to Article 8 of the Montreal Protocol were two distinct and separate procedures (UNEP/OzL.Pro/WG.3/2/3)." See Decision III/2 on Non-Compliance Procedure, supra n. 12.

${ }^{86}$ Non-compliance procedure, para. 12. 
Furthermore, in the case of pending proceedings under Article 11 of the Convention, the MOP may issue an interim call or recommendations. ${ }^{87}$

The issue of the parallel existence of the two proceedings was raised on the occasion of the review of the non-compliance procedure in 1998. The Working Group considered a proposal regarding the need to define the relationship between the noncompliance and the dispute settlement procedures and other liability actions initiated in other international forums or tribunals, but this proposal did not lead to satisfactorily answers. Indeed in its Report to the MOP,

"Noting the difficulties involved in determining precedence between different international administrative and judicial proceedings, the Working Group decided that no action should be taken on the proposal." $" 88$

Bilateral dispute settlement has in general ${ }^{89}$ proven unsuitable for managing breaches of multilateral environmental treaties and under the ozone regime this trend has been confirmed. This is largely demonstrated by the fact that no proceedings have ever been initiated under Article 11 of the Convention and all issues of non-compliance have been handled by the Implementation Committee.

Despite this practice, there is indeed an overlap between the two procedures and the safeguards provided by the above-mentioned texts may not be sufficient to avoid conflicts. In particular, it is not clear what the meaning of "without prejudice" is in relation to the operation of the non-compliance procedure in respect of the dispute settlement procedure. It must be noted that there is no analogous provision in reverse and therefore a dispute settled by traditional means may be considered to entail prejudice on the operation of the non-compliance procedure. ${ }^{90}$

An interesting aspect that follows from the issues mentioned above relates to the effect that they may have on the behaviour of the Parties involved in situation of noncompliance. As mentioned before, the non-compliance procedure creates an atmosphere of trust in the process, in order to make the non-complying Parties disclose their difficulties. This approach would be undermined if the concerned Party has justified doubts that any data and sensitive information contained in its submission in the amicable ambit of the non-compliance procedure may be used in other processes against it in a much less amicable way. ${ }^{91}$

${ }^{87}$ Ibid., para. 13.

${ }^{88}$ Report of the Ad Hoc Working Group of Legal and Technical Experts on Non-Compliance with the Montreal Protocol, supra n. 21.

${ }^{89}$ M. Fitzmaurice and C. Redgwell, "Environmental Non-Compliance Procedures and International Law", Netherlands YB Int'l L., 31 (2000) 35-65, at 35.

${ }_{90}$ See P. Sands, "Non-Compliance and Dispute Settlement", in Beyerlin, Stoll and Wolfrum (eds.), supra $\mathrm{n} .23,353-358$, at 353 .

${ }^{91}$ Ibid., at 357, poses the question "does the finding of non-compliance amount to (or should be distinguished from) a finding as to violation of a treaty obligation in international law giving rise to principles of State responsibility?" 


\section{PARTICIPATION OF THE EUROPEAN COMMUNity}

The European Community is a Party to the Ozone Convention and has approved the Montreal Protocol and all its amendments without making any declarations. ${ }^{92}$

The commitments under the Montreal Protocol are mainly implemented at the Community level.

As far as reporting obligations are concerned, Member States are reluctant to communicate their data on the import and export of chemicals relevant under the Ozone Protocol due to commercial considerations and they have reported these data only to the EC Commission, on the condition that their reports remain confidential. This situation makes it impossible for the organs of the Protocol to assess possible situations of non-compliance by individual States. ${ }^{93}$

The EU ozone policy has been effective and has achieved the targets established by the Protocol. The factors that may have contributed to this success are to be found, in the first place from a normative point of view, in the adoption of a Regulation ${ }^{94}$ to enact the ozone policy, which required all Member States and ODS producers to implement the restrictive measures simultaneously. Secondly, the increased availability of ozone substances substitutes allowed for the speeding up of the phasing-out process. Among the targets of the EC ozone layer protection policy there is also the will to strengthen the compliance mechanism of the Protocol. ${ }^{95}$

The European Court of Justice (ECJ) has dealt only on rare occasions with the issue of the relationship between multilateral environmental agreements and EC law. It is interesting to determine the role of the EC Courts in assuring the implementation of such agreements, and with regard to this matter the ECJ held that international agreements to which the EC is a Party are an integral part of the Community's legal system. The ECJ went even further, stating that also the decisions, both legally binding and of a recommendatory nature, taken by an organ established by an international agreement to which the Community is a Party, are to be considered as part of the Community's legal system by virtue of their direct connection to the international agreement. ${ }^{96}$

It could then be foreseen that a statement on a non-compliance case by the MOP could be considered as being part of the EC legal system.

92 The European Community approved the Ozone Convention on 17 October 1988, the Montreal Protocol on 16 December 1988, the London Amendment on 20 December 1991, the Copenhagen Amendment on 20 November 1995, the Montreal Amendment on 17 November 2000, the Beijing Amendment on 25 March 2002 .

93 As noted by Wettestad, supra n. 69, at 213: "This example illustrates the tension that sometimes exists between the twin roles of the EU as a policy arena and as an external actor in international regimes."

${ }^{94}$ Regulation (EC) No 2037/2000 of the European Parliament and of the Council of 29 June 2000 on Substances that Deplete the Ozone Layer, OJ (2000) L 244/1.

95 See EC website on the ozone policy, <http://ec.europa.eu/environment/ozone/index.htm > (visited on 15 July 2008).

${ }^{96}$ On this issue see E. Hey, “The European Community's Courts and International Environmental Agreements", RECIEL, 7 (1998) 4-10. 


\section{FinANCIAL ASPECTS}

There is close cooperation between the Implementation Committee and the Multilateral Fund, which provides financial and technical support to developing countries. ${ }^{97}$ As already noticed, representatives of the Multilateral Fund and of Implementing Agencies participate as observers in Implementation Committee meetings.

The GEF plays a fundamental role although it is formally not linked to the noncompliance procedure because it can provide financial assistance to countries with economies in transition, which are not eligible for funding under the Multilateral Fund.

The Implementation Committee, together with the Ozone Secretariat, is entitled to approve funding from the GEF for Parties that have triggered the non-compliance procedure.

There have been many cases of non-compliance with data reporting by developing countries where the inability of one of the financial entities to provide appropriate assistance as promised has constituted a reason for greater tolerance by the Implementation Committee.

Potential problems may arise with regard to the competence of the non-compliance procedure with regard to the obligation under the Protocol to contribute to the Protocol's Multilateral Fund. ${ }^{98}$ On this matter there has been discussion in the legal Working Group with different interpretations: some argued that non-payment is non-compliance, while others felt that it is not since the Protocol does not mention that the contributions are "assessed" as in the United Nations.

\section{Survey of Practice}

\subsection{General Overview}

Initially, the Implementation Committee's work mainly focused on reporting difficulties, especially those related to technical matters such as the baseline data.

To date there have been no cases of one or more Parties submitting reservations on non-compliance by another Party. ${ }^{99}$ This may be explained by the fact that the relevant data on the controlling and phasing out of ozone depleting substances are made available through reporting by each Party. It is therefore more likely for a situation of non-compliance to emerge from the Secretariat's data analysis, while it is quite difficult for a Party to become aware of a case of non-compliance by another State.

Most non-compliance cases were triggered by the Secretariat and relate to failure to report consumption data, especially by developing countries due to the lack of financial and technical capacity. Numerous cases of non-compliance with obligations of reduction and phase out of ozone depleting substances were brought to the

97 At the seventeenth MOP it was agreed to contribute $\$ 470$ million to assist developing countries to continue to adopt alternatives to ozone deleting substances during 2006-2008.

98 Montreal Protocol, Art. 10.

99 See Implementation Committee Primer, supra n. 36, at 15. 
Implementation Committee by Countries with economies in transition, which found the respect of these obligations particularly burdensome due to the difficulties in finding substitutes and to the lack of revenues deriving from trade in those substances.

However it should also be highlighted that there has been a steady improvement in the level of compliance after additional technical and financial assistance was granted by the Multilateral Fund and the GEF. ${ }^{100}$

The number of Parties in non-compliance has been growing steadily, particularly since 1999 when the grace period for developing countries ended and they were obliged to comply with the control and phase out obligations. With regard to these non-compliance cases the Implementation Committee has maintained a facilitative approach, as demonstrated by the fact that to date no Party has been deprived of assistance or had its rights and privileges suspended.

In 2002, in consideration of the significant growth in its workload, the Implementation Committee decided that its meetings should last for three days instead of just the one that had previously usually been scheduled. ${ }^{101}$

\subsection{The Case of the Russian Federation's Non-Compliance}

At the sixth MOP the Russian Federation made a statement, ${ }^{102}$ also on behalf of other five Parties to the Protocol (Poland, Bulgaria, Belarus, Russia and Ukraine) and a further three that intended to become Parties (Armenia, Georgia and Kyrgyzstan), where it asked the Parties to allow them a five year period of grace. This request, which was directly addressed to the MOP, was redirected to the Implementation Committee that was regarded to be the legitimate and competent forum to discuss the matter.

The Implementation Committee treated the Russian statement as a "submission" in the terms of paragraph 4 of the non-compliance procedure and hence considered the procedure to be triggered by a self-accusation of non-compliance.

Each Party was asked to submit a plan showing how the country believed it could return to compliance with its obligations but according to an initial analysis the plans resulted as being inadequate and the Implementation Committee asked for more technical details and a more convincing political commitment from the Parties concerned. The strategy adopted by the Implementation Committee to deal with these situations of non-compliance focused on working with the country in resolving the problems and monitoring the progress attained by means of periodic reviews. ${ }^{103}$

The Implementation Committee sought to agree on an approach to respond to noncompliance with the delegation of the Russian Federation and despite not having reached complete agreement it forwarded a recommendation to the MOP.

${ }^{100}$ See Decision XVI/17 on Data and Information Provided by the Parties in Accordance with Article 7 of the Montreal Protocol, doc.UNEP/OzL.Pro.16/17 (16 December 2004), at 55.

${ }_{101}$ Report of the Implementation Committee on the Work of its Twenty-Eighth Meeting, doc. UNEP/ OzL.Pro./ImpCom/28/4 (7 August 2002), para. 90.

102 The Statement is reproduced in the Report of the Eleventh Meeting of the Implementation Committee, UNEP/OzL.Pro/ImpCom/11/1 (14 September 1995), Annex II, at 14-15.

${ }^{103}$ The Implementation Committee delegated a Working Group of the Panel on Countries with Economies in Transition to carry out informal visits on site to secure relevant data. 
At the seventh MOP, even though the Russian Federation did not agree to the entire draft decision and demanded a formal vote, the MOP opted for a consensus procedure and adopted the decision by "consensus minus one". In relation to this decision-making procedure, the Secretariat made it clear that:

"The practice followed in the Meeting of the Parties to the Montreal Protocol was that, when only one Party objected to a draft decision, that decision would be carried by consensus and the position of the dissenting Party would be clearly reflected in the report of the Meeting." 104

According to the above-mentioned decision the MOP adopted trade measures against the Russian Federation, imposing a ban on the trade in ozone depleting substances with States outside the Commonwealth of Independent States. In so doing, the MOP did not explicitly refer to the List of Measures ${ }^{105}$ and it was accused by the Russian Federation of abusing of its discretion by deciding for a trade restrictive measure, without exhausting first the other facilitative measures envisaged by the List. ${ }^{106}$

\section{Bibliography}

M. Koskenniemi, "Breach of Treaty or Non-Compliance? Reflections on the Enforcement of the Montreal Protocol", YB Int'l Envt'l L., 3 (1992) 123-162; P.M. Dupuy, "Protection internationale de la couche d'ozone et spécificité relative des régimes spéciaux de contrôle de l'application du Droit International", in Weber (Hrsg), Währung und Wirtschaft. Das Geld im Recht. Festschrift für Prof. Hugo J. Hahn zum 70. Geburtstag (Baden Baden: Nomos, 1996) 539-554; D.G. Victor, "The Early Operation and Effectiveness of the Montreal Protocol's Non-Compliance Procedure", IIASA Paper ER-96-2, 1996; J. Werksman, "Compliance and Transition: Russia's Non-Compliance Tests the Ozone Regime", ZaöRV, 56 (1996) 750-773; E. Hey, "The European Community's Courts and International Environmental Agreements", RECIEL, 7 (1998) 4-10; M. Fitzmaurice and C. Redgwell, "Environmental Non-Compliance Procedures and International Law", Netherlands YB Int'l L., 31 (2000) 35-65; M. Fitzmaurice, "International Protection of the Environment", RdC, 293 (2001) 9-488; G. Bankobeza, Ozone Protection: The International Legal Regime (Utrecht: Eleven International Publishing, 2005); K. Madhava Sarma, "Compliance with the Multilateral Environmental Agreements to Protect the Ozone Layer", in U. Beyerlin, P.-T. Stoll and R. Wolfrum (eds.), Ensuring Compliance with Multilateral Environmental Agreements. A Dialogue between Practitioners and Academia, (Leiden: Martinus Nijhoff, 2006) 25-38.

${ }^{104}$ Report of the Seventh Meeting of the Parties, Comments Made at the Time of Adoption of the Decisions, doc. UNEP/OzL.Pro.7/12 (27 December 1995), para. 130.

105 See Decision VII/18 on Compliance with the Montreal Protocol by the Russian Federation, supra n. 23, para. 8 .

${ }^{106}$ Report of the Seventh Meeting of the Parties to the Montreal Protocol on Substances that Deplete the Ozone Layer, Section B (Comments made at the time of the adoption of the decisions), doc. UNEP/ OzL.Pro.7/12 (27 December 1995), paras. 128-129. 
Chapter Two

\title{
Mechanism for Promoting Implementation and Compliance with the 1989 Basel Convention on the Transboundary Movements of Hazardous Wastes and Their Disposal
}

\author{
Alessandro Fodella
}

\section{Brief InTROduction to the BASEL Convention}

The Convention on the Control of Transboundary Movements of Hazardous Wastes and their Disposal (the Convention), ${ }^{1}$ is the fundamental global treaty on the transboundary management of hazardous wastes.

The Convention aims at ensuring the environmentally sound management of dangerous and hazardous wastes by regulating the entire "wastes' cycle" from production, through transboundary movements, to disposal. In particular, the treaty requires States to reduce their hazardous wastes production; it provides for limitations to the export and import of such wastes, so that their transboundary movements take place only when absolutely necessary; it establishes procedural obligations for permitted transboundary movements, based upon the prior notification and prior informed consent of the States concerned; finally, it regulates the disposal of the wastes, by imposing their environmentally sound management, and by allocating the responsibility for the latter among the States of import and of export of the wastes.

The Convention creates also an institutional structure that is composed of a Conference of the Parties (the COP - the governing body of the Convention) and a Secretariat (the coordinating body, administered by the United Nations Environment Programme (UNEP)), together with a number of ad hoc committees and working groups (such as the Legal Working Group, which played a key role in creating the compliance mechanism, or the Compliance Committee itself) established with different mandates by the COP. ${ }^{2}$

The legal framework of the Convention has been expanded over time, mainly thanks to the normative developments brought by the COP. The latter has adopted, inter alia, a "Ban Amendment", which will prohibit all exports of hazardous wastes

\footnotetext{
${ }^{1}$ Basel, Switzerland, 22 March 1989, entered into force on 5 May 1992, ILM, 28 (1989) 649. At present the Convention accounts for 170 Parties (a full list is available at <http://basel.int/ratif/convention.htm>, visited 22 June 2008).

${ }^{2}$ For an overview of the institutional structure and relevant meetings see $<$ http://basel.int/meetings/ meetings.html > (visited 22 June 2008).
}

T. Treves et al., eds., Non-Compliance Procedures and Mechanisms and the Effectiveness of International Environmental Agreements

(C) 2009, T.M.C. AsSER PRESS, The Hague, The Netherlands, and the Authors 
from developed to developing countries, and a Protocol on Liability and Compensation for Damage Resulting from Transboundary Movements of Hazardous Wastes and their Disposal, neither of which have entered into force yet. ${ }^{3}$

\section{Legal Basis of the Mechanism and Negotiating History}

The Convention as such does not contain any explicit provision on a compliance mechanism. On matters relating to the implementation of, and monitoring of compliance with the treaty, the Convention provides only for a "verification procedure" (Article 19) and for a traditional dispute settlement mechanism (Article 20). However, the compliance mechanism was set up by the sixth meeting of the COP (Geneva, Switzerland 9-13 December 2002), relying on Article 15 para. 5 subpara. (e) of the Convention, which states that:

"5. The Conference of the Parties shall keep under continuous review and evaluation the effective implementation of this Convention, and, in addition, shall:

$[\ldots]$

(e) Establish such subsidiary bodies as are deemed necessary for the implementation of this Convention."

The establishment of the compliance mechanism came at the end of a process that had started at fifth COP three years before. ${ }^{4}$ Indeed the fifth meeting of the COP adopted Decision V/16, by which it requested the Legal Working Group of the Convention to prepare a Draft decision establishing a mechanism for promoting implementation and compliance with obligations arising out of the Basel Convention. The draft decision was submitted to an informal consultations group, chaired by the United Kingdom, for further elaboration. Parties to this group could not agree upon some of the key issues relating to the mechanism, such as the status of the members of the proposed Compliance Committee, the procedures for specific submissions, the recommendations to the $\mathrm{COP}$ on additional measures and the decision-making procedure of the Committee. The text that resulted from these informal consultations was therefore presented, still in a draft form, to the sixth meeting of the COP.

The sixth COP decided to establish a Working Group to consider the outstanding issues relating to the compliance mechanism. On 12 December 2002, the Chair of the

${ }^{3}$ The Ban Amendment was adopted during third COP (Geneva, 18-22 September 1995) with COP Decision III/1 on Amendment to the Basel Convention, doc. UNEP/CHW.3/35 (22 September 1995). It has been ratified by 63 Parties (a full list is available at $<$ http://www.basel.int/ratif/ban-alpha.htm $>$, visited 22 June 2008) and it shall enter into force (between the Parties accepting it) upon ratification by at least three-fourths of the Parties who accepted it. The Protocol was adopted during fifth COP (Basel, 6-10 December 1999) on 10 December 1999 (Protocol on Liability and Compensation for Damage Resulting from Transboundary Movements of Hazardous Wastes and their Disposal, doc. UNEP/CHW.5/29 (10 December 1999), Annex III, at 88). To date, it accounts for only eight ratifications and it requires twelve more ratifications to enter into force. The status of ratifications is available at $<$ http://basel.int/ratif/convention.htm $>$ (visited 22 June 2008).

${ }^{4}$ For the negotiating history see the Report of the Sixth Conference of the Parties to the Basel Convention, doc. UNEP/CHW.6/40 (10 February 2003), paras. 57 and ff. (Report of sixth COP). 
Working Group presented a revised text of the mechanism and recommended its adoption by the COP. Based on this revised text, on the very same day the sixth COP finally adopted Decision VI/12 on the Establishment of a Mechanism for Promoting Implementation and Compliance, which was annexed to the COP Report. ${ }^{5}$ It is with this Decision that the Mechanism for promoting the implementation and compliance of the Basel Convention (the Compliance Mechanism) was eventually established.

\section{The Text Establishing the Mechanism}

The Compliance Mechanism is governed by the above-mentioned sixth COP Decision VI/12 on the Establishment of a Mechanism for Promoting Implementation and Compliance, ${ }^{6}$ which states very general principles on the Mechanism, and by the more detailed Terms of Reference for the Mechanism for Promoting Implementation and Compliance (Terms of Reference) adopted by the COP (explicitly pursuant to Article 15 para. 5 subpara. (e) of the Convention) with the same Decision and incorporated in an appendix to it. ${ }^{\text {? }}$

There are no explicit provisions in Decision VI/12, neither in the Terms of Reference, regarding amendments or revisions to the Mechanism, or on possibilities of opting out and of making reservations.

The legal status of the Compliance Mechanism is somewhat controversial. The Convention simply gives to the COP general powers of "implementation review" of the treaty and of creating subsidiary organs to this end (Convention, Article 15). There is no doubt, therefore, about the fact that the COP has the mandate to create a Compliance Mechanism and a Compliance Committee to administer it. However, Basel COP decisions are probably non-binding in character, ${ }^{8}$ and so should be the legal texts establishing and regulating the Mechanism (contained in COP decisions), as well as the activities resulting thereof (which, in the best case scenario, will again be included in COP decisions). The non-binding nature of the Compliance Mechanism is in any case explicitly confirmed by the text governing the procedure itself. ${ }^{9}$

\footnotetext{
${ }^{5}$ Decision VI/12 on Establishment of a Mechanism for Promoting Implementation and Compliance, doc. UNEP/CHW.6/40 (10 February 2003), Annex, at 45.

6 Supra para. 2; Decision VI/12.

7 Decision VI/12, Appendix (Terms of Reference).

8 There is nothing in the text of the Convention, in the Rules of Procedure of the COP (infra n. 18), in other instruments related to the Convention, or in the practice of its institutions, suggesting the binding character of COP decisions. An indirect confirmation of this may come from the fact that the Ban Amendment (supra paragraph 1 and n. 3) was initially adopted as a COP decision, but it was "upgraded" to an amendment afterwards, probably in order to ensure its binding effect. However, the matter still remains unsettled in a clearcut and definitive way.

9 Infra para. 4.
} 


\section{The Principles Governing the Mechanism and the Procedure}

The aim of the Compliance Mechanism of the Basel Convention is to "assist Parties to comply with their obligations under the Convention", and to facilitate, promote, monitor and ensure the implementation of, and compliance with, the Convention's obligations (Terms of Reference, para. 1). ${ }^{10}$

The Mechanism is therefore non-confrontational and facilitative (with special attention devoted to "disadvantaged" Parties), ${ }^{11}$ and non-binding and preventive in nature; it shall also be transparent, cost-effective, simple and flexible (ibid., para. 2).

The Mechanism is also considered as complementary to the work performed by other Convention bodies (ibid.). ${ }^{12}$

\section{InSTITUtional ASPECTS}

\subsection{The Compliance Committee}

The Compliance Mechanism is administered by a Committee for Administering the Mechanism for Promoting the Implementation and Compliance of the Basel Convention, or Implemenation and Compliance Committee (the Committee), which is a subsidiary body of the COP created with Decision COP VI/12 pursuant to Article 15 para. 5 subpara. (e) of the Convention. ${ }^{13}$

The Committee consists of 15 members, nominated by the Parties and elected by the COP, based on equitable geographical representation of the five regional groups of the United Nations (Terms of Reference, para. 3). ${ }^{14}$ Members must be experts in areas relating to the subject-matter of the Convention (ibid., para. 5). Some of them are elected for one "term", ${ }^{15}$ some for two terms (with no member serving for more than two consecutive terms) (ibid., para. 6). ${ }^{16}$

10 This clearly emerges also from Decision VI/12 itself: "The Conference of the Parties [...] Seeking to promote the identification, as early as possible, of implementation and compliance difficulties encountered by Parties, [...] Seeking to promote the adoption of and recommendations on the most appropriate and effective solutions for resolving those difficulties, Seeking also to assist Parties to develop and implement the most appropriate and effective solutions for resolving those difficulties, [...]" (Decision VI/12, Preamble).

${ }_{11}$ The mechanism is "oriented in the direction of helping Parties to implement the provisions of the Basel Convention", it will "pay particular attention to the special needs of developing countries and countries with economies in transition", and is "intended to promote cooperation between all Parties" (Terms of Reference, para. 2).

12 See also infra para. 12.

13 Supra paras. 2-3. Nowhere is the Committee explicitly defined as a "subsidiary body of the COP". However, the constant, explicit reference to Art. 15.5(e) of the Convention on the creation of subsidiary bodies by the COP (supra paragraph 2), and the role of the Committee with respect to the COP, clearly point in that direction.

${ }_{14}$ In practice, each regional group will be represented by three members.

15 A "term" means "the period that begins at the end of one ordinary meeting of the Conference of the Parties and ends at the end of the next ordinary meeting of the Parties" (Terms of Reference, para. 6).

${ }^{16}$ The COP shall elect, at the meeting establishing the Compliance Mechanism, five members (one from each region) for one term, and ten members (two from each region) for two terms. At each ordinary meeting thereafter, it shall elect, for two terms, new members to replace those whose period of office has expired (or 
There are no detailed procedural provisions on nomination and election of Committee members. COP Decision VI/13 ${ }^{17}$ provided for an "Interim Procedure for Electing the Members of the Committee" which should continue to apply mutatis mutandis. The Decision requested Parties to nominate candidates and to submit their nomination to the Secretariat, which would then distribute the nomination to all the other Parties. No specific election procedure was envisaged, thus normal COP procedural standards should apply: the COP decides by consensus, but if all efforts have been exhausted without reaching an agreement, the decision is taken by a two-thirds majority of the Parties present and voting..$^{18}$ Elections are held by secret ballot, unless otherwise decided by the COP. ${ }^{19}$

It is unclear whether Committee members serve in their individual capacity or representing their own national States: a rather cryptic provision establishes that they "will serve objectively and in the best interest of the Convention" (Terms of Reference, para. 5). The norm seems to be more in favour of the first option, and so is an informal document prepared by the Committee and published by the Secretariat. ${ }^{20}$ However, the ambiguity of the provision remains, especially considering that this vague formula was adopted on purpose as a compromise language that would leave scope for both interpretations. ${ }^{21}$

The Committee elects a Chair, three Vice-chairs and a Rapporteur (based on equitable geographical representation) (Terms of Reference, para. 7), and it meets "at least once between each regular meeting of the Conference of the Parties, and in conjunction with meetings of other Convention bodies" (ibid., para. 8).

\subsection{The Secretariat and the COP}

The Secretariat and the COP are involved in the procedure at different stages and with different competences.

is about to expire) (ibid., para. 6). If a member resigns or is unable to complete his or her term of office, the Party who nominated that member shall nominate an alternative (ibid., para. 4).

17 Decision VI/13 on Interim Procedure for Electing the Members of the Committee for Administering the Mechanism for Promoting Implementation and Compliance, doc. UNEP/CHW.6/40 (10 February 2003), at 50 .

${ }^{18}$ Rules of Procedure for Meetings of the Conference of the Parties to the Basel Convention on the Control of Transboundary Movements of Hazardous Wastes and their Disposal, as adopted by the first COP (Decision I/1 on Rules of Procedure, doc. UNEP/CHW.1/24 (5 December 1992), Annex III, at 40) and amended by the seventh COP (Decision VII/37 on Amendment to Rule 29 of the Rules of Procedure, doc. UNEP/CHW.7/33 (25 January 2005), Annex I, at 76) (COP Rules of Procedure), Rule 40, para. 1.

19 Ibid., Rule 49. Rules 50 and 51 spell out further detailed rules on voting procedures for elections.

${ }^{20}$ See Secretariat of the Basel Convention, The Basel Convention Mechanism for Promoting Implementation and Compliance, 2006, "brochure" published on line at $<\mathrm{http}$ ://basel.int/legalmatters/compcommitee/ brochure-xx0706.pdf $>$ (visited 22 June 2008). This document states that "Although the members are nominated by Governments, they serve objectively and in the best interest of the Basel Convention" (at 4).

21 "The question was raised whether the Members of the Committee were actually representatives of their regions or their technical expertise. It was recalled that the language of the text of the mechanism is a compromise. It was underlined that members should serve their function as objectively as possible, as stated in the text of the mechanism [...]" (Report of the First Session of the Implementation and Compliance Committee, doc. UNEP/CHW/CC/1/3 (14 January 2005), para. 16; emphasis added). 
In general, the Secretariat arranges for and services the meetings of the Committee (Terms of Reference, para. 8), and it functions as the focal point for transmission of documents and information relating to the procedure. More importantly, however, it can trigger the Compliance Mechanism (ibid., para. 9(c) $)^{22}$ and it can assist the Committee by providing consultation to the latter on matters under consideration (ibid., para. $22(\mathrm{e})) .^{23}$

The COP, apart from electing the Committee members, may take additional measures if the facilitation procedure undertaken by the Committee is unsatisfactory (Terms of Reference, para. 20), ${ }^{24}$ and it directs the Committee's review of general issues of compliance and implementation (ibid., para. 21). ${ }^{25}$ More generally, the COP oversees the work of the Committee, as the latter must send a report on its activity to each ordinary meeting of the COP for its approval and consideration (ibid., paras. $23-24) .{ }^{26}$

\subsection{Observers}

Observers and civil society in general have very little role to play, if any, within the Compliance Mechanism at the institutional level. Non-State actors do not participate in the nomination and election process of Committee members, and they cannot trigger the Compliance Mechanism. ${ }^{27}$ Moreover, within the procedure before the Committee, in the majority of cases observers will not even be able to attend, as the most important meetings are not held in public as a general rule. ${ }^{28}$

\section{Functions of The Committee}

The Committee has two main functions: to address "specific submissions" (Terms of Reference, para. 9 ff.), and to review "general issues of compliance and implementation" (ibid., para. 21).

The Committee examines specific submissions relating to a specific Party's failure to comply, presented by the Parties (without limitations as to the subject-matter), or by the Secretariat (only as to the Parties' reporting obligations under the Convention) (ibid., para. 9), with a view to determining the facts and root causes of non-compliance, and to assisting the Party by providing it with advice, non-binding recommendations and information ("facilitation procedure" - ibid., para. 19). Should this be not enough, the Committee may recommend additional measures to be adopted by the COP (ibid., para. 20).

\footnotetext{
22 Infra para. 8.

23 Infra para. 9.

24 Infra para. 11

25 Infra para. 6.

26 Infra para. 11

27 Infra para. 7.

28 Infra para. 8.
} 
The Committee also reviews general issues of compliance and implementation under the Convention ("general review function") "as directed by the Conference of Parties", inter alia, on:

"(a) Ensuring the environmentally sound management and disposal of hazardous and other wastes;

(b) Training customs and other personnel;

(c) Accessing technical and financial support, particularly for developing countries, including technology transfer and capacity-building;

(d) Establishing and developing means of detecting and eradicating illegal traffic, including investigating, sampling and testing;

(e) Monitoring, assessing and facilitating reporting under article 13 of the Convention; and

(f) The implementation of, and compliance with, specified obligations under the Convention". ${ }^{29}$

\section{TRIGGER MECHANISM}

Specific submissions, i.e., submissions relating to specific cases of non-compliance by a Party, can be triggered by (Terms of Reference, para. 9):

- A Party with reference to its own compliance ("self submission"); ${ }^{30}$

- A Party with reference to another Party's failure to comply ("Party-to-Party submission"), if the failure to comply by the second Party in some way affects the first Party, ${ }^{31}$ and after trying to resolve the issue through consultation; ${ }^{32}$

- The Secretariat ("Secretariat submission"), only while performing its duties and only as to Parties' reporting obligations under the Convention, provided that the matter has not been resolved within three months by consultation with the Party concerned. ${ }^{33}$

As with the election of Committee members, non-State actors do not have a role in the triggering mechanism. Previous drafts of the Compliance Mechanism provided for such a possibility, ${ }^{34}$ but this was nonetheless dropped during negotiations.

29 Terms of Reference, para. 21.

30 "A Party that concludes that, despite its best efforts, it is or will be unable to fully implement or comply with its obligations under the Convention" (ibid., para. 9(a))

31 "A Party that has concerns or is affected by a failure to comply with and/or implement the Convention's obligations by another Party with whom it is directly involved under the Convention" (ibid., para. 9(b); emphasis added)

32 "A Party intending to make a submission under this subparagraph shall inform the Party whose compliance is in question, and both Parties should then try to resolve the matter through consultations" (ibid.).

33 "The secretariat, if, while acting pursuant to its functions under articles 13 and 16, it becomes aware of possible difficulties of any Party in complying with its reporting obligations under article 13, paragraph 3 of the Convention, provided that the matter has not been resolved within three months by consultation with the Party concerned" (ibid., para. 9(c)).

${ }^{34}$ See draft para. 8(c) of the Compliance Mechanism in Monitoring the Implementation of and Compliance with the Obligations Set out by the Basel Convention, doc. UNEP/CHW.6/9 (15 August 2002), at 6. 
Party-to-Party submissions are peculiar in the Basel Convention Compliance Mechanism, insofar as a specific, bilateral relationship is required between the two Parties involved in order to trigger the Mechanism. This solution emphasizes a bilateral, rather than collective, spirit of the mechanism, probably due to the fact that noncompliance cases under the Convention are likely to arise between States involved in a specific transboundary movement of hazardous wastes. ${ }^{35}$

General reviews are initiated by a decision of the Conference of the Parties (Terms of Reference, para. 21).

\section{The Procedure before the Compliance Committee and Procedural SAFEGUARDS}

\subsection{General Procedural Issues: Sources}

The procedure is governed by COP Decision VI/12 and the Terms of Reference thereof. These sources are supplemented by procedural rules of the COP which apply mutatis mutandis to committees as well. ${ }^{36}$ Beyond such legal texts, little can be said as to how the procedure works in practice or in detail, as no cases have been brought before the Committee so far.

\subsection{Participation and Transparency}

In general, due process guarantees and rules on transparency and participation are not entirely satisfactory. The Party whose compliance is under consideration in specific submissions has enough chances to be heard and to participate in the process in such a way that its interests are duly safeguarded. However, beyond this, participation and transparency levels are remarkably poor as far as both the public and other Parties, in particular the Party triggering the mechanism, are concerned.

Indeed meetings on specific submissions are closed to the public or to other Parties (and so it should be for observers in general) "unless the Committee and the Party whose compliance is in question agree otherwise" (Terms of Reference, para. 16). This rule is likely to affect in particular the Party submitting a case in Party-to-Party submissions, since it is excluded from the procedure notwithstanding its interest in the matter. While this may be a sign of the non-confrontational nature of the Mechanism, the requirement that a Party must be particularly affected in order to trigger the procedure $^{37}$ seems to underline a more traditional, bilateral, State-to-State dispute approach, which is undermined, however, by the reduced possibility of participation for one of the Parties. There seems to be a contradiction in this solution.

${ }_{35}$ A. Shibata, "Ensuring Compliance with the Basel Convention - its Unique Features", in U. Beyerlin, P.-T. Stoll, and W. Rüdiger (eds.), Ensuring Compliance with Multilateral Environmental Agreements: A Dialogue between Practitioners and Academia (Leiden: Martinus Nijhoff, 2006) 69-87, at 81.

36 "Unless otherwise decided by the meeting, these rules shall apply mutatis mutandis to the proceedings of committees and working groups" (COP Rules of Procedure, Rule 26, para. 6).

${ }^{37}$ Supra para. 7. 
Only in the case of an explicit decision by both the Committee and the Party under consideration, or in cases other than specific submissions (e.g., when the Committee deals with general issues of non-compliance), may the meetings be open to the public, and may non-governmental and intergovernmental organizations be able to participate as observers, as this is the general, residual rule that is applicable to COP meetings and to committees alike. ${ }^{38}$ There are thus fewer restrictions to participation in COP meetings: as a consequence, NGOs willing to follow compliance-related issues will most likely have to look for the "segment" of the compliance procedure before the COP rather than the one before the Committee.

In addition to this restrictive approach to participation, there is not much more scope for transparency, as confidentiality of information in the work of the Committee seems to be the rule, ${ }^{39}$ although the Committee has reassured that it would "post an appropriate summary of its deliberations on the Basel website in order to promote transparency of its work." ${ }^{40}$

The procedural rules in the Terms of Reference regulate essentially the facilitation procedure related to specific submissions. There are no ad hoc procedural rules for "general review" activities. In this case, general COP rules should apply. ${ }^{41}$

\subsection{The Procedure for Specific Submissions: the Preliminary Stage}

Prior to the triggering of the compliance procedure itself, in cases of Party-to-Party submissions and of Secretariat submissions, Parties must try to resolve the issue through consultations. ${ }^{42}$

Self submissions and Party-to-Party submissions are addressed to the Secretariat in writing (in any of the official working languages of the Convention). They must include "the matter of concern" and "the relevant provisions of the Convention" which are at stake. ${ }^{43}$ Party-to-Party submissions, as highlighted above, are based on a

${ }^{38}$ COP Rules of Procedure establish that "the United Nations and its specialized agencies, the International Atomic Energy Agency and any State and any political and/or economic integration organization not party to the Convention [...] may be represented by observers [...] Such observers may, upon invitation of the President, and if there is no objection from at least one third of the Parties present, participate without the right to vote in the proceedings of any meeting" (Rule 6); “[...] any body or agency [...] or non-governmental, qualified in fields relating to the transboundary movement of hazardous wastes as well as their management and disposal [...] may be represented by observers, subject to the condition that their admission to the meeting is not objected to by at least one third of the Parties present at the meeting. Such observers may, upon invitation of the President, and if there is no objection from at least one third of the Parties present, participate without the right to vote in the proceedings of any meeting in matters of direct concern to the body or agency they represent" (ibid., Rule 7). Rules 6 and 7 apply also as a residual rule to meetings of committees (supra n. 36). Moreover, COP meetings and meetings of committees are generally held in public unless otherwise decided (ibid., Rule 29).

39 "The Committee, any Party or others involved in its deliberations shall protect the confidentiality of information received in confidence" (Terms of Reference, para. 26).

${ }^{40}$ Report of the Second Session of the Implementation and Compliance Committee, doc. UNEP/CHW/ CC/2/3 (14 January 2005), para. 14

${ }^{41}$ Supra n. 36.

42 Supra paragraph 7.

${ }^{43}$ The Committee has suggested that these content requirements should apply also in case of Secretariat submissions (see Report of the First Session of the Implementation and Compliance Committee, supra n. 21, para. 12). 
"bilateral approach", according to which the submitting Party must have an interest related to the other Party's non-compliance: therefore, in this case, "information substantiating the submission" must also be included (Terms of Reference, para. 10).

Submissions are sent or forwarded by the Secretariat (within two weeks of its receiving them) to the Committee for consideration at its next meeting, ${ }^{44}$ a copy of the submission (except in cases of self submissions) is also sent to the Party whose compliance with the Convention is in question (Terms of Reference, paras. 11, 13).

The Committee may decide not to proceed with a submission which it considers de minimis or manifestly ill-founded (ibid., para. 18).

\subsection{The Role of the Party under Consideration}

A Party whose compliance with the Convention is in question may present responses or comments at every step of the proceedings (Terms of Reference, para. 12). It may also provide to the Secretariat (within three months of the date of the receipt of the submission "unless the circumstances of a particular case require an extended period of time") additional information, which is transmitted to the Committee for consideration and forwarded to the Party that made the submission in the case of Party-toParty submissions (ibid., para. 14). Moreover, the Party identified in a submission or the one self-triggering the Compliance Mechanism ${ }^{45}$ is invited to participate in the consideration of the submission by the Committee. This Party shall not take part in the elaboration and adoption of the conclusions or recommendations by the Committee, but it shall be given the opportunity to consider them and make comments which shall be forwarded to the COP together with the report of the Committee (ibid., para. 15).

\subsection{The Committee}

After verifying the admissibility of the submission, the Committee analyzes the compliance issues at stake, with the help of the Party under consideration (supra) and using other sources of information. ${ }^{46}$ The procedure will end with the adoption by the Committee of non-binding measures of assistance in favour of the Party or, if necessary, with the recommendation to the COP for the adoption of additional measures. ${ }^{47}$

${ }^{44}$ The Committee has developed an indicative timetable for the receiving of submissions in this regard (ibid., paras. 8-11).

${ }^{45}$ Para. 15 of the Terms of Reference begins with: "Where a Party is identified in a submission or itself makes a submission $[\ldots]$ ". The provision is very ambiguous: the definition of a "Party that itself makes a submission" may refer to any Party submitting a case, or only to the Party submitting the case in cases of self-submissions. Although both interpretations may be acceptable from the textual point of view, the Committee members seem to have endorsed the second one (See The Basel Convention Mechanism for Promoting Implementation and Compliance, supra n. 20, at 7; Shibata, supra n. 35, at 81).

${ }^{46}$ Infra paragraph 9.

47 Infra paragraph 11. 


\section{SOURCES OF INFORMATION}

Provisions on sources of information in the procedure are not limited as one may expect, compared to other weaknesses of the Compliance Mechanism.

Para. 17 of the Terms of Reference establishes that "a Party may also consider and use relevant and appropriate information provided by civil society on compliance difficulties." Although this does not amount to the possibility for NGOs to provide the Committee directly with relevant information, it means nonetheless that such information may become very important, as it may be used by the Parties and eventually reach the Committee anyway. Although para. 17 refers to any Party, given the general exclusion of the submitting Party from the procedure in cases of Party-to-Party submissions, this option is likely to be used more effectively by the Party whose compliance is under consideration.

The Committee, moreover, has some quite extensive powers as far as information gathering and "quasi-investigation" are concerned (Terms of Reference, para. 22). In fact, in carrying out its functions, the Committee may review national reports of the Parties provided under the Basel Convention (ibid., para. 22(f)) and it may request further information from all Parties on general issues of compliance and implementation under its consideration (ibid., para. 22(a)). It may also consult with other bodies of the Convention generally (ibid., para. 22(b)) and in particular with the Secretariat, drawing from its expertise and knowledge base, and requesting information and reports to it (ibid., para. 22(e)). It may even gather further information from any other sources and draw upon outside expertise with the consent of the Party concerned or as directed by the COP (ibid., para. 22(c)). It may finally undertake, with the agreement of the Party concerned, information gathering in its territory (ibid., para. 22 (d)).

\section{DeCISION-MAKING}

According to para. 25 of the Terms of Reference, the Committee decides "on all matters of substance" by consensus. If this is not possible, "the report and recommendations shall reflect the views of all the Committee members." If, notwithstanding this possibility, efforts to reach consensus have been exhausted and no agreement has been reached, decisions are taken by a two-thirds majority of the members present and voting (or by eight members, whichever is the greater, with ten members being the quorum).

Rules on decision-making on procedural matters are not spelled out separately. The general decision-making rules of the COP should thus apply and the Committee should therefore decide by simple majority. ${ }^{48}$ The Committee, however, has adopted a rather unconvincing interpretation of para. 25 of the Terms of Reference and has

48 "Decisions of a meeting on matters of procedure shall be taken by a simple majority vote of the Parties present and voting" (COP Rules of Procedure, para. 40.2). 
decided to provisionally apply to procedural matters the same rule applicable to substantial ones. ${ }^{49}$

\section{Outcomes}

The outcome of the facilitation procedure is the possibility for the Committee to adopt "soft" measures of assistance in relation to the Party concerned, if necessary supplemented by more incisive action by the COP.

With the facilitation procedure, the Committee considers a specific submission "with a view to determining the facts and root causes of the matter of concern", and in order to assist the Party in resolving the matter (Terms of reference, para. 19). To do so, the Committee may, "after coordination with" the Party concerned, provide this Party with advice, non-binding recommendations and information. Such assistance may concentrate, inter alia, on: establishing or strengthening the Party's regulatory regimes (ibid., para. 19(a)); facilitating assistance (in particular to developing countries and countries with economies in transition) on access to financial and technical support (ibid., para. 19(b)); elaborating voluntary compliance action plans, and review their implementation (ibid., para. 19(c)); establishing follow-up arrangements for progress reporting to the Committee (ibid., para. 19(d)). This is not an exhaustive list: the Committee is entitled to deliver advice, non-binding recommendations and information also in areas other than those listed above. In this case, however, the outcome should be provided "in agreement with" the Party.

It is not perfectly clear what the exact difference is between measures of the first kind, adopted "after coordination with" the Party, and those of the latter, provided "in agreement with" the Party. The different wording suggests that the Party concerned has a stronger role in the second case. It may be that the Committee has the power to adopt autonomously measures of the first kind, and that coordination with the Party refers only to the modalities of their implementation, whereas in the second case the measures can be adopted only with the agreement of the Party to which they are addressed.

If, after undertaking the facilitation procedure, and taking into account "the cause, type, degree and frequency of compliance difficulties, as well as the capacity of the Party" the Committee considers it necessary to adopt further measures, it may also recommend the adoption of additional measures by the COP (Terms of Reference, para. 20). The COP may consider, in this regard, providing further support to the

49 Para. 25 of the Terms of Reference states that: "The Committee shall make every effort to reach agreement on all matters of substance by consensus [...] If all efforts to reach consensus have been exhausted and no agreement has been reached, any decision shall, as a last resort, be taken by a two-third majority" (emphasis added). The Committee argues that "while the first sentence of paragraph 25 refers to "all matters of substance', the third sentence of the same paragraph reads 'any' decision as opposed to 'the' decision" and this would justify the application of para. 25 also to procedural matters (Report of the First Session of the Implementation and Compliance Committee, supra n. 21, para. 15). The two sentences, however, appear to be inextricably linked logically, despite the textual misunderstanding, and therefore both seem to refer to decisions on matters of substance. 
Party concerned (including through technical or financial assistance and capacitybuilding) (ibid., para. 20(a)) or "issuing a cautionary statement" and "providing advice regarding future compliance", in order to help Parties to implement the provisions of the Basel Convention and to promote cooperation between all Parties (ibid., para. 20(b)).

The Committee reports at each ordinary meeting of the COP on the work it has carried out within the framework of the facilitation procedure (ibid., para. 23).

As far as the "general review" function is concerned, the Committee, as directed by the COP, reviews general issues of compliance and implementation relating to certain subject-matters (ibid., para. 21). ${ }^{50}$ Conclusions and recommendations adopted by the Committee in this regard are submitted to each ordinary meeting of the COP for its consideration and approval, together with possible suggestions for future work on general issues of compliance and implementation (ibid., para. 24).

\section{Coordination with Dispute Settlement Procedures and Other Non-Compliance Procedures}

As already mentioned above, the Convention provides also for a dispute settlement mechanism and a verification procedure. The verification procedure contained in Article 19 of the Convention provides that:

"[a]ny Party which has reason to believe that another Party is acting or has acted in breach of its obligations under this Convention may inform the Secretariat thereof, and in such an event, shall simultaneously and immediately inform, directly or through the Secretariat, the Party against whom the allegations are made. All relevant information should be submitted by the Secretariat to the Parties."

Article 20 of the Convention provides for a traditional dispute settlement mechanism, whereby Parties shall seek settlement of their disputes through negotiation or other peaceful means, or, if they so agree, through recourse to the International Court of Justice (ICJ) or to arbitration.

The verification procedure appears to be a very simple monitoring and information sharing mechanism that in practice should not raise any conflict or coordination issues with the Compliance Mechanism. On the contrary, a conflict might arise between the Compliance Mechanism and that of dispute settlement if the same matter were to be brought before both mechanisms. The latter may seem to prevail over the former due to the safeguarding clause in para. 27 of the Terms of Reference:

"The present mechanism shall be without prejudice to the provisions of article 20 on settlement of disputes" (emphasis added).

This quite clearly means that recourse to Article 20 options will always be possible despite an ongoing compliance procedure. But apart from this? According to an extensive interpretation of the "no-prejudice" requirement in para. 27 of the Terms

\footnotetext{
${ }^{50}$ Supra paragraph 6.
} 
of Reference, recourse to the dispute settlement mechanism would also automatically prevent the possibility of triggering the Compliance Mechanism on the same matter, or it would automatically stop the compliance procedure if this had already been triggered. Such an interpretation, leading to an automatic and exclusive application of the dispute settlement mechanism, seems to narrow down excessively the scope for the compliance mechanism, especially if one considers that the two mechanisms have different objectives and functions. It seems fairer to consider the "no-prejudice" requirement as an interpretative tool, to be used in order to guarantee the coordination and coexistence of the two mechanisms on a case-by-case basis. The Compliance procedure will have to give way to the dispute settlement mechanism only if the former can really jeopardize the latter. Otherwise the two mechanisms should coexist and should be coordinated within their respective scope of action. This is also confirmed by other provisions, which may work not only for the dispute settlement mechanism but also more in general. The Terms of Reference, in this regard, spell out a sort of principle of complementarity, according to which the Compliance Mechanism "should complement work performed by other Convention bodies" (Terms of Reference, para. 2) and the Committee "shall take into account any specific procedures provided for under the Convention concerning failures to meet Convention obligations" (ibid., para. 28). While this does not seem to amount to a safeguarding clause tout court, it means at least that the Committee will not be able to perform its duties in isolation. This obligation to "take into account" other procedures will leave some room for flexibility, but it will probably strongly encourage the Committee to avoid conflicts with other mechanisms, both from the procedural (to avoid a "conflict of jurisdiction") and substantial (to implement the ne bis in idem principle) points of view.

\section{Financial Aspects}

There are no specific provisions on financial issues in the Terms of Reference or in COP Decision VI/12. A budget line for the Compliance Committee has been included in a proposed Basel Convention Trust Fund. ${ }^{51}$

\section{Survey of Practice}

There have been no specific submissions so far. The Committee has therefore concentrated its work on the review of general issues of compliance. In this regard, the COP has identified the following areas that the Committee should work on: identification and analysis of difficulties relating to reporting obligations, to the designation and functioning of national competent authorities and focal points and to the development

${ }^{51}$ Report of the Second Session of the Implementation and Compliance Committee, supra n. 40, para. 15. 
of national legislation to implement effectively the Convention, ${ }^{52}$ as well as on the issue of illegal traffic..$^{53}$

\section{CONCLUSIONS}

While one may argue that the establishment as such of a Compliance Mechanism within the Basel Convention should be regarded as a cause for great satisfaction, it may be equally fair to highlight that the same mechanism suffers from some great flaws and that it certainly will not be remembered for being excessively progressive and, so far, active.

The Mechanism is not extremely "strong" both in terms of possible outcomes (it is mainly facilitative, it does not provide for any sanction or quasi-sanction) and of its procedure (it requires the cooperation by the Party under consideration to function properly and it provides for little participation of the submitting Party in Party-toParty submission) which is not very detailed. The fact that there have been no cases so far does not help in understanding its functioning. Another critical issue which is probably waiting to be addressed is the precise legal status of the Mechanism itself.

The main problem, however, is the little - almost insignificant - level of civil society participation at any stage of the proceeding. If a non-binding, facilitative procedure can have any impact on a treaty's implementation and compliance, this is probably due to the active involvement of NGOs and other civil society members. But this is not the case with the present mechanism. This weakness is even more striking when looking at what NGOs are doing outside the mechanism: there are still many cases of illegal traffic and management of hazardous wastes, and NGOs are the only entities mobilizing political pressure to address these issues. One of the most active NGOs, the Basel Action Network (BAN), underlines this by publishing its reports on cases of illegal traffic in the form of non-compliance specific submissions.

It is perhaps also in connection with the absence of any role for public participation that there have been no cases brought before the Committee so far. It is also likely that the bilateral nature of State-to-State submissions is not an incentive to trigger the mechanism either. However, not even the self-submission option, which has been used in other mechanisms, has been resorted to. Whatever the reason may be, the Compliance Mechanism of the Basel Convention has not been used. This is not a secondary issue: any positive assessment of the mechanism will have to be suspended until it is eventually triggered so that one may analyze whether and how the mechanism really works in practice. ${ }^{54}$ In the meantime, one may only say that

${ }^{52}$ Decision VII/30 on Mechanism for Implementation and Compliance: Work Program for 2005-2006, doc. UNEP/CHW.7/33 (25 January 2005), at 66-67.

${ }_{53}$ Decision VIII/32 on Mechanism for Promoting Implementation and Compliance: Work Program for 2007-2008, doc. UNEP/CHW.8/16 (5 January 2007), at 55-56.

54 The Committee itself has expressed its concern that no submissions had yet been received, and that this may be due to the "perception amongst Parties that resort to the Committee could be a strong diplomatic act and that there may be doubts about what the mechanism could do in practical terms" (Report of the Fifth Session of the Implementation and Compliance Committee, doc. UNEP/CHW/CC/5/6 (11 September 2007), para. 10 . 
if all these efforts have produced a treaty body that addresses difficulties relating to matters such as the designation and functioning of national competent authorities it was probably not worth it.

\section{Bibliography}

A. Fodella, Il movimento transfrontaliero di rifiuti pericolosi nel diritto internazionale (Torino: Giappichelli, 2004), in particular at 72-89; Secretariat of the Basel Convention, The Basel Convention Mechanism for Promoting Implementation and Compliance, 2006 (available at $<\mathrm{http} / /$ basel.int/legalmatters/compcommitee/brochure-xx0706.pdf >); A. Shibata, "Ensuring Compliance with the Basel Convention - its Unique Features", in U. Beyerlin, P.-T. Stoll, and W. Rüdiger (eds.), Ensuring Compliance with Multilateral Environmental Agreements: A Dialogue between Practitioners and Academia (Leiden: Martinus Nijhoff, 2006), 69-87; A. Shibata, "The Basel Compliance Mechanism", RECIEL 12 (2003) 183-198. 


\title{
Chapter Three \\ The Compliance Procedures and Mechanisms of the 1996 Protocol to the 1972 London Convention on the Prevention of Marine Pollution by Dumping of Wastes and Other Matter
}

\author{
Seline Trevisanut
}

\section{Brief Introduction to the 1972 London Convention AND the 1996 Protocol Thereto}

The Convention on the Prevention of Marine Pollution by Dumping of Wastes and Other Matter (London, United Kingdom, 29 December 1972) (the London Convention or the Convention) ${ }^{1}$ and the 1996 Protocol Thereto (London, United Kingdom, 7 November 1996) (the Protocol) $)^{2}$ are instruments globally applicable to all marine waters other than internal waters aimed at preventing "the pollution of the sea by the dumping $^{3}$ of waste and other matter that is liable to create hazards to human health, to harm living resources and marine life, to damage amenities or to interfere with other legitimate uses of the sea."4 The Protocol substitutes the Convention for those States which are also Parties to the Convention. ${ }^{5}$

Pursuant to Article III of the Convention, dumping means "any deliberate disposal at sea of wastes or other matter ${ }^{6}$ from vessels, aircraft, platforms or other man-made

\footnotetext{
1 Entered into force on 30 August 1975, reprinted in ILM, 11 (1972) 1294. The Contracting Parties are currently 81 .

${ }^{2}$ Entered into force on 24 March 2006, reprinted in ILM, 36 (1997) 1. The Contracting Parties are currently thirty; six of these States (Angola, Bulgaria, Georgia, Saudi Arabia, St. Kitts and Nevis, Trinidad and Tobago) are not Contracting Parties to the London Convention.

${ }^{3}$ Dumping activities are generally considered as violations of customary law. See P. Sands, Principles of International Environmental law (Cambridge: Cambridge University Press, $2^{\text {nd }}$ ed., 2003), 384: "Extensive state practice, as reflected in treaties and acts of international organisations, supports the view that the unregulated disposal of any wastes would now violate rules of customary international law, and that the authorised disposal at sea of certain hazardous wastes would also violated customary law."

4 Art. I.

5 Art. 23 Protocol: "This Protocol will supersede the Convention as between Contracting Parties to this Protocol which are also Parties to the Convention."

${ }^{6}$ The wastes and other matter for which dumping may be authorised are listed in the three annexes of the Convention. Each annex corresponds to the type of wastes: Annex I (the "black list") catalogues highly hazardous waste substances whose dumping is prohibited, except in emergency situations, after consulta-
}

T. Treves et al., eds., Non-Compliance Procedures and Mechanisms and the Effectiveness of International Environmental Agreements

(C) 2009, T.M.C. Asser PREsS, The Hague, The Netherlands, and the Authors 
structures at sea" and "any deliberate disposal at sea of vessels, aircraft, platforms or other man-made structures at sea." The cornerstone provision of the Convention, reaffirmed in Article 210 Law of the Sea Convention, is the need for approval by the competent authorities of the loading State in order to realise the dumping of the authorised matter (Article VI).

The London Convention requires cooperation among Parties on training, research, monitoring, method for disposal and treatment of wastes, as well as for the development of procedures in order to assess responsibility and the settlement of disputes between Contracting Parties.

The Convention is administered by the Consultative Meeting of the Contracting Parties (MCP) held annually in London at the International Maritime Organization (IMO), which has provided the Secretariat functions since 1975 when it was designated as the competent organization (Article $\operatorname{XIV}(2))$.

The MCP is responsible for keeping under review the implementation of the Convention, amending it and its annexes, receiving the Parties' reports pursuant to Article $\mathrm{VI}(4)$ and developing and adopting procedures and criteria for determining exceptional and emergency situations (Article XV). Amendments to the Convention may be adopted by a two-thirds majority of those Parties present, and enter into force for the Parties which have accepted it on the sixtieth day after two thirds of the Parties have deposited the instrument of acceptance (Article XV(1)(a)). Amendments to the annexes may be approved by a two-thirds majority of those present at a given meeting and enter into force for each Contracting Party immediately on notification of its acceptance, except for those which before the end of 100 days after the approval make a declaration that they are not able to accept the amendment (Article XV(2)). Any other resolution adopted by the MCP is not formally binding for the Contracting Parties.

The MCP has created several subsidiary bodies such as the Scientific Group on Dumping, the ad hoc Legal Group of Experts and, in 1998, the ad hoc Working Group on Reporting and Compliance (the ad hoc Working Group) ${ }^{7}$ whose task consists of recommending to the MCP the appropriate initiatives for compliance promotion, and guidance on what the mandate, composition, scope and powers of any compliance body might be. ${ }^{8}$

The ad hoc Working Group has been working for several years on developing procedures and mechanisms to implement Article 11 of the Protocol in view of its entry into force.

tion with States eventually affected and with IMO (Art. IV(I)(a)); the dumping of Annex II (the "grey list") requires a "special" permit (Art. IV(I)(b)); the dumping of all other wastes needs a "general" permit in compliance with Annex III which requires criteria to be taken into account in deciding whether a permit should be granted (Art. VI(3)).

7 Report of the Twentieth Consultative Meeting, doc. LC 20/14 (4 February 1999), para. 9.32.8.

${ }^{8}$ Ibid., Annex 2, paras. 1.2, 1.5. 


\section{Legal Basis of the Mechanism and Negotiating History}

The establishment by the MCP of the Protocol (MCPP) $)^{9}$ of a compliance mechanism is mandatory under Article 11 of the Protocol which provides that:

"1. No later than two years after the entry into force of this Protocol, the Meeting of Contracting Parties shall establish those procedures and mechanisms necessary to assess and promote compliance with this Protocol. Such procedures and mechanisms shall be developed with a view to allowing for the full and open exchange of information, in a constructive manner.

2. After full consideration of any information submitted pursuant to this Protocol and any recommendations made through procedures or mechanisms established under paragraph 1, the Meeting of Contracting Parties may offer advice, assistance or co-operation to Contracting Parties and non-Contracting Parties."

This provision reflects the general approach of the Protocol which is more restrictive than that of the London Convention and is strongly based on the precautionary principle. ${ }^{10}$ The provision gives no information relating to the characteristics of the compliance procedure. Therefore the MCP at the twenty-fourth Consultative Meeting asked the Secretariat to elaborate a document containing compliance information on a selection of Multilateral Environmental Agreements (MEAs) ${ }^{11}$ and approved a questionnaire to solicit views from Parties in order to facilitate the development of compliance procedure and mechanisms under Article 11. ${ }^{12}$ The ad hoc Working Group elaborated a "base text" ${ }^{13}$ revised during the twenty-seventh MCP that has also established an intersessional correspondence group, co-lead by the Netherlands and the United States. ${ }^{14}$

${ }^{9}$ Since the Protocol entered into force on 24 March 2006 (supra n. 2), the first MCPP was held in conjunction with the twenty-eighth MCP on 30 October-3 November 2006 and with the twenty-ninth MCP on 5-9 November 2007. See Report of the Twenty-eight Consultative Meeting and the First Meeting of Contracting Parties, doc. LC 28/15 (6 December 2006); Report of the Twenty-ninth Consultative Meeting and the Second Meeting of Contracting Parties, doc. LC 29/17 (14 December 2007).

${ }^{10}$ See para. 2 of the Preamble and Art. 3 on "General obligations" stating that: "In implementing this Protocol, Contracting Parties shall apply a precautionary approach to environmental protection from dumping [...]". Moreover the Protocol also introduces the "polluter pays" principle at Art. 3.2: "Taking into account the approach that the polluter should, in principle, bear the cost of pollution [...]". See E.A. Kirk, "The 1996 Protocol to the London Dumping Convention and the Brent Spar", Int'l \& Comp. L. Q., 46 (1997) 957-964, at 959

11 Preparation of the Entry into Force of the 1996 Protocol: Development of Compliance Procedures and Mechanisms, doc. LC 25/INF.10 (29 September 2003), prepared by the Secretariat on request of the Twenty-fourth MCP, doc. LC 24/17 (31 January 2003), para. 3.7.4.

${ }_{12}$ Questionnaire on Compliance Procedures and Mechanisms under Article 11 of the 1996 Protocol to the London Convention 1972, in Preparation for the Entry into Force of the 1996 Protocol: Development of Compliance Procedures and Mechanisms, doc. LC 25/3 (28 July 2003), Appendix.

${ }_{13}$ Report of the Twenty-sixth Consultative Meeting, doc. LC 26/15 (17 December 2004), Annexes 2, 3 and 4

${ }^{14}$ Report of the Twenty-seventh Consultative Meeting, doc. LC 27/16 (16 December 2005), para. 3.11.3. 
The "Base Text" (the Base Text) of the ad hoc Working Group, as amended by the LC Correspondence Group on Reporting and Compliance, ${ }^{15}$ was discussed and further developed during the first MCPP, held in November 2006. ${ }^{16}$ The second MCPP was held in November $2007^{17}$ and it adopted the final text establishing the Compliance Mechanism.

\section{The Text Establishing the Mechanism}

The "Compliance Procedures and Mechanisms Pursuant to Article 11 of the 1996 Protocol to the London Convention 1992" (the Text) ${ }^{18}$ were adopted during the second MCPP and provides for the functions and the characteristics of the Compliance Group which, after being elected, ${ }^{19}$ is going to be held for the first time simultaneously with the third MCPP, on 27-29 October $2008 .^{20}$ In doing so, the MCPP has respected the letter of Article 11 which requires that the compliance procedures and mechanisms should be established "no later than two years after the entry into force of the Protocol", i.e., before 28 March 2008.

According to Article 26 of the Protocol, a State that was not a Party to the London Convention may notify the Secretary-General of the IMO, at the time it expresses its consent, that it will not be able to implement specific provisions ${ }^{21}$ of the Protocol for a transitional period that cannot exceed five years (Article 26.4). The notification may deal with Article 11 on compliance procedure. However, during this period, the Contracting Party has the obligation to establish procedures and mechanisms "to implement and monitor submitted programmes designed to achieve full compliance with [the] Protocol" (Article 26.6) and to submit reports pursuant to Articles 26.5 and 26.6 to the Secretariat before each MCPP (para. 6.5 of the Text). Some actions may be undertaken on the reports by the MCPP, including, "if appropriate, referral to the Compliance Group or the Scientific Group”.

15 Compliance Issues: Development of Compliance Procedures and Mechanism under Article 11, doc. LP 1/7 (23 June 2006), Annex 1.

16 Doc. LC 28/15, supra n. 9. The amendments agreed by the first MCPP were incorporated in Annex 1 of Compliance Issues: Development of Compliance Procedures and Mechanism under Article 11, Amended Base Text, doc. LC 29/5 (27 February 2007).

${ }^{17}$ Report of the Twenty-ninth Consultative Meeting and the Second Meeting of Contracting Parties, doc. LC 29/17 (14 December 2007).

18 Doc. LC 29/17, supra n. 9, Annex 7.

19 "The elections take place at the start of the next Meeting of Contracting Parties, allowing the Compliance Group to meet in parallel early in the week, with its recommendations being reported to the Meeting of Contracting Parties later that week", see doc. LC 29/17, supra n. 9, para. 5.20. For the elections criteria, see infra, paragraph 5.1.

20 Doc. LC 29/17, supra n. 9, para. 14.16 .

${ }^{21}$ According to para. 2 of the provision, the notification cannot affect obligations related to the "incineration at sea or the dumping of radioactive wastes or other radioactive matter". 


\section{The Principles Governing the Mechanism and the Procedure}

Article 11 of the Protocol, as recalled by para. 1.1. of the Text, clearly indicates that the mechanism has to allow the "full and open exchange of information, in a constructive manner". The former Base Text indicated that the mechanism is nonconfrontational, facilitative, cost-effective and preventive in nature, simple and flexible; an agreement was not reached on whether its non-binding nature should also be underlined..$^{22}$ These principles are however reflected in the institutional and procedural aspects of the mechanism as stated in the present Text.

\section{INSTITUTIONAL ASPECTS}

\subsection{The Compliance Group}

\section{a) Composition}

The number of members of the Compliance Group is limited to fifteen (para. 3.1). The second MCPP has discussed the institutional model of the Compliance Group and the Parties agreed on the establishment of a "standing subsidiary committee or body". ${ }^{23}$ The Compliance Group shall meet as necessary, at least once a year and when specifically requested by the MCPP (para. 3.7). The Contracting Parties will nominate the members, "based on equitable and balanced geographic representation of the five Regional Groups of the UN", who will be elected by the MCPP (para. 3.4). The members have to be selected on the basis of their scientific, technical or legal expertise (para. 3.2).

The MCPP

"shall elect five of the members for one term, five of the members for two terms, and five of the members for three terms. The [MCPP] shall, at each ordinary meeting thereafter, elect for three full terms new members to replace those members whose period of office has expired, or is about to expire. Members shall not serve for more than three consecutive terms. For the purpose of this decision, term means the period that begins at the end of one ordinary [MCPP] and ends at the next ordinary session of the [MCPP]" (para. 3.5).

The Compliance Group will elect its own Chairman and Vice-Chairman (para. 3.6).

b) Status of Members

The two options of a body composed of members serving in their personal capacity or as representatives of Contracting Parties, as set out at para. 3.1.2 of the Base Text,

${ }^{22}$ See para. 1.2 of the Base Text (doc. LP 1/7, supra n. 15) that, as it was a working paper, still had brackets in the text, as reported here: "The procedures and mechanisms shall be non-confrontational, [primarily] facilitative, transparent, cost-effective and preventive in nature, simple[,] [and] flexible[ and nonbinding]".

${ }^{23}$ Doc. LC 29/17, supra n. 9, para. 5.1.1. 
have not been confirmed by the Text even though the majority of the answers to the Questionnaire ${ }^{24}$ clearly indicated the preference for members of the body to be government representatives. In any case a provision to the effect that members should serve "objectively and in the interest of promoting compliance with the Protocol" (para. 3.3), as requested by two Governments, ${ }^{25}$ was introduced.

\section{c) Observers}

A non-Party observer is entitled to attend meetings of the Compliance Group, "except when individual situations of compliance are under consideration by the Compliance Group, the meeting shall be closed" if the Party involved so requests (para. 3.8). Moreover observers can provide information to the MCPP on the basis of which information individual situations of possible non-compliance may be raised (para. 4.1.1).

Concerning the possible status of observer for NGOs, the Text does not clarify this issue.

\subsection{The London Protocol Scientific Group}

Pursuant to Article 18.1.2 of the Protocol, ${ }^{26}$ the first MCPP established a Scientific Group under the auspices of the London Protocol (the Scientific Group), which met the first time on 18-22 June 2007, concurrently with the Scientific Group of the London Convention. ${ }^{27}$

The Secretariat submits to the Scientific Group the annual reports prepared by the competent domestic authorities under Article 9.4.1 of the Protocol. The Scientific Group will then, in accordance with its terms of reference, ${ }^{28}$ evaluate this information and advise the Compliance Group, as appropriate, as well as the MCPP (para. 6.2). A Meeting of the Parties of the Scientific Group is held annually and reports the different studies conducted. The Scientific Group may make recommendations to the MCPP and the Compliance Group, as appropriate, on the compliance issues referred to it or that have arisen in the course of its work ${ }^{29}$ and contribute, within its terms of reference, to the work of the Compliance Group (para. 2.2.9).

\footnotetext{
${ }^{24}$ Doc. LC 25/3, supra n. 12, Appendix.

${ }^{25}$ Ibid., Annex, para. 11.

${ }^{26}$ Under Art. 18.1.2, the MCPP may "establish subsidiary bodies, as required, to consider any matter with a view to facilitating the effective implementation of this Protocol."

${ }^{27}$ The LC Scientific Group is a body of the London Convention usually requested by the MCP to study and develop criteria and guidelines for improving the implementation of the Convention. About the Scientific Group's activity in general, see L. de La Fayette, "The London Convention 1972: Preparing for the Future", Int'l J. Mar. \& Coast. L., 13 (1998) 520-522.

${ }^{28}$ Terms of Reference for the Scientific Group under the London Protocol, doc. LC 29/17, supra n. 9, Annex 2.

${ }^{29}$ Ibid., para. 2.5.
} 


\subsection{The Meeting of the Contracting Parties to the 1996 Protocol (MCPP)}

The MCPP retains general powers in compliance issues. It refers compliance matters to the Compliance Group and/or the Scientific Group (para. 2.1.1) and reviews periodically the effectiveness of the compliance procedures and mechanisms (para. 2.1.3). The MCPP makes the final decision regarding any measures to be taken in response to a Party's possible non-compliance and may also consider additional measures to facilitate compliance by the Party concerned (para. 5.4). The MCPP retains overall responsibility for compliance matters (para. 1.2). Once received by the Secretariat, the MCPP refers the reports under Article 9.4.2 and 9.4.3 $3^{30}$ of the Protocol to the Compliance Group for evaluation (para. 6.3).

\section{$5.4 \quad$ The Secretariat}

The Secretariat functions are provided by the IMO.${ }^{31}$ The main task of the Organization in relation to the compliance procedure is to receive the submissions and to refer them to the Compliance Group (para. 4.4). The Parties also submit to the IMO the reports made under Articles 9.4.2 and 9.4.3 of the Protocol (para. 6.3). Under Article 10.3 of the Protocol, the Secretariat compiles the "Incident Information Forms" and then presents them to each MCPP for consideration and, "if appropriate", refers to the Compliance Group or to the Scientific Group (para. 6.4).

\subsection{The International Atomic Energy Agency (IAEA)}

For compliance matters involving radioactive wastes and other radioactive matters, the Secretariat, on behalf of the Compliance Group, has to refer the matter to the IAEA for technical evaluation and review. The Compliance Group shall take into consideration the evaluation of the IAEA in its consideration of the matter (para. 4.6).

\section{Functions of THE COMPliance Group}

The Compliance Group has a general task of monitoring on compliance issues. In particular, it makes recommendations to the MCPP on measures to undertake in relation to a Party's possible non-compliance (paras. 2.2.3, 5.1) and "review the implementation of Meeting of Contracting Parties' recommendations and decisions on compliance" (para. 2.2.5).

The Compliance Group may also consider and assess the individual situation of a Party's possible non-compliance identifying the facts, possible causes and specific circumstances of the non-compliance (para. 2.2.1). Then, giving due consideration to

${ }^{30}$ These reports regard administrative and legislative measures taken to implement the provisions of the Protocol, including a summary of enforcement measures, the effectiveness of such measures and any other problems encountered in their application.

31 See Art. 19 of the Protocol on "Duties of the Organization": "The Organization (the IMO under Art. 1.2 of the Protocol) shall be responsible for Secretariat duties in relation to this Protocol". 
the capacity of the Party concerned, the Compliance Group recommends to the MCPP the measures that may be undertaken (para. 5.1).

Upon request by a non-Party, the Compliance Group may provide advice and guidance to facilitate its becoming a Party to the Protocol (para. 5.8). The Compliance Group may request advice and information from the Scientific Group (para. 2.2.9) and has to submit a report about its activity and its future work programme to each MCPP (para. 6.6).

\section{Trigger Mechanism}

"Submission" refers to an individual situation of possible non-compliance raised either by the MCPP (para. 4.1.1) or by the concerned Party (para. 4.1.2) or by a Party that "has reservations about another Party's compliance with the obligations under the Protocol when it has an interest that is affected or likely to be affected by the possible non-compliance" (para. 4.1.3). In the latter case, it is recommended that the Party informs the Party whose compliance is in question and tries to resolve the situation through negotiation before triggering the compliance mechanism. The possibility of submission raised by organizations with observer status under the Protocol having reservations about a Party's compliance was provided by the draft text in brackets (para. 4.1.4 of the Base Text), but it has disappeared in the final version.

The Compliance Group may reject submissions which are "de minimis, manifestly ill-founded, or anonymous" (para. 4.2).

The broad provision on the power of the Compliance Group to recommend to the MCPP "on systemic compliance issues [...] that it proposes to pursue" (para. 2.2.1) suggests that the Compliance Group may also act proprio motu..$^{32}$

\section{The Procedure before the Compliance Group and Procedural SAFEGUARDS}

\subsection{Procedure of Initiating Submissions of Non-Compliance}

A submission must be addressed in writing to the Secretariat and contain the matter of concern, the relevant provisions of the Protocol and information substantiating the submission (para. 4.3). The Secretariat has to forward the submission within two weeks to the Compliance Group. In the case of a submission other than by the Party concerned, the Secretariat shall send to this Party a copy of the submission within two weeks (para. 4.4).

32 The ad hoc Working Group recommended that discussions of systemic issues could be initiated by the Compliance Group to allow it to make recommendations to the MCPP about the systemic issues to pursue; see doc. LC 28/15, supra n. 9, para. 136. 


\subsection{Consideration by the Compliance Group}

The non-exhaustive list of actions that the Compliance Group could undertake to collect further information on the submission, provided by the Base Text, ${ }^{33}$ has been substituted with a more general provision which states: "In carrying out its functions, the Compliance Group may seek, or receive, and consider relevant information from any source it considers to be reliable" (para. 3.11). This wording suggests that the Compliance Group may have at its disposal information other than that provided by interested Parties or by bodies or reports provided under the Protocol, including from the non-governmental sector. However, this argument has not yet been clarified.

After the information has been forwarded by the Secretariat, the Compliance Group has to consider it at its next meeting together with the comments provided in response by the Party concerned (para. 4.5).

\subsection{Monitoring}

Pursuant to para. 2.2.5 of the Text, the Compliance Group may review "the implementation of Meeting of the Contracting Parties' recommendations and decisions on compliance". Moreover the Compliance Group may review and provide advice to the MCPP on reports and records submitted pursuant section 6 of the Text, on "Reports and Records" (para. 2.2.6).

\subsection{Procedural Safeguards}

a) Due Process

A Party whose compliance is in question is entitled to receive from the Secretariat within two weeks a copy of the submission made (para. 4.4). It also has the right to present information or comments that must be then forwarded to the Secretariat "within three months upon receipt of the submission". The concerned Party may also ask the Chairman for an extension for the presentation of this information or comments "for a period of up to 90 days, with reasonable justification" (para. 4.5).

After its establishment, the Compliance Group will have to discuss the question whether or not one of its members may participate to the elaboration and adoption of recommendations regarding his/her country. ${ }^{34}$

\section{b) Participation and transparency}

As recalled above, any Party and any non-Party observer is entitled to participate at the Compliance Group's meeting except when an individual compliance situation is under consideration (para. 3.8). Pursuant to para. 4.4, notice of all submissions shall be sent to all Parties for their information and a copy of any full submission will be available to any Party upon request.

\footnotetext{
${ }_{33}$ Doc. LP 1/7, supra n. 15, Annex 2, paras. 9.1, 9.3.1-5.
}

${ }^{34}$ Doc. 29/17, supra n. 9, para. 5.8.2. 


\section{c) Confidentiality}

The confidentiality of proceedings is also ensured by para. 3.8, providing that any Party, other than the Party whose compliance is in question, and any non-Party observer is not entitled to participate at the meeting of the Compliance Group when individual situations are under consideration. Moreover, the Party whose compliance is under consideration may request the meetings of the Compliance Group to be closed.

\section{d) Languages}

According to the Base Text, the official language of the meetings of the Compliance Group would be only in English; however, a Party whose compliance is in question can request interpretation into another official language of the Protocol. ${ }^{35}$ This issue has not been solved yet and it is going to be the concern of the Compliance Group at its first meeting. ${ }^{36}$

\section{SOURCES OF INFORMATION}

In general terms, as already remarked above, ${ }^{37}$ in carrying out its functions the Compliance Group "may seek or receive and consider relevant information from any source it considers to be relevant" (para. 3.11).

\section{DeCISION-MaKing}

The Compliance Group shall make all efforts to reach an agreement by consensus; if it is not possible, the decision must be adopted with a three-quarters majority vote of the present and voting members. The views of all members of the Compliance Group have to be reflected in the report when consensus cannot be reached (para. 3.9). The quorum is reached when two-thirds of the members of the Compliance Body are present (para. 3.10).

Prior to referring the decision to the MCPP, the Compliance Group submits for consideration its conclusions and recommendations to the Party whose compliance is in question. This Party has the possibility to express any comments which the Compliance Group then has to describe in its report to the MCPP (para. 5.3).

${ }^{35}$ Under Art. 29, the official languages of the Protocol are Arabic, Chinese, English, French, Russian and Spanish.

${ }^{36}$ Doc. 29/17, supra n. 9, para. 5.8.1.

${ }^{37}$ See supra para. 8.2 on "Consideration by the Compliance Group". 


\section{Outcomes}

Once adopted by the Compliance Group, the decisions are referred for consideration by the MCPP. Pending the decision of the Meeting, ${ }^{38}$ the Compliance Group provides advice and guidance to the Party concerned (para. 2.2.7).

The MCPP may then make provisions consisting of: advice and recommendations; facilitation of cooperation and assistance; elaborate compliance action plans with the interested Party or Parties, including targets and timelines; or make a formal statement of concern regarding a Party's compliance situation (paras. 5.1.1-4).

The MCPP "may also consider additional more stringent measures within its mandate, as appropriate, to facilitate compliance by the Party concerned" (para. 5.4). This wording is consistent with the result of the Questionnaire ${ }^{39}$ where some delegations demanded more stringent measures in the case of the failure of the facilitative measures or of repeated or continued non-compliance, given due account of "the cause, type, degree and frequency of the compliance difficulties of a Party". ${ }^{40}$

The Party whose compliance is under consideration may also make a statement to the MCPP once it has decided the measures regarding its compliance situation (para. 5.2).

\section{Coordination with Dispute Settlement Procedures and Other Non-COMPliance Procedures}

According to para. 7, "[t]his mechanism shall be without prejudice to the provisions of Article 16 of the Protocol on settlement of disputes". Notwithstanding what is suggested in the Base Text, ${ }^{41}$ the Text gives no information about how the Compliance Group would have to act in the case of issues overlapping with the responsibilities of other bodies under the Protocol or obligations under other multilateral instruments.

38 The MCPP "shall make the final decision regarding any measures proposed by the Compliance Group to be taken in response to a Party's possible non-compliance" (para. 5.4).

39 Doc. LC 25/3, supra n. 12, Appendix, para. 33.

40 This expression has been integrated in the chapeau of para. 5 on "Measures" which now states: "[...] taking into account the capacity of the Party concerned, and the comments or information provided under 4.5, and such factors as the cause, type, degree and frequency of any non-compliance, the Compliance Group may recommend to the Meeting of Contracting Parties that one or more of the following measures be taken $[\ldots] "$.

${ }^{41}$ Doc. LP 1/7, supra n. 15, Annex 2, para. 7: "Where there is an overlap with the obligations and responsibilities under other multilateral instruments the Meeting of Contracting Parties may request the Compliance body/ Scientific Group to communicate with relevant bodies of the respective instruments, with a view to pursuing possibilities for synergies and linkages, including through organizational and practical co-operation, and report back to the Meeting of Contracting Parties." 


\section{Participation of the European Community}

The European Commission has been invited to be present at the twenty-ninth MCP and the second MCPP. ${ }^{42}$ In fact the Community is not a Contracting Party of the 1972 London Convention, nor of the 1996 Protocol thereto. However it is important to take into due account that the Community has ratified ${ }^{43}$ the Convention for the Protection of the Mediterranean Sea Against Pollution (Barcelona, Spain, 16 February 1976) (the Barcelona Convention) $)^{44}$ and the Protocol for the Prevention of Pollution by Dumping from Ships and Aircraft (Barcelona, Spain, 16 February 1976) (the Barcelona Protocol). This Protocol reaffirms at the regional level the obligations of the London Convention and the 1996 Protocol $^{45}$ as recalled by its paras. 3 and 4 of the Preamble. ${ }^{46}$

Compliance with the obligations of the Barcelona Dumping Protocol is monitored by the European Maritime Safety Agency (EMSA) created in $2002^{47}$ which shall provide "the Member States and the Commission with the technical and scientific assistance needed and with a high level of expertise, in order to help them to apply Community legislation properly in the field of maritime safety and prevention of pollution by ships, to monitor its implementation and to evaluate the effectiveness of the measures in place. ${ }^{\prime 48}$ In order to perform its tasks, the EMSA may also carry out visits to the Member States. ${ }^{49}$

The activity of the EMSA may interfere with the work of the Compliance Group and the Scientific Group of the 1996 Protocol in order to supervise the implementation by the Member States of the Community which are also Contracting Parties to

42 Doc. LC 28/15, supra n. 9, para. 25.

${ }^{43}$ Council Decision 77/585/EEC of 25 July 1977 concluding the Convention for the Protection of the Mediterranean Sea against Pollution and the Protocol for the Prevention of the Pollution of the Mediterranean Sea by Dumping from Ships and Aircraft, OJ (1977) L 240/1.

44 A list of treaties with full references is provided supra at XXXVII. See also I. Papanicolopulu, "Procedures and Mechanisms on Compliance under the 1976/1995 Barcelona Convention on the Protection of the Mediterranean Sea and its Protocols", infra 155-168.

45 According to Art. 12 of the 1996 Protocol, the Contracting Parties are invited to enhance regional cooperation including the conclusion of regional agreements consistent with the Protocol for the prevention, reduction and the elimination of pollution caused by dumping or incineration at sea of wastes or other matter.

46 "Bearing in mind that Chapter 17 of Agenda 21 of UNCED calls on the Contracting Parties to the Convention on the Prevention of Marine Pollution by Dumping of Wastes and other Matter (London, 1972) to take the necessary measures to end dumping in the ocean and the incineration of hazardous substances. Taking into account Resolutions LC 49(16) and LC 50(16), approved by the sixteenth Consultative Meeting of the 1972 London Convention, which prohibits the dumping and incineration of industrial wastes at sea"; see the Preamble of the Barcelona Convention and Protocol, as revised in 1995, and accepted by the Community by Council Decision 1999/802/EC of 22 October 1999 on the acceptance of amendments to the Convention for the Protection of the Mediterranean Sea against Pollution and to the Protocol for the Prevention of Pollution by Dumping from Ships and Aircraft (Barcelona Convention), OJ (1999) L 322/32.

${ }^{47}$ Regulation (EC) 1406/2002 of the European Parliament and of the Council of 27 June 2002 establishing a European Maritime Safety Agency, OJ (2002) L 208/1 and Regulation (EC) 724/2004 of the European Parliament and of the Council of 31 March 2004 amending Regulation (EC) 1406/2002 establishing a European Maritime Safety Agency, OJ (2004) L 129/1. See also the website of the EMSA: <www.emsa. europa.eu> (visited 4 February 2008).

48 Regulation 1406/2002, Art. 1.

49 Regulation 1406/2002, Art. 3. 
the 1996 Protocol of the existing rules consistent with the prevention, reduction and elimination of pollution caused by the dumping at sea of wastes and other matter.

\section{FinanCIAL Aspects}

The Text does not furnish any information about the eventual costs of a compliance procedure. At the moment, the Secretariat has developed a preliminary overview of financial implications in which the costs associated with the convening of the Compliance Group at IMO are included. ${ }^{50}$

\section{Bibliography}

L. de La Fayette, "The London Convention 1972: Preparing for the Future", Int'l J. Mar. \& Coast. L., 13 (1998) 515-536; International Maritime Organization, Guidelines on the Convention on the Prevention of Marine Pollution by Dumping of Wastes and other Matter, 1972, 2006 Edition (London: IMO Publication, 2006); E.A. Kirk, "The 1996 Protocol to the London Dumping Convention and the Brent Spar", Int'l \& Comp. L. Q., 46 (1997) 957-964; E.J. Molenaar, "London Convention", Int'l J. Mar. \& Coast. L., 12 (1997) 396-403; P. Sands, Principles of International Environmental Law (Cambridge: Cambridge University Press, $2^{\text {nd }}$ ed., 2003).

\footnotetext{
${ }^{50}$ Doc. LC 29/17, supra n. 9, para. 14.3.1.
} 
1 


\title{
Chapter Four \\ Procedures and Mechanisms Relating to Compliance under the 1997 Kyoto Protocol to the 1992 United Nations Framework Convention on Climate Change
}

\author{
Sabrina Urbinati
}

1. Brief Introduction to the United Nations Framework Convention on Climate Change and the Kyoto Protocol

Climate change was taken into the political arena in the 1980s by the United Nations Environmental Programme (UNEP) and the World Meteorological Organization (WMO), on the basis of alarming scientific findings and the rise in environmental concerns over acid rain and the ozone layer. Thus UNEP and WMO organized a series of workshops, such as Toronto $1988^{1}$ and the Second World Climate Conference in Geneva 1990. In response to an appeal by the latter, the UN General Assembly established the Intergovernmental Negotiating Committee for a Framework Convention on Climate Change and a Secretariat located in Geneva. ${ }^{2}$

The Intergovernmental Negotiating Committee met for the first time in February 1991. After fifteen months, on 9 May 1992, the United Nations Framework Convention on Climate Change (UNFCCC) was adopted. ${ }^{3}$

The UNFCCC identifies three main categories of State Parties and formulates differentiated responsibilities for them. The first category involves the developed countries and the "countries that are undergoing the process of transition to a market economy", such as a number of Central and Eastern European States and parts of the former USSR. These countries are listed in Annex I (Annex I State Parties). ${ }^{4}$ The

1 “The Changing Atmosphere: Implications for Global Security", Am. U. J. Int'l L. \& Pol'y, 5 (1990) $515-524$, at 515 .

2 H. Ott, "Elements of a Supervisory Procedure for the Climate Regime", ZaöRV, 56 (1996) 732-749, at 732-733; D. Zaelke and J. Cameron, "Global Warming and Climate Change - An Overview of an International Legal Process”, Am. U. J. Int'l L. \& Pol'y, 5 (1990) 249-290; A. Kiss and J.P. Beurier, Droit International de l'Environnement (Paris: Pédone, 2004), 264-270.

3 Reprinted in ILM, 31 (1992) 1330. The UNFCCC Convention was opened for signature at the UN Conference on Environment and Development (UNCED), also called "The Earth Summit", in Rio de Janeiro, Brazil, on 4 June 1992, and came into force on 21 March 1994. Currently, it has 192 State Parties.

${ }^{4}$ Parties listed in Annex I are: Australia, Austria, Belarus, Belgium, Bulgaria, Canada, Croatia, Czech Republic, Denmark, European Economic Community, Estonia, Finland, France, Germany, Greece, Hungary, Iceland, Ireland, Italy, Japan, Latvia, Liechtenstein, Lithuania, Luxembourg, Monaco, Netherlands, New

T. Treves et al., eds., Non-Compliance Procedures and Mechanisms and the Effectiveness of International Environmental Agreements

(C) 2009, T.M.C. Asser PREsS, The Hague, The Netherlands, and the Authors 
second category, involving only the "developed country Parties" listed in Annex II, comprises all Member States of the Organisation for Economic Co-operation and Development (OECD) and the EC. ${ }^{5}$ The third category regards developing countries and is not listed in either Annex (non-Annex I Parties). ${ }^{6}$

When governments adopted the UNFCCC, they knew that the commitments set out therein would not be sufficient to achieve its ultimate objective. Indeed, during the first Conference of the Parties (COP), held in Berlin in March/April 1995, a decision called "Berlin Mandate" was adopted, whereby the Parties launched a new round of talks within an ad hoc Group to decide on stronger and more detailed commitments. After two and a half years of intense negotiations, the Kyoto Protocol ${ }^{7}$ to the UNFCCC (Kyoto Protocol) was adopted at the third COP in Kyoto on 11 December 1997.

The Kyoto Protocol commits Annex I Parties to individual, legally-binding targets to limit or reduce their greenhouse gas emissions, adding up to a total cut of at least 5\% from 1990 levels in the "commitment period" 2008-2012 (Article 3). In doing so, Parties can have recourse to the flexibility mechanisms established under the Protocol: the Clean Development Mechanism, the Joint Implementation and the Emissions Trading system. These mechanisms enable State Parties to have access to cost-effective opportunities to achieve the Kyoto Protocol emissions reductions targets.

The Clean Development Mechanism enables Annex I Parties to reduce emissions by implementing projects in non-Annex I Parties in return for Certified Emission Reductions that shall be used by the Annex I Parties concerned to meet their emission targets under the Kyoto Protocol. This mechanism aims to assist the developing Party in the achievement of the different targets of the Convention. ${ }^{8}$

The basic principles of the Joint Implementation establish that any Party

"[...] included in Annex I may transfer to, or acquire from, any other such Party emission reduction units resulting from projects aimed at reducing anthropogenic emissions by sources or enhancing anthropogenic removals by sinks of greenhouse gases in any sector of the economy $[\ldots] "$. .

Zealand, Norway, Poland, Portugal, Romania, Russian Federation, Slovakia, Slovenia, Spain, Sweden, Switzerland, Turkey, Ukraine, United Kingdom of Great Britain and Northern Ireland and the United States of America.

5 State Parties listed in Annex II are: Australia, Austria, Belgium, Canada, Denmark, European Economic Community, Finland, France, Germany, Greece, Iceland, Ireland, Italy, Japan, Luxembourg, Netherlands, New Zealand, Norway, Portugal, Spain, Sweden, Switzerland, United Kingdom of Great Britain and Northern Ireland and the United States of America.

${ }^{6}$ P. Peters, N. Schrijver, and O. Kuik (eds.), Joint Implementation to Curb Climate Change (Dordrecht: Kluwer Academic Publishers, 1994), 65.

7 Reprinted in ILM, 37 (1998), at 22. The Kyoto Protocol was open for signature on 16 March 1998. In order to enter into force, the Protocol had to be ratified by 55 Parties to the Convention, including Annex I Parties accounting for $55 \%$ of carbon dioxide emissions from this group in 1990. The Protocol entered into force on 15 February 2005. Currently, the 177 State Parties account for $63.7 \%$ of carbon dioxide emissions.

${ }^{8}$ Kyoto Protocol, Art. 12.

9 Kyoto Protocol, Art. 6. 
The Emission Trading system provides that Annex I Parties can acquire units from other Annex I Parties and use them towards meeting their emissions targets under this Protocol. ${ }^{10}$

It is important to underline that the thirteenth COP adopted a decision called the "Bali Action Plan", where State Parties decide "[...] to launch a comprehensive process to enable the full, effective and sustained implementation of the Convention through long-term cooperative action, now, up to and beyond 2012, in order to reach an agreed outcome and adopt a decision at [...]" the fifteenth COP. ${ }^{11}$ The negotiation came up with many possible actions for adapting to the negative consequences of climate change, such as drought and floods, ways to reduce greenhouse gas emissions, ways to widely deploy climate-friendly technologies and for financing both adaptation and mitigation measures. To conduct this negotiation, the thirteenth COP decided to establish an ad hoc Working Group on Long-term Cooperative Action under the Convention (Working Group). It shall conclude its work in 2009. So the fifteenth COP will be able to adopt the result of the work of the Working Group.

\section{Legal Basis of the Mechanism and Negotiating History}

The legal basis of the non-compliance procedure can be found in Article 18 of the Kyoto Protocol:

"The Conference of the Parties serving as the meeting of the Parties to this Protocol shall, at its first session, approve appropriate and effective procedures and mechanisms to determine and to address cases of non-compliance with the provisions of this Protocol, including through the development of an indicative list of consequences, taking into account the cause, type, degree and frequency of non-compliance. Any procedures and mechanisms under this article entailing binding consequences shall be adopted by means of an amendment to this Protocol."

The elaboration of the non-compliance procedure under the Kyoto Protocol, as pointed out in its Article 18, was a complicated negotiation issue, along with others such as the flexibility mechanisms. Many issues concerning the non-compliance procedure were controversial, including the institutional structure and mandate of the Compliance Committee, the right to trigger the implementation procedure, the consequences that could be applied to a non-compliant Party, the procedure after a case has been brought before the Compliance Committee, the political supervision of the Compliance Committee by the Conference of the Parties serving as the Meeting of the Parties to the Protocol (COP/MOP), whether the principle of due process had to be reflected in the compliance procedure and the mode of adoption of the compliance regime under the Kyoto Protocol.

Most of these difficulties had been resolved during the negotiations of this mechanism and the non-compliance procedure was adopted by the first COP/MOP meeting

\footnotetext{
${ }^{10}$ Kyoto Protocol, Art. 17.

11 Decision 1/CP.13 on Bali Action Plan, doc. FCCC/CP/2007/6/Add.1 (14 March 2008), at 3.
} 
in Montreal by Decision 27/CMP.1. ${ }^{12}$ Several elements of this mechanism have been clarified in the Rules of procedure of the Compliance Committee of the Kyoto Protocol (Rules of Procedure), adopted by the second COP/MOP by Decision 4/CMP.2. ${ }^{13}$

It is important to underline that Article 18 mentions the development of an indicative list of consequences. These consequences should take into account the cause, type, degree and frequency of non-compliance by a State Party. It is possible to find a sort of list in Sections XIV ${ }^{14}$ and $\mathrm{XV}^{15}$ of Decision 27/CMP.1, where it foresees measures applicable by the Facilitative Branch and the Enforcement Branch of the Compliance Committee.

During the negotiations of the non-compliance procedure two important issues were raised on the basis of the second sentence of this Article, providing that: "[a]ny procedures and mechanisms under this Article entailing binding consequences shall be adopted by means of an amendment to this Protocol."

Firstly, the legal nature of the instrument setting up this procedure was discussed. It was controversial whether the compliance regime should be adopted by means of a decision of the COP/MOP or as an amendment to the Protocol, the latter being the only way to secure the application and enforcement of effective consequences. Instead, the first COP/MOP adopted the non-compliance procedure by a decision. In any case, it seems that the question has not yet been resolved. Indeed, during the first COP/MOP the delegation of Saudi Arabia asked to incorporate Decision 27/CMP.1 in the text of the Kyoto Protocol as an amendment. The first COP/MOP decided, with a view to adopting a decision during the third COP/MOP, to continue consideration of the Saudi Arabia issue. ${ }^{16}$ At the second COP/MOP the President of the Subsidiary Body for Implementation reported on his informal consultations on this topic. The second $\mathrm{COP} / \mathrm{MOP}^{17}$ decided to invite the Subsidiary Body for Implementation to continue its consideration on this issue in order to take a decision at the third COP/MOP.

The second issue concerned the understanding of the expression "binding consequences". According to one view it refers to the nature of the consequences adopted at the end of the non-compliance procedure. As will be described below, the consequences that the Compliance Committee could adopt as response to a non-compliance situation are advice, measures of assistance, recommendations, declarations, deductions of emission rights, obligations to develop and implement an action plan, suspension of eligibility to make use of the flexibility mechanisms.

By their very nature, measures like advice and recommendations are not binding. Instead, a declaration of non-compliance, the deduction of emission rights, the obligation to develop and implement action plans and the suspension of eligibility to make use of the flexibility mechanisms could be binding. It has to be noted that the nature

\footnotetext{
12 Decision 27/CMP.1 on Procedures and Mechanisms Relating to Compliance under the Kyoto Protocol, Annex, doc. FCCC/KP/CMP/2005/8/Add.3 (30 March 2006), at 92.

${ }_{13}$ Decision 4/CMP.2 on Compliance Committee, Annex, doc. FCCC/KP/CMP/2006/10/Add.1 (4 March 2007), at 17 .

${ }^{14}$ Infra paragraph 11.

15 Ibid.

${ }^{16}$ Decision 27/CMP.1, para. 2.

${ }^{17}$ Report of the Conference of the Parties Serving as the Meeting of the Parties to the Kyoto Protocol on its Second Session, doc. FCCC/KP/CMP/2006/10 (4 March 2007), para. 71.
} 
of the consequences is merely an indication of their suitability to bind subjects of a legal instrument and such subjects will not be bound by the application of such consequences without appropriate legally binding provisions to that effect. ${ }^{18}$

According to another interpretation, the expression "binding consequences" takes into consideration the legal status of decisions adopted within the framework of the non-compliance procedure. A decision would be binding if it can be enforced before a court of law. Thus, this interpretation should have a sense only if the measure adopted is provided in an amendment and not in a decision. In this case, the second sentence of Article 18 of the Kyoto Protocol would be a superfluous addition. ${ }^{19}$

Furthermore, a third interpretation may be that "binding consequences" refers to the method of adoption of the non-compliance procedure. This means that, to have binding consequences, the non-compliance procedure must be adopted by an amendment of the Protocol. However, in this case the second sentence of Article 18 would be a circular sentence..$^{20}$

\section{The Text Establishing the Mechanism}

As already mentioned above, there are two texts governing the non-compliance procedure: Decision 27/CMP.1 and Decision 4/CMP.2. The first was adopted by the first COP/MOP in 2005 and it definitely established the non-compliance procedure. ${ }^{21}$ The second contains the Rules of Procedure and it was adopted by the second COP/ MOP. 22

\section{The Principles Governing the Mechanism and the Procedure}

Decision 27/CMP.1 indicates that the "[...] procedures and mechanisms are to facilitate, promote and enforce compliance [...]." ${ }^{23}$ Different principles are enunciated for each of the two branches in which the Compliance Committee is articulated. ${ }^{24}$ Section XIV of Decision 27/CMP.1 states that the Facilitative Branch, in adopting the consequences of non-compliance, should apply the principle of common but differentiated responsibilities and respective capabilities. On the other hand, Section XV states that

\footnotetext{
${ }^{18}$ R. Lefeber, "From the Hague to Bonn to Marrakech and Beyond: a Negotiating History of the Compliance Regime under the Kyoto Protocol”, Hague YB Int'l L., 14 (2001) 25-54, at 52.

19 Ibid., at 53.

${ }^{20}$ Ibid.

${ }^{21}$ Decision 27/CMP.1, Annex. It is important to underline that the procedure was first established by Decision 24/CP.7 on Procedures and Mechanisms relating to Compliance under the Kyoto Protocol, doc. FCCC/CP/2001/13/Add.3 (21 January 2002), at 64 (Marrakech Accords), whose para. 2 recommends that "[...] the Conference of the Parties serving as meeting of the Parties to the Kyoto Protocol, at its first session, adopt the procedures and mechanisms relating to compliance [...] in terms of Article 18 of the Kyoto Protocol [...]."

${ }^{22}$ Decision 4/CMP.2, Annex.

${ }^{23}$ Decision 27/CMP.1, Annex, section I.

${ }^{24}$ Infra paragraph 5
} 
the Enforcement Branch has to take in consideration also the cause, type, degree and frequency of non-compliance.

\section{InSTitutional AsPeCts}

Different bodies having functions relating to non-compliance were established under the Kyoto Protocol and decision establishing the non-compliance procedure that performs functions relating to compliance control: the Compliance Committee, the COP/ MOP, the Secretariat and the expert review team.

\subsection{The Compliance Committee}

Decision 27/CMP.1 establishes a body responsible for verifying compliance with the obligations arising from the Kyoto Protocol and adopting any necessary decision and consequences. This body is the Compliance Committee.$^{25}$ It has a rather elaborate structure, divided into two branches, known as the Facilitative Branch ${ }^{26}$ and Enforcement Branch, ${ }^{27}$ a Plenary ${ }^{28}$ and a Bureau. In their functioning the two branches of the Committee have to cooperate and interact where appropriate.

The Compliance Committee has twenty members and twenty alternate members ${ }^{29}$ elected by the COP/MOP. The twenty members and the alternate members are divided equally between the two branches. They serve in their individual capacities, "[...] in an independent and impartial manner and avoid real or apparent conflicts of interest $[\ldots] .{ }^{{ }^{\prime 30}}$ Before assuming their service, members and alternate members have to take and agree to respect a written oath. ${ }^{31}$ It must be underlined that the Compliance Committee under the Kyoto Protocol was the first where it was decided to elect members on their individual capacities and not as government representatives.

Members and alternate members must have recognised competences relating to climate change and in relevant fields such as scientific, technical, socio-economic or legal fields. Members of the Enforcement Branch must always have legal experience.

Furthermore, each branch

25 Decision 27/CMP.1, Annex, section II.

${ }^{26}$ Ibid., section IV. In the French version of Decision 27/CMP.1, it is called Chambre de la facilitation.

${ }^{27}$ Ibid., section V. In the French version of Decision 27/CMP.1, it is called Chambre de l'application.

28 Ibid., section III.

${ }^{29}$ Alternate members serve during the absence (resignation or inability) of a member. In this case they have the right to vote. Otherwise they could attend the meeting of the branch to which they belong, without the right to vote, see Decision 4/CMP.2, Annex, Rules 3.2, 3.3, 3.4 and 3.5.

${ }_{30}$ Decision 4/CMP.2, Annex, Rule 4.1. Rules 3 to 5 provide consequences in case a member or an alternate member does not or can not act in an independent and impartial manner and avoid real or apparent conflicts of interest.

${ }_{31}$ Decision 4/CMP.2, Annex, Rule 3.2. 
"shall be composed of:

(a) One member from each of the five regional groups of the United Nations and one member from the small island developing States, taking into account the interest groups as reflected by the current practice in the Bureau of the Conference of the Parties;

(b) Two members from Parties included in Annex I; and

(c) Two members from Parties not included in Annex I." 32

The term of service of each member and alternate member is for four years: starting on 1 January, of the year immediately following the election, and finishing on 31 December, four years later. ${ }^{33}$

The Compliance Committee meets at least twice a year, unless it decides otherwise. ${ }^{34}$ From the entry into force of the Kyoto Protocol until now, the Enforcement Branch met once, the Facilitative Branch met four times and the Plenary three times.

\subsection{The COP/MOP}

Article 13.1 of the Kyoto Protocol establishes that "[ $t]$ he Conference of the Parties, the supreme body of the Convention, shall serve as the meeting of the Parties to this Protocol."

Para. 4 of the same Article provides that the COP/MOP shall keep "under regular review the implementation of this Protocol and shall make, within its mandate, decisions necessary to promote its effective implementation." In particular, as provided by Section XII ${ }^{35}$ of Decision 27/CMP.1, the COP/MOP

"[...] shall:

(a) In considering the reports of the expert review teams in accordance with Article 8, paragraphs 5 and $\left.6{ }^{36}\right]$ of the Protocol, identify any general problems that should be addressed in the general policy guidance referred to in subparagraph (c) below;

(b) Consider the reports of the plenary on the progress of its work;

(c) Provide general policy guidance, including on any issues regarding implementation that may have implications for the work of the subsidiary bodies under the Protocol;

(d) Adopt decisions on proposals on administrative and budgetary matters; and

(e) Consider and decide appeals in accordance with section XI [...]."

\footnotetext{
32 Decision 27/CMP.1, Annex, sections IV.1 and V.1.

33 Ibid., section IV.2 and V.2; Decision 4/CMP.2, Annex, Rule 3.1.

${ }^{34}$ Decision 27/CMP.1, Annex, section II.10.

35 "Relationship with the Conference of the Parties serving as the meeting of the Parties to the Protocol."

${ }^{36}$ Kyoto Protocol, Arts. 8.5 and 8.6: "5. The Conference of the Parties serving as the meeting of the Parties to this Protocol shall, with the assistance of the Subsidiary Body for Implementation and, as appropriate, the Subsidiary Body for Scientific and Technological Advice, consider: (a) The information submitted by Parties under Article 7 and the reports of the expert reviews thereon conducted under this Article; and (b) Those questions of implementation listed by the Secretariat under paragraph 3 above, as well as any questions raised by Parties. 6. Pursuant to its consideration of the information referred to in paragraph 5 above, the Conference of the Parties serving as the meeting of the Parties to this Protocol shall take decision on any matter required for the implementation of this Protocol."
} 
It is important to underline that the COP/MOP does not have the power to adopt decisions or consequences about a non-compliance situation except in deciding upon appeal against an Enforcement Branch's decision for denial of due process. ${ }^{37}$

\section{$5.3 \quad$ The Secretariat}

The Secretariat is established under the Convention and also serves as Secretariat of the Kyoto Protocol. Generally, the Secretariat is appointed (Articles 8.2 and 8.3 of the UNFCCC Convention) to provide the regular services for the institutional mechanisms. Furthermore, the Secretariat shall exercise the functions assigned to it under the Protocol. ${ }^{38}$

As far as the non-compliance procedure is concerned, the Secretariat has the essential task of coordinating the application of the procedure. ${ }^{39}$ For example, it is the body which in the initial phase and throughout the non-compliance process assists and ensures the liaison between, on the one hand, the Party not in compliance and the other Parties and, on the other hand, the COP/MOP and the Compliance Committee. ${ }^{40}$ Indeed Section V1 of Decision 27/CMP.1 provides for the Compliance Committee to receive, through the Secretariat, questions of implementation and non-compliance by a State Party indicated in reports of expert review teams. ${ }^{41}$

\subsection{The Expert Review Team}

The expert review team is established by Article 8 of the Protocol. Members of the expert review team are nominated by the Parties and, where appropriate, by intergovernmental organizations.

The expert review team controls information submitted by each Annex I State Parties, pursuant to relevant decisions and in accordance with guidelines adopted by the $\mathrm{COP} / \mathrm{MOP}$, and provides a report to the COP/MOP concerning its assessment on the implementation of the commitments by State Parties, identifying potential problems.

As we will see in paragraph 7 the expert review team is entitled to trigger the noncompliance procedure. In this regard it is possible to point out that in the report used by the expert review team to trigger the non-compliance procedure information other than that derived from government reports could be employed such as information gathered by non-governmental organizations. If this were the case, it would be possible for State Parties to find themselves exposed to various types of pressure. ${ }^{42}$

${ }^{37}$ Decision 27/CMP.1, Annex, section XI. Infra paragraph 8.

${ }_{38}$ Kyoto Protocol, Art. 14; Decision 4/CMP.2, Annex, Rule 12.

39 Decision 4/CMP.2, Annex, Rules 12, 16, 19.2, 19.3, 20.2, 20.3, 22.2 and 23.2, provide examples of Secretariat's tasks.

40 Decision 27/CMP.1, Annex, sections VI.1 and VI.2.

41 Infra paragraph 6.

42 S. Urbinati, "Non-Compliance Procedure under the Kyoto Protocol", Baltic YB Int'l L., 3 (2003) 229-251, at 239. 


\section{Functions of the CoMmittee}

The Compliance Committee has numerous functions, each of its subdivisions having different powers.

\subsection{The Plenary of the Committee}

The Plenary must report to the COP/MOP on all activities of the Committee. ${ }^{43}$ In particular, it has to submit to the COP/MOP the list of decisions taken by the Facilitative and Enforcement branches. Moreover, it must apply the general policy guidance received from the COP/MOP. ${ }^{44}$ Finally, the Plenary is required to carry out administrative and budgetary tasks and to perform such other functions as may be requested by the COP/MOP. ${ }^{45}$

\subsection{The Facilitative Branch}

The Facilitative Branch is responsible for providing advice and facilitations to Parties in implementing the Protocol and for promoting compliance with the Protocol by Parties. In doing so, the Facilitative Branch has to take into consideration the principle of common but differentiated responsibilities and respective capabilities and the peculiar circumstances of the question. ${ }^{46}$

Furthermore, the Facilitative Branch, outside the mandate of the Enforcement Branch - as we will describe below - is responsible for addressing questions concerning the reduction of emission of greenhouse gases by Annex I Parties and the application of the flexibility mechanisms by these State Parties and developing State Parties. The Facilitative Branch has also the task of providing advice and facilitations, prior to the first commitment period, to Annex I State Parties on their obligation to establish a national system for the estimation of anthropogenic emissions by sources and removals by sinks of all greenhouse gases not controlled by the Montreal Protocol. ${ }^{47}$ Moreover, it has to provide to each Party the necessary supplementary information on the basis of guidelines established by the COP/MOP. ${ }^{48}$ To this end, it is responsible for the application of the consequences described below in paragraph 11.

${ }^{43}$ Decision 27/CMP.1, Annex, section III.

${ }^{44}$ Ibid., section XII(c).

${ }^{45}$ Ibid., sections III(d) and III(e).

${ }^{46}$ Ibid., section IV.4.

${ }^{47}$ Kyoto Protocol, Arts. 5.1 and 5.2.

${ }^{48}$ Kyoto Protocol, Arts. 7.1 and 7.4; Decision 27/CMP.1, Annex, section IV.6: "With the aim of promoting compliance and providing for early warning of potential non-compliance, the facilitative branch shall be further responsible for providing advice and facilitation for compliance with: (a) Commitments under Article 3, paragraph 1, of the Protocol, prior to the beginning of the relevant commitment period and during that commitment period; (b) Commitments under Article 5, paragraph 1 and 2, of the Protocol, prior to the beginning of the first commitment period; and (c) Commitments under Article 7, paragraphs 1 and 4, of the Protocol prior to the beginning of the first commitment period." 


\subsection{The Enforcement Branch}

The Enforcement Branch determines whether an Annex I Party has respected the emission limits imposed by Article 3.1 of the Protocol, the obligation relating to the methodological and reporting requirements established in Articles 5.1 and 5.2 and in Articles 7.1 and 7.4, and the condition for eligibility to accede to the flexibility mechanisms. Moreover, it is responsible for determining whether to decide on adjustment to inventories provided by the national system established under Article 5.2, of the Protocol, and to make corrections to the annual inventories of anthropogenic emissions as indicated in Article 7.4, of the Protocol, in the case of disagreement between the expert review team and the Party involved. Finally, the Enforcement Branch is responsible for applying the consequences as described below in paragraph 11 .

As already mentioned, under the non-compliance procedure the power of decision concerning the response to a non-compliance situation lies with the Compliance Committee. Indeed the Conference of the Parties has to be merely informed of decisions taken by the Committee, which it cannot influence unless the interested Party resorts to the appeal procedure under Section XI of Decision 27/CMP.1.

\section{TRIgGer Mechanism}

The non-compliance procedure can be triggered either by an expert review team report, or by one Party with respect to another Party, or by the Party which is itself not in compliance. Non-State actors do not have a role in the triggering mechanism.

Under Section VI.1(b) of Decision 27/CMP.1, the non-compliance procedure may be initiated by: "[a]ny Party with respect to another Party [...]". The negotiations over this provision focussed on the question of guarantees for the State Party concerned. In effect, without any further specification, it could be abused by certain Parties to exert political pressure on others. Thus it was added that a Party initiating the procedure with respect to another Party must support its request with "corroborating information".

A submission introduced by a Party against another Party shall indicate the names of the Parties, the claimed question of implementation, the corroborating information, a reference to the provisions of the Kyoto Protocol and of Decision 27/CMP.1 concerned and a list of all the annexed documents. Moreover the submission should set out "[a]ny provisions of the decisions of the Conference of the Parties serving as the meeting of the Parties to the Kyoto Protocol and the reports of the subsidiary bodies that are applicable to the question of implementation [and] [t]he branch from which action is sought $[\ldots] .{ }^{.49}$

One of the distinguishing characteristics of the non-compliance procedures in general, and their most important innovation, is the possibility of "self-denunciation". In other words, a State Party which is aware that it will be unable to fulfil, or has failed to comply with, its obligations, despite having deployed all its resources, may make a

${ }^{49}$ Decision 4/CMP.2, Annex, Rule 15. 
submission to the Committee in which it explains how this has come about, endeavours to show that it has done its utmost to achieve its objectives and analyses the reasons for its having failed to do so.

Section VI.1(a) of Decision 27/CMP.1 refers merely to submissions made by: "[a]ny Party with respect to itself". Rule 14 of the Rules of Procedure state the content of this submission. All the elements required are the same as those of the submission introduced by a Party against another Party, as indicated above. Only one more element is set out for this kind of submission: the action requested from the branch. ${ }^{50}$

These provisions form part of a context of cooperation because the State Party is allowed to acknowledge its difficulties in fulfilling its obligations, despite its best efforts, to the Compliance Committee and at the same time to make known its technical or financial assistance requirements. ${ }^{51}$

The risk with this kind of trigger mechanism is that some State Parties might try to obtain facilities, and in particular financial facilities, without really having made every effort to honour their commitments.

\section{The Procedure before the Compliance Committee and Procedural SAFEGUARDS}

\subsection{The Procedure}

The procedure before the Committee is quite elaborate. Before starting on the description of the procedure stricto sensu, it is important to remember some general rules governing the procedure. Firstly, Section VIII.2 establishes that "[t]he Party concerned shall be entitled to designate one or more persons to represent it during the consideration of the question of implementation by the relevant branch [...]." The person or persons representing the Party during the hearing should not be chosen among " $[. .$.$] individuals who were members or alternate members of the Committee$ in the two years preceding the date of the submission." 52 Secondly, Rules 13.1 and 13.2 of the Rules of Procedure state that the Committee working language is English. When in a proceeding before a branch there is a representative of a Party speaking a language other than English, this Party has to provide the interpretation. All the final Committee decisions are translated into all the United Nations official languages. ${ }^{53}$

As far as the procedure stricto sensu is concerned, it can be divided into three phases: the allocation and the preliminary phase, the examination of the non-compliance situation and the appeal.

${ }^{50}$ Ibid., Art. 14

51 S. Maljean-Dubois, "La Mise en Route du Protocole de Kyoto à la Convention-Cadre des Nations Unies sur les Changements Climatiques”, Ann. Français Dr. Int., 51 (2005) 433-463, at 453 and Urbinati, supra $\mathrm{n} .42$, at 238 .

${ }^{52}$ Decision 4/CMP.2, Annex, Rule 25.2.

53 Ibid., Rule 13.3. 
Firstly, the communication must be allocated by the Bureau to the appropriate branch, within seven days from its receipt. ${ }^{54}$ Then, except in the case of a question raised by a Party with respect to itself, the branch to which the submission is allocated must undertake a preliminary examination within three weeks, to ensure that the question before it: "[(a)] is supported by sufficient information; (b) is not de minimis or illfounded; and (c) is based on the requirements of the Protocol." ${ }^{55}$

At the end of this phase, the relevant branch must decide whether to proceed or not. The Party concerned must be notified, through the Secretariat, of the decision taken and, if the branch decides to proceed, it must also be notified by a statement identifying the question of implementation.

The branch will consider the question and the information on which the question is based. The Party concerned is given an opportunity to comment in writing on the decision to proceed and on the information on which it is based. ${ }^{56}$ On the other hand, if the branch decides not to proceed, its decision must be made available by the Secretariat to the other Parties and to the public. ${ }^{57}$

\section{b) Examination of the Non-Compliance Situation}

It has to be noted that Decision 27/CMP.1 does not explain the procedure before the Facilitative Branch in further detail. Some information is provided in Rule 24 of the Rules of Procedure, which states that during the preliminary examination a dialogue may be established between the Facilitative Branch and the representative of the Party concerned.

As regards the procedure before the Enforcement Branch, it may take one of two forms known respectively as the "procedures for the enforcement branch" 58 and the "expedited procedures for the enforcement branch". ${ }^{99}$ The latter apply when the question of implementation relates to eligibility requirements for the flexibility mechanisms and it is characterised by shorter time frames.

The "procedures for the enforcement branch" is spread out over precise time frames which can be extended only in specific cases and only at the discretion of the Enforcement Branch. Within ten weeks from the date of the notification of the decision to proceed, the Party concerned may make a written submission to the branch rebutting the information on which it is based. Within the same time frame, the Party

54 Ibid., Rule 19.

55 Decision 27/CMP.1, Annex, section VII.

${ }_{56}$ Decision 27/CMP.1, Annex, section VII.7; Decision 4/CMP.2, Annex, Rule 17, where it is stated that all comments and written submissions introduced by the State Party concerned, throughout the procedure, should include: "[...] (a) A statement of the position of the Party concerned on the information, decision or question of implementation under consideration, including the grounds therefore; (b) An identification of any information provided by the Party that it requests not to be made available to the public in accordance with section VIII, paragraph 6; (c) A list of all documents annexed to the submission or comment [...]."

57 Decision 27/CMP.1, Annex, section VII.6.

58 Ibid., section IX.

59 Ibid., section X. 
concerned may also request the holding of a hearing ${ }^{60}$ at which it can express its views, by presenting expert testimony or opinion. The branch must arrange the hearing within four weeks from receipt of the request. The hearing will normally be held in public unless the Enforcement Branch decides otherwise. To some extent, the procedure places the branch and the Party concerned in a sort of "inquiring situation" since " $[t]$ he enforcement branch may put questions to and seek clarification from the Party concerned, either in the course of such a hearing or at any time in writing, and the Party concerned shall provide a response within six weeks thereafter." Upon completion of this exchange of written communications or the hearing, the Enforcement Branch adopts a reasoned "preliminary finding that the Party concerned is not in compliance with commitments under one or more of the articles of the Protocol referred to in Section V, paragraph 4; or [o]therwise determines not to proceed further with the question." The Party in question may not be present "during the elaboration and adoption of a decision of the branch". ${ }^{61}$ In this phase only members, alternate members and Secretariat officials ${ }^{62}$ can participate in the meeting of the Compliance Committee.

It is useful to remember that Rule 22 of the Rules of Procedure sets out that the preliminary decision

"[...] shall contain, mutatis mutandis:

a) [t]he name of the Party concerned; b) [a] statement identifying the question of implementation addressed; c) [t] he provisions of the Kyoto Protocol and decision 27/CMP.1 and other relevant decisions of the Conference of the Parties serving as the meeting of the Parties to the Kyoto Protocol that form the basis of the preliminary finding [...]; d) [a] description of the information considered in the deliberations [...] a confirmation that the Party concerned was given an opportunity to comment in writing on all information considered; e) [a] summary of the proceedings [...]; f) [t]he substantive decision of the question of implementation $[. ..] ; \mathrm{g})$ [c]onclusions and reasons for the decision; $\mathrm{h}$ ) [t] he place and date of the decision; i) [t]he name of the members who participated in the consideration of the question of implementation, as well as the elaboration and adoption of the decision [...]".

The Party concerned must be notified forthwith, in writing, of the branch's preliminary finding. A decision not to proceed must also be made available to the other States Parties and to the public. If the Party concerned is found not to be in compliance with its commitments, it is allowed ten weeks in which to provide the Enforcement Branch with a further written submission concerning the preliminary finding. ${ }^{63}$

If the Party provides such a submission, the branch must consider it and, within four weeks, adopt a final reasoned decision on the question of implementation. The final decision will indicate whether the preliminary finding is confirmed wholly or in

${ }^{60}$ Decision 4/CMP.2, Annex, Rule 25.1. It states that "In its request for a hearing, the Party concerned may identify: a) The issues that the Party proposes to raise and any documents that it intends to discuss during the hearing; b) Any individuals whose expert testimony or opinion it will present at the hearing [...]."

${ }^{61}$ Decision 27/CMP.1, Annex, section VIII.2.

${ }^{62}$ Decision 4/CMP.2, Annex, Rule 9.2

${ }^{63}$ Decision 4/CMP.2, Annex, Rule 22.1. The content of a preliminary finding is showed above in this section. 
part. If the State Party does not provide a further submission, the Enforcement Branch will adopt a final decision confirming its preliminary finding. In any case the final decision

"[...] shall contain, mutatis mutandis: a) [t]he name of the Party concerned; b) [a] statement identifying the question of implementation addressed; c) [t] he provisions of the Kyoto Protocol and decision 27/CMP.1 and other relevant decisions of the Conference of the Parties serving as the meeting of the Parties to the Kyoto Protocol that form the basis of the [...] final decision; d) [a] description of the information considered in the deliberations, including in the case of a final decision, a confirmation that the Party concerned was given an opportunity to comment in writing on all information considered; e) [a] summary of the proceedings, including an indication, in the case of a final decision of the enforcement branch, of whether its preliminary finding or any part of it as specified is confirmed; f) [t]he substantive decision of the question of implementation, including the consequences applied, if any; g) [c]onclusions and reasons for the decision; $h$ ) [t] he place and date of the decision; i) [t] he names of the members who participated in the consideration of the question of implementation, as well as the elaboration and adoption of the decision [...]." ${ }^{94}$

The Party concerned is notified, through the Secretariat, of the final decision, which is also made available to the other Parties and to the public. According to Section IX.12 of Decision 27/CMP. 1, where appropriate the Enforcement Branch may, at any time, refer the question to the Facilitative Branch.

c) The Appeal

The Party has 45 days after being informed of the decision, to lodge an appeal with the Secretariat against the Enforcement Branch's decision relating to Article 3.1 of the Kyoto Protocol, and the COP/MOP has to consider the appeal at its first session after the appeal has been lodged. An appeal may be lodged if the Party concerned believes it has been denied due process. If no appeal has been made, the decision of the Enforcement Branch would become definitive after 45 days. To override the decision the COP/MOP has to agree by a three-fourths majority vote, whereupon the COP/MOP will refer the matter of the appeal back to the Enforcement Branch.

\subsection{The Procedural Safeguards}

a) Transparency

It is important to underline that for the procedure in general Section VIII.6 states that:

"[a]ny information considered by the relevant branch shall be made available to the Party concerned. The branch shall indicate to the Party concerned which parts of this information it has considered. The Party concerned shall be given an opportunity to comment in writing on such information it has considered. Subject to any rules relating to confidentiality, the information considered by the branch shall also be made available to the public, unless the

\footnotetext{
${ }^{64}$ Ibid., Art. 22.1.
} 
branch decides, of its own accord or at the request of the Party concerned, that information provided by the Party concerned shall not be made available to the public until its decision has become final."

b) Publicity

Meetings of the Plenary and branches are public, provided that the Plenary or the Branch concerned may decide "of their own accord or at the request of the Party concerned [...], for overriding reasons, that part or all of the meeting shall be held in private $[\ldots] . "{ }^{\circ 5}$

\section{c) The Appeal}

See above at the end of paragraph 8.1 .

\section{SOURCES OF INFORMATION}

The first type of information that the Compliance Committee has to examine is contained in the submissions. Except where otherwise stated, for the preliminary examination each branch shall base its deliberations on any relevant information provided $^{66}$ by:

(a) The expert review teams reports, which are established under Article 8 of the Protocol;

(b) The Party concerned;

(c) The Party that has submitted a question of implementation with respect to another Party;

(d) The reports of the Conference of the Parties, the Conference of the Parties serving as the meeting of the Parties to the Protocol, and the subsidiary bodies under the Convention and the Protocol; and

(e) The other branch.

Each branch may seek expert advice ${ }^{67}$ and use the relevant factual and technical information from the competent intergovernmental and non-governmental organizations. ${ }^{68}$ It seems possible that the Compliance Committee may also use unsolicited information from each of these sources.

65 Ibid., Art. 9.1

${ }^{66}$ Decision 27/CMP.1, Annex, section VIII.3.

${ }^{67}$ Ibid., section VIII.6; Decision 4/CMP.2, Annex, Rule 21, where it is stated that when a branch " $[\ldots]$ decides to seek expert advice, it shall: (a) Define the question on which expert opinion is sought; (b) Identify the experts to be consulted; (c) Lay down the procedures to be followed [...].'

${ }^{68}$ Decision 27/CMP.1, Annex, section VIII.4; Decision 4/CMP.2, Annex, Rule 20. It has to be underlined that this is the only role recognized to non-governmental organizations in the non-compliance procedure established under the Kyoto Protocol. 


\section{DECISION-MAKING}

During the elaboration and adoption of a decision the Party concerned shall not be present. Decisions can be validly taken when at least three-fourths of members are present. Every effort has to be made to reach an agreement on any decision by consensus. Only when all efforts have been exhausted, the decision will be adopted by a majority of at least three fourths of the members present and voting. The adoption of a decision by the Enforcement Branch also requires a majority of present and voting members from both Annex I Parties and non-Annex I Parties. The expression "present and voting" means that committee members have to be present and have expressed an affirmative or a negative vote.

The relevant branch shall forthwith, through the Secretariat, notify in writing the Party concerned of its decision, including conclusions and reasons thereof. The Secretariat shall make available the final decision to other Parties and to the public. The Party concerned shall be given an opportunity to comment in writing on any decision of the relevant branch.

The COP/MOP decide appeals on the basis of a three-fourths majority vote of the present and voting Parties. Also a decision taken by the COP/MOP has to include conclusions and reasons.

\section{Outcomes}

When consideration of the alleged non-compliance situation leads to a finding of noncompliance, the relevant branch adopts a decision on its consequences. Sections XIV and XV of Decision 27/CMP.1 specify the various types of consequences. These can be divided into two main categories. On the one hand there are those that provide for assistance and can be described as measures to facilitate implementation. On the other there are consequences entailing a sort of punishment ${ }^{69}$ for the non-complying State Party. Consequences must be adjusted to the cause, type, degree and frequency of non-compliance. Thus, if the non-compliance is due to a lack of structural, financial or other resources, there is no point in imposing penalties. In this case, the appropriate response is to devise a plan for the provision of aid or assistance to enable the Party

${ }^{69}$ It has to be noted that the nature of this kind of measure is not clearly established. In Decision 27/ CMP.1 words like sanction or punishment have been avoided. Among the observers it is possible to find some that use the expression of "sanction-oriented" as in J. Brunnée, "Enforcement Mechanisms in International Law and International Environmental Law", in U. Beyerlin, P.-T. Stoll, and R. Wolfrum (eds.), Ensuring Compliance with Multilateral Environmental Agreements: a Dialogue Between Practitioners and Academia, (Leiden: Nijhoff, 2006) 1-23, at 20-21. Nevertheless, as Professor Pineschi underlines, having regard to non-compliance procedures, it is difficult to make use of the word "sanction" because of the incentive character of this kind of mechanism, L. Pineschi, "Responsabilità Internazionale e Procedure di Non-Compliance", in P. Fois (ed.), Il Principio dello Sviluppo Sostenibile nel Diritto Internazionale ed Europeo dell'Ambiente (Napoli: Editoriale Scientifica, 2007) 425-462, at 446-447. In this regard the author quotes R. Churchill and G. Ulfstein, "Autonomous Institutional Arrangements in Multilateral Environmental Agreements: a Little Noticed Phenomenon in International Law”, Am. J. Int'l L., 94 (2000) 623-659, at 646. On the more general issue of the nature of non-compliance procedures see also G. Bankobeza, Ozone Protection: the International Legal Regime (Utrecht: Eleven International Publishing, 2005), 219. 
concerned to implement the terms of the Protocol more effectively. Instead, if a State Party has deliberately not complied, that is to say, has acted in bad faith, then the consequences may take the nature of sanctions.

Section XIV stipulates that the Facilitative Branch may confine itself to the

"[p]rovision of advice and facilitation of assistance to individual Parties regarding the implementation of the Protocol, but it may also provide:

b) [f]acilitation of financial and technical assistance [...], including technology transfer and capacity building from sources other than those established under the Convention and the Protocol for the developing countries;

c) [f]acilitation of financial and technical assistance, including technology transfer and capacity building, taking into account Article 4, paragraph 3, 4 and 5, of the Convention; and

d) [f]ormulation of recommendations to the Party concerned, taking into account Article 4, paragraph 7 , of the Convention."

Likewise, Section XV of the decision describes the measures that can be adopted by the Enforcement Branch. Under this section, various consequences may be applied depending on the nature of non-compliance. In the event of non-compliance with the establishment of a national system as provided by Articles 5.1 and 5.2, ${ }^{70}$ or with the up-dating of the annual inventory in Articles 7.1 and 7.4, ${ }^{71}$ of the Protocol, it is stipulated that the Enforcement Branch shall apply the following consequences:

“1. [...] (a) Declaration of non-compliance; (b) [d]evelopment of a plan in accordance with paragraph 2 and 3 below. 2. The Party not in compliance under paragraph 1 above shall, within three months after the determination of non-compliance, or such longer period that the enforcement branch considers appropriate, submit to the enforcement branch for review and assessment a plan that includes: (a) [a]n analysis of the causes of non-compliance of the Party; (b) [m] easures that the Party intends to implement in order to remedy the non-compliance; (c) [a] timetable for implementing such measures within a time frame not exceeding twelve months which enables the assessment of progress in implementation."

Where the Enforcement Branch has determined that a Party is not in compliance with the obligation to reduce emission of greenhouse gases as provided in Article 3.1 of the Protocol, it shall apply the following consequences:

“(a) [d]eduction from the Party's assigned amount for the second commitment period of a number of tonnes equal to 1.3 times the amount in tonnes of excess emissions; (b) [d] evelopment of a compliance action plan in accordance with paragraph 6 and 7 below; and (c) [s] uspension of the eligibility to make transfers under Article 17 of the Protocol until the Party is reinstated in accordance with section X, paragraph 3 or 4."

The compliance action plan under subparagraph (b) must be drawn up by the noncomplying Party within three months, unless it can be shown that the individual

\footnotetext{
70 Supra paragraph 6 and n. 47

71 Supra paragraph 6 and n. 48 .
} 
circumstances warrant a longer period. This plan must be submitted to the Enforcement Branch for review and assessment. The compliance action plan must include:

"a) [a]n analysis of the causes of the non-compliance of the Party; b) [a]ction that the Party intends to implement in order to meet its quantified emission limitation or reduction commitment in the subsequent commitment period, giving priority to domestic policies and measures; c) [a] timetable for implementing such action, which enables the assessment of annual progress in the implementation within a time frame that does not exceed three years or up to the end of the subsequent commitment period, whichever occurs sooner. At the request of the Party, the enforcement branch may, where the circumstances of an individual case so warrant, extend the time for implementing such action for a period which shall not exceed the maximum period of three years mentioned above."

Moreover, there are provisions for monitoring the progress made with the implementation of the compliance action plan. Thus, each year the Party not in compliance must submit a progress report on the implementation of the plan.

Where a non-compliance situation is found as a result of a Party's unwillingness to act, the procedure provides for the application of consequences in the form of a suspension of the rights, benefits and privileges granted under the Convention. Under the non-compliance procedure there are two cases in which privileges and benefits may be suspended. The first is where an Annex I Party fails to meet one or more eligibility requirements to accede to the flexibility mechanism. The second is the case of noncompliance with commitments under Article 3.1 of the Protocol, to which reference has already been made.

Moreover, the suspension of rights, privileges and benefits could be construed as contrary to the spirit of implementation since they are normally granted in order to help the recipient State Party to apply the provisions of the convention and thus comply with its commitments. Nevertheless, sanctions should also have an educational effect since they are intended to discourage the Parties from yielding to the temptation of non-compliance. Furthermore, there is the idea that a State Party cannot operate without the benefits of international cooperation. Just as the advantages of cooperation induced it to become Party to the Protocol, they should also lead it to comply with its commitments. ${ }^{72}$ It is also useful to distinguish between the consequences described above and the sanctions of general international law. Whereas in the measures in question it is possible to discern the aim of restoring legality, they contain no hint of a compensation-seeking element.

Another question arises concerning the relationship between the suspension clause in Decision 27/CMP.1 and the suspension provisions of Article 60 of the Vienna Convention on the Law of Treaties namely: why not simply rely on Article 60? Suspending the application of a convention with respect to a State not in compliance may not only prove contrary to the objective pursued - the protection of the environment - but it might also turn out to be impracticable for conventions that contain

${ }^{72}$ L. Boisson de Chazournes, "La Mise en Oeuvre du Droit International dans le Domaine de la Protection de l'Environnement. Enjeux et Défis", Rev. Gén. Dr. Int. Pub., 99 (1995) 37-76, at 66-67. 
non-reciprocal obligations. ${ }^{73}$ Nevertheless, the suspension of rights, privileges and benefits for which Decision 27/CMP.1 provides has the advantage that without suspending the entire treaty with respect to a Party it leaves it bound to continue fulfilling its other obligations.

\section{Coordination with Dispute Settlement Procedures and Other Non-Compliance Procedures}

A provision concerning the coordination between the non-compliance procedure and the formal dispute settlement is contained in Section XVI of Decision 27/CMP.1: "The procedure and mechanisms relating to compliance shall operate without prejudice to Articles 16 and 19 of the Protocol" providing respectively for a consultation procedure and the applicability mutatis mutandis of the settlement of dispute mechanism provided in the Convention.

\section{Participation of the European Community}

Article 24.2 of the Kyoto Protocol establishes the possibility for regional economic integration organizations (such as the European Community (EC)) to become a Party. Two hypotheses are set out. Firstly, a regional economic integration organization could become a Party unless any of its Member States are a Party of the Protocol. In this case, only the regional economic integration organization shall be bound by the obligations under the Kyoto Protocol. Secondly, a regional economic integration organization could become a Party also when one or more of its State members are already Parties of the Protocol. In such a case, the organization and its Member States "[...] shall decide on their respective responsibilities for the performance of their obligations [...]." Moreover, Article 24.2 provides that this kind of organization and its State members "[...] shall not be entitled to exercise rights under this Protocol concurrently $[\ldots] . "$

Furthermore, Article 24.3 points out that regional economic integration organizations shall declare, in their instruments of ratification, acceptance, approval or accession, the extent of their competences within the limits of the matters of the Protocol.

The EC became a Party of the Kyoto Protocol on 31 May 2002. At the same time the EC made two declarations.

The first one is:

"The European Community and its Member States will fulfil their respective commitments under article 3, paragraph 1, of the Protocol jointly in accordance with the provisions of article 4."

${ }^{73}$ K. Bannelier-Christakis, "Techniques de Contrôle. Le Système des Rapports”, in C. Imperiali (ed.), L'Effectivité du Droit International de l'Environnement. Contrôle de la Mise en Oeuvre des Conventions Internationales (Paris: Economica, 1998), 91-110 and M. Koskenniemi, "Breach of Treaty or Non-Compliance? Reflections on the Enforcement of the Montreal Protocol", YB Int'l Envt'l L., 3 (1992) 123-162. 
The second one is:

"The European Community declares that, in accordance with the Treaty establishing the European Community, and in particular article 175(1) thereof, it is competent to enter into international agreements, and to implement the obligations resulting therefrom, which contribute to the pursuit of the following objectives:

a) preserving, protecting and improving the quality of the environment;

b) protecting human health;

c) prudent and rational utilisation of natural resources;

d) promoting measures at international level to deal with regional or world wide environmental problems.

The European Community declares that its quantified emission reduction commitment under the Protocol will be fulfilled through action by the Community and its Member States within the respective competence of each and that it has already adopted legal instruments, binding on its Member States, covering matters governed by the Protocol.

The European Community will on a regular basis provide information on relevant Community legal instruments within the framework of the supplementary information incorporated in its national communication submitted under article 12 of the Convention for the purpose of demonstrating compliance with its commitments under the Protocol in accordance with article 7 (2) thereof and the guidelines thereunder."

Regional economic integration organizations shall participate, within their competence, in the process of adopting a decision. Article 22.2 establishes that this kind of organization "[...] shall exercise their right to vote with a number of votes equal to the number of their Member States that are Parties to this Protocol [...]." It has to be underlined that such an organization and its Member States shall not exercise the right to vote at the same time.

The EC is listed in Annex I State Parties ${ }^{74}$ and in Annex II State Parties, ${ }^{75}$ thus it has the same obligations as the other Parties in these Annexes.

\section{Financial Aspects}

The COP/MOP has been charged with the adoption of decisions regarding administrative and budgetary matters, as written above. At the third COP/MOP the Compliance Committee requested the Parties to make voluntary contributions to the Fund of Supplementary Activities in support of the work of the Compliance Committee in the biennium 2008-2009. Moreover, the third COP/MOP asked the Secretariat to provide information on the consequences, which would be produced on the budget for the biennium 2010 and 2011 by an extent of funding to cover the costs of members and alternate members travel permitting them to be present at the Compliance Committee meetings.

\footnotetext{
74 Supra n. 4.

75 Supra n. 5.
} 


\section{Survey of Practice}

Since the adoption of Decision 27/CMP.1, the Plenary of the Compliance Committee has met four times, the Enforcement Branch four times and the Facilitative Branch five times.

Fifteen submissions have been presented by South Africa (as Chairman of the Group of 77 and China) to the Facilitative Branch. Submissions concerned non-compliance with Article 3.1 of the Kyoto Protocol by Austria, Bulgaria, Canada, France, Germany, Ireland, Italy, Latvia, Liechtenstein, Luxembourg, Poland, Portugal, Russian Federation, Slovenia and Ukraine. However, no submissions have been presented to the Enforcement Branch.

At its third session, held in June 2006 at the end of the preliminary examination phase, the Facilitative Branch adopted only two decisions about Latvia and Slovenia. ${ }^{76}$ It decided not to proceed against these two States because they presented their national communications and progress reports by the time the two cases came before the branch. The Facilitative Branch was unable to make decisions concerning the other countries because it was unable, firstly, to reach consensus and, secondly, to obtain the majority of three-fourths of its members. ${ }^{77}$

One submission has been presented by the expert review team before the Enforcement Branch against Greece. It concerned the compliance of Greece with the guidelines for the establishment of the national system under Article 5.1 of the Kyoto Protocol and the guidelines for the preparation of the information required under Article 7 of the Kyoto Protocol. Indeed, the submission related "to the unresolved problem of the maintenance of the institutional and procedural arrangements, the arrangements for the technical competence of the staff, and the capacity for timely performance of the national system." ${ }^{.78}$ Furthermore, the submission concerned the eligibility requirement for the flexibility mechanisms.

At its third session, held on 11 February 2008, the Enforcement Branch examined this submission in a hearing requested by Greece, where the positions of the expert review team and Greece's experts were confronted. The Enforcement Branch adopted the preliminary finding on 6 March 2008.

In the preliminary finding the Enforcement Branch first of all stated that Greece is in non-compliance with the articles mentioned above and secondly it demanded that Greece develop and present a plan of action. Third, it decided that Greece would not be eligible to participate in the flexible mechanisms pending the resolution of the question of implementation.

${ }^{76}$ Facilitative Branch of the Compliance Committee. Preliminary Examination, doc. CC-2006-8-3/ Latvia/FB (21 June 2006) and Facilitative Branch of the Compliance Committee. Preliminary Examination, doc. CC-2006-14-2/Slovenia/FB (21 June 2006). 2006)

77 Facilitative Branch of the Compliance Committee. 3rd Meeting, doc. CC/FB/3/2006/2 (6 September

78 Preliminary Finding, doc. CC-2007-1-6/Greece/EB (6 March 2008), para. 5. 
On 8 April the Enforcement Branch received a submission by Greece which was taken into consideration for the elaboration and the adoption of the final decision ${ }^{79}$ whereby the former confirmed the measures adopted in the preliminary finding.

\section{Bibliography}

R. Lefeber, "From the Hague to Bonn to Marrakech and Beyond: A Negotiating History of the Compliance Regime under the Kyoto Protocol", Hague YB Int'l L., 14 (2001) 25-54; S. Maljean-Dubois, "La Mise en Route du Protocole de Kyoto à la Convention-Cadre des Nations Unies sur les Changements Climatiques", Ann. Français Dr. Int., 51 (2005) 432-463; H. Ott, "Elements of a Supervisory Procedure for the Climate Regime", ZaöRV, 56 (1996) 732-749; S. Urbinati, "Non-Compliance Procedure under the Kyoto Protocol", Baltic YB Int'l L., 3 (2003) 229-251; J. Voinov Kohler, Le Mécanisme de Contrôle du Respect du Protocole de Kyoto sur les Changements Climatiques: entre Diplomatie et Droit (Genève: Schulthtess Médias Juridiques SA, 2006); D. Zaelke, "Cameron, James, Global Warming and Climate Change - An Overview of an International Legal Process", Am. U. J. Int'l L. \& Pol'y, 5 (1989-90) 249-290.

${ }^{79}$ Final Decision, doc. CC-2007-1-8/Greece/EB (17 April 2008). 


\title{
Chapter Five
}

\section{Draft Procedures and Mechanisms on Compliance with the 1998 Rotterdam Convention on the Prior Informed Consent Procedure for Certain Hazardous Chemicals and Pesticides in International Trade}

\author{
Stefano Brugnatelli
}

\section{Brief Introduction to the RotTERdam CONVENTION}

The Convention on the Prior Informed Consent Procedure for Certain Hazardous Chemicals and Pesticides in International Trade (Rotterdam, The Netherlands, 10 September 1998) (Rotterdam Convention or Convention) ${ }^{1}$ is an outcome of the principles included in Principle 19 of the Rio Declaration, ${ }^{2}$ and establishes an international legal framework for the transfer of hazardous substances between countries, setting up a Prior Informed Consent (PIC) procedure. ${ }^{3}$

\footnotetext{
${ }^{1}$ Entered into force on 24 February 2004, available at <www.pic.int/en/ConventionText/ONU-GB.pdf $>$ (visited on 23 June 2008). See generally P. Barrios, "The Rotterdam Convention on Hazardous Chemicals: a Meaningful Step Towards Environmental Protection?”, Georgetown Int'l Envt'l L. Rev., 16 (2004), 679-762; R. Emory, "Probing the Protections in the Rotterdam Convention on Prior Informed Consent", Colo. J. Int'l Envt'l L. \& Pol'y YB (1999), 47-69; K. Kummer, "Prior Informed Consent for Chemicals in International Trade: The 1998 Rotterdam Convention", RECIEL, 8 (1999), 323-330; C. Redgwell, "Regulating Trade in Dangerous Substances: Prior Informed Consent under the 1998 Rotterdam Convention", in A. Kiss, D. Shelton, and K. Ishibashi (eds.), Economic Globalization and Compliance with International Environmental Agreements (The Hague: Kluwer Law International, 2003) 75-88.

${ }^{2}$ Rio Declaration on Environment and Development, doc. A/CONF.151/26 (Vol. I) (12 August 1992), Annex I, according to which "States shall provide prior and timely notification and relevant information to potentially affected States on activities that may have a significant adverse transboundary environmental effect and shall consult with those States at an early stage and in good faith."

${ }^{3}$ Para. 1(g) of the UNEP's 1987 London Guidelines for the Exchange of Information on Chemicals in International Trade defined prior informed consent as: "the principle that international shipment of a chemical that is banned or severely restricted in order to protect human health or the environment should not proceed without the agreement, where such agreement exists, or contrary to the decision, of the designated national authority in the importing country." See also, General Assembly Resolution 37/137, doc. A/RES/37/137 (17 December 1982).
}

T. Treves et al., eds., Non-Compliance Procedures and Mechanisms and the Effectiveness of International Environmental Agreements

(C) 2009, T.M.C. ASSER PRESS, The Hague, The Netherlands, and the Authors 
The Convention has 114 Parties, including the European Community, ${ }^{4}$ and is open for signature by all States and regional economic integration organizations. ${ }^{5}$ The objective of the Convention is:

"[...] to promote shared responsibility and cooperative efforts among Parties in the international trade of certain hazardous chemicals in order to protect human health and the environment from potential harm and to contribute to their environmentally sound use, by facilitating information exchange about their characteristics, by providing for a national decision-making process on their import and export and by disseminating these decisions to Parties.” (Article 1).

The Convention, in order to achieve its objectives, relies on three cardinal elements: information exchange (Articles 5-11); obligations of States Parties in relation to import and export of chemicals and pesticides subject to the PIC procedure (Articles $10,11)$; export notification of domestically banned or severely restricted chemicals not subject to PIC (Article 12).

Unlike other agreements, such as the 2001 Stockholm POPs Convention, ${ }^{6}$ the Rotterdam Convention does not provide for a complete ban of the import and export of the regulated substances. The fundamental provision of the Convention only requires the prior informed consent of the importing Party before any export of a banned or severely restricted chemical or severely hazardous pesticide ${ }^{7}$ to which the Convention applies. The substances subject to PIC are those listed in Annex III (Articles 5.6 and 6.5) and may be added to, or removed from, the list on the basis of a procedure governed by the Convention (Articles 5-8 and 9) and based on the fundamental concept of information exchange. The addition of new chemicals and pesticides, as well as of banned or severely restricted chemicals, may be triggered by a "final regulatory action" that bans or severely restricts a chemical and which is taken by at least one Party in at least two "prior informed consent regions"9 (Article 5). As for pesticides, the trigger is constituted by problems in its use encountered by developing countries or countries with an economy in transition in their territories (Article 6). The Conference of the Parties (COP) is responsible for adopting the final decision on Annex III listing, on the base of detailed information provided by the Chemical Review Committee $(\mathrm{CRC})^{10}$ on the base of State notifications and communications (Article 7). The

${ }^{4}$ A complete list of the Parties to the Convention is available at <www.pic.int/home.php?type= t\&id $=63 \&$ sid $=17>$ (visited on 23 June 2008).

5 See infra paragraph 13.

6 A list of treaties with full references is provided supra at XXXVII.

7 The definitions of "banned or severely restricted chemical" and "severely hazardous pesticide" are formulated in Arts. 2(b), 2(c) and 2(d) of the Convention.

${ }^{8}$ Under Art. 2 of the Convention, final regulatory action is defined as: "an action taken by a Party, that does not require subsequent regulatory action by that Party, the purpose of which is to ban or severely restrict a chemical."

9 There are seven PIC regions: Africa, Asia, Europe, Latin America and the Caribbean, Near East, North America, South West Pacific. Decision RC-1/2 on Composition of the PIC Regions, doc. UNEP/FAO/RC/ COP.1/33 (22 October 2004), Annex I, at 25.

${ }^{10}$ The CRC was established by the COP with Decision RC-1/6 on Establishment of the Chemical Review Committee, doc. UNEP/FAO/RC/COP.1/33 (22 October 2004), Annex I, at 34. See infra this paragraph. 
$\mathrm{CRC}$, in accordance with the criteria set out in Annex II, recommends to the COP whether the chemical or pesticide in question should be made subject to the PIC procedure.

The core provisions of the PIC (Articles 10 and 11) deal with the obligations of Parties as to the import-export of chemicals and pesticides listed in Annex III. According to these provisions, once a chemical or a pesticide is listed, the Secretariat sends to the designated national authority of each Party ${ }^{11}$ a Decision Guidance Document which contains a technical summary of its toxicological and environmental characteristics, the measures which can reduce exposure and an indication of the regulatory action which other States have taken to ban or severely restrict the chemical and the reason for so doing. Within nine months from Annex III listing, importing countries shall take a final decision granting or withholding consent to future import of the chemical or pesticide concerned, or granting consent subject to specified conditions or issuing an interim response. All States Parties shall communicate such responses to any subject concerned within its jurisdiction and take appropriate legislative or administrative measures to ensure that exporters within its jurisdiction comply with decisions in each response (Article 11). Particular provisions deal with the case of a State failing to transmit a response. ${ }^{12}$ When a chemical, even if not listed in Annex III, is exported from the territory of a Party that banned or severely restricted its use within its jurisdiction, that Party shall provide an export notification to the importing Party containing all the information set out in Annex V (Article 12). ${ }^{13}$

Finally, Article 20 sets out the standard procedure for dispute settlement. ${ }^{14}$

The Rotterdam Convention sets up an institutional structure, composed of two main bodies: the Conference of the Parties (COP) and the Secretariat. The COP meets ordinarily once every two years and, according to Rule 35 of its Rules of Procedure, ${ }^{15}$ can adopt decisions with the presence of at least two thirds of its members. According to Rule 45 the Parties shall make every effort to reach agreement on all matters of substance by consensus. ${ }^{16}$ The Conference of the Parties has competence in the implementation of the Convention and in its normative development, and it has the power to adopt additional annexes and amendments to the Convention. It can also establish

${ }^{11}$ Art. 4 of the Convention provides that "[e]ach Party shall designate one or more national authorities that shall be authorized to act on its behalf in the performance of the administrative functions required by this Convention."

12 See Art. 11.2 of the Convention.

13 Although the Convention does not explicitly provide for the refusal of an importing State upon export notification of a non-Annex III substance, in accordance with the right of every State to regulate activities in its own territory, recognized under customary international law, the importing Party may in any event refuse the import. Redgwell, supra n. 1, at 84; Kummer, supra n. 1, at 328.

14 See infra paragraph 12.1.

15 The COP's Rules of Procedure were adopted by the Conference of the Parties with Decision RC-1/1 on Rules of Procedure, doc. UNEP/FAO/RC/COP.1/33 (22 October 2004), Annex 1, at 13.

${ }^{16}$ It is still a matter of discussion within the Parties if, in the case they are not capable of obtaining such consensus, decisions could be taken by two thirds majority; the matter will be discussed during the fourth meeting of the COP. 
such subsidiary bodies as it considers necessary for the implementation of the Convention. ${ }^{17}$

The Secretariat functions, according to Article 19 of the Convention, shall be performed jointly by the Executive Director of UNEP and the Director-General of FAO. Apart from its traditional administrative functions, the Convention gives the Secretariat a number of functions related to the provisions of assistance to developing countries. ${ }^{18}$

\section{Legal Basis of the Mechanism and Negotiating History}

Under Article 17 of the Rotterdam Convention the establishment of a compliance review mechanism is mandatory. It provides that:

"[t]he Conference of the Parties shall, as soon as practicable, develop and approve procedures and institutional mechanisms for determining non-compliance with the provisions of this Convention and for treatment of Parties found to be in non-compliance."

The first considerations of the matter of compliance date back to the meetings held by the Parties in the framework of the Intergovernmental Negotiation Committee for an International Legally Binding Instrument for the Application of the Prior Informed Consent Procedure for Certain Hazardous Chemicals and Pesticides in International Trade (INC) which, after the entry into force of the Rotterdam Convention in 2004, has ceased to exist. At its sixth session in 1999 the INC requested the Secretariat to prepare documentation on procedures and institutional mechanisms for determining non-compliance..$^{19}$ At its seventh session in 2000 the INC requested the Secretariat to develop a model for a procedure to handle cases of non-compliance and to submit the model to the Committee at its eighth session..$^{20}$ The Draft Text consequently prepared by the Secretariat was, after further developments, forwarded to the first meeting of the COP in 2004.

At its first meeting the COP, after having examined the Draft Text prepared by the Secretariat, decided to convene an Open-Ended $a d$ hoc working group on Article 17 (OEWG), ${ }^{21}$ with a view to preparing for and carrying forward deliberations on the issue. The OEWG met before and during the second COP in 2005, but failed to agree

${ }^{17}$ In addition, according to Art. 18.6 of the Convention, "[t]he Conference of the Parties shall, at its first meeting, establish a subsidiary body, to be called the Chemical Review Committee, for the purposes of performing the functions assigned to that Committee by this Convention." The CRC was established by the $\mathrm{COP}$ at its first meeting in 2004 with Decision RC-1/6. See supra n. 10.

${ }_{18}$ See Art. 19.2 of the Convention.

${ }_{19}$ Intergovernmental Negotiating Committee, Preparation for the Conference of the Parties: Non-Compliance, doc. UNEP/FAO/PIC/INC.7/10 (21 August 2000).

${ }^{20}$ Report of the Intergovernmental Negotiating Committee for an International Legally Binding Instrument for the Application of the Prior Informed Consent Procedure for Certain Hazardous Chemicals and Pesticides in International Trade on the Work of Its Seventh Session, doc. UNEP/FAO/PIC/INC.7/15 (9 November 2000), para. 77.

${ }^{21}$ Decision $R C-1 / 10$ on Non-Compliance, doc. UNEP/FAO/RC/COP.1/33 (22 October 2004), Annex I, at 44 . 
on some critical issues. ${ }^{22}$ The COP decided therefore to consider further the procedures and institutional mechanisms on non-compliance for adoption at its third meeting. ${ }^{23}$ The third COP, which took place in October 2006, decided to establish another working group (Working Group), chaired by Mr Denis Langlois, to continue discussion on non-compliance issues. The Working Group worked concurrently with ordinary sessions of the COP and, following its deliberations, Mr Langlois reported to the COP that the group had not been able to reach an agreement on a final text for the establishment of a compliance committee. ${ }^{24}$ The Conference of the Parties thus decided, with Decision RC-3/4, ${ }^{25}$ to consider further the matter at its fourth meeting, using as a basis for its further work the Draft Text (Draft Text) ${ }^{26}$ based on the work of the Working Group.

\section{The TeXt Establishing the Mechanism}

Notwithstanding the above-mentioned obligation under Article 17 of the Convention, ${ }^{27}$ up to now no decision has yet been adopted to establish the compliance mechanism. This delay in the establishment of a compliance procedure by the COP is due to a lack of consensus among the Parties to the Convention with regard to some crucial aspects of the procedure, i.e., the composition of the Committee, equitable geographical representation, the trigger mechanism of the procedure, non-compliance response measures, the handling of performance information. All these issues are dealt with in the Draft Text, but the relevant provisions are still bracketed.

\section{The Principles Governing the Mechanism}

Neither Article 17 of the Convention nor the Draft Text contains any indication as regards the principles governing the compliance procedure. It is likely that once such a procedure has been established by the COP, it will be possible to infer a number of principles from the text of the decision and from practice. Be that as it may, some basic indications seem to be broadly accepted by the Parties, but a certain ambiguity subsists. General consensus has been reached on the idea that the compliance mechanism should cover facilitation of compliance by the Parties, be consultative and, to a

\footnotetext{
${ }^{22}$ Report of the Open-ended Ad Hoc Working Group on Non-Compliance on the Work of Its First Session, doc. UNEP/FAO/RC/OEWG.1/3 (28 September 2005).

${ }^{23}$ Decision $R C-2 / 3$ on Non-Compliance, doc. UNEP/FAO/RC/COP.2/19 (12 October 2005), Annex I, at 22 .

${ }^{24}$ Report of the Conference of the Parties to the Rotterdam Convention on the Prior Informed Consent Procedure for Certain Hazardous Chemicals and Pesticides in International Trade on the work of its third meeting, doc. UNEP/FAO/RC/COP.3/26 (10 November 2006), paras. 82, 83.

${ }^{25}$ Decision RC-3/4 on Draft Text of the Procedures and Mechanisms on Compliance with the Rotterdam Convention, doc. UNEP/FAO/RC/COP.3/26 (10 November 2006), Annex I, at 27.

${ }^{26}$ Ibid.

27 See supra paragraph 2.
} 
certain extent, be non-confrontational and non-judicial. Other matters, like public participation and transparency, are still far from a broadly accepted agreement.

\section{INSTITUTIONAL ASPECTS}

\subsection{The Compliance Committee}

\section{a) Composition}

The Compliance Committee shall consist of fifteen members and, in its composition, due consideration shall be given to equitable geographical representation, although the Parties do not agree on how to obtain this objective in concrete terms (Draft paras. 2 and 2alt.). The Committee's members are elected by the COP among candidates nominated by the Parties (ibid.) and shall have "expertise and specific qualifications in the subject-matter covered by the Convention" (Draft para. 3). Under Draft para. 6, the Committee elects its own Chair, vice-chair and a rapporteur on a rotating basis, in accordance with Rule 30 of the Rules of Procedure of the COP. ${ }^{28}$

The Committee shall hold meetings when necessary and wherever possible in conjunction with meetings of the COP or other Convention bodies (Draft para. 7). Although the Committee is not explicitly defined in the Convention nor in the Draft Text as a subsidiary body of the COP, such a conclusion may probably be inferred by the very structure of the Convention which, apart from the Chemical Review Committee, does not contain any indication on the establishment of any organism different from what it defines "subsidiary bodies".

\section{b) Status of Members}

According to Draft para. 3 members of the Committee "shall serve objectively and in the best interest of the Convention." Such an expression is ambiguous: on the one hand it may in fact be considered as stating that members of the Committee shall serve in their own capacity and act independently from States Parties to the Convention. On the other hand however, such a formulation may also be considered as a means to avoid a far clearer expression that indisputably disposes for the independence of Committee's members from their national States (i.e., "members of the Committee shall serve in their personal capacity").

After the first election, each ordinary COP elects half of the Committee's members to replace those whose period of office has expired or is about to expire (Draft para. 4). Members of the Committee shall serve for "two terms", which are defined by the Convention as "the period that begins at the end of one ordinary meeting of the COP and ends at the end of the next ordinary meeting of the COP." (Draft para. 4). According to its Rules of Procedure, the COP's meetings after the third one shall be

${ }^{28}$ Rule 30 of the Rules of Procedure of the COP provides that: "The officers of such subsidiary bodies shall be elected with due regard to the principle of equitable geographical representation and shall not serve for more than two consecutive terms." 
held every two years (Rule 4); therefore, according to the Draft Text, the Committee's members shall serve for a period of four years. Draft para. 4 provides that Members shall not serve for more than two consecutive terms; consequently, outgoing members should not be re-elected. If a Member of the Committee is unable to complete its term, the Party who nominated that member shall nominate an alternative to serve for the reminder of the term (Draft para. 5).

c)

\section{Observers}

The Committee's meetings shall be in principle open to observers (Draft para. 8). ${ }^{29}$ Although the Draft Text contains no express regulation of the matter, it could be argued that the application mutatis mutandis to the Compliance Committee of the Rules of Procedure of the COP, explicitly provided for under Rule $26,^{30}$ would according to Rule 6 allow admission as observers to Committee's meetings to the United Nations, its specialized agencies, the IAEA and States not Parties to the Convention. Besides, pursuant to Article 7 of the Convention and Rule 7 of COP's Rules of Procedure, any body or agency, whether national or international, governmental or non-governmental, "which is qualified in matters covered by the Convention" may be admitted as an observer unless at least one third of the Parties present at the meeting objects.

Finally, pursuant to Draft para. 8, the meetings of the Committee shall be open to Parties and to the public unless the Committee decides otherwise. However, when the Committee is dealing with submissions regarding the possible non-compliance of a Party, the meetings of the Committee shall be open to Parties but closed to the public, unless the Party whose compliance is in question agrees otherwise.

\subsection{The Secretariat}

The Secretariat ${ }^{31}$ shall act as the administrative body of the mechanism. It shall arrange for and service the meetings of the Committee (Article 19 and Rules 32 and 33) and act as a liaison between the Parties, the Committee and the public ${ }^{32}$ in the handling of information to the Committee (Draft paras. 21 and 22). The Secretariat shall have its own triggering function ${ }^{33}$ (Draft paras. 12, 13 and 14).

\subsection{The Conference of the Parties}

The COP retains important competences on compliance issues. Under the Draft Text, it has the power to request the Compliance Committee to examine systemic issues of

\footnotetext{
29 See infra paragraph $8.5(\mathrm{~b})$.

${ }^{30}$ Rule 26 of the Rules of Procedure of the COP provides that: "Save as provided in rules 28-33, the present rules shall apply mutatis mutandis to the proceedings of any subsidiary bodies, subject to any modifications decided by the Conference of the Parties." See infra paragraph 8.1.

31 Under Rules 32 and 33 of the COP's Rules of Procedure, the Secretariat of the Convention shall serve as Secretariat for all the subsidiary bodies, therefore including the Compliance Committee.

32 See infra paragraph 9.

33 See infra paragraph 7.
} 
general compliance of interest to all the Parties (Draft para. 25(a)); at every ordinary meeting, it receives reports submitted by the Compliance Committee (Draft para. 26); it regularly reviews the implementation of the procedures and mechanisms set forth under the compliance mechanism (Draft para. 29). Besides all these powers, the COP retains the authority of deciding on compliance issues and in particular, upon recommendation by the Committee, on the adoption of measures to attain the Parties' compliance (Draft para. 19). ${ }^{34}$

\section{Functions of the Committee}

The Committee carries out general tasks in relation to the monitoring of compliance and deals with individual cases of non-compliance. In particular, as to the former function, the Committee may examine systemic issues of general compliance of interest to all Parties where the COP so requests (Draft para. 25(a)) or the Committee itself, on the basis of information gathered, decides that there is a need for an issue of general non-compliance to be examined and for a report on it to be made to the COP (Draft para. 25(b)).

As to individual cases of non-compliance, the Committee shall consider any submission made to it in accordance with Draft para. 12, with a view to establishing the facts and the root causes of the matter of concern, and to assisting in its resolution. To that end, the Committee may adopt facilitating measures (Draft para. 18) and may recommend the COP, if necessary, to consider measures to attain compliance (Draft para. 19). ${ }^{35}$ The Committee shall report on its work at each ordinary COP (Draft para. 26).

\section{TRIgGER Mechanism}

\subsection{Self Trigger}

Under Draft para. 12(a), a Party which believes that, despite its best endeavours, it is, or will be, unable to comply with certain obligations under the Convention, may make a submission to the Committee. Submissions must be made in writing through the Secretariat, shall include details as to which specific obligations are concerned and the reasons why the Party may be unable to comply with those obligations. Substantiating information may be provided, where possible, and the submission may include suggestions for solutions which the Party considers may be most appropriate to its particular needs.

\footnotetext{
${ }^{34}$ See infra paragraph 11.

${ }^{35}$ Ibid.
} 


\subsection{Party-to-Party Trigger}

Draft para. 12(b) provides that a Party that has concerns or is affected by a failure to comply with the Convention's obligations by another Party may make a submission to the Committee. Again, this kind of submission shall be made in writing and include details as to which specific obligations are concerned and information substantiating the submission. It must be observed that this entire provision is enclosed in square brackets, as no agreement has been reached on this issue between the Parties. In any case it appears that this disposition allows a Party not directly affected by the noncompliance of another Party, but only concerned about it, to make a submission to the Committee. Consequently, no damage requirement is provided for in this triggering mechanism.

\subsection{Submission by the Secretariat}

Under Draft para. 12(c), if the Secretariat, while acting pursuant to its functions, becomes aware of possible difficulties for any Party in complying with its obligations under the Convention, it may make a written submission to the Committee. However, no agreement has been reached by the Parties on this kind of triggering mechanism and, consequently, the whole of Draft para. 12(c) is enclosed in square brackets.

Nor is there an agreement on whether the Secretariat may rely upon sources other than information submitted to it by the Parties, and in particular from the non-governmental sector. A peculiar provision under Draft para. 12(c), under which the Secretariat may exercise its triggering power also "when it receives submissions from individuals or organizations having reservations about a Party's compliance with its obligations under the Convention" is still bracketed. This kind of possibility, not present in any other MEA's compliance procedure, may however involve dangerous consequences on the role exercised by the Secretariat under the compliance mechanism. As long as the decision to transmit submissions by the public to the Committee for consideration is reserved to a Secretariat's discretional decision, the exercise of such an authority will in fact inevitably jeopardize the impartiality of the role of the Secretariat and its image of neutral executive body of the Committee.

\section{The Procedure Before the Compliance Committee and Procedural SAFEGUARDS}

\subsection{Sources of Procedural Rules and General Remarks}

The rules governing the procedures before the Committee are to be found in the Draft Text and, presumably, in the Rules of Procedure of the COP which, according to Rule 26 , are applicable, mutatis mutandis, to the proceedings before any subsidiary body of the COP. ${ }^{36}$ The procedure may be divided into an initial stage in which the case is

\footnotetext{
36 See supra paragraph 5.1.
} 
brought to the attention of the Committee, a phase of discussion in front of the Committee, and a deliberating phase.

\subsection{Procedure for Handling Cases}

a) Self Triggering Submissions

This kind of submission is simply transmitted by the Secretariat within two weeks of receiving it to the members of the Committee for consideration at the Committee's next meeting (Draft para. 13).

\section{b) Party to Party Submissions and Submissions by the Secretariat}

In such cases, the Secretariat shall, within two weeks of receiving any submission under Draft para. 12(b) or making a submission under Draft para. 12(c), send a copy of the submission to the Party whose compliance is in question and to the members of the Committee for consideration at the Committee's next meeting (Draft para. 14).

If a Party intends to make a submission it shall, before so doing, undertake consultations with the Party whose compliance is in question (Draft para. 12(b)). Similarly the Secretariat may make a submission only provided that the matter has not been resolved within three months by consultation with the Party concerned (Draft para. 12(c)).

As Party to Party submissions and submissions by the Secretariat are not widely accepted by the Parties, Draft para. 14 is, as well as the ones establishing such trigger mechanisms, ${ }^{37}$ enclosed in square brackets.

\subsection{Consideration by the Committee}

Once a submission has been transmitted, the Committee is ready to discuss the substance of the compliance issue. Notwithstanding, under Draft para. 17, the Committee may decide not to proceed with submissions which it considers to be de minimis or ill-founded.

\section{$8.4 \quad$ Deliberation by the Committee}

If the Committee finds that a situation of concern subsists, it may decide to provide facilitation measures to the Party concerned (Draft para. 18) and, subsequently, it may decide to recommend to the COP the adoption of further measures to address the compliance issue in question (Draft para. 19) ${ }^{38}$ However Draft para. 18 does not provide that the Committee shall explicitly determine in this phase whether the Party concerned is in a situation of non-compliance, but only states that it shall establish the facts and the root causes of the matter of concern and assist in its resolution. The Draft Text only provides for an official declaration of non-compliance within the

\footnotetext{
37 See supra paragraph 7.2 and 7.3.

38 See infra paragraph 11.
} 
framework of the cited further additional measures that, under Draft para. 19, the COP may adopt to attain a Party's compliance.

\subsection{Procedural Safeguards}

a) Due Process

The Draft Text contains a number of guarantees to ensure the participation of a Party involved in the compliance procedure. Firstly, any Party whose compliance is in question is allowed to participate in any meeting of the Committee in which the matter is discussed (Draft para. 9). Accordingly, under Rule 5 of COP's Rules of Procedure, the Secretariat shall notify all Parties of the dates and location of ordinary and extraordinary meetings of the Committee, at least six days before the meeting in question is due to commence.

On the contrary, the position of the submitting party is almost ignored in the draft text, except for its right to receive information provided by the respondent Party to the Secretariat under Draft para. 16.

Parties whose compliance is in question may present responses or comments at every step of the proceeding (Draft para. 15); however they may submit additional information through the Secretariat to the COP only within three months of the date of receipt of the submission, unless the circumstances of a particular case require an extended period of time (Draft para. 16). Although no indication as to the representation of the Parties before the Compliance Committee is provided for in the Draft Text, Rule 17 of the COP's Rules of Procedure provides that "[e]ach Party participating in a meeting shall be represented by a delegation consisting of a head of delegation and such other accredited representatives and advisers as it may require."

As regards the timing of the procedure, a number of limits are pointed out in the Draft Text as to the triggering of the procedure. Apart from the one included in Draft para. 16 cited above, under Draft paras. 13 and 14 the Secretariat shall forward a submission to the members of the Committee within two weeks of receiving or making it. No indication as to the limits of the duration of the compliance procedure is provided for in the Draft Text.

\section{b) Transparency and Confidentiality}

As mentioned above, ${ }^{39}$ under Draft para. 8 the meetings of the Committee shall be in principle open to the public and to observers, which shall also have the right to take part in them. However, the Committee and the Party whose compliance is in question still have the possibility of deciding to hold meetings closed to the public or to preclude the observers' participation (Draft para. 8).

Transparency has been one of the most controversial matters between the Parties on the road to the establishment of the compliance procedure. The very concept of participation itself, and its inherent rights, is not clearly defined in the Draft Text; that

\footnotetext{
39 See supra paragraph 5.1.
} 
is another clear indication of how divisive the issue of transparency may still be for the States Parties to the Rotterdam Convention. However, the core of the right to participate at the Committee's meetings may be identified as the right to be heard and to comment on the works of the Committee, and to have such comments and interventions taken into account.

Under Draft para. 23, in accordance with Article 14 of the Convention, the Committee, any Party and any person involved in the deliberations of the Committee "shall protect the confidentiality of information received in confidence." According to the above formulation, one could say that all other information is not covered by confidentiality and is therefore public, but the Draft text does not explicitly rule on the issue. Whatever the case may be, Articles 14.3 and 14.4 of the Convention indicate a list of information which shall not be covered by confidentiality and shall therefore certainly be open to the public.

c) Languages

The Draft Text contains no indication as to the languages of the compliance mechanism; therefore, the relevant COP's Rules of Procedure shall, mutatis mutandis, be applied. Under Rule 55, the official languages of the Compliance Committee are Arabic, Chinese, English, French, Russian and Spanish, but a representative of a Party may speak in a language other than an official language if that Party provides for interpretation into one the official languages (Rule 56). Official documents, including submissions, relevant information, responses and comments, shall be drawn up in one of the official languages and be translated into all the other official languages (Rule 57).

\section{SOURCES OF INFORMATION}

Even though the handling of information is still one of the most controversial issues on the road to the establishment of a compliance mechanism, some indications may be inferred from the Draft Text; according to it, different rules shall apply to individual compliance procedures (Draft para. 21) and to the consideration of systemic issues of general compliance (Draft para. 22).

\subsection{Procedure Relating to Compliance by an Individual Party}

As to individual procedures, the Draft Text contains two alternative regulations. The former one is more general as it provides that the Committee may receive relevant information, through the Secretariat, from the Parties and from other relevant sources (Draft para. 21). The second one is more detailed: it provides that the Committee may only receive information: a) from the submitting Party and from the Party whose compliance is in question; b) from the Secretariat, which shall submit information collected from Parties while acting pursuant to its functions under the Convention; c) from any other source, even if only with the consent of the Party concerned. (Draft para. 21 alt). 


\subsection{Consideration of Systemic Issues of General Compliance}

Under Draft para. 22 the Committee, for the purpose of examining systemic issues of general compliance, may: a) request information from all Parties; b) request relevant information from any reliable source and outside experts, in accordance with relevant guidance by the COP; c) consult with the Secretariat and draw upon its experience and knowledge base.

\section{DeCISION-MAKING}

Draft para. $10 / 11^{40}$ provides that the Committee shall make every effort to reach agreement on all matters of substance by consensus. Thus far the Parties could not agree what would be the case if this was not possible; anyhow, the second part of Draft para. 10/11, still enclosed in square brackets, provides that if all efforts to reach consensus have been exhausted and no agreement has been reached, any decision shall, as a last resort, be taken by a two thirds majority of the members present and voting or by 8 members, whichever is greater. In any case all reports adopted by the Committee without consensus shall reflect the views of all its members.

For any decision to be validly taken, Draft para. $10 / 11$ provides that 10 members of the Committee shall constitute a quorum. As to the regulation of any other matter dealing with decision-making, i.e., adoption of procedural decisions and procedures and rules of conduct during voting, COP's Rules of Procedure from 45 to 51 shall apply mutatis mutandis.

\section{Outcomes}

\subsection{Facilitation Measures by the Committee}

After having collected all the information available about an individual case of noncompliance, the Committee can begin to consider the submission concerned. As specified above, ${ }^{41}$ the Committee shall not formally determine whether the Party concerned is in non-compliance, but whether a situation of concern subsists. If it finds so, and in order to assist the Party concerned in its resolution, it may address directly the Party concerned, providing it with facilitation measures: a) advice; b) non-binding recommendations; c) any further information required to assist the Party in developing a compliance plan, including timelines and targets (Draft para. 18).

40 This numeration depends on the fact that in the older versions of the Draft Text, the issues of quorum and majorities were dealt with in paras. 10 and 11, while the latest Draft Text considers them together in the same Draft para., which was therefore numbered 10/11.

${ }^{41}$ See supra paragraph 8.4 


\subsection{Possible Measures to Address Compliance Issues by the COP}

If, after adopting such measures, the Committee considers it necessary, it may recommend the COP to consider additional measures to attain compliance. ${ }^{42}$ Such further measures, which are to be taken in accordance with international law, can be divided into a first group of facilitative measures, still linked to the idea of a non-judicial and non-confrontational system, and a second group of stronger and more incisive ones. Among the first group there is the provision of further support for the Party concerned, including facilitation of access to financial resources, technical assistance and capacity-building. The second group includes the issuing of a statement of concern regarding possible future or present non-compliance, the request to the Executive Secretary to make public cases of non-compliance and, still enclosed in square brackets, the ineligibility to serve as the President of the COP or as a member of the Bureau until the non-compliant Party concerned has fulfilled its obligations. A further peculiar measure provided by Draft paragraph 19 is the possibility of recommending to a non-compliant Party to take steps to remedy or address the non-compliant situation. ${ }^{43}$ No indication is given as to whether such recommendation shall be binding for the Party concerned.

\subsection{Follow-up}

Under Draft para. 24, the Compliance Committee shall monitor the consequences of its facilitation measures and of further measures adopted by the COP. The Draft Text does not provide for any procedure for revision of the final outcome of the procedure; nothing precludes however the Committee or the COP from revising or modifying their former decisions.

\section{Coordination with Dispute Settlement Procedures and Other Non-Compliance Procedures}

\subsection{The Relationship with Dispute Settlement under the Convention}

Article 20 of the Convention provides for a dispute settlement mechanism based on a compulsory conciliation mechanism or, alternatively, on the acceptance by the Parties of the compulsory jurisdiction of an arbitral tribunal or of the International Court of Justice. As to the relationship of this mechanism with the compliance procedure, Draft para. 30 only provides that compliance procedures and mechanisms "shall be without prejudice to Article 20 of the Convention." It therefore seems that no hierarchical link

42 Before so deciding, the Committee shall take into account the cause, type, degree and frequency of compliance difficulties, including financial and technical capacities of the Parties whose compliance is in question (Draft para. 19).

43 The former version of Draft para. 19 (supra n. 23) expressly indicated as adequate measures to remedy a non-compliant situation the re-import/export of a chemical or its safe disposal at the expense of the non-compliant Party. This provision is no longer present in the latest Draft Text. 
exists between the compliance mechanism and the dispute settlement mechanism. It could then be argued that the two procedures are completely independent one from the other, and may be initiated alternatively or even jointly.

\subsection{The Relationship with Other Compliance Procedures or Dispute Settlement Mechanisms}

The Draft Text contains no clear indication as to the relationship between the compliance mechanism dealt with therein and any other compliance procedure established by other MEAs. Draft para. 28 provides only for the possibility of establishing information exchange lines, without addressing the matter of the coordination of two competing procedures in relation to different compliance mechanisms. Anyhow, it could be argued that, in the absence of clearer indications, principles of comity and mutual respect shall apply to the matter, in order to ensure the harmonic co-existence of competing compliance mechanisms.

\section{Participation of the European COMMUnity}

The European Community is a Party to the Rotterdam Convention, as are its Member States. However, no provision concerning the EC is included in the Draft Text, nor does any kind of practice exist on this matter as a compliance review procedure has not yet come into force in the framework of the Rotterdam Convention. Under the terms of the Convention, when a regional economic integration organization (as defined in Article 2(h) $)^{44}$ and its Member States are both Party to the Convention, they shall not exercise rights under the Convention concurrently (Article 25.2) and shall decide on their respective responsibilities for the performance of their obligations. In its instrument of ratification, acceptance, approval or accession a regional economic integration organization shall therefore declare the extent of its competence in respect of the matters governed by the Convention and shall inform the depositary of any relevant modification in the extent of its competence (Article 25.3).

On 19 December 2002 the Council of the European Union adopted Decision 2003/106/EC, concerning the approval, on behalf of the European Community, of the Rotterdam Convention. ${ }^{45}$ The instrument of approval, together with the Declaration of competence provided for in Article 25.2 of the Convention, was lodged with the Depositary on 20 December 2002. The Convention entered into force for the European Community on 24 December 2004.

${ }^{44}$ According to Art. 2(h) of the Rotterdam Convention, "[r]egional economic integration organization means an organization constituted by sovereign States of a given region to which its member States have transferred competence in respect of matters governed by this Convention and which has been duly authorized, in accordance with its internal procedures, to sign, ratify, accept, approve or accede to this Convention."

${ }^{45}$ Council Decision 2003/106/EC of 19 December 2002 concerning the approval, on behalf of the European Community, of the Rotterdam Convention on the Prior Informed Consent Procedure for certain hazardous chemicals and pesticides in international trade, OJ (2003) L 63/27. 
In a judgment delivered on 10 January $2006^{46}$ the European Court of Justice (ECJ) declared void the Decision of the Council as it was based solely on Article 175.1 of the EC Treaty, in conjunction with Article 300, ruling that both Articles 133 and 175.1 of the Treaty, in conjunction with the relevant provisions of Article 300, were the appropriate legal basis for the Decision of the Council. Therefore, on 25 September 2006, the Council adopted Decision 2006/730/EC concerning a new approval of the Convention on behalf of the Community. ${ }^{47}$ In the preamble the Council affirmed that in any case the Court's judgment did not affect the Community's status as Party to the Convention and that, in accordance with Article 46 of the Vienna Convention on the Law of Treaties, the deposit of a new instrument of ratification was therefore not required. Consequently the Council decided that Decision 2006/703/EC would have taken effect from the date on which Decision 2003/106/EC was adopted; in its renewed Declaration the EC stated that it was responsible for the performance of those obligations, resulting from the Convention, which are covered by Community law in force and that, by its nature, the exercise of Community competence is subject to continuous development. ${ }^{48}$

\section{Financial Aspects}

The Draft Text contains no provisions dealing with the financial aspects of the procedure set up therein, nor can indication on this regard be found in the text of the Convention. Notwithstanding, at its first meeting the COP adopted Decision RC-1/4 on "Financial rules for the Conference of the Parties, its subsidiary bodies and the Convention secretariat"; ${ }^{49}$ as this decision applies to all subsidiary bodies of the COP, it shall regulate the financial aspects of Compliance Committee's activity as well. In any case, as the Draft Text has not yet been adopted by the COP and therefore no compliance mechanism for the Rotterdam Convention yet exists, up to now there can be no clear indication as to the costs of this mechanism.

\footnotetext{
${ }^{46}$ Commission v. Council, case C-94/03, ECR (2006) I-1.

47 Council Decision 2006/730/EC of 25 September 2006 on the conclusion, on behalf of the European Community, of the Rotterdam Convention on the Prior Informed Consent Procedure for certain hazardous chemicals and pesticides in international trade, OJ (2006) L 299/23.

${ }^{48}$ The same occurred to Regulation (EC) 304/2003 of the European Parliament and of the Council of 28 January 2003 concerning the export and import of dangerous chemicals, OJ (2003) L 63/1 (recently amended by Commission Regulation (EC) 1213/2003 of 7 July 2003 amending Annex I to Regulation (EC) 304/2003 of the European Parliament and of the Council concerning the export and import of dangerous chemicals, OJ (2003) L 169/27) that was adopted on the same legal basis as Council Decision 2003/106/EC. On 10 January 2006, in its judgment in Commission v. Parliament and Council, case C-178/03, ECR (2006) I-107, the Court of Justice of the European Communities declared void the Regulation for the same reasons given for its decision in case C-94/03, saying also that, in order to avoid any legal uncertainty regarding the rules governing trade in dangerous chemicals, the effects of the Regulation were maintained until the adoption of a new Regulation based on appropriate legal bases. A proposal for a new Regulation was presented by the Commission on 30 November 2006.

49 Decision RC-1/4 on Financial Rules for the Conference of the Parties, its Subsidiary Bodies and the Convention Secretariat, doc. UNEP/FAO/RC/COP.1/33 (22 October 2004), Annex 1, at 33.
} 


\title{
Chapter Six \\ Procedures and Mechanisms on Compliance under the 2000 Cartagena Protocol on Biosafety to the 1992 Convention on Biological Diversity
}

\author{
Chiara Ragni
}

\section{Brief Introduction to the Cartagena Protocol on Biosafety to the Convention on Biological Diversity}

The Convention on Biological Diversity, negotiated under the auspices of the United Nations Environment Programme (UNEP), which entered into force on 29 December 1993 (hereinafter the Convention), is the main international instrument addressing biodiversity issues. ${ }^{1}$ It embodies the principle of sustainable development by taking into consideration both the need to protect the natural environment from the potential negative effects of modern biotechnology and the benefits that can derive from their use in fields such as agriculture, food and human health. With a view of striking a balance between these opposite but fundamental interests, the Convention provides a comprehensive and binding set of rules aimed at granting the conservation of biological diversity on the one hand, and the sustainable use of natural resources and the fair and equitable sharing of benefits deriving from genetic resources on the other.

The Convention sets up an institutional structure composed of two main bodies: the Conference of Parties (hereinafter the COP) and the Secretariat. ${ }^{2}$ The COP, whose functions are set out in Article 23 of the Convention, is essentially entrusted with the task to review the implementation of the Convention. To this end: it considers reports

\footnotetext{
1 The Convention on Biological Diversity was finalized in Nairobi in May 1992 and opened for signature at the United Nations Conference on Environment and Development (UNCED). As of January 2008, 190 instruments of ratification or accession have been deposited with the UN Secretary-General. The United States signed the Convention, but it has not ratified it yet. On the Convention see C. Redgwell, "The Convention on Biological Diversity", in K. Koufa (ed.), Protection of the Environment for the New Millennium (Athens: Sakkoulas, 2002) 341-396.

${ }^{2}$ In addition it is worth mentioning the Subsidiary Body on Scientific, Technical and Technological Advice (SBSTTA), established by Art. 24 of the Convention, charged with reporting regularly to the COP on all aspects of its work. Its tasks include providing assessments of the status of biological diversity; assessments of the types of measures taken in accordance with the provisions of the Convention; and responding to questions that the COP may put to the body.
}

T. Treves et al., eds., Non-Compliance Procedures and Mechanisms and the Effectiveness of International Environmental Agreements

(C) 2009, T.M.C. ASSER PRESS, The Hague, The Netherlands, and the Authors 
submitted by States (Article 26$)^{3}$ and by subsidiary bodies; it considers and adopts, as required, protocols or annexes to the Convention and any possible amendments to them; it establishes subsidiary bodies, entrusted with the task to provide scientific and technical advice necessary for the implementation of the Convention; it contacts, through the Secretariat, the executive bodies of conventions dealing with environmental matters related to biodiversity, with a view to establishing appropriate forms of cooperation with them; and it considers and undertakes any additional action that may be required for the achievement of the purposes of this Convention in the light of experience gained in its operation. The Secretariat, whose functions are set out by Article 24, is the administrative body of the Convention.

In accordance with Article 19.3 of the Convention, which provides the States with the power to adopt Protocols, at its second meeting, held in Jakarta in November 1995, the COP established an open-ended ad hoc Working Group to draft a protocol on biosafety. The Working Group was to provide procedures and rules aimed at ensuring an adequate level of protection in the field of the safe transfer, handling and use of living modified organisms resulting from modern biotechnology ${ }^{4}$ that may have adverse effects on the conservation and sustainable use of biological diversity, taking also into account risks to human health, and specifically focusing on transboundary movements. After a four years of negotiations a compromise was reached on the most controversial issues, such as the scope of the Protocol and its relationship with other international agreements, the type of living modified organisms concerned and the information required from the States wishing to export them, the precautionary principle and others. In 1999 the Working Group submitted a Draft Text for consideration by the COP at its first extraordinary meeting (Ex-COP).$^{5}$ The meeting was held in Cartagena in February 1999, but it was only one year later during the resumed session of the Ex-COP, and namely on 29 January $2000,{ }^{6}$ that the Protocol was finally adopted. It entered into force on 11 September 2003, ninety days after receipt of the

${ }^{3}$ With the aim of monitoring and ensuring the full implementation and respect of the obligations deriving from the treaty, Art. 26 provides that each Contracting State shall present to the Conference of Parties, the main body established by the Convention, periodical reports on measures taken in order to implement the provisions of the Convention and their effectiveness in relation to the goals of the treaty.

${ }^{4}$ Art. 19.3 provides that: "[ $\left.\mathrm{t}\right]$ he Parties shall consider the need for and modalities of a protocol setting out appropriate procedures, including, in particular, advance informed agreement, in the field of the safe transfer, handling and use of any living modified organism resulting from biotechnology that may have adverse effect on the conservation and sustainable use of biological diversity." It should be noted that while Art. 19.3 refers to biotechnology in general, the mandate of the Working Group, as resulting from the document adopted by the COP at the end of its second Meeting (Decision II/5 on Consideration of the Need for and Modalities of a Protocol for the Safe Transfer, Handling and Use of Living Modified Organisms, doc. $\mathrm{UNEP} / \mathrm{CBD} / \mathrm{COP} / 2 / 19$ (30 November 1995), is confined to modern biotechnology.

5 The meeting was convened for the purpose of discussing and performing the adoption of the Protocol on Biosafety. See Decision IV/3 on Issues Related to Biosafety, doc. UNEP/CBD/COP/4/27 (15 June 1998), at 65 .

${ }^{6}$ The Resumed Session of the Extraordinary Meeting of the Conference of the Parties (Ex-COP) for the Adoption of the Protocol on Biosafety to the Convention on Biological Diversity was held from 24-28 January 2000, in Montreal, Canada. Over 750 participants, representing 133 governments, NGOs, industry organizations and the scientific community, attended the meeting. 
fiftieth instrument of ratification (Article 37). ${ }^{7}$ In the interim period before this date the Ex-COP established an Intergovernmental Committee for the Cartagena Protocol (hereinafter ICCP) to undertake preparatory work for the decisions to be taken at the first meeting of the Conference of the Parties serving as the meeting of the Parties to the Protocol (hereinafter $\mathrm{COP} / \mathrm{MOP}){ }_{,}^{8}$ which took place shortly after its entry into force (Article 29).

With the aim of ensuring an adequate level of protection in the field of transfer (especially with regard to transboundary movement), handling and use of living modified organisms, the Protocol introduces an advance informed agreement procedure based on a precautionary approach. In particular it provides that States wishing to export such organisms have to notify the Party of import in advance of certain information, as specified by the Protocol. Once it has received the information, the importing State has the opportunity to accept or to refuse the import or make it conditional to the respect of further conditions, basing its decision on a risk assessment.

In order to grant the correct interpretation and application of the provisions included therein, the Protocol vests the Parties with the power to resort, at their discretion, either to traditional mechanisms of dispute settlement, as provided for in Article 27 of the Convention on Biological Diversity, to which the Cartagena Protocol makes reference (Article 32), or to compliance procedures which shall be established according to Article 34 .

\section{Legal Basis of the Mechanism and Negotiating History}

Article 34 of the Protocol provides that:

"The Conference of the Parties serving as the meeting of the Parties to this Protocol shall, at its first meeting, consider and approve cooperative procedures and institutional mechanisms to promote compliance with the provisions of this Protocol and to address cases of non-compliance. These procedures and mechanisms shall include provisions to offer advice or assistance, where appropriate. They shall be separate from, and without prejudice to, the dispute settlement procedures and mechanisms established by Art. 27 of the Convention."

It was noted that Article 34 takes the form of a so-called "enabling provision" since, rather then directly establishing the compliance mechanism, it simply gives the MOP the mandate to do so. ${ }^{9}$ It is not uncommon to find similar provisions in international instruments dealing with environmental issues and in particular with compliance

\footnotetext{
7 In accordance with its Art. 36 the Protocol was opened to signature during the fifth meeting of the COP in May 2000, and remained open for signature at the UN Headquarters in New York until 2001. As of October 2006, 135 instruments of ratification or accession have been deposited with the UN SecretaryGeneral.

${ }^{8}$ For the text of the Protocol see Decision EM-I/3 on Adoption of the Cartagena Protocol and Interim Arrangments UNEP/CBD/ExCOP/1/3 (20 February 2000), at 38, Annex. For a detailed guide to the provisions of the Protocol, see R. Mackenzie, F. Burhenne-Guilmin, A.G.M. La Viña and J. Werksman, An Explanatory Guide to the Cartagena Protocol on Biosafety. IUCN Environmental Policy and Law Paper note 46 (2003).

9 McKenzie et al., supra n. 8, at 193.
} 
procedures. ${ }^{10}$ The norm is characterized by the accuracy of the instructions given to the COP/MOP and by the fixation of a time frame within which the mechanism shall be established. In addition it regulates the relationship between the compliance mechanisms and the traditional procedures of dispute settlement. ${ }^{11}$

Before the entry into force of the Protocol the ICCP at its first meeting, held in Montpellier from 11 to 15 December 2000, considered a note by the Executive Secretary of the Convention on Biological Diversity regarding the development of compliance procedures and mechanisms under Article 34 and invited the Parties to the Protocol to communicate their views in writing by 30 March 2001 on the basis of a questionnaire enclosed with the note. It requested the Executive Secretary to compile the views submitted, to prepare a synthesis report for the consideration of experts, who met back-to-back with the second meeting of the ICCP. The report dealt with various significant issues related to non-compliance (such as the objective, nature and underlying principles of the procedure, institutional aspects, triggering mechanisms) and it was the starting point of the rules drafted by the Compliance Committee once it was established.

\section{The Text Establishing the Mechanism}

Pursuant to Article 34 at its first meeting, held in Kuala-Lumpur in February 2004, the COP/MOP adopted Decision BS-I/7 thus establishing an ad hoc Compliance Committee entrusted with the tasks to assist Parties in implementing the Protocol, to identify the specific circumstances and possible causes of individual cases of noncompliance referred to it, to take measures, as appropriate, or to make recommendations with a view to assisting States to comply with their obligations under the Protocol. ${ }^{12}$ The functions, structure and working procedures of the Committee are set out in the Annex to the Decision BS-I/7 which introduces (Section VII) also the possibility for the Parties to the Protocol, at their third meeting and thereafter, to review the effectiveness of procedures and mechanisms provided for therein, address repeated cases of non-compliance and take appropriate action. ${ }^{13}$

During its first meeting, which took place in Montreal between 14 and 16 March 2005, the Committee adopted by consensus its Rules of Procedure as contained in Annex I to the final report on the work of the meeting. In accordance with Section II paragraph 7 of the Annex they were then submitted to the COP/MOP for consideration and approval. The rules covered various issues related to the functioning of the

${ }^{10}$ See for example Montreal Protocol, Art. 8; the UNFCCC Convention, Art. 13; the Kyoto Protocol, Art. 18; the Rotterdam PIC Convention, Art. 17 and the Stockholm POPs Convention, Art. 17. A list of treaties with full references is provided supra at XXXVII.

${ }^{11}$ Most MEAs provide both procedures for dispute settlement and compliance mechanisms, stating that they operate independently from and without prejudice to one another.

12 See Decision BS-I/7 on Establishment of Procedures and Mechanisms on Compliance under the Cartagena Protocol on Biosafety, doc. UNEP/CBD/BS/COP-MOP/1/15 (27 February 2004), Annex I, at 98 (Non-compliance procedure).

${ }_{13}$ On the highly contentious question of whether stronger measures can be invoked in cases of persistent non-compliance, the Parties failed to reach a consensus and left the issue for the third COP/MOP to decide. 
Committee: in particular they dealt with dates and notice of meetings; agenda; distribution and consideration of information; publication of documents and information; members; officers; participation in Committee proceedings and voting procedure. They were adopted by the second meeting of the COP/MOP, held in Montreal between 30 May and 3 June 2005, ${ }^{14}$ with the exception of those concerning the voting procedure and the question whether to have an open or closed session of the Committee.

At its second meeting, held in Curitiba (Brazil) from 6 to 8 February 2006, the Compliance Committee discussed some questions related to its Rules of Procedure and adopted recommendations for submission to the third COP/MOP, in particular with regard to the voting quorum. At its third meeting the Committee reiterated its recommendation in favour of removing the square brackets around Rule 18 on voting (see supra n. 14). ${ }^{15}$ At its fourth meeting, that took place from 21 to 23 November 2007 in Montreal, the Committee assessed general issues of compliance on the basis of the information made available by Parties through their first national reports submitted four years after the entry into force of the Protocol; it also refined further its report on experiences of other multilateral environmental agreements regarding measures concerning repeated cases of non-compliance.

\section{The Principles Governing the Mechanism and the Procedure}

Section I of the Annex to the Decision BS-I/7 states that compliance procedures shall be simple, facilitative, non-adversarial and cooperative in nature. It further expressly mentions the principles of transparency, fairness, expedition and predictability as those governing the procedure. In addition Section I of the Annex provides that particular attention should be paid to the special needs of developing country Parties, in particular the least developed and small island developing States, and Parties with economies in transition, and takes into full consideration the difficulties they face in the implementation of the Protocol. All these principles are broadly reflected in institutional and procedural aspects of the mechanism.

14 Decision BS-II/1 on Rules of Procedure for Meetings of the Compliance Committee, doc. UNEP/ $\mathrm{CBD} / \mathrm{BS} / \mathrm{COP}-\mathrm{MOP} / 2 / 15$ (6 June 2005), Annex, at 29. Rule 18 of the rules of procedure of the Compliance Committee as approved during its first meeting stated that: "The Committee shall make every effort to reach agreement on all matters of substance by consensus. If all efforts to reach consensus have been exhausted and no agreement has been reached, any decision shall, as a last resort, be taken by a two-thirds majority of the members present and voting or by eight members, whichever is the greater. Where consensus is not possible, the report shall reflect the views of all members of the Committee. 2. For the purposes of these rules, the phrase 'members present and voting' means members present at the session at which voting takes place and casting an affirmative or negative vote. Members abstaining from voting shall be considered as not voting."

15 See Report of the Compliance Committee under the Cartagena Protocol on Biosafety on the Work of its Third Meeting, doc. UNEP/CBD/BS/CC/3/3 (7 March 2007), para. 43. 


\section{INSTITUTIONAL ASPECTS}

The main bodies in the compliance procedure are the Compliance Committee, the Secretariat and the COP/MOP.

\subsection{The Compliance Committee}

The Committee consists of fifteen members nominated by the Parties to the Protocol and elected for a period of four years by the COP/MOP on equitable geographical representation of the five regional groups of the United Nations (Section II of the Decision BS-I/7). ${ }^{16}$ They must be chosen from among persons with a recognized competence in the field of biosafety or other relevant matters and serve objectively in a personal capacity (Section II paragraph 3 of the Decision BS-I/7). At the time of writing the Committee is reconsidering Rule 10.2 of its Rules of Procedure that provides for the case of replacement of members that resign before their term of office. According to the norm, when such circumstance occurs the Bureau of the COP/MOP "shall, in consultation with the appropriate regional group, appoint a replacement."17 Since some of its members resigned in the last months and before the expiration of their office, the Committee noted how this circumstance can affect the effectiveness of its work until the next COP/MOP. In order to remedy this situation, the Committee explored some possible solutions and among them the opportunity that regional groups act promptly as soon as they receive from the Secretariat notice of the resignation or of the non-availability of one or more members in order to obtain nominations for the replacement; in any case it recommended the Parties to the Protocol to discuss the question in the next COP/MOP and to seek an alternative solution to replace any missing member of the Committee during the inter-session period. ${ }^{18}$

To perform its functions the Committee shall meet twice a year unless it decides otherwise. As stated above (supra paragraph 3), one of the most controversial issues was whether the meetings should be held in an open or closed session. The Committee at its second meeting, after taking into consideration the advantages and disadvantages of both solutions, agreed to decide on a case-by-case basis ${ }^{19}$ and it addressed the

${ }^{16}$ See Non-compliance procedure, Section II.4 expressly provides that: "At its first meeting, the Conference of the Parties serving as the meeting of the Parties to the Cartagena Protocol on Biosafety shall elect five members, one from each region, for half a term, and ten members for a full term. Each time thereafter, the Conference of the Parties serving as the meeting of the Parties to the Cartagena Protocol on Biosafety shall elect for a full term, new members to replace those whose term has expired. Members shall not serve for more than two consecutive terms."

17 Rules of Procedure of the Compliance Committee, Rule 10.2.

18 See Report of the Compliance Committee under the Cartagena Protocol on Biosafety on the Work of its Third Meeting, doc. UNEP/CBD/BS/CC/3/3 (7 March 2007), paras. 37 and following; Report of the Compliance Committee under the Cartagena Protocol on Biosafety on the Work of its Fourth Meeting, doc. $\mathrm{UNEP} / \mathrm{CBD} / \mathrm{BS} / \mathrm{CC} / 4 / 3$ (23 November 2007), paras. 29-30; Report of the Compliance Committee under the Cartagena Protocol on Biosafety, doc. UNEP/CBD/BS/COP-MOP/4/2 (5 December 2007), para. 23.

${ }_{19}$ With regard to the meeting in progress, members of the Committee reaffirmed their decision to have a closed session in order to assess various implications and possible options of implementing rules of procedure. With regard to the third meeting that took place in Kuala Lumpur, Malaysia from 5 to 7 March 2007, the Committee decided to have it in an open session and to admit to the meeting interested observers from 
question as to who should be allowed to participate in an open session. As a general rule it stated that only Parties who expressed their wishes to the Secretariat could be present at the session, provided that an appropriate balance in the involvement of developing and developed countries in each open session were taken into account. Members of the Committee agreed that, to this end, the COP/MOP might consider the allocation of some financial resources in the budget with a view to supporting eligible country Parties' participation.

Finally the Committee noted the opportunity to leave participation at open sessions of its meetings open also to observers, where appropriate. ${ }^{20}$

At its third meeting, held in Kuala Lumpur between 5 and 7 March 2007, the Committee chose to have an open session and noted how this experience proved to be a positive one. Taking note of this, it decided to have the fourth meeting in an open session, and then to decide on the opportunity to review Rule 14 of its Rules of Procedure. At its fourth meeting, held in Montreal from 21 to 23 November 2007, the Committee finally agreed to conduct, as a general practice, its upcoming meeting in an open session, unless specific circumstances required otherwise; it decided not to change its Procedure, since this practice seems to be in accordance with Rule 14 of Decision BS/II-1 (supra n. 14).

\subsection{The Secretariat}

The Secretariat is the administrative body of the mechanism. It receives candidatures for the Committee; it arranges for and services its meetings and it acts as a liaison between Parties and the Committee in receiving any submission relating to compliance. Unlike other compliance procedures, the Secretariat is not entrusted with a triggering function.

\subsection{The COP/MOP}

The COP/MOP is the body under whose guidance the Committee shall discharge its functions. As we mentioned above it is entrusted with the task to elect members of the Committee and to examine and approve its Rules of Procedure. It may provide the Compliance Committee with relevant information on compliance matters and decides upon the measures to take in order to promote compliance and to address cases of non-compliance according to the Committee's recommendations.

\subsection{The Biosafety Clearing-House}

In order to ensure to promote and facilitate technical and scientific cooperation within and between countries and to develop a global mechanism for exchanging and

Parties, other governments, and relevant international organizations, including non-governmental organizations. See the Note of the Chairman of the Committee, doc. UNEP/CBD/BS/CC/3/INF/1 (12 February 2007).

${ }^{20}$ The Committee noted that the participation of observers could provide information, enrich the deliberations and facilitate the resolution of issues being considered by the Committee. 
integrating information on biodiversity, a "Clearing-House Mechanism" has been established under the Convention on Biological Diversity. Within the framework of this mechanism Article 20, para. 1, of the Cartagena Protocol established a Biosafety Clearing-House $(\mathrm{BCH})$ with the aim of facilitating the exchange of scientific, techni$\mathrm{cal}$, environmental and legal information on, and experience with, living modified organisms and to assist Parties to implement the Protocol, taking into account the special needs of developing country Parties. ${ }^{21}$ From the report prepared by the Compliance Committee at the end of its fourth meeting, dealing with general issues of compliance by the Parties with their obligations under the Protocol, it results that a gap exists "with respect to implementing the requirement to adopt national measures addressing illegal transboundary movements of living modified organisms and reporting the occurrence of such movements to the $\mathrm{BCH} .{ }^{.22}$ Indeed from the first national reports on the implementation of the Protocol it appears that while over a quarter of respondent States (most of which were developed States) identified the occurrence of cases of illegal movements of living modified organisms (LMOs) to their countries, just a very few of them transmitted information concerning the occurrence of these incidents to the $\mathrm{BCH}$ in accordance with Article 25.3 of the Protocol. The Committee came to the conclusion that Parties, especially the least developed and developing ones, lacked the capacity to identify the presence of LMOs and consequently provide an account on it. It drew this conclusion from the fact that most of the incidents of illegal movement of LMOs were reported by developed countries, while it seems farfetched that they are the only ones interested by the problem..$^{23}$

In addition to the tasks described above the $\mathrm{BCH}$ has the faculty to submit relevant information to the Compliance Committee once the mechanism has been triggered by a Party. Until now however no case of non-compliance results as being submitted to the Committee.

\section{Functions of the Committee}

According to Section III of the Annex to the Decision BS-I/7 the Committee performs general tasks in relation to promoting compliance and addressing individual cases

${ }^{21}$ In addition to facilitating the general exchange of information, the $\mathrm{BCH}$ is established as the only means through which Parties can provide certain information required under the Protocol, including information provided by Parties for the advance informed agreement procedure. The $\mathrm{BCH}$ will also provide the mechanism by which Parties are informed about final decisions regarding domestic use (including the placing on the market) of LMOs that may be subject to transboundary movement.

${ }_{22}$ See Report of the Compliance Committee under the Cartagena Protocol on Biosafety, doc. UNEP/ CBD/BS/COP-MOP/4/2 (5 December 2007), para. 18.

${ }^{23}$ See the Note by Executive Secretary of 14 November 2007, prepared with a view to assisting the Committee in its consideration of general issues of Compliance as identified through the analysis of the information contained in the first national reports submitted to the Secretariat. Preliminary Suggestions and Information for Consideration in relation to Items 4, 6 and 7 of the Provisional Agenda, doc. UNEP/CBD/ BS/CC/4/2/Add.1, para. 6. See also on the same issue Report of the Compliance Committee under the Cartagena Protocol on Biosafety, doc. UNEP/CBD/BS/CC/4/3 (23 November 2007), para. 21. 
of non-compliance. In accordance with its mandate, the Committee is required to: (a) identify the specific circumstances and possible causes of individual cases of noncompliance referred to it; (b) consider information submitted to it regarding matters relating to compliance and cases of non-compliance; (c) provide advice and/or assistance, as appropriate, to the concerned Party, on matters relating to compliance with a view to assisting it to comply with its obligations under the Protocol; (d) review general issues of compliance by Parties with their obligations under the Protocol, taking into account what transpires from the analysis of the interim national reports transmitted by States Parties ${ }^{24}$ and the assessment of information available in the Biosafety Clearing House; (e) take measures, as appropriate, or make recommendations, to the COP/MOP in the case it reaches a finding of non-compliance; (f) carry out any other functions as may be assigned to it by the Conference of the Parties serving as the meeting of the Parties to the Protocol.

As until now, as stated above, no case has been brought to its attention, the Committee has been able to perform just a part of its functions; among them it is worth noting that it gathered and assessed information deriving from the reports transmitted by the States and from the notes collected by $\mathrm{BCH}$ in order to prepare a synthesis report on general issues of compliance by Parties with their obligations under the Protocol. The issues taken into consideration were: 1) the low number of first national reports received by the deadline of 16 October 2007, in accordance with paragraph 1(d) of section III of the compliance procedure and mechanisms contained in the annex to decision BS-1/7;2) the continued existence of significant gaps regarding the obligation to put in place at the national level the necessary measures to implement the Cartagena Protocol; 3 ) the lack of compliance to the obligation of reporting to the $\mathrm{BCH}$ the occurrence of illegal movement of LMOs (see supra paragraph 5.4); 4) the lack of adequate implementation of the duty to promote public awareness and participation..$^{25}$

With particular regard to the first point, the Compliance Committee noted that only about $35 \%$ of the Parties to the Protocol submitted national reports and that this can negatively influence the analysis and the evaluation of the effectiveness of the Protocol in accordance with its Article 33 and prejudice the implementation of the other norms included therein. The Committee stressed the importance to submit the problem to the COP/MOP as a general issue of compliance; indeed a gap exists between the high number of reports transmitted by States under the Convention and those prepared in accordance with the Protocol. The suggestion is that the difference depends on the funds available to support the preparation of national reports, since it is easier for eligible Parties to assess resources from the Global Environment Facility (GEF) in order to implement the obligations under the Convention rather than those provided

${ }^{24}$ At this regard in the report resulted from its second meeting the Committee expressed its concern about the fact that only the $38 \%$ of the Parties to the Protocol submitted their interim reports fulfilling their obligation under Art. 33 of the Protocol and of the decision BS-I/9 of the first meeting of the COP/MOP. See Report of the Second Meeting of the Compliance Committee under the Cartagena Protocol on Biosafety, doc. UNEP/CBD/BS/COP-MOP/3/2 (8 February 2006), para. 32.

${ }_{25}$ See Report of the Compliance Committee under the Cartagena Protocol on Biosafety, doc. UNEP/ CBD/BS/COP-MOP/4/2 (5 December 2007) 
for in the Protocol. In this connection the Committee recommended that the question be included in the scope of the dialogue session between Parties to the Convention and the Chief Executive Officer of GEF to be held in Bonn on 17 May 2008. In addition it requested the Secretariat of the compliance mechanism to compile a report on reporting rates under other MEAs.

\section{TRIGGER MechanisM}

The Cartagena Protocol, unlike some other MEAs, provides that the non-compliance procedure can be triggered only by Parties. Section IV of the Annex to the Decision BS-I/7 states that they are entitled to bring before the Committee, through the Secretariat, submission related to compliance, both when, despite their efforts, they are unable to implement or comply with the Protocol provisions (self-trigger), and when they hold that they are affected or likely to be affected by the failure of another Party to fulfil its obligations (Party-to-Party trigger). In the latter case the communication may be rejected when it is ill-founded, bearing in mind the objectives of the Protocol.

No provision concerning referral by the Secretariat or submission by the public of alleged cases of non-compliance is included in the Protocol, even though this option, like that of the opportunity of entrusting NGOs with triggering power, was taken into consideration.

\section{The Procedure before the Compliance Committee and Procedural SAFEGUARDS}

\subsection{The Procedure}

The rules governing the non-compliance procedure are to be found in two different sources. Some aspects are directly dealt with by the Annex to the Decision BS-I/7. Other are regulated by the Rules of Procedure ("Procedure"), approved by the COP/ MOP at its second meeting. ${ }^{26}$ According to Section I.2 of the Decision BS-I/7, the procedure before the Committee is quite simple. It can be divided into three different moments: the initial stage, the discussion and the deliberating phases.

In accordance with Section IV.1 of the Annex, submissions of non-compliance must be presented by the Party to the Secretariat which shall, if the request involves a problem regarding another Party, make the submissions available to the Party concerned within fifteen days of its receipt. Once a response or further information have been received by the Secretariat from the Party involved, the Secretariat shall forward them to the Committee. ${ }^{27}$ If the Secretariat receives no response or information within six months from receipt of the submission, it shall transmit the latter to the

See Rules of Procedure of the Compliance Committee, supra $\mathrm{n} .14$.

27 According to the non-compliance procedure, Section IV.3: "the Party that has received a submission regarding its compliance with the provisions of the Protocol should respond and, with recourse to the Committee for assistance if required, provide the necessary information preferably within three months and 
Committee. With regard to cases of self-triggering, the submission received by the Party shall be transmitted by the Secretariat to the members of the Committee as soon as possible, but no later than ninety days of its receipt (Rule 8 of the Procedure).

Once it has received the submission from the Party through the Secretariat, and after acquiring or taking into account all the information necessary for deliberation, the Committee shall discuss the substance of the matter. ${ }^{28}$

On the basis of the information collected and as a result of the discussion, the Committee firstly establishes whether or not the Party concerned fulfilled its obligations under the Protocol. If the Committee reaches a finding of non-compliance, it can consider, where appropriate, whether to take measures as described in Section IV.1 of the Annex to the Decision BS-I/7 or to make recommendations to the COP/MOP in accordance with para. 2 of the same Article. In any case, in deciding on the measure to be adopted, the capacity of the Party concerned should take into account, especially if they are developing countries (and in particular the least developed and small island developing States among them), together with such factors as the cause, type, degree and frequency of non-compliance.

\subsection{Procedural Safeguards}

In order to grant full respect of the principles governing the procedure within the rules developed by the Committee, some safeguards have been provided for concerning the rights of Parties during the proceedings, conflict of interest and language issues.

a) Rights of the Parties

With regard to the first aspect, paragraph 4 of section IV of the Annex to the Decision BS-I/7 provides that a Party, in respect of which a submission is made or which makes a submission, is entitled to take part in the deliberations of the Committee, save for those regarding the adoption of recommendations. However, the Party concerned shall be given an opportunity to present in writing its comments on such recommendations, which shall be enclosed with the Committee's report and forwarded to the $\mathrm{COP} / \mathrm{MOP}$.

As a further safeguard of Parties' rights the Committee shall - at their express and motivated request - consider confidential the information given by them.

\section{b) Conflict of interests}

As mentioned above, members of the Committee shall sit in a personal capacity. In order to guarantee the fairness of the procedure, Rule 11 of the Procedure provides that where a member of the Committee finds himself or herself faced with a direct or indirect conflict of interest, he/she shall bring the issue to the attention of the Committee before consideration of that particular matter and shall not participate in the

in any event not later than six months. This period of time shall commence on the date of the receipt of the submission as certified by the Secretariat."

28 Infra paragraph 9. 
elaboration and adoption of a recommendation related to the case concerned. The Rule is aimed at ensuring that members of the Committee, in performing their functions in relation with a submission, shall avoid being in "conflict of interest", but it does not clarify what the expression means. For this reason the COP/MOP invited the Committee to give further consideration to the issue during its second meeting. ${ }^{29}$ The Committee noted that it is impossible to identify all the possible circumstances under which a conflict of interests arises, given also the limited experiences in this regard of compliance mechanisms existing under other MEAs. It considered that Rule 11 and Section II paragraph 3 of the Decision BS-I/7 provided a general guidance to the members of the Committee with respect to conflict of interest and that, as a consequence, it was not necessary to change or review the existing rules for the moment.

\section{c) Languages}

The working language of the Compliance Committee is English. With regard to the request presented when triggering the mechanism, the Committee, in the course of its second meeting, noted that if a submission made by a Party regarding itself is in English, it may be transmitted to it immediately. In the case where such submission is made in an official language of the United Nations other than English, the Secretariat should transmit the English translation within ninety days of receipt of the submission to the members of the Committee. Each of them, however, may request the Secretariat for the copy of the submission in its original form. ${ }^{30}$

\section{SOURCES OF INFORMATION}

According to section $\mathrm{V}$ of Decision BS-I/7 the Committee shall consider relevant information transmitted by the triggering Party and by the Party concerned. In addition it may request or evaluate, when received, pertinent information from other sources, namely the $\mathrm{BCH}$, the Conference of the Parties to the Convention (COP), the COP/MOP, subsidiary bodies of the Convention or of the Protocol and relevant international organizations.

In its report to the third COP/MOP the Committee underlined the importance of the availability of significant information in the Biosafety Clearing-House in a timely manner, expressing its concern about the attitude shown by States in this regard. In particular it noted the shortage and the lack of clarity of information on focal points, presumably due to the insufficient capacity of States in terms of expertise, infrastructure and predictable funding to cover the running costs necessary to gather relevant

29 See Report of the Second Meeting of the Conference of the Parties to the Convention on Biological Diversity Serving as the Meeting of the Parties to the Cartagena Protocol on Biosafety, doc. UNEP/CBD/ BS/COP-MOP/2/15 (6 June 2005), para. 59.

${ }^{30}$ See Report of the Compliance Committee on the Work of its First Meeting, doc. UNEP/CBD/BS/ COP-MOP/2/2 (16 March 2005), para. 11(c). 
information available at the national level and to provide such information to the $\mathrm{BCH} .{ }^{31}$

Unlike other MEAs the Cartagena Protocol does not emphasize the advisory function of NGOs and - more generally - of civil society but, as we have seen, it makes a general reference to "relevant international organisations", without further specification. The question of the entitlement of these subjects to provide the Committee with information on compliance issues was actually one of the most controversial points during the negotiating phase. The first draft of the Rules of Procedure elaborated by the ICCP included also NGOs and civil society among those allowed to submit information, but no mention can be found in the final text.

\section{DeCISION-MAKING}

During the negotiations one of the most controversial points was the one related to the quorum required in the Committee for it to deliberate. At its first meeting the COP/ MOP favoured a solution based on a majority vote in cases where all efforts made to reach consensus had been exhausted. This option, included in Rule 18 of the Rules of Procedure, is therefore still in square brackets as a result of the lack of consensus on it at the second COP/MOP. As a response the Committee, at its second meeting, considered that the Rules of Procedure of compliance mechanisms adopted under other MEAs provide for a qualified majority voting as a last resort..$^{32}$ This reasoning led members of the Committee to call upon the COP/MOP to reconsider the question at its third meeting and to remove the square brackets from Rule 18. The COP/MOP decided to remain seized of the matter and to address the issue at its fourth meeting within the framework of the overall evaluation of the effectiveness of the Protocol in accordance with Article 35 of the Protocol and according to the modalities established in decision BS-III/15.

\section{Outcomes}

As mentioned above the Compliance Committee and the COP/MOP, upon its recommendation, can adopt measures described by Section VI of the Annex to Decision

31 The Committee noted that this problem is often exacerbated by the fact that relevant information is held by multiple national competent authorities. In addition it noted that the lack of time as well as financial resources makes it particularly difficult to have all the necessary information, available at the national level in local languages, translated into English or into one of the official United Nations languages before submission to the Biosafety Clearing-House. See Report of the Second Meeting of the Compliance Committee under the Cartagena Protocol on Biosafety, doc. UNEP/CBD/BS/COP-MOP/3/2 (8 February 2006), para. 36.

${ }^{32}$ In this regard the Committee mentioned the compliance mechanism provided for in the Kyoto Protocol. 
BS-I/7 when they find that a Party to the Protocol failed to comply with or found difficulties in implementing provisions included therein..$^{33}$

The characteristics of the possible measures to be taken seem to suggest the essentially facilitative and cooperative nature of the mechanism, especially regarding actions that the Committee can perform without the intermediation of the COP/MOP. According to Section VI.1, with a view to promoting compliance and addressing cases of non-compliance it may, for example, provide advice or assistance to the Party concerned, as appropriate; make recommendations to the COP/MOP regarding the provision of financial and technical assistance, technology transfer, training and other capacity-building measures; request or assist, as appropriate, the Party concerned to develop a compliance action plan regarding the achievement of compliance with the Protocol within a timeframe to be agreed upon between the Committee and the Party concerned; and invite the Party concerned to submit progress reports to the Committee on the efforts it is making to comply with its obligations under the Protocol. The COP/MOP, upon recommendation by the Committee, may decide measures aimed at providing assistance to the Party concerned, but it may also take action in the case of repeated non-compliance by a State.

In order to assess the effectiveness of the measures adopted, especially when they consist in developing and implementing a compliance strategy, it is provided that the Party concerned shall report on the steps taken in order to return in compliance with its obligations under the Protocol. It must be stressed that, as mentioned above, both the Committee and the COP/MOP shall take into account the capacity of the Party concerned when deciding on an action directed at tackling situations of non-compliance, with special regard to developing States. Moreover Section VI, in making a distinction between promoting compliance and addressing non-compliance, seems to imply that the choice of the measure to be adopted depends on the situation of the Party concerned, but also on the ratio of the measure. However it should be noted that sanctioning actions are not provided for.

Regarding such sanctions Section VI requires the COP/MOP to decide at its third meeting which measures have to be taken in the case of repeated non-compliance. Accordingly, on the occasion of the third COP/MOP the Executive Secretary prepared a note in which it suggested some options to be considered by the Conference through a comparative assessment of the experience of other environmental agreements. ${ }^{34}$ From this assessment it emerged that in most cases such measures include issuing cautions or suspending, in accordance with the applicable rules of international law related to the deferral of the functioning of a treaty, the special rights and privileges accorded to the Party concerned under the Convention whose provisions

33 Non-compliance procedure, Section VI: "To this end, upon the recommendation of the Committee and taking into account the capacity of the Party concerned to comply, the COP/MOP may decide upon one or more of the following measures: (a) provide financial and technical assistance, technology transfer, training and other capacity-building measures; (b) issue a caution to the concerned Party; (c) request the Executive Secretary to publish cases of non-compliance in the Biosafety Clearing-House (see infra); and (d) in cases of repeated non-compliance, take such measures as may be decided by the COP/MOP at its third meeting."

${ }^{34}$ See Compliance (Article 34): Measures in cases of repeated non-compliance, doc. UNEP/CBD/BS/ COP-MOP/3/2/Add. 1 (10 January 2006). 
were the object of the non-compliance procedure. The third COP/MOP agreed not to decide on the matter immediately, but to resume the discussion at its fourth meeting, within the framework of the overall evaluation of the effectiveness of the Protocol in accordance with Article 35, and it requested the Compliance Committee to compile further information on the experience of other multilateral environmental agreements regarding repeated cases of non-compliance for its consideration. ${ }^{35}$ To assist the Committee in fulfilling that request the Secretariat accordingly compiled a document based on information and experiences from other MEAs to be reviewed at its third meeting, ${ }^{36}$ during which it was recommended that the report should have been updated taking into account some more MEAs. Basing its work on the document drafted by the Secretariat, ${ }^{37}$ the Committee prepared a compilation of the experience of other non-compliance mechanisms, derived some observations from their assessment and drew conclusions about the possible measures that could be adopted in cases of repeated non-compliance. All this was to be submitted to the COP/MOP at its fourth meeting.

The Committee noted that in all the MEAs taken into account, the frequency of cases of non-compliance regarding the same State is a factor to be taken into consideration in recommending or determining the measures to adopt and that, as a general rule, those measures are listed in an order of increasing severity, meaning that the most restrictive ones should be taken just in the most significant cases of non-compliance with the obligations under the MEAs, such as those of repeated non-compliance. In this regard the Committee noted that remedies affecting trade are not only provided for just in the MEAs that directly regard trade in certain goods or substances, such as the Montreal Protocol or the CITES, but also that they should be adopted as an extrema ratio. In any case the Committee stressed that the measures intended to address cases of repeated non-compliance should not usually be pursued in the event the Party concerned has been working and continues to work towards compliance. ${ }^{38}$

On the basis of the above observations and of the analysis of the measures provided for under other mechanisms, the Committee identified some possible actions to take in cases of repeated non-compliance that go beyond those mentioned in paragraphs 1 and 2 of Section VI of the Annex to Decision BS-I/7. The Committee listed the possible measures in an order of increasing severity starting with those providing for technical assistance to the Party concerned and arriving to contemplate also the possibility to adopt trade restrictions. ${ }^{39}$

${ }^{35}$ Decision BS-III/1 on Compliance, doc. UNEP/CBD/BS/COP-MOP/3/15 (8 May 2006), at 33, paras. $1-2$.

${ }^{36}$ See supra n. 35.

${ }^{37}$ Further Information and Experience Regarding Cases of Repeated Non-Compliance under the Compliance Mechanisms of Other Multilateral Environmental Agreements, Note by the Executive Secretariat, doc. UNEP/CBD/BS/CC/4/2 (18 October 2007).

${ }^{38}$ Further Information and Experience Regarding Cases of Repeated Non-Compliance under the Compliance Mechanisms of Other Multilateral Environmental Agreements, Compilation by the Compliance Committee, doc. UNEP/CBD/BS/COP-MOP/4/2/Add.1 (6 December 2007).

${ }^{39}$ Ibid., paras. 93-95. 


\section{Coordination with Dispute Settlement Procedures and other Non-Compliance Procedures}

As mentioned above, with the aim of ensuring compliance with the provisions included therein the Cartagena Protocol provides that both the traditional confrontational means of dispute resolution and compliance mechanism are available also with regard to issues arising from the same facts or situations. Due to their different purpose and approach the two methods can coexist within the same treaty; that conclusion is enshrined in Article 34 of the Cartagena Protocol where it is stated that the dispute settlement system and compliance procedure are separate from, and without prejudice to each other. ${ }^{40}$ The Protocol provides that no hierarchy exists as to the status or order of procedural precedence between the two. It is possible therefore to expect that Parties would choose to submit their problems to the Compliance Committee before resorting to traditional means of dispute settlement and that, in any case, the findings, if any, reached within the framework of the procedure triggered first should be taken into account. ${ }^{41}$

With regard to the relationship between compliance mechanism and traditional and adversarial methods of dispute resolution provided for under other international instruments some problems might arise as to whether an issue does not only regard environmental matters but also trade law. For example, if a Party refuses the import of some genetically modified products because of the failure by the exporting State to comply with the Protocol, a conflict could occur with obligations under a trade agreement (e.g., the WTO agreement) to which both States may be Parties. A dispute could be brought before the WTO dispute settlement body, since the attitude of the importer State could be seen as a restriction to free trade and a violation of WTO law, and at the same time the procedures created under the Cartagena Protocol could be triggered. The question has been broadly explored by scholars, but at the time of writing it has never occurred in practice. ${ }^{42}$

\section{Participation of the European Community}

The European Community (EC) is Party to the Cartagena Protocol, as are all its Member States. By ratifying the Protocol on 27 August 2002 the EC, as results from the declaration that accompanied its ratification, acted in accordance with Article 175.1

40 The Protocol does not include specific provisions on the settlement of disputes arising from its interpretation or application, but it makes reference to Art. 27 of the Convention on Biological Diversity which, in this regard, provides for optional recourse to judicial settlement by the International Court of Justice or arbitration, or a conciliation procedure that is compulsory at the request of one of the Parties to a dispute.

${ }^{41}$ If so, the compliance mechanism may be seen as a means to prevent dispute settlement.

42 Actually in a recent dispute brought before the WTO by the United States against the EC, some Member States of which had ordered a ban on the import of GMO and GMO foods, the defendant States attempted to justify their position by making reference to the Cartagena Protocol, but the panel concluded that the agreement was not applicable in the case of specie since the United States are not Party to it. European Communities - Measures Affecting the Approval and Marketing of Biotech Products, docs WT/DS291, WT/DS292, WT/DS293, Panel Report circulated on 29 September 2006. 
of the EC Treaty, which provides for the EC's competence to enter international agreements which contribute to preserving, protecting and improving the quality of environment; to protecting human health; to promoting the prudent and rational utilisation of natural resources and the adoption of measures at international level that deal with regional or worldwide environmental problems. Moreover, the EC declared that it had already adopted legal instruments, binding on its Member States, covering matters governed by the Protocol.

The Protocol has indeed been implemented in EC Law first with Directive 2001/18/ EC, then through Regulation (EC) No. 1946/2003 of the European Parliament and of the Council of 15 July 2003, which respectively deal with the release into the environment and with transboundary movements of genetically modified organisms. Unlike the Cartagena Protocol, which applies only to States Parties, the EC Regulation extends the Advanced Informed Agreement Procedure to all prospective importing States. ${ }^{43}$

As regards the compliance mechanism, during its negotiation the EC pushed for the inclusion in the Rules of Procedure of the possibility for the Committee to consider all the relevant information coming not only from the Party concerned, but also from those that made the submission with regard to another Party and the opportunity to adopt strong sanctions, such as the suspension of the rights and privileges of the Party concerned, in cases of repeated non-compliance. ${ }^{44}$ The idea was that the mechanism should be as effective as possible in promoting compliance and addressing noncompliance with the Protocol.

Even though it is not specified, it seems that the EC may be Party to the Compliance Procedure. The use of the term "Party" instead of "State" in the text of Decision BS-I/7 validates this assumption. In addition, since the EC in its declaration stated that it is responsible for the performance of those obligations resulting from the Protocol which are covered by the Community law in force, it is questionable whether it should be a Party to the procedure even when a Member State, and not the EC itself, does not to comply with the Protocol.

\section{FinANCIAL ASPECTS}

The Cartagena Protocol (Article 28, para. 2) provides that the costs related to its functioning and implementation will be covered through the financial mechanism established under the Convention on Biodiversity, whose Conference of the Parties designated the restructured GEF to serve as the institutional

43 This is the most relevant difference between the Regulation and the Protocol, but the two texts differ in some other significant aspects. See on the subject D. Langlet, "Advance Informed Agreement on Biosafety: the Elaboration, Functioning and Implications of AIA in the Cartagena Protocol”, Eur. Env'l L. Rev., 14 (2005) 291-310, at 308.

${ }_{44}$ As seen above the idea of mechanism cooperative and facilitative in nature prevails in the final version of Decision BS-I/7 (supra n. 12) and it is possible that the Parties of the Protocol will agree on the opportunity not to include the possibility to take sanctions even in case of repeated non-compliance by the Party concerned. 
structure to operate the financial mechanism under the Convention on an interim basis. $^{45}$

Following the recommendation by the first COP/MOP, the COP at its seventh meeting provided detailed guidance to the GEF with regard to the Cartagena Protocol, which included eligibility criteria, strategy and priorities ${ }^{46}$ It was in particular stressed that all developing countries, especially the least developed ones, and States with economies in transition, which are Parties to the Protocol, are eligible for funding by the GEF in accordance with its mandate. States not Parties in the same situation that show a real commitment to take part to the Protocol are eligible too. With regard to the objectives the COP/MOP, in its recommendations to the COP, emphasized the importance of financial support to ensure a rapid working of its initial strategy for assisting countries to prepare for the ratification and implementation of the Protocol and to support capacity-building. At its second and third meetings the COP/MOP encouraged the GEF and the Executive Secretary of the Convention to continue their strong collaboration in advancing and strengthening support for the implementation of the Protocol ${ }^{47}$ and submitted recommendations to the eighth meeting of the COP to the Convention so that the latter provides further guidance to the GEF. ${ }^{48}$

In addition the Protocol, in Article 28, paras. 1 and 6, encourages developed country Parties to provide additional financial and technological resources, over and above the financial mechanism, to enable developing country Parties and Parties with economies in transition to implement the provisions of the Convention.

\section{Survey of Practice}

At the time of writing no submission of non-compliance has been received by the Committee, which has decided to take into consideration and to discuss the possible reasons why no specific case has been brought to its attention and to eventually come up with recommendations. A possible reason could be the fact that the mechanism

${ }^{45}$ Decision I/2 on Financial Resources and Mechanism, doc. UNEP/CBD/COP/1/17 (28 February 1995), at 32.

${ }^{46}$ Decision VII/20 on Further Guidance to the Financial Mechanism, doc. UNEP/CBD/COP/7/20 (13 April 2004), Annex, at 314, paras. 20-26.

${ }^{47}$ Decision BS-II/5 on Matters Related to the Financial Mechanism and Resources, doc. UNEP/CBD/ BS/COP-MOP/2/15 (6 June 2005), at 44.

${ }^{48}$ Decision BS-III/5 on Matters Related to the Financial Mechanism and Resources, doc. UNEP/CBD/ BS/COP-MOP/3/15 (8 May 2006). In line with the guidance provided by the COP, the GEP Council in 2000 approved a global UNEP-GEF project to assist all eligible countries to develop national biosafety frameworks. The project was launched in June 2001, and assisted 123 countries. Under the initial strategy, the GEF also provided support to 12 demonstration projects for capacity-building in implementation of national biosafety frameworks. In November 2003, the GEF approved an add-on project to the UNEP-GEF project on the Development of national biosafety frameworks entitled Building Capacity for Effective Participation in the BCH of the Cartagena Protocol. In the GEF Strategic Business Plan FY04-FY06, capacity-building for the implementation of the Cartagena Protocol on Biosafety is one of the strategic priorities in the biodiversity focal area to be funded, in line with the guidance from the COP. 
under the Cartagena Protocol, unlike those established under other MEAs, ${ }^{49}$ can be triggered only by the Parties.

\section{Conclusions}

During the negotiation of the Rules of Procedure of the Compliance Committee two views emerged with regard to the legal nature the mechanism should have assumed. Most of the States Parties to the Protocol favoured procedures and mechanisms for a compliance regime that were non-confrontational and non-judicial. Some have stressed that the Protocol itself, by contemplating compliance procedures without prejudice to the dispute settlement means established by Article 27 of the Convention, leaves no other option than to seek a simple and advisory mechanism that is non-confrontational in nature.

There was, however, an alternative minority approach that favoured procedures that were judicial and punitive in nature where non-compliance involve exporting countries, and facilitative and non-judicial in cases involving LMO-importing countries. During the first meeting of ICCP, similar minority views were expressed in favour of procedures that treated developing and developed countries differently. According to this approach, failure to comply with the obligations of the Protocol by a developed country Party or an LMO-exporting Party should have set in motion a judicial process and entailed sanctions, whereas non-compliance by a developing Party or an importing Party should have only triggered a non-judicial cooperative procedure.

As seen the first approach prevailed. The examination of the institutional and procedural aspects of the mechanism established according to Article 34 of the Cartagena Protocol seems indeed to suggest that it is to be considered cooperative, facilitative and non-judicial in nature. Provisions dealing with the relationship between the explored procedures and traditional dispute settlement means may be considered to confirm this conclusion.

\section{Bibliography}

D.K. Anton, "Regulating an increasingly genetically modified world under the Cartagena Protocol on Biosafety", in Environmental Law Reporter (2000), available at $<\mathrm{http}$ :/www.elr.info/ International/currentinternational.cfm >; C. Bail, R. Falkner and H. Marquard (eds.), The Cartagena Protocol on Biosafety: Reconciling Trade in Biotechnology with Environment and Development (London: Earthscan, 2002); S.W. Burgiel, "The Cartagena Protocol on Biosafety: Taking the steps from negotiation to implementation", RECIEL, 11 (2002) 53-61; A. Cosbey and S.W. Burgiel, "The Cartagena Protocol on Biosafety: An Analysis of Results", IISD

49 See for example the Montreal Protocol (See F. Romanin Jacur, "The Non-Compliance Procedure of the 1987 Montreal Protocol to the 1985 Vienna Convention on Substances that Deplete the Ozone Layer", supra 11-32, at 20) or the Aarhus Convention (See C. Pitea, "Procedures and Mechanisms for Review of Compliance under the 1998 Aarhus Convention on Access to Information, Public Participation and Access to Justice in Environmental Matters", supra 221-250, at 228). The mechanisms established under the MEAs mentioned were mostly triggered by the Secretariat and by NGOs respectively. 
Briefing Note (2000) available at $<$ http://iisd.ca/pdf/biosafety.pdf $>$; E. Duall, "A liability and redress regime for genetically modified organisms under the Cartagena Protocol", Geo. Wash. Int'l L. Rev., 36 (2004) 173-201; B. Eggers and R. Mackenzie, "The Cartagena Protocol on Biosafety", J. Int'l Econ. L., 3 (2000) 525-543; R. Falkner, "Regulating Biotech Trade: The Cartagena Protocol on Biosafety”, Int'l Aff., 36 (2000) 299-313; D. French, “The International Regulation of Genetically Modified Organisms: Synergies and Tensions in World Trade", Env'l Liab., (2001) 127-139; V. Koester, "Cartagena Protocol: A New Hot Spot in the TradeEnvironment Conflict”, Env'1 Pol. \& L., 31 (2001) 82-94; R. Mackenzie, “The Cartagena Protocol after the First Meeting of the Parties", RECIEL, 13 (2004) 271-278; R. Mackenzie, F. Burhenne-Guilmin, A.G.M. La Viña and J. Werksman, An Explanatory Guide to the Cartagena Protocol on Biosafety. IUCN Environmental Policy and Law Paper note 46 (2003); R. Pavoni, Biodiversità e biotecnologie nel diritto internazionale e comunitario (Milano: Giuffrè, 2004); E. Righini, "Il Protocollo di Cartagena sulla biosicurezza e gli accordi sul commercio internazionale", Riv. Dir. Int., 84 (2001) 654-685; S. Safrin, "Treaties in Collision? The Biosafety Protocol and the World Trade Organization Agreements", Am. J. Int'1 L., 96 (2002) 606-628; P.T. Stoll, "Controlling the Risks of Genetically Modified Organisms: The Cartagena Protocol on Biosafety and the SPS Agreement”, YB Int'l Env'1 L., 10 (2000) 82-119. 


\title{
Chapter Seven \\ Draft Non-Compliance Procedure under the 2001 Stockholm Convention on Persistent Organic Pollutants
}

\author{
Giulia Bigi
}

\section{Brief Introduction to the Stockholm Convention}

The Stockholm Convention on Persistent Organic Pollutants (Stockholm, Sweden, 22 May 2001) (Stockholm Convention or Convention) ${ }^{1}$ aims to protect human health and the environment from persistent organic pollutants (POPs): these are chemical substances which are persistent and toxic, bioaccumulative and can be transported through air, water and migratory species across international boundaries.

The Convention is, by its nature, precautionary: it presses for the elimination of specific substances even though some uncertainties may still exist as to their adverse effect. Article 1 recalls the precautionary approach as enshrined in Principle 15 of the Rio Declaration on Environment and Development of $1992,{ }^{2}$ and refers to it as an instrument to be used in achieving the main objective of the Convention. Also the procedure for adding new harmful substances to the Convention list is regulated by the use of the precautionary action based on scientific uncertainty (Article 8 of the Convention and Annexes D, E and F thereto).

The Stockholm Convention addresses, in the current and not yet amended text, only twelve POPs, ${ }^{3}$ which are divided into three groups: intentionally produced

1 In $I L M, 40$ (2001) 532. The Convention was signed on 23 May 2001 by 91 countries and entered into force on 17 May 2004. It has now 152 Signatories and 150 Parties, including the European Community. The text of the Convention and its annexes are also available at $<$ www.pops.int $>$ (visited on 2 July 2008). See, generally, C. Vanden Bilcke, "The Stockholm Convention on Persistent Organic Pollutants", RECIEL, 11 (2002) 328-342; P. Lallas, "The Stockholm Convention on Persistent Organic Pollutants", Am. J. Int'l L., 95 (2001) 692-708; J. Mintz, "Two Cheers for Global POPs: A Summary and Assessment of the Stockholm Convention on Persistent Organic Pollutants", Georgetown Int'l Envt'l L. Rev., 14 (2001) 319-332; M. Olsen, Analysis of the Stockholm Convention on Persistent Organic Pollutants (New York: Oceana, 2003).

2 Rio Declaration on Environment and Development, doc. A/CONF.151/26 (Vol. I) (12 August 1992), Annex I. According to Principle 15 of the Declaration "In order to protect the environment, the precautionary approach shall be widely applied by States according to their capabilities. Where there are threats of serious or irreversible damage, lack of full scientific certainty shall not be used as a reason for postponing cost-effective measures to prevent environmental degradation."

3 At its nineteenth session the Governing Council of the United Nations Environment Programme (UNEP) adopted Decision 19/13C on International Action to Protect Human Health and the Environment through Measures which Reduce and/or Eliminate Emissions and Discharges of Persistent Organic

T. Treves et al., eds., Non-Compliance Procedures and Mechanisms and the Effectiveness of International Environmental Agreements

(C) 2009, T.M.C. Asser PREsS, The Hague, The Netherlands, and the Authors 
chemicals, unintentionally produced ones and stockpiles. Annexes A and B list intentionally produced substances (which are mainly pesticides), differentiating between those pollutants that are to be phased-out (Annex A) and those whose production and use are to be restricted (Annex B) ${ }^{4}$ Annex C lists POPs formed and released unintentionally from anthropogenic sources (so-called "By-Products") and which, according to Article 5 of the Convention, are to be gradually reduced and, where feasible, totally eliminated. Stockpiles and wastes containing Annex A, B and C chemicals are to be managed and stored in a manner protective of human health and of the environment (Article 6 of the Convention). In this context, Article 6.2 establishes that the Conference of the Parties (COP) shall "cooperate closely with the appropriate bodies" of the UNEP Basel Convention. ${ }^{5}$

In relation to the obligations concerning the chemicals listed in Annexes A and B, the Convention allows States, at the moment of becoming a Party, to register one or more "specific exemptions", which are subjected to a specified process for review and termination (five years). ${ }^{6}$ The Register established for identifying the Parties that avail themselves of specific exemptions will be maintained by the Secretariat and will be available to the public. This rule intends to maintain the elimination aims of the obligations under the Convention, while giving to the countries the possibility to clarify their particular positions and needs.

As a complement to these basic obligations, Article 3.2 of the Convention contains restrictions on trade and, unlike other environmental treaties, ${ }^{7}$ does not contemplate any "saving" or "supremacy" clause concerning WTO-rules. The result of the very detailed mechanism set out in this provision is that, for substances listed in Annexes A and B, trade between States Parties remains possible only for the purpose of environmentally sound disposal or if specific exemptions are in effect. With regard to the issue of trade with non-parties and only for POPs subjected to special exemptions, the Convention (Article 3.2(b)(iii)) allows export to those countries only as long as they have provided an annual certification to the exporting Party; such documentation has to specify the intended use of the chemical and must include a statement obliging the country to protect human health and the environment. In any case, each Party that has a specific exemption or an "acceptable purpose" shall take appropriate measures to

Pollutants, Including the Development of an International Legally Binding Instrument, doc. UNEP/GC.19/34 (17 June 1997), paras. 41-42. Para. 4 of the Decision states that "immediate international action should be initiated to protect human health and the environment through measures which will reduce and/or eliminate $[\ldots]$ the emissions and discharges of the twelve persistent organic pollutants specified in Governing Council decision 18/32, and, where appropriate, eliminate production and subsequently the remaining use of those persistent organic pollutants that are intentionally produced" (emphasis added), therefore limiting the future Convention to focus only on POPs and not on all chemicals.

${ }^{4}$ According to Art. 3 of the Convention, Parties are required to prohibit and/or take the legal and administrative measures necessary to eliminate chemicals listed in Annex A and to restrict those listed in Annex B (emphasis added).

${ }^{5}$ A list of treaties with full references is provided supra at XXXVII.

${ }^{6}$ The Register established for identifying the Parties that have specific exemptions will be maintained by the Secretariat and will be available to the public (Art. 4.1).

7 See, e.g., Art. 22.1 of the Convention on Biological Diversity. 
ensure that the production or use is carried out in a manner that prevents or minimises human exposure and release into the environment (Article 3.6 of the Convention).

In order to promote the successful implementation of the Convention, Articles 12 and 13 contain provisions about technical and funding assistance for developing Parties and Parties with economies in transition. With reference to the first issue, each Party shall fully consider the "specific needs and special situation of least developed countries" (Article 12.5 of the Convention) and take account of "the fact that sustainable economic and social development and eradication of poverty are the first and overriding priorities of the developing country Parties" (Article 13.4 of the Convention). To this end, another provision of the Convention, namely Article 9, requires Parties to facilitate or to undertake the exchange of information relevant to the reduction or elimination of the production, use and release of POPs as well as to alternatives to these substances. As to the second aspect, the mechanism created to provide funding assistance is to function under the authority and guidance of, and be accountable to, the COP, but may also include other entities giving both types of support (technical and financial). For this purpose, subsequent Article 14 provides that on an interim basis the institutional structure of the Global Environment Facility (GEF) shall be the main entity entrusted with the operations described above. In this way the Convention does not create a separate body, but prefers to use existing organs as the main source for the functioning of the fund.

As usual for Multilateral Environmental Agreements (MEAs), the Convention sets up an institutional structure, consisting of two main organs: the COP (Article 19) and the Secretariat (Article 20). The COP's ordinary meetings are to be held at regular intervals; according to Rule 4 of the Rules of procedure of the $\mathrm{COP}^{8}$ the second and the third ordinary meetings shall be held annually and, thereafter, they shall be held every second year. The functions of the COP consist prominently in keeping "under continuous review and evaluation the implementation" of the Convention. To this end, each Party shall report on the measures taken and on their effectiveness, which will be evaluated by the COP every four years on the basis of available scientific, environmental, technical and economic information. The Secretariat, whose functions are to be performed by the Executive Director of the UNEP, is the administrative body of the Convention.

\section{Legal Basis of the Mechanism and Negotiating History}

The establishment by the COP of procedures and institutional mechanisms for determining non-compliance and for the treatment of those Parties found to be in noncompliance is mandatory under Article 17 of the Convention, which reads as follows: "The Conference of the Parties shall, as soon as practicable, develop and approve institutional mechanisms for determining non-compliance with the provisions of this Convention and for the treatment of Parties found to be in non-compliance."

8 The Rules of Procedure for the COP were adopted by the COP itself during its first meeting; see Decision SC-1/1 on Rules of Procedure for the Conference of the Parties, doc. UNEP/POPS/COP.1/31 (6 May 2005), Annex I. 
During its first meeting held in Punta del Este on 2-6 May 2005, the COP invited all Governments (both Parties and non-Parties) and relevant organizations to submit to the Secretariat their views and proposals on this issue, and decided to convene an open-ended ad hoc working group on non-compliance (OEWG). ${ }^{9}$ To this end, the Secretariat was required to prepare, for submission to the OEWG, a compilation of these different views ${ }^{10}$ and to develop, again for submission to the OEWG, a draft text of procedures and institutional mechanisms on non-compliance under Article 17 of the Convention, bearing in mind the recent developments concerning compliance within other MEAs. ${ }^{11}$

Accordingly, the first meeting of the OEWG was held on 28 and 29 April 2006 in Geneva, Switzerland, ${ }^{12}$ which reported on its work to the second meeting of the COP ${ }^{13}$ which was also held in Geneva on 1-5 May 2006; during this meeting, the Working Group did not reach an agreement on all issues so, on that occasion, the COP decided that the OEWG should meet again in order to continue its work. The second meeting of the Working Group was held in Dakar, Senegal, from 25 to 27 April 2007. ${ }^{14}$ There, after some discussion, the Group agreed that some provisions of the Draft Text, in particular those relating to the establishment, composition, election and meetings of the Compliance Committee, should be based on the norms that had been negotiated in the context of the discussions on the non-compliance procedures for the Rotterdam PIC Convention. ${ }^{15}$

This Draft Text, ${ }^{16}$ some parts of which were still in square brackets, was then forwarded to the COP for its consideration during its third meeting, which took place from 30 April to 4 May $2007,{ }^{17}$ with a recommendation to establish a contact group (Contact Group) to work further on the matter. The Contact Group, chaired by Ms. Daniel (Canada), worked concurrently with ordinary sessions of the third meeting of the COP and, following its deliberations, produced a revised text on the procedures and mechanisms pursuant to Article 17 of the Convention, which was then approved by the Committee of the Whole. As the Contact Group did not reach any agreement

\footnotetext{
9 See Decision SC-1/14 on Non-Compliance, doc. UNEP/POPS/COP.1/31 (6 May 2005), Annex I.

${ }^{10}$ A compilation of these submissions is found in Views and Proposals on Procedures and Institutional Mechanisms on Non-Compliance Submitted by Governments and Relevant Organizations. Note by the Secretariat, doc. UNEP/POPS/OEWG-NC.1/INF/1 (18 January 2006).

11 See Draft Procedures and Institutional Mechanisms on Non-Compliance under the Stockholm Convention, doc. UNEP/POPS/OEWG-NC.1/2 (28 February 2006), Annex.

${ }^{12}$ See Report of the Open-Ended Ad Hoc Working Group on Non-Compliance on the Work of its First Meeting, doc. UNEP/POPS/OEWG-NC.1/3 (30 April 2006).

${ }_{13}$ See Report of the Conference of the Parties of the Stockholm Convention on Persistent Organic Pollutants on the Work of its Second Meeting, doc. UNEP/POPS/COP.2/30 (15 May 2006).

${ }^{14}$ See Report of the Open-Ended Ad Hoc Working Group on Non-Compliance on the Work of its Second Meeting, doc. UNEP/POPS/OEWG-NC.2/2 (27 April 2007).

15 See S. Brugnatelli, "Draft Procedures and Mechanisms on Compliance with the 1998 Rotterdam Convention on the Prior Informed Consent Procedure for Certain Hazardous Chemicals and Pesticides in International Trade", supra 85-100.

${ }^{16}$ [Non-Compliance] [Compliance] Procedures under Article 17 of the Stockholm Convention, doc. UNEP/POPS/OEWG-NC.2/2 (27 April 2007), Annex.

17 See Report of the Conference of the Parties of the Stockholm Convention on Persistent Organic Pollutants on the Work of its Third Meeting, doc. UNEP/POPS/COP.3/30 (4 May 2007).
} 
on some issues, the COP decided to consider the matter again at its fourth meeting (which will take place from 4 to 8 May 2009 in Geneva, Switzerland) using as a basis for its work the Draft Text of the Contact Group contained as annex to the last mentioned Decision.

As yet there is not an ultimate version of the compliance procedures and mechanisms pursuant to Article 17 of the Convention, so the present work will be based on the current version of the Draft Text contained as Annex to the mentioned Report of the third meeting of the COP (Draft Text).

\section{The Text Establishing the Mechanism}

Although the Convention provides that the COP shall, as soon as it is possible, develop and approve compliance procedures and institutional mechanisms related thereto, until now such a decision has not been adopted. To date, what the legal value will be of the text establishing and governing such procedures and mechanisms has not been established.

\section{The Principles Governing the Mechanism and the Procedure}

Article 17 of the Convention does not contain any reference to the principles which have to govern the non-compliance procedure. However, the Draft Text describes the objective, the nature and the underlying principles of the non-compliance/compliance regime, which, according to Draft para. 4 , shall regulate all obligations under the Convention.

As to the first issue, there was general agreement that the procedures of non-compliance would have the objective to "assist Parties to comply with their obligations under the Convention and to facilitate, promote, monitor, assist in, advise on and aim to secure the implementation of and compliance with the obligations under the Convention" (Draft para. 1). This approach favours developing country Parties and Parties with economies in transition, by taking account of their special situations and different needs (Draft para. 4).

With regard to the nature and to the underlying principles of the mechanism, it was agreed that it should be "simple, effective, non-confrontational, non-adversarial, forward-looking, flexible, transparent, fair, predictable and cooperative" (Draft para. 2) and take into account all principles contained in the Convention (Draft para. 4). 


\section{INSTITUTIONAL ASPECTS}

\section{$5.1 \quad$ The Compliance Committee \\ a) Composition and Election of its Members}

The Compliance Committee established by the Draft Text is a subsidiary body of the COP pursuant to Article 19.5(a) of the Convention.

The number of its members has not yet been decided [10/15/19/20], but it is clear that they shall be nominated by the Parties and elected by the COP; the election will be based either on the principle of equitable geographical representation of the regional groups of the United Nations, or of balance between developed and developing country Parties and Parties with economies in transition and also gender balance (Draft para. 6). The Committee has the power to elect its own Chairperson (Draft para. 10), it shall hold meetings at least once a year and, whenever possible, in conjunction with meetings of the COP or other Convention bodies (Draft para. 11).

b) Status of its Members

The Draft Text contains also an explicit reference to the status of the members of the Committee, as it provides that they shall have expertise and specific qualifications in the subject of the Convention and shall act objectively and in the best interest of the Convention itself (Draft para. 7).

The paragraphs of the Draft Text dedicated to the process of decision-making seem to express the principle that, in any case, the members of the Committee shall be impartial, as it is expressly stated that each member of the Committee shall avoid direct or indirect conflicts of interests and that, in the event that a member is a citizen of a Party whose compliance is examined, he has to abstain from proceedings on the case (Draft para. 16) in order to avoid any risk concerning the impartiality of the procedure.

\section{c) Observers}

Unless decided otherwise by the Committee itself, its meetings shall be open to Parties and to the public, but the Party and the observers to whom the meeting is open shall not have the right to participate in the meeting (Draft paras. 13 and 14).

\subsection{The Secretariat}

The Secretariat is the administrative body of the compliance mechanism and shall therefore arrange for the provision of staff and services required. It has its own triggering function (Draft para. 17(c)) and is the body responsible for the handling of non-compliance cases for the Committee (Draft paras. 17(a), 17(b), 18, 19, 20 and 23). In addition, the Secretariat shall serve as a "clearing-house mechanism" for information on POPs (Article 9.4 of the Convention). 


\subsection{The Conference of the Parties}

As the organ which created the Compliance Committee as its subsidiary body, the COP has general powers concerning different aspects of the compliance procedure.

Firstly, Draft paras. 27 and 28 are specifically aimed at regulating possible actions taken by the COP itself. According to the first mentioned provision, if the Committee, after having undertaken the facilitation procedure contained in Draft para. $26,{ }^{18}$ considers it necessary to undertake further action in relation to the Party whose compliance is in question, it can request the COP to consider one of the measures listed in that norm. Draft para. 28 provides that some of those actions cannot be applied if the Party concerned is a developing country found to be non-compliant because of a lack of technical and financial assistance.

Additionally, the Committee shall submit a report to each ordinary meeting of the $\mathrm{COP}$ about its work, its conclusions and recommendations and the future programme of its work (Draft para. 33). Finally, the COP is entitled to regularly review the implementation and the effectiveness of the compliance mechanism (Draft para. 36).

\section{The Functions of the Committee}

The Compliance Committee is the main body of the institutional mechanism set up by the Draft Text, which divides its functions into general compliance issues and individual cases.

As to the first aspect, the Committee has the task to examine systemic issues of "general compliance and implementation of interest to all Parties" (Draft para. 32) as requested by the COP when - on the basis of information obtained by the Secretariat - it decides that there is a need for an issue on general non-compliance and when the Secretariat draws attention to relevant information it has obtained.

However, the main function of the Committee is to adopt final recommendations after having considered, on the one hand, any submission made to it by the Parties or by the Secretariat and, on the other, the cases initiated proprio motu..$^{19}$ The consideration of submissions shall be carried out with the aim of establishing the facts and the main causes of the matter and, finally, of assisting in its resolution (Draft para. 26).

The Draft text does not distinguish between different types of obligations under the Convention and the review by the Committee extends both to procedural and to substantive obligations.

\section{Trigger MechanisM}

The Draft text provides that submissions to the Committee may be made either by a Party or by the Secretariat; in addition, the Committee can also initiate a procedure proprio motu.

\footnotetext{
${ }^{18}$ See infra paragraph 11.2.

${ }^{19}$ See infra paragraph 7.
} 


\subsection{Submission by a Party}

There are two means by which the Parties can submit an individual situation to the Committee: on the one hand by "self triggering", that is to say the situation of a Party which, despite its best endeavours, is or will be unable to comply with its obligations under the Convention; and on the other hand, the "Party-to-Party trigger", which consists of a submission made by a Party that is affected or may be affected by an alleged failure of another Party to comply with the Convention's obligations (Draft paras. 17(a) and 17(b)).

\subsection{Submission by the Secretariat and Initiation by the Committee Proprio Motu}

The Draft text provides that the submissions made by the Secretariat are alternative to the initiation of the procedure by the Committee itself. According to the first version of Draft para. 17(c), a submission can be made by the Secretariat when, while acting pursuant to its functions under the Convention, it becomes aware of a Party's possible difficulties in complying with the obligations under the Convention, and provided that the matter is not settled through consultation with the Party concerned within ninety days; the power to initiate compliance proceedings seems to be discretionary, since the Secretariat may also decide not to bring the case to the attention of the Committee.

The second alternative establishes that the Committee can act proprio motu if a Party's second or subsequent report to the COP, pursuant to Article 15 of the Convention, indicates difficulties in complying with its obligations.

\subsection{Form of Submissions}

The submissions made by the Parties or by the Secretariat are to be addressed to the Committee, they shall be made in writing and shall indicate in detail which specific obligations under the Convention are concerned as well as substantiating information. In the case of the "self-trigger", the submissions are forwarded to the members of the Committee by the Secretariat within fifteen days after their receipt for consideration at the Committee's next meeting (Draft para. 18), while in the case of the "Party-to-Party trigger" the Secretariat shall also send a copy of the submission to the Party whose compliance is in question (Draft para. 19).

When a submission is made by a Party in relation to its own difficulties in complying with the Convention's obligations, it should be corroborated by an assessment of the reasons why it is unable to comply, and should also include suggestions for appropriate solutions in accordance with the particular needs of the Party concerned (Draft para. $17(\mathrm{a}))$.

\subsection{Admissibility Criteria}

It is expressly stated that the Committee shall reject submissions which it considers to be either de minimis or manifestly ill-founded (Draft para. 25). 
8. The Procedure before the Compliance Committee and Procedural SAFEGUARDS

\subsection{The Sources of Procedural Rules}

The rules governing the Committee's procedures for cases of non-compliance are to be found in two different sources, namely in the Draft Text and in the Rules of Procedure of the COP which, according to Rule 26 and to Draft para. 38, shall apply mutatis mutandis to the meetings of the Committee, except as otherwise provided.

The procedure can be broadly divided into an initial phase in which individual cases are brought to the attention of the Committee, a subsequent stage in which the cases are examined and discussed and the relevant information collected, and a final phase in which the Committee may adopt recommendations concerning the measures aimed at assisting the resolution of the compliance problems of the Party concerned.

\subsection{Procedure for Handling Cases}

a) Submissions

As to "self-triggering", the Secretariat shall forward the submissions to the Committee for consideration at the next meeting within fifteen days from receipt (Draft para. 18). In the case of "Party-to-Party triggering", before making any submission the Party intending to make a submission shall undertake consultations with the Party whose compliance is in question; afterwards, i.e., if after these consultations the Party is still affected by another Party's failure to comply with the Convention's obligations, the Secretariat shall send a copy to the Party concerned and to the Committee within fifteen days (Draft para. 19). When, acting pursuant to its functions under the Convention, the Secretariat becomes aware of the possible non-compliance of a Party with its obligations under the Convention, and if the matter has not been resolved within ninety days by consultation with the Party concerned, it shall send the submission to the Party and directly to the Committee within fifteen days after the conclusion of the ninety-day period mentioned above (Draft para. 20).

\subsection{Consideration by the Committee of the Submissions}

Once the case has been forwarded to the Compliance Committee or the procedure has been initiated by the Committee proprio motu, the discussion phase of the substantial aspects of the compliance matters can start.

At this stage of the proceeding, like at any other stage of it, the Party whose compliance is at issue has the right to present responses or comments (Draft para. 21). This Party has the right to participate in the consideration of the submission by the Committee and shall therefore be invited by the Committee itself; however, it does not have the right to participate in the elaboration of the final recommendation (Draft para. 22). Comments or additional information in response to a submission are to be sent by the Party whose compliance is in question to the Secretariat within ninety 
days after receipt of the submission; the Secretariat shall then forward this information to the Committee for consideration at its next meeting. In cases of the "Party-to-Party trigger" the Secretariat has to forward the comments received also to the Party which initiated the procedure (Draft para. 23).

The main function of the Committee consists of considering each case submitted to it in order to determine the facts and the causes and to assist the Party concerned in the resolution of the matter; if necessary, it can undertake consultations with the Party whose compliance is at issue (Draft para. 26).

\subsection{Deliberation by the Committee}

During the deliberation phase the Committee shall make every effort in order to reach an agreement on the matter by consensus; if this does not happen, the decision is taken by a majority - which has yet to be decided. In any case, when despite all efforts it is not possible to reach an agreement by consensus, the final report of any meeting shall contain specific reference to the single views expressed by all members (Draft para. 15).

\subsection{Procedural Safeguards}

a) Due Process

In conformity with the cooperative nature of the compliance procedure, which is intended to be non-confrontational and non-adversarial, the Draft Text and the other applicable provisions contain a number of safeguards which have the aim of ensuring the involvement of the Party whose compliance is in question.

In the first instance, the Party involved in a procedure of non-compliance shall be entitled to participate in the meeting in which the submission is considered by the Committee; for this purpose, the Party is invited by the Committee itself, no later than sixty days before the start of the discussions, to participate in the discussions on the submission, but this Party shall not be entitled to take part in the elaboration of the recommendation (Draft para. 22). As already mentioned above, it also has the power to forward comments and additional information to the Secretariat, which shall afterwards transmit them to the members of the Committee (Draft para. 23).

According to Rule 17 of the Rules of Procedure of the COP, the Party participating in the Committee's meeting is represented by a delegation composed of a head of the delegation and those other accredited or alternate representatives and advisers that can be required.

Secondly, as already mentioned the Parties involved in the procedure on non-compliance may present responses and comments at every step of the proceedings and have the right to reply to submissions made by others (namely, another Party or the Secretariat).

A third issue regards the recommendations adopted by the Committee, since they shall be shared with the Party concerned, which shall be given the possibility to make comments within ninety days after receipt of the draft conclusions; all comments shall then be reflected in the final report of the Committee (Draft para. 24). 
Fourthly, even if the provision of the first OEWG-Draft text (30 April 2006) ${ }^{20}$ concerning the duration and the timing of the procedure was deleted from the new proposal we are dealing with, it can be argued that, on the basis of the principles enshrined in the Convention which shall be the guide to the implementation of the mechanism (Draft para. 4), the whole proceeding shall take place in an expeditious manner. The objective of a swift proceeding is balanced with the right of the Party whose compliance is in question to request an extended period for giving further comments and additional information in response to a submission, if the particular circumstances of the case so require or if there are reasonable justifications thereto (Draft para. 23).

\section{b) Transparency and Confidentiality}

The principle of transparency is one of the most important ones guiding the implementation of the compliance procedure (Draft para. 2). That is why the meetings of the Committee, if not otherwise provided, shall be open to the public and to the Parties; however, when the Committee is dealing with specific cases of compliance pursuant to Draft para. 17, the meetings shall be open only to the Parties but not to the public, unless the Party whose compliance is at issue decides otherwise (Draft para. 13). This means, in principle, that the meetings in which individual compliance matters are considered take place in sessions which are not open to observers and that only the Parties are entitled to participate in the discussion of the case.

In one case the Draft Text expressly aims to protect confidentiality, that is regarding the information received in confidence by the Committee, the Parties and any other Party or person involved in the deliberation of the Committee (Draft para. 31); this provision is however subject to Article 9.5 of the Convention which establishes the principle that information on health, safety of humans and the environment shall not be considered as confidential.

\section{c) Conflict of Interests}

The Draft Text requires that the Committee shall be composed of people who have expertise and specific qualifications in the subject-matter of the Convention (Draft para. 7). With regard to the decision-making, it is provided that if a member of the Committee has the same nationality of the Party whose compliance is in question, that member shall automatically abstain from participating to the taking of the decision. In general, each member shall avoid direct or indirect conflict of interests: if this happens, the member concerned shall inform the Committee of the situation and he shall not participate in the elaboration of the recommendation of the Committee as regards that specific matter (Draft para. 16).

\footnotetext{
${ }^{20}$ See supra n. 12.
} 


\section{d) Languages}

Even though the first and the second Draft Texts prepared by the OEWG considered the official languages of the COP (which are the same as those of the United Nations) to be the working languages of the Compliance Committee, the new Draft Text of the Contact Group does not contain any provision about the working languages of the Committee. However, it could be argued that as the Committee is a subsidiary body of the COP, the official languages of these organs will coincide. The Rules of Procedure of the COP provide that any statement made in an official language shall be interpreted into the other ones; the same shall also happen as far as the official documents of the meetings are concerned.

\section{SOURCES OF INFORMATION}

In addition to the information and comments submitted to it by the interested Parties, the Committee has the power to collect any other relevant and necessary information on a case of possible non-compliance.

In particular, the Committee may request any further information on issues of general compliance from all Parties, it can consult with other bodies of the Convention, consult with the Secretariat, request information from experts, review any national reports of the Parties given pursuant to the relevant provisions of the Convention and, generally, use and consider any other source it deems necessary (Draft para. 30). Additionally, in carrying out its functions the Committee can, inter alia, consult directly with other bodies of the Convention, such as the COP and the POPs Review Committee, pursuant to Article 19.6 of the Convention.

\section{DECISION-MAKING}

The Draft Text provides that every effort should be made to reach an agreement on all matters of substance and that, failing that consensus, any decision shall be taken by majority: in any case, the report of any meeting at which agreement is not reached shall reflect the different views of all members of the Committee (Draft para. 15). This mechanism is to be applied without distinction to the adoption of every decision of the Committee, namely for the recommendations taken in relation to individual cases as well as for the reports on general issues of non-compliance. As for the rules to be followed for the adoption of the decisions, these are to be found in the Rules of Procedure of the COP, which contain provisions about the voting mechanism (Rule $44 \mathrm{ff}$.). 


\section{Outcomes}

After collecting all the necessary and appropriate information about an individual situation concerning possible non-compliance, the Compliance Committee can adopt its final conclusion, that is to say it decides whether a Party is in non-compliance or not.

\subsection{The Notion of Non-Compliance}

In determining whether a Party is in non-compliance the Compliance Committee applies the same criteria to all Parties. Although the Draft Text does not contain any specific definition about the notion of non-compliance, it can be argued that this concept refers to that situation in which a Party is not able or has difficulties in respecting the obligations established under the Convention; in particular, because of the failure to establish the necessary measures and implementation plans at the national level or to apply these measures and plans (See Articles 3, 5, 6 and 7 of the Convention).

\subsection{The Facilitation Measures}

In order to assist in the resolution of the matter submitted to it in accordance with the procedures described above, the Compliance Committee may take a number of measures after coordination or consultation with the Party whose compliance is in question; these measures include, inter alia, providing advice, issuing non-binding recommendations, facilitating the provision and obtaining of technical and financial assistance, requesting the Party concerned to develop a compliance action plan, providing help on the review of the action plan, reporting to the COP about the efforts made by the Party in order to return to compliance (Draft para. 26). If it considers it necessary, and in particular if the Party's compliance problems persist despite the facilitation procedure described, the Committee may recommend to the COP to take into consideration the adoption of any other measures it deems appropriate to promote compliance (Draft para. 27). On the one hand these measures can be divided into facilitative ones - which once more consist of the provision of further support, further financial and technical assistance, and further advice aimed at promoting cooperation between all Parties. On the other hand there are stronger measures which can even, in cases of repeated or persistent non-compliance (as a last resort), consist of the suspension of the rights and privileges under the Convention, or of any other action that may be required to achieve the objectives of the Convention. However, some of these additional measures, in particular the more incisive ones, shall not be applicable to the developing country Parties whose non-compliance depends on the lack of technical and financial assistance (Draft para. 28).

\subsection{Follow-up}

The Draft text expressly provides that the Committee has the power to monitor the consequences of the actions taken in accordance with the provisions described above and to report on the matter to the COP (Draft para. 29). 


\section{Coordination with Dispute Settlement Procedures and Other Non-Compliance Procedures}

\subsection{The Relationship with the Dispute Settlement under the Convention}

All obligations under the Convention are subject to the non-compliance procedures and mechanisms described above (Draft para. 4), but they shall be without prejudice to Article 18 of the Convention concerning the settlement of disputes (Draft para. 37). According to Article 18 of the Convention, Parties shall settle any dispute between them through negotiation or other peaceful means of their own choice; when ratifying, accepting, approving or acceding to the Convention, or at any time thereafter, they also have the option of accepting arbitration, or the International Court of Justice as a compulsory means of dispute resolution, which can only be used in relation to Parties accepting the same obligations. If this does not happen, or if the dispute has not been settled within twelve months, it shall be submitted to a conciliation commission, which shall render a final report.

\subsection{The Relationship with other Compliance Procedures or Dispute Settlement Mechanisms}

The Draft Text does not contain any specific provision as to the relationship between the mechanism set up therein and the compliance procedures established by other conventions; however, where relevant the Committee may ask information from compliance committees dealing with hazardous substances and wastes under other MEAs and then report on these activities to the COP (Draft para. 35). By so doing, the provision creates a connection and a communication mechanism with different existing compliance bodies, and expresses the principle of mutual respect, in order to assure a harmonic coexistence and coordination of competing compliance mechanisms.

\section{Participation of the European Community}

The European Community is a Party to the Stockholm Convention as are its Member States. The Draft Text does not contain any specific provision concerning the European Community.

Under the terms of the Convention, when a regional economic integration organization (as defined in Article 2(b) of the Convention) and its Member States are both Party to the Convention, they must decide on their respective responsibilities for the performance of their obligations under the Convention; in any case, the organization and its Member States are not entitled to exercise rights under the Convention concurrently. In its instrument of ratification, acceptance, approval or accession, a regional economic integration organization must declare the extent of its competence in respect of the matters governed by the Convention and must inform the depositary of any relevant modification in the extent of its competence (Article 25 of the Convention). 
On 14 October 2004, the Council of the European Union adopted the Decision concerning the conclusion, on behalf of the European Community, of the Convention. ${ }^{21}$ Afterwards, the European Community deposited the Declaration approving the Convention in accordance with Article 25.3 of the Convention, ${ }^{22}$ thereby affirming its responsibility for the performance of those obligations resulting from the Convention which are covered by the Community law in force. The Convention entered into force for the European Community on 14 February 2005.

\section{FinANCIAL AsPects}

The Draft Text does not contain any reference to the financial aspects of the procedures set up therein and does not clarify who will be entrusted with those functions; however, it could be argued that the GEF, which, according to Article 14 of the Convention, shall be - on an interim basis - the principal entity entrusted with the operations of financial support until the COP decides which institutional structure will be designated thereto, will play a fundamental role, since it may provide financial assistance to developing country Parties and Parties with economies in transition. That is why Draft para. 30(c) provides that, in carrying out its function, the Committee may maintain an exchange of information with the GEF.

As a final version of a decision pursuant to Article 17 of the Convention has not yet been either approved nor adopted, until now there can be no consideration as to the costs of the procedure.

${ }^{21}$ Council Decision 2006/507/EC of 14 October 2004 Concerning the Conclusion, on Behalf of the European Community, of the Stockholm Convention on Persistent Organic Pollutants, OJ (2006) L 209/1.

${ }_{22}$ The Declaration in Accordance with Article 25(3) on behalf of the European Community is available at the Convention's website. 
1 


\title{
Chapter Eight
}

\section{Draft Procedures and Operational Mechanisms to Promote Compliance and to Address Issues of Non-Compliance under the 2001 International Treaty on Plant and Genetic Resources for Food and Agriculture}

\author{
Luigi Crema
}

\section{BRIEF INTRODUCTION TO THE ITPGRFA}

The International Treaty on Plant and Genetic Resources for Food and Agriculture (the Treaty or ITPGRFA) is the first legally binding instrument dedicated to the treatment of genetic resources for agriculture. ${ }^{1}$ Together with the Bonn Guidelines adopted in April 2002 under the Convention on Biological Diversity and the International Undertaking on Plant and Genetic Resources (International Undertaking) it forms the regulation framework of access to genetic resources and benefit sharing. ${ }^{2}$ The Treaty was conceived, discussed and endorsed within the Food and Agriculture Organization

\footnotetext{
${ }^{1}$ Rome, Italy, 3 November 2001, entered into force on 29 June 2004. The Treaty consists of the text and two annexes: the first annex lists the major food crops covered under the multilateral system, while annex II contains conciliation rules pursuant to Art. 22 of the Treaty. On the Treaty in general terms see H.D. Cooper, "The International Treaty on Plant Genetic Resources for Food and Agriculture", RECIEL, 11 (2002) 1-16; L.R. Helfer, "Using Intellectual Property Rights to Preserve the Global Genetic Commons: the International Treaty on Plant Genetic Resources for Food and Agriculture", in K.E. Maskus and J.H. Reichman (eds.), International Public Goods and Transfer of Technology under a Globalized Intellectual Property Regime (Cambridge-UK: Cambridge University Press, 2005) 217-224; A. Mekouar, "A Global Instrument on Agrobiodiversity: The International Treaty on Plant Genetic Resources for Food and Agriculture", FAO Legal Papers Online 24 (2002), available at <www.fao.org/Legal/prs-ol/lpo24.pdf > (visited on 18 January 2008); G. Moore and W. Tymowski, Explanatory Guide to the International Treaty on Plant Genetic Resources for Food and Agriculture (Gland/Cambridge-UK: IUCN, 2005); G. Rose, "International Law of Sustainable Agriculture in the 21st Century: the International Treaty on Plant Genetic Resources for Food and Agriculture", Georgetown Int'l Envt'l L. Rev., 15 (2003) 583-632.

${ }^{2}$ A list of treaties with full references is provided supra at XXXVII. For the Bonn Guidelines on Access to Genetic Resources and Fair and Equitable Sharing of the Benefits Arising out of their Utilization, see Decision VI/24 on Access and Benefit-Sharing as Related to Genetic Resources, Annex, A, doc. UNEP/ $\mathrm{CBD} / \mathrm{COP} / 6 / 20$ (27 May 2002), at 262. For a parallel analysis of the two instruments see A. Smagadi, "The Impact of the Convention on Biological Diversity on the Utilization of Plant Genetic Resources and Benefit Sharing", YB Eur. Envt'l L., 6 (2006) 119-178. The Treaty is closely linked to the International Undertaking (see the declarations in the FAO Resolution 3/2001 on Adoption of the International Treaty on Plant
}

T. Treves et al., eds., Non-Compliance Procedures and Mechanisms and the Effectiveness of International Environmental Agreements

(C) 2009, T.M.C. ASSER PRESS, The Hague, The Netherlands, and the Authors 
(FAO), more specifically under the auspices of the FAO Commission on Genetic Resources for Food and Agriculture (CGRFA) and it constitutes another step in the treatment of genetic resources. ${ }^{3}$

\section{$1.1 \quad$ Negotiating History}

The first official international step taken towards addressing the international plant and genetic resources issue was the adoption of FAO Resolution 6/81. This Resolution opened the debate between western and soviet countries, with strong opposition between the two. The debate evolved into the International Undertaking, a non-binding text, adopted by FAO Resolution $8 / 83 .{ }^{4}$ The solution adopted was contested by key State players, and the topic was put on hold for an extensive period of time. Ten years later the 1993 FAO Conference called for negotiations under Resolution 7/93 to revise the International Undertaking within the framework of the CGRFA. This was intended to harmonise the International Undertaking with the Convention on Biological Diversity. ${ }^{5}$ At the end of a tormented journey, including seven years of negotiations and substantial corrections, ${ }^{6}$ a broad consensus was reached on the Treaty text. ${ }^{7}$

\subsection{The Treaty}

The causes that gave rise to the adoption of this Treaty can be summarized in three principal ideas: first, the preservation of the value of diversity in the variety of food and agricultural products developed across centuries is common heritage and can be reached only through common commitments. Second, in view of the special character of these resources forming the basis of human nutrition, is the importance of

Genetic Resources for Food and Agriculture and Interim Arrangements for its Implementation, doc. CGRFA/ MIC-1/02/Inf.1 (3 November 2001), voted by the FAO at the moment of the ITPGRFA adoption).

3 The FAO Commission on Genetic Resources for Food and Agriculture, established in 1983 by Resolution 9/83. Twenty-Second Session of the FAO Conference. Establishment of a Commission on Plant Genetic Resources (23 November 1983), available at <ftp://ftp.fao.org/ag/cgrfa/Res/C9-83E.pdf > (visited 15 July 2008 ) is the first permanent intergovernmental forum devoted to this topic.

4 The International Undertaking on Plant and Genetic Resources for Food and Agriculture was adopted by Resolution 8/83 of the Twenty-Second Session of the FAO Conference (5-23 November 1983), available at $<\mathrm{ftp}$ ://ftp.fao.org/ag/cgrfa/Res/C8-83E.pdf $>$ (visited 15 July 2008). Japan, Canada, United States (but also China, Brazil and Malaysia) contested the concept that the genetic resources "should be available without restriction".

${ }_{5}^{5}$ On the special relationship between the two Conventions see K. Raustiala and D.G. Victor, "The Regime Complex for Plant Genetic Resources”, International Organization, 58 (2004) 277-310, and Smagadi, supra n. 2.

6 After the International Undertaking and its three subsequent interpretative Resolutions, and Resolution 7/93. Twenty-Seventh Session of the FAO Conference. Revision of the International Undertaking on Plant Genetic Resources, (22 November 1993), available at <ftp://ftp.fao.org/ag/cgrfa/Res/C7-83E.pdf $>$ (visited 15 July 2008), other important steps towards the adoption of the Treaty are the fifth session of the CGRFA, in 1993, and the FAO Leipzig International Technical Conference on Plant Genetic Resources in 1996. On the history of the formation of the Treaty, see Cooper, supra $\mathrm{n} .1$.

7 As of 25 February 2007, 102 States have ratified the Treaty, as has an international organization, the European Community. According to Art. 29.2 the European Community shall not be counted as additional to those ratifications deposited by its Member States. 
establishing facilitated access to their use, by means of a global system through which they are collected, explored, commonly developed and shared. Third, the exchange of the resources on the basis of mutually agreed terms, and a fair use of the incomes arising out of the commercial exploitation of those resources to finance the Treaty's implementation through a specific trust fund. ${ }^{8}$

The institutional structure of the Treaty is composed of two main bodies: the Governing Body and the Secretariat. The Governing Body is the political organ where all Parties to the Treaty are represented; it performs such functions as may be necessary for the fulfilment of the objectives of the Treaty. ${ }^{9}$ The Secretariat is a permanent organ with an administrative and impartial nature, managing information on the Treaty and its implementation. It assists the Governing Body in carrying out its functions, including the activities of any subsidiary bodies (such as the Compliance Committee); it reports on its activities to the Governing Body, and it communicates the decisions of the Governing Body and information received from Contracting Parties to all the Contracting Parties and to the Director-General of the FAO.

In order to achieve these three broad aims, the Treaty establishes rights and duties for the sustainable use of plant and genetic resources, and for their conservation, exploration and collection, and it sets up a Multilateral System of Access and Benefitsharing (Multilateral System). The Multilateral System's functioning is described in Part IV ${ }^{10}$ which is the core of the Treaty; Part IV establishes rules for collaboration, exchanges (of seeds and of information) between plant and genetic resources grown in their proper ecosystem and those collected in seed banks or, in the wording of the Treaty, in situ and ex situ. ${ }^{11}$

The general provisions of the Treaty cover all plant and genetic resources for food and agriculture (Article 2). The genera and species covered by the Multilateral System are those listed in Annex 1 to the Treaty: they consist of 64 of the most widespread and important plant varieties, such as rice, maize, wheat, oats, potatoes, legumes and grass forages. ${ }^{12}$ During the Governing Body's first meeting held in Madrid, the Standard Material Transfer Agreement was adopted by Resolution $2 / 2006$. This establishes a standard agreement outlining the rights and duties of private or institutional providers and recipients of seeds. ${ }^{13}$ The Financial Rules were also

\footnotetext{
${ }^{8}$ Its institution was highly controversial, especially because of the first difficult experiences of benefit sharing systems established under the International Undertaking, which at Art. 1 uses the contested terms freely available. Now this institution is envisaged in part IV of the Treaty, establishing a trust for the funding and the management of the Multilateral System, see ITPGRFA, Arts. 13.1, 13.2(d)(ii) and 19.3(f).

9 See ITPGRFA, Art. 19.

${ }^{10}$ This is an important part of the Treaty (see Arts. 4, 11, 12.4 and 12.5). It establishes a Multilateral System to share the most important crops and species (listed in the first Annex of the Treaty) and share the benefits deriving from their utilization and it describes its functioning.

${ }^{11}$ See Arts. 14-17. Quoting Art. 2 of the Treaty, “'in situ conservation' means the conservation of ecosystems $[\ldots]$ in the surroundings where they have developed their distinctive properties. 'Ex situ conservation' means the conservation of plant genetic resources for food and agriculture outside their natural habitat." The definitions echo the language used in the Convention on Biological Diversity, Art. 2.

12 See Art. 11 and Annex I of the Treaty.

13 The model agreement was approved in the second Resolution adopted during the first Meeting of the Governing Body, see Appendix M. Relationship Agreement between the Global Crop Diversity Trust and the Governing Body of the International Treaty on Plant Genetic Resources for Food and Agriculture,
} 
adopted, creating the Trust Fund to manage the incomes deriving from the commercial exploitation of seeds. ${ }^{14}$ The system does not include only State-collections: it involves also intergovernmental organizations, such as the International Agricultural Research Centres of the Consultative Group on International Agricultural Research (hereinafter IARCs) and private parties, such as farmers. ${ }^{15}$

The Treaty is closely linked with other programs, agreements or institutions related to analogous topics. In addition to the FAO and CGRFA roles previously mentioned, the Treaty is expressly related to the Global Plan of Action for the Conservation and Sustainable Use of Plant Genetic Resources for Food and Agriculture, ${ }^{16}$ and to the IARCs. The Treaty also relates to other existing plant genetic resources for food and agriculture networks, and to the Convention on Biological Diversity (see part $\mathrm{V}$ of the Treaty). ${ }^{17}$

doc. GB-1/06/Report (12-16 June 2006), Appendix, at 2, Arts. 1-3; The law applicable to the agreement are "the General Principles of Law, including the UNIDROIT Principles of International Commercial Contracts 2004, the objectives and the relevant provisions of the Treaty, and, when necessary for interpretation, the decisions of the Governing Body" (Art. 7); Art. 8 provides for a traditional dispute settlement resolution: amicable settlement, mediation and, if the dispute has not been settled by negotiation or mediation, any party may submit the dispute to arbitration under the Arbitration Rules of an international body as agreed by the parties to the dispute. Failing such agreement, the dispute shall be finally settled under the Rules of Arbitration of the International Chamber of Commerce, by one or more arbitrators appointed in accordance with the said Rules.

${ }^{14}$ Report of the First Session of the Governing Body of the International Treaty on Plant Genetic Resources for Food and Agriculture, doc. IT/GB-1/06/Report (June 2006) (Madrid Report), para. 10. The Trust Fund was envisaged by Appendix E. International Treaty on Plant Genetic Resources for Food and Agriculture. Financial Rules, ibid. The concrete modalities to contribute to the Trust are described in the Appendix G. Standard Material Transfer Agreement, Annex II, ibid.

${ }^{15}$ Regarding ex situ collections, Art. 15 expressly refers to already existing and working centres for the maintenance of plant genetic resources for agriculture such as the International Agricultural Research Centres (IARCs) of the Consultative Group on International Agricultural Research (CGIAR). The legal status of these Centres has not been precisely clarified: they are on the dividing line between non-governmental and governmental organizations: they are not international organizations in the proper sense, but they have signed agreements with FAO (see The International Network Ex Situ Germplasm Collections and the CGIAR Centres. Joint Report by FAO and the International Plant Genetic Resources Institute, on behalf of the CGIAR Centres, on the Implementation of the Agreement Signed between FAO and the CGIAR Centres on 26 October, 1994, doc. CPGR-6/95/12, add.1 (June 1995), Progress Report on the International Network of Ex Situ Collections under the Auspices of FAO, doc. CGRFA-8/99/7 (April 1999), Agreement between the Government of India, the International Plant Genetic Resources Institute (IPGRI) and the Food and Agriculture Organization of the United Nations (FAO), Placing Coconut Germplasm Collections under the Auspices of FAO, doc. CGRFA-8/99/Inf.6 (April 1999).

${ }^{16}$ The Global Plan of Action for the Conservation and Sustainable Use of Plant Genetic Resources for Food and Agriculture (17-23 June 1996), available at <http://www.fao.org/ag/AGP/AGPS/Pgrfa/Pdf/ GPAENG.PDF $>$ (visited 15 July 2008) is another instrument approved within the FAO framework, and it has been endorsed also by the COP to the Convention on Biological Diversity (and by Heads of State and Government at the World Food Summit).

${ }^{17}$ Initially it was also proposed that the Treaty might be discussed and approved as a protocol to the Convention on Biological Diversity (Decision III/11 on Conservation and Sustainable Use of Agricultural Biological Diversity, doc. UNEP/CBD/COP/3/38 (11 February 1997), Annex 2, at 72, para. 18). This special relation with the Convention on Biological Diversity is pointed out in the first article of the Treaty, which states: "1.1 The objectives of this Treaty are the conservation and sustainable use of plant genetic resources for food and agriculture and the fair and equitable sharing of the benefits arising out of their use, in harmony with the Convention on Biological Diversity, for sustainable agriculture and food security. 1.2 These 


\section{Legal Basis of the Mechanism and Negotiating History}

The Treaty reference to compliance procedures is mandatory under Article 21, which reads as follows:

"The Governing Body shall, at its first meeting, consider and approve cooperative and effective procedures and operational mechanisms to promote compliance with the provisions of this Treaty and to address issues of non-compliance. These procedures and mechanisms shall include monitoring, and offering advice or assistance, including legal advice or legal assistance, when needed, in particular to developing countries and countries with economies in transition."

Two considerations can be drawn from a brief analysis of the text: first, there is a clear reference to a time limit that the Governing Body fulfilled by approving the provisional procedure (the functioning of which is described below). ${ }^{18}$ Second, the Article is quite detailed in its content, and provides for a few principles that the Parties have to take into account when laying down the compliance procedure (see the second sentence of Article 21); for example, an explicit mention of the monitoring function of the procedure is envisaged in the Treaty text and not in a subsequent document: this is a pretty unique case compared to other Multilateral Environmental Agreements. ${ }^{19}$

Since the Treaty entered into force, and the first meeting of the Governing Body was held, the CGRFA acted as an interim committee for the implementation of the Treaty. In this capacity, the CGRFA was assigned the task of drawing up a proposal on compliance mechanisms to be discussed at the First Meeting of the Governing Body. In its meeting held in $2002^{20}$ it requested the FAO Director-General to collect countries' views on compliance. After consultations with the Governments an openended working group, which met in Rome from 14 to 17 December 2005, consolidated the Governments' submissions into a Draft Resolution (Draft Procedures Rome '05). This was presented at the first session of the Governing Body held in Madrid

objectives will be attained by closely linking this Treaty to the Food and Agriculture Organization of the United Nations and to the Convention on Biological Diversity" (emphasis added). The CBD is also mentioned by the ITPRGFA in Arts. 15.3, 19.3(1), 19.3(m) and 20.5. On the other hand, Resolution 3 of the Nairobi Conference for the Adoption of the Agreed Text of the Convention on Biological Diversity. The Interrelationship between the Convention on Biological Diversity and the Promotion of Sustainable Agriculture (22 May 1992) expressly called for attention to matters concerning plant genetic resources and the rights of farmers.

${ }^{18}$ In general on this article see M. Goote and R. Lefeber, "Compliance Building under the International Treaty on Plant Genetic Resources for Food and Agriculture", Background Study Paper 20 (UNEP), available at $<$ http://www.unep.org/DEC/docs/Compliance_Building_under_the_ITPGRFA_paper.pdf $>$ (visited 18 January 2008).

19 A similar provision could be found in the Espoo Convention, see E. Fasoli, "Procedures and Mechanisms for Review of Compliance under the 1991 Espoo Convention on Environmental Impact Assessment in a Transboundary Context and its 2003 Protocol on Strategic Environmental Assessment", infra 181-204, at 184 .

${ }^{20}$ See Report of the First Meeting of the CGRFA Acting as Interim Committee for the International Treaty on Plant Genetic Resources for Food and Agriculture, doc. CGRFA-MIC-1/02/REP (9-11 October 2002), para. 13. 
from 12 to 16 June 2006. ${ }^{21}$ The Governing Body adopted the Draft Resolution with minor amendments. The Resolution contains a provisional compliance procedure as well as an annex with a draft of more elaborate compliance procedures that were subject to further negotiations (Draft Procedures Madrid '06). ${ }^{22}$ Nevertheless, during the Madrid Meeting the Governing Body established a Compliance Committee by resolution: ${ }^{23}$ the latter will not commence its work until further decisions on the procedures and operational arrangements have been taken. ${ }^{24}$ This should take place, in accordance with the same decision, at the third session of the Governing Body, ${ }^{25}$ after discussion on outstanding issues on the basis of the Draft Procedure Madrid '06 and of comments submitted by Parties and observers. ${ }^{26}$

Pending this decision the Governing Body has decided on the rudimental procedure for addressing compliance, by virtue of which any Party may raise before the Governing Body any matter concerning its compliance, including potential non-compliance, with the Treaty, and the Governing Body

"shall consider the matter, and shall decide on an appropriate approach for addressing the matter raised by the Contracting Party, which may include, inter alia, designating a Contracting Party or Contracting Parties to meet intersessionally with the Contracting Party raising the matter, in order to offer advice or assistance, including legal advice or legal assistance, where needed." ${ }^{27}$

${ }^{21}$ See Draft Procedures and Operational Mechanisms to Promote Compliance with the International Treaty and to Address Issues of Non-Compliance, doc. IT/GB-1/06/7 (12-16 June 2006).

${ }_{22}$ See Draft Procedures and Operational Mechanisms to Promote Compliance and to Address Issues of Non-Compliance, Annex I (Draft Procedures Madrid '06), doc. GB-1/06/Report (12-16 June 2006).

${ }_{23}$ See Resolution 3/2006 on Compliance, doc. GB-1/06/Report (12-16 June 2006).

24 Ibid., para. 1.

${ }_{25}$ See Resolution 1/2007 on Compliance, doc. IT/GB-2/07/Report, (29 October-2 November 2007), at 11, para. 69, and infra n. 27.

${ }^{26}$ See Resolution 3/2006 on Compliance, doc. GB-1/06/Report (12-16 June 2006) para. 2; 20 Governments deposed their comments on compliance for the first consultation round on that topic (see website $<$ http://www.fao.org/ag/cgrfa/compliance.htm $>$ ). Before the Madrid meeting another consultation round collected 17 comments, most of them vague. The EC affirmed generic support for the Treaty. The Japanese Government proposed more specific and critical observations (available at $<\mathrm{ftp}$ //ftp.fao.org/ag/cgrfa/ comp\&fs2/JapanC\&FS.pdf>, visited 18 January 2008). It affirms that robust institutions such as a "standing infraction committee" may be premature, and so it supports, as does the United States which is expressly referred to a practical and proportionate approach to the Treaty's progressive development (see paras. 1 and 2). Japan is also of the view that, as a matter of procedure, items I (Objectives), II (Principles), III (Institutional Mechanisms), IV (Functions of the Committee), and VIII (Review of the procedure and Mechanisms) need to be considered as priorities and consensus needs to be explored on these issues before we go on to other items (see para. 3). Japan also observes "that the sovereignty of Member nations should not be excessively undermined under such internal mechanism" and "that the mechanism of compliance should not be unnecessarily coercive, but be a collective encouraging approach for a series of autonomous actions by Member nations." In addition it specifies that if a "compliance committee" is to be established, such an institution should be composed of national representatives of member nations, not of individual specialists in their personal capacity or other non-governmental entities, but that "technical contribution by individual specialists or organizations will be welcomed when and where appropriate but it is supplementary and could be done through the Secretariat as a resource person/entity." See also infra n. 36.

27 See Resolution 3/2006 on Compliance, doc. GB-1/06/Report (12-16 June 2006). 


\section{The Text Establishing the Mechanism}

As already mentioned above, the Governing Body has not yet approved a definitive procedure to promote compliance, which should be considered and approved at the Third Meeting. ${ }^{28} \mathrm{At}$ the moment the only procedure approved is the provisional light mechanism envisaged by the Madrid Resolution 3/2006.

\section{The Principles Governing the Mechanism and the Procedure}

The objective of the compliance procedures and mechanisms is to promote compliance with the provisions of this Treaty, including monitoring and offering advice or assistance. ${ }^{29}$ Section II of the Draft Procedures Madrid '06 requires that the mechanism be "simple, facilitative, non-adversarial, non-judicial and cooperative in nature" and that its operation "shall be guided by the principles of transparency, fairness, expeditiousness, predictability". ${ }^{30}$ Confidentiality is another procedural principle that is mentioned in brackets, although it is not present in this list, in other Sections of the Draft Procedures Madrid '06, namely Section III.7 (institutional aspect), Section V.6 (procedure functioning), and Section VI.4 (information collection). ${ }^{31}$

Most of the Articles of the Treaty between and including Article 21 and Section I of Draft Procedures Madrid '06 single out developing countries and countries with economies in transition as privileged targets for advice and assistance. However, the inclusion of principles and specific rules on differential treatment has not been generally accepted and the relevant provisions remain bracketed for the time being. ${ }^{32}$

\section{InSTITUtional ASPECTS}

The bodies entrusted with functions in the compliance procedures are the Compliance Committee, the Secretariat and the Governing Body of the Treaty.

\subsection{The Compliance Committee}

Article 21, in envisaging "cooperative and effective procedures and operational mechanisms to promote compliance", does not expressly mention a compliance committee.

\footnotetext{
${ }^{28}$ During the second meeting, held in Rome, the Governing Body approved a Resolution that postpones the discussion and the approval of the compliance procedures to the third meeting, on the basis of the same proposal drafted in Madrid: see Resolution 1/2007 on Compliance, doc. IT/GB-2/07/Report (29 October2 November 2007), at 11, para. 69, and Draft Procedures and Operational Mechanisms to Promote Compliance and to Address Issues of Non-Compliance, doc. IT/GB-2/07/14 (29 October-2 November 2007).

${ }^{29}$ See Art. 21 of the Treaty and Art. II of the Draft Procedures Madrid ' 06.

${ }^{30}$ This is the part which is not in brackets in the proposal.

${ }^{31}$ See Draft Procedures Madrid ' 06.

32 Section II.3: "[The operation of the compliance procedures and mechanisms shall to take into account and adequate balance between developed and developing countries]." See also Section VII.2.
} 
During the negotiations different views were expressed on the institutional aspects of the mechanisms, ranging from the referral of compliance issues directly to the CGRFA $^{33}$ or to ad hoc Committees, ${ }^{34}$ or to the establishment of a permanent compliance committee. ${ }^{35}$ As already recalled, in accordance with Article 19.3, which confers broad powers on the Governing Body in order to implement the treaty - including the establishment of subsidiary bodies ${ }^{36}$ - the Governing Body, at its first meeting in Madrid, established a "frozen" Committee through Resolution 3/2006. ${ }^{37}$

Consensus was not reached on the exact number of the members of the Committee and on their status: the number might consist of 1 or 2 members from each of the 5 regional groups of the $\mathrm{UN}$, or of the 7 of the FAO (the solutions proposed provide for 7,10 or 14 members). ${ }^{38}$ As far as their status is concerned, the Japanese Government proposed that members act as State representatives, but in the Draft Procedures Madrid '06 there are now two alternative versions: one says that the members shall serve in their individual capacity; the other says that they shall act objectively and in the best interests of the Treaty. ${ }^{39}$ Pursuant to Draft Procedures Madrid '06, Section III, the Committee's members are appointed by the Governing Body for a four-year term (renewable once) from among candidates having recognized competence in the field of genetic resources or other relevant fields for the Treaty, including legal or technical expertise, proposed by Parties. ${ }^{40}$ The Committee elects its Chair and Vice$\mathrm{Chair}^{41}$ and shall develop and submit any further rules of procedure to the Governing Body for its consideration and approval, bearing in mind Rule 1.1 of the Rules of

33 See Compilation and Analysis of Governments' Views on Compliance with the International Treaty on Plant Genetic Resources for Food and Agriculture, doc. CGRFA/MIC-2/04/3 (15-19 November 2004), UAE Government Observations, at 25.

${ }^{34}$ See Compilation and Analysis of Governments' Views on Compliance with the International Treaty on Plant Genetic Resources for Food and Agriculture, doc. CGRFA/MIC-2/04/3 (15-19 November 2004), USA Government Observations, at 26. See also Japanese Government, supra n. 26.

35 Compilation and Analysis of Governments' Views on Compliance with the International Treaty on Plant Genetic Resources for Food and Agriculture, doc. CGRFA/MIC-2/04/3 (15-19 November 2004), EC, Kenya and Switzerland suggests: EC at 18: "The EU favours a small (e.g. about 7 members) Committee composed of technical and legal experts who serve in their personal capacity." On the same view, see Kenya (at 21), and Switzerland (at 27).

${ }^{36}$ Art. 19.3: "The functions of the Governing Body shall be to promote the full implementation of this Treaty, keeping in view its objectives, and, in particular, to: (a) provide policy direction and guidance to monitor, and adopt such recommendations as necessary for the implementation of this Treaty and, in particular, for the operation of the Multilateral System; (e) consider and establish subject to the availability of necessary funds such subsidiary bodies as may be necessary, and their respective mandates and composition."

${ }_{37}$ See Resolution 3/2006 on Compliance, doc. GB-1/06/Report (12-16 June 2006).

${ }_{38}$ It could be relevant to note that in other resolutions held in Madrid a regional subdivision into 7 parts has been chosen: see, inter alia, Resolution 1/2006 on The Funding Strategy, doc. GB-1/06/Report (12-16 June 2006), point 15; see also the same Draft Procedures Madrid '06, at Section III.4, probably not modified in view of the amendment of Art. III.2.

39 For observations by Japan see supra n. 26. The two alternative versions are drafted in the Draft Procedures Madrid '06, at Section III.3.

40 Parties, not States: the European Community is also included.

${ }^{41}$ Draft Procedures Madrid '06, Section III.8. 
Procedure of the Governing Body. ${ }^{42}$ The Parties did not reach consensus on the frequency of the Committee meetings. ${ }^{43}$

\subsection{The Role of the Governing Body}

Apart from its interim functions as a full compliance body, pursuant to Draft Procedures Madrid '06 the Governing Body is responsible for guiding and supervising the activities of the Compliance Committee..$^{44}$ Moreover it receives recommendations from the Committee on the adoption of some of the possible measures to address compliance, and decides thereupon. ${ }^{45}$ It may also seek reports from the Parties regarding compliance with the Treaty. ${ }^{46}$

Finally, the Governing Body shall review the effectiveness of the procedure within an unspecified number of years after its adoption, and subsequently on a regular basis, and take appropriate action. ${ }^{47}$

\subsection{The Secretariat}

In the Draft Compliance Procedures Madrid '06 the Secretariat acts as a liaison for the transmission of submissions relating to compliance ${ }^{48}$ and of reports on the measures taken to implement the Treaty. ${ }^{49}$ Even if this has not been agreed upon, the Secretariat has an important role in the management of the initial stage of the compliance procedure.

\subsection{Civil Society and Other Organizations}

It should be stressed that in order to comply with its aims the Treaty established a special relationship between the institution governing the Treaty and other supporting components, such as inter-governmental organizations, non-governmental

42 Appendix D. International Treaty on Plant Genetic Resources for Food and Agriculture. Rules of Procedure of the Governing Body, doc. GB-1/06/Report (12-16 June 2006), Appendix, Rule I: "These rules of procedure shall apply to all sessions of the Governing Body and the activities of its Secretary. They shall also apply, mutatis mutandis, to subsidiary bodies of the Governing Body unless the Governing Body should decide otherwise, in accordance with Rule 9.2."

${ }^{43}$ Draft Procedures Madrid '06, Section III.5: “[The Committee shall meet [twice]/[once] a year, unless it decides otherwise.]/[The Committee shall hold meetings as necessary and, wherever possible, in conjunction with meetings of the Governing Body or other Treaty bodies.]/[The Committee shall hold meetings as necessary, taking [also] into account meetings of the Governing Body]."

${ }^{44}$ Draft Procedures Madrid '06, Section IV.1.

45 See Draft Procedures Madrid '06, Sections IV and VII, voted between brackets. Section IV: "The Committee shall [...] take [measures][actions], as defined [in Section VII] below[, [or make recommendations,] as appropriate, to the Governing Body]." Section VII: "The Committee may [...] make recommendations to the Governing Body to the Treaty regarding the provision of financial and technical assistance, technology transfer, training and other capacity building measures."

46 See Draft Procedures Madrid '06, Section VIII, not between brackets.

47 See Draft Procedures Madrid '06, Section VIII, between brackets.

48 Draft Procedures Madrid '06, Section V.1.

${ }^{49}$ Draft Procedures Madrid '06, Section IX.1. 
organizations or private individuals and corporations (see Treaty text, Part V): Article 16 refers generally to 'networks' cooperating for plant genetic resources, including the private sector. ${ }^{50}$ Moreover, Article 19.5 of the Treaty confers to any other body or agency the right to participate as observers at the Governing Body sessions. ${ }^{51}$

As far as the current compliance procedures are concerned, the only reference to non-State actors in the Draft Procedures Madrid '06 envisages a role in the providing of information. ${ }^{52}$ This role is applicable to either civil society in general or the IARCs. ${ }^{53}$ The matter does not concern only issues of transparency. Civil society plays an active role in the Multilateral System's functioning: ${ }^{54}$ some scholars have already stressed the crucial task of the IARCs, but it could also be relevant to note that the Governing Body, at its third meeting, will deal with the enlargement of the Multilateral System to natural and legal persons, such as farmers.

\section{Functions of The Committee}

The provisional compliance mechanism gives the Governing Body the power to decide upon any matter raised by a Contracting Party concerning its own compliance with the Treaty, including potential non-compliance. Action taken by the Governing Body to address the matter raised may include the designation of a Contracting Party or Contracting Parties to meet intersessionally with the Contracting Party raising the

${ }^{50}$ According to Art. 16: "1. Existing cooperation in international plant genetic resources for food and agriculture networks will be encouraged or developed on the basis of existing arrangements and consistent with the terms of this Treaty, so as to achieve as complete coverage as possible of plant genetic resources for food and agriculture. 2 Contracting Parties will encourage, as appropriate, all relevant institutions, including governmental, private, non-governmental, research, breeding and other institutions, to participate in the international networks."

${ }^{51}$ See Art. 19.5: "The United Nations, its specialized agencies and the International Atomic Energy Agency, as well as any State not a Contracting Party to this Treaty, may be represented as observers at sessions of the Governing Body. Any other body or agency, whether governmental or non-governmental, qualified in fields relating to conservation and sustainable use of plant genetic resources for food and agriculture, which has informed the Secretary of its wish to be represented as an observer at a session of the Governing Body, may be admitted unless at least one third of the Contracting Parties present object. The admission and participation of observers shall be subject to the Rules of Procedure adopted by the Governing Body."

52 See Draft Procedures Madrid '06, Section IV.2: "The Committee may seek or receive and consider relevant information, including from: a) [Non-governmental organizations, the private sector and other civil society organizations and relevant inter-governmental organizations, [including the International Agricultural Research Centres]]."

${ }_{53}$ The European Community suggested that IARCs should have an active role in the Committee, a power to trigger the mechanism and tasks of monitoring (See Second Meeting of the Commission on Genetic Resources for Food and Agriculture Acting as the Interim Committee for the International Treaty on Plant Genetic Resources for Food and Agriculture - Summary and Analysis, doc. CGRFA/MIC-2/04/3 (22 November 2004), at 19-20).

54 The Treaty is full of links to non-State actors: see the Farmer's Rights in the Preamble; Art. 9 (especially 9.2(c); Art. 11.5; Arts. 13.2(d)(i) and 13.3; Art. 15 (expressly dedicated to the IARCS); Art. 16.2; Art. 19.5 "Any other body or agency, whether governmental or non-governmental, qualified in fields relating to conservation and sustainable use of plant genetic resources for food and agriculture, which has informed the Secretary of its wish to be represented as an observer at a session of the Governing Body, may be admitted unless at least one third of the Contracting Parties present object." 
matter, in order to offer advice or assistance, including legal advice or legal assistance, where needed. ${ }^{55}$

The very function of the Committee is still the object of disagreement among Parties. This is reflected in the options currently included in Draft Section IV.1. Indeed, apart from agreement about the Committee providing the Party with advice and assistance and monitoring implementation of the Treaty in very generic terms,${ }^{56}$ both the possibility of considering individual cases of non-compliance and the task of considering general compliance issues are still bracketed. ${ }^{57}$

\section{TRIGgER MechanisM}

As mentioned above, both in the provisional procedure and in the Draft Procedures Madrid '06 Parties were able to agree that only matters of compliance can be raised by the Party concerned (self-trigger) ${ }^{58}$ Other solutions, namely Party-to-Party trigger, and Governing Body trigger, are enclosed in brackets.

Neither initiation proprio motu by Secretariat nor trigger by non-State actors are included: an EC proposal to recognise a triggering power for the IARCs has been rejected..$^{59}$

\section{The Procedure before the Complance Committee and Procedural SAFEGUARDS}

The provisional Procedure, which takes place entirely before the Governing Body, is governed by the latter's Rules of Procedure.

As far as draft Procedures are concerned, some rules of procedure are provided in Draft Procedure Madrid '06. Some others are to be drawn, mutatis mutandis, from the rules of procedures of the Governing Body. ${ }^{60}$

\footnotetext{
${ }_{55}$ Resolution 3/2006 on Compliance, doc. GB-1/06/Report (12-16 June 2006).

${ }^{56}$ A detailed procedure for implementation monitoring is set out in Section XI of the Draft Procedure, but is still bracketed.

${ }^{57}$ See Draft Procedures Madrid '06, Section IV.1.

${ }_{58}$ Resolution 3/2006. Compliance, doc. GB-1/06/Report (12-16 June 2006), para. 4: “[A] Contracting Party may, in advance of a session of the Governing Body, raise any matter concerning its compliance with the Treaty, including potential noncompliance with the Treaty." Draft Procedures Madrid '06, Section V: "The Committee shall receive, through the Secretariat, any submissions relating to compliance from any Contracting Party with respect to itself' (emphasis added in both quotations).

${ }^{59}$ Compilation and Analysis of Governments' Views on Compliance with the International Treaty on Plant Genetic Resources for Food and Agriculture, doc. CGRFA/MIC-2/04/3 (15-19 November 2004), at $19-20$.

${ }^{60}$ See Appendix D. International Treaty on Plant Genetic Resources for Food and Agriculture. Rules of Procedure of the Governing Body, doc. GB-1/06/Report (12-16 June 2006), Appendix, Rule I: "These rules of procedure shall apply to all sessions of the Governing Body and the activities of its Secretary. They shall also apply, mutatis mutandis, to subsidiary bodies of the Governing Body unless the Governing Body should decide otherwise, in accordance with Rule 9.2"; Rule VI: "Decision-making: All decisions of the Governing
} 
Section V of the Draft Procedures Madrid '06 is a controversial provision still bracketed and drafted in two opposite solutions. According to the first, the procedure should take place in two discrete phases: the first is conducted under the guidance of the Secretariat and consists of a short dialogue with the Party concerned, and of an inquiry. If the dialogue process should fail, the Secretariat publishes the submission encouraging "any information from other sources"; other States, IARCs and also private parties, such as farmers, could be included in this broad and general prescription. This phase cannot last more than 60 days, and it is not specified whether it could also be conducted orally. The second solution consists of a period, not exceeding 90 days, during which the Committee analyses and produces its responses. During this second phase the Party concerned can attend the deliberations of the Committee but cannot participate in the elaboration and adoption of the final recommendation.

According to the second solution, the first phase does not include a process of dialogue, and the inquiry involves just the Party concerned and the Secretariat. The Committee has the power to reject a de minimis or ill-founded submission and the Party concerned may present responses or comments at every step of the proceedings or participate in the deliberations of the Committee, but it shall not participate in the elaboration and adoption of the final recommendation.

In both alternative hypotheses the Party which has received a submission regarding its compliance shall respond within three months, and in any event not later than six months.

The last part of the Section (common to both solutions) is still bracketed and it provides that confidentiality will be an essential requirement of the process. ${ }^{61}$

\section{SOURCES OF INFORMATION}

The Draft Procedures Madrid '06 provides for a closed list of subjects enabled to give information to the Committee: at the moment it is envisaged that the Committee shall consider information obtained by the Party concerned. It may also seek or receive and consider relevant information from the Secretariat. The application of the principle of confidentiality has prevented the Governing Body from reaching an agreement on the role of the other Parties to the Treaty, NGOs, and other institutions involved, such as farmers and IARCs, and on the role of expert advice. ${ }^{62}$ Pursuant to Section $\mathrm{V}$, first option, the Secretariat publishes the submission made by the State concerned and encourages "the submission of any information from other sources". In this very broad and general prescription other States, IARCs and also private parties, such as farmers, could be included. In the second option there is no mention of private parties or of the other parties.

Body shall be taken by consensus unless by consensus another method of arriving at a decision on certain measures is reached."

${ }^{61}$ See Draft Procedures Madrid '06, Section V.

${ }^{62}$ See Draft Procedures Madrid '06; see also the part above dedicated to Civil Society. 


\section{DeCISION-MAKING}

Pursuant to the Rules of Procedures of the Governing Body, to apply, mutatis mutandis, to its subsidiary bodies, all decisions of the Committee will be taken by consensus, unless another rule is established by consensus on specific decisions. ${ }^{63}$

\section{Outcomes}

The Committee may take only advisory measures: it (provides/offers) advice or assistance to the Party concerned; requests or assists, as appropriate, the Party concerned to develop a compliance action plan regarding the achievement of compliance with the Treaty; invites the Party concerned to submit progress reports to the Committee on the efforts it is making (Section VII.1). ${ }^{64}$

The adoption of other measures, which is still a disputed matter, falls within the competence of the Governing Body upon recommendations by the Committee. These may include financial or legal assistance, issuing a caution and publishing cases (Section VII.2). Although the Draft Procedure Madrid '06 does not explicitly mention the possibility of suspending rights and privileges under the Treaty, one may wonder whether this measure could be taken in the framework of the residual general power of the Governing Body to "take any other actions it deems appropriate in accordance with the Treaty and for the fulfilment of the Treaty's objectives."

\section{Coordination with Dispute Settlement Procedures and Other Non-Compliance Procedures}

The Draft provides that the Compliance Procedures are separate from, and without prejudice to, the dispute settlement procedures and mechanisms established by Article 22. This Article provides for an obligation to resort to diplomatic means of settlement, with the option of accepting the compulsory jurisdiction of either the ICJ or an ad hoc

\footnotetext{
${ }^{63}$ Pursuant to Section III.7 of the Draft Procedures Madrid '06, and Rule I.1 and Rule VI of the Rules of Procedures of the Governing Body.

${ }^{64}$ The full text of provisional Section VII.1 reads as follows: "1. [The Committee may take one or more of the following measures] with a view to promoting compliance and addressing [cases][a case] of noncompliance [which is raised in accordance with Article V.1 and taking into account such factors as the cause, type, degree, and frequency of noncompliance, the Committee may [only]]: a) [Provide]/[Offer] advice or [and or facilitate] assistance [,including legal advice or legal assistance] [or non-binding recommendations] to the Party concerned, as appropriate; b) [Make recommendations to the Governing Body to the Treaty regarding the provision of financial and technical assistance, technology transfer, training and other capacity building measures]; c) Request or assist, as appropriate, the Party concerned to develop a compliance action plan regarding the achievement of compliance with the Treaty within a timeframe to be agreed upon between the Committee and the Party concerned, [taking into account its existing capacity to comply]; and d) Invite the Party concerned to submit progress reports to the Committee on the efforts it is making to comply with its provisions under the Treaty."
} 
arbitral tribunal. When the Parties involved have not accepted the same mechanism, the dispute is deferred to a conciliation commission. ${ }^{65}$

Rules referring to potential overlapping with other formal dispute settlement mechanisms or compliance procedures are not envisaged.

\section{PARTICIPATION OF THE EUROPEAN COMMUnity}

The ITPGRFA is opened to signature, ratification, acceptance, approval and accession only to all members of FAO and any States that are not members of FAO but are members of the United Nations (Article 25). The European Community is the only organization member of the $\mathrm{FAO} ;{ }^{66}$ in this capacity, on the basis of Articles 37 (Agriculture) and 175 (Environmental Policy) of the Treaty establishing the European Community, it signed the ITPGRFA on 6 June 2002, and ratified it on 31 March $2004 .{ }^{67}$

The distribution of competences between international organizations and their Member States are governed by Article 29 of the ITPGRFA, by Article II. 5 of the FAO Constitution, and by Rule XLI of the FAO General Rules. According to Article 29.1 of the ITPGRFA, ${ }^{68}$ when a member organization of FAO deposits an instrument of ratification, acceptance, approval or accession for the ITPGRFA, the organization shall notify any change regarding its distribution of competence to its declaration of competence submitted under the FAO Constitution as may be necessary in the light of its acceptance of the ITPGRFA. ${ }^{69}$ The European Community declared that its

${ }^{65}$ See Art. 22 and Annex II to the Treaty.

${ }^{66}$ The FAO modified its Constitution in order to allow the European Community's accession. By a decision of 26 November 1991, taken under Art. II(3) and (5) of its renewed Constitution, relating to membership by a regional economic integration organization, the FAO admitted the European Economic Community as a member, alongside its Member States. See R. Frid, "The European Economic Community: A Member of a Specialized Agency of the United Nations", Eur. J. Int'l L., 4 (1993) 239-255.

${ }^{67}$ Council Decision 2004/869/EC of 24 February 2004 Concerning the Conclusion, on behalf of the European Community, of the International Treaty on Plant Genetic Resources for Food and Agriculture, OJ (2004) L 378/1. Other references are available at <http://eur-lex.europa.eu/Notice.do?val=432154:cs\&lang $=$ en $\&$ pos $=1 \&$ phwords $=\&$ checktexte $=$ checkbox $>$. See also, Proposal for a Council Decision, COM (2003) 602-final (14 October 2003), available at <http://europa.eu/eur-lex/en/com/pdf/2003/com2003 0602en01. pdf $>$ (visited 18 January 2008). In general, on this topic see A. Leidwein, "Protection of Traditional Knowledge Associated with Biological and Genetic Resources. General Legal Issues and Measures Already Taken by the European Union and its Member States in the Field of Agriculture and Food Production", J. W. Intell'l Prop., 9 (2006) 251-275.

${ }_{68}$ This article reproduces other previous provisions adopted under the FAO, such as Art. XVII of the FAO International Treaty for Plant Protection. See also Council Decision Approving the Accession of the European Community to the International Plant Protection Convention, doc. 2004/597/EC (19 July 2004), as revised and approved by Resolution 12/97. Amendments to the International Plant Protection Convention, doc. C 1997/REP (7-18 November 1997).

${ }^{69}$ See Arts. II.5, II.6 e II.7 of the FAO Constitution: "5) Each regional organization applying for membership in the Organization shall, at the time of such application, submit a declaration of competence specifying the matters in respect of which competence has been transferred to it by its Member States. 6) Member States of a Member Organization shall be presumed to retain competence over all matters in respect of which transfers of competence have not been specifically declared or notified to the Organization. 7) Any change regarding the distribution of competence between the Member Organization and its Member States shall be 
declaration of competence submitted to FAO on 4 October 1994 under Article II.5 of the FAO Constitution still applies in the light of its acceptance of the International Treaty on Plant Genetic Resources for Food and Agriculture. ${ }^{70}$

Rule XLI of the FAO General Rules provides that before any meeting of the FAO the member organization or its Member States shall indicate which, between the member organization and its Member States, has competence with regard to any specific question to be considered in the meeting and which, between the member organization and its Member States, shall exercise the right to vote with regard to each particular agenda item. ${ }^{71}$ For example, during the recent meeting of the Governing Body held in Rome in 2007, the European Community and its Member States declared their competences and attributed their voting rights in an official statement, as some competences are shared between the EC and its Member States; for other areas covered by the Treaty, Member States have exclusive competence. ${ }^{72}$

With Regulation 870/2004 the European Council established a Community programme on the conservation, collection and utilization of genetic resources in agriculture. The Regulation defines the procedure the Community can follow to conclude grant agreements to support financially the actions referred to in Articles 5, 6 and 7 of the Regulation (targeted, concerted and accompanying actions)..$^{73}$ The implementation of the Regulation gave priority to the use of genetic resources for: diversification of production in agriculture; improved product quality; sustainable management and use of natural and agricultural resources; improved quality of the environment and the countryside; and identification of products for new uses and markets.

notified by the Member Organization or its Member States to the Director-General, who shall circulate such information to the other Member Nations of the Organization."

${ }^{70}$ Council Decision of 24 February 2004 Concerning the Conclusion, on behalf of the European Community, of the International Treaty on Plant Genetic Resources for Food and Agriculture, doc. 2004/869/EC (24 February 2004), Annex C.

${ }^{71}$ In 1999, for example, during the hundred-sixteenth session of the FAO Council, the European Community and its Member States submitted a common statement on their competences and voting rights, available at $<\mathrm{http}$ //www.fao.org/docrep/meeting/x2134e.htm $>$ (visited 18 January 2008). Analogous declarations are attached to the meeting reports of the FAO Committees, such as the Committee on Agriculture, or the Committee on World Food Security.

72 Statement of Competence and Voting Rights, Submitted by the European Community (EC) and its Member States, doc. IT/GB-2/07/Inf.10 (29 October-2 November 2007). Under this document, voting rights were all attributed to Member States; competences were declared mixed, except for the elections of Chairpersons and vice Chairpersons, for the Adoption of the agenda and timetable, for the establishment of the Budget Committee, for the Date and place of the next meeting of the Governing Body, that are exclusive to Member States. These allocations are consolidated, and a similar subdivision of competences is present in the Statements of competence submitted in 2004 for the Meeting held in Rome, and in 2006 for the first Meeting of the Governing Body.

73 See Council Regulation (EC) 870/2004 of 24 April 2004 establishing a Community programme on the conservation, characterisation, collection and utilisation of genetic resources in agriculture and repealing Regulation (EC) No. 1467/94, OJ (2004), L 162/18, as rectified on 30 April 2004, OJ (2004) L 111/22 (the subsequent publishing of the identical Regulation (EC) 1590/2004 of 26 April 2004, OJ (2004) L 304/1, was due to a mistake, see Corrigendum to Council Regulation (EC) 1590/2004 of 26 April 2004 Establishing a Community Programme on the Conservation, Characterisation, Collection and Utilisation of Genetic Resources in Agriculture and Repealing Regulation (EC) No 1467/94 (OJ L 304/1), OJ (2004) L 117/22). For a comment, see A. Leidwein, supra n. 67, passim. 


\section{FinanCIAL AsPeCtS}

As a subsidiary body of the Governing Body, the Committee relies on the former's budget and funding strategy. During the Meeting held in Rome in November 2007 the Governing Body approved a budget programme structured into four modules, each one consisting of clearly defined and cost-defined work programme elements: implementation of the Multilateral System; funding strategy of the Treaty; implementation of the ITPGRFA; and the fourth, Module D, on Secretariat services, meetings of the Governing Body and any subsidiary bodies. Thus the Governing Body and the Compliance Committee can rely on an autonomously regulated budget. ${ }^{74}$ This fraction of the budget consists entirely of the Core Administrative Budget that includes those ongoing activities that form part of the core operational functions of the Treaty System, which will exist beyond the current start-up phase of the Treaty, and without which the Treaty cannot properly function. Pending the adoption of the Financial Rules, ${ }^{75}$ the resources are provided by the FAO and for the most part by the voluntary contributions of the Parties. ${ }^{76}$

\section{Bibliography}

M. Goote and R. Lefeber, "Compliance Building under the International Treaty on Plant Genetic Resources for Food and Agriculture", Background Study Paper 20 (UNEP), available at http://www.unep.org/DEC/docs/Compliance_Building_under_the_ITPGRFA_paper.pdf(visited 18 January 2008); E. Tsioumani, "International Treaty on Plant and Genetic Resources for Food and Agriculture: Legal Policy Questions from Adoption to Implementation", YB Int'l Envt'l L., 15 (2006) 119-144.

74 See Draft Work Programme and Budget for the 2008-09 Biennium, doc. IT/GB-2/07/20, (29 October2 November 2007), at $3 \mathrm{ff}$.

75 "The Governing Body did not reach consensus on the need to finalize its Financial Rules at the current session, and decided to consider its Financial Rules at its Third Session", Second Session of the Governing Body of the International Treaty on Plant Genetic Resources for Food and Agriculture, doc. IT/GB-2/07/ Report, (29 October-2 November 2007), at 7, para. 43.

76 The Core Administrative Budget for the Treaty's Implementation in the 2008-09 Biennium amount to USD 6.594 millions: 1,607,000 provided by the FAO, and 4,987,861 to be funded, Draft Work Programme and Budget for the 2008-09 Biennium, doc. IT/GB-2/07/20 (29 October-2 November 2007), at 5-6. 
Section I

Non-Compliance Procedures and Mechanisms

in Environmental Agreements

Regional Treaties 
1 


\title{
Chapter Nine
}

\section{Procedures and Mechanisms on Compliance under the 1976/1995 Barcelona Convention on the Protection of the Mediterranean Sea and its Protocols}

\author{
Irini Papanicolopulu
}

\section{Brief Introduction to the Barcelona Convention and its Protocols}

The Convention for the Protection of the Marine Environment and the Coastal Region of the Mediterranean (Barcelona, Spain, 16 February 1976) (the Barcelona Convention or the Convention) ${ }^{1}$ was among the first treaties adopted for the protection of a regional sea.

Under the Barcelona Convention, States have the obligation "to prevent, abate, combat and to the fullest possible extent eliminate pollution of the Mediterranean Sea Area and to protect and enhance the marine environment in that Area so as to contribute towards its sustainable development" (Article 4.1). To achieve this aim, the application of some basic principles of environmental law (precaution, polluter pays, environmental impact assessment, cooperation, integrated management of coastal zones) is rendered mandatory (Article 4.3), as well as the use of the best available techniques and best environmental practices (Article 4.4).

\footnotetext{
1 The Convention, originally entitled Convention for the Protection of the Mediterranean Sea Against Pollution, in UNTS, 1102 (1978) 45-54, entered into force on 12 February 1978. Also following the 1992 Rio Conference, the Barcelona Convention was amended (and renamed) in 1995 and the amendments, adopted on 10 June 1995, entered into force on 9 July 2004. The amended Convention is binding on 18 States and 1 international organization (Albania, Algeria, Croatia, Cyprus, Egypt, European Community, France, Greece, Israel, Italy, Malta, Monaco, Montenegro, Morocco, Slovenia, Spain, Syria, Tunisia, Turkey); while three States (Bosnia Herzegovina, Lebanon, Libya) are still bound by the original agreement, having so far not ratified the amendments. The text of the amended Convention and of the Protocols, as well as of related documents, is available at the website <www.unepmap.org $>$ (visited 23 June 2008). On the Barcelona system see E. Raftopoulos, The Barcelona Convention and Protocols: The Mediterranean Action Plan Regime (London: Simmonds \& Hill Publishing, 1993); J. Juste Ruiz, "International Law Facing Mediterranean Sustainable Development: The Revision of the Barcelona Convention and Its Related Protocols", in S. Belfiore, M.G. Lucia, and E. Pesaro (eds.), Regional Seas Towards Sustainable Development (Milano: FrancoAngeli, 1996), 230-255; and T. Scovazzi, "The Updating of the Barcelona System for the Protection of the Mediterranean Against Pollution", in S. Marchisio, M. Tamburelli, and L. Pecoraro (eds.), Sustainable Development and Management of Water Resources: A Legal Framework for the Mediterranean (Roma: CNR, 1999), 48-62
}

T. Treves et al., eds., Non-Compliance Procedures and Mechanisms and the Effectiveness of International Environmental Agreements

(C) 2009, T.M.C. ASSER PRESS, The Hague, The Netherlands, and the Authors 
The Barcelona Convention is a framework agreement completed by Protocols relating to marine protected areas, ${ }^{2}$ the integrated management of the coastal zone ${ }^{3}$ and pollution from ships, ${ }^{4}$ land-based sources, ${ }^{5}$ dumping, ${ }^{6}$ the exploitation of the continental shelf ${ }^{7}$ and transboundary movements of hazardous waste. ${ }^{8}$

The institutional framework created by the Convention includes the Meeting of the Contracting Parties (MOP), the Bureau and the Secretariat.

The MOP takes place every two years to keep under review the implementation of the Convention and the Protocols (Article 18) and adopts decisions regarding the reviews of the state of marine pollution, the reports submitted by Parties, the adoption and amendment of annexes to the Convention and Protocols, and financial matters. The MOP further recommends the adoption of new protocols or amendments to the Convention and existing Protocols and may create working groups to examine any matter related to the Convention and Protocols.

Secretariat functions are carried out by the United Nations Environmental Programme (UNEP) through the Mediterranean Action Plan (MAP) Coordination Unit.

The Bureau, composed of six representatives of the Parties elected on a rotation basis, advises the Secretariat during intersessional periods.

\section{Legal Basis of the Mechanism and Negotiating History}

Under the Barcelona Convention, compliance control lies with the MOP and is conducted through the revision of periodical reports submitted by States Parties (Articles 18.2 and 27). Similar provisions are included in some of the Protocols.

2 Protocol Concerning Mediterranean Specially Protected Areas of 3 April 1982, in force since 23 March 1986. The Protocol is replaced, as between parties to both treaties, by the Protocol Concerning Specially Protected Areas and Biological Diversity in the Mediterranean of 10 June 1995, in force since 12 December 1999.

${ }_{3}$ Protocol on Integrated Coastal Zone Management in the Mediterranean, adopted on 21 January 2008, not yet in force.

4 Protocol concerning Co-operation in Combating Pollution of the Mediterranean Sea by Oil and Other Harmful Substances in Cases of Emergency of 16 February 1976, in force since 12 February 1978. The Protocol is replaced, as between parties to both treaties, by the Protocol concerning Co-operation in preventing Pollution from Ships and, in Cases of Emergency, Combating Pollution of the Mediterranean Sea of 25 January 2002, in force since 17 March 2004.

5 Protocol for the Protection of the Mediterranean Sea against Pollution from Land-Based Sources of 17 May 1980, in force since 17 June 1983. The Protocol should be replaced by the Protocol for the Protection of the Mediterranean Sea Against pollution from Land-Based Sources and Activities of 7 March 1996.

${ }^{6}$ Protocol for the Prevention of Pollution of the Mediterranean Sea by Dumping from Ships and Aircraft of 16 February 1976, in force since 12 February 1978. The Protocol should be replaced by the Protocol for the Prevention of Pollution of the Mediterranean Sea by Dumping from Ships and Aircraft or Incineration at Sea of 10 June 1995.

7 Protocol for the Protection of the Mediterranean Sea against Pollution Resulting from Exploration and Exploitation of the Continental Shelf and the Seabed and Its Subsoil of 14 October 1994, not yet in force.

${ }^{8}$ Protocol on the Prevention of Pollution of the Mediterranean Sea by Transboundary Movements of Hazardous Wastes and Their Disposal of 1 October 1996, not yet in force. 
The Barcelona Convention provided since the beginning for a reporting system, according to which Parties had to transmit to the Secretariat reports on the implementation of the Convention and Protocols. This system has been further elaborated upon during the revision of the Convention in the early nineties, by specifying in more detail the content of the reports and providing for a compliance control by the MOP on the basis of these reports. The relevant provisions are the following:

"1. The Contracting Parties shall transmit to the Organization reports on:

(a) the legal, administrative or other measures taken by them for the implementation of this Convention, the Protocols and of the recommendations adopted by their meetings;

(b) the effectiveness of the measures referred to in sub-paragraph (a) and problems encountered in the implementation of the instruments as mentioned above.

2. The reports shall be submitted in such form and at such intervals as the Meetings of Contracting Parties may determine." (Article 26).

"The meetings of the Contracting Parties shall, on the basis of periodical reports referred to in Article 26 and any other report submitted by the Contracting Parties, assess the compliance with the Convention and the Protocols as well as the measures and recommendations. They shall recommend, when appropriate, the necessary steps to bring about full compliance with the Convention and the Protocols and promote the implementation of the decisions and recommendations." (Article 27).

At the thirteenth ordinary meeting (Catania, Italy, 11-14 November 2003), the MOP decided to establish a Working Group of Legal and Technical Experts (Working Group) to "elaborate a platform to promote the implementation of and compliance with the Barcelona Convention." The results were to be examined by the following MOP. The Working Group, composed of six experts nominated by the Parties respecting geographical distribution, along with one representative from the MAP partners, met twice (Athens, Greece, $8-9$ November 2004, ${ }^{9}$ and 11-12 April 2005 ${ }^{10}$ ). At its fourteenth ordinary meeting (Portoroz, Slovenia, 8-11 November 2005), the MOP extended the mandate of the Working Group with a view to developing a full non-compliance mechanism and enlarged its membership to include all Parties to the Barcelona Convention. ${ }^{11}$ The Working Group held two more meetings (Loutraki, Greece, 5-6 December 2006, ${ }^{12}$ Istanbul, Turkey, 23-25 May 2007'13), eventually producing a draft resolution on Procedures and Mechanisms on Compliance with the Obligations under the Barcelona Convention and Its Protocols. The text was adopted by the fifteenth MOP (Almeria, Spain, 15-18 January 2008) as an annex to the decision establishing the non-compliance mechanism.

${ }^{9}$ Report of the First Meeting of the Working Group on Implementation and Compliance under the Barcelona Convention, doc. UNEP(DEC)/MED WG.260/4 (21 December 2004) (WG First Report).

${ }^{10}$ Report of the Second Meeting of the Working Group on Implementation and Compliance under the Barcelona Convention, doc. UNEP(DEC)/MED WG.272/5 (25 April 2005) (WG Second Report).

${ }^{11}$ Recommendation I.A.1.5 Compliance mechanism under the Barcelona Convention, doc. UNEP(DEPI)/ MED IG.16/13 (30 November 2005), Annex III, at 3.

${ }^{12}$ Report of the Third Meeting of the Working Group on Implementation and Compliance under the Barcelona Convention, doc. UNEP(DEPI)/MED WG.300/4 (29 December 2006) (WG Third Report).

${ }^{13}$ Report of the Fourth Meeting of the Working Group on Implementation and Compliance under the Barcelona Convention, doc. UNEP(DEPI)/MED WG. 315/4 (30 July 2007) (WG Fourth Report). 


\section{The Text Establishing the Mechanism}

Decision IG 17/2 on Procedures and Mechanisms on Compliance under the Barcelona Convention and its Protocols (2008 Decision or Decision), ${ }^{14}$ adopted by the fifteenth MOP, established the non-compliance mechanism, created the Compliance Committee (Committee) and elected its members. More detailed provisions on the functioning of the compliance mechanism are contained in the Annex to the Decision..$^{15}$ The 2008 Decision was approved by consensus; under the rules of the Barcelona Convention, no opting-out is possible.

The 2008 Decision requests the Committee to draft rules of procedure for its work, to be presented at the following MOP. These rules of procedure, once approved, will also govern the mechanism.

\section{The Principles Governing the Mechanism and the Procedure}

The 2008 Decision explicitly states that the Committee shall be guided by the principle of "due process" (para. 28).

Though not expressly stated in the Decision, the compliance mechanism was clearly intended from the beginning as "non confrontational, non judicial, transparent, cost effective and preventive in nature, simple, flexible, and oriented in the direction of helping parties to comply with and implement the provisions" of the Convention, the protocols and the MOP decisions. ${ }^{16}$ This is reflected in its institutional and procedural aspects, as well as in the language used in drafting the Decision.

Another principle that was strongly supported by many States and is reflected in the language of the Decision is that of shared and differentiated responsibilities (paras. 1, 32 and 33). ${ }^{17}$

It may be doubted whether the principle of impartiality, which is not formally stated in the Decision, is also applicable to the procedure. On one hand, the need for an impartial body was stressed during the first meeting of the Working Group ${ }^{18}$ and the Decision provides that members of the Committee shall act in their personal capacity (para. 11); on the other, there are no specific safeguards to avoid pressure from States and there are no specific incompatibilities established to bar membership to individuals closely related with a State.

${ }_{14}$ Decision IG 17/2 on Procedures and Mechanisms on Compliance under the Barcelona Convention and its Protocols, doc. UNEP(DEC)/MED IG. 17/10 (18 January 2008) (the Almeria Report), Annex V, at 21 .

15 Ibid.

${ }^{16}$ Findings and Conclusions of the First Meeting of the Working Group on Implementation and Compliance WG First Report, supra n. 9, Annex III, at 1.

17 See also WG Second Report, supra n. 10, para. 18, and WG Fourth Report, supra n. 13, para. 49. The inclusion of a "principle of proportionality", according to which measures adopted should be proportionate to the ability of a Party to meet its obligations, was rejected by the Working Group (WG Second Report, supra $\mathrm{n}$. 10, paras. 40-41).

18 See WG First Report, supra n. 9, para. 32. 


\section{INSTITUTIONAL ASPECTS}

\section{$5.1 \quad$ The Compliance Committee}

\section{a) Composition}

The Compliance Committee is composed of seven members and seven alternates, elected by the MOP from a list of candidates nominated by the Parties. Candidates must be nationals of the Parties (2008 Decision, para. 6) and must be "persons of recognized competence in the matters dealt with by the Barcelona Convention and its Protocols and in relevant scientific, technical, socio-economic, legal or other fields" (para. 8). ${ }^{19}$ Parties "may consider the nomination of candidates from civil society and academia". ${ }^{20}$ In the election of the members of the Committee, the MOP must take into consideration equitable geographical representation, ${ }^{21}$ rotation, and, to the extent possible, a balance of scientific, legal and technical expertise (para. 11). Since the Decision does not contain any specific indication, the MOP elects Members of the Committee by the ordinary majority of two-thirds of the Parties present and voting.

The term of service of members begins at the end of the ordinary meeting of the Parties in which they are nominated and lasts until the end of the second ordinary meeting of the Parties thereafter. ${ }^{22}$ In order to ensure continuity in the work of the Committee, for the first election it was decided to elect four members and four alternates for a full term, and three members and three alternates for a half term. ${ }^{23}$

The Committee elects its Chairperson and two Vice-Chairpersons (para. 10).

19 Other requisites were discussed by the Parties but were not inserted in the final text.

${ }^{20}$ This provision, which was intended as a compromise between those States which wanted to attribute a major role to members of civil society and those States which wanted to exclude civil society from the mechanism (see WG First Report, supra n. 9, paras. 22-23, and WG Fourth Report, supra n. 13, para. 18), risks however to create further doubts as to the objective character of the Compliance Committee. Since the nomination of members from civil society and academia may be "considered" (but is not even supported), it is to be expected that members of the Committee will be State officials, though acting in a personal capacity.

${ }_{21}$ According to the detailed formula of the Decision, the Committee shall be composed of "two members and two alternates to be nominated by the following southern and eastern Mediterranean countries: Algeria, Egypt, Lebanon, Libya, Morocco, Syria, Tunisia; two members and two alternates to be nominated by the seven EU Member States which are Party to the Barcelona Convention: Cyprus, Greece, France, Italy, Malta, Slovenia, Spain and the EC; two members and two alternates to be nominated by the other Parties: Albania, Bosnia and Herzegovina, Croatia, Israel, Monaco, Turkey and Montenegro once it becomes Party to the Barcelona Convention; one additional member and one alternate to be nominated from each group on a rotation basis every four years". The 2008 MOP decided that the additional member and the additional alternate should be nominated for the first compliance Committee by the group of southern and eastern Mediterranean countries.

${ }^{22}$ According to Art. 18.1, of the Barcelona Convention, the ordinary meetings take place every 2 years. Committee members, therefore, serve for a term of 4 years.

${ }^{23}$ The Committee is presently composed of the following persons: Mr. Ahmed Elanwer (Egypt), Mr. Hawash Shahin (Syria), Ms. Angeliki Tsachali Kalogirou (Greece) and Mr. Osman Atila Arikan (Turkey) were elected as members for a full term, Mr. Dali Najeh (Tunisia), Mr. Didier Guiffaut (France) and Mr. Perparim Zaimi (Albania) were elected as members for a half term. Mr. Ali Abufajed (Libyan Arab Jamahiriya), Ms. Daniela Addis (Italy) and Ms. Martina Sorsa (Croatia) were elected as alternates for a full term, and Mr. Robert Kojc (Slovenia) and Ms. Andja Kalem Peric (Bosnia and Herzegovina) were elected as alternates for a half term. As Lebanon and Algeria had not yet nominated alternates, the meeting agreed that 
Members of the Committee "shall serve in their individual capacities and shall act objectively in the interests" of the Convention and its protocols (para. 11).

\section{c) Observers}

The Decision expressly provides for the possibility of observers attending the meetings of the Committee (para. 12). They include both States Parties to the Barcelona Convention, considered observers since they are not members of the body, and "regular" observers under Article 20 of the Barcelona Convention. ${ }^{24}$ Observers may be excluded from a meeting if the Committee or the Party, whose compliance is in question, so decide.

\subsection{The Meeting of Contracting Parties}

The MOP retains its function of keeping under review the implementation of the Convention and the Protocols (Barcelona Convention, Article 18.2) and of assessing compliance with these instruments (Article 27). It may decide appropriate measures to bring about full compliance (Decision, paras. 33 and 34), may request the Committee to consider general compliance issues and, more generally, may submit to the Committee any issue for consideration (para. 17). Furthermore, the MOP must regularly review the implementation and effectiveness of the compliance mechanism and take appropriate action (para. 35). Finally, the MOP considers the report prepared by the Committee on its activities (para. 31).

\subsection{The Secretariat}

Secretariat functions are provided by UNEP through the MAP Coordination Unit (Decision, para. 38). The Secretariat plays an important role in the mechanism: along with the usual functions of assisting the Committee and the MOP ${ }_{2}^{25}$ it is also assigned an active part in the non-compliance procedure (Decision, para. 23). In the first place, it is the first among the bodies involved to check the reports of the Parties, on the basis of which compliance is evaluated. At this stage, the Secretariat is assigned a supportive function: it notifies the Party concerned of its findings and discusses with it how to overcome difficulties in the implementation of the Convention and the Protocols. In the second place, it may trigger the non-compliance mechanism, by

the Bureau should assume responsibility for endorsement once the nominations were submitted (Almeria Report, supra n. 14, para. 29).

${ }^{24}$ According to Art. 20.1, "The Contracting Parties may decide to admit as observers at their meetings and conferences: (a) any State which is not a Contracting Party to the Convention; (b) any international governmental organization or any non-governmental organization the activities of which are related to the Convention."

${ }^{25}$ The Secretariat, inter alia, arranges and services the meetings of the Committee, receives submissions and other documents and informs the Parties in conformity with the Decision. 
referring, under the conditions provided by para. 23 , cases of non-compliance to the Committee.

\section{Functions of the Compliance Committee}

The mandate of the Compliance Committee is twofold (Decision, para. 17). In the first place, the Committee examines specific cases of actual or potential ${ }^{26}$ non-compliance with provisions of the Convention and the Protocols. In this respect, it has a facilitating function, as the decision of sanctions still lies with the MOP, according to Articles 18.2.vi, and 27 of the Barcelona Convention. The Committee's mandate is quite wide, as it relates to the Convention and all Protocols as well as to all binding acts adopted on the basis of, or endorsed by, these instruments, such as decisions of the Parties, strategic plans and time schedules. Though this latter case is not explicitly spelled out in the 2008 Decision, it is implicit in the wording of para. 1, which refers to "compliance with the obligations under the Barcelona Convention and its Protocols" and may also be inferred from the preparatory works for the Decision. ${ }^{27}$

In the second place and if requested by the MOP, the Committee may consider "general compliance issues, such as recurrent non-compliance problems, including in relation to reporting, taking into account the reports referred to in Article 26 of the Convention and any other report submitted by the Parties; and any other issues as requested by the Meeting of the Contracting Parties" (Decision, paras. 17(b) and 17(c). The fifteenth MOP has requested the Committee to "consider during the next biennium 2008-2009, inter alia, general compliance issues such as compliance problems with reporting requirements under the Barcelona Convention and its Protocols" and to indicate in its report "difficulties encountered and any recommendations for amending the Procedures and Mechanisms."

\section{Trigger Mechanism}

The mechanism may be triggered only by a Party or, under specific conditions, by the Secretariat. The Committee has no power to act proprio motu.

\subsection{Submissions by a Party}

Submissions may be effected by a Party in respect to its own situation (self-trigger) (Decision, para. 18(a)) or to that of another Party (party-to-party trigger) "after it has undertaken consultations through the Secretariat with the Party concerned and the matter has not been resolved within three months at the latest, or a longer period as the circumstances of a particular case may require, but not later than six months" (para. 18(b)).

${ }^{26}$ Potential non-compliance may be brought to consideration only by the State involved, as evidenced by the wording of paras. 18 and 23 of the Decision. See also WG Third Report, supra n. 12, para. 49.

27 See WG Second Report, supra n. 10, paras. 34-36. 


\subsection{Referrals by the Secretariat}

Referrals by the Secretariat (Decision, para. 23) are considered as a last possibility, after other roads have been explored. In the case that the Secretariat "becomes aware from the periodic reports referred to in Article 26 of the Convention and any other reports submitted by the Parties that a Party is facing difficulties in complying with its obligations under the Convention and its Protocols, the Secretariat shall notify the Party concerned and discuss with it ways of overcoming the difficulties." The reports referred to in this provision are not only the report envisaged by Article 26 of the Convention but also reports mandatory under other instruments, such as the Protocols, as well as reports required by a MOP decision and even reports requested by the Committee on the basis of a previous deliberation. As the text is actually worded, it is not possible however to include in these reports the ones presented by organs connected with the Barcelona Convention and its Protocols, such as the regional Activity Centres. ${ }^{28}$

If, within three months, these difficulties may not be overcome, ${ }^{29}$ the Party will make a submission to the Committee, under para. 17(a) of the Decision. It is only if the Party does not comply with the obligation to submit the matter to the Committee, within 6 months from the notification by the Secretariat, that the Secretariat is entitled to refer the issue to the Compliance Committee.

\section{The Procedure before the Compliance Committee and Procedural SAFEGUARDS}

\subsection{The Procedure before the Committee}

Submissions by a State, either in respect of its own situation or of that of another Party, have to be addressed in writing to the Committee through the Secretariat, supported by substantiating information setting out the matter of concern and the relevant provisions (Decision, para. 19). In the case of a State-to-State submission, the Secretariat must send a copy to the interested State within two weeks.

The Committee examines submissions during its meeting, which must take place at least once a year (para. 12). It may decide to hold additional meetings, in order for example to examine urgent cases. The Committee may decide not to proceed with a

${ }^{28}$ For example, under Art. 4.3 of the Protocol concerning Co-operation in preventing Pollution from Ships and, in Cases of Emergency, Combating Pollution of the Mediterranean Sea, the Regional Marine Pollution Response Centre for the Mediterranean Sea (REMPEC) shall present a report on the basis of the information received by Parties on the implementation of the article.

${ }^{29}$ The Decision does not define what "resolution of the problem" (in other words, "compliance") is. An ample debate was held during negotiations on this point. In particular, it was debated to what extent the State had to act in order to fulfil the requirement and avoid the obligation of bringing its own case before the Committee. For some States, a show of political will should suffice to avoid submission to the Committee (WG Third Report, supra n. 12, para. 64) while others considered that "the Party concerned was not expected to resolve the problems overnight, but to demonstrate its willingness to seek solutions" (WG Fourth Report, supra n. 13, para. 4). 
submission considered anonymous, de minimis, or manifestly ill founded (para. 21). In this case, the Secretariat informs the State concerned and, if applicable, the Party which presented a State-to-State submission, about this decision.

The State concerned is entitled to participate in the discussions of the Committee (para. 27) and may present information and comments at any stage of the proceedings (para. 24). When the Committee has elaborated its draft findings, measures and recommendations, it communicates them through the Secretariat to the State concerned, fixing a time limit for the presentation of comments (para. 29). If it is considered necessary, the Committee may ask the State concerned to participate in the preparation of its findings, measures and recommendations (para. 27) though the final decision is adopted by the Committee alone.

The activities of the Committee shall be included in a report to be submitted to the MOP through the Secretariat (para. 31).

\subsection{Procedural Safeguards}

\section{a) Due Process}

The principle of "due process" applies to the proceedings "in order to ensure fairness and transparency" (Decision, para. 28). In order to allow the State concerned to present its observations on all elements at the disposal of the Committee, the latter must make all the information at its disposal available to the State. In addition, the State may present comments and additional information at any stage of the proceedings (para. 24) and has the right to see the draft findings of the Committee and comment on them (para. 29). Even though this is not clearly spelled out in the Decision, it would seem that the Party receives communication of the findings and measures decided by the Committee.

\section{b) Participation and Transparency}

In order to permit the participation of States other than the one concerned, the Secretariat informs all Parties to the Convention (but a similar obligation is not provided with respect to observers) of the date and venue of the meetings of the Committee. ${ }^{30}$ The participation of observers (including, in this case, Parties to the Convention not directly concerned by the submission) at the meetings of the Committee is effected in accordance with Article 20 of the Convention and the Rules of Procedure for the meetings and the conference of the Contracting Parties; the Committee or the Party involved in the procedure may nonetheless exclude the presence of observers (para. 13).

The Decision does not mention the principle of transparency and it is doubtful whether it applies. While observers may attend the meetings of the Committee, they do not have a corresponding right of access to the information gathered by the Committee, nor to its final findings and measures.

30 The possibility to allow for the participation of States other than the concerned one, as well as of observers, was amply debated during the negotiation of the Decision. 


\section{c) Confidentiality}

According to the Decision, the "Committee, any Party or others involved in its deliberations shall protect the confidentiality of information transmitted in confidence by the Party concerned" (para. 30). Confidentiality, however, does not concern solely the information submitted by Parties, but seems to attach also to the outcome of the procedure, at least as far as the Committee is concerned. Indeed the Decision does not provide for the publication of the findings of the Committee and, bearing in mind that the publication of such findings may constitute a sanction imposed by the MOP during the following stage, it seems that such silence is to be interpreted as a prohibition of publicity. ${ }^{31}$

\section{SOURCES OF INFORMATION}

Reports presented by States under Article 26 of the Barcelona Convention (and other relevant provisions of the various Protocols) ${ }^{32}$ are the main source of information for ascertaining compliance by States. They serve as the basis for referrals by the Secretariat, and the information submitted by Parties triggering the mechanism, in accordance with Decision para. 19. Additional information may be presented by the State concerned, either proprio motu (para. 24) or in response to a request by the Committee (para. 25(a)), and may be obtained by the Committee itself. The Committee in fact may: undertake on-site appraisals at the invitation of the Party concerned (para. 24); with the consent of the State, gather information on the territory of the latter (para. 25(b)); solicit information from compliance committees dealing with comparable matters (para. 35).

An issue to be considered is whether the Committee may consider information provided by other sources, e.g., private individuals or NGOs. The Decision does not say anything on this point, though it provides that in its deliberations "the Committee shall take into account all the available information concerning the issue in question." In addition, with regard to Article 20, para. 2, of the Barcelona Convention, which provides the possibility for observers to "present any information or report relevant to the objectives of the Convention", it would seem that observers attending the meetings of the Committee may present information relating to the specific case under examination by the Committee. On the contrary, Article 15 of the Barcelona Convention, relating to public information and participation, does not seem sufficient to allow

${ }^{31}$ A different solution has been adopted with regard to the reports presented by Parties. Decision IG 17/3 Format for the Implementation of the Barcelona Convention and its Protocols, Almeria Report, supra n. 14, Annex V, at 29) invites the Parties "to publish, in conformity with the provisions of art. 15 of the Barcelona Convention, their reports on the implementation of the Barcelona Convention and its Protocols on their websites or through other means."

32 The fifteenth MOP has approved a new reporting format which "should be conducive to the collation and provision of comprehensive information, reduce duplication of effort and facilitate the work of the Compliance Committee". The new reporting format applies to the Barcelona Convention, its Protocols and action plans adopted by the MOP. See Decision IG 17/3, supra n. 31 . 
for information provided by other subjects (e.g., NGOs not accredited as observers or private persons).

\section{DeCISION-MAKING}

For each meeting of the Committee a quorum of seven members is required (para. 15). In the absence of a member, the respective alternate shall serve as member (para. 14). ${ }^{33}$ The Committee should make every effort to reach agreement by consensus on its findings, measures and recommendations (para. 16). If this is not possible, the Committee shall adopt its findings, measures and recommendations by a three-fourth majority of the members present and voting, i.e., casting an affirmative or negative vote. ${ }^{34}$ Decisions must thus be approved by at least six members out of seven, if all members cast a vote.

In the case where it is not possible to adopt findings, measures and recommendations by consensus, the report of the Committee to the MOP shall reflect the views of all the Committee members (para. 31(a)). The same applies in the case the Report cannot be adopted by consensus.

\section{Outcomes}

The Decision provides for a series of measures that may be taken in cases of noncompliance by the Committee and by the MOP. In both instances, in adopting a measure two factors must be taken into account (paras. 32 and 33). The first is related to the principle of shared and differentiated responsibilities, and consists of the "capacity of the Party concerned, in particular if it is a developing country". The second relates to the characteristics of the specific conduct resulting in non-compliance, and consists of taking into account its "cause, type, degree and frequency".

\subsection{Measures by the Committee}

The Committee may decide a series of measures which have the prevalent aim of ensuring compliance, rather than sanctioning non-compliance. It may provide advice and facilitate assistance; it may "request or assist, as appropriate, the Party concerned to develop an action plan to achieve compliance within a time frame to be agreed" and may consequently invite the Party to submit progress reports on the efforts it is making to comply with its obligations; finally, if it finds that the case should be dealt

33 Though alternates act as members only in the absence of the ordinary member, they are encouraged to attend all meetings in order to be updated on the work of the Committee. See WG Fourth Report, supra n. 13 , para. 33

34 The possibility to include in the number of members voting also those abstaining was debated during the negotiations but was finally rejected on the grounds that, as abstention is a political choice, it was not considered in keeping with the independent character of the Committee and would consist of a failure to comply with a member's responsibilities (WG Third Report, supra n. 12, para. 37). 
with by the MOP, it may make recommendations to the latter. The Committee therefore may not adopt compulsory measures other than the request of an action plan and the subsequent submission of reports. More stringent measures must be deferred to the MOP.

\subsection{Measures by the Meeting of Parties}

The MOP may, on the basis of the report presented by States and the recommendations by the Committee, adopt measures to "bring full compliance with the Convention and the Protocols" (Decision, para. 33). Such measures include: facilitate implementation of the advice by the Committee and assistance; recommendations to the State concerned; request to submit progress reports; publication of cases of non-compliance. It is only in the event of "a serious, ongoing or repeated situation of non-compliance by a Party" that the MOP may adopt stronger measures: the issuance of a caution, the issuance of a report of non-compliance and any other action that may be required to achieve the purposes of the Convention and the Protocols (para. 34). ${ }^{35}$ Action is therefore left with the MOP and any sanction must be decided by the Parties themselves.

\section{Coordination with Dispute Settlement Procedures and Other Non-Compliance Procedures}

According to para. 36 of the Decision "[t]hese procedures and mechanisms shall operate without prejudice to the settlement of disputes provisions of Article 28 of the Convention." Article 28 provides that, in the case of a dispute between the parties, they shall seek to settle it through negotiation "or any other peaceful means of their own choice". If it is not possible to solve the dispute, it will be submitted, by common agreement, to arbitration under the conditions laid down in Annex A to the Barcelona Convention.

As the Barcelona Convention and its Protocols cover subjects addressed also by other international agreements, it is to be expected that State conduct may become the subject of submissions under different procedures. The possibility for the Committee to consult, upon request by the MOP or by its own initiative, with other committees and to request relevant information from them could help to avoid duplication of work.

35 The proposal to include the possibility to suspend the rights and privileges of a Party as a possible sanction for non-compliance (a measure envisaged for States, in arrears with the payment, with respect to the right of voting by the Rules of Procedure for Meetings and Conferences of the Contracting Parties to the Convention for the Protection of the Mediterranean Sea against Pollution and its Related Protocols, Rule 42.2a) was not retained "since that might lead to resentment" (WG Second Report, supra n. 10, para. 54). 


\section{Participation of the European Community}

The European Community (EC) is a party to the Barcelona Convention and to four out of seven Protocols. ${ }^{36}$ The EC has participated at the Working Group for the establishment of the Committee and has concurred in the adoption of the 2008 Decision.

The EC is under the same obligation as States to report on the implementation of the Convention and its Protocols. It is therefore to be supposed that its conduct might become the subject of examination and assessment by the Committee. In this case, the Decision does not provide any indication (e.g., as far as access to the territory is concerned). Another issue not addressed by the Decision is the possibility to nominate as a member of the Committee a person that is a national of an EC Member State, which however is not a Party to the Convention (e.g., Germany or Sweden). ${ }^{37}$

\section{FinANCIAL ASPECTS}

The text of the Decision does not provide any information about the eventual costs of the compliance procedure and their apportionment, not does it establish any financial resources at the disposal of the Committee in order to be able to carry out its role. Financial aspects were nonetheless discussed during the negotiations for the Deci$\operatorname{sion}^{38}$ and led to the inclusion of the provision according to which additional meetings of the Committee may in particular be held "in conjunction with those of other Convention bodies" (Decision, para. 12). ${ }^{39}$

\section{CONCLUSIONS}

Any comments about the Committee and, more generally, the compliance mechanism just created by Mediterranean States cannot be but partial, as they rely only on the

36 They are the Protocol Concerning Specially Protected Areas and Biological Diversity in the Mediterranean, the Protocol concerning Co-operation in preventing Pollution from Ships and, in Cases of Emergency, Combating Pollution of the Mediterranean Sea, the Protocol for the Protection of the Mediterranean Sea against Pollution from Land-Based Sources and the Protocol for the Prevention of Pollution of the Mediterranean Sea by Dumping from Ships and Aircraft. See supra nn. 2-8.

37 The relevant provisions of the Decision (paras. 25 and 7) refer to a "Party" (the members of the Committee "shall be nationals of Parties" and the Committee may "with the consent of the Party concerned, gather information in the territory of that Party".

38 Issues debated were the possibility to provide the Committee with financial resources to help States comply with the provisions of the Convention and the Protocols (WG First Report, supra n. 9, para. 35) and more generally the financial implications of measures eventually decided by the Committee or the MOP (WG Second Report, supra n. 10, para. 33), the need to strengthen the MAP Coordination Unit to facilitate the work of the Committee and the budgetary implications thereof (WG Fourth Report, supra $\mathrm{n}$. 13, para. 64), as well as the costs for the participation of members at the meetings of the Committee (WG Second Report, supra n. 10, para. 24).

${ }^{39}$ During negotiations "there was widespread support for the idea that any additional meetings should be held back-to-back with major meetings of other Convention bodies for reasons of economy" (WG Third Report, supra n. 12, para. 27). 
legal texts adopted and not on actual practice. It seems however quite clear that the Committee is not an independent organ of the Parties to the Convention, but rather a subsidiary organ of the MOP. ${ }^{40}$ Indeed it has no autonomy with respect to the MOP, either in initiating proceedings against a Party that does not comply with the Convention's provisions or in adopting measures to discourage such behaviour.

The creation of a non-compliance mechanism for the Barcelona Convention and its Protocols was apparently aimed at ensuring the public that Mediterranean States cared about the environment and were willing to make each other respect the rules set by the Convention and Protocols. ${ }^{41}$ While the adoption of the 2008 Decision could be considered a step forward in this direction, the actual regime it creates may leave some doubt as to its effective capacity in enhancing compliance. It is a rather "Statefriendly" regime, in which the protection of Parties' interests seems to be the main concern and where the role of the Committee as a "facilitator" is overstressed, leaving little or no room for the possibility of more effective action.

Another aspect that raises concern is the absence of transparency in the Committee's procedure. There is no provision imposing publicity on either the findings of the Committee or the reports submitted by States as a consequence of a decision by the Committee. In such a situation, it will be the observers' task to control the work of the Committee and to ensure, as far as practicable, ${ }^{42}$ publicity of it.

${ }^{40}$ As such, it could be considered, lato sensu, as one of the working groups whose creations is envisaged by Art. 18.2.v, of the Convention.

${ }^{41}$ See the statement by the MAP Coordinator during negotiations for the Decision: "for some time the Barcelona Convention had been facing a serious credibility problem: public opinion and the media especially felt that non-compliance with the Convention's legal provisions was of no consequence for Mediterranean States and raised the question why they should bother to apply them at all" (WG Second Report, supra n. 10, para. 41).

${ }_{42}$ It is to be supposed, in fact, that also observers are bound by any decision of the confidential character of information. 


\title{
Chapter Ten
}

\section{Procedures and Mechanisms for Review of Compliance under the 1979 Long-Range Transboundary Air Pollution Convention and its Protocols}

\author{
Enrico Milano
}

\section{BRIEF INTRODUCTION TO THE 1979 LRTAP CONVENTION}

The 1979 Long-Range Transboundary Air Pollution Convention (LRTAP Convention) was signed in Geneva on 13 November 1979. ${ }^{1}$ The LRTAP Convention was the first multilateral treaty dealing with air pollutants. A proposal for setting up an international convention on long-range transboundary air pollution to be adopted by the Economic Commission for Europe of the United Nations (UNECE) was launched in 1977 by Norway, which found full support by the USSR and other socialist countries in Europe. The following year all the Scandinavian countries, which had been affected by the phenomenon of acid rain throughout the 1970s, presented a joint draft for a Convention on trans-boundary air pollution starting from the recommendations issued by the 1972 Stockholm Conference. This document represented the basis for negotiation and eventual adoption in 1979 at Geneva. All 35 countries in UNECE signed the Convention, which entered into force in 1983 after 24 countries had ratified it. Other countries joined it later on, and the number has risen to 50 at the time of writing.

11979 Long-Range Transboundary Air Pollution Treaty, reprinted in ILM, 18 (1979), 1442-1450. Generally, on the Convention, see T. Kuokkanen, "The Convention on Long-Range Transboundary Air Pollution”, in G. Ulfstein, T. Marahun, and A. Zimmermann (eds.), Making Treaties Work: Human Rights, Environment and Arms Control, (Cambridge: Cambridge University Press, 2007) 161-178; Economic Commission for Europe, Handbook for the 1979 Convention on long-range transboundary air pollution and its protocols (New York: United Nations Publication, 2004); J. Sliggers and W. Kakebeeke (eds.), Clearing the Air: 25 years of the Convention on Long-range Transboundary Air Pollution (Geneva: United Nations Publication, 2004); P. Sands, Principles of International Environmental Law (Manchester: Manchester University Press, 2000), 248-255; P. Oekewa, State Responsibility for Transboundary Air Pollution in International Law (Oxford: Oxford University Press, 2000), 24-44; K. Hillman, "International control of persistent organic pollutants: the UN Economic Commission for Europe for Europe Convention on Long-range Transboundary Air Pollution, and beyond", RECIEL, 8 (1999) 105-112; N. Castells, International Environmental Agreements: Institutional Innovation in European Transboundary Air Pollution Policies (Brussels: European Commission Publications, Ispra, 1999); L. Boisson de Chazournes, R. Desgagne and C. Romano (eds.), Protection internationale de l'environnement, Recueil d'instruments juridiques (Paris: éd. Pédone, 1998) 533-536.

T. Treves et al., eds., Non-Compliance Procedures and Mechanisms and the Effectiveness of International Environmental Agreements

(C) 2009, T.M.C. ASSER PRESS, The Hague, The Netherlands, and the Authors 
The need for a Convention on transboundary air pollution developed as a result of numerous scientific studies demonstrating the link between sulphur emissions in continental Europe and the acidification of Scandinavian lakes; these studies also showed how air pollutants could travel several thousands of kilometres before depositing and damaging the environment. The conclusion was that the problem could only be tackled through multilateral cooperation. The Convention was one of the first treaties in international environmental law and the first internationally legally binding instrument to deal with problems of air pollution on a broad regional basis. The other striking feature was its ability to bring together Western European countries and Socialist countries (including the USSR) at a time of profound international division.

The Convention is a typical framework convention. It created a framework for cooperation in the field of scientific research, collection and exchange of data, monitoring air pollution and its impact on the environment and for coordination of national policies against air pollution including long-range transboundary air pollution. However, it did not as such create any target on emissions of air pollutants for the Contracting Parties as a result of the opposition by Western European countries, which did not trust the good faith of the USSR and other Socialist countries in entering into this type of commitments. The only general obligation contained in Article 2 has a due diligence character and it states that Parties "... shall endeavour to limit, and, as far as possible, gradually reduce and prevent air pollution including long-range transboundary air pollution." It is only at a later stage with the adoption of several protocols - whose conclusion is not foreseen in the Convention - that the dimension of coordination and cooperation in scientific, industrial and environmental policies related to transboundary pollution was matched by the adoption of specific obligations of result related to the emission of air pollutants.

The main body created under the LRTAP Convention framework is the Executive Body, whose establishment is provided under Article 10. Article 10.2 sets out the functions of the Executive Body which are to a) review the implementation of the Convention; b) establish, as appropriate, working groups to consider matters related to the implementation and development of the Convention and to that end to prepare appropriate studies and other documentation and to submit recommendations to be considered by the Executive Body; c) fulfil such other functions as may be appropriate under the provisions of the Convention. The Executive Body meets annually and it is composed of the representatives of the Contracting Parties. With regard to information on the emission, transport and deposition of air pollution, it works in cooperation with the Steering Board of the Cooperative Programme for Monitoring and Evaluation of the Long-Range Transmission of Air Pollutants in Europe (EMEP), set up in the 1970s within UNECE to monitor the trends of air pollution in Europe. The Executive Body is supported by a Secretariat within the Executive Secretary of UNECE. $^{2}$

The Executive Body has had a leading role in advancing the LRTAP Convention system in terms of new conventional instruments. Through special working groups it has designed and facilitated the adoption of protocols that would provide for specific

\footnotetext{
2 See the web-site of the Convention and the main features of the Executive Body at $<$ http://www.unece.
} org/env/eb/welcome.html> (last visited on 27 January 2008). 
emission targets. Currently, the LRTAP Convention has been enriched by the adoption of a series of protocols setting out specific reduction targets, i.e., two protocols on the reduction of sulphur emissions, ${ }^{3}$ one on nitrogen oxide, ${ }^{4}$ one on volatile organic compounds, ${ }^{5}$ one on heavy metals, ${ }^{6}$ one on persistent organic pollutants, ${ }^{7}$ one on acidification, eutrophication and ground ozone-level. ${ }^{8}$ The list is completed by the protocol on long-term financing of EMEP. ${ }^{9}$

In terms of compliance mechanisms, the Executive Body has set up an Implementation Committee which currently plays a central role in supervising and monitoring the compliance of Contracting Parties with their reduction targets under the protocols. So let us now turn to the discussion of the compliance mechanism and the role of the Implementation Committee.

\section{Legal Basis of the Mechanism and Negotiating History}

In 1997 the Executive Body established the Implementation Committee (hereinafter IC) to review compliance with all Protocols to the Convention (Executive Body decision 1997/2)..$^{10}$ The establishment of the Implementation Committee was quite uncontroversial at a time when actors in many multilateral environmental regimes recognised that, without regular and meaningful scrutiny of Parties' compliance, a treaty may have only limited impact in reaching its targets. ${ }^{11}$ The Executive Body developed the Committee's structure and functions in the light of experience already gained in operating such a committee under the Montreal Protocol and in furtherance of its decision on compliance taken three years earlier when adopting the 1994 Sulphur Protocol.

${ }^{3}$ Protocol on the Reduction of Sulphur Emissions or their Transboundary Fluxes by at least 30 per cent (Helsinki, Finland, 8 July 1985), ILM 27 (1988) 707, entered into force on 2 September 1987; Protocol on Further Reduction of Sulphur Emissions (Oslo, Norway 14 June 1994), ILM 33 (1994) 1542; entered into force on 5 August 1998 (Second Sulphur LRTAP Protocol).

${ }_{4}$ Protocol Concerning the Control of Nitrogen Oxides or their Transboundary Fluxes (Sofia, Bulgaria, 31 October 1988), ILM 28 (1989) 212, entered into force on 14 February 1991

${ }^{5}$ Protocol Concerning the Control of Emissions of Volatile Organic Compounds or their Transboundary Fluxes (Geneva, Switzerland, 18 November 1991), ILM 31 (1992) 568, entered into force on 29 September 1997.

${ }^{6}$ Protocol on Heavy Metals (Aarhus, Denmark, 24 June 1998), <http://www.unece.org/env/lrtap/hm h1.htm $>$ (visited on 27 January 2008), entered into force on 29 December 2003 (Heavy Metals LRTAP Protocol).

7 Protocol on Persistent Organic Pollutants (POPs) (Aarhus, Denmark, 24 June 1998), 37 ILM (1998) 505, entered into force on 23 October 2003 (POPs LRTAP Protocol).

8 Protocol to Abate Acidification, Eutrophication and Ground-level Ozone (Gothenburg, Sweden, 13 November 1999), <http://www.unece.org/env/lrtap/multi_h1.htm> (visited on 27 January 2008), entered into force on 17 May 2005 (Acidification LRTAP Protocol).

${ }^{9}$ Protocol on Long-term Financing of the Cooperative Programme for Monitoring and Evaluation of the Long-range Transmission of Air Pollutants in Europe (EMEP) (Geneva, Switzerland, 28 September 1984, ILM 27 (1988) 701, entered into force on 28 January 1988.

${ }^{10}$ Decision 1997/2 on the Implementation Committee, its Structure and Functions and Procedures for Review of Compliance, doc. ECE/EB.AIR/53 (7 January 1997), Annex III, at 28.

11 Sliggers and Kakebeeke (eds.), supra n. 1, at 119. 
The legal basis under which the IC compliance mechanism was created is set out in the preamble of Decision 1997/2 and may be traced back to Article 10.2 of the Convention, Article 7 of the 1994 Sulphur Protocol (also named Oslo Protocol) and Article 3.3 of the 1991 Protocol on Volatile Organic Compounds. Amendments to the composition rules of the IC and to one of its reporting procedures were adopted by the Executive Body in 2001 as a result of recommendations issued by the IC itself. ${ }^{12}$ A new and more comprehensive instrument setting out the structure and functions of the IC and incorporating the amendments of 2001 was adopted by the Executive Body in $2006 .{ }^{13}$

\section{The Text Establishing the Mechanisms}

The text establishing and governing the procedure is Decision 1997/2 Concerning the Implementation Committee, Its Structure and Functions and Procedures for Review of Compliance, which was approved by the Executive Body by consensus. Para. 1 of the decision on composition and para. 3(c) on the adoption of reports or recommendations were amended by the Executive Body in 2001. ${ }^{14}$ As mentioned above, such amendments were incorporated in a new comprehensive instrument adopted in 2006. ${ }^{15}$ The main features of the Committee, its working procedures and its functions are set out in this latter text. No opt-out or review mechanisms of the procedure are provided in the Decision.

\section{The Principles Governing the Mechanism and the Procedure}

The main objective of the IC and Executive Body procedure is to promote and ensure compliance of all Parties with their obligations under the protocols to the LRTAP Convention. ${ }^{16}$ The working procedure of the IC is non-confrontational, non-contentious and transparent in nature. The Parties found to be not in compliance with their emission targets have not questioned the finding of non-compliance but instead explained the reasons and problems faced. It is also based on the open participation of Parties to the discussions concerning their possible violations of protocols, even if the Party under examination does not play any role in adopting the report and recommendation to the Executive Body. ${ }^{17}$

\footnotetext{
12 Decision 1997/2, supra $\mathrm{n} .10$.

${ }_{13}$ Decision 2006/2 on the Implementation Committee, its Structure and Functions and Procedures for Review of Compliance, doc. ECE/EB.AIR/2006/2 (3 October 2006).

14 Ibid.

15 Supra n. 13

${ }_{16}$ Decision 1997/2, Preamble, supra n. 10; Decision 2006/2, Preamble, supra n. 13.

17 Ibid., para. 8.
} 


\section{INSTITUTIONAL ASPECTS}

As mentioned above, the central bodies in the compliance procedure are the Implementation Committee and the Executive Body. The Committee consists of nine Parties to the Convention, each elected for a term of two years by the Executive Body. Each member of the Committee must, according to the mandate, be party to at least one protocol. ${ }^{18}$ The members represent the Party of which they are nationals, but appointment is also based on independent quality and technical expertise. The IC elects its own Chairman and Vice-Chairman and it meets twice a year.

Decision 1997/2 concerning the establishment of the Implementation Committee and Decision 2006/2 on its structure and functions do not envisage the admission of observers. However, NGOs representing environmental and industrial interests and even ad hoc observers have been regularly admitted as observers in the work of EMEP and of the Executive Body, especially when dealing with the negotiation of new instruments, but occasionally also when dealing with compliance issues. ${ }^{19} \mathrm{We}$ could find no evidence that NGOs have also participated at meetings of the IC.

The Executive Body is the meeting of the representatives of the Parties to the Convention and it is the main decision-making body also in the compliance procedure. It is responsible for taking action to implement the fundamental principles of the Convention, reviewing the implementation of the Convention and setting up subsidiary bodies to carry out the work on implementation and development.

Finally, the Secretariat acts as the administrative body of the compliance mechanism, by executing the decisions taken by the Executive Body and the Implementation Committee. Under para. 5 of Decision 2006/2 it may bring to the attention of the Committee any suspect case of non-compliance by State Parties.

\section{Functions of The Committee}

According to para. 3 of Decision 2006/2, the IC has three main functions: to review compliance with reporting obligations, to consider any submission or referral especially concerned with individual parties' compliance and to prepare in-depth reviews of compliance with specified obligations in individual protocols. The IC adopts recommendations or reports to be submitted to the attention of the Executive Body, which may decide to act upon them.

With regard to reviewing compliance with reporting obligations, it must be pointed out that Parties are required to report both information on strategies and policies that serve as a means of reducing emissions and information on their emissions. The Committee reviews both the timeliness and the completeness of reporting.

\footnotetext{
${ }^{18}$ Ibid., para. 1. Currently the Parties to the IC are Austria, Canada, Cyprus, Croatia, Germany, Norway, the Netherlands, Slovenia, Switzerland (chair).

${ }_{19}$ See Decision 2006/11 on Accreditation of Non-Governmental Organizations to attend meetings under the Convention, doc. ECE/EB.AIR/89/Add.1 (5 February 2007).
} 


\section{TRIGGER MECHANISM}

The non-compliance procedure can be triggered by means of submission by Parties or referrals by the Secretariat. A submission may be brought either by one or more Parties against another Party (para. 4(a)) or by a Party with respect to itself (para. 4(b)). If the Secretariat becomes aware of a case of possible non-compliance, it may bring the matter to the attention of the IC by means of a referral (para. 5). The IC may also become aware of instances of non-compliance by individual Parties as a result of its reviews under para. $3(\mathrm{~d})$. There is neither provision nor practice concerning the submission by the public of alleged cases of non-compliance.

\section{The Procedure before the Implementation Committee And Procedural SAFEguards}

The procedural aspects and safeguards of the compliance mechanisms established under the Convention are mostly set out in Decision 2006/2.

In accordance with para. 4(a) submissions of non-compliance presented by one or more Parties to the Protocol against another Party must be submitted in writing to the Secretariat and supported by corroborating information. The Secretariat shall, within two weeks of receiving a submission, send a copy of it to the Party whose compliance is at issue. Any reply and information in support thereof shall be submitted to the Secretariat and to the Parties involved within three months or such longer period as the circumstances of a particular case may require. The Secretariat shall transmit the submission and the reply, as well as the corroborating and supporting information, to the Committee, which shall consider the matter as soon as practicable.

As far as self-submissions under para. 4(b) are concerned, they must be addressed in writing to the Secretariat and explain the specific circumstances that the Party considers to be the cause of its non-compliance. The Secretariat shall transmit the submission to the Committee, which shall consider the matter as soon as practicable.

With regard to the non-compliance procedure initiated by the Secretariat, para. 4(c) provides that the Secretariat should first request the Party concerned to furnish the necessary information about the matter. If there is no response or the matter is not resolved within three months or such longer period as the circumstances of the matter may require, the Secretariat shall bring the matter to the attention of the Committee.

With regard to non-compliance proceedings initiated as a result of an action by the Committee in the context of in-depth reviews in accordance with para. 3(d), the IC decided in 2002 that the Executive Body should not take steps unless and until the Implementation Committee had properly and individually reviewed the case (including, for example, listening to any arguments that the Party in question might wish to make).$^{20}$ This was in order to afford all due process rights to the Party concerned.

${ }^{20}$ The Fifth Report of the Implementation Committee, doc. EB.AIR/2002/2/Add.1 (30 September 2002). See T. Kuokkanen, "Practice of the Implementation Committee under the Convention on Long-Range Transboundary Air Pollution", in U. Beyerlin, P.T. Stoll and R. Wolfrum (eds.), Ensuring Compliance with Multilateral Environmental Agreements (Leiden: Martinus Nijhoff, 2006), at 47. 
Moreover, upon conducting its review of compliance with reporting obligations, the Committee has recognised the need for good discipline and the importance of clearly identifying the sources of information relied upon. In this regard, the Committee agreed that it should be sure to treat all Parties equally. Hence, it should give no special preference or advantage to the Parties represented on the Committee.

With regard to participation, para. 8 provides for a right for the concerned Party to participate in the consideration by the Committee of that submission or referral; however, the concerned Party shall not take part in the preparation and adoption of any report or recommendations of the Committee. Moreover, in accordance with para. 10, only those Committee members that are Parties to the protocol in respect of which compliance procedures are being undertaken may fully participate in those procedures. For non-Party members, participation is allowed in the discussion of the factual background to the case and identification and analysis of the legal and policy considerations involved. However, the non-Party member does not have a right to participate in the preparation of the IC conclusions and recommendations. ${ }^{21}$ If as a result of this restriction the size of the Committee is reduced to five members or less, the Committee shall refer the matter to the Executive Body.

Another important procedural aspect to highlight is the confidentiality of any information submitted to the IC when that is required by the Party submitting such information.

\section{SOURCES OF INFORMATION}

In accordance with para. 3(c), the Committee must be satisfied, before considering a submission or a referral, that the quality of the data reported by a Party has been evaluated by a relevant technical body under the Executive Body and/or, where appropriate, by an expert nominated by the Bureau of the Executive Body. The work of EMEP has represented the most useful tool in providing and assessing data on emissions targets under the Protocol. To date, however, the possibility of using outside experts to evaluate the reliability of data has not been used.

Most of the information is provided by the Parties, but as we have seen the IC may acquire its own information in the course of in-depth reviews. There seems to be no limitation on the sources of such information (thus possibly including environmental NGOs and industrial organizations), as long as they are reliable. A special role as a source of information has been played by the Working Group on Effects and the mechanisms created thereunder, including the Coordination Centre for Effects which has provided data on air pollution effects, trends and risks in Europe since 1990. ${ }^{22}$

\footnotetext{
${ }^{21}$ Decision 2006/2, supra n. 13, para. 10.

${ }^{22}$ The Coordination Centre for Effects was established by the Ministry for the Environment of the Netherlands. For background documents and information see $<$ http://www.mnp.nl/cce/> (visited on 27 January 2008)
} 


\section{DECISION-MAKING}

Decision 2006/2 provides at para. 11 that any decision by the Executive Body on measures in the implementation of IC reports or recommendations should be taken by consensus. This provision follows more generally the practice established by the Executive Body that decisions are made by consensus, despite the formal adoption of the UNECE rules of procedure in 1983 that provide at Rule 35 that decisions shall be taken by majority. ${ }^{23}$ We may consider this consistent practice as indicative of an unwritten amendment in the rules of procedure regarding decision-making by the Executive Body.

\section{Outcomes}

As already mentioned, the compliance procedure under the LRTAP Convention provides for the issuing of recommendations by the IC to the Executive Body, which eventually takes a decision concerning non-compliance by adopting the IC recommendation.

Szell, Keizer and Kuokkanen have identified three main elements in the recommendations of the IC and the related decisions of the Executive Body. First, there must be a conclusion of non-compliance. Second, the Party concerned is urged to fulfil its obligations as soon as possible. Third, the Party concerned is requested to provide a periodic progress report to the IC. Depending on the circumstances of the matter, the IC and the Executive Body may use different wording nuances in their reports, such as "express disappointment", "note with concern", "remain concerned", "urge" or "strongly urge" in order to put increasing pressure on the Party in breach. ${ }^{24}$

With regard to the third element, each Party found in breach is called on to report by a specified date on the steps that it has taken to achieve compliance, in particular to set out a timetable by which it expects to be in compliance, to list the specific measures taken or be taken to fulfil its obligations under the protocol and to set out the projected effects of each of these measures up to and including the year of compliance. The purpose of these requirements is to put pressure on the Parties in question to bring about full compliance as soon as possible. The IC has placed much emphasis on the preparing of timetables and on offering practical suggestions to accelerate emission reductions. Each year it has reviewed the steps taken by the Parties found in breach and, when necessary, it has made recommendations for follow-up decisions by the Executive Body until the Parties concerned have achieved compliance. Once compliance is achieved, the Executive Body normally decides that there is no reason for the IC to continue to review a particular submission or referral. ${ }^{25}$

With regard to the legal nature of these decisions, the language used, including such expressions as "requests", "calls on" or "urges", seems to imply that the

${ }^{23}$ P. Szell, V. Keizer, and T. Kuokkanen, “Compliance and Consensus", in Sliggers and Kakebeeke (eds.), supra n. 11, at 130 .

${ }^{24}$ Ibid., at 124.

${ }^{25}$ Ibid. 
measures taken by the Executive Body are not legally binding upon the Party concerned, given the non-confrontational nature of the non-compliance procedure and the lack of sanctioning mechanisms. Moreover, there is no provision in the LRTAP Convention conferring such powers on the Executive Body. However, the Executive Body is the leading political organ in the framework of the LRTAP Convention and it is composed of all the representatives of States Parties acting by consensus; when dealing with compliance it acts in fulfilment of its implementation function under Article 2(a). Its display of legal authority in the compliance procedure seems to be based on its implied powers under the Convention itself. The rate of compliance with its decisions is indeed very high. A possible conclusion on the legal nature of these decisions is that they do create obligations of due diligence upon Parties, with a view to complying with the targets set out by the relevant protocol. These obligations reinforce those obligations of result deriving directly from the reduction targets provided in the protocols.

\section{Coordination with Dispute Settlement Procedures and Other Non-Compliance Procedures}

Article 13 of the LRTAP Convention provides for the solution of any dispute between Parties on the application and interpretation of the Convention on the basis of negotiation or any other means of settlement accepted by the Parties.

Para. 12 of Decision 2006/2 provides that the application of the IC compliance procedure is "without prejudice to the settlement of disputes provisions of the protocol."

Each protocol provides for additional means of dispute settlement, including, remarkably, the submission of disputes to the International Court of Justice (ICJ) or to arbitration subject to a written declaration made at the time of ratification, approval or accession. ${ }^{26}$ At any rate, unilateral submissions are regulated by the relevant provisions.

In practice, a problem of coordination with dispute settlement procedures or other compliance procedures has not arisen, since the Parties have always relied on the IC and Executive Body procedure. This can be seen as indicative of the success obtained by the non-compliance procedure in the implementation of the Convention and its Protocols.

\section{Participation of The European Community}

The European Community (EC) took part actively in the negotiations leading to the adoption of the LRTAP Convention and is among its original signatories. It became

${ }^{26}$ Acidification LRATP Protocol, Art. 11; POPs LRTAP Protocol, Art. 12; Heavy Metals LRTAP Protocol, Art. 11; Second Sulphur LRTAP Protocol, Art. 9. 
a Party to the instrument through approval on 15 July $1982 .{ }^{27}$ The EC is also Party to all protocols to the Convention promoted by the Executive Body, with the exception of the 1985 Sulphur Protocol and the 1991 VOC Protocol.

With regard to the 1994 Sulphur Protocol approved in 1998, the Community has deposited with instruments of approval the following declaration:

"The European Community states that the ceiling for emissions and the weighted average percentage of the European Community ought not to exceed the sum of the obligations of the Member States of the European Union which have ratified the Protocol, while stressing that all its Member States must reduce their SO2 emission ceilings set in Annex II to the Protocol and in line with the relevant Community legislation." 28

With regard to the implementation of these instruments, the EC has adopted Directive 97/68 of 16 December 1997 on the approximation of the laws of the Member States relating to measures against the emission of gaseous and particulate pollutants from internal combustion engines to be installed in non-road mobile machinery, which has been an important tool in the achievement of the reduction targets set out in the 1988 NOX Protocol and in the 1991 VOC Protocol (which quite interestingly was only signed but never ratified by the EC). ${ }^{29}$

Another important act of implementation by the EC is the more recent Regulation No. 850/2004 of 29 April 2004 on persistent organic pollutants, which has amended Directive 79/117 and given effect internally to the act of approval of the 1998 POPs Protocol of 30 April 2004. ${ }^{30}$

\section{Financial Aspects}

We were unable to track down anything specific concerning the scope and nature of institutional costs related to the compliance procedure as such; as a result, we must assume that the costs concerning the working of the Executive Body and Implementation Committee are borne by the UNECE budget and the contributions offered by the Parties.

${ }^{27}$ Council Decision 81/462/EEC of 11 June 1981 on the conclusion of the Convention on long-range transboundary air pollution, OJ (1981) L 171/11.

${ }_{28}$ Council Decision 98/686/EC of 23 March 1998 on the conclusion by the European Community of the Protocol to the 1979 Convention on long-range transboundary air pollution on further reductions of sulphur emissions, OJ (1998) L 326/34.

${ }^{29}$ Directive 97/68/EC of the European Parliament and of the Council of 16 December 1997 on the approximation of the laws of the Member States relating to measures against the emission of gaseous and particulate pollutants from internal combustion engines to be installed in non-road mobile machinery, OJ (1998) L 059/1.

${ }^{30}$ Regulation (EC) No. 850/2004 of the European Parliament and of the Council of 29 April 2004 on persistent organic pollutants and amending Directive 79/117/EEC, OJ (2004) L 158/7. 
In general, in order to encourage participation of representatives of countries with economies in transition, the Secretariat has established a Trust Fund which covers part of the expenses related to participation at meetings in Geneva. ${ }^{31}$

\section{Survey of Practice}

At the time of writing, the IC has considered a total of 12 individual submissions and referrals relating to compliance by individual Parties with substantive obligations. Six were self-submissions and six were referrals by the Secretariat.

In seven of the twelve cases the Committee, and subsequently the Executive Body, has concluded that there was non-compliance at a certain point in time: namely the cases of Norway, Finland, Italy, Greece, Ireland and Spain. With regard to Sweden's submission, it became clear in 2003 - as a result of a reappraisal of its volatile organic carbon (VOC) emission data and method of calculation - that Sweden had been in compliance with its 1991 VOC Protocol obligations from the very outset. ${ }^{32}$ The same applied to Luxembourg with regard to its obligations under the same protocol. ${ }^{33}$ In the case of Italy's self-submission with regard to the 1991 VOC Protocol, compliance was reached in 2002. ${ }^{34}$ Equally, Ireland reached compliance with its NOX Protocol in $2003 .{ }^{35}$

One has also to underline that all the submissions and referrals handled so far by the IC have been non-contentious in nature and Parties have not challenged the IC findings. As explained above, the Parties concerned have sought to explain the reasons behind non-compliance; the IC has always tried to offer practical suggestions to the Parties on how to reach compliance. In most cases, the Parties have identified one or more sectors that have proved problematic. Szell, Keizer and Kuokkanen report that the main reason for the failure by Norway to reduce its VOC emissions in accordance with the 1991 Protocol was the delay in developing the necessary technologies to control emissions in the offshore oil sector, which was responsible for a large share of Norway's emissions. ${ }^{36}$ In Ireland the extraordinary rates of economic growth in the 1990s caused an unexpectedly large increase in its VOC emissions. In addition to that, one should mention the so-called "fuel tourism" between Northern Ireland and the Republic, which contributed to the increase in Ireland's emissions. ${ }^{37}$ In Finland emission reductions in the road transport sector - its largest source of VOC emissions

\footnotetext{
31 Executive Body Decision 2001/6 on the Facilitation of Participation of Countries with Economies in Transition, doc. ECE/EB.AIR/75 (16 January 2002), Annex X.

${ }^{32}$ Executive Body Decision 2003/4 on Compliance by Sweden with the 1991 VOC Protocol, doc. ECE/EB.AIR/79/Add. 1 (21 January 2004), Annex IV.

${ }^{33}$ Executive Body Decision 2004/11 on Compliance by Luxembourg with the 1991 VOC Protocol, doc. ECE/EB.AIR/83/Add. 1 (16 December 2004), Annex XI.

${ }^{34}$ Executive Body Decision 2005/3 on Compliance by Italy with the 1991 VOC Protocol, doc. ECE/ EB.AIR/87/Add. 1 (11 January 2006), Annex XI.

${ }^{35}$ Executive Body Decision 2005/5on Compliance by Ireland to the 1988 NOX Protocol, doc. ECE/ EB.AIR/87/Add. 1 (11 January 2006), Annex V.

${ }^{36}$ Szell, Keizer and Kuokkanen, supra n. 23, at 122.

37 Ibid.
} 
- had fallen below expectations due to the economic recession at the beginning of the 1990s. As a consequence, the renewal of the vehicles fleet was slower than predicted. Increases in emissions due to road transport have been one of the main causes of Italy's, Greece's and Spain's problems with compliance. A common problem in cases of non-compliance has been the reliability of the national data provided. ${ }^{38}$

In general, we can conclude that the practice of the IC has been successful insofar as it has represented a flexible instrument for putting gentle pressure on Parties and for monitoring their patterns of compliance. While some cases show some resistance to improvement due to the structural deficits of the countries involved, in most cases compliance has been achieved. Moreover, the institution of the IC has considerably increased the level of compliance with reporting obligations, which is in itself important progress in renewing the Parties' commitment towards achieving compliance with the obligations of result contained in the protocols. ${ }^{39}$

\section{Bibliography}

T. Kuokkanen, "Practice of the Implementation Committee under the Convention on LongRange Transboundary Air Pollution", in U. Beyerlin, P.T. Stoll and R. Wolfrum (eds.), Ensuring Compliance with Multilateral Environmental Agreements (Leiden: Martinus Nijhoff, 2006) 39-51; J. Lehmann, "A Comparative Analysis of the Long-Range Transboundary Air Pollution, Ozone Layer Protection and Climate Change Regimes", in M. Bothe and E. Rehbinder (eds.), Climate Change Policy (Utrecht: Eleven International Publishing, 2005), at 73-84; P. Szell, V. Keizer, and T. Kuokkanen, "Compliance and Consensus", in J. Sliggers and W. Kakebeeke (eds.), Clearing the Air: 25 years of the Convention on Long-range Transboundary Air Pollution (Geneva: United Nations Publication, 2004) 119-133; T. Kuokkanen, "Putting gentle pressure on parties: recent trends in the practice of the Implementation Committee under the 1979 Convention on Long-Range Transboundary Air Pollution", in J. Klabbers and J. Petman (eds.), in Nordic Cosmopolitanism: Essays in International Law for Martti Koskenniemi (Leiden: Martinus Nijhoff, 2003), at 315-326; P. Oekewa, State Responsibility for Transboundary Air Pollution in International Law (Oxford: Oxford University Press, 2000) at 231-237.

\footnotetext{
38 Ibid.

${ }^{39}$ Kuokkanen, supra n. 20, at 43.
} 


\title{
Chapter Eleven
}

\section{Procedures and Mechanisms for Review of Compliance under the 1991 Espoo Convention on Environmental Impact Assessment in a Transboundary Context and its 2003 Protocol on Strategic Environmental Assessment}

\author{
Elena Fasoli
}

\section{Brief Introduction to the Espoo Convention}

The Convention on Environmental Impact Assessment in a Transboundary Context (hereinafter "the Convention") ${ }^{1}$ requires environmental impact assessment (EIA) to be extended across borders between Parties of the Convention when a planned activity - listed in Appendix I - may cause significant adverse transboundary impact. The Convention was a response to a growing concern about transboundary emissions and the emergence of environmental impact assessment as a tool for reducing the negative environmental effects of new activities. It sets out the obligations for Parties to assess the environmental impact of certain activities at an early stage of planning. ${ }^{2}$

The Convention establishes two main obligations: on the one hand, as a form of cooperation between the Parties, it provides that the Party under whose jurisdiction the proposed activity is envisaged to take place (Party of origin) must notify of such proposed activity "any Party which it considers may be affected" by it (affected Party)

\footnotetext{
1 Espoo, Finland, 1991, entered into force on 10 September 1997, reprinted in UNTS, 30 (1991) 302. As of 27 January 2008, there are 30 Signatories and 41 Parties to the Convention. See $<\mathrm{http}$ ://www.unece.org/ env/eia/convratif.html> (visited 23 June 2008).

2 In general, about the Espoo Convention, see L. Pineschi, "Environmental Impact Assessment", in T. Scovazzi, and T. Treves (eds.), World Treaties for the Protection of the Environment (Milano: Istituto per l'ambiente, 1992), 485-490; P. Sands, Principles of International Environmental Law (Cambridge: Cambridge University Press, $2^{\text {nd }}$ edn., 2003), at 799 ff.; T. Koivurova, "The Transnational EIA procedure of the ESPOO Convention", Finnish YB Int'l L., 8 (1997) 161-199; D.M. Dzidzornu, "Environmental Impact Assessment Procedure Through the Conventions", Eur. Envt'l L. Rev., 10 (2001) 15-26.; J.H. Knox, “The Myth and Reality of Transboundary Environmental Impact Assessment", Am. J. Int'l L., 96 (2002) 291-319, at $301 \mathrm{ff}$., and T. Koivurova, "The Convention on Environmental Impact Assessment in a Transboundary Context (Espoo Convention)", in G. Ulfstein, T. Marauhn, and A. Zimmermann (eds.), Making Treaties Work: Human Rights, Environment and Arms Control (Cambridge: Cambridge University Press, 2007) 218-239.
}

T. Treves et al., eds., Non-Compliance Procedures and Mechanisms and the Effectiveness of International Environmental Agreements

(C) 2009, T.M.C. ASSER PRESS, The Hague, The Netherlands, and the Authors 
as early as possible and that such Parties enter into consultations and discussions. ${ }^{3}$ On this score the Convention requires Parties to consider transboundary effects in their domestic EIA procedures and to open those procedures to full participation by affected Parties.

On the other hand, the Convention requires the Party of origin to bring such domestic EIA procedures into compliance with the principle of non-discrimination. ${ }^{4}$ In particular, the Convention enables foreign residents to have access to domestic environmental impact assessment procedures to the same extent as local residents. The public of the affected Party shall receive notice of, and an opportunity to comment on, the proposed activity and the EIA documentation prepared by the Party of origin. ${ }^{5}$

The Convention describes two possible scenarios. As to the first, if the affected Party decides not to participate in the procedure, the operational provisions of the Convention do not apply and the Party of origin can decide on the basis of its national law and practice whether to carry out an assessment. ${ }^{6}$ As to the second, once the affected Party decides to participate in the procedure, it must promptly provide the Party of origin, at its request, with reasonably obtainable information relating to the potentially affected environment under its jurisdiction, where such information is necessary for the preparation of the environmental impact assessment. ${ }^{7}$

In the absence of notification, when a Party considers that it would be affected by a significant adverse transboundary impact of a proposed activity, the Convention provides that the Parties involved exchange sufficient information for the purpose of holding a discussion and, in the case of disagreement on whether a significant adverse transboundary impact is likely, any such Party may submit the fact to an inquiry commission. ${ }^{8}$

Under Article 5 consultation must take place between the Parties concerning the potential transboundary impact and measures to reduce or eliminate the impact. In taking the final decision on the proposed activity the Parties must take due account of the outcome of the environmental impact assessment and, furthermore, the Party of origin must inform the affected one of the final decision and the reasons and consideration on which it was based. ${ }^{9}$

As a form of cooperation between States, the Convention deals also with the carrying out of post-project analysis, ${ }^{10}$ the assumption of stricter duties through the signature of bilateral and multilateral agreements, ${ }^{11}$ the setting up, or the intensification of,

${ }^{3}$ See, respectively, Arts. 3 and 5 of the Convention.

${ }^{4}$ On the principle of non-discrimination see also Knox, supra n. 2, at $311 \mathrm{ff}$.

${ }_{5}^{5}$ Arts. 2.2, 2.6, 3.1, 3.8. and 4.2.

${ }^{6}$ Art. 3.4 .

7 Art. 3.6.

${ }^{8}$ Art. 3.7. For further details on the Inquiry Commission procedure see also infra paragraph 12.

${ }^{9}$ See, respectively, Arts. 5 and 6 of the Convention.

${ }^{10}$ Art. 7.

${ }^{11}$ Art. 8. For the list of the bilateral and multilateral agreements in force see, in particular, $<\mathrm{http}: / / \mathrm{www}$. unece.org/env/eia/agreements.html $>$ (visited 28 January 2008). 
specific research programmes, ${ }^{12}$ and the organisation of the Meeting of the Parties (hereinafter MOP).$^{13}$ Article 11 provides that:

"[t]he Parties shall meet, so far as possible, in connection with the annual sessions of the Senior Advisers to ECE Governments on Environmental and Water Problems [...]. Thereafter, meetings of the Parties shall be held at such other times as may be deemed necessary by a meeting of the Parties, or at the written request of any Party, provided that, within six months of the request being communicated to them by the secretariat, it is supported by at least one third of the Parties."

With regard to the institutional structure, MOP has been given the power to establish subsidiary bodies. ${ }^{14}$ It created an extensive institutional structure, including a Working Group (hereinafter WG), the Implementation Committee (the Committee) and a Bureau. The first was established to assist in the implementation of the Convention and the management of the work-plan; the second - the subject of this work - was created to review compliance by the Parties with their obligations under the Convention with a view to assisting them to meet their commitments fully. A Secretariat, acting as the administrative body of the Convention, supports the activity both of the MOP and of the subsidiary bodies. ${ }^{15}$

The EIA Convention has been supplemented by a Protocol on Strategic Environmental Assessment (Kiev, Ukraine, 2003, hereinafter "SEA Protocol"). This has been an initiative of the Second Meeting of the Parties to the Convention, which in February 2001 created an ad hoc Working Group to develop the Protocol. ${ }^{16}$ The group completed its work in January 2003 with finalization of the draft Protocol text. ${ }^{17}$ The Protocol was adopted and opened for signature at the Ministerial "Environment for Europe" Conference in Kiev, Ukraine, on 21 May 2003. ${ }^{18}$

The difference between the Protocol and the Convention regards the fact that the former concerns a much earlier phase in the decision-making process than the latter. In particular, the aim of the Protocol is not just to minimize the environmental impact of a proposed activity envisaged to take place, but rather to ensure that Parties take

12 Art. 9. As to the difficulties in sharing research results see, particularly, Report of the Tenth Meeting of the Implementation Committee, doc. ECE/MP.EIA/WG.1/2007/3 (6 February 2007), para. 15.

${ }_{13}$ For an overview of MOPs/COPs under MEAs, see, in particular, R. Churchill and G. Ulfstein, "Autonomous Institutional Agreements in Multilateral Environmental Agreements: a Little-Noticed Phenomenon in International Law", Am. J. Int'l L., 94 (2000) 623-659.

14 Rule 23.2 of the MOP's Rules of Procedure provides that "[t]he Meeting of the Parties may establish such subsidiary bodies as are deemed necessary for the performance of its functions". Rules of Procedure of the Meeting of the Parties to the Convention on Environmental Impact Assessment in a Transboundary Context (MOP's Rules of Procedure) are set out in the Annex to Decision I/1 on Rules of Procedure, doc. ECE/MP.EIA/2 (10 November 1998), Annex I, at 10.

15 See Art. 13 of the Convention and Rules 24 and 25 of the MOP's Rules of Procedure, supra n. 14.

${ }^{16}$ See Decision II/9 on Strategic Environmental Assessment, doc. ECE/MP.EIA/4 (7 August 2001), Annex IX, p. 131. 2003).

17 See Provisional Agenda for the Extraordinary Meeting, doc. ECE/MP.EIA/2003/1 (13 February

${ }^{18}$ See, in particular, Report of the Fifth Ministerial Conference 'Environment for Europe', doc. ECE/ CEP/96 (28 July 2003), at 5-6. As of 27 January 2008 there are 38 Signatories and 7 Parties to the Protocol. See $<$ http://www.unece.org/env/eia/protocol status.html $>$ (visited 23 June 2008). 
into account environmental considerations - i.e., environmental consequences - in the development of their official draft plans and programmes, irrespective of the fact that the activities may cause significant adverse transboundary impact. The Protocol allows the identification and prevention of possible environmental impact right from the beginning of decision-making - for example, developing a more sustainable transport policy rather than just minimizing the environmental impact of building a road and it enables environmental objectives to be considered on a par with socio-economic ones, bringing sustainable development closer. ${ }^{19}$

The main body created under the Protocol is the Meeting of the Signatories whose aims are to identify activities that need to be undertaken pending the entry into force of the Protocol itself, to report on progress made in respect of the ratification of the Protocol to the MOP and to prepare for the first Meeting of the Parties to the Convention serving as the Meeting of the Parties to the Protocol. ${ }^{20}$

\section{Legal Basis of the Mechanism and Negotiating History}

The Convention does not contain a specific provision envisaging the establishment of a compliance procedure. ${ }^{21}$ Accordingly, reliance was placed upon Article 11.2.f, which provides that

" $[t]$ he Parties shall keep under continuous review the implementation of this Convention, and, with this purpose in mind, shall [...] [c]onsider and undertake any additional action that may be required for the achievement of the purposes of this Convention."

Indeed, after the compliance procedure had been already established, the Parties sought to give to it a sounder legal basis by introducing, by way of an amendment, a provision regarding the "Review of Compliance" which is not yet in force. According to Article 14bis

"1. [t]he Parties shall review compliance with the provisions of this Convention on the basis of the compliance procedure, as a non-adversarial and assistance-oriented procedure adopted by the Meeting of the Parties. The review shall be based on, but not limited to, regular reporting by the Parties. The Meeting of Parties shall decide on the frequency of regular reporting required by the Parties and the information to be included in those regular

${ }^{19}$ See the dedicated website at $<$ http://www.unece.org/env/eia/sea_protocol.htm $>$ (visited 23 June 2008).

${ }^{20}$ On this point, see Report of the Second Meeting of the Signatories, doc. MP.EIA/AC.3/2005/2 (13 July 2005) and Report of the Third Meeting of the Signatories, doc. ECE/MP.EIA/6 (13 September 2004).

${ }^{21}$ See, in particular, Koivurova, supra n. 2, at 227 ff. In general, on this subject-matter see, among other sources, Guidelines for Strengthening Compliance with and Implementation of Multilateral Environmental Agreements (MEAs) in the ECE Region, doc. ECE/CEP/107 (20 March 2003). For an overview of the development of compliance procedures and mechanisms under multilateral environmental agreements (MEAs), see, in particular, H. Adsett, A. Daniel, M. Husain, and T.L. McDorman, "Compliance Committees and Recent Multilateral Environmental Agreements: The Canadian Experience with Their Negotiation and Operation”, Canadian YB Int'l L., 42 (2004) 91-142. 
reports. 2. The compliance procedure shall be available for application to any protocol adopted under this Convention". ${ }^{22}$

The Implementation Committee is a creation of the Meeting of the Parties (MOP). The first reference to compliance issues was included in the Work-Plan for the Implementation of the Convention for the period 1998 to 2000, adopted during the first MOP in 1998. ${ }^{23}$ The Parties decided to outline "the possible framework and options for a non-compliance system under the Convention, based on relevant experience under other international agreements." Accordingly, they decided to develop "possible approaches for non-compliance guidelines", to be presented at the second Meeting of the Working Group for discussion and finalization and thereafter to the second Meeting of the Parties for possible adoption. ${ }^{24}$ They designated the United Kingdom as lead country. ${ }^{25}$

During the second Meeting of the Parties in 2001, the delegation of the United Kingdom introduced draft Decision II/4 on the review of compliance, whose aim was to allow the review of Parties' compliance with their obligations under the Convention in an effort to assist them to meet these obligations fully. The structure and functions of this system should have been reviewed at the subsequent Meeting of the Parties. ${ }^{26}$ Accordingly, the second MOP decided to adopt the decision and established the Implementation Committee. ${ }^{27}$

During the third meeting of the Committee, a discussion arose as to the "[r]eport and the recommendations for draft decisions for the third MOP." The Committee requested its President to draft a proposal for the new decision on the procedure for review of compliance, based on Decision II/4, and proposed some changes. ${ }^{28}$ The draft decision has been subsequently transmitted to the Working Group, which agreed

22 The second amendment of the Convention was adopted in 2004 during the third MOP, held in Cavtat, Croatia, from 1 to 4 June 2004, in accordance with the procedure laid down in Art. 14.3 of the Convention (see Decision III/7 on Second amendment to the Espoo Convention, doc. ECE/MP.EIA/6 (13 September 2004), Annex VII, at 93). For the status of ratification see $<$ http://www.unece.org/env/eia/amend2ratif.html $>$ (visited 27 January 2008).

${ }^{23}$ See Report of the First Meeting of the Parties, doc. ECE/MP.EIA/2 (10 November 1998), Annex VII, at 48 .

${ }^{24}$ For actions and outline time schedule of each body involved in creating non-compliance guidelines, see ibid., Annex VI, at $56 \mathrm{ff}$.

${ }^{25}$ As far as negotiating history is concerned, the delegation of the United Kingdom presented the document MP.EIA/WG.1/2000/9, with a draft decision on a possible non-compliance system under the Convention. See also Report of the Second Meeting of the Working Group, doc. ECE/MP.EIA/WG.1/2000/2 (18 July 2000), at 3. Afterwards, the delegation of the United Kingdom presented a revised draft of the same document (doc. ECE/MP.EIA/WG.1/2000/9/Rev.1) based on the discussion held at the second meeting of the Working Group, which proposed to recommend that the Meeting of the Parties adopt it with the some changes (see Report of the Third Meeting of the Working Group, doc. ECE/MP.EIA/WG.1/2000/18 (24 November 2000), at 3, para. 11).

${ }^{26}$ See Report of the Second Meeting of the Parties, ECE/MP.EIA/4 (7 August 2001), Annex IV, at $72-73$

27 See ibid., at 7.

${ }^{28}$ See Report of the Third Meeting of the Implementation Committee, doc. ECE/MP.EIA/WG.1/2003/8 (10 July 2003), at 4-5. 
to submit it to the Parties at their third Meeting. ${ }^{29}$ The latter finally adopted the Decision III/2 revising the Committee's structure and functions, taking into account the work undertaken in the period between the second and the third MOP. ${ }^{30}$

\section{The Text Establishing the Mechanism}

Decision III/2 and its Appendix deal with the structure and functions of the Implementation Committee as well as the procedures for the review of compliance. ${ }^{31} \mathrm{Com}-$ paring its provisions with the structure and functions provided for in the original decision, the new text contains some differences regarding both public participation and the expansion of the role of the Committee. ${ }^{32}$

As far as public participation is concerned, para. 3 of the Appendix to Decision III/2 provides that the Committee's meetings

"shall be open to other Parties and the public, unless the Committee decides otherwise. Parts of meetings dealing with specific submissions relating to compliance shall not be open to other Parties or to the public, unless the Committee and the Party whose compliance is in question agree otherwise." 33

Points 3 and 4 of the Preamble of Decision III/2 address the extension of the role of the Committee - i.e., the application of the review of compliance - to the Convention and any amendments to it, and to the Protocol on Strategic Environmental Assessment, respectively. ${ }^{34}$

Furthermore, as to the revision of the mechanism, Decision III/2 provides that the MOP shall

"keep under review and develop if necessary the structure and functions of the Committee at the fourth meeting of the Parties in the light of experience gained by the Committee in the interim, including with public involvement, and in this context requests the Committee to prepare any necessary proposals for the fourth meeting of the Parties." ${ }^{35}$

${ }^{29}$ See Report of the Seventh Meeting of the Working Group doc. ECE/MP.EIA/WG.1/2004/2 (16 March 2004), at 2, paras. 9-10.

${ }^{30}$ For the draft decision then adopted at the third Meeting of the Parties see Report of the Fourth Meeting of the Implementation Committee, doc. ECE/MP.EIA/WG.1/2004/3 (17 December 2003).

${ }^{31}$ Decision III/2 on Review of Compliance, doc. ECE/MP.EIA/6 (13 September 2004), Annex II, at 49. While the decision establishes the Committee, its structure, functions and procedure are set out in the Appendix thereto.

${ }_{32}$ See Report of the Third Meeting of the Implementation Committee, doc. ECE/MP.EIA/WG.1/2003/8 (10 July 2003), at 4, para. 19.

${ }^{33}$ It is notable that this disposition is in line with Rule 26 of the MOP's Rules of Procedure, supra n. 14, (" $[t]$ he meetings of the Parties and the meetings of its subsidiary bodies established by the Meeting shall be held in public unless the Meeting decides otherwise").

${ }^{34}$ See also Preamble to Decision II/4 on Review of Compliance, doc. ECE/MP.EIA/4 (7 August 2001), Annex IV, point 3.

${ }^{35}$ See Preamble to Decision III/2, supra n. 31, point 5. It is remarkable that the Committee has already prepared a draft decision on the review of compliance, further to Decision III/2 (see Report of the Eleventh 


\section{The Principles Governing the Mechanism and the Procedure}

The main objective of the compliance procedure is not to declare a State in violation of its international obligations established by the Convention, but rather to help and to assist the State to comply with them. ${ }^{36}$ Leaving aside the traditional bilateral adversarial approach, the working procedure of the Committee appears to be non-adversarial - i.e., non-confrontational - and assistance-oriented, as mentioned in Article 14bis of the Convention - not yet in force - and in para. 14 of the Appendix to Decision $\mathrm{III} / 2 .^{37}$

The mechanism is also based on the open participation of Parties in the discussions concerning their possible violations of the Convention, even if the Party under examination does not play any role in adopting the report and recommendation of the Committee. ${ }^{38}$

As for the transparency of the proceeding, it must be noted that on the one hand para. 3 of Appendix to Decision III/2 provides that the Committee's meetings shall be open to other Parties and to the public but, on the other, the same provision makes this possibility of participation conditional to the Committee's decisions and to the fact that it is not dealing with specific submissions relating to compliance, ${ }^{39}$ which does not seem to be entirely in line with the aims of the Implementation Committee. ${ }^{40}$ It is therefore difficult to affirm that transparency is a principle governing the compliance procedure.

\section{InSTITUtional AsPects}

The Committee shall consist of eight Parties to the Convention. Each of the eight Parties shall appoint a member of the Committee. At their second meeting, the Parties elected four Parties to the Committee for two terms and four Parties for one term. At each session thereafter, the MOP shall elect four new Parties for two terms. Outgoing Parties may be re-elected once, unless in a given case the MOP decides otherwise. The Committee shall elect its own Chair and Vice-Chair. ${ }^{41}$ It is notable that the

Meeting of the Implementation Committee, doc. ECE/MP.EIA/WG.1/2007/4 (12 March 2007), paras. 19-20), to be presented to the Working Group (see Annotated Provisional Agenda for the Eleventh Meeting of the Working Group, doc. ECE/MP.EIA/WG.1/2007/7) and, afterwards, to the fourth MOP (see Draft Decision IV/2 on the Review of Compliance, doc. ECE/MP.EIA/2008/4 (21 February 2008)).

36 See infra paragraph 12.

${ }^{37}$ For the text of Art. 14bis see supra paragraph 2. On this point, see also Report of the Seventh Meeting of the Implementation Committee, doc. ECE/MP.EIA/WG.1/2004/2 (16 March 2004), at 2, para. 10.

${ }^{38}$ See Appendix to Decision III/2, supra n. 31, para. 9. On this point see, more precisely, infra paragraph 8.

39 For the complete text of the provision, see the previous paragraph

${ }^{40}$ Indeed, in dealing with public participation the Report of the Third Meeting of the Implementation Committee had affirmed that the Implementation Committee should take 'into account the importance of transparency, efficiency of procedure, decision-making, resources and improving compliance' (emphasis added). See doc. ECE/MP.EIA/WG.1/2003/8 (10 July 2003), para. 6.

${ }^{41}$ Ibid., para. 1(a) 
Committee has States as members - i.e., individuals representing and appointed by States. ${ }^{42}$

A delicate issue is related to the structure and functions of the Implementation Committee when considering matters under the Protocol on Strategic Environmental Assessment. The Committee agreed to recommend that its own structure and functions be amended to reflect the Committee's functions under both instruments. ${ }^{43}$ Discussion arose on this score: on the one hand with regard to the possibility of enlarging the number of the Implementation Committee's members when considering matters under both the Convention and the SEA Protocol - once it had entered into force; on the other, with reference to the issue as to whether the Meeting of the Parties to the Convention, and the Meeting of the Parties to the Convention serving as the Meeting of the Parties to the Protocol, ${ }^{44}$ might jointly nominate certain members. Moreover, debate ensued on how Vice-Chairs might be nominated and what would happen if a member nominated when a Party to only one of the instruments would later become a Party to the other. ${ }^{45}$

The Implementation Committee shall, unless it decides otherwise, meet at least once a year. ${ }^{46}$ There was discussion as to the frequency of future MOPs in relation with the Committee's activity to report and make recommendations regarding compliance with the Convention at each MOP. ${ }^{47}$ In particular, it was noted that the Implementation Committee met regularly and that a meeting of the Parties usually took place once every three years. This could lead to a situation where the Committee prepared a recommendation regarding compliance with the Convention that could be considered by the MOP only at a very late stage. ${ }^{48}$ To cope with this problem, the Working Group has welcomed a proposal on the frequency of the MOPs, characterised by a "flexible approach after the fourth Meeting of the Parties, built around

${ }^{42}$ See, also Adsett, Daniel, Husain, and McDorman, supra n. 21, at 106.

${ }^{43}$ See the Report of the Ninth Meeting of the Implementation Committee, doc. ECE/MP.EIA/ WG.1/2006/4 (28 April 2006), para. 23 ff. It must be noted that a small Working Group on this issue was also established to prepare a proposal on the modalities for the application to the Protocol of the compliance procedure of the Convention (Report of the Seventh Meeting of the Implementation Committee, doc. ECE/ MP.EIA/WG.1/2005/4 (20 July 2005), paras. 9-11).

44 See Art. 14 of the SEA Protocol.

${ }^{45}$ Report of the Eighth Meeting of the Implementation Committee, doc. ECE/MP.EIA/WG.1/2006/3 (20 January 2006), at 5, para. $23 \mathrm{ff}$. On the structure and functions of the Committee when considering matters under the Protocol on Strategic Environmental Assessment see, more recently, Report of the Eleventh Meeting of the Implementation Committee, doc. ECE/MP.EIA/WG.1/2007/4 (12 March 2007), para. 14.

46 See Appendix to Decision III/2, supra n. 31, para. 2.

47 "The Committee shall report on its activities at each meeting of the Parties through the Secretariat and make such recommendations as it considers appropriate, taking into account the circumstances of the matter, regarding compliance with the Convention. Each report shall be finalized by the Committee not later than ten weeks in advance of the session of the Meeting of the Parties at which it is must be considered. Every effort shall be made to adopt the report by consensus. Where this is not possible the report shall reflect the views of all the Committee members. Committee reports shall be available to the public" (ibid., para. 11). For the functions of the Committee see also infra next paragraph.

${ }_{48}$ See Report of the Fifth meeting of the Implementation Committee, doc. ECE/MP.EIA/WG.1/2004/4 (8 April 2004), at 3, para. 15. 
triennial low-profile meetings, with the option of occasional high-profile meetings of the Parties." 49

The important issue of public participation arose at an early stage of the Implementation Committee's activity and the choices reflect the debate related to it. ${ }^{50}$ First of all, particular attention was devoted to the possibility for the public to be informed of submissions to the Committee..$^{51}$ The reports of the Committee's meetings are made publicly available as they are submitted to the Working Group. Similarly, the reports of the Committee's activities, to be drafted in accordance with para. 11 of the Appendix to Decision III/2, and reports requested by the MOP under para. $4 . \mathrm{d}$ of the same text, are made publicly available once they have been submitted to the MOP. The agenda of each meeting of the Implementation Committee is publicly available (via the Convention's website), although the Committee decides on the information to be included in the agenda. ${ }^{52}$

Secondly, as to the possibility for the public to participate at its meetings, ${ }^{53}$ the Committee considered a request from an NGO (UNISFERA) to attend its meeting. It noted that if the MOP's Rules of Procedure were to be applied mutatis mutandis ${ }^{54}$ observers, including NGOs, could participate in its discussion without the right to vote. On this score, the Implementation Committee reflected on the experience of the participation of observers and on the difficulties that this could create. In particular it was suggested that extending participation rights to observers would create a situation where observers would have greater participation rights than Parties that were not members of the Implementation Committee.$^{55}$ However, the Committee made it clear that the decision to admit observers was taken on an ad hoc and experimental basis,

${ }^{49}$ Report of the Ninth Meeting of the Working Group, doc. ECE/MP.EIA/WG.1/2006/2 (3 July 2006), at 6, para. 37.

${ }^{50}$ Yet the second Meeting of the Committee noted that the involvement of the public in its work was a decision to be taken by the Meeting of Parties. The Committee also noted that experience with the compliance regime under the EIA Convention as well as with other compliance regimes, such as under the Aarhus Convention, could be useful to assess how to deal with this issue. However, in order to fulfil the request by the Meeting of Parties to the Implementation Committee to prepare the necessary proposals for the review of the structure and functions of the Committee at the third Meeting of Parties, the Committee was to present proposals on ways for public involvement (Report of the Second Meeting of the Working Group, doc. ECE/ MP.EIA/WG.1/2003/3 (13 December 2002), at 3, para. 13 ff.). During the third Meeting of the Committee, based on a discussion paper presented by the delegation of Canada, possible options were examined in view of future adoption at the third MOP (see doc. ECE/MP.EIA/WG.1/2003/8 (10 July 2003), para. $5 \mathrm{ff}$ ).

${ }^{51}$ See ibid., paras. 7-10.

${ }^{52}$ At present (27 January 2008), the Provisional Agenda for the Twelfth, Thirteenth and Fourteenth Meeting of the Implementation Committee to the Convention on Environmental Impact Assessment in a Transboundary Context are available on the Convention's official website.

${ }^{53}$ On this point see, also, the previous paragraph.

${ }^{54}$ About rules of procedure see infra paragraph 8 .

${ }^{55}$ See Report of the Fourth Meeting of the Implementation Committee, doc. ECE/MP.EIA/WG.1/2004/3 (17 December 2003), paras. 3 and 12. Furthermore, the Committee noted other potential issues that would be addressed if observers were to be allowed to participate, such as whether they would need to announce their participation in advance. Guidance on all of these aspects should be sought from the next MOP and from the development of new operating rules (see infra paragraph 8). 
that the view expressed by the NGO representative would not be reflected as such in the report and that the NGO representative was bound by confidentiality rules. ${ }^{56}$

Finally, with regard to the public's direct and active participation as members of the Implementation Committee, reference was made to this issue at the third Committee's meeting. In particular, para. 1 of the Appendix to Decision II/4 - which now corresponds to para. 1 of Appendix to Decision III/2 - allows a Party to nominate whomever it wishes, with nothing preventing the latter from nominating an individual from an NGO or from the private sector. It was noted, however, that all the members of the Committee would be bound by the rules of confidentiality. ${ }^{57}$

With reference to the respective role and the main tasks of the MOP in connection with Implementation Committee's activity, para. 4(d) of the Appendix to Decision III $/ 2$ provides that MOP could request the Implementation Committee to prepare a report on compliance with, or implementation of, specified obligations in the provisions of the Convention. Furthermore, according to para. 13 the MOP may, upon consideration of the report presented by the Implementation Committee, decide upon appropriate general measures to bring about compliance with the Convention and measures to assist an individual Party's compliance..$^{58}$

The Implementation Committee is classified as a subsidiary body of the MOP, established by and supporting the latter. ${ }^{59}$

\section{Functions of the Committee}

According to para. 4 of the Appendix to Decision III/2, the Implementation Committee has four main functions: to consider any submission of non-compliance according to the Convention's provisions with a view to securing a constructive solution (para. 4(a)); to review periodically, in accordance with guidelines or criteria formulated by the MOP, compliance by the Parties with their obligations under the Convention on the basis of the information provided in their reports (para. 4(b)); to prepare the reports for the MOPs with a view to providing any appropriate assistance to the Party or Parties concerned, for example by clarifying and assisting in the resolution of questions; to provide advice and recommendations relating to procedural, technical or administrative matters; to provide advice on the compilation and communication of information (para. 4(c)); and to prepare, at the request of the Meeting of the Parties,

${ }^{56}$ On this point see also C. Pitea, "NGOs in Non-Compliance Mechanisms under Multilateral Environmental Agreements: From Tolerance to Recognition?", in T. Treves, M. Frigessi di Rattalma, A. Tanzi, A. Fodella, C. Pitea, and C. Ragni (eds.), Civil Society, International Courts and Compliance Bodies (The Hague: T.M.C. Asser Press, 2005) 205-224, at 210.

${ }^{57}$ Report of the Third Meeting of the Implementation Committee, doc. ECE/MP.EIA/WG.1/2003/8 (10 July 2003), at 3, para. 14.

${ }_{58}$ As for procedural aspects, "[t]he Parties shall make every effort to reach a decision by consensus. If all efforts at consensus have been exhausted, and no agreement reached, the decision shall, as a last resort, be adopted by a three-fourths majority vote of the Parties present and voting at the meeting" (para. 13). See also para. 11.

${ }_{59}$ See, among the other sources, the website at $<$ http://www.unece.org/env/eia/bodies.htm $>$ (visited 27 January 2008). 
and based on relevant experience acquired in the performance of its functions under subparas. (a), (b) and (c) above, a report on compliance with or implementation of specified obligations in the provisions of the Convention (para. 4(d)).

In light of the above, the Implementation Committee is empowered both with general issues on compliance and with individual non-compliance cases. As to the first task, the Committee discusses matters of compliance/non-compliance with the aim of developing a common understanding of non-compliance. ${ }^{60}$ In particular, at its third meeting the MOP requested the Secretariat to bring to the Committee's attention "general compliance issues identified in the Review of Implementation 2003", 61 and requested the Implementation Committee to take these matters into account in its work. ${ }^{62}$ Accordingly, the Committee agreed that each of its members should have to examine a part of the first review of implementation ${ }^{63}$ noting, in particular, the need to identify both compliance issues and possible remedies. ${ }^{64}$ As explained further on, one of the sources of information by which the Committee might become aware of a possible case of non-compliance is, among others, the reviews of implementation, including Parties' responses to questionnaires regarding their implementation of the Convention. ${ }^{65}$ On this score, one of the main tasks of the Implementation Committee is to prepare recommendations for a revision of the questionnaire used for future reviews of the implementation of the Convention. ${ }^{66}$ The Committee has made good progress with revising and simplifying the questionnaire on implementation, which is now in the form of a national report. ${ }^{67}$

${ }^{60} \mathrm{See}$, for example, Report of the Second Meeting of the Implementation Committee, doc. ECE/MP.EIA/ WG.1/2003/3 (13 December 2002), at 2.

${ }^{61}$ Report of the Third Meeting of the Parties, ECE/MP.EIA/6 (13 September 2004), at $17 \mathrm{ff}$. See, also, infra n. 67.

62 See ibid., at 15 , no. 5 .

${ }^{63}$ See Report of the Sixth Meeting of the Implementation Committee, doc. ECE/MP.EIA/WG.1/2005/3 (1 February 2005), para. 10.

${ }^{64}$ The Committee discussed parts of the review on the basis of reports by the Committee members. The Committee asked the Secretariat to circulate a table into which the members would insert information on general compliance issues. Each entry in the table should be accompanied by a paragraph describing the general compliance issue and by a recommended remedy (see Report of the Eight Meeting of the Implementation Committee, doc. ECE/MP.EIA/WG.1/2006/3 (20 January 2006), para. $8 \mathrm{ff}$. and Report of the Ninth Meeting of the Implementation Committee, doc. ECE/MP.EIA/WG.1/2006/4 (28 April 2006), paras. 10-19).

${ }^{65}$ It must be noted that the legal obligation for Parties to report does not exist, provided that Art. 14bis which states that the review of compliance shall be based on, but not limited to, regular reporting by the Parties - has not yet entered into force. For these reasons the Committee considered that the MOP had expressed a strong desire for Parties to report (see Report of the Sixth Meeting of the Implementation Committee, doc. ECE/MP.EIA/WG.1/2005/3 (1 February 2005), para. 8). The Secretariat reported that it had received 36 completed revised questionnaires to report on the implementation of the Convention in the period to 2005, of which 33 were from the 40 States Parties to the Convention (Report of the Eleventh Meeting of the Implementation Committee, doc. ECE/MP.EIA/WG.1/2007/4 (12 March 2007), para. 4 ff.).

${ }^{66}$ The aim of the task was to improve the questionnaire so that it provides information on how the obligations of the Convention have been complied with, both at the general level and by particular Parties (see Report of the Third Meeting of the Parties, doc. ECE/MP.EIA/6 (13 September 2004), at $20 \mathrm{ff}$.).

${ }^{67}$ For the blank questionnaire for the period 2003-2005 and the responses received up to now from Parties and non-Parties to the Convention, see the website at $<$ http://www.unece.org/env/eia/review2006.htm> (visited 28 January 2008). See also, in ibid., the Draft Second Review of Implementation (29 October 2007). On this point, with particular reference to the European Community, see infra paragraph 13. 
With regard to the specific compliance issues, the Report of the eighth meeting of the Committee deserves particular attention. Starting with the consideration that the Committee could decide to send a letter to those Parties from which clarification was needed with regard to the implementation of or compliance with the Convention, asking them to clarify their situation and offering them assistance, ${ }^{68}$ the Secretariat has identified three specific compliance issues on the basis of the previous review of implementation. The Committee considered these issues to be "pilot cases", with all three Parties concerned (Armenia, Finland and Kyrgyzstan) being members of the Committee. ${ }^{69}$

\section{TRIGGER MECHANISM}

According to para. 5 of the Appendix to Decision III/2, a submission may be brought before the Implementation Committee by one or more Parties to the Convention that have concerns about another Party's compliance (para. 5(a)), or similarly by a Party that concludes that, despite its best endeavours, it is or will be unable to comply fully with the obligation under the Convention (para. 5(b)) ${ }^{70}$ Furthermore, where the Committee becomes aware of possible non-compliance by a Party with its obligations, it may request the Party concerned to furnish the necessary information about the matter (para. 6) $;^{71}$ which suggests that the Implementation Committee may also act proprio motu. Closely linked to this point is the handling of unsolicited information. Letters were sent by non-governmental organizations (NGOs) to the Implementation Committee alleging potential non-compliance issues regarding a specific Party to the Convention. In one case the Committee agreed that the information provided so far was insufficient for it to be considered ${ }^{72}$ and accordingly drafted a letter in reply to the NGO, acknowledging the letters and explaining that they did not provide sufficient

${ }^{68}$ See Report of the Seventh Meeting of the Implementation Committee, doc. ECE/MP.EIA/WG.1/2005/4 (20 July 2005), para. 7 and para. 6 of the Appendix to Decision III/2, supra n. 31, regarding "Committee initiative" which is better explained in the next paragraph.

69 The Committee decided that a member whose country's compliance was being discussed should be allowed to participate in the discussion, though it might choose not to do so. Should recommendations be drawn up, paras. 9 and 10 of Appendix to Decision III/2, supra n. 31, should be applied to avoid a conflict of interest (see Report of the Eight Meeting of the Implementation Committee, doc. ECE/ MP.EIA/WG.1/2006/3 (20 January 2006), para. 13 ff.). For the survey of practice see, infra paragraph 15.

${ }^{70}$ As to self-referral, the Committee is dealing with ways to encourage it. The Committee underlines, for example, the fact that it would ensure confidentiality on the information provided to it in confidence. See, in particular, Report of the Eighth Meeting of the Implementation Committee, doc. ECE/MP.EIA/WG.1/2006/3 (20 January 2006), at 6, para. 29; Report of the Eleventh Meeting of the Implementation Committee, doc. ECE/MP.EIA/WG.1/2007/4 (12 March 2007), para. 17; and Adsett, Daniel, Husain, and McDorman, supra n. 21, at $106 \mathrm{ff}$.

${ }^{71}$ It must be noted that the EU asked the Committee to clarify the words "to become aware of possible non-compliance", see Report of the Ninth Meeting of the Working Group, doc. ECE/ MP.EIA/WG.1/2006/2 (3 July 2006), Annex, at 10.

${ }^{72}$ In particular, it was insufficient to demonstrate either that there was a transboundary effect, or that the activity described fell within the scope of the Convention. 
information..$^{73}$ In another case the majority of the Implementation Committee's members agreed not to consider the information received "because considering unsolicited information from NGOs and the public relating to specific cases of non-compliance was not within the Committee's existing mandate." "74 It must be noted that a minority disagreed, interpreting the mandate - as results from para. 5 of Decision II/4, now as para. 6 of Decision III/2 - to mean that there were no restrictions on how the Committee can become aware of a case of possible non-compliance and preferring to examine the information further. ${ }^{75}$ As a result, at its ninth meeting, the Committee specifically examined criteria for dealing with information other than submissions from Parties. In particular the Committee agreed to propose to the Working Group that the next MOP adopt a decision on review of compliance that would consider, among the sources of information from which the Committee could become aware of a possible case of non-compliance, also information from the public, non-governmental organizations and "any other public sources, including the media". ${ }^{76}$ The Working Group provided advice on the Committee's proposal. On the whole it agreed with the comments and suggestions offered by the European Union (EU), which recommended the inclusion of criteria for dealing with information other than submissions from Parties in future Operating Rules, rather than through revising the description of the structure and functions of the Implementation Committee. ${ }^{77}$

Furthermore, the EU specified that is entirely up to the Committee whether or not to start an action in the light of information received. The wording of para. 6 of Decision III/2 indicates that there is no right for non-Parties to initiate any action by the Implementation Committee..$^{78}$ On this score it must be noted that proposals to reform the existing mechanism had already been considered in order to enable the initiation of proceedings by the public; nevertheless, the Implementation Committee decided not to address them at that stage and proposals on the subject have been postponed for consideration at the fourth MOP. ${ }^{79}$

${ }^{73}$ See, in particular, Report of the Fourth Meeting of the Implementation Committee, doc. ECE/MP.EIA WG.1/2004/3 (17 December 2003), para. $7 \mathrm{ff}$.

${ }^{74} \mathrm{See}$, in particular, Report of the Fifth Meeting of the Implementation Committee, doc. ECE/MP.EIA/ WG.1/2004/4 (8 April 2004), paras. 5-8.

${ }^{75}$ Ibid. On this point see also Pitea, supra n. 56, at 215, who affirms that " $[\mathrm{t}]$ he relevance of this precedent is, however, limited, since the Espoo NCM, contrary to most NCMs, does not afford the Secretariat the entitlement to initiate proceedings."

${ }^{76}$ See Report of the Ninth Meeting of the Implementation Committee, doc. ECE/MP.EIA/WG.1/2006/4 (28 April 2006), para. $5 \mathrm{ff}$

${ }^{77}$ In particular, the EU recommends that the rules concerning possible sources of information should not be formulated too strictly nor should certain sources of information be overemphasized. In the EU's opinion, it would be sufficient to say: "[ $\mathrm{t}$ ]he sources of information by which the Committee might become aware of a possible non-compliance can be: (i) Parties' work under the Convention and (ii) any other source' (see Report of the Ninth Meeting of the Working Group, doc. ECE/ MP.EIA/WG.1/2006/2 (3 July 2006), at $10(\mathrm{f})$ and $(\mathrm{g}))$

78 Ibid.

79 See Report of the Second Meeting of the Implementation Committee, doc. ECE/MP.EIA/WG.1/2003/3 (13 December 2002), para. 13 and Report of the Third Meeting of the Implementation Committee, doc. ECE/ MP.EIA/WG.1/2003/8 (10 July 2003), para. 13. See, also, C. Pitea, NGOs in Non-Compliance Mechanisms cit., supra n. 56, at 213 . 
In light of the above, the Implementation Committee agreed to propose to the Working Group the adoption of a decision regarding the review of compliance at the next Meeting of the Parties, taking into account the following sources of information by which the Committee might become aware of a possible case of non-compliance: a) the reviews of implementation, including Parties' responses to questionnaires regarding their implementation of the Convention; b) the reports of the meetings of the Parties, including their annexes; c) information from the Secretariat; d) bilateral and multilateral agreements and national legislation implementing the Convention; e) the results of activities within the current work-plan of the Convention, including case studies; f) information from intergovernmental organizations; g) information from the public, including non-governmental organizations; and h) any other public sources, including the media. ${ }^{80}$

\section{The Procedure before the Implementation Committee and Procedural Safeguards}

Rule 23 of the Rules of Procedure of the $\mathrm{MOP}^{81}$ provides that they apply mutatis mutandis to the proceedings of subsidiary bodies.

Nevertheless, the Implementation Committee decided to assign its members to the specific task of developing autonomous operating rules that could provide practical arrangements for the conduct of the Committee's meetings, ${ }^{82}$ basing this action on the rather ambiguous text of para. 5 of Decision III/2. ${ }^{83}$ It must be noted that the Working Group and the EU, giving advice on this issue, did not envisage particular problems in elaborating such rules, but considered that they should be adopted by the MOP. ${ }^{84}$ This issue is still under consideration. ${ }^{85}$

Having already addressed the non-confrontational nature of the compliance proceeding, as well as the doubts about its transparency, let us now turn to the procedural safeguards which are closely linked to the Implementation Committee's internal practice for handling cases.

First of all it must be noted that Parties are entitled to participate in any meeting in which the matter is discussed. ${ }^{86}$ Para. 9 of Appendix to Decision III/2 provides that "[a] Party in respect of which a submission is made or which makes a submission

${ }^{80}$ See Report of the Ninth Meeting of the Implementation Committee, doc. ECE/MP.EIA/WG.1/2006/4 (28 April 2006), para. 6.

${ }^{81}$ See MOP's Rules of Procedure, supra n. 14.

${ }^{82}$ See Report of the Eighth Meeting of the Implementation Committee, doc. ECE/MP.EIA/WG.1/2006/3 (20 January 2006), para. $26 \mathrm{ff}$.

${ }^{83}$ See Report of the Third Meeting of the Parties, doc. ECE/MP.EIA/6 (13 September 2004), at 49.

${ }^{84}$ See Report of the Ninth Meeting of the Working Group, doc. ECE/MP.EIA/WG.1/2006/2 (3 July 2006), para. 10 and p. 11).

${ }^{85}$ The draft Operating Rules of the Implementation Committee are set out in Draft Decision IV/2 on the Review of Compliance, doc. ECE/MP.EIA/2008/4 (21 February 2008), Annex, submitted to the fourth MOP. For further details on the elaboration of operating rules, see J. Jendrośka, "Practice and Relevant Cases that Emerged in the Context of the Espoo Convention Implementation Committee", infra 319-336, at 323-324.

${ }^{86}$ See, also, supra paragraph 4. 
shall be entitled to participate in, or be present during, the consideration by the Committee of that submission, but shall not take part in the preparation and adoption of any report or recommendations of the Committee." On this score, as a matter concerning the conflict of interests, the legal text provides that "[a] member of the Committee that represents a Party in respect of which a submission is made or which makes a submission shall be entitled to participate in the consideration by the Committee of that submission but shall not participate in, or be present during, the preparation and adoption of any part of a report or recommendation of the Committee that relates to that submission" (para. 10). ${ }^{87}$

Regarding information and the possibility to respond to it and timing of the procedure as due process issues, different situations may arise depending on the trigger mechanism. The submission brought before the Implementation Committee by one or more Parties to the Convention shall be addressed in writing to the Secretariat and supported by corroborating information. ${ }^{88}$ Any reply or information shall be presented within three months (or such longer period as the Parties involved agree) and anyway the Secretariat shall transmit the submission and the reply, as well as all corroborating and supporting information, to the Committee, which shall consider the matter as soon as possible (para. 5.a). The submission made by a Party unable to comply fully with its obligations under the Convention shall be in writing to the Secretariat and shall explain, in particular, the specific circumstances that the Party considers to be the cause of its non-compliance. Then the Secretariat shall transmit the submission to the Committee, which shall consider it as soon as possible (para. 5.b). Finally, if the Committee becomes aware of possible non-compliance issues and, accordingly, requests a Party to clarify its position, "[a]ny reply [of the latter] and information in support shall be provided to the Committee within three months or such longer period as the circumstances of a particular case may require". The Committee shall consider the matter as soon as possible in the light of any reply that the Party may provide (para. 6).

As to the deliberation by the Committee, after the submission - however it might be made - the Committee decides on the content of any report or recommendations by consensus, sends a copy of the draft report or recommendations to the Parties concerned, and shall take into account any representations from such Parties in the finalization of the report (para. 9).

As already mentioned regarding NGOs, observers are admitted to participate in the Implementation Committee's proceedings. ${ }^{89}$ According to MOP's rule of procedure which apply also to the proceedings of subsidiary bodies - the Secretariat shall notify them of any meeting, so that they may be present, subject to the condition that their admission to the meeting is not objected to by at least one third of the Parties present

\footnotetext{
${ }^{87}$ Furthermore, according to para. 12 "[i]f as a result of the operation of paragraph 10 the size of the Committee is reduced to five members or less, the Committee shall forthwith refer the matter in question to the Meeting of the Parties."

${ }^{88}$ The Secretariat shall, within two weeks of receiving a submission, send a copy of it to the focal point of the Party whose compliance is at issue.

${ }^{89}$ See supra paragraph 5. An "observer" may be considered every relevant body or agency, whether national or international, governmental or non-governmental, qualified in fields relating to environmental impact assessment which has informed the Secretariat of its wish to be represented.
} 
at the meeting. Furthermore, such observers may, at the invitation of the Chair and if there is no objection from the Parties present, participate, without the right to vote, in the proceedings of any meeting in matters of direct concern to the bodies or agencies that they represent (Rule 7).

\section{SOURCES OF INFORMATION}

With regard to information gathering once the compliance procedure starts, para. 7 of the Appendix to Decision III/2 provides that

"to assist the performance of its functions [...] the Committee may: a) request further information on matters under consideration, through the Secretariat; b) undertake, at the invitation of the Party of origin and/or the affected Party, information gathering in the territory of that Party; c) consider any information forwarded by the Secretariat concerning compliance with the Convention; and d) as appropriate, seek the services of scientific experts and other technical advice or consult other relevant sources."

Regarding time limits, as already said, any reply and information related to the submission brought before the Implementation Committee shall be submitted to the Secretariat and to the focal point of the Parties involved within three months or such longer period as the Parties involved agree or as the circumstances of a particular case may require. ${ }^{90}$

\section{DeCISION-MAKING}

The rules on decision-making are contained in Appendix to Decision III/2. According to para. 9, when considering a particular submission, the Implementation Committee shall decide on the content of any report or recommendations by consensus. ${ }^{91}$ Furthermore, according to para. 11, when reporting its activities to the MOP through the Secretariat, the Implementation Committee shall adopt the report by consensus as well. However, if no agreement has been reached, the report shall reflect the views of all the Committee's members.

It is notable that the "consensus rule" is to be found in the MOP's Rules of Procedure, which apply mutatis mutandis, pending the adoption of the new Committee's Operating Rules..$^{92}$ The only difference regards the fact that according to MOP's rules, if all efforts at consensus have been exhausted, and no agreement reached, the decision shall be adopted by a three-fourths majority vote of the Parties present and voting at the meeting. ${ }^{93}$ Furthermore, decisions on procedural matters shall be taken by a simple majority vote of the Parties present and voting at the meeting and if the

90 See Appendix to Decision III/2, supra n. 31, paras. 5 and 6.

91 The Committee shall also send a copy of the draft report or recommendation to the Parties concerned and shall take into account any representations from such Parties in the finalization of the report.

92 See supra paragraph 8.

93 See MOP's Rules of Procedure, supra n. 14, Rule 37. 
question arises whether a matter is one of a procedural or substantive nature, the Chair shall rule on the question. An appeal against this ruling shall be immediately put to vote and the Chair's ruling shall stand unless overruled by a majority of the Parties present and voting. ${ }^{94}$

As already mentioned regarding the principles governing the procedure and the procedural safeguards ${ }^{95}$ if the Committee's meeting is dealing with specific submissions regarding compliance, other Parties or the public are not allowed to participate, unless the Implementation Committee and the Party whose compliance is at stake agree otherwise. ${ }^{96}$ Moreover, during the preparation and adoption of any report or recommendations, the Party in respect of which a submission is made - or which makes a submission - cannot participate in the meeting. ${ }^{97}$ The same is true for the member of the Implementation Committee that represents a Party in respect of which a submission is made..$^{9}$

\section{Outcomes}

According to the Appendix to Decision III/2, when a submission is made the Implementation Committee must determine whether the Party is in compliance or not with the Convention. When a finding of non-compliance is reached the Committee may make recommendations to the MOP, which upon consideration of the report and any recommendations decides on appropriate general measures to bring about compliance with the Convention and measures to assist an individual Party's compliance. ${ }^{99}$ The Committee therefore does not have the power to take any measures vis-à-vis a Party as it only has advisory powers to the MOP.

The only way to address the Parties directly regards the possibility for the Committee to request further information from the Party whose compliance is being discussed, based on the results of the review of implementation. As seen above, ${ }^{100}$ and better explained further on, ${ }^{101}$ practice can offer some examples of correspondence on specific compliance issues.

\section{Coordination with Dispute Settlement Procedures and Other Non-Compliance Procedures}

Considering the relationship between Implementation Committee's procedure and other procedures under the Convention, two issues deserve special consideration. First, it must be noted that there is a specific provision regarding the relationship

\footnotetext{
94 Ibidem.

95 See supra paras. 4 and 8 respectively.

96 See Appendix to Decision III/2, supra n. 31, para. 3.

97 Ibid., para. 9.

98 Ibid., para. 10

99 Ibid., paras. 9 and 10 and supra paragraph 5.

100 See, supra paragraph 6.

101 See, infra paragraph 15.
} 
between Article 15 of the Convention, ${ }^{102}$ dealing with the settlement of disputes, and the compliance procedure. In particular, it provides that the latter is without prejudice to the former. ${ }^{103}$ Accordingly, the question arises as to whether a Party is prevented from having recourse to the formal dispute settlement procedure when a matter is under consideration by the Implementation Committee. On this score, an interpretation in good faith may suggest that Parties should primarily use the mechanism under the Convention and, only subsidiarily, have recourse to formal dispute settlement procedures. Moreover, since most MEAs obligations are not of a bilateral nature, it would normally prove difficult to identify an "injured State" that could establish a sufficient legal interest to invoke State responsibility for breaches of the obligations under consideration. Accordingly, it would be highly unlikely for a State to obtain standing before a competent international court or tribunal with regard to a breach of the obligations of the kind contained in the Convention. ${ }^{104}$

As for the second point at stake, the relationship between the inquiry procedure under the Convention and the compliance procedure needs to be analysed. Indeed the Convention provides a particular procedure to be exhausted when a Party considers that it would be affected by a significant adverse transboundary impact of a proposed activity - listed in Appendix I to the Convention - and when no notification has taken place. In this case the Convention provides that the Parties involved exchange sufficient information for the purpose of holding a discussion and, in the case of disagreement on whether a significant adverse transboundary impact is likely, any such Party may submit the fact to an inquiry commission, according to the provisions of Appendix IV. ${ }^{105}$

On this score para. 15 of the Appendix to Decision III/2 provides explicitly that "when a matter is being considered under an inquiry procedure under Article 3, paragraph 7, of the Convention, that matter may not be subject of a submission under it." The problem emerged in practice for the first time with the reconstruction of the "Danube-Black Sea Deep Water Navigation Canal in the Ukrainian Sector of the Danube Delta" (the Ukrainian Bystroe Canal Project). ${ }^{106}$

102 Art. 15 of the Convention provides that "[i]f a dispute arises between two or more Parties about the interpretation or application of this Convention, they shall seek a solution by negotiation or by any other method of dispute settlement acceptable to the parties to the dispute. 2. When signing, ratifying, accepting, approving or acceding to this Convention, or at any time thereafter, a Party may declare in writing to the Depositary that for a dispute not resolved in accordance with paragraph 1 of this Article, it accepts one or both of the following means of dispute settlement as compulsory in relation to any Party accepting the same obligation: (a) Submission of the dispute to the International Court of Justice; (b) Arbitration in accordance with the procedure set out in Appendix VII. 3. If the parties to the dispute have accepted both means of dispute settlement referred to in paragraph 2 of this Article, the dispute may be submitted only to the International Court of Justice, unless the parties agree otherwise."

${ }^{103}$ See para. 14 of the Appendix to Decision III/2, supra n. 31. On this subject-matter see, also, Koivurova, "The Convention ...", supra n. 2, at 222-226.

${ }^{104}$ On this subject-matter see, among other sources, Establishing a Compliance Review Mechanism Under the 1999 Protocol on Water and Health to the 1992 UN/ECE Water Convention, doc. MP.WAT/ WG.4/2004/2 (19 February 2004), at $6 \mathrm{ff}$.

105 See Art. 3.7 of the Convention.

${ }^{106}$ In particular, the Ukrainian Project planned the dredging of a Danube-Black Sea Deep Water Navigation Route, partly in the Ukrainian part of the Danube Delta and partly in the Danube River, which forms the boundary between Ukraine and Romania. 
Ukraine began development of the Bystroe Canal project without notifying Romania under the Convention. Accordingly, on 26 May 2004 Romania made a submission to the Implementation Committee as it was concerned about Ukraine's compliance with its obligations under the Convention. Furthermore, Romania on 19 August 2004 requested an inquiry under the Espoo Convention, believing that it should have been applied to the canal project. In January 2005 an Inquiry Commission was established to advise on the likelihood of significant adverse transboundary impact. ${ }^{107}$ As far as the relationship between the inquiry procedure and the Implementation Committee's activity is concerned, it must be noted that the latter recalled that although Romania had made a submission to it in May 2004, it was not in a position to consider that submission because of para. 15 of the Appendix to Decision III/2, ${ }^{108}$ and made the request to the Secretariat to be informed of any progress in the inquiry procedure. ${ }^{109} \mathrm{On}$ 10 July 2006 the Commission unanimously concluded that the building of the canal was likely to have significant adverse transboundary impacts, ${ }^{110}$ and handed over its report to the Ambassadors of Romania and Ukraine and to the Executive Secretary of the UNECE. On 23 January 2007 Romania made a second submission to the Implementation Committee that superseded the first one and, accordingly, the Implementation Committee agreed to consider the submission at its twelfth meeting. ${ }^{111}$ At its fourteenth meeting the Committee finalized its findings and recommendations. ${ }^{12}$

In light of the above it is not clear why the second MOP - the one which in 2001 established the Implementation Committee based on Decision II/4 - decided to deal with "non-compliance issues", explicitly addressing, alongside Article 15 of the Aarhus Convention, ${ }^{113}$ the Inquiry Commission, instead of the Implementation Committee. ${ }^{114}$ The answer may be found in the fact that at that time the Implementation Committee had just been established but was not yet operational. However, even on this score, it is doubtful whether we can compare Article 3.7 of the Convention - the inquiry procedure - with Article 15 of the Aarhus Convention which deals with the establishment of the mechanism for reviewing compliance. The former - as one of the

107 The Commission included two scientific or technical experts, one nominated by Romania and the other by Ukraine, and a third independent expert who acted as president of the Commission.

108 See Report of the Sixth Meeting of the Implementation Committee, doc. ECE/MP.EIA/WG.1/2005/3 (1 February 2005), para. 14.

109 Beside analyzing the Inquiry Commission's report, in the following meetings the Committee will have to decide whether para. 15 means that a submission to the Committee is suspended or terminated because the matter is being considered under an inquiry procedure (Report of the Ninth Meeting of the Implementation Committee, doc. ECE/MP.EIA/WG.1/2006/4 (28 April 2006), para. 37).

110 The final report of the Commission is available at $<$ http://www.unece.org/env/eia/documents/inquiry/ Final\%20Report\%2010\%20July\%202006.pdf> (visited 28 January 2008).

111 See Report of the Eleventh Meeting of the Implementation Committee, doc ECE/MP.EIA/WG.1/2007/4 (12 March 2007), para. 23. At present (28 January 2008), only the Informal Provisional Agenda for the Twelfth Meeting of the Implementation Committee is available on the Convention's official website.

112 See Findings and Recommendations further to a Submission by Romania Regarding Ukraine (EIA/ IC/S/1), doc. ECE/MP.EIA/2008/6 (27 February 2008) and Addendum to Findings and Recommendations further to a submission by Romania regarding Ukraine (EIA/IC/S/1), doc. EIA/IC/S/1/Rev.1 (7 May 2008).

113 A list of treaties with full references is provided supra at XXXVII.

114 See Report of the Second Meeting of the Parties, doc. ECE/MP.EIA/4 (7 August 2001), at 100. 
main procedural steps contained in the Convention - has been established to answer the question on whether transboundary impacts are likely to arise; the latter was created with the aim of reviewing compliance by the Parties with their obligations under that Convention with a view to fully assisting them to meet their commitments.

\section{Participation OF THE European COMMUnity}

The EC is a Party to the Convention. Upon signature and ratification of the Convention it declared that

"the Community Member States, in their mutual relations, will apply the Convention in accordance with the Community's internal rules, including those of the EURATOM Treaty, and without prejudice to appropriate amendments being made to those rules."

"The European Community considers that, if the information of the public of the Party of origin takes place when the environmental impact assessment documentation is available, the information of the affected Party by the Party of origin must be implemented simultaneously at the latest."

"The Community considers that the Convention implies that each Party must assure, on its territory, that the public is provided with the environmental impact assessment documentation, that it is informed and that its observations are collected." 115

Furthermore, upon approval of the Convention the EC declared that

"[i]n the field covered by the Espoo Convention, Council Directive 85/337/EEC of 27 June 1985 [on the assessment of the effect of certain public and private projects on the environment], annexed to this Declaration, applies. It enables the Community to comply with most of the obligations under the Espoo Convention. Member States are responsible for the performance of those obligations resulting from the Espoo Convention not currently covered by Community law and more specifically by Directive 85/337/EEC. The Community underlines that Directive 85/337/EEC does not cover the application of the Espoo Convention between the Community on the one hand and non-Member States party to the Espoo Convention on the other hand. The Community will inform the depositary of any future amendment to Directive 85/337/EEC.

From this, it follows that the Community, within the limits indicated above, is competent to enter into binding commitments on its own behalf with non-member countries which are Contracting Parties to the Espoo Convention." 116

With reference to the responses to the questionnaire on implementation for the period 2003-2005, ${ }^{117}$ the EC on 8 February 2006 confirmed the statements presented

\footnotetext{
115 See $<$ http://www.unece.org/env/eia/convratif.html $>$ (visited 28 January 2008).

116 Ibid.

117 On this point, see also supra paragraph 6, in particular, nn. 66 and 67.
} 
upon completion of the previous Review of Implementation 2003,118 and recalled that Directive 85/337/EEC (EIA Directive) ${ }^{119}$ had been modified by Directive 97/11/ $\mathrm{EC},{ }^{120}$ in order to fully align the EC law with the obligations arising from the Convention. ${ }^{121}$

It is worth noting that the EC, while it is a Party to the Convention, is not vested as the Party of origin or the affected Party - with the responsibility of applying the detailed procedures provided for by the Convention. ${ }^{122}$ Indeed, the European Community was not included by Decision I/3 in the list of contact points to which the proposed activities likely to cause significant adverse transboundary impact must be notified. ${ }^{123}$ Thus, the reference in the questionnaire to the implementation of the Espoo Convention obligations and of the procedures put in place by the Parties indicates those procedures put in place by the Member States of the EC (domestic law) in order to meet the obligations laid down in both the Espoo Convention and the EIA Directive. ${ }^{124}$

\section{FinANCIAL ASPECTS}

Costs concerning the activities of the Implementation Committee are covered by the UNECE regular budget and by the contributions made by the Parties. The first Meeting of the Parties decided that the Parties should contribute to the budget of the Convention on a voluntary basis. ${ }^{125}$ Accordingly, each MOP deals with the budget and financial arrangements necessary to support the activities planned under the Convention for the period until the subsequent meeting. ${ }^{126}$

118 See the documents at <http://www.unece.org/env/eia/review2006.htm> (visited 28 January 2008).

119 Council Directive of 27 June 1985 on the assessment of the effects of certain public and private projects on the environment, OJ (1985) L 175/40.

${ }^{120}$ Council Directive 97/11/EC of 3 March 1997 amending Directive 85/337/EEC on the assessment of the effects of certain public and private projects on the environment, OJ (1997) L 073/5.

${ }_{121}$ As for the Report for the application and effectiveness of the EIA Directive (97/11/EC) for the EU Member States up to 2003, see <http://www.unece.org/env/eia/review_eia_directive.html > (visited 28 January 2008) and COM(2003)334 final, available at $<$ http://eurlex.europa.eu/LexUriServ/site/en/com/2003/ com2003_0334en01.pdf> (visited 28 January 2008). For a comparison of the relevant articles of the Espoo Convention and the EIA Directive, see, in particular, Report of the Second Meeting of the Parties, doc. ECE/ MP.EIA/4 (7 August 2001), at $85 \mathrm{ff}$. See also the studies, reports and guidance documents initiated by the European Commission at $<$ http://ec.europa.eu/environment/eia/eia-support.htm $>$ (visited 28 January 2008).

${ }^{122}$ For the procedures provided for by the Convention see supra paragraph 1.

123 Decision I/3 on Points of Contact, doc. ECE/MP.EIA/2 (10 November 1998), Annex III, at 17.

124 With regard to the implementation in European Community law of the SEA Protocol - not yet in force - see Directive 2001/42/EC of the European Parliament and of the Council of 27 June 2001 on the assessment of the effects of certain plans and programmes on the environment (SEA Directive), OJ (2001) L197/30.

125 See Decision I/8 on the Budget and Financial Arrangements for the Period Until the Second Meeting of the Parties, doc. ECE/MP.EIA/2 (10 November 1998), Annex VIII.

126 See ibid. and Decision II/13 on the Budget and Financial Arrangements for the Period up to the Third Meeting of the Parties, doc. ECE/MP.EIA/4 (7 August 2001), Annex XIII. Among all the other activities, the decisions deal with the funding for reporting system activities and the Committee's meetings. 
A delicate issue is the introduction of a system of shares. Provided that not all the activities in the previous work plan (Decision II/11) were undertaken because of a lack of funding, the third MOP (13 September 2004) decided that the Parties should choose to make contributions equivalent in value to a number of shares of the budget. ${ }^{127}$ Furthermore, the MOP urged Parties and encouraged non-Parties and relevant international organizations to contribute resources to the budget in cash or in kind. ${ }^{128}$

\section{Survey of Practice}

From the survey of practice - still at an early stage - it emerges that there have been, on the one hand, four cases of consideration of specific compliance issues for which the Implementation Committee decided to request the Parties to furnish the necessary information about the implementation of or the compliance with the Convention and, on the other, the case of Romania making a new submission on 23 January 2007 regarding its concerns about Ukraine's compliance with its obligations under the Convention. The latter has already been dealt with. ${ }^{129}$ As to the former, the Secretariat was assigned the specific task of sending letters on behalf of the Implementation Committee to those Parties from which clarification was needed. We have already mentioned the "pilot cases" of Armenia, Kyrgyzstan and Finland, all three Parties being members of the Committee. ${ }^{130}$ By way of an example Finland was asked by the Secretariat to clarify its position regarding the right of the public to comment and to receive EIA documentation. ${ }^{131}$ More recently, the Secretariat wrote to Moldova, on behalf of the Implementation Committee's Chair, requesting information about its procedure for carrying out transboundary EIAs. The Implementation Committee, after considering the response and examining the completed revised questionnaire submitted to it, agreed that it was satisfied with the information received. ${ }^{132}$

127 In particular, it was decided that activities under the work plan for the period up to the fourth meeting of the Parties not covered by the United Nations regular budget should be covered by contributions of 1312 shares of one thousand United States dollars each, of which 520 shares would cover the core requirements and 792 shares would cover the remaining non-core requirements (Decision III/10 on the Budget and Financial Arrangements for the Period until the Fourth Meeting of the Parties, doc. ECE/MP.EIA/6 (13 September 2004), Annex X, point 2). See the Fourth Biannual Financial Report (for period to 31 December 2006), available at $<$ http://www.unece.org/env/eia/budget.htm $>$.

128 To this end the Trust Fund on Local Technical Cooperation was established to which all the contributions in cash were to be addressed (see Decision III/10, supra n. 127), point 7).

129 See supra paragraph 12. For further details on the procedure and on the findings and recommendations taken by the Committee, see Jendrośka, supra n. 85, at 331-332.

130 See supra paragraph 6 and 11.

131 For more details see all the examples of correspondence regarding the specific compliance issue at $<\mathrm{http}$ //www.unece.org/env/eia/implementation_committee_letters.htm> (visited 28 January 2008).

${ }_{132}$ See ibid. and Report of the Tenth Meeting of the Implementation Committee, doc. ECE/MP.EIA/ WG.1/2007/3 (6 February 2007), para. 20 and, more recently, Report of the Eleventh Meeting of the Implementation Committee, doc. ECE/MP.EIA/WG.1/2007/4 (12 March 2007), paras. 8-13. 


\section{Bibliography}

H. Adsett, A. Daniel, M. Husain, and T. L. McDorman, "Compliance Committees and Recent Multilateral Environmental Agreements: The Canadian Experience with Their Negotiation and Operation", Canadian YB Int'l L., 42 (2004) 91-142; R. Churchill and G. Ulfstein, "Autonomous Institutional Agreements in Multilateral Environmental Agreements: a Little-Noticed Phenomenon in International Law", Am. J. Int'l L., 94 (2000) 623-659; T. Koivurova, "The Convention on Environmental Impact Assessment in a Transboundary Context (Espoo Convention)", in G. Ulfstein (ed.), Making Treaties Work: Human Rights, Environment and Arms Control (Cambridge: Cambridge University Press, 2007), 218-239; C. Pitea, "NGOs in NonCompliance Mechanisms under Multilateral Environmental Agreements: From Tolerance to Recognition?", in T. Treves, M. Frigessi di Rattalma, A. Tanzi, A. Fodella, C. Pitea, and C. Ragni (eds.), Civil Society, International Courts and Compliance Bodies (The Hague: T.M.C. Asser Press, 2005) 205-224. 
1 


\title{
Chapter Twelve
}

\section{The Compliance Mechanism of the 1991 Convention on the Protection of the Alps and its Protocols}

\author{
Laura Pineschi
}

\section{Brief Introduction to the Alpine Convention}

The Convention on the Protection of the Alps (Salzburg, 7 November 1991) [hereinafter: the Alpine Convention] ${ }^{1}$ is the first multilateral treaty devoted to the sustainable development of a mountain area, the largest in Europe (surface area: 190.600 $\mathrm{km}^{2}$; population: $\left.13.6 \mathrm{~m}\right),{ }^{2}$ on the basis of a cross-sectoral, comprehensive approach of social, economic and environmental issues. Eight States (Austria, France, Germany, Italy, Liechtenstein, Monaco, ${ }^{3}$ Slovenia and Switzerland) and one international organization, the European Community, are bound by the Alpine Convention, which entered into force at the international level on 6 March 1995.

The Alpine Convention is a framework agreement completed by several implementing protocols. They cover eight of the twelve areas where the Parties are particularly requested by the Convention to take action (Article 2.2): ${ }^{4}$ the Protocol on Nature

\footnotetext{
1 The text of the Alpine Convention in the four authentic (French, German, Italian and Slovene) languages is available at the official Alpine Convention's website: <http://www.convenzionedellealpi.org/ index.htm> (last visited on 23 June 2008). For an unofficial English version see W. Burhenne (ed.), International Environmental Law - Multilateral Treaties (Alphen aan den Rijn: Kluwer Law International, from 1974 loose-leaf) (hereinafter: $B U), 991: 83$.

2 See Permanent Secretariat of the Alpine Convention, The Multi-Annual Work Programme of the Alpine Conference, 2005-2010, Innsbruck, 2005, 6. The Framework Convention on the Protection and Sustainable Development of the Carpathians (Kiev, 22 May 2003), a multilateral treaty for the protection of another mountain area in Europe, was adopted only recently. The Convention entered into force on 4 January 2006. For the text of the Carpathians Convention see $B U, 2003: 39$.

3 Whether the Protocol on the Adhesion of Monaco to the Alpine Convention (Chambéry, 20 December 1994) has entered into force seems more mysterious than clear. See L. Pineschi, "The Convention for the Protection of the Alps and Its Protocols: Evaluation and Expectations", in T. Treves, L. Pineschi and A. Fodella (eds.), Sustainable Development of Mountain Areas. Legal Perspectives beyond Rio and Johannesburg (Milano: Giuffrè, 2004) 191-232, note 3, at 191.

4 After long negotiations a Declaration (not a Protocol) on population and culture was adopted in 2006 by the $9^{\text {th }}$ Alpine Conference. At the same session, the Alpine Conference established a working group with the task of drafting a report on the issue of waters in the Alps. This could be the first step towards the adoption of a Protocol on water management (Art. 2.2(e)). The adoption of a Protocol on the prevention of
}

T. Treves et al., eds., Non-Compliance Procedures and Mechanisms and the Effectiveness of International Environmental Agreements

(C) 2009, T.M.C. ASSER PRESS, The Hague, The Netherlands, and the Authors 
Protection and Landscape Conservation (Chambéry, 20 December 1994); ${ }^{5}$ the Protocol on Mountain Agriculture (Chambéry, 20 December 1994); the Protocol on Regional Planning and Sustainable Development (Chambéry, 20 December 1994); the Protocol on Mountain Forests (Brdo, 27 February 1996); the Protocol on Tourism (Bled, 16 October 1998); the Protocol on Soil Protection (Bled, 16 October 1998), the Protocol on Energy (Bled, 16 October 1998); the Protocol on Transport (Lucerne, 31 October 2000). A Protocol on Dispute Settlement was also adopted in Lucerne, on 31 October 2000.

All the Protocols are in force at the international level, but Italy and Switzerland, whose territories cover, respectively, the $27.3 \%$ and $13.2 \%$ of the Convention's area, ${ }^{6}$ have not yet completed the process of ratifying the Protocols. Only certain Protocols have been ratified by Monaco. ${ }^{7}$ The European Union has only approved four Protocols. ${ }^{8}$ During the ratification of the Protocol on Transport, France made an interpretative declaration that caused concern among other Parties who consider the French declaration to amount to a reservation. Reservations are not prohibited by the Convention and its Protocols, but the consistency of the French declaration with the object and purpose of the Protocol on Transport is questionable. This scenario must be duly taken into account when the assessment of the effective implementation of and compliance with the obligations provided for by the Alpine Convention and its Protocols is under discussion.

Under the Alpine Convention, the Parties agree to establish a "comprehensive policy" for the preservation and protection of the Alps (Article 2). To achieve this holistic approach, some basic principles (prevention, "polluter pays", precaution, sustainable development, exchange of information and data, planning and public participation) are explicitly mentioned or can be inferred by the Convention and its Protocols. In principle, specific measures should be contained in the latter, but many obligations are expressed in the Protocols in very broad and vague terms with some exceptions being explicitly admitted. ${ }^{9}$ No Protocol provides for specific parameters (for instance, emission limits in the atmosphere, or discharge into soil or waters) or particular procedures. Very minimal requirements are expressed in the field of prior consultation for projects which can have transboundary effects.

The weakness of many provisions actually reveals the inability of the Parties to achieve a convergence on more ambitious goals in certain crucial issues. Obviously, the "programmatic" nature of certain duties does not mean that the undertaking of appropriate action can be deferred by States Parties ad libitum. However, the vagueness of many obligations under the Convention and its Protocols raises problems of

air pollution (Art. 2.2(c)) and a Protocol on waste management (Art. 2.2(1)) have never been inserted in the agenda of the meeting of the Parties.

5 The text of this and following Protocols is available at the official Alpine Convention's website (see supra $\mathrm{n} .1$ ).

${ }^{6}$ See Permanent Secretariat of the Alpine Convention, The Multi-Annual Work Programme, supra n. 2, at 6 .

7 Monaco is not bound to the Protocols on agriculture, forests, energy and transport.

8 The European Community has not approved the Protocols on nature protection and landscape conservation, regional planning and sustainable development, forests, transport and settlement of disputes.

9 See, for instance, the Protocol on transports, Art. 8.2, and Art. 11.3. 
interpretation on the effective content of the duties undertaken by the Parties. The bodies operating under the verification procedure recently established to monitor the effective implementation of the Alpine Convention and its Protocols ${ }^{10}$ could therefore contribute considerably towards clarifying the content of these obligations and resolving problems of divergent interpretations.

The Alpine Convention also provides for the establishment of an institutional structure, composed of three main bodies: the Conference of the Contracting Parties (the Alpine Conference), the Standing Committee and the Permanent Secretariat. The Alpine Conference, which has been regularly meeting every two years since $1996,{ }^{11}$ is competent to adopt amendments and Protocols to the Convention and to recommend measures both in the areas of cooperation covered by the Convention and in the implementation process of the Convention and its Protocols (Article 6). Governmental (IGOs) ${ }^{12}$ and non-governmental organizations (NGOs), ${ }^{13}$ representatives of all European countries and cross-border associations of Alpine territorial authorities can take part in the meetings of the Alpine Conference as observers.

The Standing Committee - the executive body - can propose measures and recommendations for the achievement of the purposes of the Convention and Protocols to the Conference of the Parties. It also informs the Conference about the implementation of the Convention, its Protocols and the Conference's decisions (Article 8). Delegates of the Parties to the Convention and representatives of IGOs and NGOs ${ }^{14}$ (as observers) attend the meetings of the Standing Committee.

The Secretariat - the administrative body of the Convention - was established by the Conference of the Parties in 2002. ${ }^{15}$ It operates in two seats: Innsbruck (Austria), where political and administrative functions are carried out, and Bolzano (Italy), for technical and operative activities. ${ }^{16}$

\footnotetext{
${ }^{10}$ See infra paragraph $2 \mathrm{ff}$
}

11 Three Alpine Conferences were held before the entry into force of the Convention: the first in Berchtesgaden (October 1989); the second in Salzburg (November 1991), where the Alpine Convention was opened to signature; the third in Chambery (November 1994).

12 Art. 5.5 of the Alpine Convention expressly mentions the United Nations, its specialized agencies and the Council of Europe.

13 According to Art. 5.5 of the Alpine Convention, international NGOs, "actives dans ce domain", may be admitted to the Conference as observers. At present, 12 NGOs enjoy this status within the Alpine Conference.

${ }^{14}$ According to Art. 8.4 of the Alpine Convention, the Standing Committee decides on the procedures for any participation of representatives of governmental and/or non-governmental organizations at its meetings. See also Art. 3.2 of the Rules of the Standing Committee. At present, 12 entities enjoy the status of observer. For the complete list see: $<$ http://www.convenzionedellealpi.org/page4FP_it.htm\#A2 > (visited on 14 February 2007).

15 Decision VII/2 sur le Secrétariat permanent de la Convention sur la protection des Alpes (Convention Alpine) (19-20 November 2002) (French version), in Treves, Pineschi, and Fodella (eds.), supra n. 3, available at $<\mathrm{http}$ ///www.convenzionedellealpi.org/archive/2002/VII Conferenza Alpi/VII2 Segretariato Permanente_fr.pdf $>$ (visited 15 July 2008). For a non-official English translation see Envt'l Pol'y \& L., 33 (2003), at $179 \mathrm{ff}$.

16 The text of the Headquarters Agreements of the Secretariat with Austria and Italy is reprinted in Treves, Pineschi, and Fodella (eds.), supra n. 3, at $338 \mathrm{ff}$. 


\section{Legal Basis of the Mechanism and Negotiating History}

The legal basis for the establishment of a non-compliance-procedure can be implicitly inferred by the Alpine Convention, where a reporting system, based on the information given by the Parties about their progress in implementing the Convention and its Protocols, is regulated by Articles 5.4, 6(g), and 8.6(a). ${ }^{17}$ The information is "analysed" by the Standing Committee and "reported" to the Conference of the Parties, which "shall take note" ("prend connaissance") of the information. All the Protocols contain similar provisions, ${ }^{18}$ however, it is added that the Alpine Conference can adopt recommendations if it ascertains non-compliance ("un manquement") by the Parties with their obligations. It is left to the Conference to decide at which intervals reports have to be submitted.

In recognition of the International Year of Mountains 2002 and with a view to the World Summit on Sustainable Development in 2002, the VI ${ }^{\text {th }}$ Alpine Conference (Lucerne, October 2000) called Parties to make all efforts to conclude the ratification procedures of the Protocols and to focus their cooperation on their effective implementation. An ad hoc Working Group on "Implementation mechanisms" was therefore established by the Conference with the mandate to draft a proposal for a regular assessment of the implementation of the Alpine Convention and its Protocols. The Resolution establishing the Working Group added as well that

"The proposal should, in particular, comment on conditions for reporting and address the following issues: a mechanism to analyse and evaluate reports that have been submitted, the support of contracting Parties who have problems with implementation and a mechanism for consensual problem solving." 19

The Working Group, chaired by Switzerland, immediately agreed on the need for a simple and efficient mechanism, adaptable to development needs. It held three meetings in Bern (14-15 March 2001; 12-13 November 2001; 22-24 April 2002), open to the Parties to the Alpine Convention and observers represented at the Standing Committee. No delegate of the European Union took part in the meetings.

In November 2002, the Alpine Conference adopted Decision VII/4, providing for the establishment of a Compliance Mechanism of the Alpine Convention and its Protocols. $^{20}$

17 This assumption is confirmed by the Preamble of Decision VII/4 (see infra, para. 3), according to which the reporting procedure under Art. 5.4 of the Alpine Convention is recognized as an essential precondition for the functioning of the planned mechanism (para. 3).

${ }_{18}$ See, e.g., Art. 20 of the Protocol on Agriculture or Art. 17 of the Protocol on Regional Planning and Sustainable Development.

19 Resolution 5.4 (5) of 31 October 2000 as translated by T. Enderlin, "A Different Compliance Mechanism", Envt'l Pol'y \& L., 33 (2003) 155-159, note 1, at 159.

${ }_{20}$ Décision VII/4 sur le Mécanisme de verification du respect de la Convention alpine et de ses protocols d'application (19-20 November 2002) (French text). The text is also available at $<$ http://www.convenzionedellealpi.org/archive/2002/VII_Conferenza_Alpi/VII4_Meccanismo_Verifica_fr.pdf $>$ (visited on 15 July 2008). For a non-official English version, see Envt'l Pol'y \& L., 33 (2003), at 179. 


\section{The Text Establishing the Mechanism}

The procedure is not regulated by an amendment to the Convention or to the Protocols, but by a decision of the Alpine Conference. Decision VII/4 specifies that the mechanism should apply also to future amendments of the Alpine Convention and its Protocols as well as to new Protocols (Preamble, para. 9). The same decision expressly points out that the entire procedure can be amended by the Alpine Conference (Preamble, para. 10).

No possibilities of opting out are envisaged.

\section{The Principles Governing the Mechanism and the Procedure}

The aim of the compliance procedure is to ensure the effective implementation of obligations undertaken by Parties to the Alpine Convention and its Protocols. Decision VII/4 explicitly spells out that the procedure is non-confrontational, non-judicial and non-discriminatory (Preamble, last paragraph).

\section{InSTITUtional ASPECTS}

\subsection{The Reviewing Committee}

Decision VII/4 provides for the establishment of a permanent working group, the Reviewing Committee (Comité de verification), which considers issues of implementation and compliance and makes appropriate recommendations to the Alpine Conference. The power of the Alpine Conference to establish the Reviewing Committee relies upon Article 6(e) of the Alpine Convention, according to which the Conference can approve the establishment of working groups deemed necessary for the implementation of the Convention. The Rules of Procedure of the Standing Committee apply to the Reviewing Committee, unless the latter decides to expand on or diverge from these Rules (Section II, para. 1.3).

\section{a) Composition}

The Reviewing Committee is composed of two representatives of each Party to the Alpine Convention and, taking into account the role that observers have always played within the Standing Committee and the Alpine Conference, two delegates of each observer are admitted to take part in the meetings of the Standing Committee. ${ }^{21}$ The Decision does not specify whether members must be experts in areas relating

${ }^{21}$ From the textual reading of the relevant rule of Decision VII/4 (Section II, para. 1.1) it could be inferred that only two representatives of all observers taking part in the meetings of the Standing Committee are admitted in the Reviewing Committee. However, the practice of the Reviewing Committee clearly shows that the meetings of the Committee can be attended by representatives of one or all observers admitted in the Standing Committee. At the $25^{\text {th }}$ Session of the Standing Committee, observers declared that they would 
to the subject-matter of the Convention; however, according to Article 3.2 of the Rules of Procedure of the Standing Committee, ${ }^{22}$ NGOs may be admitted as observers if they have a certain competence in matters covered by the Alpine Convention. ${ }^{23}$ Experts can be consulted, if necessary.

\section{b) Status of Members}

Decision VII/4 does not contain provisions requiring the members of the Committee to be impartial and independent or, at least, to serve objectively in the best interest of the Convention and its Protocols as other compliance procedures do. ${ }^{24}$ Therefore, members designated by the Parties to Convention do not operate in their individual capacity.

\section{c) Observers}

As already stressed, observers may take part in the meetings of the Reviewing Committee. Neither Decision VII/4 nor the Rules of Procedure of the Standing Committee $^{25}$ specify the rights of observers, but the right to comment and the right to be heard are ensured by an established practice within the Standing Committee. It is instead explicitly provided for that, considering the confidential character of the discussions during the entire procedure, one or all observers can be excluded from discussions. Decision VII/4 spells out two specific causes of exclusion: the observer infringed the rules on confidentiality; information classified as confidential is treated as such (Section II, para. 3.1.5). The list is not exhaustive.

\section{d) Functions}

The task of the Reviewing Committee is threefold: it performs a general duty of regular monitoring on the state of implementation of the Convention and its Protocols ("regular procedure"); ${ }^{26}$ it considers specific situations of non-compliance by the Parties with certain obligations of the Convention and its Protocols ("incidental

send only one person to the meetings of the Reviewing Committee; the second person is appointed as an alternate, see: Enderlin, supra n. 19, at 157.

${ }^{22}$ Available at <http://www.convenzionedellealpi.org/NR/rdonlyres/5B104D6B-61EC-4D12-B368E810CCC0DEE1/0/regCP_fr.pdf $>$ (visited on 14 July 2008).

${ }^{23}$ In particular, NGOs aiming to obtain the observer status within the Standing Committee must, inter alia, pursue in their Statutes the objectives of the Alpine Convention, be active in the whole Alpine area and have their seat in the Alpine space.

${ }^{24}$ See, for instance, the Compliance procedure adopted within the Basel Convention, Decision VI/12 of 2002, doc. UNEP/CHW.6/40 (10 February 2003) at $45 \mathrm{ff}$.

${ }^{25}$ As it was already stressed, the Rules of Procedure of the Standing Committee apply to the Reviewing Committee, unless the Committee decides to expand on or diverge from these Rules.

${ }^{26}$ The expression is of M. Reiterer, "The Alpine Convention and beyond: Recent Developments concerning Mountainous Regions”, Austrian Rev. Int'l Eur. L., 6 (2001) 245-256, at 247. 
procedure"): ${ }^{27}$ it assists the Parties, at their request, in the implementation of the Convention and its Protocols.

Both in relation with the regular and incidental procedures, the Reviewing Committee reports to the Standing Committee.

\subsection{The Secretariat}

The Secretariat exercises functions of support and assistance to the Reviewing Committee, according to its instructions (Section II, para. 1.2). It receives the country reports and transmits them to the Reviewing Committee, other Alpine Convention's Parties and the observers represented at the Standing Committee. It also has the duty to make the reports public, with the exception of the information that the relevant Party has classified as confidential (Section I, para. 1.3 and Section II, para. 3.2.2). Finally, it transmits to the Standing Committee the reports of the Reviewing Committee (Section III, para. 3.2.6).

\subsection{The Standing Committee}

The Standing Committee receives the reports of the Reviewing Committee and forwards them "unchanged" ("en l'état", in the French version, Section II, para. 3.2.7) to the Alpine Conference. However, the role played by the Standing Committee is not limited to a mere forwarding of documents from the Reviewing Committee to the Alpine Conference. Decision VII/4 allows comments of the Standing Committee on the Reviewing Committee's reports ("Le Comité permanent transmet les rapports (...) éventuellement accompagnés d'évaluations", Section II, para. 3.2.7). ${ }^{28}$ Furthermore, the Preamble of Decision VII/4 specifies that the Reviewing Committee operates "in agreement" ("en concertation") with the Standing Committee. Considering that the members of the Reviewing Committee do not operate in their individual capacity, this condition can be interpreted more as the wish to coordinate a political body exercising specific competences (assessment of effective implementation of and compliance with their obligations by Contracting Parties) with a political body competent on all matters covered by the Alpine Convention and its Protocols, than an attempt to limit the independence of the body exercising monitoring functions.

\subsection{The Alpine Conference}

The Conference of the Parties concludes the procedure on the basis of the reports of the Reviewing Committee and adopts resolutions and recommendations on the action to be taken (Section II, para. 4.1 and 4.2).

\footnotetext{
${ }^{27}$ Ibid., at $248 \mathrm{ff}$.

${ }^{28}$ On the negotiations that preceded the adoption of this rule, see Enderlin, supra n. 19, at 158.
} 


\section{Functions of The Committee}

From the above description of the basic functions of the Reviewing Committee, ${ }^{29}$ it can be concluded that the powers of this body are not limited to a review of the procedural obligations, but include the assessment of compliance with substantive obligations. However, the Committee has not the power to force Parties to comply with their treaty obligations. It only has the duty to monitor their behaviour, give them advice and support, if requested, and suggest appropriate action to the Alpine Conference. The latter is, in fact, the only body which can take action vis-à-vis Contracting Parties.

\section{TRIGGER MeCHANISM}

\subsection{Submissions by Parties and Observers}

Situations may be referred to the Reviewing Committee by Contracting Parties and observers (Section II, para. 2.3) at any time (Section II, para. 3.2.8). Submissions must be made in writing and supported with reasons. The involvement of NGOs in the verification process is much more extensive than in other non-compliance procedures. The observers' trigger power can be seen as a "natural" consequence of the particular role that observers have always played within Alpine Convention system.

\subsection{Initiation Motu Proprio}

The relevant provision of Decision VII/4 (Section II, para. 2.3) is sufficiently vague to allow a self-triggering procedure.

\subsection{Referrals by the Secretariat}

The Secretariat has no triggering functions.

\subsection{Communications by Territorial Entities and the Public}

Not having been mentioned by Decision VII/4, territorial authorities and the public cannot refer situations to the Reviewing Committee. However, nothing prevents territorial authorities and the public from acting through a Contracting Party or observers represented in the Reviewing Committee.

\footnotetext{
29 See supra paragraph 5.
} 
8. The Procedure before the Reviewing Committee and Procedural SAFEGUARDS

\subsection{General Procedural Issues}

The procedure is governed by Decision VII/4. The rules of the "regular" procedure apply mutatis mutandis to the "incidental" procedure (Section III, para. 3.2.8). The procedure consists in three stages. After the reception of a request to investigate an alleged case of non-compliance, the Reviewing Committee transmits to the Party concerned a preliminary report containing its observations, as well as the opinion of other Contracting Parties and observers represented at the Standing Committee. If the relevant Party declares to be ready to remedy the shortcomings identified by the Reviewing Committee, the process can be interrupted, since the Reviewing Committee can refrain from addressing recommendations to the Alpine Conference. Yet, in this case, the Reviewing Committee is requested to exercise a follow-up competence, i.e., to monitor the effective implementation of the measures notified by the Party concerned (Section II, para. 3.2.5). The opportunity of the Party concerned to conclude at any time the monitoring process through the acceptance of the observations raised by the Reviewing Committee has been admitted in order to simplify and accelerate the procedure as far as possible.

At the second stage, the Reviewing Committee transmits its final report to the Standing Committee (Section III, para. 3.2.6). According to this provision, the report is forwarded two months after the Reviewing Committee has received the comments of the Party concerned. It follows that the report should be drafted taking into account these observations.

The final stage is handled by the Alpine Conference, which can adopt resolutions or recommendations on the basis of the report of the Reviewing Committee.

\subsection{Procedural Safeguards}

The rights of the Party concerned to be heard and to participate in the non-compliance procedure are fundamentally respected. Both the submitting Party and the Party under scrutiny are entitled to take part in the entire process, to have access to all relevant documents and to make comments on the work of the Reviewing Committee (Section II, para. 3.1.1).$^{30}$ The right to comment on the draft report of the Reviewing Committee to the relevant Party is also expressly recognised (Section II, para. 3.2.4). Furthermore, it has already been stressed that the Party concerned can avoid the scrutiny of the Alpine Conference if it declares its readiness to remedy the identified shortcomings. ${ }^{31}$ Decision VII/4 does not explicitly exclude the Party concerned from taking part in the elaboration and adoption of the report of the Reviewing Committee. However, a right of veto of the Party concerned is excluded. The Reviewing Committee adopts its reports by consensus, but if all efforts to achieve consensus have been

\footnotetext{
${ }^{30}$ See also Section II, para. 2.4

${ }^{31}$ In this case, the Reviewing Committee monitors the effective implementation of the measures notified by the Party concerned. See supra paragraph 8.1 .
} 
exhausted and the Chairperson expressly ascertains it, the reports can be adopted with a three-quarters majority (Section II, para. 3.2.9).

A more restrictive approach is adopted for the participation of observers. The provision according to which any Party is entitled to take part in the entire process, to have access to all relevant documents and to make comments on the work of the Reviewing Committee is not explicitly extended to observers. Furthermore, as already stressed, in certain cases observers can be excluded from discussions. ${ }^{32}$

In principle, transparency is ensured. The reports of the Parties (Section II, para. 1.3), the reports of the Reviewing Committee and the resolutions and recommendations of the Alpine Conference (Section II, para. 4.3) are made public. Only discussions under the entire process are confidential (Section II, para. 3.1.5).

No appellate procedures against resolutions and recommendations of the Alpine Conference are envisaged by Decision VII/4.

\section{SOURCES OF INFORMATION}

The Reviewing Committee may rely on a variety of sources to collect objective information. The main source is the reports that each Party has the duty to submit to the Reviewing Committee every four years (Section I, para. 1.1). A specific provision requires the Parties to indicate areas where they face difficulties in complying with obligations envisaged by the Protocols (Section I, para. 2.4). Information is also contained in the communications submitted under the "incidental procedure".

Additional information can be collected in different manners. Decision VII/4 enables the Reviewing Committee to ask for more information from the Parties or to obtain information from other (not specified) sources (Section II, para. 2.1). The Committee can also gather information in the territory of the Parties to the Alpine Convention and its Protocols with the prior consent of the Party concerned.

From the vague wording of Decision VII/4 it can also be inferred that information may be collected both through the experts that can be invited by the Reviewing Committee to take part in its meetings whenever it deems it necessary (Section II, para. 1.1) and the observers represented within the Committee. The collection of additional information through the Permanent Secretariat cannot be excluded either, considering the broad powers that have been granted to the Reviewing Committee in the regulation of the duties of assistance of this body.

\section{DeCISION-MAKING}

Decision VII/4 regulates the decision-making process within both the Reviewing Committee and the Alpine Conference. The procedure within the Reviewing Committee has already been illustrated. ${ }^{33}$ The same procedure is envisaged for the adoption of resolutions and recommendations by the Alpine Conference (Section II, para. 4.1).

\footnotetext{
32 See supra paragraph 5.1(a).

33 See supra paragraph 8.2.
} 
Therefore, the Conference adopts its reports by consensus. Reports can be adopted with a three-quarters majority only if the Chairperson expressly determines that all efforts at achieving consensus have been exhausted and no agreement can be reached (Section II, para. 3.2.9).

As regards matters falling under a Protocol, only Parties to that Protocol are entitled to vote (Section II, para. 3.1.2).

\section{Outcomes}

Both in the "regular" and in the "incidental" procedure the final stage of the process is handled by the Alpine Conference. According to Decision VII/4, resolutions and recommendations of the Conference encompass: advice and assistance to the Party concerned; assistance to the same Party in the setting-up of a strategy for complying with its obligations; arrangements for experts; enquiries on the territory of the Party concerned with the consent of this Party in order to identify compliance problems and possible solutions; measures to promote cooperation between the Party concerned, other Contracting Parties, inter-governmental and non-governmental organizations; inviting the Party concerned to draft a strategy for the compliance with its obligations; requiring a time-table for the compliance with the Convention and its Protocols (Section IV, para. 4.2). No measures that can be adopted by the Alpine Conference have a "sanctionary" nature. Some stronger outcomes, such as the withdrawal of voting rights for continued non-compliance with treaty obligations had been discussed by the Working Group requested to draft the verification procedure. However, as its Chairman very clearly explained:

“(...) it was necessary not to overstep the legal framework of the Alpine Convention, so as not to produce an amendment to the Convention that requires ratification. The measures listed above are contained within the existing legal framework: they also seem appropriate for the requirements of the regionally anchored Alpine Convention". ${ }^{34}$

From the wording of Decision VII/4 it can be inferred that the Alpine Conference is free to conclude the procedure with no action (the Alpine Conference can adopt recommendations and resolutions), but it cannot adopt measures which are not mentioned by Decision VII/4. In other words, the list contained in Section IV, para. 4.2 is exhaustive.

With regard to the legal nature of the measures adopted by the Alpine Conference, the text of Decision VII/4 contains sufficient elements to conclude that they are not binding. The measures adopted by the Alpine Conference are contained in "resolutions" or "recommendations". No provision of the Alpine Convention deals with the legal nature of these measures nor specifies when they take effect. Article 7 regulates the voting procedure. No further specification is contained in the Rules of Procedure

\footnotetext{
34 Enderlin, supra n. 19, at 158.
} 
of the Alpine Conference. ${ }^{35}$ However, the omission of the expression "decision" a hypothesis that in certain cases is explicitly envisaged by the Alpine Convention ${ }^{36}-$ can be considered as a deliberate choice of the drafters and the Alpine Conference that adopted Decision VII/4 (expressio unius est exclusio alterius). This conclusion is further supported by the last preambular paragraph of Decision VII/4, where the Conference "notes" ("constate", in the French version) that the procedure established by that instrument is of a "consultative nature".

In any case, it is useless to say that States are under the duty to respect their treaty obligations in good faith. ${ }^{37}$ The non-compliance procedure adopted within the Alpine Convention system is regulated by a decision of the Alpine Conference. Therefore, the Parties that do not comply with resolutions and recommendations adopted by the Alpine Conference at the end of the verification process should at least give an explanation for their behaviour.

No follow-up procedures are envisaged by Decision VII/4.

\section{Coordination with Dispute Settlement Procedures and Other Compliance Procedures}

The Alpine Convention Compliance mechanism is independent from the dispute settlement procedure envisaged by the Protocol to the Alpine Convention on the Settlement of Disputes and it does not prejudice its proceedings (Decision VII/4, Section II, para. 4.4).

As far as the consistency of the mechanism adopted within the Alpine Convention with the infringement proceedings envisaged by the European Community Treaty is concerned, a specific declaration was made by the European Commission during the negotiations of the compliance procedure. In November 2001, in a letter announcing its absence from the meetings of the Working Committee, the European Commission explicitly asserted that the instrument under negotiation was consistent with the duties of the members of the European Treaty under Community law. ${ }^{38}$

\section{Participation of the European Community}

The European Community is a Party to the Alpine Convention, ${ }^{39}$ but it has approved only a few Protocols ${ }^{40}$ It does not regularly attend the meetings of the Alpine

\footnotetext{
35 Available at <http://www.convenzionedellealpi.org/NR/rdonlyres/A27E9EFA-D3B6-4E03-9F01707C42CC4B64/0/regConfP_fr.pdf $>$ (visited on 15 July 2008).

${ }^{36}$ See, for instance, Art. $6(\mathrm{e})$.

${ }^{37}$ Pacta sunt servanda principle, Art. 26 of the Vienna Convention A list of treaties with full references is provided supra at XXXVII.

38 Second Report of the Working Group on "Implementation mechanisms" (6 December 2001).

${ }^{39}$ Council Decision 96/191/EC of 26 February 1996 concerning the conclusion of the Convention on the protection of the Alps (Alpine Convention), OJ (1996) L 61/31.

40 See supra $\mathrm{n} .8$.
} 
Convention's bodies and in principle it has always shown a very prudent attitude towards the Alpine Convention system. ${ }^{41}$

Since 2007, the new Secretary-General of the Alpine Convention, Marco Onida, has undertaken various initiatives to improve synergies between the activities undertaken under the Convention and within the European Union as well as to promote the participation of representatives of the European Institutions at the meetings of the Alpine Convention's bodies. ${ }^{42}$

\section{FinANCIAL AsPeCts}

No specific provisions either on financial aid measures for Parties facing compliance difficulties or on other financial issues are spelled out in Decision VII/4.

\section{Survey of Practice}

The verification process under the "regular procedure" was brought into operation in 2005 for the first time. The Reviewing Committee met four times under the Austrian Chairmanship, but it had no time to report to the Alpine Conference on all matters under its competence within the deadline prescribed by Decision VII/4. It therefore submitted an interim report where it points out the strengths and weaknesses of the activities undertaken by the Parties to comply with the Alpine Convention and its Protocols, but it did not proposed to the Alpine Conference the adoption of resolutions or recommendations vis-à-vis the Parties.

The inability of the Reviewing Committee to conclude the verification process was due to several factors. First of all, most of the national reports ${ }^{43}$ were submitted by the Parties after the expected deadline ( 31 August 2005) ${ }^{44}$ and not all the reports received were drafted in all the Convention languages. Furthermore, an overall and in-depth discussion of the national reports was not possible because certain delegations did not take part in meetings of the Reviewing Committee. Finally, the questionnaire on which the national reports were based ${ }^{45}$ was so detailed and long that all the Parties

${ }^{41}$ For a comment on the attitude of the European Union towards the Alpine Convention system, see J. Juste Ruiz, “L'action de l’Union Européenne en faveur des régions de montagne”, in T. Treves, L. Pineschi and A. Fodella (eds.), International Law and Protection of Mountain Areas (Milano: Giuffrè, 2002) 143-158, and A. Fodella, and L. Pineschi, "Environmental Protection and Sustainable Development of Mountain Areas", ibid., at 60. See also supra paragraph 2.

${ }^{42}$ Comité permanent de la Conférence alpine, Dimension européenne de la Convention alpine: cooperation avec les institutions européennes, Rapport du Secrétariat permanent, doc. PC36/14b (2007).

${ }^{43}$ National reports are available at $<$ http://www.convenzionedellealpi.org/page4CC_fr.htm $>$ (visited on 14 February 2007). The European Union submitted its report on 11 October 2005. It is available at the same website.

${ }^{44}$ At the time of drafting the interim report, one Party (Monaco) had not yet delivered its report.

45 A standard model questionnaire (of 160 pages!) was drafted by the Reviewing Committee and adopted by the Standing Committee in 2004. The questionnaire is available at $<$ http://www.convenzionedellealpi. org/NR/rdonlyres/21C19D95-7563-43A8-94D5-12994F04DD07/0/quest_fin_fr.pdf $>$ (visited on 14 February 2006) 
submitted very in-depth responses. Scepticism on the standard model questionnaire to which the Parties must refer in the drafting of their reports ${ }^{46}$ was also expressed by certain Parties. For instance, Switzerland, in a letter attached to its report, which was, inter alia, drafted in its entirety - even though this country had not yet ratified the implementing Protocols of the Alpine Convention - openly stated that the standard model is too long, too bureaucratic and scarcely useful for giving an account of the Alpine States' practice in the area of sustainable development. ${ }^{47}$

Taking into account all these factors, the Alpine Conference was requested by the Reviewing Committee: to re-consider the time limits envisaged by Decision VII-4, as the deadlines are too short in comparison with the resources allocated to the Committee; to recommend that future national reports do not cover all aspects of compliance at once; and to authorize the same Committee to select obligations which the Parties do not fully comply with.

Beyond these practical limits, the interim report drafted by the Reviewing Committee gives a good survey of the information submitted by the Parties. Possible weaknesses, contradictions and good practices are clearly pointed out with regard to compliance with general obligations under the Alpine Convention and specific duties deriving from different Protocols. The interim report also highlights the role played by one observer, CIPRA, which did not hesitate to stress the poor compliance with certain substantial matters by several Parties, the excessively positive character of certain answers to the questionnaire and clear discrepancies in the information provided by different Parties on the same matter. ${ }^{48}$

During the period under examination, neither the Parties nor the observers submitted claims for suspected non-compliance with the Convention and its Protocols.

\section{CONCLUSIONS}

As with other non-compliance procedures, the mechanism established within the Alpine Convention system has a consultative and non-confrontational nature. Its facilitative approach is particularly stressed by the Preamble of Decision VII/4 (the procedure can effectively contribute towards the effective implementation of the obligations undertaken by the Parties) $)^{49}$ and by the "soft" outcomes of the procedure.

Obviously, no definitive assessment of the mechanism can be made before it really works in practice. For the time being, the participation of observers in the Reviewing Committee and the triggering role that they can play in cases of non-compliance are the most prominent feature of the procedure. The readiness of certain observers to

46 See supra n. 40

47 The letter of the Swiss Government is available at <http://www.convenzionedellealpi.org/NR/ rdonlyres/DBE7ACA6-51E8-4862-8A1A-89C5678D17F6/0/letterCHfr.pdf> (visited on 14 February 2007).

${ }^{48}$ For instance, while Austria declares that it never informed other Parties on planned economic or legal measures which could produce particular effects on the Alpine regions or parts thereof other Parties maintained that they had always been sufficiently informed, Interim Report of the Chairman of the Reviewing Committee to the IX Alpine Conference (Alpbach, 9 November 2006).

49 Preamble, para. 2. 
play a substantive role in the control of the effective implementation of Alpine Convention obligations emerges as well from the practice. ${ }^{50}$

However, in the end it depends on the Parties to show whether they really are willing to operate for the effective functioning of this mechanism (therefore, for the effective implementation of the Convention) and to cooperate with Parties facing difficulties, as it was explicitly stressed in the resolution establishing the Working group on "Implementation mechanisms".

\section{Bibliography}

“Alpine Convention. Unique Innovations Now in Working Order", Envt'l Pol'y \& L., 36 (2006) 172; T. Enderlin, "A Compliance Mechanism within the Alpine Convention", in T. Treves, L. Pineschi and A. Fodella (eds.), International Law and Protection of Mountain Areas (Milano: Giuffrè, 2002) 159-162; T. Enderlin, "A Different Compliance Mechanism", Envt'l Pol'y \& L., 33 (2003) 155-159; L. Pineschi, "The Convention for the Protection of the Alps and Its Protocols: Evaluation and Expectations", in T. Treves, L. Pineschi and A. Fodella (eds.), Sustainable Development of Mountain Areas. Legal Perspectives beyond Rio and Johannesburg (Milano: Giuffrè, 2004) 191-232; C. Caldwell, "The Black Diamond of Harmonization: The Alpine Convention as a Model for Balancing Competing Objectives in the European Union", Boston University International Law Journal, 21 (2003) 137-155; M. Reiterer, "The Alpine Convention and beyond: Recent Developments concerning Mountainous Regions", Austrian Rev. Int'l Eur. L., 6 (2001) 245-256.

\footnotetext{
${ }^{50}$ See supra paragraph 14.
} 
1 


\title{
Chapter Thirteen
}

\section{Procedures and Mechanisms for Review of Compliance under the 1998 Aarhus Convention on Access to Information, Public Participation and Access to Justice in Environmental Matters}

\author{
Cesare Pitea
}

\section{Brief Introduction to the Aarhus Convention}

The Aarhus Convention ${ }^{1}$ is the first treaty transposing into a comprehensive and binding legal framework the principles enshrined in Principle 10 of the Rio Declaration. The Convention has 41 Parties, including the European Community, ${ }^{2}$ all belonging to the UNECE region, and particularly to its European component. However, the Convention has potentially a global scope: accession by any UN Member, subject to approval of the Meeting of the Parties (MOP), is possible (Article 19.3) and encour-

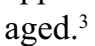

The Convention adopts a rights-oriented approach. It defines the rights that each Party's legal system shall recognise to the members of the public in three areas (socalled "pillars"): access to information (Articles 4-5), participation in decisionmaking (Articles 6-7-8) and access to justice (Article 9) in environmental matters.

\footnotetext{
${ }^{1}$ Convention on Access to Information, Public Participation in Decision-Making and Access to Justice in Environmental Matters (Aarhus, Denmark, 25 June 1998), entered into force on 30 October 2001, ILM, 38 (1999) 517. On the Convention see S.T. McAllister, "The Convention on Access to Information, Public Participation in Decision-Making, and Access to Justice in Environmental Matters", Colo. J. Int. Envt'l L. \& Pol'y YB (1998) 187-198; J. Harrison, "Legislazione ambientale europea e libertà di informazione: la Convenzione di Aarhus", Riv. Giur. Amb., 15 (2000) 27-46; M. Lee and C. Abbot, "The Usual Suspects? Public Participation Under the Aarhus Convention", Mod. L. Rev., 66 (2003) 80-108; E. Morgera, "An Update on the Aarhus Convention and its Continued Global Relevance", RECIEL, 14 (2005) 138-147. See also the special numbers of the Rev. Jur. Env., num. spéc. (1999), and of the J. Eur. Envt'l Plan. L., 2 (2005).

${ }^{2}$ Up-to-date figures on status of ratification may be found at $<\mathrm{http} / / / \mathrm{www}$.unece.org/env/pp/ratification. $\mathrm{htm}>$ (visited 20 January 2008).

${ }^{3}$ See Art. 19.3 opening the Convention to accession of other UN Members, subject to approval by the Meeting of the Parties, and Decision II/9 on Accession of Non-UNECE Member States to the Convention and Advancement of the Principles of the Convention in Other Regions and at the Global Level, doc. ECE/ MP.PP/2005/2/Add.13 (10 June 2005).
}

T. Treves et al., eds., Non-Compliance Procedures and Mechanisms and the Effectiveness of International Environmental Agreements

(C) 2009, T.M.C. Asser PREsS, The Hague, The Netherlands, and the Authors 
The Convention's objectives are to be achieved through regulatory, legislative or otherwise necessary measures, including enforcement measures (Article 3.1). Parties must also promote the principles of the Convention in international forums (Article 3.7). ${ }^{4}$ The "public" is broadly defined as "one or more natural or legal persons, and, in accordance with national legislation or practice, their associations, organizations or groups" (Article 2.4).

The access to information pillar has two components. Firstly, public authorities of a Party ${ }^{5}$ holding any environmental information ${ }^{6}$ must provide such information when a request is made by any member of the public, without the need for an interest to be stated. The Convention defines the modalities, timeframes and the costs for the requested information to be made available (Articles 4.1 and 4.2). An exhaustive list of grounds for refusal, including confidentiality, is provided and it shall be interpreted restrictively (Articles 4.3 and 4.4). Secondly, public authorities shall actively collect and disseminate environmental information, in accessible formats, including through the use of information technologies (Article 5). The first pillar of the Convention is complemented by the Protocol on Pollutant Release and Transfer Registers (Kiev, 2003) that has not yet entered into force. ${ }^{7}$

The public participation pillar includes extensive participatory rights in relation to the authorisation of specific activities that may have a significant environmental impact, including those listed in Annex I (Articles 6.1.a and 6.1.b). Parties may exclude the application of these provisions to activities serving a national defence purpose on a case-by-case basis (Article 6.1.c) and are encouraged, but not obliged, to extend it to the deliberate release of genetically modified organisms (GMOs) into the environment (Article 6.11). ${ }^{8}$ Article 6 requires Parties to set up a transparent regulatory framework for participation, providing for effective opportunities at an early stage of the decision-making process when options are still available (Article 6.3), establishing clear time frames enabling participation (Articles 6.3 and 6.4) and ensuring that the outcome of participation is taken into due account (Article 6.8). To this effect specific provisions on the information given or made available to the public (Articles 6.2 and 6.6), including that relating to the outcome of the process (Article 6.9) and to the modalities of participation (Article 6.7), are provided. These rights are mostly to be afforded to the "public concerned", e.g., those members of the public actually or potentially affected by, or having an interest in, the decision. Interestingly, this always includes environmental NGOs (Article 2.5). Less stringent provisions on

\footnotetext{
${ }^{4}$ See the "Almaty Guidelines on Promoting the Application of the Principles of the Aarhus Convention in International Forums" adopted by the second MOP with Decision II/4 on Promoting the Application of the Principles of the Aarhus Convention in International Forums, Annex, doc. ECE/MP.PP/2005/2/Add.5 (20 June 2005).

5 This includes any natural or legal person having public responsibilities or functions, or providing public services, in relation to the environment, under the control of a public authority (Art. 2.2).

6 As broadly defined in Art. 2.3.

7 See C. Pitea, "Procedures and Mechanisms for Review of Compliance under the 2003 Protocol on Pollutant Release and Transfer Registers to the 1998 Aarhus Convention", infra 263-274.

${ }^{8}$ An amendment introducing an Art. 6bis containing more stringent requirements on information of GMOs has been adopted by the second MOP, Decision II/1 on Genetically Modified Organisms, doc. ECE/ MP.PP/2005/2/Add.2 (20 June 2005), but has not yet entered into force.
} 
public participation apply also to the drafting of plans and programmes (Article 7) and, to an even lesser extent, to the preparation of executive regulations and/or generally applicable legally binding normative instruments (Article 8).

The access to justice pillar is composed of three discrete aspects. Firstly, for disputes relating to access to information as defined in the Convention, Parties shall recognise access to a court of justice or another impartial body of review (Article 9.1). Secondly, certain members of the public concerned shall be given the opportunity to challenge the substantive and procedural legality of any decision, act or omission subject to the Conventional provisions on public participation contained in Article 6 and, where so provided for under national law, of other relevant provisions of the Convention. This right is afforded only to those members of the public concerned that have a "sufficient interest" or maintain the impairment of a right, in accordance with requirements established under domestic law. These requirements must be in accordance with the Convention objective of ensuring wide access to justice and environmental NGOs must always be deemed to have a sufficient interest (Article 9.2). Finally, access to administrative or judicial procedures must be recognised, subject to criteria laid down in national law, to challenge acts and omissions by private persons and public authorities which contravene provisions of national environmental law (Article 9.3). Furthermore, the Convention establishes that all these procedures shall provide adequate and effective remedies, including injunctive relief as appropriate, and dictates basic procedural principles that they must respect (Article 9.4).

As usual for MEAs, the Convention sets up an institutional structure, composed of two main bodies: the MOP and the Secretariat. The MOP (Article 10) meets ordinarily every two years. It oversees the implementation of the Convention and adopts new Protocols and amendments to be submitted for ratification by the Parties. It has the power to establish subsidiary bodies and financial mechanisms and has created an extensive institutional structure. ${ }^{9}$ The Secretariat (Article 12), whose functions are performed by the UNECE Executive Secretary, is the administrative body of the Convention.

\section{Legal Basis of the Mechanism and Negotiating History}

The establishment by the MOP of a mechanism for reviewing compliance is mandatory under Article 10 of the Convention on "review of compliance". It provides that:

"The Meeting of the Parties shall establish, on a consensus basis, optional arrangements of a non-confrontational, non-judicial and consultative nature for reviewing compliance with the provisions of this Convention. These arrangements shall allow for appropriate public involvement and may include the option of considering communications from members of the public on matters related to this Convention." 10

9 See the Convention's website at the page $<$ http://www.unece.org/env/pp/tfwg.htm $>$ (visited 20 January 2008)

${ }^{10}$ In the Draft Elements for the Convention on Access to Environmental Information and Public Participation in Environmental Decision-Making, Art. 7.2.f, doc. CEP/AC.3/R.1 (11 April 1996), elaborated by the UNECE Secretariat as a first negotiating draft, the establishment of a compliance mechanism was included 
This wording has been considered controversial. On the one hand, it was considered weak by NGOs and Commentators in that it requires the establishment of "optional arrangements" and "on a consensus basis". "However, provisions on participation and trigger by the public were at the time tremendously innovative if compared with compliance arrangements in other MEAs. Be that as it may, the Signatories at their first meeting established a Task Force on Compliance with aim of drafting a text for the establishment of the mechanism envisaged in Article 15. At their second meeting the Signatories decided to set up, in the framework of the preparatory working group for the first MOP, an open-ended intergovernmental working group to draw up a text for a draft decision establishing a compliance mechanism, in view of its adoption at the first MOP.

\section{The Text Establishing the Mechanism}

In accordance with Article 15 and with the procedure designed by the Signatories, the first MOP, held in Lucca in 2002, adopted Decision I/7 establishing a Compliance Committee (the Committee) and deciding its structure, functions and procedure, in accordance with the Annex thereto. ${ }^{12}$ A marginal amendment of the decision, regarding the number of members of the Committee, was decided by the Parties at their second meeting. ${ }^{13}$

\section{The Principles Governing the Mechanism and the Procedure}

Article 15 of the Convention clearly indicates that the procedure shall be non-confrontational, non-judicial and consultative and shall allow for involvement of the public. These principles are broadly reflected in the institutional and procedural aspects of the mechanism established by Decision I/7, as well as in the language used. Other principles such as the independence of the Committee's members and transparency, although they are not spelt out as such, emerge from the procedure.

among the MOP prerogatives, but a consensus emerged that this issue was to be given more visibility through an ad hoc provision (see the United Kingdom proposal in Report on the Sixth Session of the Ad Hoc Working Group for the Preparation of a Draft Convention on Access to Environmental Information and Public Participation in Environmental Decision-Making, doc. CEP/AC.3/12 (22 July 1997), Annex IV, at 10). After the rejection of an NGOs' proposal to include in the Convention a detailed regulation of the mechanism (ibid., Annex VI, at 14) and after lengthy negotiations an agreement on the final text was reached.

${ }^{11}$ See McAllister, supra n. 1, at 195 and K. Brady, "New Convention on Access to Information and Public Participation in Environmental Matters", Envt'l Pol'y \& L., 28 (1998) 69-75.

${ }_{12}$ Decision I/7 on Review of Compliance, doc. ECE/MP.PP/2/Add.8 (2001, subsequently issued on 2 April 2004). The annex is divided into fourteen sections and 39 paragraphs. In the following text, references to Decision I/7 and related numbering of paragraphs must be understood as referring to the Annex.

${ }_{13}$ See Decision II/5 on General Issues of Compliance, doc. ECE/MP.PP/2005/2/Add.6 (13 June 2005), para. 12 . 


\section{INSTITUTIONAL ASPECTS}

\subsection{The Compliance Committee}

\section{a) Composition}

The Committee, originally composed of eight members (para. 1), will be integrated after the third MOP by an additional member in order to better cope with its growing workload. The Committee's members are elected by the MOP (through consensus or, failing consensus, through secret ballot, para. 7) from among candidates proposed by the Parties, the Signatories and NGOs eligible to observer status before the MOP (para. 4). The entitlement of NGOs to formulate candidatures has been harshly criticised by those opposing extensive participation of non-state actors. ${ }^{14}$ Candidates must be nationals of Parties or Signatories and be "persons of high moral character and recognized competence in the fields to which the Convention relates, including persons having legal experience" (para. 2). No two members may have the same nationality (para. 3). Geographical balance is to be respected and diversity of experience encouraged in the composition (para. 8). The Committee elects its own Chairperson and vice-chairperson (para. 9). The Committee must meet at least once a year, but it ordinarily holds four meetings per year.

\section{b) Status of Members}

The Committee's Members "shall serve in their personal capacity" (para. 1). This solution, one of the distinguishing features of the Aarhus Compliance Committee, finally prevailed over that of a Committee composed of Parties representatives. ${ }^{15}$ After the first election, each ordinary MOP elects either four or five of the new Committee's members (para. 9). This means that the normal term of office is four years. The same person shall not sit for more than two consecutive terms, except if otherwise decided by the MOP (para. 9). If a member is unable to complete its term, a substitute for the remainder shall be appointed by the Bureau, subject to the approval of the Committee (para. 10).

The Committee is a body of independent experts, ${ }^{16}$ although "independence" is not mentioned in Decision I/7, as confirmed by the obligation to make a solemn

\footnotetext{
${ }^{14}$ See the statement of the U.S. delegation, Report of the First Meeting of the Parties, doc. ECE/MP.PP/2 (17 December 2002), para. 45 and Annex.

15 See Report on the First Meeting of the Task Force on Compliance Mechanisms, doc. CEP/WG.5/2000/4 (17 April 2000), Annex I, at 11 and Report on the First Meeting of the Working Group on Compliance and Rules of Procedure, doc. CEP/WG.5/AC.1/2001/2 (16 March 2001), Annex II, at 19.

${ }^{16}$ See C. Pitea, "The Non-Compliance Procedure of the Aarhus Convention: Between Environmental and Human Rights Control Mechanisms”, Italian YB Int'l L., 16 (2006) 85-116, at 89-90.
} 
declaration of impartiality, the practice of excluding civil servants from candidatures ${ }^{17}$ and the exclusion from the deliberative phase of members in conflict of interest. ${ }^{18}$

\section{c) Observers}

In the absence of express regulation, the Committee has admitted observers, including from the non-governmental sector, on a regular basis. This practice is based on the application mutatis mutandis of the requirement that the meetings should be open to the public, contained in the Rules of Procedure of the MOP. ${ }^{19}$ This reasoning leads to the result that each and every person, other than the members, present at a Committee's meeting is treated as being an "observer" ${ }^{20}$ This outcome is questionable in that it blurs the position and legal status of two categories (observers and members of the public attending open meetings) that are clearly distinguished in the Convention and in the Rules of Procedure. ${ }^{21}$

\subsection{The Secretariat}

The Secretariat acts as the administrative body of the mechanism. It receives candidatures for the Committee (para. 5(a)), arranges for and services its meetings (para. 12) and acts as a liaison between Parties and the public and the Committee in the handling of non-compliance cases (paras. 15-18). It has its own triggering function (para. 17) ${ }^{22}$ and plays an important role in information gathering. ${ }^{23}$

\subsection{The Meeting of the Parties}

The MOP has the last word on compliance matters. Upon recommendation of the Committee, it makes final decisions on compliance issues including on response measures (para. 37) ${ }^{24}$ More generally, it oversees and evaluates the Committee's activity, and may address general recommendations or requests to it. In particular the

${ }^{17}$ See V. Koester, "Review of Compliance under the Aarhus Convention: A Rather Unique Compliance Mechanism", J. Eur. Envt'l Plan. L., 2 (2005) 31-44, at 34. During the negotiations it was proposed to introduce a provision to the effect that Committee's members should not be employed by a public authority of any Party (nor, quite interestingly, by those NGOs in a position to propose candidatures), but this provision was not included in the final text, see Report on the First Meeting of the Task Force on Compliance Mechanisms, doc. CEP/WG.5/2000/4 (17 April 2000), Annex II, para. 3.

18 See infra paragraph 8.4 .

${ }^{19}$ Report on the First Meeting, doc. MP.PP/C.1/2003/2 (16 June 2003), para. 11 and Guidance Document on Aarhus Convention Compliance Mechanism, available at http://www.unece.org/env/pp/ compliance/manualv6.doc (visited 15 July 2008) (hereinafter Guidance Document), at 8. The Rules of Procedure have been adopted by the Parties at their First Meeting, see Decision I/1 on Rules of Procedure, doc. ECE/MP.PP/2/Add.2 (subsequently issued on 2 April 2004).

20 "All meetings should in principle be open to the public as observers", Report on the First Meeting, supra $\mathrm{n} .19$, paras. 15-16.

21 See for more details Pitea, supra n. 16, at 91-92.

22 See infra paragraph 7.2.

23 See infra paragraph 9.

24 See infra paragraph 11.2. 
MOP may request the Committee to prepare reports on general issues of compliance (para. 13(b)). Moreover, the MOP retains the power to amend Decision I/7 or even cancel it. The Committee seems to qualify as a subsidiary body of the MOP, ${ }^{25}$ although it has explicitly refused this label, probably to underline its own independence. ${ }^{26}$ However, it should be noted that since the Committee has been established as an independent body, the MOP should refrain (and so far has refrained) from interfering with the handling of specific communications or submissions.

\section{Functions of The Committee}

The Committee performs general tasks in relation to the monitoring of compliance and considers individual cases of non-compliance. More generally, the Committee has a very broad power to examine compliance issues and make recommendations if and as appropriate (para. 14). It reports on its work at each ordinary MOP (para. 36).

\subsection{General Tasks in Relation to Compliance Issues}

The Committee shall monitor, assess and facilitate the implementation of and compliance with the Convention's reporting requirements (para. 13(c)) and prepare, at the request of the MOP, a report on compliance with or implementation of the provisions of the Convention (para. 13(b)). These provisions make clear that, in the reporting procedure, the Committee merely acts as a facilitator for the effective functioning of the mechanism and does not discuss the substance of individual reports with the submitting Party. The most notable action taken by the Committee in this respect is the preparation of a guidance document on reporting requirements submitted to the seventh meeting of the Working Group of the Parties for consideration. ${ }^{27}$

\subsection{Individual Cases of Non-Compliance}

The main function of the Committee is to consider issues of non-compliance by a Party with any conventional provision that has been brought to its attention in conformity with Decision I/7 (para. 13(a)) and to make recommendations to the MOP

${ }^{25}$ D. Sarooshi, "The Legal Framework Governing United Nations Subsidiary Organs", British YB Int'l L., 67 (1996) 413-478, at 414-422 (indicating that a UN body may be qualified as subsidiary when it is created by a principal organ of the UN within its powers as delimitated by the UN Charter, and when it operates under the authority and control of that organ, provided that it possess a certain degree of independence. The Author contends that these are also the requirements of general international institutional law), and R. Churchill and G. Ulfstein, "Autonomous Institutional Arrangements in Multilateral Environmental Agreements: A Little-Noticed Phenomenon in International Law”, Am. J. Int'l L., 94 (2000) 623-659, at 632-633 (arguing, with direct reference to the power of COP/MOPs to institute subsidiary bodies, that international institutional law, including the doctrine of implied powers, applies to institutional arrangements under MEAs).

${ }^{26}$ Report on the First Meeting, supra n. 19, para. 11.

${ }^{27}$ See Guidance on Implementation of Reporting Requirements for the Third Meeting of the Parties, doc. ECE/MP.PP/WG.1/2007/L.4 (20 February 2007). 
on response measures (para. 36) and to take certain interim measures (para. 37), as explained in more detail in the following paragraphs.

\section{TRIGGER MECHANISM}

\subsection{Submission by a Party (Party-to-Party Trigger and Self-Trigger)}

"Submission" refers to an issue of compliance brought before the Committee by a Party having reservations on another Party's compliance (Party-to-Party trigger) (para. 15) or concluding that, despite its efforts, it is unable to comply with the Convention (self-trigger) (para. 16). Submissions must be made in writing to the Secretariat and be supported by corroborating information or, in self-triggered cases, by the specific circumstances that the Party considers to be the causes of its non-compliance.

\subsection{Referrals by the Secretariat}

"Referral" refers to the issue of compliance brought to the Committee's attention by the Secretariat when it becomes aware of possible non-compliance by a Party, when the matter is not settled through consultation with the Party concerned (para. 17). The Secretariat's triggering power is not limited to issues emerging from the examination of Parties' reports, though special attention should be placed on such issues. This means that the input for the Secretariat's action may come, inter alia, from nongovernmental sources, provided that the information on which the referral is based is published or transmitted in written form. ${ }^{28}$

\subsection{Communications from the Public}

"Communication" refers to the trigger by "members of the public", e.g., individuals or organizations, without a particular interest to be stated.

\section{a) Grace Period and Opt-Out Clause}

Decision I/7 provides for a one-year "grace" period, starting from the establishment of the procedure or the entry into force of the Convention for a Party, whichever is the latest, in which the communication procedure is not applicable to that Party. Moreover, in application of the requirements set out in Article 15 of the Convention, Parties may declare that they are unable to accept, for a period of not more than four years, the consideration of such communications by the Committee (para. 18). This very narrow opt-out clause, which prevailed over other options such as opting-in systems or unlimited opting out, ${ }^{29}$ has not been resorted to by any Party to date.

\footnotetext{
28 Guidance Document, supra n. 19, at 13.

${ }^{29}$ See Report of the Working Group on Compliance and Rules of Procedure, doc. CEP/WG.5/ AC.1/2001/2 (16 March 2001), Annex II, at 24-26.
} 
A communication shall be addressed to the Committee through the Secretariat in writing and in an official language of the Convention (English, French or Russian), but English is preferable. ${ }^{30}$ Anticipation of communications and annexed materials by e-mail are accepted and encouraged. To facilitate perspective applicants the Committee has prepared guidelines for the submission and handling of communications that contain a checklist of items to be covered by the communication. ${ }^{31}$ This includes information on the communicant, identification of the Party concerned, a statement of facts, the identification of the conventional provision allegedly violated, information about domestic remedies and the steps taken to exhaust them, requests on confidentiality of certain aspects of the communication and copies of relevant documents.

\section{c) Admissibility Criteria}

The communication is not admissible if it is (a) anonymous, (b) an abuse of the right to make such communications, (c) manifestly unreasonable, and (d) incompatible with the provisions of this decision or with the Convention (para. 20). The Committee should also "take into account any available domestic remedy unless the application of the remedy is unreasonably prolonged or obviously does not provide an effective and sufficient means of redress" (para. 21). This means that, although formal exhaustion of available and effective domestic remedies is not strictly required, the Committee may decide "not to pursue the substance of a communication if it considers that the communicant has not sufficiently explored the possibilities for resolving the issue through national administrative or judicial review procedures. ${ }^{.32}$ This flexibility also allows the Committee to consider a communication when domestic remedies had been explored, to no avail, by a person other than the communicant. ${ }^{33}$ So far the Committee has refused to entertain a case because the communication concerned a matter that had just been submitted to the domestic court of appeal, stating at the same time that it was ready to re-open the file if the remedies at issue were to prove to be ineffective or unreasonably prolonged..$^{34}$ In other cases the existence of pending domestic procedures has not been considered as an obstacle to consideration by the Committee, especially when these have proved to be unreasonably prolonged. ${ }^{35}$

Decision I/7 does not mention among the inadmissibility criteria the fact that the issue has already been considered by the Committee, nor does it establish a time-limit to make a communication after the facts have occurred. However, the Committee has

See infra paragraph $8.5(\mathrm{~d})$

${ }^{31}$ Guidance Document, supra n. 19, at 29-41.

32 Ibid., at 32.

${ }_{33}$ Report on the First Meeting, supra n. 19, para. 37.

${ }^{34}$ Comm. ACCC/C/2004/09, Armenia, Preliminary Determination on Admissibility, 24 September 2004, paras. 4-5. See also Report on the Fifth Meeting, doc. MP.PP/C.1/2004/6 (26 November 2004), para. 28.

${ }^{35}$ Comm. ACCC/C/2004/02, Kazakhstan, Preliminary Determination on Admissibility, 14 May 2004, para. 4. 
considered that these situations may fall within the notion of "abuse of the right to make a communication". ${ }^{36}$

Two other situations are treated by the Committee as admissibility issues, although they are rather issues of jurisdiction ratione personae (the communication concerns a State that is not a Party, or has become a Party less than one year before the communication was made, or has opted out from the mechanism) and ratione temporis (the communication refers to facts prior to the entry into force of the Convention for the Party concerned) ${ }^{37}$ In this respect, it is remarkable that the Committee has in principle accepted to consider communications based on facts that took place before the time in which the Committee had competence on individual communications.

\subsection{Initiation Proprio Motu}

The broad provision on the Committee's power "to examine compliance issues and make recommendations if and as appropriate" suggests that the Committee may also act proprio motu. ${ }^{38}$

\section{The Procedure before the Compliance Committee and Procedural SAFEGUARDS}

\subsection{Sources of Procedural Rules and General Remarks}

The procedural rules of the Committee, in particular those for considering cases of non-compliance, are partly found in Decision I/7 and, residually, in the rules procedure of the MOP, that are applicable mutatis mutandis. ${ }^{39}$ Remaining issues have been dealt with by the Committee on a case-by-case basis and practices (modus operandi) have been collected by the Secretariat ${ }^{40}$ in a Guidance Document. ${ }^{41}$ This evolving text does not contain formal rules of procedures, but it plays an important role in ensuring the transparency and predictability of the procedure, notwithstanding its limited legal value.

The procedure may be divided into an initial stage, in which the case is handled by the Committee and brought to the attention of the Party concerned, a phase in which the substance of the case is discussed and a deliberating phase. The procedure for handling cases varies considerably depending on the triggering mechanism, while the other stages are more homogeneous.

\footnotetext{
${ }^{36}$ Report on the First Meeting, supra n. 19, para. 36.

37 Guidance Document, supra n. 19, at 32.

38 Ibid., at 7.

${ }^{39}$ Report on the First Meeting, supra n. 19, para. 11 and Guidance Document, supra n. 19, at 8.

${ }^{40}$ Report on the Second Meeting, doc. MP.PP/C.1/2003/4 (15 October 2003), para. 9.

${ }^{41}$ Guidance Document, supra n. 19.
} 


\subsection{Procedure for Handling Cases}

a) Submissions

The handling of a "self-triggered" case is quite unproblematic since the Secretariat must simply transmit the submission to the Committee without delay, even if it considers that essential information is lacking. ${ }^{42}$

When a submission is made by another Party the Secretariat must send a copy of the submission to the Party whose compliance is at issue (the Party concerned) and the Committee (para. 16). ${ }^{43}$ The Party concerned is also invited to reply within the deadline established in Decision I/7 (three months or a longer period that the Party itself deems to be required by the circumstances of the case, but not later than six months) and to communicate whether it envisages any difficulty in replying by the ordinary deadline. If the reply is not received within three months, the Secretariat should send a first remainder and a further remainder may be sent when the final deadline approximates. When the Secretariat receives a reply this should be forwarded without delay to the Committee. If the six months deadline for replying expires and no reply is received, the Secretariat informs the Committee accordingly and notifies the Party concerned. ${ }^{44}$

\section{b) Referrals}

When the Secretariat becomes aware of possible non-compliance by a Party, it may request information from the Party concerned in order to resolve the matter and inform the Committee of such a step. If the request remains unanswered after three months (or in particular circumstances in a longer period of time not exceeding six months), it shall bring the matter to the Committee's attention (para. 17). This provision does not prevent the Secretariat from entering into consultation with the Committee even before requesting information from the Party concerned. The Secretariat's power to initiate compliance proceedings is discretionary, because it may simply ignore possible non-compliance issues or avoid requesting information from the Party concerned, possibly because of a resource-related choice. It may also enter into consultation with a Party outside the compliance procedure. ${ }^{45}$ However, once the

${ }^{42}$ Decision I/7, supra n. 12, para. 16, Report on the Second Meeting, supra n. 40, para. 17 and Guidance Document, supra n. 19, at 12.

43 Practice has clarified that the Party concerned and the Committee shall receive the relevant information contextually, although the wording of Decision I/7 may suggest otherwise, see Report on the Fifth Meeting, supra n. 34, para. 31 .

44 The procedure has been recorded in the Report on the Second Meeting, supra n. 40, para. 16 and Guidance Document, supra n. 19, at 11-13.

45 The Secretariat may enter into consultation with parties on compliance-related matters also as part of its general tasks or during the preparation of the "synthesis report" (summarizing the progress made in the implementation of the convention and identifying significant trends, challenges and solutions) to be prepared before each MOP in accordance with Decision I/8 on Reporting Requirements, doc. ECE/MP.PP/2/Add.9 (subsequently issued on 2 April 2004), the Secretariat must prepare a synthesis report before each MOP. Such prerogatives are not affected by Decision I/7, see Guidance Document, supra n. 19, at 12-13. 
Secretariat has made the choice to treat a request for information as a formal step of the compliance procedure, e.g., when the request for information is notified to the Committee, and a solution is not found with the Party concerned by the abovementioned deadline, the Secretariat is under an obligation to bring the matter to the Committee.

\section{c) Communications}

The procedure for handling communications is far more elaborated, since communications from the public constitute the bulk of the Committee's activity, and quite peculiar. Unlike submissions, communications are to be addressed directly to the Committee and not to the Secretariat. When information from the public regarding a Party's compliance is addressed to the Secretariat, the latter must ascertain whether this is due to an error and give information about the communication procedure. Moreover, communications are subject to admissibility criteria and this alters to some extent the procedure by which a provisional decision on these issues is taken preliminarily and inaudita altera parte. The Committee has found that certain admissibility grounds may well apply to Party-to-Party submissions, or even to the Secretariat's referrals ${ }^{46}$ but it has not elaborated any procedural rule in this respect.

When the Secretariat receives a communication it must register it, acknowledge receipt to the communicant, verify whether it contains all the essential information and, when necessary, request the communicant to add any that is missing. ${ }^{47}$ The communication is then circulated to the Committee members, together with a data-sheet prepared by the Secretariat. ${ }^{48}$ The Committee, once it has received the communication, must ensure that it is brought to the attention of the Party concerned "as soon as possible", that is, according to the Committee, at the latest before the second meeting of the Committee following its receipt. ${ }^{49}$ Before doing so, however, the Committee shall ascertain whether the admissibility criteria and the requirement on exhaustion of domestic remedies have been fulfilled. To proceed more expeditiously the Committee may decide by e-mail ${ }^{50}$ and take advantage of the assistance of a particular member, generally familiar with the type of case or national situation but not a national of the Party concerned, ${ }^{51}$ that acts as rapporteur (or curator, as it is sometimes called by the Committee), upon request of the chairperson or after an offer by the member itself. ${ }^{52}$

If one of the admissibility requirements is not fulfilled, the communication may be either dismissed (e.g., when manifestly unreasonable or an abuse of right) or sent back to the communicant for clarification (e.g., when it is not clear whether it falls within the scope of the Convention). Inadmissible communications are not forwarded

${ }^{46}$ Koester, supra n. 17, at 39.

${ }^{47}$ Report on the Fourth Meeting, doc. MP.PP/C.1/2004/4 (19 July 2004), paras. 23-25.

48 Guidance Document, supra n. 19, at 35.

49 Report on the Fourth Meeting, supra n. 47, para. 32.

${ }^{50}$ See infra paragraph 10.

${ }^{51}$ Report on the Fourth Meeting, supra n. 47, para. 20.

52 This possibility has been considered following the example of the procedure used by the Human Rights Committee, see Report on the First Meeting, supra n. 19, para. 19; Report on the Fourth Meeting, supra n. 47 , paras. 20 and 35. 
to the Party concerned, except when the Committee decides otherwise ${ }^{53}$ If the Committee is provisionally satisfied that admissibility conditions are met, a "file" is opened and the communication is brought to the attention of the Party concerned, ${ }^{54}$ together with the points or questions raised by the Committee. At the same time, the communication and the data-sheet are posted on the website. The Party concerned then has up to five months to submit written explanations or statements clarifying the matter and describing any response that it may have made, but the Committee requests that comments on admissibility should be forwarded as soon as possible..$^{55}$

\subsection{Consideration by the Committee of Submissions, Referrals and Communications ${ }^{56}$}

Once the Party concerned has responded or the applicable deadline is expired without a response, the Committee is ready to discuss the substance of the matter. In the case of communications, it first makes a final determination on admissibility, taking into account any observations made by the Party concerned. In the other cases, or when the provisional determination of admissibility is not reversed, the Committee may decide on the basis of available information or request further information.

At the meeting following the moment in which sufficient information is available, the Committee begins the formal discussion on the substance of the case. ${ }^{57}$ It shall take place at least two weeks after the response has been received or the deadline expired and the communicant and the Party concerned are invited to take part in it, to take the floor to introduce their position and to answer questions from Committee members. Although the Committee may also hold formal hearings, it has refrained from doing so, preferring a more informal and open discussion with the subjects involved.

The discussion may extend over several meetings, until the Committee considers that it has a complete and clear picture of the situation and that it is ready for the preparation of draft findings, measures or recommendations.

\subsection{Deliberation by the Committee}

Deliberation on individual cases of non-compliance takes place in closed session. ${ }^{58}$ This means that only the members of the Committee, except those in conflict of interest, may participate. The Committee establishes whether or not the Party concerned is in compliance and considers whether to make recommendations to the MOP in accordance with Decision I/7, para. 36, or, when necessary, to take measures in

\footnotetext{
${ }^{53}$ Report on the First Meeting, supra n. 19, para. 27.

${ }_{54}$ Report on the Fifth Meeting, supra n. 34, paras. 33-34.

${ }_{55}$ Report on the First Meeting, supra n. 19, para. 28.

${ }_{56}$ The procedure has been decided by the Committee at its fifth meeting, see Report on the Fifth Meeting, supra n. 34, paras. 35-48 and is reproduced in the Guidance Document, supra n. 19, at 17-19 and 37-38.

${ }^{57}$ For a fairly detailed description of the form of discussion see Report on the Fifth Meeting, supra n. 34, para. 40 .

${ }_{58}$ Decision I/7, supra n. 12, Annex, para. 33; Report on the First Meeting, supra n. 19, para. 17.
} 
accordance with para. $37 .{ }^{59}$ At the meeting following the expiry of the deadline fixed for comments by the Parties involved on Draft findings, measures or recommendations (para. 34), the Committee finalises its deliberations.

The "Findings and Recommendations" are published as an addendum to meeting reports and are transmitted to the Party concerned and the submitting Party or the communicant. Their structure is that of a quasi-judicial report, with an introduction on the development of the procedure and three sections on facts, the reasoning ("evaluation and consideration by the Committee"), the findings and recommendations strictu sensu ("conclusions"). The latter section is also appended to the Report of the Committee to the MOP. When the Committee provisionally makes recommendations and takes measures directly towards the Party concerned ${ }^{60}$ and the matter is not resolved at the moment of the preparation of its following report to the MOP, earlier findings and measures are reformulated as recommendations to the MOP and are included as an addendum to such report.

\subsection{Procedural Safeguards}

\section{a) Due Process and Fairness of Proceedings}

In keeping with its cooperative nature, the procedure provides for a number of safeguards aimed at ensuring full involvement of the Party concerned and of the submitting Party or the communicant. They are entitled to participate in any meeting in which the matter is discussed, and should be notified accordingly. In certain cases the Committee may consider the possibility of requesting the Secretariat to provide financial assistance to individual communicants and eligible governments from the Convention's trust fund. ${ }^{61}$ The same subjects are entitled to comment on draft findings, measures and recommendations, before these are adopted, with the partial exception of determination of admissibility, which may be decided inaudita altera parte, and even by e-mail, without previous discussion in a meeting. However, such determination is only provisional and the Party concerned has the right to elaborate on admissibility in its response, and to have the matter reconsidered by the Committee in the light of the points made. If the Committee modifies its provisional determination on admissibility the communicant is given the chance to comment.

A different due process issue relates to information and the possibility to respond to it. Subjects involved may submit information and reply to that submitted by others. ${ }^{62}$ The procedure is flexible enough not to impose strict deadlines, but the Committee in principle considers at each meeting only information received in advance by

\footnotetext{
${ }^{59}$ See infra paragraph 11.3.

60 Ibid.

${ }^{61}$ Guidance Document, supra n. 19, at 37.

${ }^{62}$ Decision I/7, supra $\mathrm{n} .12$, para. 32.
} 
at least fifteen days, ${ }^{63}$ and may fix $a d$ hoc deadlines for the supply of information to be considered at a particular meeting. ${ }^{64}$

Timing of the procedure also relates to procedural fairness. Decision I/7 fixes deadlines only for the response by the Party concerned and in other cases uses vague expressions like "promptly" or "as soon as possible". The Committee has clarified these provisions by fixing stricter time frames. In order to speed up the process it encourages the use of electronic communication tools and deliberates extensively through electronic means. The practice of assigning communication to a curator also goes in the same direction. In certain cases, however, the need for the Committee to have a clear picture of a situation before making any finding may justify discussions prolonged over several meetings.

\section{b) Transparency and Confidentiality}

Transparency emerges as one of the most important principles of the procedure. Meetings of the Committee are normally held in public, ${ }^{65}$ with the exception of the deliberation phase ${ }^{66}$ and of the application of the rules on confidentiality. As already observed, in the Committee's practice this means that anyone is entitled to participate as an observer at such meetings. ${ }^{67}$ In order to enable participation, wide publicity about meetings and documents is given through the Convention website. ${ }^{68}$

The Committee (and any person involved in its work, in particular the Secretariat) shall ensure confidentiality of information provided in confidence that falls within the exceptions provided for by the Convention or that has been provided in confidence by a Party making a self-submission. ${ }^{69}$ Moreover confidentiality must be ensured when required by a person (normally, but not necessarily a communicant) because of a concern that he or she may be penalized, persecuted or harassed.

As to the first case, should a controversy arise between the Committee and a Party over the applicability of confidentiality provisions to any given information, the Committee has taken a very soft approach. In fact it has decided to enter into consultation with the Party concerned and, when the matter cannot be settled, to refer it to the MOP. ${ }^{70}$

As far as the second situation is concerned, some problems have also emerged. Communicants wishing to keep their identity or other information confidential shall clearly make a request to this effect and they are advised that otherwise all information contained in the communication will be disclosed. The Committee may not refuse a request for confidentiality of identity or other information, nor is it in a position to

\footnotetext{
${ }^{63}$ Report on the Sixth Meeting, doc. MP.PP/C.1/2004/8 (25 January 2005), para. 36 and Guidance Document, supra $\mathrm{n} .19$, at 17.

${ }^{64}$ Guidance Document, supra n. 19, at 19.

${ }^{65}$ Report on the First Meeting, supra n. 19, para. 16.

${ }^{66}$ Ibid., para. 17.

${ }^{67}$ See supra paragraph 5.1(c).

${ }^{68}$ See Report on the First Meeting, supra n. 19, para. 18, Report on the Second Meeting, supra n. 40, paras. 10 and 20 .

${ }^{69}$ See Arts. 4.3(c) and 4.4 of the Convention.

${ }^{70}$ Report on the First Meeting, supra n. 19, para. 38.
} 
assess whether the communicant's fears are grounded. This has a double effect. On the one hand, it makes room for extending the grounds of confidentiality beyond the provisions of Decision I/7. This is the case, for instance, of confidentiality requested to protect a person who is not the provider of the information. This is clearly not covered by the letter of Decision I/7, but at the same time it is plainly in keeping with the object and purpose of the confidentiality provisions. Thus, the Committee has clearly stated that this rule on confidentiality is applicable to fears relating to third persons. ${ }^{71}$ On the other hand, confidentiality may limit the possibility of the Party concerned to express its points and thus the Committee has warned future-applicants that "if too much information is required to be kept confidential, this may impede the processing of the case." 72

\section{c) Conflict of Interest}

As a consequence of it being composed by independent experts, the Committee has found that "normal rules" on conflict of interest should apply to its work. Although it has not defined what constitutes conflict of interest in general terms it has excluded such occurrence in some situations. ${ }^{73}$ Any member facing a possible or apparent conflict of interest in relation to a particular case should declare that to the Committee and, if the Committee so decides, that member shall be treated as an observer throughout the procedure. ${ }^{74}$

\section{d) Languages}

Submissions and communications should be submitted in one of the official languages of the Convention, i.e., English, French or Russian. However, English is the internal working language of the Committee and its use can significantly speed up the process. Communicants are informed accordingly. ${ }^{75}$ Communications in other official languages will be translated into English. ${ }^{76}$ The same applies to corroborating information, but if this is too burdensome a member familiar with the language may be assigned the task of preparing summaries and identifying important documents, or parts of them, that need to be translated. The issue of translation of documentation submitted in a non-official language will be addressed on ad hoc basis.

${ }^{71}$ Report on the Fourth Meeting, supra n. 47, para. 32.

${ }_{72}$ On confidentiality see Report on the First Meeting, supra n. 19, para. 39 and Guidance Document, supra $\mathrm{n} .19$, at $34-35$.

${ }^{73}$ Thus there is no conflict of interest when a Party involved is the State of citizenship of a member, nor when a member is, or has been, involved in academic activities or has participated in workshops and conferences relating to the Committee's activities.

${ }^{74}$ On conflict of interest see Report on the First Meeting, supra n. 19, para. 19 and Guidance Document, supra $\mathrm{n} .19$, at 10. In different cases the Committee's members have declared a conflict of interest and have therefore been treated as observers, see Report on the Fourth Meeting, supra n. 47, para. 19

${ }^{75}$ Ibid.

${ }^{76}$ Report on the First Meeting, supra n. 19, para. 21 and Report on the Fourth Meeting, supra n. 47, paras. 27-29. See also Guidance Document, supra n. 19, at 9. 
Official documents, including findings, measures and recommendations are issued in the three languages, in accordance with general UNECE rules, but provisional documents (such as draft findings, recommendations or measures) are issued only in English.

\section{SOURCES OF INFORMATION}

The Committee's ability to collect relevant and necessary information on an alleged situation of non-compliance is topical for the effectiveness of its work. Decision I/7 enables the Committee to request information and to consider information submitted to it, to undertake, with the consent of any Party concerned, information gathering in the territory of that Party and to seek the services of experts and advisers (para. 25).

The Secretariat, at the Committee's request, has further elaborated on these provisions and has clarified certain aspects of the information gathering activity of the Committee. ${ }^{77}$ In the first place it has made it explicit that the Committee may rely upon a variety of sources to collect objective information and views or opinions. This includes the Government of the Party concerned, the communicant, NGOs and the scientific and academic community, in addition to information already in the public domain or in the knowledge of individual members of the Committee or officers of the Secretariat. The Committee should be mindful of the interests the information provider may bear.

Secondly, the important role of the Secretariat in information gathering has been stressed. Thus, the Secretariat may undertake information gathering activities on behalf of the Committee. In certain cases, such as information available on the internet, contained in reports submitted by the Parties or requested from the communicant at the moment of the initial handling of the communication, the Secretariat may proceed in complete autonomy. In other cases, when economic or political concerns are more sensitive, the Secretariat should act after an indication by the Committee to this effect.

The third aspect which is dealt with in the Committee's modus operandi is on-thespot information gathering. This is defined as "the event whereby some experts travel to the State Party concerned by the alleged non-compliance to establish the facts and assess the situation in a particular case" 78 and may take place only with the consent of the Party concerned. It may be carried out by the Committee's members or the Secretariat's staff, possibly with the assistance of IGOs having a field mission on that Party's territory and having expertise in the fields of the Convention, such as OSCE or UNDP. Due to the political sensitivity of this type of action and to its economic cost - which is to be borne by the Convention's trust fund with a possible contribution by the Party concerned - the Committee considers that it should be undertaken only when strictly necessary and on the basis of terms of reference to be discussed with the subjects involved in the procedure. The possibility to use information gathering has

\footnotetext{
77 Guidance Document, supra n. 19, at 20-24.

${ }^{78}$ Ibid., at 24
} 
not been used yet. Quite interestingly, the Secretariat was involved in an EU led factfinding mission on a matter, the construction of the Bystroe Canal on the Danube, which was the subject of a communication and a submission to the Committee. However, the Committee has specified that such activity was not to be considered as information gathering under Decision I/7, ${ }^{79}$ but nonetheless the information contained in the Report of the fact-finding mission was considered by the Committee.

\section{DECISION-MAKING}

Decision I/7 contains only one rule on decision-making which states that every effort should be made to reach consensus in adopting its Report to the MOP and that the latter shall reflect the views of all members of the Committee (para. 35). The Rules of Procedure of the MOP integrates this provision. Hence, the majority of the members (five) must be present for any decisions to be validly taken (Rule 26) and, failing consensus, decisions on substantive matters can only be taken with the support of three fourths of the members present and voting (Rule 35). However, the Committee has agreed that for any decision to be taken at least five members should vote in its favour, regardless of the number of members present. ${ }^{80}$

Special rules on decision-making are contained in the detailed procedure established for decision-making by e-mail, ${ }^{81}$ which may cover virtually any decision taken by the Committee. ${ }^{82}$ The procedure consists of the preparation and circulation, under the responsibility of the Chairperson possibly with the assistance of one or more members, of a draft decision. The Chairperson collects amendment proposals and circulates a new draft with a view of reaching consensus. Adoption of decision through this procedure always requires the "satisfaction" (i.e., the consent) of all of the members.

\section{Outcomes}

After collecting all the necessary information, the Committee is ready to adopt its findings, in accordance with the procedures already described. The Committee determines whether a Party is in compliance or not. When a finding of non-compliance is reached, the Committee may take two different paths. It may make recommendations the MOP, including on the need to take response measures or, in certain cases, address itself directly to the Party concerned, and in cooperation with it, on an interim

\footnotetext{
${ }^{79}$ Report on the Fifth Meeting, supra n. 34, para. 25.

${ }^{80}$ Report on the First Meeting, supra n. 19, para. 12 and Guidance Document, supra n. 19, at 8.

${ }^{81}$ Report on the Fourth Meeting, supra n. 47, paras. 39-40 and Guidance Document, supra n. 19, at $15-16$.

${ }^{82}$ Report on the First Meeting, supra n. 19, para. 15; Report on the Eighth Meeting, doc. ECE/ MP.PP/C.1/2005/4 (4 July 2005), para. 29; Report on the Ninth Meeting, doc. ECE/MP.PP/C.1/2005/6 (28 October 2005), para. 5; Report on the Eleventh Meeting, doc. ECE/MP.PP/C.1/2006/2 (10 May 2006), para. 39 .
} 
basis. If a finding of non-compliance is not reached, the Committee may nonetheless proceed in the same vein, especially when non-compliance is foreseeable. ${ }^{83}$

\subsection{The Notion of Non-Compliance}

In determining whether a Party is in compliance or not, the same benchmark applies for all Parties. ${ }^{84}$ A Party is considered to be in non-compliance when, because of the failure to establish the necessary implementing measures or to apply such measures, ${ }^{85}$ the level of protection ensured by its domestic legal system falls below the common minimum standard established by the Convention. Some interesting issues have already emerged in the Committee's practice relating to the definition of non-compliance.

In a case concerning Hungary, the Committee was faced with a situation where a special regulation on the construction of expressways reduced public participation entitlements deriving from generally applicable law, but did not fall under the minimum standard established by the Convention. The Committee, though expressing its concern, ${ }^{86}$ did not find the Party concerned in non-compliance. ${ }^{87}$ It considered that the Convention does not contain a consolidation or non-regression clause, and that this principle could not derive from the application of other international treaties, particularly in the field of human rights protection. ${ }^{88}$ However, in this context the Committee has not excluded "the possibility when determining issues of non-compliance to take into consideration general rules and principles of international law, including international environmental and human rights law." 89

Another interesting issue has emerged in a case concerning the failure by Kazakhstan to provide for public participation in a permitting procedure for the construction of overhead electric power lines of a size falling below the threshold set by the Convention for the applicability of Article $6 .^{90}$ In that particular case, however, Article 6 of the Convention was applicable, since the activity at issue was subject to public participation requirements in the context of the environmental impact assessment under

\footnotetext{
${ }^{83}$ See Findings and Recommendations with Regard to Compliance by Belgium with its Obligations under the Aarhus Convention in Relation to the Rights of Environmental Organizations to Have Access to Justice (Communication ACCC/C/2005/11 by Bond Beter Leefmilieu Vlaanderen VZW (Belgium)), adopted on 16 June 2006, doc. ECE/MP.PP/C.1/2006/4/Add.2 (28 July 2006).

${ }^{84}$ Report on the First Meeting, supra n. 19, para. 42.

85 Guidance Document, supra n. 19, at 18.

${ }^{86}$ Findings and Recommendations with Regard to Compliance by Hungary in the Case of Act on the Public Interest and the Development of the Expressway Network (Communication ACCC/C/2004/04 by Clean Air Action Group (Hungary)), adopted on 18 February 2005, doc. ECE/MP.PP/C.1/2005/2/Add.4 (14 March 2005), para. 17.

87 Ibid., para. 20.

88 Ibid., para. 18

89 Ibid.

90 The power line at issue was one kilometre long with a voltage of $200 \mathrm{kV}$, while Art. 6 para. 1(a) is applicable to power lines of at least $220 \mathrm{kV}$ in voltage and $15 \mathrm{~km}$ in length, see Aarhus Convention, Annex I, para. 17
} 
domestic law. ${ }^{91}$ The Committee observed that when the applicability of the Convention is contingent on the existence of national requirements, and thus the Convention does not require a level playing field or a common set of standards, ${ }^{92}$ "[ $\left.t\right]$ his is certainly an important mitigating factor in considering the gravity of any non-compliance arising with respect to that particular provision." 93

\subsection{Consideration of Response Measures by the MOP}

The Aarhus convention non-compliance procedure reserves to the MOP the competence of deciding on appropriate measures to bring about full compliance with the Convention, upon consideration of a report and any recommendations of the Committee, including on the need to take one or more of the measures listed in Decision I/7 (para. 37). This list is indicative and includes facilitative measures and more incisive ones.

Among the first group one may mention the provision of advice and the facilitation on assistance to individual Parties regarding the implementation of the Convention, the issuing of recommendations to the Party concerned, including in cases of communications from the public, recommendations on specific measures to address the matter raised by the member of the public, and the request to the Party concerned to submit a strategy, including a time schedule, to the Compliance Committee regarding the achievement of compliance with the Convention and to report on the implementation of this strategy.

The second group includes the issuance of declarations of non-compliance and cautions, as well as the suspension, in accordance with the applicable rules of international law concerning the suspension of the operation of a treaty, of the special rights and privileges accorded to the Party concerned under the Convention. The latter acquires a peculiar meaning in the context of the Convention, due to the fact that the beneficiaries of its provisions are individuals rather then States. Thus, while the provisions of the Vienna Convention on the law of treating ${ }^{94}$ on suspension and termination for material breach seem to be broadly inapplicable, the provision may well apply to the suspension of rights (such as participation and voting in subsidiary bodies) and privileges (such as eligibility for financial support from the trust fund) conferred upon Parties through the law-making activity of the MOP and not directly by the Convention. ${ }^{95}$

The list is only indicative, meaning that it does not prevent the adoption of other appropriate non-confrontational, non-judicial and consultative measures, nor it

${ }_{91}$ Para. 20 of Annex I to the Convention requires that, if public participation is provided under an EIA procedure in accordance with national legislation, the provisions of Art. 6 shall apply.

92 The Committee thoroughly observed that "a country which had no public participation requirement with respect to EIA for such an activity would not be in non-compliance in such a case, and yet its system would be less in harmony with the objective of the Convention than that of Kazakhstan", see Findings and Recommendations with Regard to Compliance by Kazakhstan in the Case Construction of High-Voltage Power Line (Communication ACCC/C/2004/02 by Green Salvation (Kazakhstan)), adopted on 18 February 2005, doc. ECE/MP.PP/C.1/2005/2/Add.2 (14 March 2005), para. 31.

93 Ibid.

94 A list of treaties with full references is provided supra at XXXVII.

95 See more in detail Pitea, supra n. 16, at 107-111. 
requires a specific sequence in which the various measures are to be taken, ${ }^{96}$ although in practice a certain progression from facilitative to enforcement-oriented measures may be observed. ${ }^{97}$

\subsection{Consideration of Response Measures by the Committee}

Pending consideration by the MOP, the Committee may also consider the matter itself and take some of the above-mentioned measures of a facilitative nature. In consultation with the Party concerned, it may provide advice and facilitate assistance. With the agreement of the Party concerned, it may make recommendations to it, including on specific measures in cases of communications, or agree on a compliance strategy. As may immediately be seen, the Committee's power to adopt recommendations directly towards the Parties is severely limited by the requirement of consent by the latter, thus excluding such action in the case of lack of cooperation. The Committee has tried to limit the drawbacks of this provision by indicating that, failing consent by the Party concerned due to lack of cooperation, it might decide to reformulate its recommendations as advice in order to avoid the requirement of consent. ${ }^{98}$

The Committee has indicated that it would not consider it necessary to take such action when the following MOP is to take place within few months of the finalisation of the decision. In this case the Committee would report directly to the MOP. ${ }^{99}$ If the time between the conclusion of the procedure before the Committee is longer, then the Committee would consider the matter and take interim measures as described above with a view to providing an opportunity for the Party concerned to address the problems identified. In that case, it will re-evaluate the matter in proximity of the MOP, including considering any new information available, and determine whether the matter is resolved or whether further recommendation to the MOP on the case is needed.

\subsection{Follow-up}

Decision I/7 does not establish a mechanism to follow up MOP decisions in compliance matters. However the MOP, after considering the first cases, has decided to reexamine the matter at its next meeting and has established a mechanism, led by the Committee, to review implementation of its compliance decisions. It has requested each non-complying Party to submit relevant information to the Committee at least four months in advance before the next MOP, and has given the Committee the task of considering such information, requesting it to provide advice and assistance in

\footnotetext{
96 Guidance Document, supra n. 19, at 18.

97 See Pitea, supra n. 16, at 112-113 (where it is argued that enforcement-oriented measures target lack of cooperation rather than lack of compliance).

${ }_{98}$ Report on the Tenth Meeting, doc. ECE/MP.PP/C.1/2005/8 (22 December 2005), para. 12.

99 The Committee finalised its first cases at its seventh meeting that took place on the occasion of the second MOP. Thus, the Committee directly referred the matter to the MOP, see Report of the Compliance Committee to the Second Meeting of the Parties, doc. ECE/MP.PP/2005/13 (11 March 2005) and its addenda.
} 
implementation to the concerned Parties ${ }^{100}$ and to report on the issue to the MOP. Action taken by the Committee in the follow-up procedure may also include on-thespot information gathering. ${ }^{101}$

\section{Coordination with Dispute Settlement Procedures and Other Non-Compliance Procedures}

\subsection{The Relationship with Dispute Settlement under the Convention}

Decision I/7 states that "the present compliance procedure shall be without prejudice to Article 16 of the Convention on the settlement of disputes." The consequences of this statement are not entirely clear. Is a Party prevented from having recourse to the (indeed rather weak) $^{102}$ formal dispute settlement mechanism under the Convention when a matter is under consideration by the Committee or the MOP? If a compliance procedure already took place, is there an obligation by the negotiating parties or the dispute settlement body to take its outcome into account? Good faith may suggest that the non-confrontational procedure should be exhausted before having recourse to a formal dispute settlement (especially if judicial or arbitral) and that the latter should take into due account any finding by the Committee on compliance.

Be that as it may, the "no prejudice" wording of Decision I/7 leaves no room for these considerations, and formal dispute settlement appears to be completely independent from the compliance procedure. However, the provision does not answer other questions, such as whether the existence of an ongoing formal dispute over a matter precludes its examination by the Committee, by considering that this would result in prejudice to Article 16.

\subsection{The Relationship with other Compliance Procedures or Dispute Settlement Mechanisms}

Decision I/7 contains a paragraph on "enhancement of synergies" dealing with compliance procedures under other agreements. It establishes that the MOP may request the Committee to communicate as appropriate with the relevant bodies of those agreements and report back to it, including with recommendations as appropriate and that the Committee may submit a report to the MOP on relevant developments between its sessions. This provision is important, in that it envisages a communication channel between different compliance bodies, including those established under non-environmental treaties. At the same time this provision is rather clumsy, since it does not provide strong guidance on how coordination between two competing compliance

${ }^{100}$ Decision II/5 on General Issues of Compliance, doc. ECE/MP.PP/2005/2/Add.6 (13 June 2005), para. 3 .

101 See Report on the Eleventh Meeting, supra n. 82, para. 16.

102 Art. 16 provides for an obligation to settle the dispute by negotiation or other means chosen by the Parties to the disputes and for the possibility to accept the compulsory jurisdiction of the ICJ or of an arbitral tribunal set up in accordance with Annex II of the Convention. 
procedures should take place. Moreover, it does not deal with the coexistence with dispute settlement procedures other than those under the Convention.

The wording of Decision I/7 seems to suggest that current or past consideration of the same matter by another compliance or dispute settlement procedure is not a bar for consideration by the Committee. This is in keeping with the non-confrontational nature of the mechanism and is confirmed by the decision not to include a provision of inadmissibility of a communication under consideration by another compliance body. ${ }^{103}$ However, the Committee has broad discretion in deciding whether to take this fact into account, and requires communicants to mention if the matter has been submitted to any other international procedure.

In the Committee's practice the issue has emerged in the case regarding the construction of the Bystroe Canal in the Danube delta, which was submitted for review under different international environmental treaties. These included two procedures under the Espoo Convention: the inquiry procedure to assess the existence of the significant transboundary impact necessary for the Convention to be applicable, ${ }^{104}$ and the compliance review procedure before the Implementation Committee. ${ }^{105}$ Since the existence of transboundary harm is also required in order to apply Article 6.2(e) of the Aarhus Convention, which the Committee was called to rule upon, the Committee decided that it would consider the issue of compliance "in the light of the findings of the inquiry procedure being undertaken under the Espoo Convention"106 and "to defer discussions on those aspects of the submission and communication and to restrict its discussions to other aspects." 107 After the report was delivered, and transboundary effect ascertained, the Committee took the very practical view that the issue would be monitored in the framework of the follow-up process on the implementation of the recommendation adopted by the first MOP. ${ }^{108}$

A similar attitude emerges in another case of overlap with a different procedure considered by the Committee. It noted that the issues of public participation in certain decision-making processes, which was raised in a Communication in relation to Albania, might be also considered in the course of inspection proceedings carried out by the Panels established by the World Bank and the European Bank for Reconstruction and Development. The Committee, recognising "the need to avoid duplication of effort and enhance synergies, (...) agreed to inform these institutions that it was considering a communication on the matter and to inquire about their involvement in the

${ }^{103}$ Report of the First Meeting of the Task Force on Compliance Mechanisms, doc. CEP/WG.5/2000/4 (17 April 2000), Annex VI, para. 7(a).

${ }^{104}$ See Art. 3.7 of the Espoo Convention.

${ }^{105}$ For further information and reference, see E. Fasoli, "Procedures and Mechanisms for Review of Compliance under the 1991 Espoo Convention on Environmental Impact Assessment in a Transboundary Context and its 2003 Protocol on Strategic Environmental Assessment”, supra 181-203, at 199.

${ }^{106}$ See Finding and Recommendations with Regard to Compliance by Ukraine with the Obligations under the Aarhus Convention in the Case of Bystre Deep-Water Navigation Canal Construction (submission ACCC/S/2004/01 by Romania and communication ACCC/C/2004/03 by Ecopravo-Lviv (Ukraine)), adopted 18 February 2005, doc. ECE/MP.PP/C.1/2005/2/Add.3 (14 March 2005), para. 8.

${ }_{107}$ Ibid. See also Report on the Fifth Meeting, supra n. 34, para. 12.

108 Report on the Thirteenth Meeting, doc. ECE/MP.PP/C.1/2006/6 (16 November 2006), paras. 11-14. 
proposed projects and about whether their respective inspection panels were addressing the issue." 109

\section{Participation of the European Community}

\subsection{The Participation to, and Implementation of, the Convention by the European Community}

The European Community (EC) became a Party to the Aarhus Convention following the deposit of its instrument of approval. ${ }^{110}$ In accordance with Articles 19.4 and $19.5,{ }^{111}$ it has declared upon approval, inter alia, that the Community "is responsible for the performance of those obligations resulting from the Convention which are covered by Community law in force" and that "the legal instruments in force do not cover fully the implementation of the obligations resulting from Article 9.3 of the Convention as they relate to administrative and judicial procedures to challenge acts and omissions by private persons and public authorities other than the institutions of the European Community." Consequently "Member States are responsible for the performance of these obligations at the time of approval of the Convention by the European Community" and until relevant Community law is adopted.

The EC has enacted several pieces of implementing legislation. In this respect a distinction must be drawn between EC law imposing on Member States obligations relating to the field covered by the Convention, with regard to their national institutions and procedures, and the implementation of the Convention to Community institutions and procedures as such.

As to the first, specific legislation has been enacted to ensure the implementation of the access to information pillar ${ }^{112}$ and the participation of the public in decision-

\footnotetext{
109 See Report on the Eleventh Meeting, supra n. 82, para. 17.

110 Council Decision 2005/370/EC of 17 February 2005 on the conclusion, on behalf of the European Community, of the Convention on access to information, public participation in decision-making and access to justice in environmental matters, OJ (2005) L 124/1. The Convention is open to signature by "regional economic integration organizations constituted by sovereign States members of the Economic Commission for Europe to which their member States have transferred competence over matters governed by this Convention, including the competence to enter into treaties in respect of these matters" (Art. 16). Such an organization may become a Party upon ratification, acceptance or approval (Art. 19.1) or accession (Art. 19.2). Following the deposit of its instrument of approval on 17 February 2005, the EC became a Party on 17 May 2005. On the substantive connections between the Aarhus Convention and EC law, see also J. Jendroska, “Aarhus Convention and Community Law: the Interplay”, J. Eur. Envt'l Plan. L., 2 (2005) 12-21.

111 If, along with the Organization, also one or more of its Member States are Parties, "the organization and its member States shall decide on their respective responsibilities for the performance of their obligations under this Convention" (Art. 19.4). When becoming a Party, the organizations "shall declare the extent of their competence with respect to the matters governed by this Convention" and subsequently "inform the Depositary of any substantial modification to the extent of their competence" (Art. 19.5).

112 Directive 2003/4/EC of the European Parliament and of the Council of 28 January 2003 on public access to environmental information and repealing Council Directive 90/313/EEC, OJ (2003) L 41/26.
} 
making processes relating to specific activities. ${ }^{13}$ Other instruments implement the provisions of the Convention by providing for public participation requirements in the drawing up of certain plans and programmes. ${ }^{114}$ As to the third pillar, besides the provisions on access to justice to review decisions on access to information and public participation contained in the above-mentioned instruments, a proposal for a Directive on access to justice in environmental matters ${ }^{115}$ was presented on 24 October 2003 by the Commission, but it has not yet been approved.

The application of the provisions of the Convention to Community institutions and bodies is provided for by Regulation (EC) 1367/2006 of 6 September 2006. ${ }^{116}$

\subsection{The Participation of the EC and the Functioning of the Compliance Mechanism}

The nature of the Convention as a mixed agreement and the declaration made by the EC raises complex issues as to whether, when and to what extent the Community may assume the position of a "Party concerned" in proceedings before the Committee. In discussing this issue, rules on the international responsibility of international organizations shall be taken into account, with the caveat that in any case the Committee, a non-judicial body whose task is not to ascertain international responsibility, would not be strictly bound to relevant rules on attribution deriving therefrom.

With regard to non-compliance with the requirements of the Convention by the Community institutions themselves, it is clear that the Community is subject to the scrutiny of the Committee as much as any other Contracting Party. Indeed, a communication concerning the EC for the failure by the European Investment Bank to require respect of the Convention as a condition for the financing of a development plan in Albania is currently under consideration by the Committee. ${ }^{117}$

With regard to non-compliance by Member States, the picture is far more complex. Until the adoption of the proposed directive on access to justice, it may be generally accepted that the Community should not be held responsible for non-compliance by its Member States with obligations under Article 9.3. In one case, for instance, an EC

113 Implementation of the second pillar lies with Directive 2003/35/EC of the European Parliament and of the Council of 26 May 2003 providing for public participation in respect of the drawing up of certain plans and programmes relating to the environment and amending with regard to public participation and access to justice Council Directives 85/337/EEC (EIA Directive) and 96/61/EC (IPPC Directive), OJ (2003) L $156 / 17$.

114 Directive 2001/42/EC of the European Parliament and of the Council of 27 June 2001 on the assessment of the effects of certain plans and programmes on the environment (SEA Directive), OJ (2001) L 197/30, and in Directive 2000/60/EC of the European Parliament and of the Council of 23 October 2000 establishing a framework for Community action in the field of water policy (Water Framework Directive), OJ (2000) L 327/1.

115 Directive on access to justice in environmental matters, has been presented on 24 October 2003 by the Commission, $\mathrm{COM}(2003) 624$ of 24 October 2003.

116 Regulation (EC) 1367/2006 of 6 September 2006 on the application of the provisions of the Aarhus Convention on Access to Information, Public Participation in Decision-making and Access to Justice in Environmental Matters to Community institutions and bodies, OJ (2006) L 264/13.

117 Communication ACCC/C/2007/21. For further references, see the Convention's website at $<$ http:// www.unece.org/env/pp/pubcom.htm> (visited 15 July 2008). 
Member State, Belgium, was found in non-compliance with this provision, without the EC being involved in the process. ${ }^{118}$

As to other obligations, the EC and its Member States can be considered jointly (and possibly severally) responsible under the law of international responsibility. ${ }^{119}$ However, the compliance mechanism is not a tool for invoking international responsibility and it has been already observed that the Committee is not necessarily bound to strictly observe rules of attribution when dealing with such kinds of cases. Therefore failure to comply with the Convention by a Member State does not necessarily require or allow the Committee to consider compliance also by the Community.

So far the Committee has reviewed compliance by the Community in a communication originating from non-compliance by a Member State only in one case. The case concerned the failure by Lithuania to comply with public participation requirements in the process of authorising and building a landfill. The communicant made two distinct communications regarding Lithuania and the EC. The latter, however, was submitted only after the EC Commission rejected the complaint that Lithuania infringed Community law, since this decision was based on an interpretation of the relevant directives that the communicant considered not be in line with certain requirements of Article 6.

The Committee considered the merits of the Communication without finding the $\mathrm{EC}$ in non-compliance. ${ }^{120}$ Without entering into too many details on the substance of the Communication, some indications of a general nature seem to emerge from the Committee's decision and reasoning.

In the first place, the Committee has stated that, in assessing compliance,

"the structure of the European Community and its legislation differs from those of all other parties to the Convention in the sense that while relevant Community legislation has been adopted to ensure public participation in various cases of environmental decision-making, it is the duty of its Member States to implement Community directives." ${ }^{121}$

This justifies an approach to compliance review that is different to that which would have been adopted with regard to a State Party. The test applied by the Committee is whether relevant EC Law "allow the Member States to make the relevant decisions for landfills without a proper notification and opportunities for participation." 222

Secondly, the communicant contended that, because of the discrepancies between Annex I to the Convention and Annexes I to the EIA and IPPC Directives, EC Member States would not be obliged under EC law to provide public participation for

118 See Findings and Recommendations with Regard to Compliance by Belgium with Its Obligations under the Aarhus Convention in Relation to the Rights of Environmental Organizations to have Access to Justice (Communication ACCC/C/2005/11 by Bond Beter Leefmilieu Vlaanderen VZW (Belgium)), adopted by the Compliance Committee on 16 June 2006, doc. ECE/MP.PP/C.1/2006/4/Add.2 (28 July 2006)

119 See ILC, Second Report on Responsibility of International Organizations by Mr. Giorgio Gaja, Special Rapporteur, doc. A/CN.4/541 (2 April 2004), especially para. $5 \mathrm{ff}$.

120 See Compliance by the European Community with its Obligations under the Convention, doc. ECE/MP.PP/2008/5/Add.10 (2 May 2008) (Compliance by the EC).

121 Ibid., para. 44.

122 Ibid., para. 45. 
decisions relating to certain activities that, conversely, are covered by obligations deriving from Article 6 of the Convention. ${ }^{123}$ In this respect, the Committee seems to have accepted the argument by the Commission that implementing directives are to be interpreted in accordance with the Convention, the latter being integral part of the EC legal order. Accordingly, Member States are obliged to subject to EIA, and related public participation requirements, any projects covered by Annex I of the Convention, even when such project is not included in Annex I of the EIA Directives (projects for which EIA is mandatory), but in its Annex II (projects for which EIA is optional). ${ }^{124}$ Hence, with regard to public participation relating to landfills, the obligation to provide early participation is respected. However, the Committee has maintained that it "does not rule out the possibility that with respect to activities in annex I other than landfills, the Party concerned fails to comply with the Convention." 125

Hence, the Committee will be ready to consider communications regarding the Community for failures by its Member States if EC law allows its Member States to deviate from the Convention. Of course, this must take place in harmony with rules governing the non-compliance procedure, among which the above-mentioned soft requirement of exhaustion of domestic remedies. One may imagine that the Committee will normally consider, as it did in the case under consideration, such kinds of cases only when the Communicant has sought, to no avail, a remedy within the Community legal order (i.e., the Commission has decided not to open infringement proceedings or the ECJ has decided that Community Law was not violated).

As to the possibility and limits for EC Member States to make submissions to Committee on non-compliance by another EC Member State one may recall that, in the Mox Plant Case, ${ }^{126}$ the ECJ asserted its exclusive jurisdiction on disputes between Member States relating to mixed agreements to which the Community is also a Contracting Party. This jurisprudence is not automatically applicable to non-judicial proceedings, such as those before the Committee. However, one may still wonder whether EC Member States should refrain from this course of action. If, nevertheless, a submission of this kind is made, the Committee could envisage inviting, as a matter of comity, the submitting Party to have recourse to EC mechanisms first and decline competence or suspend proceedings upon considerations of comity or opportunity.

\section{FinANCIAL ASPECTS}

The functioning of the Committee depends in part on the UN ordinary budget, to the extent that this covers the Secretariat's services, translation of certain documents and other general expenses, and on the Convention's Trust Fund for other items, such as

\footnotetext{
123 As already mentioned, these obligations are implemented in EC law through public participation requirements in the procedures of environmental impact assessment (EIA) and integrated pollution prevention and control (IPPC), see supra n. 113.

124 This argument has been summarized by the Committee in Compliance by the EC, supra n. 120, para. 23.

125 Ibid., para. 45.

126 Commission v. Ireland, case C-459/03, ECR (2006) I-4635.
} 
additional staff expenditures, equipment, meetings, expert missions and translation services. ${ }^{127}$ The Committee's members are not paid for their services, but they receive financial support for travel and subsistence.

The Convention does not have a financial mechanism to support compliancerelated activities.

\section{Survey of Practice}

As of 23 May 2008, the Committee has received twenty-three communications from the public and one Party-to-Party submission. The Secretariat initiated the procedure for a referral, but did not pursue it after the same matter was brought to the Committee through a communication. ${ }^{128}$ All but six of the communications received were filed by NGOs. Five, two of which where forwarded by the same individual communicant on the same matter, have been declared inadmissible, ${ }^{129}$ and five out of the nine which have reached the stage of the merits have led to findings of non-compliance by the Committee. ${ }^{130}$ The MOP has endorsed the conclusions and recommendations of the Committee in all of the cases it has considered. ${ }^{131}$ The Party-to-Party submission related to the same matter of a communication and was considered jointly with the latter.

The communications and the submission related to a great variety of provisions of the Convention, including all three of its pillars as well as general provisions. In some cases it has touched upon sensitive political issues, such as the construction of a navigational canal in the Danube delta by Ukraine or the legislation on NGOs in Turkmenistan. Most of them are directed towards non-EU Member Parties, although some communications concerning EU-Member Parties and one concerning the EC itself have been received.

These figures indicate that the Committee has been successful and that the right of communication has not been abused by NGOs and individuals, contrary to what was predicted by its opponents. The main problem that emerges in the functioning of the mechanism is rather the poor record of cooperation by some of the parties concerned. The Committee has repeatedly deplored this attitude and the MOP has remarked the obligation upon parties to cooperate with the Committee, especially in the important phase of implementation of its recommendations.

127 In 2005 the Committee accounted for expenditures for a total of 156,049 US\$, see Report on Financial Contributions and Expenditures in 2005, doc. ECE/MP.PP/WG.1/2006/8 (21 March 2006).

128 Report on the Fifth Meeting, supra n. 34, paras. 14-15.

129 Comm. ACCC/C/2004/10, Comm. ACCC/C/2005/14 and Comm. ACCC/C/2007/19.

130 Detailed information and figures on the state of communications can be found in the Committee's page on the Convention website at $<\mathrm{http}$ ///www.unece.org/env/pp/pubcom.htm $>$ (visited 15 January 2008).

131 See the addenda from 6 to 9 to the Report of the Second Meeting of the Parties, doc. ECE/ MP.PP/2005/2 (12 July 2005) and from 9 to 14 to the Report of the Third Meeting of the Parties, doc. ECE/ MP.PP/2008/2 (26 September 2008) 


\section{Conclusions}

The mechanism established by Decision I/7 is very peculiar. Although it uses the language of other compliance review procedures adopted under other MEAs, it also shares some noteworthy features with mechanisms established to monitor compliance with human rights treaties. Among these one may mention the independent nature of the committee and the important role recognised to non-state actors, including the possibility for individuals and NGOs to file communications alleging non-compliance with the Convention.

However, a close scrutiny of practice highlights that the boundaries of a "non-confrontational, non-judicial and consultative" arrangement have not been trespassed. Indeed the procedure before the Committee avoids confrontation between the Party concerned and the author of a communication and submission, and the effort to clarify the scope of the obligations under the Convention and to engage the Party concerned in a constructive dialogue seems to prevail over any will to just sanction non-compliance. This is also reflected in the nature and content of response measures. One challenge that the Committee will have to face in the short-term is how to react when, this notwithstanding, Parties still refuse to cooperate. Indeed the Committee has been successful vis-à-vis communicants, and recourse to it may expand as knowledge about it spreads among the public and especially the NGO community. However, if this does not meet with a constructive attitude by Parties, the whole efficacy of the mechanism is likely to fail.

\section{Bibliography}

V. Koester, "Review of Compliance under the Aarhus Convention: A Rather Unique Compliance Mechanism", J. Eur. Envt'l Plan. L., 2 (2005) 31-44; C. Pitea, "The Non-Compliance Procedure of the Aarhus Convention: Between Environmental and Human Rights Control Mechanisms", Italian YB Int'l L., 16 (2006) 85-116; F. Marshall, "Two Years in the Life: The Pioneering Aarhus Convention Compliance Committee 2004-2006", Int. Comm. L. Rev., 8 (2006) 123-154; V. Koester, "The Convention on Access to Information, Public Participation in Decision-Making and Access to Justice in Environmental Matters (Aarhus Convention)", in G. Ulfstein, T. Marauhn, and A. Zimmermann (eds.), Making Treaties Work. Human Rights, Environment and Arms Control (Cambridge: Cambridge University Press, 2007) 179-217; V. Koester, "The Compliance Committee of the Aarhus Convention. An Overview of Procedures and Jurisprudence", Envt'l Pol'y \& L., 37 (2007) 83-96; S. Kravchenko, "The Aarhus Convention and Innovations in Compliance with Multilateral Environmental Agreements", Colo. J. Int. Envt'l L. \& Pol'y, 18 (2007) 1-50. 
1 


\title{
Chapter Fourteen
}

\section{Procedures and Mechanisms for Review of Compliance under the 1999 Protocol on Water and Health to the 1992 Convention on the Protection and Use of Transboundary Watercourses and International Lakes}

\author{
Cesare Pitea
}

\section{Brief Introduction to the Protocol on Water and Health}

The Protocol on Water and Health ${ }^{1}$ is a peculiar instrument of international law in the field of the environment. It establishes a normative link between a sound management of water resources and the protection and promotion of human health, thus contributing to the realisation of the human rights to health and water. The main obligation upon Parties to the Protocol is to secure the prevention, control and reduction of water-related disease, in a framework of integrated water-management systems aimed at sustainable use of water resources, through an ambient water quality which does not endanger human health (Article 4.1). The peculiarity of the Protocol as an instrument regulating the use of freshwater resources lies in the fact that it does not aim at regulating the use of transboundary waters, but it sets out obligations relating to water management at the purely domestic level.

The normative mechanism of the Protocol is also peculiar. The Protocol does not set a common minimum standard through the fixation of specific obligations or targets relating to water management and water-related diseases, nor does it provide for the elaboration of such obligations or targets through future protocols or other binding international processes. Rather it identifies critical areas in which action by Parties is required, it sets a general duty of due diligence for action taken in those areas and it establishes a process whereby Parties are to set, individually and where appropriate jointly, their own targets and target dates and to maintain those targets under constant review, within an institutional and administrative framework whose implementation

\footnotetext{
1 Protocol on Water and Health to the Convention on the Protection and Use of Transboundary Watercourses and International Lakes (London, United Kingdom, 17 June 1999), entered into force on 4 August 2005. Up-to-date figures on the status of ratification may be found at $<$ http://www.unece.org/env/water/ status/lega_wh.htm> (visited 22 January 2008).
}

T. Treves et al., eds., Non-Compliance Procedures and Mechanisms and the Effectiveness of International Environmental Agreements

(C) 2009, T.M.C. Asser PRESS, The Hague, The Netherlands, and the Authors 
is deemed to be instrumental to the creation of a framework of governance enabling the attainment of substantive targets.

More specifically the Protocol requires Parties to fix, publish and periodically revise targets and target-dates covering the items listed in Article 6.2. Targets are to be fixed and published within two years after the Protocol's entry into force, together with timeframes (deadlines and phases) for achieving them. The aspects to be covered by the targets are quite heterogeneous. Some of them concern directly the control and improvement of water quality, others request the fixation of quantitative targets for the water supply and sanitation, some relate to the administrative process and its effectiveness, as well as to the control of water related diseases. After setting the required targets, Parties are under an obligation to collect and evaluate data on progress towards their achievement and on indicators designed to show how far that progress has contributed towards preventing, controlling or reducing water-related diseases (Article 7.1). The results of this collection and evaluation shall be published at the intervals to be established by the MOP, provided that data relating to water sampling are made available to the public.

The institutional and administrative arrangement needed to promote the effective attainment of the standards and targets under the Protocol are sketched in Article 6.5. This requires the establishment of national or local arrangements to coordinate the Protocol-related activities of competent authorities (lett. a), the development of water management plans at the transboundary, national or local level, on the basis of catchment areas or groundwater aquifers (lett. b), as well as the establishment of a legal and institutional framework to monitor and enforce standards relating to drinking water and, where appropriate, the other standards and levels of performance for which the Protocol requires the fixation of targets.

In addition, Article 8 requires the establishment, maintenance and improvement of comprehensive national or local surveillance and early warning systems, as well as contingency plans for responses, in the case of outbreaks or incidents of water-related disease or significant threats of such outbreaks or incidents, including those resulting from water-pollution incidents or extreme weather events. Such systems and plans must be established within three years after the Protocol's entry into force.

An important part of the Protocol is devoted to provisions relating to international cooperation (Article 11). Article 12 requires Parties to take coordinated action at the international level in certain areas relating to the Protocol's implementation, including the fixation of targets, the development of indicators, surveillance, early warning and response systems and the exchange of information. Article 14, on the other hand, covers cooperation in implementation at the national and local level of the Protocol and lists, as areas of action, the preparation of plans and schemes, the formulation and execution of projects, the establishment of surveillance and early-warning systems, contingency plans and response capacities, the preparation of implementing legislation, education, monitoring and assessment techniques. Additional efforts in international cooperation are required by Article 13, in relation to transboundary waters shared by two or more Parties. In particular lett. (b) requires Parties to establish joint or coordinated water-management plans and surveillance and early-warning systems and contingency plans and lett. (c) to adapt their existing agreements to the Protocol's requirements. 
The Protocol sets out an institutional structure composed of the Meeting of the Parties (MOP), which may create subsidiary bodies (Article 16), and of a Secretariat, whose functions are performed jointly by the Executive Secretary of the Economic Commission for Europe and the Regional Director of the Regional Office for Europe of the World Health Organization (Article 17).

\section{Legal Basis of the Mechanism and Negotiating History}

The adoption of "compliance arrangements" under the Protocol is required by its Article 15, which calls for the establishment by the first MOP of "(m)ultilateral arrangements of a non-confrontational, non-judicial and consultative nature for reviewing compliance" and further specifies that "these arrangements shall allow for appropriate public involvement". Compared to the corresponding provision of the Aarhus Convention, which evidently inspired the drafters of the Protocol, the possibility of recognising a trigger by non-state actors is not mentioned.

The task of drafting the legal documents regulating the procedure envisaged in Article 15 was entrusted by the Working Group on Water and Health of the Convention to the Legal Board established by the Parties to the Convention at their third meeting. ${ }^{2}$ The Legal Board managed to reach an agreement on a text that, after being endorsed by the Working Group on Water and Health, was submitted to the first $\mathrm{MOP}^{3}$ and adopted as Decision $\mathrm{I} / 2$.

\section{The Text Establishing the Mechanism}

Decision I/2 establishes a Compliance Committee (the Committee) and decides its structure, functions and procedure, in accordance with the Annex thereto. ${ }^{4}$ It also stipulates that the Parties, at their third meeting, shall review the procedure, with special regard to the provisions on communications from the public, on the basis of the experience gained by the Compliance Committee. This paragraph was introduced as an element of the negotiating package that led to the acceptance of the provisions on communications from the public.

${ }^{2}$ Decision III/3 on Work under the Convention in the Period 2004-2006, doc. ECE/MP.WAT/15/Add.1 (8 April 2004), Annex III, para. 3. The text was negotiated on the basis of a background paper and a draft procedure presented by a consultant, see doc. MP.WAT/WG.4/2004/2 - EUR/5047016/2004/2 (19 February 2004).

${ }^{3}$ See Establishing a Compliance Procedure under the Protocol on Water and Health, doc. MP.WAT/ WG.4/2005/3-EUR/05/5047554/3 (11 July 2005). The document contains a Draft Decision and, in the Annex, a Draft Compliance procedure, to be presented to the MOP.

${ }^{4}$ Decision I/2 on Review of Compliance, doc. ECE/MP.WH/2/Add.3 - EUR/06/5069385/1/Add.3 (3 July 2007). The Annex is divided into thirteen sections and 38 paragraphs. In the following text, references to Decision I/2 and the related numbering of paragraphs must be understood as referring to the Annex. 


\section{The Principles Governing the Mechanism and the Procedure}

Article 15 of the Protocol clearly indicates that the procedure shall be non-confrontational, non-judicial and consultative and shall allow for the involvement of the public. Decision I/2 elaborates on these issues by introducing further objectives and principles. The objective of the procedure is to "facilitate, promote and aim to secure compliance, (...) with a view to preventing disputes" (para. 1). The procedure "shall be simple, facilitative, non-adversarial and cooperative in nature and its operation shall be guided by the principles of transparency, fairness, expedition and predictability" (para. 2). The interests to be taken into consideration by the Committee in the exercise of its functions are that of the Party facing problems in complying with the Protocol, of the Parties as a whole and, quite interestingly, of the populations potentially or actually adversely affected by non-compliance (para. 3). The existing link between Protocol obligation and the interests and rights of individuals is thus underlined.

\section{INSTITUTIONAL ASPECTS}

\section{$5.1 \quad$ The Compliance Committee}

\section{a) Composition}

The Committee is composed of nine members (para. 4), elected by the MOP in accordance with its Rules of Procedure. Candidatures are proposed only by Parties, "taking into consideration any proposal for candidates made by Signatories or Non-Governmental Organizations (NGOs) qualified or having an interest in the fields to which the Protocol relates" (para. 5). This wording mediates between the full recognition of the right of NGOs to propose candidatures and their total exclusion from the process. This enabled some NGO-proposed candidates to be actually elected as Committee Members at the first MOP. Candidates "must be persons of high moral character and have recognized expertise in the fields to which the Protocol relates, including persons having legal and/or technical expertise" (para. 5). No nationality requirements are set, ${ }^{5}$ but geographical balance is to be respected and diversity of experience encouraged in the composition (para. 7). The Committee elects its own Chairperson and vice-chairperson (para. 8) and meets at least once a year (para. 9). The Committee held its first meeting on 12 March $2008 .{ }^{6}$

\section{b) Status of Members}

The Committee's Members "shall serve in their personal capacity and objectively in the best interests of the Protocol" (para. 4). Thus, as already happened for the

\footnotetext{
${ }_{5}$ See also Report of the Third Meeting of the Legal Board, doc. MP.WAT/AC.4/2005/2 (11 July 2005), para. 10 .

${ }^{6}$ See Report on the First Meeting of the Compliance Committee, doc. ECE/MP.WH/C.1/2008/ 2-EUR/08/5069385/6 (21 April 2008).
} 
Committees established under the Kyoto Protocol, the Aarhus Convention and the Cartagena Protocol, the option of a committee composed of independent experts prevailed over that of a committee composed of a restricted number of Parties. However, in line with the prevailing view and in contrast with the practice under the Aarhus Convention, this has not prevented individuals from sitting as government delegates in other bodies to be elected as Committee members. To enhance the independence of its members and avoid conflict of interest, the Committee has agreed that they cannot represent Governments or organizations in meetings of other bodies of the Protocol. ${ }^{7}$

At their first meeting the Parties elected five members for a full term of office and four members for a half term of office. Subsequently, the MOP shall elect for a full term new members to replace those whose term has expired (para. 7). A full term of office commences at the end of an ordinary meeting of the Parties and runs until the second ordinary meeting of the Parties thereafter, meaning that the normal term of office is six years. The same person shall not sit for more than two consecutive terms (para. 7). As already happens in the Aarhus Committee, if a member is unable to complete its term, a substitute for the remainder shall be appointed by the Bureau, subject to the approval of the Committee (para. 7).

\section{c) Observers}

Decision $\mathrm{I} / 2$ does not envisage explicitly the admission of observers. Proposals to the effect of recognising such status to a fixed number of NGOs have been rejected out of the consideration that this would have afforded non-state actors greater entitlement than States (Parties and signatories, for instance) and that the presence of "institutional" observers made a little sense in a body composed of independent experts. However, it was also noted that other provisions, such as those on the openness of meetings and powers of the Committee to invite and accept the presence of any person deemed useful for the performance of its tasks, constitute a basis for NGOs or other actors to participate at the Committee's meetings. ${ }^{8}$

At its first meeting the Committee decided to recognise automatically observer status to NGOs enjoying the same status within the MOP. As to other NGOs, observer status will be granted on a case-by-case basis. ${ }^{9}$ The Committee also noted that the status of the attending public is different from the one of observers. However, this does not prevent the Committee to give the floor to the public, whenever it deems it useful. ${ }^{10}$

\subsection{The Secretariat}

The Secretariat acts as the administrative body of the mechanism. It receives candidatures for the Committee (para. 6(a)), arranges for and services its meetings (para. 9) and acts as a liaison between Parties and the public and the Committee in the handling

\footnotetext{
${ }^{7}$ See Report on the First Meeting of the Compliance Committee, supra n. 6, para. 37.

${ }^{8}$ See Report of the Third Meeting of the Legal Board, supra n. 5, para. 13.

${ }^{9}$ See Report on the First Meeting of the Compliance Committee, supra n. 6, para. 18.

10 Ibid., para. 19
} 
of non-compliance cases (paras. 13-17). In addition, it has its own triggering function (para. 15). ${ }^{11}$

\subsection{The Meeting of the Parties}

The main role of the MOP in the non-compliance procedure is to decide, upon recommendation by the Committee, on compliance matters, including the response measures to be taken (para. 35). ${ }^{12}$ It may also request the Committee to prepare reports on general issues of compliance (para. 11(b)).

\section{Functions of THE COMmittee}

The Committee performs general tasks in relation to the monitoring of compliance and considers individual cases of non-compliance. More generally, the Committee has a very broad power to examine compliance issues and make recommendations if and as appropriate (para. 12). It reports on its work at each ordinary MOP (para. 33).

The Committee shall monitor, assess and facilitate the implementation of and compliance with the Protocol reporting requirements (para. 11(c)) and prepare, at the request of the MOP, a report on compliance with or implementation of the provisions of the Convention (para. 11(b)).

The main function of the Committee is to consider issues of non-compliance by a Party with any conventional provision that has been brought to its attention in conformity with Decision I/2 (para. 11(a)), to decide upon certain facilitative response measures (para. 34) and to make recommendations to the MOP on response measures (para. 35).

\section{TRIGGER MECHANISM}

\subsection{Submission by a Party (Party-to-Party Trigger and Self Trigger)}

"Submission" refers to an issue of compliance brought before the Committee by a Party having reservations on another Party's compliance (Party-to-Party trigger) (para. 13) or concluding that, despite its efforts, is itself unable to comply with the Protocol (self-trigger) (para. 14). Submissions must be made in writing to the Secretariat and be supported by corroborating information or, in self-triggering cases, by the specific circumstances that the Party considers to be the causes of its non-compliance.

\footnotetext{
${ }^{11}$ See infra paragraph 7.2

${ }^{12}$ See infra paragraph 11.
} 


\subsection{Referrals by the Secretariat}

"Referral" refers to the issue of compliance brought to the Committee's attention by the Secretariat when it becomes aware of possible non-compliance by a Party, when the matter is not settled through consultation with the Party concerned, but only upon consideration of the Reports submitted by the Parties in accordance with the Protocol (para. 15).

\subsection{Communications from the Public}

"Communication" refers to the trigger by "members of the public", e.g. individuals or organizations, without a particular interest to be stated. The mechanism is broadly similar to that provided for by Decision I/7 under the Aarhus Convention. It provides for a one-year "grace" period for any Party and for the possibility of opting-out for no more than four years (para. 16). To be admissible, communications must not be (a) anonymous, (b) an abuse of the right to make such communications, (c) manifestly unreasonable, and (d) incompatible with the provisions of the compliance procedure or with the Protocol (para. 18). A soft requirement of exhaustion of domestic remedies is also set (para. 19).

\subsection{Initiation Proprio Motu}

The broad provision on the Committee's power "to examine compliance issues and make recommendations if and as appropriate" suggests that, as happens under the Aarhus Convention, the Committee may also act proprio motu.

\section{The Procedure before the Compliance Committee and Procedural SAFEGUARDS}

\subsection{Sources of Procedural Rules and General Remarks}

Decision $\mathrm{I} / 2$ is not exhaustive in regulating the procedural aspects of the mechanism and it is completed by the application of the Rules of Procedure of the MOP. ${ }^{13}$ In accordance with Rule 21 of the Rules of Procedure of the MOP, the latter are applicable mutatis mutandis to the Compliance Committee (and other bodies established by the MOP), with the exclusion of those on representation and credentials, on the establishment of the bureau and on official languages. Special rules are provided on the distribution of documents (Rule 21(5)), quorum (Rule 21(6)) and the voting rights of the Chairperson (Rule 21(7)). Rules on dates of meeting and working languages are left to the Committee itself, whereas those on attendance by the public and participation without the right to vote are to be found either in Decision I/2 or, failing regulation, in subsequent decisions or practice of the Committee.

13 Decision I/1 on Rules of Procedure for the Meetings of the Parties to the Protocol, doc. ECE/ MP.WH/2/Add.1-EUR/06/5069385/1/Add.1 (3 July 2007). 
At its first meeting the Committee held a preliminary discussion on Rules of Procedure and on procedures for the handling of submissions, referrals and communications. The view prevailed that the precedent under the Aarhus Convention could be an important guidance, both as to the format and to the content of the procedural rules to be elaborated by the Committee.

\subsection{Procedural Safeguards}

As generally stated in the section on objective, nature and principles, the compliance procedure "shall be guided by the principles of transparency, fairness, expedition and predictability" (para. 2). This statement is reflected in several provisions throughout the procedure. First of all, the Party whose compliance is at issue has the right to be promptly informed of any referral, submission or communication made in its respect. Arguably, this includes the right to receive all the relevant information and documents available to the Committee and to respond to it in a set time framework (paras. 14, 15, 20 and 21). Secondly, together with the submitting Party or with the member of the public making the communication, it has the right to take part in the discussion of the submission, referral or communication (para. 30), except for the part in which findings, measures or recommendations are prepared and adopted (para. 31). However, the Party concerned and the submitting party or the communicant, as applicable, are entitled to receive a draft of the findings, measures and/or recommendations for comments. These comments are to be taken into account by the Committee (para. 32).

Another set of safeguards relates to the confidentiality of proceedings. Decision I/2 contains a general rule of "non-confidentiality" of the information held by the Committee, with an exception for information provided in confidence by a Party making a self-submission (para. 26) and for information falling within the scope of exceptions referred to in Articles 10.4(c) and 10.5 of the Protocol and that have been provided in confidence (para. 24). In these cases the Committee's members and any other person involved in the procedure are bound to a duty of confidentiality. An additional ground for confidentiality was set, after a long debate, in order to preserve the security of those submitting information to the Committee, when they risk being penalised, prosecuted or harassed because of the communication. Thus a request not to disclose their identity may be made to the Committee, which could deny it when there are no reasonable grounds to believe that the risk may be real (para. 27).

As already mentioned, "attendance by members of the public" is one of the issues that the Rules of Procedures of the MOP exclude from application mutatis mutandis to bodies with a limited membership created under the Protocol. The regulation of this aspect of the procedure is thus left to a case-by-case decision by the MOP or by the body concerned (Rule 21(9)). "Transparency" is one of the guiding principles of the whole procedure (para. 2). It is reflected in the general rule that meetings shall be held in public (para. 28). Apart from holding close meetings when findings and recommendations are prepared, in accordance with para. 31 , the Committee may also decide to close meetings on a case-by-case basis, but only if this is necessary to ensure the confidentiality of information in accordance with the rules set out above (para. 28). 
An innovative provision of Decision I/2 contained in para. 33 requires the Committee to list the sources of information used and to give a reasoning for its decisions and recommendations. The rule is contained in the paragraph dealing with the Committee's report to the MOP, but should be deemed to be applicable to any decision of the Committee and in particular on decisions on response measures in accordance with para. 34

\section{SOURCES OF INFORMATION}

Decision I/2 affords the Committee with broad powers to seek, receive and consider information, through written proceedings, oral hearings and, with the consent of the Party concerned, on-site activities (para. 22). The Legal Board opted for a general provision, not listing specific sources of information, except for experts and advisers, including from NGOs or the public. However, this should not be interpreted as excluding non-governmental sources in the other information gathering activities.

\section{DECISION-MAKING}

Decision I/2 contains a general rule on decision-making (para. 10), stating that the Committee shall make every effort to adopt its decisions and recommendations by consensus and that when consensus cannot be reached, a two-thirds majority of the members present and voting or five positive votes, whichever is the greater, are necessary. This provision codifies the practice already adopted by the Aarhus Committee.

\section{Outcomes}

As usually found in compliance mechanisms, Decision I/2 provides for both facilitative and stronger measures as outcomes of the procedure. Those of a facilitative nature are directly entrusted to the Committee (para. 33), who can address itself to the Party concerned to provide advice and facilitate assistance on compliance, to invite it to develop an action plan to restore compliance, to request the submission of progressive reports on the action taken and to make specific recommendations in relation to communications from the public. The Committee is also afforded with the unusual power to issue cautions to a Party aimed at inducing compliance with the Protocol. In addition to these measures, and other facilitative ones relating to financial and technical assistance, capacity building and technology transfer, the MOP is empowered to take stronger measures (para. 34) including the issuance of declarations of non-compliance, the decision of special forms of publicity for a given case and the suspension of rights and privileges according to general international law.

This division of competence between the two bodies is justified by the necessity to ensure a prompt collective response to non-compliance, which would have proved difficult if left within the exclusive competence of a body, the MOP, which ordinarily meets only every three years. However, the powers afforded to the Committee are 
unusually broad. It has the power to address recommendations directly to the Party concerned and this power is not "provisional", nor subject to the Party cooperation or consent, as happens in the Aarhus procedure. Moreover, in addition to recommending facilitative measures, the Committee may also "issue cautions". For political and legal reasons, the MOP is left with the power to decide, upon the Committee's recommendation, those measures possibly requiring additional financial efforts by the Parties as well as those more oriented towards enforcement and sanctions.

Although the measures indicated in Decision $\mathrm{I} / 2$ are not to be considered as requiring a specific sequence, in practice it is foreseeable that in normal situations the Committee, after finding a Party to be in non-compliance, will request that Party to submit a plan to achieve compliance and to report on its implementation. In the case of lack of cooperation by the Party, it may issue a caution that it will recommend more stringent measures to be adopted by the MOP.

A last issue concerns the use, in para. 34, of the expression "the Committee decides upon one or more of the following measures", which should not be interpreted as suggesting that the Committee's determinations are binding upon the Party concerned. First, this paragraph is to be read in the context of the kinds of measures it may "decide upon", which are facilitative and cooperative. Certainly, the refusal to submit a plan for achieving compliance seems to carry with it legal consequences, but these may be derived from the general duty of implementing the treaty in good faith. Moreover, the object and purpose of the mechanism, as clearly envisaged in Article 15, excludes the adoption of binding decisions by the Committee. Finally, one may wonder whether it would be consistent with international law to entrust with the power of issuing acts creating obligations upon Parties a body created by a decision of the MOP, without each Party expressing its consent to it in accordance with the law of treaty.

\section{Coordination with Dispute Settlement Procedures and Other Non-Compliance Procedures}

As usually found in this kind of mechanism, Decision I/2 specifies that the compliance procedure shall be "without prejudice" to the dispute settlement clause of the Protocol (Article 20).

The multiplication of compliance procedures within MEAs is likely to raise issues of duplication of proceedings, due to the existing overlaps in substantive provisions. By way of example, the Protocol's provisions on access to information, public participation and environmental impact assessment may overlap with provisions of the Aarhus and Espoo conventions. In order to promote the efficiency and consistency of the various mechanisms, Decision I/2 takes an innovative approach by enabling the Committee to communicate, upon specific directions by the MOP, with other compliance bodies (para. 36), to transmit information to the secretariats of other MEAs and invite members of other committees dealing with issues related to those pending before it (para. 37). 


\section{PARTICIPATION OF THE EUROPEAN COMMUNITY}

The Protocol on Water and Health is open to ratification, acceptance, approval or accession

"by regional economic integration organizations constituted by sovereign States members of the Economic Commission for Europe or members of the Regional Committee for Europe of the World Health Organization to which their member States have transferred competence over matters governed by this Protocol, including the competence to enter into treaties in respect of these matters" (Article 21),

while Article 22 specifies that the Organization and its Member States that are a Party to it "shall decide on their respective responsibilities for the performance of their obligations under this Protocol" and "shall not be entitled to exercise rights under this Protocol concurrently". Thus the instrument of ratification, acceptance, approval or accession by the Organization in point shall contain a declaration of "the extent of their competence with respect to the matters governed by this Protocol".

Those provisions clearly envisage the participation in the Protocol of the European Community (EC). It may be recalled that the EC has not signed the Protocol yet, while setting in motion the process for ratification. A Proposal for a Decision on the conclusion of the Protocol by the EC was submitted by the Commission to the Council on 17 August 2001, ${ }^{14}$ and the European Parliament, consulted by the Council, has also taken a favourable stand, ${ }^{15}$ but the Council has not yet made a final decision. In the Draft Declaration annexed to the Draft Decision it is stated that, besides having competence under Article 174.4 of the Treaty establishing the European Community (EC Treaty), legal instruments, binding on the Member States, covering all matters governed by the Protocol have already been adopted at the Community level. One may also recall that the Explanatory Statement accompanying the Draft Legislative resolution of the European Parliament on the point at issue states that " $\mathrm{t}]$ he Protocol does not create new legal obligations for the Community in the field of water policy." Notwithstanding the fact that this assertion may be disputed, the Commission has decided to withdraw its proposal ${ }^{16}$ and the process of accession has been consequently stopped.

\footnotetext{
14 Proposal for a Council Decision relating to the conclusion, on behalf of the Community, of the Protocol on Water and Health to the 1992 Convention on the Protection and Use of Transboundary Watercourses and International Lakes, 2001/C 332 E/03), COM(2001) 483 final-2001/0188(CNS), OJ (2001) C 332 $\mathrm{E} / 237$.

15 Report on the proposal for a Council Decision relating to the conclusion, on behalf of the Community, of the Protocol on Water and Health to the 1992 Convention on the Protection and Use of Transboundary Watercourses and International Lakes, COM(2001) 483 - C5-0644/2001 - 2001/0188(CNS)), Committee on the Environment, Public Health and Consumer Policy, A5-0462/2001 of 19 December 2001.

${ }^{16}$ See Communication from the Commission to the Council and the European Parliament, Outcome of the screening of legislative proposals pending before the Legislator, $\operatorname{COM(2005)~} 462$ final and 2006/ C 64/03, OJ (2006) C 64/3.
} 


\section{FinanCIAL AsPeCtS}

The Committee's members are not paid for their services, but they will receive financial support for travel and subsistence. The estimated cost of the compliance procedure for the triennium 2007-2009 is between $\$ 214,000$ and $\$ 256,000$ (US dollars). ${ }^{17}$ The costs will be borne in part by the UN ordinary budget, to the extent that this covers the Secretariat's services, translation of certain documents and other general expenses, and in part by the Protocol's trust and voluntary funds constituted respectively with the UNECE and the WHO-EURO, ${ }^{18}$ for other items.

The Protocol does not have a financial mechanism to support compliance-related activities.

\section{SurVey OF PRACTICE}

There is not yet any relevant practice, since the Committee has met only once and it exclusively dealt with organizational matters.

\section{CONCLUSIONS}

Decision I/2 designs a particularly advanced compliance mechanism, building on the precedent of the Aarhus NCP. The most qualifying aspects are the broad powers conferred on the Committee, composed of independent experts, which may take a vast array of action directly vis-à-vis Parties. The provision on communications from the public are also very relevant, although they may be revised at the third MOP. Being largely inspired by the precedent set by Decision I/7 under the Aarhus Convention, it will be interesting to see to what extent this will provide a model also in the practical functioning and in the modus operandi of the Committee.

\section{Bibliography}

C. Pitea, "Towards the Entry into Force of the UNECE Protocol on Water and Health. Report on the First and Second Meeting of the Legal Board of the Helsinki Water Convention", Envt'l Pol'y \& L., 34 (2004) 267-272.

${ }^{17}$ See Programme of Work for 2007-2009 adopted by the Meeting of the Parties, doc. ECE/MP.WH/2/ Add.5-EUR/06/5069385/1/Add.5 (3 July 2007), para. 54.

${ }^{18}$ Decision I/5 on Financial Arrangements to Support the Implementation of the Protocol, doc. ECE/MP.WH/2/Add.2-EUR/06/5069385/1/Add.2 (3 July 2007). 


\title{
Chapter Fifteen \\ Procedures and Mechanisms for Review of Compliance under the 2003 Protocol on Pollutant Release and Transfer Registers to the 1998 Aarhus Convention
}

\author{
Cesare Pitea
}

\section{Brief Introduction to the Protocol on Pollutant Release and Transfer Registers to the Aarhus Convention}

The Protocol on Pollutant Release and Transfer Registers (PRTRs) ${ }^{1}$ is an element of the international effort to prevent pollution from the release into the environment of dangerous substances, through the establishment of national registers of the release and transfer of certain pollutants. The basic idea is that enhancement of transparency and broad public access to emission data would put pressure on economic actors to reduce emissions in order not to publicly appear as "polluters". The Protocol has been developed in the framework of the Aarhus Convention whose Article 5.9 requires each Party to

"take steps to establish progressively, taking into account international processes where appropriate, a coherent, nationwide system of pollution inventories or registers on a structured, computerized and publicly accessible database compiled through standardized reporting. Such a system may include inputs, releases and transfers of a specified range of substances and products, including water, energy and resource use, from a specified range of activities to environmental media and to on-site and offsite treatment and disposal sites."

Article 10.2(i) also states that the Parties, at their first meeting, shall review their experience in implementing these provisions and

"consider what steps are necessary to develop further the system referred to in that paragraph, taking into account international processes and developments, including the elaboration of an appropriate instrument concerning pollution release and transfer registers or inventories which could be annexed to the Convention."

\footnotetext{
1 Protocol on Pollutant Release and Transfer Registers (Kiev, Ukraine, 21 May 2003), not yet in force. Figures on status of ratification may be found at $<\mathrm{http}$ ://www.unece.org/env/pp/ratification.htm $>$ (visited 24 January 2008).
}

T. Treves et al., eds., Non-Compliance Procedures and Mechanisms and the Effectiveness of International Environmental Agreements

(C) 2009, T.M.C. Asser PRESS, The Hague, The Netherlands, and the Authors 
On this basis the Signatories to the Convention at their first meeting established a Task Force to review national experience with PRTRs. ${ }^{2}$ Lately, it was proposed that this body should be replaced by an intergovernmental working group on PRTRs, charged with the task of preparing a legally binding instrument on PRTRs under the auspices of the Convention, with a view to its being ready for adoption at the fifth Ministerial Conference "Environment for Europe" to be held in Kiev in May 2003. ${ }^{3}$ The UNECE Committee on Environmental Policy endorsed this proposal and established the Working Group that was lately reconvened as a Working Group on PRTRs under the Aarhus Convention in 2002 after the latter entered into force. ${ }^{4}$ An extraordinary meeting of the Parties to the Aarhus Convention took place in Kiev back to back with the fifth Ministerial Conference "Environment for Europe", and the PRTRs Protocol was adopted. ${ }^{5}$

Although being negotiated on the basis and in the framework of the Aarhus Convention, the Protocol is a fully self-standing instrument: it is open to accession by all States (and certain regional economic organizations) whether or not they are Parties to the Aarhus Convention or UNECE members.

The Protocol has the objective of securing the establishment and maintenance of comprehensive and easily accessible national registers of the release and transfer of certain pollutants. At present Annex II to the Protocol covers eighty-six pollutants, covering greenhouse gases, acid rain pollutants, ozone-depleting substances, and certain heavy metals and carcinogens.

The mechanism is based on the obligation to be placed by Parties on owners and operators of certain facilities within their jurisdiction to report annually detailed information (Article 7, paras. 5 and 6) on the release and transfer of covered pollutants to national authorities. Parties have a choice between two systems for singling out concerned facilities, provided that these exercise an activity included in Annex I. ${ }^{6}$ The first method (Article 7.1(a)) is based on a combination between the capacity of the facility and the release or transfer of covered pollutants and hazardous wastes above established thresholds. The second method (Article 7.1(b)) is based on the combination between a minimum number of employees and the manufacture, processing or use of covered pollutants in certain threshold quantities. Reporting obligations arise only with respect to the pollutants for which thresholds are exceeded. A mechanism of review of the type of facilities, of the type of pollutants and of the relevant thresholds is provided (Article 6.2). Parties shall also take measures to ensure the quality of reported data (Article 10).

\footnotetext{
${ }^{2}$ Report on the First Meeting of the Signatories, doc. CEP/WG.5/1999/2 (5 July 1999), Annex, paras. $41-44$.

${ }^{3}$ Report on the Second Meeting of the Signatories, doc. CEP/WG.5/2000/2 (19 July 2000), paras. $25-28$.

${ }^{4}$ See Decision I/2 on Pollutant Release and Transfer Registers, doc. ECE/MP.PP/2/Add.3 (2 April 2004)

${ }_{5}^{5}$ Report of the First Extraordinary Meeting of the Parties, doc. ECE/MP.PP/4 (5 August 2003), para. 23.

${ }^{6}$ The Annex mentions, inter alia, thermal power stations, refineries, mining and metallurgical industries, chemical plants, waste and waste-water management plants, and paper and timber industries.
} 
The data collected shall then be organised, together with certain data on pollution from diffuse sources, by the designated national competent authority (subject to public participation requirements, Article 12) in a register that shall be accessible to the general public (Article 11), especially through electronic means and public telecommunication services (i.e., internet) (Article 11.1), in a way that permits the retrieval of the emission information in a variety of forms, including points of emission (i.e., specific facilities), owner or operator, type of pollutants and medium of release (air, water, soil, etc. ...) (Article 5). Confidentiality may be maintained on certain grounds, but these must be interpreted restrictively (Article 12).

The Protocol establishes an institutional structure composed of the Meeting of the Parties and a Secretariat, whose functions are carried out by the Executive Secretary of the UNECE. The MOP may establish subsidiary bodies.

\section{Legal Basis of the Mechanism and Negotiating History}

Under the heading "Review of Compliance", Article 22 of the Protocol states that:

"At its first session, the Meeting of the Parties shall by consensus establish cooperative procedures and institutional arrangements of a non-judicial, non-adversarial and consultative nature to assess and promote compliance with the provisions of this Protocol and to address cases of noncompliance. In establishing these procedures and arrangements, the Meeting of the Parties shall consider, inter alia, whether to allow for information to be received from members of the public on matters related to this Protocol."

This provision, which fails to make a mandatory reference to public involvement and to the option of communications from the public, has been described by $\mathrm{NGOs}^{7}$ as weakening previous drafts $^{8}$ and a serious step back from the mechanism already established under the Aarhus Convention. ${ }^{9}$

At the request of the Signatories to the Protocol, ${ }^{10}$ the Parties to the Convention established a Working Group on Protocol on PRTRs ${ }^{11}$ with, inter alia, the task of drafting the legal documents regulating the procedure envisaged in Article 22. The Working Group requested the Secretariat to prepare a paper describing possible options, especially with regard to the relationship with the non-compliance

\footnotetext{
7 Report on the Second Meeting of the Working Group on Pollutant Release and Transfer Registers, doc. MP.PP/AC.1/2003/2 (12 August 2003), para. 73.

${ }^{8}$ See Elements for Final Provisions of a Draft Instrument on Pollutant Release and Transfer Registers (PRTR) Prepared by the Secretariat, doc. CEP/WG.5/AC.2/2001/6 (7 May 2001), Annex, Art. 20.

9 On which see C. Pitea, "Procedures and Mechanisms for Review of Compliance under the 1998 Aarhus Convention on Access to Information, Public Participation and Access to Justice in Environmental Matters", supra 221-249.

${ }^{10}$ Resolution on Pollutant Release and Transfer Registers, doc. MP.PP/2003/1/Add.1/Rev.1 (21 August 2003), para. 1(a)(iii)

${ }^{11}$ Report of the First Extraordinary Meeting of the Parties, doc. ECE/MP.PP/4 (5 August 2003), para. 23.
} 
mechanism under the Aarhus Convention. ${ }^{12}$ On this basis ${ }^{13}$ the Working Group agreed on the establishment of a separate committee and procedure, albeit based on that under the Convention. ${ }^{14} \mathrm{~A}$ first draft was then presented ${ }^{15}$ singling out some discrete issues to be decided upon: whether there is a need for a specific provision on objectives; number of members and regional representation; entitlement to nominate candidates; capacity and expertise (scientific, technical, legal) of members; frequency of meetings; public trigger and any "grace" period; confidentiality; relative functions of the Committee and the MOP; range of measures to be taken to address non-compliance. ${ }^{16}$ A Contact Group was then established to further negotiate the text. ${ }^{17}$ After extensive negotiations the Contact Group reached an agreement on a compromise text that was submitted to the fifth meeting of the Working Group on PRTRs.

\section{The Text Establishing the Mechanism}

The Draft Decision on Review of Compliance prepared by the Contact Group, which establishes the Compliance Committee and determines its structure and functions in its Annex hereinafter, Draft Decision, ${ }^{18}$ was endorsed by the Working Group on PRTRs at its fifth meeting, where it was agreed to submit it to the Parties at their first meeting. ${ }^{19}$

\section{The Principles Governing the Mechanism and the Procedure}

Article 22 of the Protocol describes the procedures and institutional arrangements as cooperative and of a non-judicial, non-adversarial and consultative nature. The Draft Decision does not contain a section on objective and/or principles, but some other principles emerge, particularly transparency.

${ }_{12}$ Report of the First Meeting of the Working Group on Pollutant Release and Transfer Registers, doc. MP.PP/AC.1/2004/2 (18 March 2004), para. 44.

${ }_{13}$ An Analysis of Options for a Compliance Mechanism to the UNECE Protocol on Pollutant Release and Transfer Registers (PRTRs), doc. ECE/MP.PP/AC.1/2005/4 (4 April 2005).

${ }^{14}$ Report of the Second Meeting of the Working Group on Pollutant Release and Transfer Registers, doc. ECE/MP.PP/AC.1/2005/2 (20 May 2005), para. 18.

${ }^{15}$ Draft Decision I/[..] on Review of Compliance, doc. ECE/MP.PP/AC.1/2006/4 (8 March 2006).

${ }^{16}$ Explanatory Note on Draft Texts on Compliance Mechanism and Rules of Procedure for the Protocol on Pollutant Release and Transfer Registers, doc. ECE/MP.PP/AC.1/2006/5 (8 March 2006), para. 14.

${ }^{17}$ Report of the Third Meeting of the Working Group on Pollutant Release and Transfer Registers, doc. ECE/MP.PP/AC.1/2006/2 (28 July 2006), para. 15 ff.

${ }_{18}$ Draft Decision on Review of Compliance, doc. ECE/MP.PP/AC.1/2007/L.10 (18 July 2007) and Annex. In the following text, references to the Draft Decision and related numbering of the paragraphs must be understood as referring to the Annex.

${ }^{19}$ Report of the Working Group on Pollutant Release and Transfer Registers on its Fifth Meeting, doc. ECE/MP.PP/AC.1/2007/4 (4 March 2008), para. 24. 


\section{INSTITUTIONAL ASPECTS}

\section{$5.1 \quad$ The Compliance Committee}

\section{a) Composition}

The Committee will be composed of nine members (para. 1), elected by the MOP by consensus (para. 7). After lengthy discussion, the issue whether NGOs may nominate candidates or propose candidatures to individual Parties has been agreed upon, allowing only Parties to nominate candidates, but "taking due account of any proposal for candidates made by Signatories or by non-governmental organizations qualified or having an interest in the fields to which the Protocol relates." This wording reflects the approach already adopted in the non-compliance procedure under the Protocol on Water and Health ${ }^{20}$ and does not restrict such entitlement only to "environmental" NGOs, as requested by the latter. Candidates "shall be persons of high moral character and recognized competence in the fields to which the Protocol relates, including persons having technical or legal experience" (para. 2). No two members may have the same nationality (para. 3) and geographical balance and diversity of experience in the composition are encouraged (para. 4). The Committee elects its own Chairperson and vice-chairperson (para. 8), meets at least once a year (para. 11) and may, in appropriate circumstances, undertake some of its activities through electronic communications (para. 12).

b) Status of Members

The Committee's Members "shall serve in their personal capacity" (para. 1). Contrary to what happened in other negotiations this solution was easily accepted from the very beginning of the negotiation. It remains to be seen whether it will be interpreted, as in the Aarhus Convention non-compliance procedure, as precluding civil servants from being members or whether a more flexible understanding will prevail, as in other settings. At their first meeting the Parties shall elect four members for a full term of office and five members for a half term of office. Subsequently, the MOP shall elect for a full term new members to replace those whose term has expired (para. 8). A full term of office begins at the end of an ordinary session of the Meeting of the Parties and runs until the second ordinary session of the Meeting of the Parties thereafter, meaning that the normal term of office is four years. Outgoing members may be reelected once for a further full term of office, unless in a given case the Meeting of the Parties decides otherwise (ibid.). As already happens in the Aarhus and Water and Health committees, if a member is unable to complete its term, a substitute for the remainder shall be appointed by the Bureau, subject to the approval of the Committee (ibid.).

20 See C. Pitea, "Procedures and Mechanisms for Review of Compliance under the 1999 Protocol on Water and Health to the 1992 Convention on the Protection and Use of Transboundary Watercourses and International Lakes", supra 251-262, at 254. 
c) Observers

The Draft Decision does not envisage explicitly the admission of observers. However, provisions on the openness of meetings constitutes a sound basis for NGOs or other actors to participate in the Committee's meetings.

\subsection{The Secretariat}

The Secretariat acts as the administrative body of the mechanism. It receives candidatures for the Committee (para. 5(a)), arranges for and services its meetings (para. 11) and acts as a liaison between Parties and the public and the Committee in the handling of non-compliance cases (paras. 15, 16 and possibly 19). In addition, it has its own triggering function (para. 17).

\subsection{The Meeting of the Parties}

The MOP has the power to request the Committee to prepare reports on compliance with or implementation of provisions of the Protocol (para. 13(a)) or to assign to it any other compliance-related function (para. 13(e)). Upon recommendation of the Committee it decides on compliance matters, including the response measures to be taken (para. 41).

\section{Functions of The CoMmittee}

The main function of the Committee is to consider issues of non-compliance by a Party with any conventional provision that has been brought to its attention in conformity with the Draft Decision (para. 13(a)). In this framework it shall take facilitative response measures under para. 40 (para. 13(d)) and may make recommendations to the MOP including on measures under para. 41 (para. 14(a)).

The Committee shall monitor, assess and facilitate the implementation of and compliance with the Protocol reporting requirements (para. 13(c)) and prepare, at the request of the MOP, a report on compliance with or implementation of the provisions of the Convention (para. 13(b)).

The Committee may perform any other function assigned to it by the MOP (para. 13(e)) and may examine any other compliance issues not referred to in the Draft Decision (para. 14(b)).

\section{TRIGGER Mechanism}

\subsection{Submission by a Party (Party-to-Party Trigger and Self-Trigger)}

"Submission" refers to an issue of compliance brought before the Committee by a Party having reservations on another Party's compliance (Party-to-Party trigger) (para. 15) or concluding that, despite its efforts, is itself unable to comply with the 
Protocol (self-trigger) (para. 16). Submissions must be made in writing to the Secretariat and be supported by corroborating information or, in self-triggering cases, by the specific circumstances that the Party considers to be the causes of its non-compliance.

\subsection{Referrals by the Secretariat}

"Referral" refers to the issue of compliance brought to the Committee's attention by the Secretariat when it becomes aware of possible non-compliance by a Party, when the matter is not settled through consultation with the Party concerned (para. 17). The Secretariat's triggering power is not limited to issues emerging from the examination of Parties' reports, though special attention should be placed on such issues.

\subsection{Communications from the Public}

The introduction of a trigger by non-State actors has been one of the most controversial negotiating issues. Several options had been proposed, including a system of communications from the public, similar to that under the Aarhus Convention and the Protocol on Water and Health, or granting NGOs entitlement to initiate the procedure.

Finally, an Aarhus Convention-like system of communications from the public has been included, with a one-year "grace" period and the possibility of opting-out from it for a period not longer than four years.

\subsection{Initiation Proprio Motu}

The explicit recognition of a Committee initiative, which was flagged in some previous drafts, has not been included in the final Draft Decision since it was conceived as an alternative to the system of communications from the public or NGOs. However, the Draft Decision provides that the Committee may examine any compliance issue other than those explicitly envisaged in the Draft Decision (para. 14(b)).

\section{The Procedure before the Compliance Committee and Procedural SAFEGUARDS}

\subsection{Sources of Procedural Rules and General Remarks}

The procedure will be regulated by the Draft Decision establishing the Committee and the Rules of Procedure of the MOP should be applicable mutatis mutandis, with some exceptions. ${ }^{21}$

Party-to-Party submissions

"shall be addressed in writing to the secretariat and supported by corroborating information. The secretariat shall, within two weeks of receiving a submission, send a copy of it

\footnotetext{
${ }^{21}$ See Draft Decision on Rules of Procedure, doc. ECE/MP.PP/AC.1/2007/L.9 (18 July 2007), rule 23.
} 
to the Party whose compliance is at issue and, for the purposes of information, to the Committee. Any reply and supporting information shall be submitted to the secretariat and to the Parties involved within three months or such longer period as the circumstances of a particular case may require, but in no case later than within six months. The secretariat shall transmit the reply and supporting information to the Committee, which shall consider the matter as soon as practicable, unless the submission is manifestly ill-founded or de minimis" (para. 15).

\section{Self-submissions}

"shall be addressed in writing to the secretariat and should explain, in particular, the specific circumstances that the Party considers to be the cause of its non-compliance or potential non-compliance. The secretariat shall transmit the submission to the Committee, which shall consider the matter as soon as practicable" (para. 16).

Communications from the public must be made in writing, also in electronic form, to the Committee through the Secretariat. To be admissible, Communications must not be (a) anonymous communications, (b) an abuse of the right to make such communications, (c) manifestly unreasonable, (d) incompatible with the provisions of this decision or with the Convention, (e) manifestly ill-founded, or (f) de minimis (para. 20). The two latter grounds are not found in either the non-compliance mechanism of the Aarhus Convention or that of the Protocol on Water and Health and they replicate those provided for Party-to-Party submissions. A soft requirement of exhaustion of domestic remedies is also set (para. 19).

\subsection{Procedural Safeguards}

\section{a) Due Process and Fairness of Proceedings}

The Party concerned has the right to be promptly informed of any referral, submission or communication made in its respect. Arguably, this includes the right to receive all the relevant information and documents available to the Committee and to respond to it in a set time framework (paras. 14, 15, 22 and 23). Together with the submitting Party or the communicant, it is entitled to participate in the Committee's meetings when the case is discussed (para. 36), with the exception of the sessions in which findings and recommendations are prepared (para. 37). The Party concerned and the submitting Party or the communicant, as applicable, are entitled to receive a copy of any draft findings and recommendations for comments (para. 38).

\section{b) Transparency and Confidentiality}

Transparency emerges as a fundamental principle of the procedure: as a rule, the Committee's meetings shall be open (para. 33), except when findings and recommendations are prepared (para. 34(b)), no information held by the Committee shall be kept confidential (para. 27) and the Committee's reports shall be made available to the public (para. 39). These general statements are limited by the provisions on 
confidentiality. These appear to reverse the rule in self-submission cases, since the "Committee and any person involved in its work shall ensure the confidentiality of information that has been provided to it in confidence by a Party when making a submission in respect of its own compliance" (para. 30). In other cases, confidentiality of information may be requested by a Party submitting the information when the disclosure may impact on the protected interest listed in para. 28, when information concerns material in the course of completion or concerns internal communications of public authorities where such an exemption is provided for in national law or customary practice. If the Committee, taking into account general interests in disclosure, has concerns about the request to keep a certain piece of information confidential it shall enter into consultation with the relevant Party in order to obtain a restrictive application of the confidentiality rules (para. 29). Finally, the confidentiality of information may be also requested by any submitting person because of a concern that any member or members of the public may be penalized, persecuted or harassed as a result of disclosure.

When rules of confidentiality apply the Committee shall hold closed sessions - if necessary (para. 34(b)) - and relevant information cannot be included in the Report (para. 32). However, such information must be put at the disposal of the Parties upon request, provided that confidentiality is ensured by the accessing Party. This does not apply to confidentiality requested to safeguard the safety of persons involved under para. 31 (ibid.).

The principle of the openness of meetings is counterbalanced by the discretion the Committee enjoys in holding closed sessions in any cases where it deems it appropriate to do so, taking into account the desirability of the transparency of proceedings (para. 35).

\section{SOURCES OF INFORMATION}

The Draft Decision affords the Committee with broad powers to request, gather and consider information, through written proceedings, oral hearings and, with the consent of the Party concerned, on-site activities (paras. 25-26). Information from nongovernmental sources, although not explicitly mentioned, are covered.

\section{DeCiSION-MaKing}

The Draft Decision contains a general rule on decision-making, stating that the Committee shall make every effort to adopt its decisions and recommendations by consensus. Other decisions should be taken in accordance with the Rules of Procedure of the MOP, e.g., three-fourths majority vote of the Parties present and voting for substantive decisions (Rule 35.4) and a simple majority vote of the Parties present and voting for procedural decisions (Rule 35.3).

The provision on activities undertaken through electronic communications enables the Committee to develop procedures for decision-making by e-mail or other similar means. 


\section{Outcomes}

As usually found in compliance mechanisms, the Draft Decision provides for two kinds of measures which may result from the procedure. Those of a facilitative nature are directly entrusted to the Committee (para. 40), which can: provide advice and facilitate assistance on compliance to the Party concerned; request it to develop an action plan to restore compliance, to submit progressive reports on the action taken and to appear before the MOP and make a presentation concerning the matter raised; and make recommendations on specific measures for addressing the matter raised.

In addition to these measures, and other facilitative ones relating to financial and technical assistance, capacity building and technology transfer, the MOP is empowered to take measures of the second kind, i.e., stronger measures (para. 41) including: the issuance of declarations of non-compliance or cautions; the decision on special forms of publicity for a given case; and the suspension of special rights and privileges in accordance with general international law.

The powers afforded to the Committee are broad. It can address recommendations directly to the Party concerned, and this power is not "provisional" nor subject to the Party's cooperation or consent, which is instead what happens in the non-compliance procedure under the Aarhus Convention. For political and legal reasons the MOP is left with the power to decide, at the Committee's recommendation, those measures possibly requiring additional financial efforts by the Parties and those that are more enforcement-oriented.

The use, in para. 40, of the expression "the Committee decides upon one or more of the following measures" should not be interpreted as implying that the Committee's "decisions" are binding upon the Party concerned. This may be easily understood by considering that the measures the Committee may "decide upon" are facilitative and cooperative and that the object and purpose of the mechanism, as clearly envisaged in Article 22, excludes the adoption of binding decisions by the Committee. Finally, the reference to "special rights and privileges" seems to suggest that treaty-based rights, such as the right to vote in the MOP, cannot be suspended.

\section{Coordination with Dispute Settlement Procedures and other Non-Compliance Procedures}

As usually found in this kind of mechanism, the Draft Decision specifies that the compliance procedure shall be "without prejudice" to the dispute settlement clause of Article 23 of the Protocol (para. 42).

Drawing on the precedent of the non-compliance procedure of the Aarhus Convention, in order to promote the efficiency and consistency of the various mechanisms the Procedure enables the Committee to communicate with other compliance bodies according to the specific directions of the MOP (para. 43). 


\section{PARTICIPATION OF THE EUROPEAN COMMUNITY}

The European Community is a signatory to the Protocol and it has already deposited its instrument of approval (e.g., ratification). ${ }^{22}$ In accordance with Articles 26.3 and 26.4 of the Protocol, ${ }^{23}$ it declared upon approval, inter alia, that the Community "is responsible for the performance of those obligations resulting from the Convention which are covered by Community law in force" and that "it has already adopted legislation, binding on its Member States, covering matters governed by this Protocol and will submit and update, as appropriate, a list of that legislation in accordance with Article 26.4 of the Protocol."

When the negotiations for an instrument on PRTRs began in the UNECE framework, the only provision in community law addressing the issue was Article 15.3 of the IPPC directive requiring Member States to inventory and supply data on principal emissions and responsible sources. This led in 2000 to establishment of a European Public Emissions Register (EPER) through Decision 2000/479/EC. ${ }^{24}$ After the negotiations for the Protocol ended successfully, Regulation 166/2006/EC ${ }^{25}$ establishing a European Pollutant Release and Transfer Register (E-PRTR) was adopted. To bring EC law fully in line with the PRTRs Protocol, the E-PRTR Regulation extends the number of facilities included and the substances to be reported and provides additional coverage of releases to land, off-site transfers of waste and releases from diffuse sources, public participation and annual instead of triennial reporting.

Although established at the Community level and through Regulation, thus leaving no room for legislative implementation at the national level, the E-PRTR heavily relies upon the activity of information gathering on emissions from the facilities covered and, when applicable, from diffuse sources. The information so collected will be regularly reported to the Commission and introduced into the database.

An EU Member State that is also a Party to the Protocol should therefore be held accountable, possibly jointly with the EC, for non-compliance with the obligations

${ }^{22}$ Council Decision 2006/61/EC of 2 December 2005 on the conclusion, on behalf of the European Community, of the UN-ECE Protocol on Pollutant Release and Transfer Registers, OJ (2006) L 32/54. The Protocol is open to signature by "regional economic integration organizations constituted by sovereign States members of the United Nations to which their member States have transferred competence over matters governed by this Convention, including the competence to enter into treaties in respect of these matters" (Art. 23). This organization may become a Party upon ratification, acceptance or approval (Art. 23.1) or accession (Art. 19.2)

${ }^{23}$ If the organization becomes a Party without any of its Member States being a Party, it shall be bound by all the obligations under the Protocol. If, along with the Organization, also one or more of its Member States are Parties, "the organization and its member States shall decide on their respective responsibilities for the performance of their obligations under this Convention" (Art. 26.3). When becoming a Party the organizations "shall declare the extent of their competence with respect to the matters governed by this Protocol" and subsequently "inform the Depositary of any substantial modification to the extent of their competence" (Art. 19.5)

${ }^{24}$ Commission Decision of 17 July 2000 on the implementation of a European pollutant emission register (EPER) according to Article 15 of Council Directive 96/61/EC concerning integrated pollution prevention and control (IPPC), OJ (2000) L 192/36.

${ }^{25}$ Regulation (EC) No. 166/2006 of the European Parliament and of the Council of 18 January 2006 concerning the establishment of a European Pollutant Release and Transfer Register and amending Council Directives 91/689/EEC and 96/61/EC, OJ (2006) L 33/1. 
under the Protocol when this relates, for example, to a concrete failure to report correct data by a facility which is situated in the territory of that particular State.

\section{Financial Aspects}

No information is available on the financial aspects of the procedure, but it is foreseeable that the issues will be similar to those raised under the non-compliance procedure of the Aarhus Convention. 
Section II

Selected Studies on Practice 
1 


\title{
Chapter Sixteen
}

\section{The Compliance Mechanisms of the Aarhus Convention and the Cartagena Protocol on Biosafety: A Comparative Analysis of the Negotiation Histories and their Outcomes}

\author{
Veit Koester*
}

\section{INTRODUCTION}

The first part of the chapter introduces briefly the nature of the Aarhus Convention on Access to Information, Public Participation in Decision-Making and Access to Justice in Environmental Matters (Aarhus Convention) and the Cartagena Protocol on Biosafety (Cartagena Protocol) ${ }^{1}$ as well as the legal basis of their compliance mechanisms (para. 2). The second part presents the negotiation processes leading to the adoption of the mechanisms (paras. 3, 4 and 5). Part three addresses in general terms the nature of the two negotiation processes (para. 6). Part four consists of an introduction regarding the subject and scope of the comparative analysis of the two negotiation processes, followed by a rather detailed analysis focusing in particular on differences and attempting to identify factors that determined differences (paras. 7 and 8). The final part contains some concluding remarks (para. 9).

* Chairperson of the Compliance Committee of the Aarhus Convention on Access to Information, Public Participation in Decision-Making and Access to Justice in Environmental Matters and Chairperson of the Compliance Committee of the Cartagena Protocol on Biosafety. The opinions expressed in the present paper are those of the author in his personal capacity. I thank Worku Damena YIFRU, Secretariat of the Convention on Biological Diversity, for a number of very useful comments. Needless to say that the responsibility for any errors remains with the author.

1 A list of treaties with full references is provided supra at XXXVII.

T. Treves et al., eds., Non-Compliance Procedures and Mechanisms and the Effectiveness of International Environmental Agreements

(C) 2009, T.M.C. ASSER PRESS, The Hague, The Netherlands, and the Authors 


\section{The Aarhus Convention and the Cartagena Protocol and the Legal Basis of their Compliance Mechanisms}

\subsection{The Nature of the Aarhus Convention and the Cartagena Protocol}

There is little doubt that both the Aarhus Convention and the Cartagena Protocol are multilateral environmental agreements (MEAs) because they both have the protection of the environment or its components as their ultimate objective. While the imposition on the Parties to the Aarhus Convention of obligations towards their own citizens creates a striking similarity between the Convention and international human rights law, the main subject of the Cartagena Protocol, i.e., regulating transboundary movements of living modified organisms (LMOs), brings the latter closer to the trade agreements. ${ }^{2}$ Although both instruments aim at protecting the environment, they differ very much in the way they intend to achieve this. In addition, the Aarhus Convention is an UNECE agreement and hence its compliance mechanism was developed in a European context, while the Cartagena Protocol is a global instrument, which implies that a number of developing countries took part in the negotiations and the adoption of its compliance mechanism. These factors clearly have a bearing on the nature of the two instruments and subsequently on their respective compliance mechanisms. A common feature is, however, that a number of countries with economies in transition, which are normally considered in the same manner as developing countries with regard to global MEAs, participated in the development and adoption of both compliance mechanisms.

\subsection{Legal Basis of the Compliance Mechanisms of the Aarhus Convention and the Cartagena Biosafety Protocol}

Considering the legal basis of the compliance mechanisms ${ }^{3}$ of the Aarhus Convention and of the Cartagena Protocol it is obvious that there are significant differences. Article 15 of the Aarhus Convention provides that:

2 In Opinion 2/00 (Cartagena Protocol on Biosafety), ECR (2001) I-9713, the European Court of Justice considered that the main purpose of the Cartagena Protocol was the protection of biodiversity against possible harmful effects dealing with LMOs in particular from their transboundary movements, whether or not for commercial purposes. Therefore, the Community and its Member States shared competence to conclude the Cartagena Protocol. Hence, the legal basis for the conclusion was Art. 175.1 in conjunction with Art. 300.2, first subpara., and not Art. 133 and 174.4 in conjunction with Art. 300.2, first subpara. as maintained by the Commission. On Recital 9 of the Preamble of the Cartagena Protocol on mutual supportiveness of trade and environment agreements, see R. Pavoni "Biodiversity and Biotechnology: Consolidation and Strains in the Emerging Legal Regime", in F. Fracioni and T. Scovazzi (eds.) Biotechnology and International Law (Oxford and Portland: Hart, 2006) 29-57, at 50.

3 The expression "compliance committee" is used throughout the footnotes to indicate the body in charge of the compliance mechanism, irrespective of whether the body is named an Implementation Committee or Compliance Committee. 
"Review of Compliance

The Meeting of the Parties shall establish, on a consensus basis, optional arrangements of a non-confrontational, non-judicial and consultative nature for reviewing compliance with the provisions of this Convention. These arrangements shall allow for appropriate public involvement and may include the option of considering communications from members of the public on matters related to this Convention."

while Article 34 of the Cartagena Protocol prescribes that:

"The Conference of the Parties serving as the meeting of the Parties to this Protocol shall, at its first meeting, consider and approve cooperative procedures and institutional mechanisms to promote compliance with the provisions of this Protocol and to address cases of non-compliance. These procedures and mechanisms shall include provisions to offer advice or assistance, where appropriate. They shall be separate from, and without prejudice to, the dispute settlement procedures and mechanisms established by Article 27 of the Convention."

The negotiation histories of the two articles are also quite different. Article 15 of the Aarhus Convention belongs to the most controversial provisions during the negotiations ${ }^{4}$ while the wording of Article 34 of the Cartagena Protocol did not cause that many problems. This, of course, is closely connected with the content of the two provisions. The essence of Article 34 "procedures and institutional mechanisms to promote compliance $[\ldots]$ and to address cases of non-compliance" in the context of specifications like "cooperative" and "provisions to offer advice or assistance" was not controversial as a legal basis for a compliance mechanism. Rather, the issue was whether there should at all be a provision on the establishment of a compliance mechanism. ${ }^{5}$ On the other hand, it is apparent that negotiators were entering a completely new field of the history of compliance mechanisms of MEAs when addressing the notions "appropriate public involvement" and "communications from members of the public" in Article 15 of the Aarhus Convention.

There are also some other differences between the two provisions: Article 15 does not contain a requirement to establish the compliance mechanism at the first Meeting of the Parties (MOP), only a requirement for the compliance mechanism to be agreed by consensus. According to Article 34 of the Cartagena Protocol, on the other hand, the compliance mechanism shall be approved at the first Meeting of the Conference of the Parties to the Convention on Biological Diversity serving as the Meeting of the Parties to the Protocol (COP/MOP), and there is no specific requirement for it to be approved by consensus. Perhaps it was considered to be obvious. In practice,

${ }^{4} \mathrm{~K}$. Brady, "New Convention on Access to Information and Public Participation in Environmental Matters", Envt'l Pol'y \& L., 28 (1998) 69-75, at 73.

${ }^{5}$ For a detailed account of the negotiation history of Art. 34 with further references, see FIELD, "The Cartagena Protocol on Biosafety: A Record of the Negotiations" (Secretariat of the Convention on Biological Diversity, 2003), at 95. On the traditional features of Art. 34 compared to the corresponding provisions of other MEAs, see V. Koester, "The Compliance Mechanism of the Cartagena Protocol on Biosafety: Development, Adoption, Content and First Years of Life", in Biosafety Becomes Binding: Legal Aspects of Implementing the Cartagena Protocol (working title, forthcoming). 
however, there were no differences. Both compliance mechanisms were established at the first meeting of their governing bodies, ${ }^{6}$ and both were agreed by consensus. ${ }^{7}$

\section{Some Introductory Remarks on the Negotiation Processes in ReSPeCt of the Compliance Mechanisms of the Aarhus Convention and the Cartagena Protocol on Biosafety}

With regard to both the Aarhus Convention and the Cartagena Protocol, processes were initiated almost immediately after the adoption of the agreements in order to prepare for the entry into force of the instruments and the first meeting of their governing bodies, by the establishment of, respectively, the Meeting of the Signatories to the Aarhus Convention and the Intergovernmental Committee for the Cartagena Protocol (ICCP). ${ }^{8}$

${ }^{6}$ See respectively Decision I/7 on Review of Compliance, doc. ECE/MP.PP/2/Add.8 (2002, officially issued on 2 April 2004), as amended by Decision II/5 on General Issues of Compliance, doc. ECE/ MP.PP/2005/2/Add.6 (13 June 2005), para. 12 (Aarhus Convention NCP); and Decision BS-I/7 on Establishment of Procedures and Mechanisms on Compliance under the Cartagena Protocol on Biosafety, doc. UNEP/CBD/BS/COP-MOP/1/15 (27 February 2004), Annex I, at 98 (Cartagena Protocol NCP). Art. 34 of the Cartagena Protocol corresponds to a large extent to Art. 21 of the International Treaty on Plant Genetic Resources for Food and Agriculture (ITPGRFA), inter alia, by its reference to the nature of the compliance mechanism and to non-compliance response measures. Probably Art. 21 ITPGRFA was influenced by Art. 34 Cartagena Protocol adopted prior to ITPGRFA which is more related to the Convention on Biological Diversity and the Cartagena Protocol than other MEAs. However, Art. 21 ITPGRFA, opposite to Art. 34 of the Cartagena Protocol, does not address the interrelationship between the compliance mechanism and the dispute settlement mechanism (Art. 29). Art. 21 ITPGRFA, similar to Art. 34 of the Cartagena Protocol, provides that the Governing Body shall consider and approve the compliance mechanism at its first meeting, but the first meeting (2006) only adopted a resolution establishing a Compliance Committee which will commence its work following the approval of the compliance mechanism, see Further Information on Experience Regarding Cases of Repeated Non-Compliance, doc. UNEP/CBD/COP/MOP/4/2 Add. 1 (December 2007) (hereinafter Note by the Compliance Committee on Cases of Repeated Non-Compliance), para. 79, and a compliance mechanism has not been adopted as yet (January 2008).

7 Rule 40, para. 1, of the rules of procedure (RoP) for meetings of the COP of the Convention on Biological Diversity (CBD) being applicable for meetings of the COP/MOP provides for decisions on matters of substance to be taken by a two-thirds majority, if all efforts to reach consensus have been exhausted. However, this provision has from the outset been - and still is - bracketed, entailing that decisions on matters must be taken by consensus. See Decision I/1 on Rules of Procedure for the Conference of the Parties, doc. UNEP/CBD/COP/1/17 (28 February 1995), at 31 and Annex, ibid., Annex III, at 70 (RoP of the COP/ MOP) and Decision BS-I/1 on Rules of Procedure for Meetings of the Conference of the Parties Serving as the Meeting of the Parties to the Protocol, doc. UNEP/CBD/BS/COP-MOP/1/15 (14 April 2004), Annex I. Decisions of the COP of the Convention on Biological Diversity and of the COP/MOP of the Cartagena Protocol are accessible at $<\mathrm{http}: / /$ www.biodiv.org $>$ (visited 15 July 2008). Decisions taken up to the seventh $\mathrm{COP}$ and at the Extraordinary COP as well as decisions of the first COP/MOP are included in the Handbook of the Convention on Biological Diversity, $3^{\text {rd }}$ edn., Secretariat of the Cartagena Protocol on Biosafety 2005 (hereinafter Handbook).

8 The Meeting of the Signatories to the Aarhus Convention was established by a decision of the Committee on Environmental Policy of the UNECE and the ICCP by a decision of the resumed session of the Extraordinary Conference of the Parties to the Convention on Biological Diversity, which adopted the Cartagena Protocol, see Decision EM-1/3 on Adoption of the Cartagena Protocol and Interim Arrangements, para. II. 
The two processes leading to the adoption of the respective compliance mechanisms share some features, but there are also major differences. To the common features belongs the fact that it took approximately three years to complete each of the processes. The first Meeting of the Signatories to the Aarhus Convention took place in April 1999 and the compliance mechanism was adopted by the first MOP in October 2002, almost four years after the adoption of the Aarhus Convention in June 1998. The first ICCP of the Cartagena Protocol was held in December 2000 and the compliance mechanism was adopted in February 2004, four years after the adoption of the Cartagena Protocol in January 2000. The processes were running partly in parallel, although the process under the Aarhus Convention was completed before that under the Cartagena Protocol. Hence, the Aarhus Convention compliance mechanism as adopted was available when the final round of the Cartagena Protocol compliance mechanism took place, but also apart from that there were, at least from a theoretical point of view, some possibilities of mutual influence of the two processes.

The two processes share an additional feature, namely that the Government of the United States being neither a Party nor a Signatory to either of the agreements indicated concerns about the consistency of some provisions of the compliance mechanisms with international environmental law. Hence, strange as it may seem, the US Government felt obliged to stand up as a defender of international law, especially regarding the compliance mechanisms of MEAs, and in particular with respect of the compliance mechanisms of some MEAs to which the United States were - and still are - not a Party. ${ }^{9}$

The accounts (infra paragraph 4 and 5) of the two processes focus on those elements of the two compliance mechanisms which they share or, theoretically, might have shared. However, some elements which are closely connected with the particularities of the Aarhus Convention compliance mechanism, notably that it may be triggered by communications from members of the public, are only referred to in the footnotes.

\section{Development of the Compliance Mechanism of the Aarhus CONVENTION}

4.1 The Meeting of the Signatories to the Convention and the Meetings of the Task Force on Compliance (1999 and 2000)

At the First Meeting of the Signatories to the Aarhus Convention (April 1999) a task force was established to draft elements for a compliance mechanism. ${ }^{10}$ At the first meeting of the Task Force (November 1999) consensus was reached to recommend that the compliance mechanism should be established by a decision of the MOP (i.e., not by means of a protocol), and that a separate Compliance Committee with a

9 Infra paragraph 4.4 and infra n. 49.

${ }_{10}$ Report of First Meeting of Signatories, doc. CEP/WG.5/1999/2 (July 1999) (hereinafter First Meeting of Signatories), para. 49. The meeting took note of the need to have in the Task Force experts with experience in compliance mechanisms under human rights instruments. 
limited number of members should be created. These recommendations were never questioned. The Task Force concentrated on identifying particular questions to be answered and drafting options. ${ }^{11}$ Many of the elements which were later included as provisions in the compliance mechanism appeared already as outcomes of the first meeting of the Task Force, or at least as options. Some of these elements were building on or taken over from the compliance mechanism of the LRTAP Convention, ${ }^{12}$ including, inter alia:

- a standing committee consisting of eight members (representatives of Parties or serving in their personal capacity);

- triggering of the compliance mechanism by a Party in respect of itself, by a Party in respect of another Party and by a referral of the Secretariat including procedural aspects;

- entitlement of concerned Parties to participate in the discussions of the Committee, but not in the preparation of recommendations;

- reporting to the MOP.

These elements were later included in the compliance mechanism as adopted, some of them almost ad verbatim, i.e., they were never questioned. ${ }^{13}$ The draft also contained some options for closing meetings of the Compliance Committee indicating (perhaps) implicitly that the general rule would be open meetings. ${ }^{14}$

Also other features of the compliance mechanism as adopted can clearly be identified as originating from the first meeting of the Task Force, especially those relating to one of the options discussed regarding the composition of the Compliance Committee, namely a committee consisting of individual members as opposed to a committee composed by Parties. ${ }^{15}$

11 Report on the First Meeting of the Task Force on Compliance, doc. ECE/CEP/WG.5/2000/4 (April 2000) (hereinafter First Meeting of Task Force), para. 4. The meeting report contains in paras. 12-30 the various questions identified (e.g., optional compliance mechanism, public involvement, submissions and referrals, reporting, gathering of information, confidentiality, and participation in meetings of the Compliance Committee), and as Annex I-VIII a series of options or elements. Annex IX presents an overview of compliance procedures established under other MEAs and special considerations arising under the Aarhus Convention. Annex X, prepared by the ECO Forum NGO Coalition, is outlining that organization's proposal.

${ }_{12}$ Decision 1997/2 Concerning the Implementation Committee, its Structure and Functions and Procedures for Review of Compliance, doc. ECE/EB.AIR/53 (7 January 1998), Annex III, at 28, subsequently amended. Consolidated text in Decision 2006/2 on Implementation Committee, its Structure and Functions and Procedures for Review, doc. ECE/EB.AIR/89/Add.1 (5 February 2007), at 4 (LRTAP Convention $\mathrm{NCP}$ ).

${ }^{13}$ First Meeting of Task Force, supra n. 11, Annexes I, III-V, VII-VIII. Paras. 15, 16 and 17 of the Aarhus Convention NCP correspond to Annexes III-V.

14 Ibid., Annex I, para. 7 (6).

15 The requirement of Article 15 that the compliance arrangements shall allow for appropriate public involvement was reflected in two options or elements, one related to the composition of the Compliance Committee, and the other to the question of empowering the Compliance Committee to consider communications from the public. Furthermore, the Task Force identified the very options that became the most controversial issues of the negotiations process. These issues, some of which were only resolved at the last negotiation meeting before the first MOP, may be summarized as the following questions: 1) Should the Compliance Committee be made up (mainly or entirely) of Parties, or should it comprise individual members 
The Second Meeting of the Signatories (July 2000) decided that the Task Force should meet again to carry out further work on the compliance mechanism, inter alia, by elaborating a catalogue of possible non-compliance response measures. Following this, an open-ended intergovernmental working group should be established in order to draw up a text for a draft decision establishing the compliance mechanism, with the intention that this would be adopted at the first MOP. ${ }^{16}$

The second meeting of the Task Force (November 2000) refined some of the elements identified at its first meeting (e.g., on Compliance Committee reports to the MOP) and developed some additional elements, including:

- entitlement of the Compliance Committee to consider "any relevant information submitted to it" (replacing "any information forwarded by the Secretariat, a Party or the public concerning compliance with the Convention"); ${ }^{17}$

- confidentiality of any information falling within the scope of the exceptions provided for in Article 4(3)(c) and 4(4) of the Aarhus Convention and that has been provided in confidence; ${ }^{18}$

- every effort be made to adopt the report to the MOP by consensus, and the report to reflect the views of all members of the Compliance Committee, if consensus is not possible; ${ }^{19}$

- assignment of the Compliance Committee to examine general compliance issues and make recommendations if and as appropriate as well as to make recommendations relating to the reporting requirements of the Aarhus Convention..$^{20}$

(being nationals of Parties only? and nominated by Parties only?); 2) should the optional element be limited to specific parts of the compliance mechanism only, i.e., arrangements relating to consideration of communications from the public, while all other aspects would be mandatory, or should Parties have the option of not participating in the arrangements in their entirety?; 3) should options be formulated as opt-out or as opt-in provisions?; and 4) should such provisions include time frames?

${ }^{16}$ Report on Second Meeting of the Signatories, doc. ECE CEP/WG.5/2000/2 (July 2002) (hereinafter Second Meeting of Signatories), paras. 22-23, and Report on the First Meeting of the Working Group on Compliance and Rules of Procedure, doc. ECE/CEP/WG.5/AC.1/2001/2, (March 2001) (hereinafter First Meeting of Compliance Working Group), para. 1, according to which the establishment of the Working Group was agreed by the Committee on Environmental Policy of UNECE.

${ }^{17}$ First Meeting of Task Force, supra n. 11, para. 28, and Report on the Second Meeting of the Task Force on Compliance, doc. ECE/CEP/WG.5/AC.1/2001/3 (hereinafter Second Meeting of Task Force) (January 2001), Annex I, para. 9. The wording suggested by the Task Force was included in the NCP as adopted, Aarhus Convention NCP, para. 25(c). It was never questioned that the Compliance Committee should have the power to consider information forwarded by the public.

${ }_{18}$ Second Meeting of Task Force, supra n. 17, Annex I, para. 10, option 2, corresponding to para. 28 of the Aarhus Convention NCP. The issue of confidentiality of information within the scope Art. 4 of the Aarhus Convention originates from First Meeting of Task Force, supra n. 11, Annex VI, para. 29.

19 Second Meeting of Task Force, ibid., Annex I, para. 12.

${ }^{20}$ Second Meeting of Task Force, ibid., Annex I, paras. 3(1)(c) and 3(1)(2), reflecting the first traces of the Aarhus Convention NCP, para. 13(c) and 14. One of the options relating to general compliance issues at that early stage was that such issues would only be examined on the basis of national reports. Recommendations on reporting requirements were at that stage related to the elaboration of the reporting requirements, and not - as they later became - related to compliance with reporting requirements. 
Several other elements appear in the final compliance mechanism, either untouched or slightly modified. ${ }^{21}$ A number of elements identified at the first meeting are repeated without major changes in the outcome of the second meeting. One of these concerned the requirement that members of the Compliance Committee should be independent. ${ }^{22}$ The element concerning independency is noteworthy for several reasons. First, when the element concerning independency disappeared in the provisions themselves it still remained as a characterization of a Compliance Committee composed of individuals acting in their personal capacity as opposed to one consisting of Parties. ${ }^{23}$ Second, independency is also referred to in reports of the Working Group for the Preparation of the first MOP as a Compliance Committee composed of independent experts. ${ }^{24}$ Finally, this was probably also the common understanding of Parties when they elected the members of the Compliance Committee, because they were all independent in the sense that none of them were part of or represented the executive branch of a government of a Party or Signatory. In view of the negotiation history and the practice of the MOP it may be argued that the provisions on the structure of the Compliance Committee contain an implicit requirement to the effect that its members shall be independent. ${ }^{25}$

${ }^{21}$ E.g., which requirements communications should meet in order to be considered, elements regarding exhaustion of local remedies, and procedures of the Compliance Committee for handling communications. Also the provision that information shall be kept confidential if submitted by a person who asks that it be kept confidential because of concern that he or she may be penalized, persecuted or harassed originates from the second meeting of the Task Force, Aarhus Convention NCP, para. 29, and Second Meeting of Task Force, ibid., Annex I, para. 10(3).

${ }^{22}$ First Meeting of Task Force, supra n. 11, Annex II, para. 3 and Second Meeting of Task Force, supra n. 17, Annex I, para. 1(3): "The members ... may not be part of or representing the executive branch of a government of a Party or ...". Another element was to the effect that the Compliance Committee should not consider a communication if the same matter was being examined under another procedure of international investigation or settlement, First Meeting of Task Force, Annex VI, para. 7(a) and Second Meeting of Task Force, Annex I, para. 2(c). This element is interesting because it does not correspond to the general view that compliance procedures, due to their very nature, should not be prevented from considering matters that are being considered at the same time under other international procedures, at least not as long as the matter is not sub judice under such procedures, M.A. Fitzmaurice and C. Redgwell, "Environmental Non-Compliance Procedures and International Law", Netherlands YB Int'l L., 31 (2000), 35-65, at 49 and 56, M. Koskenniemi, "Breach of Treaty or Non-Compliance? Reflections on the Montreal Protocol", YB Int'l Envt'l L., 3 (1992), 123-162, at 155, and T. Treves, "The Settlement of Disputes and Non-Compliance Procedures", infra 499-518. This might be the reason why the element was not accepted by the negotiating body.

${ }^{23}$ First Meeting of Compliance Working Group, supra n. 16, Annex II, para. 1: "Alternative 2 on structure - a committee with independent members", and Report on Second Meeting of the Working Group on Compliance and Rules of Procedure, doc. ECE/CEP/WG.5/AC.1/2001/6, (January 2002) (hereinafter Second Meeting of Compliance Working Group), para. 8 and Appendix, para. 1, Alternative 2.

${ }^{24}$ Report on the First Meeting of the Working Group for the Preparation of the First MOP, doc. ECE/ CEP/WG.5/2001/2 (January 2002) (hereinafter First Meeting of Preparatory Group), para. 27(b), and Report on the Second Meeting of the Working Group for the Preparation of the First MOP, doc. ECE/CEP/ WG.5/2002/2 (June 2003) (hereinafter Second Meeting of Preparatory Group), para. 28.

${ }^{25}$ The issue of independency is perhaps more important than it seems at first glance. Individuals serving in their personal capacity (Aarhus Convention NCP, para. 1) is also a requirement under the Cartagena Protocol NCP, Section. II.2 "Members [...] shall [...] serve objectively and in a personal capacity"), but that requirement did not prevent Parties from electing members the majority of which were - and still are - governmental civil servants. In respect of the practice applied regarding replacement of some members of the Aarhus Convention Compliance Committee at the second MOP, and in the event of vacancies, see 
The Task Force developed as requested a catalogue of non-compliance response measures most of which are included with only few amendments in the final compliance mechanism, including: provide advice and facilitate assistance (or provide advice, assistance and financial support); make recommendations; request the Party concerned to submit a strategy regarding the achievement of compliance and to report on the implementation of the strategy; publicize non-compliance; issue cautions. The catalogue also included, however in square brackets, a decision on "such other measures as may be appropriate". The MOP was retained as the only decision-making body in this respect of non-compliance response measures. ${ }^{26}$

\subsection{The First Meeting of the Working Group for the Preparation of the First Meeting of the Parties and the Meetings of the Working Group on Compliance and Rules of Procedure (2001 and 2002)}

The negotiation process started at the first meeting of the Working Group on Compliance and Rules of Procedure (February 2001). The Working Group produced the first coherent draft, but not many new elements were added to the outcome of the work of the Task Force. However, suspension of "the rights and privileges of the Party concerned under the Convention" was added in the list of non-compliance measures while at the same time the possibility of taking "such other measures as may be

\footnotetext{
V. Koester, "The Convention on Access to Information, Public Participation in Decision-Making and Access to Justice in Environmental Matters", in G. Ulfstein, et al. (eds.), Making Treaties Work: Human Rights Environment and Arms Control (Cambridge: Cambridge University Press, 2007) Chapter 8, 179-217, at 193 and C. Pitea, "The Non-Compliance Procedure of the Aarhus Convention: Between Environmental and Human Rights Control Mechanisms", Italian YB Int'l L., 16 (2006) 85-116, at 89. A further feature was the specification required for recommendations of the Compliance Committee concerning communications from members of the public on specific matters. Such recommendations should give 1) a clear description of the established facts; 2) legally qualify these facts under the Convention; 3) establish if a provision of the Convention had been violated; and 4) propose measures of redress for the satisfaction of the public concerned, Second Meeting of Task Force, supra n. 17, Annex I, para. 3(3). The reason why this element was not accepted by the negotiating body is obscure; maybe because it was considered to be too prescriptive, or maybe because it did not belong to traditional features of compliance mechanisms. However, the element is interesting in two respects. First, the duties of the Compliance Committee under point (1-3) are reminiscent to some extent of procedural rules which the Compliance Committee itself has agreed to apply generally when considering Party-to-Party submissions, referrals or communications, Modus Operandi of the Compliance Committee and Meeting Reports of the Compliance Committee available at $<$ www.unece.org/env/pp/ compliance.htm>. See, as an example, Report on the Fifth Meeting, doc. MP.PP/C.1/2004/6 (October 2004), para. 42, on "[...] making appropriate conclusions as to whether or not the Party concerned is in compliance." Second, due to concern expressed at a meeting of the Working Group of the Parties (subsidiary body of the MOP) the Compliance Committee decided in 2004 to include in its Information Sheet on the compliance mechanism (Report on the Third Meeting, doc. ECE/MP.PP/C.1/2004/2 (March 2004), para. 5, that the compliance mechanism is designed to improve compliance with the Convention, and accordingly, with regard to communications concerning a person's rights under the Convention, is not a redress procedure for violations of individual rights. See also Koester, supra n. 25, at 197.

${ }^{26}$ Second Meeting of Task Force, supra n. 17, para. 14.
} 
appropriate" was retained. ${ }^{27} \mathrm{~A}$ number of provisions were finalized later without any substantive change made to them. ${ }^{28}$

A similar broad agreement existed with regard to the entitlement of concerned Parties and members of the public concerned to participate in discussions of the Compliance Committee with respect to submissions, referrals, or communications, although not in the Compliance Committee's preparation of draft findings and recommendations..$^{29}$

The second meeting of the Working Group on Compliance (November 2001) took place after the entry into force of the Convention (30 October 2001). ${ }^{30}$ The meeting managed to settle a number of outstanding issues. In the catalogue of non-compliance response measures "publicizing non-compliance" was replaced by "issue declarations of non-compliance". A few new provisions were added, inter alia, one pertaining to the entitlement of the Compliance Committee to decide upon some non-compliance response measures, i.e. - pending considerations by the MOP - providing advice and facilitating assistance in consultation with the Party concerned and making recommendations or requesting a compliance strategy subject to agreement with the Party concerned, corresponding to provisions of the compliance mechanism as adopted. ${ }^{31}$ The measure referred to supra paragraph 4.1 of suspension of rights and privileges was reformulated, probably inspired, to some extent, by the Montreal Protocol compliance mechanism. ${ }^{32}$ Also the provision on "other measures as may be appropriate" was amended. Hence, at the first meeting of the Working Group for the Preparation of the first MOP, which met back to back with the Working Group on Compliance (November 2001), one of the two issues which remained to be solved, and which the Working Group did not manage to resolve, was whether the Compliance Committee should be made up of Parties or of experts serving in a personal capacity (and if the latter, whether NGOs as well as Parties should be entitled to nominate their experts for election). Other outstanding issues were considered to be drafting points. ${ }^{33}$

${ }^{27}$ First Meeting of Compliance Working Group, supra n. 16, Annex II, Appendix para. 12(g). Also a measure relating specifically to communications from members of the public was added (Annex II, Appendix, para. $12(\mathrm{~d}))$.

28 Aarhus Convention NCP, e.g., paras. 15-18, 25-31, 35, 37-38. The elements referred to supra in n. 25 vanished without any explanation provided in the report on the meeting, reflecting that there was probably a consensus in the group that the elements should be deleted. The fact that there were almost no brackets in the provisions dealing with communications from the public did reflect a broad agreement already at that stage that the compliance mechanism would need to include the possibility of being triggered by communications from members of the public.

${ }^{29}$ Ibid., paras. 18 and 32-33.

30 Second Meeting of Compliance Working Group, supra n. 23.

${ }^{31}$ Second Meeting of Compliance Working Group, ibid., Appendix, para. 12, and Aarhus Convention NCP, para. 36.

${ }^{32}$ Aarhus Convention NCP, para. 37(g): "Suspend, in accordance with the applicable rules of international law concerning the operation of a treaty, the special rights and privileges accorded to the Party concerned under the Convention."

${ }^{33}$ First Meeting of Preparatory Group, supra n. 2, para. 27. Due to the entry into force of the Aarhus Convention the Meeting of Signatories was replaced by the Working Group for the Preparation of the First Meeting of the Parties to the Aarhus Convention. Another unresolved issue was whether the opt-out possibility concerning communications from the public should be indefinite in time or limited to a specific time period. 


\subsection{The Second and the Third Meeting of the Working Group for the Preparation of the first Meeting of the Parties (2002)}

At the second meeting of the Preparatory Working Group (May 2002) the chairperson presented a compromise. The proposal included a Compliance Committee composed of "independent" experts to be nominated by Parties, Signatories and NGOs and to be elected by the Parties. ${ }^{34}$ The compromise proposal was accepted at the third meeting of the Preparatory Working Group (July 2002). ${ }^{35}$ At the same meeting it was agreed to insert a new subparagraph on procedures for the nomination of candidates for the Compliance Committee. ${ }^{36}$

\subsection{The First Meeting of the Parties (2002)}

The compliance mechanism, as agreed by the Preparatory Working Group, was adopted by acclamation at the first MOP (21-23 October 2002), and members of the Compliance Committee were elected by consensus. So, the question may be asked: why was the start that difficult, but the outcome that successful? Why a rather weak Article 15, but a rather strong compliance mechanism (e.g., members acting in their personal capacity, consideration of communications from members of the public, inclusion of quite strong non-compliance response measures) at the end? The answer is probably that some Governments which were opposed to a strong compliance mechanism ${ }^{37}$ did not sign and/or ratify the Aarhus Convention. Neither did they participate in the negotiations of the compliance mechanism. On the other hand, the United States, belonging to the group of UN Economic Commission for Europe (UNECE) Member States which did not sign and/or ratify the Convention, circulated and presented a written statement at the first MOP expressing concerns with respect to the compliance mechanism..$^{38}$

${ }^{34}$ Second Meeting Preparatory Working Group, supra n. 24, paras. 27-33. The proposal also included the opt-out option to be limited to four years.

${ }^{35}$ Report on the Third Meeting of the Working Group for the Preparation of the first MOP, doc. ECE/CEP/WG.5/2002/14, (August 2002) (hereinafter Third Meeting of Preparatory Group).

36 Aarhus Convention NCP, para. 5.

${ }^{37}$ In particular the Russian Federation and Turkey.

38 Report on the First Meeting of the Parties, doc. ECE/MP.PP/2 (December 2002), para. 45 and Annex. The statement is printed in Envt'l Pol'y \& L., 33 (2003) at 178. A discussion of the statement exceeds the scope of the present paper, but some of the points raised in the statement seem to be rather dubious. EC stated in its response to the statement that the compliance mechanism was fully compatible with international law. See also Pitea, supra n. 25, at 87 with further references, and V. Koester, "Review of Compliance under the Aarhus Convention: A Rather Unique Compliance Mechanism”, J. Eur. Envt'l Plan. L., 2 (2005) at 35. 


\section{Development of the Compliance Mechanism of the Cartagena PROTOCOL}

\subsection{First Meeting of the Intergovernmental Committee for the Cartagena Protocol (2000)}

At the first meeting of ICCP (December 2000) (supra paragraph 3) elements and options of the compliance mechanism were discussed, although no detailed discussions took place neither in Plenary nor in the Working Group which was established by Plenary and to which the item was referred. The report of the first ICCP, which includes a summary of the discussions of WGII, ${ }^{39}$ demonstrates already at that early stage of the discussions what would later become some of the most controversial issues, and yet what could probably be rather easily resolved.

There was consensus on the need for the establishment of an effective compliance mechanism, that it should be of an advisory, facilitative, open, transparent, simple and non-confrontational nature, ${ }^{40}$ that the objective would be to promote and facilitate compliance, and that it should be triggered by Parties. There was broad support for the establishment of a standing committee with a limited membership (ranging from 8 to 20 members, the final result being in between, i.e., 15 members) composed of legal and technical experts nominated by Parties and based on the principle of equitable geographical distribution. ${ }^{41}$ There was also broad support for decisions on compliance to be taken by the COP/MOP based on recommendations of the Compliance Committee, and for the need to address non-compliance response measures.

Disagreement centred on important points concerning who should make a submission with respect to a Party's non-compliance (trigger), structure, i.e., whether members should serve in their individual capacity, and on response measures. NGOs were mentioned in connection with triggering the compliance mechanism. NGOs never appeared again in that connection in later discussions, but they reappeared in the Draft compliance mechanism as an explicit source of information and remained there almost to the very end (infra paragraph 5.3 and 5.4 at note 56).

The first ICCP adopted a decision inviting Parties to communicate their views in writing regarding the elements and options on the basis of a questionnaire, and requesting the Executive Secretary to compile the views and prepare a synthesis

${ }^{39}$ Report of the Intergovernmental Committee for the Cartagena Protocol on Biosafety on the Work of its First Meeting, doc. UNEP/CBD/ICCP/1/9 (December 2000) (hereinafter Report of the first ICCP), paras. 104-111 and Annex paras. 44-55 as well as the Decision by the first ICCP on item 4.5, Compliance.

${ }^{40}$ It is a common trend of almost all compliance mechanisms that a number of adjectives and notions are included in order to characterize the mechanisms with, however, the Aarhus Convention compliance mechanism as a notable exception (only the enabling provision, Art. 15 of the Convention, includes a specification of the character of the mechanism). The meaning of such words does not differ very much, thus demonstrating the creative minds - or perhaps "a belt and braces approach" - of Governments. All words, except the word "open" (and non-confrontational later replaced by non-adversarial), were in fact included in the final result and further specifications included, namely cooperative, fairness, expedition and predictability.

${ }^{41}$ One delegation was so seized with its own "bright idea" (i.e., members of the Compliance Committee should represent a balance between importing and exporting countries) that it pursued this idea to the very end of the negotiations in spite of the fact that there was almost no support from other delegations (Report of the first ICCP, supra n. 39, paras. 51 and 54). 
report for the consideration of an open-ended meeting of experts to be held back to back with the second ICCP. ${ }^{42}$ The questionnaire addressed, inter alia, the above controversial issues. ${ }^{43}$

\subsection{Second Meeting of the Intergovernmental Committee (2001)}

In accordance with the above decision of the first ICCP an expert group meeting was held immediately before the second ICCP (September/October 2001) with a view of considering elements and options for a compliance regime based on a note by the Executive Secretary. ${ }^{44}$ The note contained the synthesis report of responses received from Parties and Governments ${ }^{45}$ to the questionnaire (supra paragraph 5.1). The report confirmed more or less the outcome of the first ICCP, but also reflected some new elements which would soon become parts of the most controversial issues, e.g., the proposal to include in the compliance mechanism some principles of international law, in particular the principle of "common but differentiated responsibility" (Principle 7 of the Rio Declaration) ${ }^{46}$

The outcome of the expert group meeting was a draft recommendation which was adopted by the second ICCP as Recommendation $2 / 11,{ }^{47}$ with the understanding, however, that all elements of the draft would be subject to further discussion. The operative part of the recommendation dealt with the future process, while, more

${ }^{42}$ Report of the first ICCP, supra n. 39, para. 49

43 Ibid., Annex. Question 7 in the Annex on whether the compliance body should "make binding decisions (emphasis added), such as the imposition of compliance measures ..." is probably meant to be synonymous with final decisions.

${ }^{44}$ Note of the Executive Secretary on Elements and Options, doc. UNEP/CBD/ICCP/2/13 (July 2001) (hereinafter Note ICCP 2/13).

45 I.e., States not being Parties to Convention on Biological Diversity, primarily the United States. Art. 32.1 of the Convention on Biological Diversity provides that only a Party to the Convention can become a Party to a protocol. The United States took part in all negotiations of the Cartagena Protocol NCP. So did Parties to the Convention on Biological Diversity which, based on the perceptions at that time, were not likely to become Parties to the Convention, at least not in the near future, such as Argentina, Australia, Canada, and Chile which, together with Uruguay, during the negotiations of the Cartagena Protocol formed the Miami Group (on the Miami Group, see FIELD, The Cartagena Protocol on Biosafety: A Record of the Negotiations (Secretariat of the Convention on Biological Diversity 2003)). Of the Cartagena Protocol negotiating groups the Miami Group was the one that was opposed to the project of a biosafety protocol and, therefore, not very favourable to an effective compliance regime (personal recollection based on the author's position as head of the Danish delegation during the negotiations of the compliance regime and as chairperson of the contact group on compliance at the third ICCP, but some evidence may also be found in Earth Negotiation Bulletin Vol. 9, No. 203 (Oct. 2001), second ICCP, and Vol. 9, No. 244 (April 2003), third ICCP)). Normally, the views of the United States would be "presented" by other members of the former Miami Group.

${ }^{46}$ Note ICCP 2/13, supra n. 44, para. 12. It was also suggested that the Compliance Committee should develop its own rules of procedure to be submitted to the COP/MOP for its consideration and approval (ibid., para. 21). A provision to that effect was included in the Draft compliance mechanism. This provision was never questioned. Accordingly, it is included in the Cartagena Protocol NCP, as Section I.7.

${ }^{47}$ Report of the Open-Ended Meeting of Experts on a Compliance Regime, doc. UNEP/CBD/ICCP/2/13 Add 1 (September 2001), and Report of the Intergovernmental Committee for the Cartagena Protocol on Biosafety on the Work of its Second Meeting, doc. UNEP/CBD/ICCP/2/15 (October 2001), para. 177, with Annex I containing Recommendation 2/11, which includes the Draft NCP (hereinafter Recommendation 2/11). 
importantly, the outcome of substantive discussions was presented as "Draft procedures and mechanism on compliance under the Cartagena Protocol" (Draft compliance mechanism) ${ }^{48}$ Bracketed language reflected disagreement on a number of issues adding to the controversial points identified in paragraph 5.2, inter alia, the following issues:

- reflection of principle 7 of the Rio Declaration on common but differentiated responsibilities;

- Party-to-Party and COP/MOP trigger of the compliance mechanism;

- entitlement of the Compliance Committee to consider information from a Party having triggered the mechanism as well as information from bodies of the Convention on biodiversity and the Cartagena Protocol, relevant international organizations, NGOs, and the Secretariat;

- non-compliance response measures, in particular the issue of cautions, to publicize cases of non-compliance and the suspension of rights and privileges.

A final clause on reviewing the compliance mechanism was also included, however, without being put in square brackets.

Leaving aside contentious issues the compliance mechanism was already at that stage almost fully developed in the sense that the structure of the mechanism and most of its provisions represented agreed text that would "survive" until the final adoption of the compliance mechanism at the first COP/MOP (infra paragraph 5.4).

The operative part of Recommendation 2/11 envisaged a new round of submissions from Parties and other Governments focusing on the bracketed language of the Draft compliance mechanism and a compilation of the views by the Executive Secretary. At the time of the second ICCP no further meetings of the ICCP were envisaged and the outcomes of the first and the second ICCP as outlined in Recommendation 2/11 were expected to be submitted to the first COP/MOP. However, since the Cartagena Protocol had not entered into force in time to hold a COP/MOP in connection with the sixth COP (2002), a third meeting of ICCP was organized to be held immediately after the sixth COP.

\subsection{Third Meeting of the Intergovernmental Committee (2002)}

Only a very limited number of Parties and other Governments submitted views or understandings to the Executive Secretary with respect to the bracketed language of the Draft compliance mechanism to be considered by the third ICCP (April 2002) ${ }^{49}$

48 Recommendation 2/11, supra n. 47.

49 Compilation of Views on Compliance Procedures and Mechanisms, doc. UNEP/CBD/ICCP/3/INF/3 (April 2002). Responding Parties and Governments may be seen as an indication of the two major groups holding to some extent quite opposite views, on the one side the EU arguing in favour of a strong and effective compliance mechanism and on the other side those against, namely Australia and the USA, while Canada in the meantime had moved away from the former Miami Group, see supra n. 45. E.g., the United States argued (again) that a standing compliance committee went beyond the scope of Art. 34 and that a compliance committee, therefore, should only be established on an ad hoc basis. Apart from those Parties and Governments already mentioned, only the Republic of Korea and Slovenia made submissions. The 
A note by the Executive Secretary summarized the views, indicating at the same time the rather wide range of options for resolving outstanding issues which existed in spite of the very small number of submissions. ${ }^{50}$

A procedural discussion took place in WGII and the third ICCP on whether discussions should focus only on bracketed language or also the remainder of the draft. However, an open-ended contact group was established to address only the outstanding areas of bracketed text. ${ }^{51}$ Both in the Contact Group and later in WGII and the Plenary of the third ICCP the scope of the discussions on the Draft compliance mechanism became again a controversial issue.

Only little progress was made at the third ICCP. Solutions were found in respect of:

- sources of information (subsidiary bodies of the Convention on biodiversity and the Cartagena Protocol as well as relevant international organizations, while NGOs and the Secretariat remained in brackets);

- an issue relating to non-compliance response measures (factors to be taken into account when deciding upon measures)..$^{52}$

Not surprisingly, the most contentious issues remained unsolved. Among those were the inclusion of Principle 7 of the Rio Declaration in the compliance mechanism (Draft compliance mechanism Section I, para. 3 on objective, nature and underlying principles); whether members of the Compliance Committee should serve in their individual capacity (Section II, para. 3); the Party-to-Party trigger (Section $\mathrm{V}$, para. 1(a)); and some of the non-compliance measures (issue of cautions, publicize cases of non-compliance and suspension of rights and privileges) (Section VI, paras. 2(b), 2(c) and 2(d))..$^{53}$

A number of options other than retaining bracketed or deleting bracketed texts were made during the discussions, some of which were outside the scope of the

submission of the United States contained, inter alia, a request for the deletion of suspension of rights and privileges as a non-compliance response measure, arguing that there was no authority for this in international law, and it suggested replacing the provision with a reference to measures consistent with international law as reflected in Art. 60 of the Vienna Convention on the Law of Treaties. See on the same subject Koester, supra n. 25 at 211. The United States returned to this subject at the first COP/MOP, see Earth Negotiation Bulletin Vol. 9 No. 289 (March 2004) at 8. The United States did play a similar role at the adoption of the Aarhus Convention NCP, arguing that the compliance mechanism was not in conformity with international law, see supra paragraph 4.4

${ }^{50}$ Note by the Executive Secretary on Summary of Views or Understandings on the Contents in Square Brackets of the Draft Compliance Mechanism, Annex, doc. UNEP/CBD/ICCP/3/4 (March 2002) (hereinafter Note ICCP 3/4).

${ }_{51}$ Report of the Intergovernmental Committee for the Cartagena Protocol on Biosafety on the work of its Third Meeting, doc. UNEP/CBD/ICCP/3/10 (April 2002) (hereinafter Report of the third ICCP), para. 77. The chair of the ICCP, however, had stated at its second meeting that an opportunity to make comments on the remainder of the draft would be provided later (para. 69).

${ }_{52}$ See Recommendation 3/2 annexed to Report of the third ICCP, supra $\mathrm{n} .51$.

${ }_{53}$ Other unresolved issues included the question of a balance between importing and exporting countries (Section II.2), triggering of the compliance mechanism by the COP/MOP (Section IV.1), and consideration by the Compliance Committee of information from NGOs and the Secretariat (Section V.2). 
concepts of existing texts. The procedural discussions which were raised due to new concepts being de facto new proposals resulted in adding to the Draft compliance mechanism an annex containing options for the resolution of outstanding issues including the new proposals. ${ }^{54}$

The operative part of Recommendation $3 / 2^{55}$ followed the same line as Recommendation 2/11 (supra paragraph 5.2), i.e., submission of the Draft compliance mechanism to the first COP/MOP as well as submissions by Parties and Governments to the Executive Secretary of views with respect to the contents of bracketed language and a compilation of those views by the Executive Secretary.

\subsection{First Conference of the Parties to the Convention on Biodiversity Serving as the Meeting of the Parties to the Cartagena Protocol (2004)}

At the first COP/MOP (Kuala Lumpur, 23-27 February 2004) the Working Group, to which the Draft compliance mechanism was referred to by the Plenary, decided to set up a contact group to deal with the text that remained in brackets. Apparently, no efforts were made to reopen discussions on other parts of the text. ${ }^{56}$ Outstanding issues were resolved by trade-offs and/or compromise language,${ }^{57}$ the most contentious issues (supra paragraph 5.3), however, by means of a package which included:

- the reference to Principle 7 of the Rio Declaration being replaced by language on paying particular attention to the needs of developing country Parties, etc., and taking into consideration their difficulties in the implementation of the Cartagena Protocol (compliance mechanism Section I, para. 3);

- members of the Compliance Committee serving in their personal capacity (Section II, para. 3);

- the Party-to-Party trigger restricted to a Party which is affected or likely to be affected, with respect to another Party (Section IV, para. 1(b));

- the maintenance of issuing cautions and publicizing cases of non-compliance, however, restricted to publishing such cases in the Biosafety Clearing-House (Section VI, paras. 2(b) and 2(c));

${ }^{54}$ Report of the third ICCP, supra n. 51, paras. 82, 85, and 89 and Recommendation 3/2, supra n. 52, pp. 37-43. See also Earth Negotiation Bulletin Vol. 9 No. 244 (April 2002) p. 9 referring to the closing Plenary discussions on whether (unbracketed text of) the draft Compliance mechanism would still be open for discussion at the first COP/MOP. One of the new proposals that were introduced was a provision on admissibility criteria in respect of Party-to-Party submissions, Recommendation 3/2, supra n. 52, Annex II, Section IV, para. 1, option 4, now Cartagena Protocol NCP, Section IV.1.

${ }_{55}$ Recommendation $3 / 2$, supra $\mathrm{n}$. 52, at 34 .

${ }^{56}$ Report of the First Meeting of the Conference of the Parties Serving as the Meeting of the Parties to the Protocol on Biosafety, doc. UNEP/CBD/BS/COP/MOP/1/15 (February 2004) (hereinafter Report of the first COP/MOP) paras. 116-126. The text is in Earth Negotiation Bulletin Vol. 9 No. 289, 1 March 2004, p. 11 characterized as "heavily bracketed". On the negotiations at the first COP/MOP, see also R. MacKenzie, "The Cartagena Protocol after the First Meeting of the Parties", RECIEL, 13 (2004) 270-278, at 272.

${ }^{57}$ E.g., consideration by the Compliance Committee of "relevant information including from" NGOs and the Secretariat was replaced by "relevant information from sources, such as" and the deletion of NGOs and the Secretariat as explicit sources of information. 
- while suspension of rights and privileges was replaced by a new paragraph leaving to the third COP/MOP 3 to decide on measures to be taken in cases of repeated non-compliance (Section VI, para. 3).

The first COP/MOP adopted the outcome of the negotiations in WGII as Decision BS-1/7.58

\section{Similarities and Differences between the two Negotiation Processes}

Negotiations leading to the adoption of the compliance mechanisms of the Aarhus Convention and the Cartagena Protocol followed some common patterns which are also shared by other international governmental negotiations related to the environment. The fact that both negotiation processes were completed more or less by means of four meetings ${ }^{59}$ and over a period of about three years is coincidental, but of course also linked to the determination of the Parties to achieve a final result at the respective first meeting of the Parties. On the other hand, each of the negotiation processes were characterized by their respective negotiation cultures, the Aarhus Convention being a regional agreement in the framework of UNECE, and the Cartagena Protocol a global agreement in the framework of the UN (UNEP).

There is no doubt that the EU played a major role in both processes. The EU was a driving force in the Cartagena Protocol compliance mechanism process, arguing in favour of a strong and effective compliance mechanism. Regarding the Aarhus Convention compliance mechanism process, the EU was an important factor by virtue of representing a proportional dominant part of negotiating Governments. However, the EU can hardly with respect to that process be characterized as the most progressive negotiating group, mainly due to internal difficulties in connection with common positions, e.g., regarding communications from members of the public in conjunction with the nomination and composition of members of the Compliance Committee. ${ }^{60}$

\section{Subject and Scope of the Analysis of the Outcomes of the Two Negotiation Processes}

To what extent may differences between the two compliance mechanisms at hand be explained by the two negotiation processes and the nature of the two agreements? An

${ }^{58}$ Report of the first COP/MOP, supra n. 56, para. 128 and Handbook, supra n. 7, at 1404. See also supra n. 6.

${ }^{59}$ I.e., two meetings of Aarhus Convention Task Force on Compliance and two meetings of the Aarhus Convention Working Group on Compliance with a few outstanding points settled by the Preparatory Working Group, and with regard to the Cartagena Protocol the first meeting of the Intergovernmental Committee (ICCP), one Expert Group Meeting in connection with the second ICCP, the third ICCP and the first COP/MOP.

${ }^{60}$ Personal recollection of the author of the present paper as the head of the Danish delegation in both negotiation processes and in charge of the EU Presidency at the last meeting of the Aarhus Convention Preparatory Working Group as well as chairperson of the Contact Group at IPPC 3. 
in-depth analysis of this question covering all similarities and differences exceeds the scope of the present paper. In addition, more far-reaching and firm conclusions on the extent to which the nature of MEAs, influences the development of their compliance mechanisms would need extensive review and analysis of more compliance mechanisms and their negotiation histories. In that regard, the examination below only presents an attempt to provide preliminary answers to some aspects of the question raised, leaving aside, however, differences between the two compliance mechanisms attributable to the fact that the Aarhus Convention compliance mechanism includes the public trigger mechanism, which is a feature clearly connected with the nature of that compliance mechanism. ${ }^{61}$

\section{A Comparison of the Compliance Mechanisms of the Aarhus Convention and the Cartagena Protocol on Biosafety ${ }^{62}$}

\subsection{Principles Governing the Compliance Procedures}

The objective of both compliance mechanisms is to promote compliance, but while the compliance mechanism of the Cartagena Protocol includes a number of principles (e.g., facilitative, non-adversarial, cooperative and transparency), the compliance mechanism of the Aarhus Convention does not include any such principles. This might be explained by the fact that the legal basis of the Aarhus Convention itself, Article 15, characterizes the nature of the compliance mechanism as being non-confrontational, non-judicial and consultative, and that the Aarhus Convention Decision $\mathrm{I} / 7$ is referring to Article 15. The omission of a description of the nature of the Aarhus Convention compliance mechanism might also be due to the negotiation process, i.e., that this issue was never raised.

According to the Cartagena Protocol compliance mechanism it shall pay particular attention to the special needs of developing country Parties, and Parties with economies in transition, and take into full consideration the difficulties they face in the implementation of the Protocol. This requirement represented a compromise solution, replacing a reference to the Rio Principle 7 on common but differentiated responsibility which might have been interpreted as a differentiated obligation to implement the Protocol. ${ }^{63}$ On the other hand it was also obvious that implementation of the

${ }^{61}$ Regarding analyses of the compliance mechanisms under the Aarhus Convention and the Cartagena Protocol, see in this book, C. Pitea, "The 1998 Aarhus Convention Non-Compliance Procedure", supra 221-250 and C. Ragni, "The 2000 Cartagena Protocol on Biosafety Non-Compliance Procedure", supra 101-120. The Cartagena Protocol NCP is also analysed in Koester, supra n. 5.

${ }^{62}$ The comparison of the two compliance mechanisms is, more or less, based on the same division of elements of compliance mechanisms which has been used as a basis for the analyses of various compliance mechanisms in the publication, supra n. 61. In so far as the comparison includes references to non-compliance mechanisms other than those under the Aarhus Convention and the Cartagena Protocol observations are based on these analyses, to which, generally speaking, they are referred, including for detailed references to relevant documents.

${ }^{63}$ A varying level of compliance would undermine the principle of pacta sunt servanda. The same, however, does not apply in respect of a variation regarding the application of non-compliance response 
Cartagena Protocol would be difficult and represent a major challenge, especially to developing countries. Although implementation of the Aarhus Convention in many ways represented a major challenge to Parties with economies in transition in Europe, the inclusion of a provision on paying particular attention to those Parties was never raised during the Aarhus Convention compliance mechanism negotiation process.

\subsection{Institutional Aspects}

Both negotiation processes opted very early for a standing committee with a rather limited number of members.

In both processes the issue of whether the Compliance Committee should consist of representatives of Parties or members serving in a personal capacity was one of the most contentious issues, and it was only resolved by means of compromise packages, with the result being Compliance Committees composed of members serving in their personal capacity. The difficulties were probably due to the fact that at the time of the negotiation processes no obvious precedents existed, neither in the UNECE framework, nor in the context of the UN/UNEP. ${ }^{64}$ However, the Aarhus Convention compliance mechanism was adopted before the compliance mechanism of the Cartagena Protocol, and was used as precedent by the EU at the final round of the Cartagena Protocol compliance mechanism negotiation process. ${ }^{65}$

The two negotiation processes and their outcomes with regard to the structure of the Compliance Committees demonstrate rather clearly that this issue is not related to the concerned agreements, but rather to conflicting views on to what extent Parties should be able to control the Compliance Committees, in spite of the fact that the power to impose non-compliance response measures, or at least measures being considered as stringent measures, normally lies with the governing body itself.

\subsection{Functions of the Compliance Bodies}

Apart from considering individual cases of non-compliance and carry out functions assigned to them, ${ }^{66}$ both compliance committees of the Aarhus Convention and of the Cartagena Protocol may examine compliance issues (general issues of compliance)

measures. On the academic debate on whether the level of compliance should vary, inter alia, in relation to the capacities and level of development, see Pitea, supra n. 38, at p. 104.

${ }_{64}$ The Espoo Convention and the LRTAP Convention compliance committees consist of members representing Parties, and so does the $\mathrm{CC}$ of the Montreal Protocol, while members of the Compliance Committee of the Basel Convention (only) "serve objectively and in the best interest of the Convention". The Cartagena Protocol NCP includes that members are serving "objectively" in addition to serving in a personal capacity.

65 Personal recollection of the author of the present article. A common trait of the two compliance mechanisms, however not included in the compliance mechanisms themselves, is that the costs of members' participation in meetings of compliance committees are financed by the budgets of the agreements. Also in that respect the Aarhus Convention NCP was used as precedent by the EU (personal recollection).

${ }^{66}$ Aarhus Convention NCP, paras. 13(a) and 13(b), and Cartagena Protocol NCP, Section III(a) and III(f). 
and make recommendations to their governing bodies. ${ }^{67}$ Surprisingly enough, neither of the provisions was seriously questioned during the negotiations, although they provide a power to the compliance committees to act on their own initiatives. As regards the Cartagena Protocol compliance mechanism this is probably due to the fact that the competence of the Compliance Committee does not include an authority to address on its own initiative individual cases of non-compliance.

\section{$8.4 \quad$ Trigger Mechanisms}

Both compliance mechanisms may be triggered by a Party with respect to itself or by a Party with respect to another Party. However, with regard to the Cartagena Protocol compliance mechanism the Party-to-Party trigger is limited to a Party "which is affected or likely to be affected". ${ }^{68}$ This restriction is clearly linked to the negotiation process where the issue of a Party-to-Party trigger belonged to the controversial issues and was only resolved by means of a compromise between Parties that were opposed to a Party-to-Party trigger and those holding the opposite view, and was probably inspired by the Basel Convention compliance mechanism. ${ }^{69}$ The compromise is only justified as a compromise, and cannot be substantiated by the nature of the Cartagena Protocol, since the Protocol is closely linked to the conservation of biological diversity which is "a common concern of humankind". ${ }^{70}$

The Aarhus Convention compliance mechanism provisions on the Party-to-Party trigger almost literally reflect corresponding provisions of the LRTAP Convention compliance mechanism to the effect that the Secretariat, upon receipt of a Party-toParty submission, only has to transmit the submission to the Compliance Committee when the concerned Party has replied or the commenting period has expired. These provisions were apparently not discussed during the negotiations (apart from some insignificant amendments). Hence, theoretically speaking, the Compliance Committee of the Aarhus Convention only becomes aware of a Party-to-Party submission months after the complaint has been submitted, without any opportunity for the Compliance Committee to pose relevant questions right from the outset. The Cartagena Protocol compliance mechanism contains more or less the same rather obscure rule which did not raise any difficulties either during the negotiation process of the Cartagena Protocol compliance mechanism. ${ }^{71}$

The Secretariat trigger of the Aarhus Convention compliance mechanism, which was equally copied from the LRTAP Convention compliance mechanism, ${ }^{72}$ did not cause any problems during the negotiation process. To the contrary, a Secretariat trigger was identified as an element to be considered at the first ICCP of the Cartagena

${ }^{67}$ Aarhus Convention NCP, para. 14, and Cartagena Protocol NCP, Section III(d) and III(e) according to which, however, the Compliance Committee shall take into account information provided in national reports.

${ }^{68}$ Cartagena Protocol NCP, Section IV.1(b).

69 Adopted in December 2002.

${ }^{70}$ Cartagena Protocol, Art. 1 and Convention on Biological Diversity, Preamble, para. 3.

71 Aarhus Convention NCP, para. 15 and Cartagena Protocol NCP, Sections IV.2 and IV.3.

72 Aarhus Convention NCP, para. 17. The Espoo Convention NCP does not include a Secretariat trigger. 
Protocol. However, the Secretariat trigger had disappeared already as an outcome of the second ICCP, apparently because no delegation, in spite of the fact that both the Montreal Protocol compliance mechanism and the Basel Convention compliance mechanism (although to a rather limited extent) did include this trigger mechanism, insisted on keeping this option open. It is likely that the focus at the second ICCP shifted from the Secretariat trigger to the Secretariat as a source of information, because this element remained an option until the first COP/MOP, where issues related to information gathering were resolved by compromise language. It is equally possible that the dropping of the "Secretariat" as a trigger is related to (some) Parties' endeavours to be able to control the Secretariat to the extent possible, a trend which is probably more predominant in the framework of UN/UNEP than in the context of UNECE.

An NGO trigger mechanism in the framework of the Cartagena Protocol compliance mechanism was never seriously discussed, since even a Party-to-Party trigger was contentious. The same applies to the rather curious idea introduced at the first ICCP that the COP/MOP should be entitled to trigger the compliance mechanism.

\subsection{Procedural Safeguards and Some Other Procedural Aspects}

Some procedural aspects concerning the handling of submissions are referred to supra paragraph 8.4. It is noteworthy, however, that procedures regarding the handling of submissions are more elaborate in the compliance mechanism of the Aarhus Convention than in that of the Cartagena Protocol, in particular the provision of the former providing for draft findings and recommendations to be send to the Parties concerned and an obligation of the Compliance Committee to take into account any comments made. ${ }^{73}$ Such provision was never introduced in the Cartagena Protocol negotiation process. However, even though the provision might be regarded as being closely related to the issue of communications from members of the public, there would have been no apparent reason to reject a similar provision if it had been introduced in the negotiation process of the Cartagena Protocol compliance mechanism.

Confidentiality provisions relating to the relevant articles of the Aarhus Convention and the Cartagena Protocol on confidentiality did not cause any problems in either of the two negotiation processes. The same observation applies to the entitlement of the Parties concerned to participate in Compliance Committee discussions of submissions (but not in the preparation-elaboration of recommendations).$^{74}$ Both kinds of provisions may be considered as standard provisions.

The issue of open or closed meetings of the compliance committees was not discussed as such in either of the negotiation processes. There were some indications in

\footnotetext{
73 Aarhus Convention NCP, para. 34. The provision was introduced at the Second Meeting of Task Force, supra n. 17, Annex I, para. 11 and appears without brackets in the outcome of the immediately following meeting, First Meeting of Compliance Working Group, supra n. 16, Appendix, para. 9(c).

74 Aarhus Convention NCP, paras. 27 and 34, and Cartagena Protocol NCP, Section IV.4 and Section V.21. On the other hand the Compliance Committee of the Aarhus Convention may only take non-compliance response measures in consultation or agreement with the Party concerned, Aarhus Convention NCP, para. 36. However, the timeframe for the development of a compliance action plan requested by the Compliance Committee of the Cartagena Protocol has to be in agreement with the Party concerned, Cartagena Protocol NCP, Section VI.1(c).
} 
the Aarhus Convention compliance mechanism negotiations that the general rule would be open meetings, but an explicit rule to that (or the opposite) effect was never formulated. Neither does the Cartagena Protocol compliance mechanism include a provision on the nature of meetings of the Compliance Committee.

Regarding both compliance mechanisms it seems somewhat strange that there are no explicit provisions governing this issue. Meetings of the compliance committees of the most obvious precedents to the Cartagena Protocol compliance mechanism, the Montreal Protocol and the Basel Convention, are generally speaking not open at all (Montreal Protocol), or not open when the Compliance Committee is considering specific submissions (Basel Convention). On the other hand a provision to the effect that the Compliance Committee should develop Rules of Procedure to be approved by the COP/MOP, which was included in the first Draft compliance mechanism and also in the compliance mechanism as adopted and which never raised any discussions, did in principle retain Parties' control of the nature of the meetings of the Compliance Committee. ${ }^{75}$

As far as the Aarhus Convention compliance mechanism is concerned, it was probably obvious that a body dealing with compliance with provisions of an instrument aiming at public involvement in environmental matters could not operate with closed meetings, and that an explicit provision to that effect, therefore, was not needed. On the other hand it is, in the same token, rather strange that there is no explicit provision on rules of procedure of the Compliance Committee, since there is no reference in the compliance mechanism to Article 10.2(d) of the Aarhus Convention on the establishment of subsidiary bodies. Accordingly, the Compliance Committee does not meet the criteria of a subsidiary body as defined by the MOP itself in its own Rules of Procedure, implying both that the MOP does not consider the Compliance Committee as a subsidiary body and that the Rules of procedure does not automatically apply mutatis mutandis to the Compliance Committee. ${ }^{76}$ The absence of a provision in the Aarhus Convention-compliance mechanism on Rules of Procedure (RoP) is also curious, because rules on the decision-making of the Compliance Committee are scarce and that it was obvious that more rules would be needed. In fact there is only one rule on decision-making, namely a provision on every effort to be made to adopt the report of the Compliance Committee by consensus and the views of all members of the Compliance Committee to be reflected in the report where this is not possible. ${ }^{77}$

${ }^{75}$ Cartagena Protocol NCP, Section II.7. The reasons for the provision are vague. Maybe the true incentive to the provision was to avoid an automatic application mutatis mutandis of the rules of the RoP of the COP/MOP (i.e., the RoP of the COP of the Convention on Biological Diversity) by virtue of considering the Compliance Committee as a subsidiary body to the COP/MOP, entailing, inter alia, decisions of the Compliance Committee to be taken by a simple majority and open meetings.

${ }^{76} \mathrm{RoP}$ of the COP/MOP, supra n. 7, Rule 2. 7 in conjunction with Rules 23.1 and 23.2. This is why the author of the present paper does not consider the Compliance Committee as a subsidiary body to the MOP in any other way than the MOP, of course, may exercise its power to amend Decision I/7 in order to establish the Compliance Committee as a subsidiary body. These observations differ to some extent from those presented in Pitea, supra n. 38, at 90.

77 Aarhus Convention NCP, para. 35. The Compliance Committee of the Aarhus Convention has decided to apply parts of the RoP of the MOP mutatis mutandis, inter alia, Rule 35, para. 2 providing for decisions on substantive matters to be taken, as a last resort, by a three-fourths majority vote. Since the Compliance Committee is not a subsidiary body to the MOP in the sense of the RoP (see supra n. 76) and since there are 
While the Cartagena Protocol-compliance mechanism includes some admissibility criteria in respect of Party-to-Party submissions ${ }^{78}$ this is not the case as far as the Aarhus Convention-compliance mechanism is concerned. The reasons are probably that provisions on Party-to-Party submissions were copied from corresponding provisions of the LRTAP Convention compliance mechanism, that the issue of Party-to-Party submissions was never controversial in the course of the negotiation process, and that the negotiators were preoccupied with admissibility criteria in respect of communications from members of the public. It is difficult to contemplate any good reason that could have prevented Parties from including a provision on admissibility criteria regarding Party-to-Party submissions similar to the provisions of the Cartagena Protocol compliance mechanism, if the issue had been raised during the negotiations. This difference is therefore probably related to the respective negotiation histories and not to the nature of the two instruments.

\subsection{Sources of Information}

While the issue of sources of information was quite easily settled in respect of the Aarhus Convention compliance mechanism, ${ }^{79}$ the same issue was rather controversial during the negotiations of the Cartagena Protocol compliance mechanism, especially as regards the entitlement of the Compliance Committee to consider information from the Secretariat and NGOs. The scepticism towards information being provided by the Secretariat is hard to understand in the light of the rather central roles played by the secretariats of the Montreal Protocol and the Basel Convention as sources of information in relationship with their compliance mechanisms. This observation is to some extent also applicable to information to the Compliance Committee of the Aarhus Convention from NGOs, taking into account the general openness of the above compliance mechanisms to reliable information from all sources. The compromise solution found at the first COP/MOP, however, does not explicitly exclude either the Secretariat or NGOs as sources of information. ${ }^{80}$

no provisions to the opposite effect, the question may be raised, whether the Compliance Committee is free to opt for a rule providing for decisions on compliance/non-compliance to be taken by a simple majority. Determination of non-compliance, which is a decision of a quasi-judicial nature, by a qualified majority is inappropriate and may lead to rather absurd results. If, e.g., five out of the eight members of the Compliance Committee hold the view that a Party has violated the Aarhus Convention and the other three have the opposite view, a finding of non-compliance could not be made, but the report to the MOP would, in accordance with para. 35 of the Aarhus Convention NCP, indicate that five members of the Compliance Committee were of the opinion that there was a situation of non-compliance.

${ }^{78}$ Cartagena Protocol NCP, Section IV.1 on rejection of a Party-to-Party submission that is de minimis or ill-founded, corresponding more or less to paras. 20(b) and 20(c) of the Aarhus Convention NCP, on communications which are an abuse of the right to make communications or manifestly unreasonable.

79 Aarhus Convention NCP, para. 25(c) entitling the Compliance Committee to consider any relevant information submitted to it originates from the Second Meeting of Task Force, supra $\mathrm{n}$. 17. The provision corresponds to comparable provisions of the Espoo Convention and LRTAP Convention NCPs.

${ }^{80}$ Cartagena Protocol NCP, Section V.2 provides that " $[\mathrm{t}]$ he Committee may seek or receive and consider relevant information from sources, such as: ..." (emphasis added) 


\subsection{Non-Compliance Response Measures}

It is noteworthy that the power of the Compliance Committee of the Aarhus Convention to make recommendations directly to the Parties concerned was included only at the fourth negotiating meeting and that the competence is very limited, because it presupposes consultation or agreement with the Party concerned (supra paragraph 4.2). However, the introduction and adoption of this provision apparently did not cause any difficulties, while - at the same time - no efforts were made in order to strengthen the power of the Compliance Committee. It is doubtful whether the limited power of the Compliance Committee is due to its entitlement to consider communications from members of the public ${ }^{81}$ and/or to its composition. On the other hand, the compliance bodies of the LRTAP and Espoo Convention, composed of representatives of the Parties, are only empowered to make recommendations to their governing bodies. Be it as it may, it is not easily understandable, and certainly not a feature following directly from the nature of the Aarhus Convention and the Cartagena Protocol, that while the competence of the Compliance Committee of the Aarhus Convention is very limited the Compliance Committee of the Cartagena Protocol is empowered to a certain degree to make recommendations directly to the Party concerned, including to request a compliance action plan. ${ }^{82}$ These provisions were introduced early in the negotiation process and apparently did not cause any difficulties.

Few stringent measures are available to the governing bodies, i.e., as regards the Aarhus Convention compliance mechanism, declarations of non-compliance and the issue of cautions, and, as regards the Cartagena Protocol compliance mechanism, the issue of cautions and publishing cases of non-compliance. These measures did not cause major negotiation problems in respect of the Aarhus Convention compliance mechanism (supra paragraph 4.2). Regarding the compliance mechanism of the Cartagena Protocol the measures referred to were closely linked to the issue of Partyto-Party submissions. Accordingly, they were only agreed upon at the first COP/MOP in connection with the solution found in respect of the Party-to-Party trigger. However, the measures discussed do not differ very much. A common source of inspiration might have been the indicative list of measures of the Montreal Protocol compliance mechanism ${ }^{83}$ and measures being available to the COP according to the compliance mechanism of the Basel Convention.

Both compliance committees of the Aarhus Convention and of the Cartagena Protocol have the power to recommend to their governing bodies to take the more stringent measures referred to, and in both cases the governing bodies would have to take into account the cause, degree and frequency of the non-compliance. In addition, measures available to the governing bodies are not mutually exclusive. ${ }^{84}$ With the exception of the reference in the relevant provision of the compliance mechanism of

${ }^{81}$ See Koester, supra n. 25, at 203 describing the provision as "a compromise indicating a kind of checks-and-balances approach and some hesitation vis-à-vis the prominent role that NGOs (and other members of the public) play in the framework of the Aarhus compliance mechanism."

${ }^{82}$ Cartagena Protocol NCP, Section VI.1(c).

${ }^{83}$ Note by the Compliance Committee on Cases of Repeated Non-Compliance, supra n. 6, para. 39.

${ }^{84}$ Aarhus Convention NCP, para. 37 and Cartagena Protocol NCP, Section VI.2. 
the Cartagena Protocol to take into account the capacity of developing country Parties and Parties with economies in transition to comply, ${ }^{85}$ none of the provisions seems to have cause major negotiation problems. The last-mentioned difference between the provisions of the two compliance mechanisms is due to the fact that the Aarhus Convention is a European regional convention (supra paragraph 3), and that the Cartagena Protocol is of a global character, and, therefore, is not related to the subject-matter of the two instruments.

The most stringent measure, suspension of rights and privileges ${ }^{86}$ caused considerable difficulties in both negotiation processes, and solutions were only found at very late stages of the processes, due to partly the nature of the measure.$^{87}$ However, the final results differ very much, since this measure is available to the MOP of the Aarhus Convention ${ }^{88}$ but, so far, not to the COP/MOP of the Cartagena Protocol (supra paragraph 5.4).

The kind of blank-cheque available to the MOP of the Aarhus Convention to take "such other non-confrontational, non-judicial and consultative measures as may be appropriate" 89 and which did not cause any problems during the negotiation process of the Aarhus Convention compliance mechanism, was never suggested in the course of the negotiations of the Cartagena Protocol compliance mechanism, perhaps because it did not occur to the negotiators or, if it did, it was considered to be too controversial.

\section{SOME CONCLUding Remarks}

The scope of the above analysis is rather limited, since the negotiation processes and their outcomes only relate to the compliance mechanisms of two instruments focusing mainly on their differences. Furthermore, some of the observations are of a hypothetical nature. On the other hand, the Aarhus Convention and the Cartagena Protocol differ considerably as to the subjects of the agreements (supra paragraph 2.1) and their coverage and approach. Some of the variations in approach could be attributed to the

\footnotetext{
${ }^{85}$ Cartagena Protocol NCP, ibid.

${ }^{86}$ Trade restrictions were never considered in the framework of the Cartagena Protocol NCP although the Cartagena Protocol is related to (but not restricted to) trade.

${ }^{87}$ With regard to the Aarhus Convention NCP, at the Second Meeting of Working Group on Compliance, supra paragraph 4.2, and in respect of the Cartagena Protocol NCP, at the first COP/MOP, being part of a compromise package, supra paragraph 5.2. The provision on suspension of rights and privileges in the Cartagena Protocol NCP which was retained in square brackets until the first COP/MOP (i.e., "[suspend the specific rights and privileges of the concerned Party under the Protocol [consistent with International Law]]") differed from the comparable provision of the Montreal Protocol NCP "Indicative list", see Note by the Compliance Committee on Cases of Repeated Non-Compliance, supra n. 6, para. 39 (i.e., "Suspension, in accordance with the applicable rules of international law concerning the suspension of the operation of a treaty, of specific rights and privileges under the Protocol ...") and of the Aarhus Convention NCP, para. 37(g) (i.e., "Suspend, in accordance with the applicable rules of international law concerning the suspension of the operation of a treaty, the special rights and privileges accorded to the Party concerned under the Convention").

${ }^{88}$ Aarhus Convention NCP, para. 37(g)

89 Ibid., para. 37(h)
} 
fact that the Aarhus Convention is a regional European MEA (thus, less divergence of views among negotiating members) whereas the Cartagena Protocol, being a global one, has to undergo a lot of compromise. Nonetheless, differences between their compliance mechanisms should probably be assigned only to a rather limited extent to the divergent nature of the instruments. A number of distinctions seem to be connected with the negotiation processes as such and/or precedents used rather than being logical consequences of the agreements themselves. Some differences simply cannot be explained in any reasonable manner. The analysis might be seen as an attempt to contribute to the debate on whether each compliance mechanism depends fully on the nature of the MEA it is designed to serve, i.e., whether differences between compliance mechanisms are due only to differences between MEAs. ${ }^{90}$ The assumption, at least of the present author, is that there are no logical reasons why the compliance mechanisms of MEAs, generally speaking, should differ as much as they actually do, and that compliance mechanisms and thus, ultimately, the objectives of MEAs would benefit from less differentiation, i.e., by the inclusion of the innovative and effective features of some of the existing compliance mechanisms. ${ }^{91}$

${ }^{90}$ Although it might be worthwhile to discuss theoretically to what extent other compliance mechanisms and their MEAs might be suitable for and might benefit from a public trigger like the Aarhus Convention NCP, a public trigger does not belong to the traits referred to. Admittedly, also the Kyoto Protocol NCP includes a number of particularities which cannot be transposed to other compliance mechanisms.

${ }^{91}$ V. Koester and T. Young, "Compliance with Environmental Conventions: The Role of Public Involvement”, Envt'l Pol'y \& L., 37 (2007) 399-401. 


\title{
Chapter Seventeen
}

\section{The Practice of the Compliance Committee under the Kyoto Protocol to the United Nations Framework Convention on Climate Change (2006-2007)}

\author{
René Lefeber*
}

\section{INTRODUCTION}

The procedures and mechanisms relating to compliance under the 1997 Kyoto Protocol to the 1992 United Nations Framework Convention on Climate Change (UNFCCC) ${ }^{1}$ were adopted by the First Conference of the Parties serving as the meeting of Parties to the Kyoto Protocol (CMP) in December 2005. ${ }^{2}$ Following the adoption of this decision, which established the Compliance Committee of the Kyoto Protocol (Committee), the members and alternate members of the Committee were elected. The Committee commenced its work in 2006 and had submitted two annual reports to the CMP by 31 December 2007, including further rules of procedure that were adopted by the second CMP. ${ }^{3}$ Its work load is expected to increase following the commencement of the first commitment period of the Kyoto Protocol on 1 January 2008 .

* The views expressed in this paper are the author's and do not necessarily reflect those of the Minister of Foreign Affairs or the Government of the Kingdom of the Netherlands. The author would like thank Niels Blokker, Amy Hindman and Sebastian Oberthür for their comments on an earlier version of this contribution.

${ }^{1}$ A list of treaties with full references is provided supra at XXXVII.

2 See Decision 27/CMP.1 on Procedures and Mechanisms Relating to Compliance under the Kyoto Protocol, doc. FCCC/KP/CMP/2005/8/Add.3 (30 March 2006), at 92 (Kyoto Protocol NCP). On the development of these procedures and mechanisms, see R. Lefeber, "From The Hague to Bonn to Marrakesh and Beyond: A Negotiating History of the Compliance Regime under the Kyoto Protocol", Hague YB Int'l L., 14 (2004) 25-54.

${ }^{3}$ Rules of Procedure of the Compliance Committee of the Kyoto Protocol, in Decision 4/CMP.2 on Compliance Committee, Annex, doc. FCCC/KP/CMP/2006/10/Add.1 (2 March 2007) at 18 (hereinafter RoP). For the first two annual reports of the Compliance Committee to the CMP, see Annual Report of the Compliance Committee to the Conference of the Parties serving as the Meeting of the Parties to the Kyoto Protocol (Second Session), doc. FCCC/KP/CMP/2006/6 (22 September 2006) (Annual Report of the Compliance Committee to the Second COP/MOP) and Annual Report of the Compliance Committee to the Conference of the Parties Serving as the Meeting of the Parties to the Kyoto Protocol (Third Session), doc. FCCC/KP/CMP/2007/6 (26 September 2007) (Annual Report of the Compliance Committee to the Third $C O P / M O P)$

T. Treves et al., eds., Non-Compliance Procedures and Mechanisms and the Effectiveness of International Environmental Agreements

(C) 2009, T.M.C. ASSER PRESS, The Hague, The Netherlands, and the Authors 
This chapter covers the work of the Committee during the first biennium of its existence that ended on 31 December 2007. It identifies issues that are not necessarily specific for the Compliance Committee of the Kyoto Protocol. This approach has been chosen to allow for a comparative analysis of these issues in relation to the compliance committees of other multilateral environmental agreements. The issues are grouped in three paragraphs, namely the organization of work in the Committee (paragraph 2), the members of the Committee (paragraph 3), and the powers of the Committee (paragraph 4).

\section{The Organisation of Work in the Committee}

\subsection{The Structure of the Committee}

The Committee functions through a bureau, a plenary and two branches, viz. the Facilitative Branch and the Enforcement Branch. This complex structure is a reflection of the principle of common but differentiated responsibilities and respective capabilities of States. During the negotiations on the decision establishing the Committee, the developing countries, i.e., countries without emission limitation or reduction commitments (non-Annex I Parties), wanted to ensure that they would not be subject to the jurisdiction of the Enforcement Branch in view of the stringent nature of the measures it was envisaged to apply. The developed countries, i.e., countries with emission limitation or reduction commitments (Annex I Parties), were willing to accept such distinction, but wanted to increase their weight in the decision-making if the Enforcement Branch was only to consider cases involving such countries. This is reflected in (a) the mandate of the Enforcement Branch that only relates to Annex I Parties; and (b) the voting rule for the Enforcement Branch that increases the relative weight of members from Annex I Parties in the decision-making. ${ }^{4}$

Following the acceptance of the idea to establish two branches, it became apparent that further organs were required within the Committee. This resulted in the establishment of the plenary, composed of all members of the Committee, and the bureau, composed of the chairs and the vice-chairs of the two branches. The establishment of a bureau was a consequence of the establishment of the two branches as questions of implementation received by the Committee had to be allocated to either of the two. In practice, the bureau plays a central role in the Committee. It organises the work of the Committee and prepares substantive discussions in the plenary. The respective chair and vice-chair of each of the branches perform a similar role in the branches. The members of the bureau have thus become the management of the Committee that deliberates sessionally on a daily basis and intersessionally as required.

Although the branches have separate mandates and could, in theory, act independently of one another, it has become apparent in the course of the proceedings of the Committee that the acts of one branch may affect the functioning of the other branch, e.g., the interpretation of their respective mandates or the application of their

\footnotetext{
${ }^{4}$ See Kyoto Protocol NCP, sections V.4-V.6 and II.9.
} 
respective voting rules (see below). Since the fourth meeting of the plenary (September 2007), the branches report to the plenary which enables a plenary discussion of the work and the outcomes of each branch.

\subsection{Transparency in the Committee}

The level of transparency of the conduct of the meetings and the release of their outcomes was only partially addressed in the decision establishing the Committee. Besides an obligation to publish final decisions in specific cases, ${ }^{5}$ the decision establishing the Committee only provides that hearings of the Enforcement Branch are held in public, unless the Enforcement Branch decides, on its own accord or at the request of the Party in respect of which a question of implementation has been raised, that part or all of the hearing shall take place in private. ${ }^{6}$ This procedure for hearings has now been extended to all meetings of the plenary and the branches, except for the part of the meetings concerned with the elaboration and adoption of decisions. This part of the meetings may only be attended by the members and alternate members of the Committee, and secretariat officials. The other parts of the meeting can be observed by anybody who has registered as an observer for a meeting. The category of observers has thus not been limited to entities which qualify as observer under the Kyoto Protocol, ${ }^{7}$ and encompasses all members of the public. Observers may be present in the room, unless space constraints prevent this in which case live video feed will be made available in an adjacent room. Observers may not interfere in any way with the conduct of the meeting. Since the meeting of the Committee in September 2007, the meetings of the plenary and the branches are furthermore recorded and broadcast on the Internet through the UNFCCC website. ${ }^{8}$ In view of the politicised character of a significant part of the deliberations in the Committee and its branches, this advanced level of transparency is a valuable asset. However, the meetings of the bureau are held in private, and only attended by the bureau members and secretariat officials.

The advanced level of transparency of the meetings may be affected by the use of electronic means. In view of the need to take decisions within the time limits set by the decision establishing the Committee and the practical difficulties to obtain a quorum for meetings called on short notice, the frequent use of electronic means for the elaboration and adoption of decisions will be inevitable (see also below). As a result, electronic deliberations are likely to replace face-to-face deliberations. It may be noted that the use of electronic means for the elaboration and adoption of decisions creates a number of practical problems, such as the establishment of an electronic quorum and the security of communication via Internet, which could not yet be resolved by rules of procedure. Only the Facilitative Branch has adopted decisions

\footnotetext{
5 Ibid., section VIII.7.

6 Ibid., section IX.2.

7 See Kyoto Protocol, Art. 13.8 for the list of entities which qualify as observer under the Kyoto Protocol.

${ }^{8}$ See working arrangements adopted by the plenary at its fourth meeting from 5 to 7 September 2007, reported in Annual Report of the Compliance Committee to the Third COP/MOP, supra n. 3, paras. 13-18.
} 
during the first biennium (see below). All those decisions were adopted by electronic means.

\section{The Members of the Committee}

\subsection{The Participatory Rights of Members}

The Committee consists of 20 members and 20 alternates. When the plenary of the Committee considered the adoption of further rules of procedure during its first meeting (March 2006), it discussed the participatory rights of alternate members. It was clear that alternate members did not have the right to cast a vote when their member was casting a vote, but it was to be discussed whether they would have the right to attend the meeting and the right to speak when the member is present. All alternates had been invited for the first meeting of the Committee. By the end of that meeting, their full right of participation, with the exception of the right to cast a vote when their member was casting a vote, was accepted and the Committee has in fact consisted of 40 members ever since. Their participatory rights were confirmed by the CMP in the further rules of procedure of the Committee that were adopted by the second CMP (Rules of Procedure). ${ }^{9}$ The added value of alternates in a committee that may have to meet at short notice and has a high quorum for decision-making (three fourths) is established. Since alternates may have to partake in the adoption of farreaching decisions, their active participation in the proceedings of the Committee is necessary to ensure informed decision-making by the Committee. It may be added that the alternates have already made significant contributions to the debates of the Committee. Their participation to date deserves a positive assessment. Notwithstanding this positive assessment, it must be added that the large number of participants in the debates also poses a challenge to the effective functioning of the Committee.

\subsection{The Personal Capacity of Members}

The members of the Committee serve in their personal capacity and must take an oath of service. ${ }^{10}$ This has not prevented Parties to the Kyoto Protocol from nominating, and the CMP from electing, members who are in the service of governments, including former and current members of delegations to the meetings of the CMP. This has contributed to the politicised nature of a significant part of the deliberations in the Committee. Since the nominations are not, as yet, subject to rigorous scrutiny in the CMP and full respect for the nominations by another UN regional group is the rule, this is not likely to change, at least not in the near future.

The personal capacity in which members serve has generated several further issues that still need to be resolved, namely the reimbursement of the costs of travelling and subsistence, and the enjoyment of privileges and immunities. Pursuant to the current policy of the CMP, only members and alternate members of non-Annex I Parties are

\footnotetext{
9 See Rules 3.2-3.4 RoP.

${ }^{10}$ See Kyoto Protocol NCP, section II.6 and Rule 4 RoP.
} 
eligible for the reimbursement of travel-related expenses. The members from Annex I Parties, including those who are not working in the service of governments, are reimbursed for their travel-related expenses by their respective governments or have to bear their own costs. The Committee has recognised that this limited reimbursement policy may affect the independence, or even the presence, of members and alternate members of Annex I Parties. ${ }^{11}$ The Committee's request to the CMP to extend the reimbursement of travel-related expenses to these members has, to date, not been accommodated..$^{12} \mathrm{~A}$ further related issue is whether members should take leave when they attend meetings of the Committee and should receive remuneration for their work - it may be noted that all members of the Executive Board of the Clean Development Mechanism (CDM) of the Kyoto Protocol are reimbursed for their travel expenses and receive a daily subsistence allowance (DSA) of $40 \%$ more than the standard UN rate. ${ }^{13}$

The enjoyment of privileges and immunities by individuals serving in their personal capacity in bodies constituted under the Kyoto Protocol is on the agenda of the CMP following threats to members of the CDM Executive Board that they could be sued for malpractice. Members of international bodies who serve in their personal capacity do neither represent governments nor the UNFCCC Secretariat. The acts performed in this capacity are therefore neither attributable to a State nor to the UN to which the UNFCCC Secretariat is institutionally linked. ${ }^{14}$ In the context of the Kyoto Protocol, this applies to members of the Committee, the CDM Executive Board, the Joint Implementation Supervisory Committee, and expert review teams. These members are to a certain extent protected by the relevant provisions of agreements concluded between the UN and States with respect to the establishment of the secretariat and the hosting of UNFCCC meetings. These host country agreements protect such members through provisions relating to persons invited to participate in the official business of the UNFCCC and/or the application of the Convention on UN Privileges and Immunities to experts on mission. ${ }^{15}$ However, these agreements only afford protection in the host countries and, with the exception of the headquarters agreement of the UNFCCC Secretariat, for a limited period of time.

In view of the institutional linkage of the UNFCCC to the UN, it may be argued that the members who serve in their personal capacity on bodies constituted under the Kyoto Protocol qualify as experts on mission for the UN and are protected by the

11 See Annual Report of the Compliance Committee to the Second COP/MOP, supra n. 3, para. 26, and Annual Report of the Compliance Committee, supra n. 3, paras. 26-27.

${ }^{12}$ For the Committee's requests, see Annual Report of the Compliance Committee to the Second COP/ MOP, supra n. 3, para. 3(b), and Annual Report of the Compliance Committee to the Third COP/MOP, supra n. 3, paras. 5(a) and 5(b).

13 See Decision 7/CMP.1 on Further Guidance relating to the Clean Development Mechanism, doc. FCCC/KP/CMP/2005/8/Add.1 (30 March 2006), at 93, paras. 17-18.

${ }_{14}$ See Decision 14/CP.1 on Institutional Linkage of the Convention Secretariat to the United Nations, doc. FCCC/CP/1995/7/Add.1 (6 June 1995), at 42.

15 See, e.g., 1996 Agreement among the United Nations, the Government of the Federal Republic of Germany and the Secretariat of the United Nations Framework Convention on Climate Change, as amended in 2005, reproduced in Administrative and Financial Matters, Establishment of the Permanent Secretariat and Arrangements for its Functioning, doc. FCCC/CP/MISC.1 (3 July 1996). 
Convention on UN Privileges and Immunities on that basis. The International Court of Justice (ICJ) has stated that the purpose of the provision relating to experts on mission of the Convention on UN Privileges and Immunities is "to enable the United Nations to entrust missions to persons who are not an official of the Organization, and to guarantee them such privileges and immunities as are necessary for the independent exercise of their functions." ${ }^{\prime 16}$ The Court then noted that, according to UN practice, such persons may be entrusted with specific tasks, including mediation, preparing reports, preparing studies, conducting investigations, or finding and establishing facts; or they may serve in their personal capacity as members of bodies set up within the UN, including bodies established under autonomous instruments that are institutionally linked to the UN. ${ }^{17}$ Although the Kyoto Protocol is an autonomous instrument that is institutionally linked to the UN, the UN Office of Legal Affairs has concluded that "[a]s the bodies under the UNFCCC and the Kyoto Protocol are not United Nations organs, experts and any other individuals serving on such bodies cannot be accorded the status of experts on mission for the United Nations under the General Convention [i.e., the Convention on UN Privileges and Immunities]." 18

As a result, individuals serving in their personal capacity in bodies constituted under the Kyoto Protocol are not adequately protected by international law, and may be held liable in domestic courts for their acts while serving on the Committee. Besides the enjoyment of immunity from jurisdiction, there is also a need to guarantee the enjoyment of privileges of these individuals, such as the right to depart from the State of residence to attend a meeting and the right to enter the State where a meeting is convened. It is recognised that only a treaty can adequately address this issue in spite of the fact that even a treaty cannot provide full protection against the acts of domestic courts. Provisional measures have been adopted by the CMP to afford some level of protection, notably in the form of legal assistance, to these individuals with regard to any concerns or issues raised in connection with the exercise of their official functions. ${ }^{19}$ The CMP has recognised the need for additional measures and is expected to consider a legally binding solution to enhance the level of protection of these individuals. ${ }^{20}$

${ }^{16}$ See Applicability of Article VI, Section 22, of the Convention on the Privileges and Immunities of the United Nations, Advisory Opinion of 15 December 1989, ICJ Reports, 1989, 177, at 194 (para. 47).

${ }^{17}$ Ibid., para. 48.

${ }_{18}$ See Consultations by the Secretariat with the Secretary-General of the United Nations on Privileges and Immunities for Individuals Serving on Constituted Bodies Established under the Kyoto Protocol, doc. FCCC/SBI/2006/20 (19 September 2006), Annex, para. 4.

${ }_{19}$ See Decision 9/CMP.2 on Privileges and Immunities for Individuals Serving on Constituted Bodies under the Kyoto Protocol, doc. FCCC/KP/CMP/2006/10/Add.1 (2 March 2007), at 34.

${ }^{20}$ See Decision 4/CMP.3 on Scope and Content of the Second Review of the Kyoto Protocol Pursuant to its Article 9, doc. FCCC/KP/CMP/2007/9/Add.1(14 March 2008), at 19, para. 6(c). 


\section{The Powers of the Committee}

\subsection{The Mandates of the Organs of the Committee}

\section{a) Introduction}

The explicit powers of the organs of the Committee are laid down in the decision establishing the Committee. The plenary has been mandated (a) to report on activities of the Committee (two reports to date), (b) to apply the general policy guidance received from the CMP (none to date), (c) to submit proposals on administrative and budgetary matters (see above for an example), (d) to develop any further rules of procedure (see above and below), and (e) to perform such other functions as may be requested by the CMP (none to date). ${ }^{21}$ Any further rules of procedure developed by the plenary must be adopted by the CMP by consensus. At its third meeting (September 2006), the plenary decided to provisionally apply the further rules of procedure it had adopted pending their adoption by the CMP, and it asked and received a mandate of the CMP to provisionally apply any amendments to those rules of procedure. ${ }^{22}$ In addition, the plenary noted in its first annual report that it also might have to develop working arrangements to complement and give effect to the rules and procedure. ${ }^{23} \mathrm{At}$ its fourth meeting, the plenary proceeded accordingly and adopted working arrangements with respect to the recording and broadcasting of meetings as well as the registration and presence of observers (see above).

The bureau has been mandated (a) to allocate questions of implementation to the appropriate branch in accordance with the mandates of each branch (once to date), (b) to designate members of one branch to contribute to the work of the other branch on a non-voting basis (none to date), and (c) to draft, in agreement with the secretariat, the provisional agenda of the plenary (four times to date) ${ }^{24}$ In practice, the members of the bureau are responsible for the organization of the work of the Committee and even prepare substantive discussions (see above).

The Facilitative Branch is responsible for providing advice and facilitation to Parties in implementing the Kyoto Protocol, and for promoting compliance by Parties with their commitments under it. ${ }^{25}$ This general mandate is elaborated in more detail to illustrate its functions and this has given rise to questions of interpretation relating to the mandate of the Facilitative Branch (see below). It has been specified that the Facilitative Branch is responsible for (a) addressing questions of implementation relating to the obligation of Annex I Parties to strive to implement their emission limitation or reduction commitments in such a way as to minimise the adverse social, environmental and economic impacts on developing countries (Article 3.14 Kyoto Protocol); (b) addressing questions of implementation relating to the provision of information on the use of the flexible mechanisms (joint implementation (Article 6),

\footnotetext{
21 See Kyoto Protocol NCP, section III.2.

22 See Rule 26.2 RoP.

${ }_{23}$ See Annual Report of the Compliance Committee to the Second COP/MOP, supra n. 3, para. 11.

${ }^{24}$ See Kyoto Protocol NCP, sections VII.1 and II.7 and Rule 7.1 RoP.

${ }_{25}$ See Kyoto Protocol NCP, section IV.4.
} 
clean development mechanism (Article 12), and emissions trading (Article 17)) to achieve emission limitations or reductions as supplemental to domestic action to achieve such limitations or reductions; (c) providing advice and facilitation for compliance with emission limitation or reduction commitments prior to and during a commitment period (Article 3.1); (d) providing advice and facilitation for compliance with methodological requirements (Articles 5.1 and 5.2) prior to the beginning of the first commitment period; and (e) providing advice and facilitation for compliance with reporting requirements (Articles 7.1 and 7.4) prior to the beginning of the first commitment period. ${ }^{26}$ The last three provisions have been drafted so as not to encroach on the mandate of the Enforcement Branch. By 31 December 2007, the Facilitative Branch had been called upon once to act pursuant to this mandate (see below), but refrained from doing so.

The mandate of the Enforcement Branch has been specified in detail. This branch is only responsible for determining whether (a) an Annex I Party has complied with its emission limitation or reduction commitments at the end of a commitment period; (b) an Annex I Party has complied with the methodological and reporting requirements after the beginning of the first commitment period; (c) an Annex I Party has complied with the eligibility requirements for the use of the flexible mechanisms; (d) to apply adjustments to inventories in the event of a disagreement between an expert review team and an Annex I Party; and (e) to apply corrections to the compilation and accounting database for the accounting of assigned amounts in the event of a disagreement between an expert review team and an Annex I Party. ${ }^{27}$ Questions of implementation relating to matters not listed in the mandate of the Enforcement Branch fall outside the jurisdiction of this branch and must be allocated to the Facilitative Branch. By 31 December 2007, the Enforcement Branch had not been called upon to act pursuant to its mandate, but refused to entertain a request related to the eligibility requirements to use the flexible mechanisms (see below).

Both branches have discussed the extent of their powers in connection with information submitted to the Committee. These discussions invariably addressed the question whether this information provided a basis for further action by a branch and the existence of implied powers of a branch. However, the branches have, to date, refrained from invoking implied powers to take action.

Pursuant to the case law of the ICJ, an organization is deemed to have those powers which, though not expressly provided in its constituent document, are conferred upon it by necessary implication as being essential to the performance of its duties. ${ }^{28}$ There would not seem to be any legal impediment to apply the doctrine of implied powers to an autonomous institutional arrangement, such as the Kyoto Protocol, under the condition formulated by the ICJ. The organ invoking implied powers will thus have to demonstrate that such powers are essential to the performance of its duties.

${ }^{26}$ Ibid., sections IV.5-IV.6.

${ }^{27}$ Ibid., sections V.4-V.5.

${ }^{28}$ See Reparations for Injuries Suffered in the Service of the United Nations, Advisory Opinion of 11 April 1949, ICJ Reports (1949) 174, at 182. 
b) Failure to Submit National Communications and Reports on Demonstrable Progress

Annex I Parties were required to submit national communications and reports on demonstrable progress in preparing for the implementation of their commitments under the Kyoto Protocol by 1 January 2006. Several Parties had not submitted the information on time. Delays in submitting this information beyond six weeks after this date had to be brought to the attention of the Committee as well as the CMP, and had to be made public. ${ }^{29}$ Initially, the plenary merely took note of the delays. ${ }^{30}$ In the Facilitative Branch, the issue was raised whether the branch could provide, to the Parties concerned, advice and facilitation for compliance with emission reduction commitments prior to and, if necessary, during the first commitment period in view of the failure of these Parties to submit information and demonstrate progress. Since the aim of this power is to promote compliance and provide for early warning of potential non-compliance, it was argued by some members that the Facilitative Branch could proceed on its own accord without the submission of a question of implementation to it. Although the decision establishing the Committee only envisages the submission of questions of implementation by expert review teams, by a Party with respect to itself (self trigger), or by a Party with respect to another Party (Party-to-Party trigger), ${ }^{31}$ it was debated whether the mandate of the Facilitative Branch allowed it to take action without the submission of a question of implementation. The relevant provision in the specific mandate of the Facilitative Branch does not make reference to questions of implementation and the question arose whether this provision could be seen in isolation from the general mandate which does make reference to such questions of implementation. Divergent views prevented the Facilitative Branch from taking further action on its own accord beyond expressions of concern in respect of the delays.

Since two Annex I Parties (Italy and Luxembourg) had still not submitted the required information in whole or in part by September $2007,{ }^{32}$ the plenary considered the issue again at its fourth meeting in September 2007. It expressed its concern over the delays in the submission of information and invited the CMP "to clarify whether it requests the Compliance Committee to take any specific action when delays in the submission by a Party included in Annex I to the Convention of its national communication have been brought to its attention by the secretariat." 33 Thus, the Committee refrained from taking action on its own accord, but requested the supreme organ of the Kyoto Protocol to interpret its mandate. The CMP, at its third meeting in Decem-

${ }_{29}$ See Decision 22/CMP.1 on Guidelines for review under Article 8 of the Kyoto Protocol, Annex, para. 139, doc. FCCC/KP/CMP/2005/8/Add.3 (30 March 2006).

${ }^{30}$ See Annual Report of the Compliance Committee to the Second COP/MOP, supra n. 3, paras. $15-17$.

31 See Kyoto Protocol NCP, section VI.1.

${ }^{32}$ See Status of National Communications and Reports Demonstrating Progress of Annex I Parties, doc. CC/4/2007/4 (6 September 2007).

33 See Annual Report of the Compliance Committee to the Third COP/MOP, supra n. 3, para. 4(b); see also para. 22. 
ber 2007, also expressed its concern, ${ }^{34}$ but refrained from providing the clarification requested. Hence, no answer was given by the CMP to the question whether the Committee can take action on its own accord when delays in the submission of information have been brought to its attention. Although the Committee correctly considered "[t]he timely submission and review of information essential to the functioning of the procedures and mechanisms relating for compliance review established by decision 27/CMP.1", ${ }^{35}$ it is not essential to the performance by the Committee of its duties. If Parties fail to submit the required information, it will evidently hamper the review of their compliance with the Kyoto Protocol - apart from the review of their compliance with reporting requirements. This will render it difficult to identify questions of implementation and submit them to the Committee together with corroborating information. However, this is not an institutional gap in the procedures and mechanisms relating to compliance that needs to be filled to enable the Committee to perform its duties. Accordingly, the doctrine of implied powers does not provide a legal basis for the Committee to extend its mandate in respect of the delays in the submission and review of such information. The Committee correctly refrained from invoking them for this purpose.

Annex I Parties were, furthermore, required to submit a report to facilitate the calculation of a Party's assigned amount of emissions and to demonstrate its capacity to account for emissions and the assigned amount (initial report) by 1 January 2007 or one year after the entry into force of the Kyoto Protocol for that Party. ${ }^{36}$ An Annex I Party is eligible to use the flexible mechanisms after the lapse of 16 months following the submission of its initial report. ${ }^{37}$ This automatic eligibility was introduced in order to ensure that delays in the review of the initial report by an expert review team (beyond 12 months) or in the consideration of any questions of implementation by the Enforcement Branch (beyond 4 months) would not unduly delay the use of the flexible mechanisms by an Annex I Party. In order to be eligible for the use of the flexible mechanisms from the start of the first commitment period on 1 January 2008, these Parties had to submit their initial report by 1 September 2006 - only Hungary, Japan and New Zealand met this deadline. In the case that a question of implementation is identified by an expert review team and the Enforcement Branch decides not to proceed with that question of implementation before the lapse of 16 months following the submission of the initial report, the Annex I Party would become eligible to use

${ }^{34}$ See Decision 5/CMP.3 on Compliance under the Kyoto Protocol, doc. FCCC/KP/CMP/2007/9/Add.1 (14 March 2008), at 21, para. 2.

${ }^{35}$ See Annual Report of the Compliance Committee to the Third COP/MOP, supra n. 3, para. 22.

${ }^{36}$ See Decision 13/CMP.1 on Modalities for the Accounting of Assigned Amounts under Article 7, paragraph 4, of the Kyoto Protocol, doc. FCCC/KP/CMP/2005/8/Add.2 (30 March 2006), at 23, para. 2.

${ }^{37}$ See Decision 3/CMP.1 on Modalities and Procedures for a Clean Development Mechanism as Defined in Article 12 of the Kyoto Protocol, Annex, para. 32; Decision 9/CMP.1 on Guidelines for the Implementation of Article 6 of the Kyoto Protocol, Annex, para. 22; and Decision 11/CMP.1 on Modalities, Rules and Guidelines for Emissions Trading under Article 17 of the Kyoto Protocol, Annex, para. 3, all in doc. FCCC/KP/CMP/2005/8/Add.1. (30 May 2006). 
the flexible mechanisms on the date of such decision of the Enforcement Branch. ${ }^{38}$ However, the CMP has not provided, at least not explicitly, for such early eligibility if no questions of implementation have been identified by an expert review team. As a result, the initial eligibility of Annex I Parties which had submitted their initial report after 1 September 2006 would unnecessarily be delayed by four months if no questions of implementation have been identified by an expert review team.

Perceived political and market considerations prompted the secretariat to raise this issue in the Enforcement Branch, at its second meeting in September 2007..$^{39}$ Two options for the adoption of one or more decisions by the Committee were presented to secure automatic eligibility in the case that no questions of implementation have been identified by an expert review team. The Enforcement Branch considered the issue, but did not take any further action. ${ }^{40}$ It was argued by some members that the relevant decisions implicitly provided for automatic eligibility if no questions of implementation have been identified by an expert review team and by others that the interpretation and, if need be, the amendment of those decisions were the prerogative of the CMP. After the meeting of the Enforcement Branch, the Executive Secretary issued an information note from which it can be inferred that an Annex I Party will become eligible 16 months following the submission of its initial report. ${ }^{41}$ In other words, it was assumed by the Executive Secretary that the relevant decisions do not provide for automatic eligibility in the case that no questions of implementation have been identified by an expert review team. The CMP, at its third session, did not challenge this approach and must be deemed to have accepted it. Apparently, the political and market considerations, as originally referred to by the secretariat, were not of such a nature that urgent action was considered necessary by the CMP.

In this case too, the question was raised whether the Enforcement Branch was competent to take action. It was clear that the issue was not part of the explicit mandate of the Enforcement Branch. Although the smooth functioning of the Kyoto Protocol might have benefited from early action by the Enforcement Branch on this issue, the Enforcement Branch correctly refrained from taking action and from invoking the doctrine of implied powers to justify such action. Such action would not have been essential for the performance by the Enforcement Branch of its duties and could thus not be based on the doctrine of implied powers. Even if it had been established that such action was essential for the functioning of the Kyoto Protocol, it would have been for the CMP to take the necessary action in this case. The Enforcement Branch would not have been competent in this case to interpret, let alone amend, decisions of the CMP.

38 Ibid.

39 See Eligibility Requirements under Articles 6, 12 and 17 of the Protocol: Initial Eligibility, doc. CC/ EB/2/2007/2 (2 August 2007).

${ }^{40}$ See Annual Report of the Compliance Committee to the Third COP/MOP, supra n. 3, paras. 24-25.

${ }^{41}$ See Information Note of Executive Secretary of on the Initial Eligibility of Austria, Hungary, Japan, New Zealand and Switzerland, doc. LA/INF/SEP/07 (19 September 2007). 


\subsection{The Application of Powers by the Organs of the Committee}

\section{a) Failure to Submit National Communications and Reports on Demonstrable Progress}

The delays in the submission of national communications and reports on demonstrable progress in preparing for the implementation of their commitments under the Kyoto Protocol (see above) were reason for South Africa, on behalf of the Group of 77 and China, to submit a question of implementation to the Committee on 26 May 2006 in respect of 15 Annex I Parties. ${ }^{42}$ The submission did not only raise the failure to submit reports demonstrating progress, but also suggested that the Facilitative Branch should ascertain whether continued non-compliance with the requirement to provide timely information constitutes early warning of potential non-compliance by these Parties with their emission limitation or reduction commitments. The question of implementation was allocated by the bureau to the Facilitative Branch on 31 May 2006. Since two of the Annex I Parties concerned (Latvia and Slovenia) submitted a national communication and a report demonstrating progress pending the consideration of the question by the Facilitative Branch, the branch decided not to proceed with the question of implementation in respect of these two States on 21 June 2006. ${ }^{43}$ With respect to the other Annex I Parties concerned, the Facilitative Branch was neither able to take a decision to proceed nor a decision not to proceed with the question of implementation. The voting rule requires that three fourths of the members present and voting support a draft decision. ${ }^{44}$ This qualified majority could not be reached one way or the other. In practice, this meant that the Facilitative Branch could not and did not proceed with the question of implementation.

Pursuant to the decision establishing the Committee, the Facilitative Branch was required to undertake a preliminary examination of the question of implementation to ensure that the question before it is (a) supported by sufficient information, (b) not de minimis or ill-founded, and (c) based on the requirements of the Kyoto Protocol. ${ }^{45}$ Several members of the Facilitative Branch expressed doubts whether these conditions were met. In particular, these members observed that the submission (a) was not by a Party on its own behalf through a representative duly authorised for this purpose, (b) did not clearly and individually name the Parties with respect to which it purported to raise a question of implementation, and (c) was not supported by information corroborating the question of implementation and did not substantiate how that question related to any of the specific commitments of these Parties under the Kyoto Protocol. ${ }^{46}$

${ }^{42}$ See the letter of South Africa of 26 May 2006, reproduced in docs. CC-2006-1-1/FB to CC-2006/-15-1/ FB; the Parties concerned were: Austria, Bulgaria, Canada, France, Germany, Ireland, Italy, Latvia, Liechtenstein, Luxembourg, Poland, Portugal, Russian Federation, Slovenia, and Ukraine.

43 See Preliminary Examination, doc. CC-2006-8-3/Latvia/FB (21 June 2006), and Preliminary Examination, doc. CC-2006-14-2/Slovenia/FB (21 June 2006).

${ }^{44}$ See Kyoto Protocol NCP, section II.9.

45 Ibid., section VII.2.

${ }^{46}$ See Report to the Compliance Committee on the Deliberations in the Facilitative Branch Relating to the Submission Entitled "Compliance with Article 3.1 of the Kyoto Protocol", reproduced in doc. FCCC/KP/ CMP/2006/6, Annex IV (22 September 2006). 
The submission would manifestly not have been admissible under the Rules of Procedure, but these had not yet been adopted when this case was brought before the Facilitative Branch. ${ }^{47}$ At the time of the submission, the admissibility of submissions was not governed by formal requirements, such as the designation of representatives of Parties authorised to communicate with the Committee, or the identification in the submission of the names of all Parties making the submission and the names of all Parties with respect to which the submission was made. In the absence of any specific rules, it would seem unjust to argue on these grounds that the submission was not admissible. With respect to the argument that the question of implementation was not corroborated by information, it is necessary to distinguish between (a) the failure to submit reports demonstrating progress and (b) the failure to demonstrate progress. Since the information on the failure to submit reports had already been reported to the Committee, a fact which was mentioned in the submission together with the relevant provisions of and decisions under the Kyoto Protocol, it could hardly be maintained that the submission was not supported by information corroborating the question of implementation in this respect.

The submission also asked the Facilitative Branch to ascertain whether continued non-compliance with the requirement to provide timely information constituted early warning of potential non-compliance with emission limitation or reduction commitments. This was perceived by some members as an attempt to submit that the Annex I Parties concerned had failed to demonstrate progress with their emission limitation or reduction commitments. In support of this contention, reference was also made to the title of the submission - Compliance with Article 3.1 of the Kyoto Protocol - that suggested that the essence of the submission related to emission limitation or reduction commitments, and not to reporting requirements, under the Kyoto Protocol. Information to support such contention was not included in the submission. However, a decision to proceed would not have prevented the Facilitative Branch from concluding at a later stage that this was not the essence of the submission and that it only had to consider whether the failure to submit reports demonstrating progress as such could be an early warning of potential non-compliance with emission limitation or reduction commitments.

\section{The Review of Initial Reports}

All reports by expert review teams on the initial reports submitted by Annex I Parties are to be forwarded to the Committee. ${ }^{48}$ On the basis of the current number of States Parties to the Kyoto Protocol that are Annex I Parties, the Committee will receive 38 reports. On 31 December 2007, the Committee had received 29 reports; five Annex I Parties (Bulgaria, Canada, Iceland, Romania and Russian Federation) had failed to meet the deadline for the submission of their initial reports. A question of implementation had been identified in one report (Greece); and no unresolved disagreements had arisen between expert review teams and Annex I Parties on the appli-

\footnotetext{
47 See Rules 15 and 18 RoP.

48 See Kyoto Protocol NCP, section VI.3.
} 
cation of adjustments to inventories or corrections to the compilation and accounting databases for the accounting of assigned amounts.

On 31 December 2007, the question of implementation in the case of Greece had yet to be allocated. The question of implementation relates to compliance with the methodological and reporting requirements under the Kyoto Protocol, in particular the maintenance of institutional and procedural arrangements, the technical competence of staff, and the capacity to meet deadlines for the submission of information. ${ }^{49}$

\section{Conclusions}

The Committee has only been operational for two years and any conclusions can evidently only be of a preliminary nature. First, the membership of and the debates in the Committee were politicised to a significant extent in these early years and this contributed to the failure of the Facilitative Branch to act in a responsible manner in the first and only case that has thus far been considered. The subsequent debates on and adoption of the Rules of Procedure and working arrangements have, however, improved the spirit of cooperation. It is, furthermore, positive that the Facilitative Branch resisted pressure from its own members, and the Enforcement Branch from the secretariat, to act outside its competence.

Second, it appeared during these early years that the procedures and mechanisms relating to compliance under the Kyoto Protocol contain a serious defect. In the case of the submission of questions of implementation to the Committee, the absence of the required majority in support of a proposed decision will result in a decision not to proceed by default, as occurred in the case before the Facilitative Branch on the failure of a significant number of Annex I Parties to submit national communications and reports on demonstrable progress in preparing for the implementation of their commitments under the Kyoto Protocol. This may evidently hamper the functioning of the Committee as a whole, but it may become a particularly serious problem for the functioning of the Enforcement Branch. The voting rule of this branch does not only require a qualified majority for the adoption of a decision, but also a simple majority of members from Annex I Parties and of those from non-Annex I Parties (double majority rule). ${ }^{50}$ In addition to this complicating factor, the Enforcement Branch may be confronted with cases where there is not a decision by default. In the case of unresolved disagreements between expert review teams and Annex I Parties on the application of adjustments to inventories or corrections to the compilation and accounting databases for the accounting of assigned amounts, the Enforcement Branch will have to determine a figure: the figure proposed by the expert review team, the figure proposed by the Party concerned, or a figure it has calculated itself. To prevent the deadlock that would arise from a failure to agree to a proposed decision in such a case, the Committee should address this question in abstract terms and consider solutions,

${ }^{49}$ See Report of the Review of the Initial Report of Greece, doc. FCCC/IRR/2007/GRC (28 December 2007)

${ }^{50}$ See Kyoto Protocol NCP, section II.9. 
including the adoption of the figure proposed by the expert review team as a default and a proposal to the CMP to amend the voting rule.

But the Kyoto Protocol is working. The vast majority of initial reports -32 out of $37^{51}$ - were submitted on time; the expert review teams reviewed these reports within twelve months and, hence, on time $;^{52}$ and so far only one question of implementation has been identified, and no unresolved disagreements have arisen between expert review teams and Annex I Parties on the application of adjustments to inventories or corrections to the compilation and accounting databases for the accounting of assigned amounts. The Committee does not have much work and that must mean that the Kyoto Protocol, including the procedures and mechanisms relating to compliance, has made a good start.

51 The initial report of Croatia is due on 28 August 2008 and cannot yet be accounted for.

52 Only the review of the initial report of Belarus has not been completed within twelve months. This is related to the pending entry into force of an amendment of the Kyoto Protocol on the adoption of a quantified emission reduction commitment for Belarus; see Decision 10/CMP.2 on Proposal from Belarus to Amend Annex B to the Kyoto Protocol, doc. FCCC/KP/CMP/2006/10/Add.1 (2 March 2007), at 36. 
1 


\title{
Chapter Eighteen
}

\section{Practice and Relevant Cases that Emerged in the Context of the Espoo Convention Implementation Committee}

\author{
Jerzy Jendrośka*
}

\section{INTRODUCTION}

The Implementation Committee (hereinafter referred to as the Committee) has recently been acquiring a more and more prominent role in monitoring compliance with the Espoo Convention (hereinafter referred to as the Convention). ${ }^{1}$ Bearing in mind that the genesis and legal basis of the Committee as well as its structure and procedures are comprehensively described elsewhere, ${ }^{2}$ the aim of this chapter is much more modest. It is limited to providing some personal observations concerning the status of the Committee and its activities. It describes some particular features related to its legal basis, modus operandi, structure, and public involvement and the practical consequences of these features. Finally, the paper offers a brief account of the recent case in front of it related to the Bystroe Canal project.

\section{LEGAL BASIS}

\section{$2.1 \quad$ Origins}

The original text of the Convention, as adopted in Espoo in 1991, did not envisage any particular compliance mechanism, and in fact did not even mention the word "compliance". At the time when the Convention was entering into force, however, the issue of compliance with international treaties was gaining increasing recognition, and a number of initiatives, both at the global and regional level, were launched to promote and strengthen compliance with multilateral environmental treaties. These

* The views expressed in this article represent personal opinions of the author and should not be seen as an official position related to his official capacities.

${ }^{1}$ A list of treaties with full references is provided supra at XXXVII

2 See E. Fasoli, "Procedures and Mechanisms for Review of Compliance under the 1991 Espoo Convention on Environmental Impact Assessment in a Transboundary Context and its 2003 Protocol on Strategic Environmental Assessment", supra 181-203.

T. Treves et al., eds., Non-Compliance Procedures and Mechanisms and the Effectiveness of International Environmental Agreements

C 2009, T.M.C. Asser PRESS, The Hague, The Netherlands, and the Authors 
initiatives, pushed by a couple of particularly active countries, ${ }^{3}$ resulted eventually in adopting some global ${ }^{4}$ and regional guidelines, ${ }^{5}$ as well as in developing compliance mechanisms under a number of particular conventions that originally had not envisaged such mechanisms. This was also the case of the Espoo Convention, whereby already at the first Meeting of the Parties (MOP) held in Oslo in 1998 a decision was taken to:

"collect and analyse relevant experience with existing non-compliance procedures under international agreements with a view to considering the advisability of establishing noncompliance guidelines and to preparing relevant recommendations."

This decision was taken within the framework of the work-plan for the Convention (Decision I/6). ${ }^{6}$ Furthermore Decision I/6 envisaged the method of work, ${ }^{7}$ organizational aspects, ${ }^{8}$ and the time schedule of activities which eventually were supposed to be leading to adoption of the guidelines at the second MOP. ${ }^{9}$

The legal basis for Decision $\mathrm{I} / 6$, as it is indicated in the preamble, were

"Articles 9 and 11, paragraph (f), of the Convention stipulating that further research as well as additional action that may be required shall be undertaken to achieve the purposes of the Convention."

In fact, there is no paragraph $\mathrm{f}$ ) in Article 11 but, as the context indicates, there is a subparagraph f) under paragraph 2 in Article 11. Thus, the proper reference should indicate Article 11 paragraph 2 subparagraph $\mathrm{f}$ ), which would make it clear that the entire Work-plan, and in particular the above-mentioned activities concerning "noncompliance guidelines" form part of the activities aiming to "keep under continuous review the implementation of this Convention" as required by paragraph 2 in Article 11 , and within this context to "consider and undertake any additional action that may be required for the achievement of the purposes of this Convention." 10

Worth noting is that the first MOP in its Decision I/6 formally was envisaging adoption of only "non-compliance guidelines" and not the entire non-compliance

\footnotetext{
3 Worth mentioning in this context is the role of some European Countries, in particular the Netherlands and the United Kingdom, which at that time actively supported all such initiatives.

${ }^{4}$ See UNEP Governing Council, Guidelines on Compliance with and Enforcement of Multilateral Environmental Agreements, 2002.

5 UNECE Guidelines for Strengthening Compliance with and Implementation of Multilateral Environmental Agreements in the UNECE, adopted by the Kiev Ministerial Conference Environment for Europe in 2003.

${ }^{6}$ Decision I/6 of the First Meeting of the Parties, doc. ECE/MP.EIA/2 (10 November 1998), Annex VI, at 46.

7 Ibid., at 48: "On the basis of a discussion paper [...] two meetings will be convened to develop a report containing possible approaches for non-compliance guidelines."

8 Ibid., at 49: "The United Kingdom will act as lead country. The report containing approaches for noncompliance guidelines will be submitted to the Working Group for discussion and thereafter to the Meeting of the Parties for possible adoption."

${ }^{9}$ Ibid.: "The report [...] will be presented at the second meeting of the Working Group for discussion and finalization and thereafter to the Meeting of the Parties for possible adoption."

${ }_{10}$ As required by subpara. f).
} 
mechanism. However, in a somewhat hidden way, Decision $\mathrm{I} / 6$ addressed also the broader issue of non-compliance, since it required that the report would be

"outlining the possible framework and options for a non-compliance system under the Convention, based on relevant experience under other international agreements."

This sentence indeed opened the door for recommending development of such a noncompliance system. Moreover, the above activities resulted not so much in preparing any "non-compliance guidelines", ${ }^{11}$ but in a draft decision proposing establishment of a non-compliance system concentrated around a special body called the Implementation Committee.

\subsection{Towards a Proper Legal Basis}

The second MOP held in Sofia in 2001 adopted Decision II/4 on the review of compliance and established the Implementation Committee. The Decision, introduced by the delegation of the United Kingdom, was meant to "allow the review of Parties' compliance with their obligations under the Convention in an effort to assist them to meet these obligations fully." 12 It provided also some details concerning the structure and functions of this system, which was to be "reviewed at the next meeting of the Parties". ${ }^{13}$ The decision clearly mentioned the issue of compliance, ${ }^{14}$ but the legal basis for Decision II/4 was again Article 11 para. 2 requiring Parties to "keep under continuous review the implementation of this Convention" although this time without a reference to subpara. $\mathrm{f}$ ). The same legal basis was quoted in the Preamble to Decision III/2, taken by the third MOP which was held in 2004 in Cavtat, which revised and replaced Decision II/4 as a legal basis for the compliance system of the Espoo Convention. ${ }^{15}$

At the same time, within the wider ambit of reviewing the Convention through the second amendment, the third MOP decided to introduce to the Convention a special legal basis for the review of compliance. The new article $14 \mathrm{bis},{ }^{16}$ entitled "Review of compliance", reads:

"1. The Parties shall review compliance with the provisions of this Convention on the basis of the compliance procedure, as a non-adversarial and assistance-oriented procedure adopted by the Meeting of the Parties. The review shall be based on, but not limited to, regular reporting by the Parties. The Meeting of Parties shall decide on the frequency of regular reporting required by the Parties and the information to be included in those regu-

${ }^{11}$ In fact, in the Report of the Second Meeting of the Parties, doc. ECE/MP.EIA/4 (7 August 2001) there is not even a mention about such guidelines.

${ }_{12}$ Ibid., para. 18.

${ }^{13}$ Ibid.

${ }^{14}$ Ibid., at 72: "Determined to promote and improve compliance with the Convention and recalling Article 11, para. 2, of the Convention and Decision I/6."

${ }^{15}$ Decision III/2 on Review of Compliance, doc. ECE/MP.EIA/6 (13 September 2004), Annex II, at 49.

${ }^{16}$ Not yet in force. 
lar reports 2 . The compliance procedure shall be available for application to any protocol adopted under this Convention."

The above provisions, when they enter into force, shall constitute a separate and proper legal basis for the non-compliance system. This system consists of three basic elements commonly associated with such a system: a compliance procedure making it possible to deal with specific compliance cases, a reporting system based on regular reporting by Parties and a special body to deal with reviewing compliance. Worth special mention in this context is the fact that the new Article 14 bis provides a solid legal basis in the Convention itself for regular reporting and a clear link between such reporting and a compliance body.

\section{$2.3 \quad$ "Implementation" or "Compliance" Committee}

Hitherto, arrangements - whereby a compliance mechanism is based on the general provisions related to "implementation" - have been a bit misleading. The scope of "implementation" under Article 11 para. 2 of the Convention covers a broad range of activities, with an emphasis on methodological issues, and only subpara. f) may be considered as covering compliance since it is a "catch-all" general provision authorising Parties to do nearly anything they consider useful "for the achievement of the purposes of this Convention".

The very name of the special body established specifically to deal with reviewing compliance ("Implementation Committee") reflects the above described current situation with the legal basis for the entire compliance system and in particular for this special body. Interestingly, despite providing a separate specific legal basis for the compliance system, the name of this body, being the central element of the compliance system, remained the same. One could argue that in the light of the new legal basis in Article 14 bis renaming this body from "Implementation Committee" into "Compliance Committee" would better reflect its role and functions under the Convention.

\section{MOdus Operandi}

\section{1 "Structure and Functions ..."}

As already mentioned above, the second MOP, when deciding to establish the Implementation Committee, provided also some details as to the structure and functions of the Implementation Committee and the procedures for review of compliance. ${ }^{17}$ Moreover, it requested these to be "reviewed at the next meeting of the Parties" ${ }^{18}$ Indeed, the already mentioned Decision III/2, taken by the third MOP, included also "Structure and functions of the Implementation Committee and the procedures for review

\footnotetext{
17 Report of the Second Meeting of the Parties, supra n. 11
}

18 Ibid., para. 18. 
of compliance", ${ }^{19}$ which is a slightly revised version of the document "Structure and functions ..." that was appended to Decision II/4.

The new "Structure and functions ..." does not differ much from the previous one. It has the same structure and level of detail, and in fact most of the provisions remained exactly the same. The biggest difference between the old and the new version is that the latter has some new provisions making the Committee more transparent and open to the public. However, despite long discussions preceding adoption of the new "Structure and functions ...", the Parties have not decided in favour of introducing a public trigger, i.e., allowing the public to formally initiate the compliance procedure under the Committee.

Procedural rules provided in both versions of "Structure and functions ..." are rather vague and do not address all the details important for organizing the activities of the Committee. Therefore the Committee, both in its first term and in the second term, was spending much of its time trying to interpret its mandate envisaged in the vague provisions of "Structure and functions ..." and to find appropriate ways of performing its functions. As an attempt to clarify any ambiguities and to provide practical arrangements for the conduct of the Committee's meetings, the Committee started to discuss the issue of preparing its own operating rules.

\subsection{Operating Rules}

At its sixth meeting the Committee reviewed its mandate (as set out in its structure and functions, appended to Decision III/2) and considered that para. 5 of Decision III/2 provided the mandate for the development of the operating rules for the conduct of its meetings. The Committee discussed issues to be included in its operating rules, inter alia, general principles of operation, procedures for handling submissions and self-referrals, procedures for discussing submissions and self-referrals, information gathering, preparing recommendations, reporting to the Meeting of the Parties, initiatives, and technical issues such as the representation of its members by substitutes at its meetings. ${ }^{20}$

The Committee, at its seventh meeting, decided that the above list of issues, developed at its last meeting, was a starting point for its work on the proposed operating rules and designed a procedure for such work. ${ }^{21}$ At its ninth meeting the Committee reviewed the work done and decided that before asking the MOP to approve the draft operating rules as a separate legal document it should seek the advice of the Working Group on environmental impact assessment (EIA) on the mandate for developing

\footnotetext{
19 Decision III/2, supra n. 15, Appendix.

${ }^{20}$ Report of the Sixth Meeting of the Implementation Committee, doc. MP.EIA/WG.1/2005/3 (1 February 2005), para. 6

${ }^{21}$ Report of the Seventh Meeting of the Implementation Committee, doc. MP.EIA/WG.1/2005/4 (20 July 2005), para. 13.
} 
such rules and whether and how they required adoption. ${ }^{22}$ The Working Group on EIA advised that a legally-sound and evidence-based justification was required for proposing operating rules. ${ }^{23}$

The Committee therefore drafted such rules and provided such a justification in a preambular paragraph to the proposed operating rules stating that the operating rules would guide the Implementation Committee in the execution of its functions and would provide more detail on how the Committee should operate within its structure and functions. The Committee added also that it had considered that the rules were needed to facilitate its work.

The rules incorporate decisions made by the Committee in its meetings and reflected in their reports. The rules are intended by the Committee to promote consistency, predictability, credibility, transparency, accountability and efficiency in the work of the Committee, particularly with regard to procedures for the review of compliance. It is also intended that the rules will provide a flexible means of adapting the Committee's mode of operation in the light of its experience. ${ }^{24}$

The Working Group subsequently welcomed the draft operating rules, while providing a period for detailed comments by delegations. ${ }^{25}$ Since no such comments were received, the Committee considered it could reasonably expect the Parties to share its views about the need for and content of the operating rules. As a result the proposed operating rules were appended to draft Decision IV/2 submitted to the fourth MOP. ${ }^{26}$

The draft operating rules include a number of interesting features and merit an indepth analysis. Providing such an analysis would be much beyond the scope of this paper. However, one of the issues has to be at least mentioned here, because of its consequences for the way the Committee operates. This is the issue of working language.

\subsection{Working Language}

The document "Structure and functions ..." (both the one that was appended to Decision II/4 and the one that was appended to Decision III/2), is silent on the issue of working language. Since the official languages of the Convention are the same as the official languages of the UNECE (English, French and Russian) and with no clear decision to the contrary, the same languages were deemed to serve as the working languages of the Implementation Committee. Thus the issue of language abilities was not considered when electing members of the Committee.

In practice, since most of the members of the Committee spoke English, the working language of the Committee appeared to be English. Some of the members also

${ }^{22}$ Report of the Ninth Meeting of the Implementation Committee, doc. ECE/MP.EIA/WG.1/2006/4 (28 April 2006), para. 28.

${ }^{23}$ Report of the Working Group on Environmental Impact Assessment, doc. ECE/MP.EIA/WG.1/2007/3 (6 February 2007), para. 23.

${ }^{24}$ Draft Decision IV/2 on the Review of Compliance, doc. ECE/MP.EIA/2008/4 (21 February 2008), Annex, at 1 .

${ }^{25}$ Report of the Working Group on Environmental Impact Assessment, doc. ECE/MP.EIA/WG.1/2007/2 (2 August 2007), para. 15.

${ }^{26}$ See supra n. 24. 
knew a second official language but no one knew all three languages. The issue of a working language become acute with the election as a member of the Committee of a country that was not in a position to provide as its representative a person speaking English but only people who spoke Russian. This has caused some difficulties in assuring the smooth conduct of the Committee's activities. First of all, the Secretariat has not been in a position to provide on a regular basis UN interpretation in the case of all the meetings. When UN interpretation was not provided, a question arose as to whether a member of the Committee was entitled to be accompanied with his "own" interpreter. The Committee agreed, on a provisional basis, that it would be allowed. The Committee decided also that, while its meetings would continue to be interpreted into English and Russian, only English would be used for communications by e-mail between its members and for informal papers. ${ }^{27}$ The above practical arrangements have been somehow "legalised" by the respective stipulations in the draft operating rules.

According to Rule 20 para. 1, the working language of the Committee should be English. However the Secretariat, for meetings of the Committee held at the United Nations Office at Geneva, might arrange interpretation in one of the other official languages, if needed and agreed by the Committee. The same would apply for the host country in the case of meetings held elsewhere.

The draft operating rules envisage also in Rule 20 para. 2 that the Committee might allow members to be accompanied by their own interpreters at their own cost. In such case members of the Committee are responsible for ensuring that their own interpreters ensure the confidentiality of information in accordance with these rules.

According to Rule 20 para. 3, the communication by electronic means and informal Committee papers should be in English. Official documents of the meetings should be drawn up in English and translated into the other official languages.

The above provisions indicate clearly that it is expected that the persons nominated to work in the Committee are supposed to be able to communicate in English and that there is no "subjective right" to have interpretation provided by the Secretariat. In fact even if interpretation is provided, having some members of the Committee unable to communicate in the working language makes the work very difficult, in particular when the Committee needs to continue deliberations outside the working hours of the interpreters.

The draft operating rules address also another important issue: language requirements for the documents. According to Rule 21 a submission from a Party, the reply and further documents and information should be in English. This is a very important requirement, which puts the burden of translation on the Parties involved in the submission procedures. Bearing in mind the fact that, as has already been indicated, usually members of the Committee speak mostly only English, such a provision will no doubt contribute to much faster and easier deliberations by the Committee.

Unfortunately, unlike in other cases (for example Rule 17), there is no clear provision that this rule should be applied mutatis mutandis in the case of a Committee

${ }^{27}$ See Report of the Sixth Meeting of the Implementation Committee, doc. MP.EIA/WG.1/2005/3 (1 February 2005), para. 19. 
initiative. This may indeed have a detrimental effect and result in unnecessary differences in the way of handling the two procedures by the Committee.

\section{Structure}

\subsection{Membership}

The document "Structure and functions ..." provides in para. 1 the framework for the structure of the Committee. According to it the Committee shall consist of eight Parties to the Convention. Each of the eight Parties shall appoint a member of the Committee. Four Parties shall be elected to the Committee for two terms and four Parties for one term. At each session thereafter, the MOP shall elect four new Parties for two terms. ${ }^{28}$ Outgoing Parties may be re-elected once, unless in a given case the MOP decides otherwise.

Following the above arrangements, at the second MOP in Sofia in 2001 the Meeting elected Canada, the Netherlands, the Republic of Moldova and the United Kingdom to serve in the Committee for one term and Armenia, Finland, Slovakia and the former Yugoslav Republic of Macedonia to serve for two terms. At the third MOP in Cavtat in 2004 the Meeting elected four new members to the Implementation Committee: Croatia, Germany, Kyrgyzstan and Poland to replace Canada, the Netherlands, the Republic of Moldova and the United Kingdom.

The MOP of the Espoo Convention chose one of the possible options concerning composition of the compliance body: one in which these are the countries elected to serve in the Implementation Committee and not individual persons serving in their individual capacity. This choice has certain advantages but also disadvantages. It has also clear consequences for the work of the Committee.

The biggest advantage is that each country has a choice whom to nominate to participate in the work of the Committee and other Parties have no say in this respect. This could be the way for certain Parties to promote their views concerning the profile of the Committee. As the Committee itself noted: "paragraph 1 of the appendix to decision II/4 allowed a Party to nominate whomever it wished: nothing prevented it from nominating an individual from an NGO or from the private sector." ${ }^{29}$ Thus certain Parties may promote participation of representatives of NGOs in the works of the Committee without having the agreement of Parties to do so.

There are disadvantages too. Theoretically it is the risk of making the Committee too politically driven and therefore not objective in its views. This, however, does not seem to be the case in relation to the Espoo Implementation Committee.

The most visible disadvantage of the chosen option in the case of the Espoo Implementation Committee is the fluctuation of the persons participating in meetings of the Committee. It was already the second meeting of the Committee which "recognized

${ }_{28}$ According to para. 1(b), for the purposes of this paragraph "term(s)" means the period that begins at the end of one meeting of the Parties and ends at the end of the next meeting of the Parties.

${ }^{29}$ See Report of the Third Meeting of the Implementation Committee, doc. MP.EIA/WG.1/2003/8 (10 July 2003), para. 14. 
that since its first meeting a number of representatives had been replaced by others, because of a reorganization of government institutions. ${ }^{.30}$ Despite the fact that the Committee assessed this fact rather negatively by indicating that it "was felt that continuation of membership is an important element for the work of the Committee", ${ }^{31}$ the same phenomenon has troubled the work of the Committee constantly ever since. One of the countries changed its representatives in the Committee three times during one term, most of the other countries often provided ad hoc replacements. This practice does not seem to contribute well to the effectiveness of the work of the Committee and sometimes even hinders its activities.

The draft operating rules attempt to address the issue without, however, changing the basic principle. According to Rule 4, para. 1:

"Each Party elected by the Meeting of the Parties should appoint a member of the Committee for two terms. The term of office of a member shall commence with the appointment by a Party. This paragraph should apply without prejudice to the right of a Party elected by the Meeting of the Parties to appoint in exceptional cases a permanent re-placement for that member."

This follows with an obligation in para. 2 that

"members are expected to participate in every meeting of the Committee. If in exceptional cases a member is unable to participate in a meeting of the Committee, the respective Party should make all efforts to provide a suitable replacement of that member for the meeting of the Committee."

The above provisions do not seem to limit much the discretion of Parties in nominating their representatives and to help in preventing fluctuation of persons working in the Committee. Such fluctuation and resulting consequences seem to be inevitable elements of the chosen option concerning composition of the Committee. This is reinforced by the lack of any requirements concerning the education or expertise of the persons appointed by Parties to serve in the Committee.

\subsection{Requirements}

Neither the document "Structure and functions ..." nor the draft operating rules provide for any requirements concerning geographical balance in electing Parties to serve in the Committee nor requirements to be met by the persons appointed by Parties to represent them in the Committee.

Despite formal requirements, hitherto the elections have shown that the MOP strives to provide in practice some geographical balance and makes efforts that all sub-regions are being represented in the Committee. One can consider the abovementioned rules concerning provision of interpretation as serving in practice the

${ }^{30}$ See Report of the Second Meeting of the Implementation Committee, doc. MP.EIA/WG.1/2003/3 (13 December 2002), para. 3.

31 Ibid. 
purpose of assuring that also Parties from sub-regions where English is not well known can be elected.

Much more visible is the lack of any requirements to be met by the persons appointed by Parties to represent them in the Committee. Despite the already mentioned almost unlimited freedom of Parties in this respect, they usually choose to be represented by the relevant officials dealing with EIA in their respective central governments. Such officials generally have either a technical or a scientific background and rarely any experience in handling legal issues. Indeed, in compositions of the Committee hitherto, lawyers have always been rather sparsely represented (no more than $25 \%$ ) which makes the work of the Committee rather difficult.

The tasks of the Committee relate mostly to legal issues and require some legal expertise. Without a legal background and without experience in handling legal issues it is extremely difficult to investigate and address the issues of non-compliance.

\section{$4.3 \quad$ Officers}

The document "Structure and functions ..." envisages that the Implementation Committee has its own officers. Originally they were called "President" and "Vice-President" but the document "Structure and functions ..." that was appended to Decision III/2 renamed them "Chair" and "Vice-Chair" respectively.

Whatever their names they were meant to be elected by the Committee itself. Interestingly enough the reports of both the second and the third MOP seem to be suggesting that the Meeting of the Parties itself decided to nominate the persons in charge of the work of the Implementation Committee.

The report of the second MOP makes it clear that "As the United Kingdom was lead country for this activity, Mr. Alistair McGlone was elected as president." ${ }^{\prime 32}$

The report of the third MOP is less direct in this respect. In para. 12 it indicates that "Mr. Terje Lind (Norway) proposed officers for the period up to the fourth meeting of the Parties" while in para. 49 it indicates that "The nominations by Mr. Lind (para. 12) were endorsed by the Meeting, including [...] Chair of the Implementation Committee: Ms. Seija Rantakallio (Finland). ${ }^{{ }^{33}}$

\section{Public Involvement and Transparency}

\subsection{Legal Basis and Approach}

The issue of the involvement of the public in the work of the Implementation Committee was in practice not addressed in the original "Structure and functions ..." that was appended to Decision II/4. The MOP was, however, aware of the importance of the issue and in the decision itself requested the Committee to consider the issue and to come up with some proposals in this respect.

\footnotetext{
${ }^{32}$ Report of the Second Meeting of the Parties, doc. ECE/MP.EIA/4 (7 August 2001), at 7.
}

${ }^{33}$ Report of the Third Meeting of the Parties, doc. ECE/MP.EIA/6 (13 September 2004). 
The issue has been discussed by the Committee, starting already from its second meeting where, in order to fulfil the request by the MOP to prepare the necessary proposals for review of the structure and functions of the Committee at the third MOP, the Committee identified as many as five possible ways for public involvement. ${ }^{34}$ The issue was further discussed in subsequent meetings and indeed, as already mentioned above, the Committee eventually proposed to the third MOP some new provisions making the Committee more transparent and open to the public. As far as the issue of public trigger is concerned (i.e., allowing the public to formally initiate the compliance procedure under the Committee) the Committee decided at its third meeting to propose that this matter should not be addressed at this stage. It was recommended, however, that the matter would be reviewed in the light of experience and a recommendation might be made to the Parties at their fourth meeting. ${ }^{35}$

Meanwhile, however, the issue has come up on several occasions, including a case whereby the Committee had not only to debate it in abstracto but having a concrete communication from the public had to address the issue in concreto and to decide whether a letter from an NGO alleging non-compliance by a Party should formally initiate the procedure under the Committee. ${ }^{36}$ The approach of the Committee towards the issue of public trigger has somewhat fluctuated, with the Committee in its composition before Cavtat being rather sceptical and after Cavtat rather sympathetic to the possibility of accepting the possibility of NGOs and the public at large to initiate the procedure.

Following changes in the approach and a clear practical need to develop some more precise legal basis for public involvement, the Committee has decided to address the issue in the draft operating rules and to elaborate some rules concerning openness and access to the Committee's documents and some rules concerning the role of the public in initiating the compliance procedure under the Committee.

\subsection{Openness and Public Access to Documents}

The issue of the openness of the Committee's meetings and public access to the relevant documents was addressed in the revised "Structure and functions ...", but not in a comprehensive and sufficient way. Therefore it is further elaborated in the draft operating rules. The draft operating rules provide much more clarity here and they seek to achieve a proper balance between the hitherto existing tradition of confidentiality and total openness. While the approach taken in Rule 17 towards the participation of the public in its meetings generally follows the approach taken in the "Structure and functions ..." appended to Decision III/2, ${ }^{37}$ much more elaborated is the issue of public accessibility to the documents. Rule 16 provides, albeit in rather

\footnotetext{
${ }^{34}$ See Report of the Second Meeting of the Implementation Committee, doc. MP.EIA/WG.1/2003/3 (13 December 2002).

${ }^{35}$ See Report of the Third Meeting of the Implementation Committee, doc. MP.EIA/WG.1/2003/8 (10 July 2003).

${ }^{36}$ See, for example, Reports of the Fourth and Fifth Meeting of the Implementation Committee, respectively docs MP.EIA/WG.1/2004/3 (17 December 2003) and MP.EIA/WG.1/2004/4 (8 April 2004).

37 Worth mentioning here is that the draft rules make it clear in Rule 17 that while the meetings are generally open, the parts related to specific compliance cases are not open unless decided otherwise, and
} 
a convoluted way, a detailed instruction on how to treat various categories of documents. In principle it divides the documents into three categories: 1) those that have to be made available on the Convention website (such as short summaries of each submission as well as meeting reports and other official documents adopted by the Committee); 2) those that are confidential (for example working documents and any corroborating information related to a specific submission if it is requested to be treated as confidential); and finally 3 ) all other documents and information that do not require to be posted on the Convention website and were not required as confidential but nevertheless are accessible upon request. Worth noting is the fact that the draft operating rules not only follow the recent worldwide trend whereby openness is considered as a rule while confidentiality is only an exception, but they also limit the scope of confidentiality by requiring in most cases an active approach, i.e., submitting a request for a specific document to be considered confidential.

\subsection{Public Trigger}

The issue of public trigger, as already mentioned above, has always been quite controversial but the Committee was obliged to consider it while preparing the draft operating rules and elaborating the sources of information by which the procedure could be initiated. This obviously could not neglect the possibilities of the NGOs or the public at large to initiate the procedure. The Committee originally formulated certain proposals formally acknowledging such possibilities, ${ }^{38}$ but after seeking advice from the Working Group, it decided to not specify the sources of information by which the procedure could be initiated but rather to focus on the criteria that must be met for the procedure to be initiated.

Following the advice from the Working Group, the draft operating rules do not specify the sources of information by which the procedure could be initiated. Therefore, formally speaking, there is no specific mention of the possibility of the NGOs or the public at large to initiate the procedure. However, such possibilities are implicitly envisaged in Rule 15 related to the so called "Committee Initiative" under para. 6 of the Appendix to Decision III/2. Rule 15 para. 1 provides for that "sources of information by which the Committee might become aware of a possible non-compliance could be: (a) Parties' work under the Convention; and (b) Any other source."

The term "any other source" is an open-ended formulation which is further specified in para. 2 by formulating some criteria that must be met for the procedure to be initiated. Thus, in determining whether to begin a Committee initiative,

"the Committee should take into account, inter alia, the following: (a) The source of the information is known and not anonymous; (b) The information relates to an activity listed in Appendix I to the Convention likely to have a significant adverse transboundary impact;

(c) The information is the basis for a profound suspicion of non-compliance; (d) The

that this rule applies not only to cases under procedure for submissions but also to cases under procedure for Committee initiative.

38 See Report of the Ninth Meeting of the Implementation Committee, doc. ECE/MP.EIA/WG.1/2006/4 (28 April 2006). 
information relates to the implementation of Convention provisions; and (e) Committee time and resources are available."

Moreover, according to para. 3: "The Committee should consider the information on a non-discriminatory, non-arbitrary and unbiased basis".

In the light of the above stipulations it is obvious that both NGOs and the public at large may, albeit somewhat indirectly, initiate the procedure. Moreover, one can speculate that in practice they can constitute a significant source of information for the Committee initiative. In this respect worth noting is that the draft operating rules do not specify further what the role of the "sources of information" could be in the procedure, and in particular they do not grant such "sources" any procedural rights within the procedures initiated by them.

\section{Bystroe Canal Case - Romania v. Ukraine}

\subsection{The Case and Its Procedural History}

On 26 May 2004 the Government of Romania made a submission to the Implementation Committee expressing concerns about Ukraine's compliance with its obligations under the Convention with respect to the Bystroe Canal Project. ${ }^{39}$

Since Ukraine denied that the project was likely to have a significant adverse transboundary impact on the environment, Romania requested the establishment of an inquiry commission under Article 3 para. 7 of the Convention, with respect to the same project. ${ }^{40}$ At its sixth meeting (3-5 November 2004), the Implementation Committee noted paragraph 15 of its structure and functions ${ }^{41}$ which stipulates that where a matter is being considered under an inquiry procedure it may not be the subject of a submission. Thus, the Implementation Committee decided that it was not in a position to consider the submission of Romania. ${ }^{42}$

The Inquiry Commission completed its work on 10 July 2006 with the unanimous opinion that the project was likely to have a significant adverse transboundary impact on the environment. Following this, the Government of Romania made a second submission expressing concerns about Ukraine's compliance with its obligations under the Convention with respect to the Bystroe Canal Project and in the light of the opinion of the Inquiry Commission on the environmental impact of the project. ${ }^{43}$ The submission alleged that, in spite of repeated demarches, Ukraine did not indicate that it

\footnotetext{
39 A summary of the submission is available on the Convention's website at $<\mathrm{http}$ //www.unece.org/env/ eia/implementation_committee_matters.htm>.

${ }^{40}$ A description of the inquiry procedure and of the work of the Inquiry Commission is available at $<\mathrm{http}: / /$ www.unece.org/env/eia/inquiry.htm>

${ }^{41}$ See Appendix to Decision III/2, supra n. 15.

${ }^{42}$ Report of the Sixth Meeting of the Implementation Committee, doc. MP.EIA/WG.1/2005/3 (1 February 2005), para. 14.

43 A summary of the submission is available on the Convention's website at $<\mathrm{http}$ ://www.unece.org/env/ eia/implementation_committee_matters.htm>.
} 
was considering applying the relevant provisions of the Convention and in particular that no EIA documentation had been made available to Romania.

At its twelfth meeting on 26-28 June 2007, the Committee considered the matter of the submission, first inviting the Romanian delegation and thereafter the Ukrainian delegation to present the submission and the reply, respectively, and then to respond to the other Party's presentation. The two delegations also replied to questions posed by members of the Implementation Committee.

For the preparation of its draft findings and recommendations at its thirteenth meeting (30 October-1 November 2007), the Committee considered the information brought to its attention prior to and during its twelfth meeting. It took note also that the Bystroe Canal project has been subject to investigations under various international agreements. In particular, the Aarhus Convention compliance committee noted an insufficiently clear regulatory framework for public participation in relation to the Bystroe Canal project. ${ }^{44}$

The Committee sent its draft findings and recommendations to the two parties concerned further to paragraph 9 of the appendix to Decision III/2. At its fourteenth meeting (15-17 January 2007) the Committee finalized its findings and recommendations, taking into account representations received from the two parties. The Committee decided to provide the Committee's findings in a separate document to be submitted while its recommendations are included in the draft decision on the review of compliance submitted to the fourth MOP for its consideration.

After having finalized its findings and recommendations, the Committee was informed by Romania that it had been informed by Ukraine about the final decision being taken concerning Phase II.

\subsection{Facts and Legal Basis}

The submission concerns the project "The Danube-Black Sea Deep-Water Navigation Canal in the Ukrainian Sector of the Danube Delta". The project is covered by item 9 in Appendix I to the Convention. Although the canal already existed and therefore it could not be considered as a new activity, the Implementation Committee is of the opinion that according to the definition of "Proposed activity" of Article 1(V) of the Espoo Convention, the works on the Bystroe Canal fall under the scope of "major change".

The project is divided into Phase I and Phase II, each being subject to a separate national environmental authorization procedure (or "state ecological examination").

In 2002 the procedure for authorizing Phase I was initiated with the revised Feasibility Study together with the EIA Report being submitted to competent Ukrainian authorities. The final decision was taken in April 2004 and the works began shortly thereafter (in May 2004).

Ukraine maintained that it had notified Romania about the project with a number of notes starting with a note of 18 December 2002 as well as providing it with the EIA report concerning Phase I on 5 August 2004. Romania acknowledged receiving

${ }_{44}$ Decision II/5b on Compliance by Ukraine with its obligation under the Aarhus Convention, doc. ECE/ MP.PP/2005/2/Add.8 (13 June 2005). Further information is available at $<\mathrm{http}: / /$ www.unece.org/env/pp $>$. 
the above documents but maintained, however, that neither of them met the requirements as stipulated by the respective provisions of the Convention. Moreover, Romania maintained that despite its demarches Ukraine failed to undertake all the steps envisaged in the Convention to allow Romanian authorities and the public to participate in the EIA procedure before the decision on Phase I was taken. Ukraine maintained that, while they informed Romania about the project, they did not consider it likely to have any significant adverse transboundary environmental impact and therefore did not consider it necessary to follow in detail the requirements of the Convention. Any further works concerning the channel were suspended in June 2005 but resumed in November 2006. ${ }^{45}$

Work on the design of Phase II commenced in 2004 and on the basis of the EIA report an environmental authorization (state ecological examination) was given in 2006. The precise date and details of the authorization vary in the communications from Ukraine. Romania alleges that the final decision on Phase II was taken when the Cabinet of Ministers of Ukraine approved Phase II on 30 May 2007, whereas the Ukrainian delegation in the twelfth meeting of the Committee maintained that the final decision was not the approval by the Cabinet but a construction permit to be granted by local authorities, which had not - however - yet been granted.

A notification dated 18 April 2007 was submitted to Romania on 24 April 2007. An EIA report was submitted later. According to a press release by the Ministry of Transport of Ukraine, the official opening of the canal was celebrated on 2 May 2007. According to the official note received by the Secretariat from Ukraine in February 2008, the final decision was taken at the end of December 2007.

\subsection{Main Legal Issues}

The Bystroe Canal case was precedential not only because it was subject to the first submission under the Committee alleging breach of the Espoo Convention but also because it brought to light a number of important legal issues. At least some of them should be mentioned here.

The first important question is whether the Committee should accept submissions concerning pending projects or should rather wait with its findings until the project in question has been finalized. Bearing in mind the preventive function of the mechanism envisaged in the Convention it seems appropriate that the Committee should accept involvement in the projects pending. That was the case with the Bystroe Canal project. It was easier in this respect because it was divided into two phases, with Phase I being completed at the time of submission. Therefore the findings of the Committee concerning Phase I related to a fait accompli, while in relation to the pending procedure concerning Phase II the findings were conditional. In this respect the Committee stated that Ukraine cannot be considered as being in non-compliance with the Convention as long as the final decision regarding Phase II has not been

${ }^{45}$ See Findings and Recommendations further to a Submission by Romania Regarding Ukraine (EIA/ IC/S/1), doc. ECE/MP.EIA/2008/6 (27 February 2008) and Addendum to Findings and Recommendations further to a submission by Romania regarding Ukraine (EIA/IC/S/1), doc. EIA/IC/S/1/Rev.1 (7 May 2008), at $11-12$. 
made and as long as before it is made all the necessary steps envisaged by the Convention have been taken.

The risk of accepting submissions concerning pending projects is, however, that the findings and recommendations may no longer be valid as the situation develops. This was the case in relation to Phase II of the Bystroe canal project whereby, after the Committee had finalized its findings and recommendations but before submitting them to the MOP, the final decision was taken allegedly without fulfilling obligations stemming from the Espoo Convention and which had been pointed out in the findings. If the facts are confirmed, the legal effect of the findings seems to be clear - not meeting the conditions means non-compliance! The recommendations, however, would need to be reviewed in the light of a clear and allegedly intentional breach of the Convention.

Another important legal issue (or set of issues) worth mentioning here relate to the legal effect of the opinion of the Inquiry Commission. Of particular importance for assessing the case was to answer the question whether such an opinion has ex nunc or ex tunc effects and whether there is any suspensive effect.

The Committee expressed the view that while the opinion of the Inquiry Commission is a matter of fact and takes effect immediately, the Convention does not clearly stipulate what are the legal consequences of the findings of the Inquiry Commission, in particular whether it has ex nunc or ex tunc effects and whether there is any suspensive effect. After long deliberations the Committee reached the opinion ${ }^{46}$ that accepting an ex tunc effect would lead to the unnecessary broadening of the scope of the obligations and therefore considered that it has only an ex nunc effect.

As far as the suspensive effect is concerned, the Committee reached the conclusion that, while the Convention did not clearly require the implementation of Phase I to be immediately suspended as a result of the establishment of the Inquiry Commission, the immediate suspension of implementation could however be invoked from international customary law. ${ }^{47}$

The Committee is of the opinion that, while the Convention's primary aim, as stipulated in Article 2 para. 1, is to "prevent, reduce and control significant adverse transboundary environmental impact from proposed activities", even a low likelihood of such an impact should trigger the obligation to notify affected Parties in accordance with Article 3. This would be in accordance with the Guidance on the Practical Application of the Espoo Convention as endorsed by the third MOP. ${ }^{48}$ This means that notification is necessary unless a significant adverse transboundary impact can be excluded with certainty.

Therefore the Committee finds that the fact of authorizing and implementing Phase I cannot be considered as being in clear non-compliance with the Convention at the

46 In particular the Convention does not provide for the Parties to "assess" such an opinion.

47 As the International Court of Justice (ICJ) put it, "existence of the general obligation of States to ensure that activities within their jurisdiction and control respect the environment of other States [...] is now part of the corpus of international law" (Legality of the Threat or Use of Nuclear Weapons, Advisory Opinion of 8 July 1996, ICJ Reports (1996), para. 29) and "vigilance and prevention are required on account of often irreversible character of damage to the environment" (Gabcikovo-Nagymaros Project (Hungary) Slovakia), Judgment of 25 September 1997, ICJ Reports (1997), para. 140).

48 Appendix to Decision III/2, supra n. 15, para. 28. 
time of the decision-making, because Ukraine was of the opinion that the project was not likely to have a significant adverse transboundary impact. However, the Committee is of the opinion that respect for the generally accepted international customary law would have required a suspension of works pending the opinion of the Inquiry Commission and therefore the Committee finds that not notifying Romania immediately after the opinion of the Inquiry Commission should be considered as noncompliance with the Convention, compounded by the later resumption of works.

Yet another legal issue addressed in the case relates to the legal consequences related to entering into transboundary procedure. In this context the Committee noted that acknowledging the likelihood of "significant adverse transboundary environmental impact from proposed activities" for the purpose of triggering the Convention's procedures should be treated as willingness to cooperate with the Parties concerned to "prevent, reduce and control" such impact before the activity is authorized. The Convention does not, however, prevent the Party of origin from undertaking such proposed activities after having carried out the transboundary procedure.

\section{Conclusions}

The legal status of the Implementation Committee and its role in monitoring compliance with the obligations under the Espoo Convention have not been clearly defined. Despite a new legal basis provided by the second amendment and certain clarifications in the draft operating rules, the operation of the Committee is seriously hindered by some of the features related to its composition and modus operandi. The Bystroe Canal case has involved a number of legal issues and no doubt will not only shed some light on the obligations stemming from the Convention but also provide impetus for further development of the compliance system under the Convention. 
1 


\title{
Chapter Nineteen
}

\section{In Search of New Ways to Ensure Effective Compliance with Environmental Procedures and Policies: The Experience of the European Bank for Reconstruction and Development with its Internal Recourse Mechanism}

\author{
Francesco Seatzu
}

\section{INTRODUCTION}

The Independent Recourse Mechanism (hereinafter IRM) was established by the Board of Directors of the European Bank for Reconstruction and Development (hereinafter EBRD) on 29 April $2003^{1}$ in an attempt to increase the Bank's accountability vis-à-vis non-State entities, and to improve compliance with its environmental policies and procedures. ${ }^{2}$ The need to improve compliance with the EBRD's environmental procedures and policies can be easily explained if one considers what commentators have recognized - that is that both the increasingly significant role which

\footnotetext{
${ }^{1}$ See EBRD, Independent Recourse Mechanism Rules of Procedure available at $<\mathrm{http}: / / \mathrm{www}$.ebrd.com/ about/irm/about/procedur.e.pdf $>$ (visited 3 February 2008). See also BIC/CIEL/Central and Eastern European Bank Watch, Joint Comments on the EBRD's Proposed Independent Recourse Mechanism, available at $<$ www.bicusa.org $>$ (visited 3 February 2008).

${ }^{2}$ See the International Law Association (ILA), Report of the International Committee on the Accountability of International Organizations (August 2004), 45, which provides that "[t]he establishment of non-judicial mechanisms is an inherent part of the accountability regime for IOs". Similarly the US State Department of Commerce in the Safe Harbor page of its Export Portal $(<\mathrm{http}: / /$ www.export.gov/safeharbor/ sh overview.html>, visited 15 July 2008) states that: "To ensure compliance with the 'safe harbour' principles, there must be (a) readily available and affordable independent recourse mechanisms so that each individual's complaints can be investigated and resolved and damages awarded where the applicable law or private-sector initiatives so provide; (b) procedures for verifying that the commitments companies make to adhere to the safe harbor principles have been implemented; and (c) obligations to remedy problems arising out of a failure to comply with the principles. Sanctions must be sufficiently rigorous to ensure compliance by the organization. Organizations that fail to provide annual self certification letters will no longer appear in the list of participants and safe harbor benefits will no longer be assured"; S. Levinson, "Multilateral Financing Institutions. What Form of Accountability?", Am. U. J. Int'l L.\& Pol'y, 8 (1992), 47-71; K. Wellens, "The Primary Model Rules of Accountability of International Organizations: The Principles and Rules Governing their Conduction or the Yardsticks for their Accountability", in H.G. Schermers and N. Blokker (eds.), Proliferation of International Organizations: Legal Issues (Leiden: Brill Academic Publishers, 2001), 433.
}

T. Treves et al., eds., Non-Compliance Procedures and Mechanisms and the Effectiveness of International Environmental Agreements

(C) 2009, T.M.C. ASSER PRESS, The Hague, The Netherlands, and the Authors 
multilateral development banks, such as the EBRD and the International Bank for Reconstruction and Development (hereinafter IBRD), can play in implementing sustainable development principles and standards, and the emergence of environmental civil society organizations as global actors, seeking arenas in which to affect policy and decision-making above the level of national governments. ${ }^{3}$ Thus, unsurprisingly, the purpose of this mechanism is to carry out independent administrative reviews, not to conduct judicial proceedings. It should collect information on issues of complaint, provide an independent assessment and make recommendations to the President and the Executive Directors of the Bank. Like other similar accountability mechanisms, such as notably the World Bank Inspection Panel, ${ }^{4}$ it does not have the power to make any remedial recommendations.

The IRM reveals the EBRD's complexity with regard to the institution's structural and legal characteristics, as much as in respect to the nature of its relations with its partners. Indeed, by establishing the IRM, the Board of Directors contributed to what has become recognized as a clear advance in the development of international regional banks. This is mainly because IRM reports can influence the development of the applicable law by providing significant guidelines on the interpretation and implementation of Bank environmental and social safeguard procedures and policies. Indeed the invention of the IRM has strengthened both the application and influence of these policies, since they represent the applicable law in complaints before the IRM. Again, the activity of the IRM enhances transparency in Bank operations. ${ }^{5}$ Moreover, the IRM's findings disclose the environmental and social consequences of project deficiencies arising from the Bank's non-compliance with international standards, and generic problems in the project cycle of financed projects. Furthermore, the IRM's activity gives private individuals, non-governmental entities, representing individuals and local communities the possibility to use not only domestic mechanisms for protection of their rights. Finally, IRM reports can also encourage legal developments in different areas of public international law, such as human rights and environmental law.

Clearly, the creation of the IRM can be regarded as a response to the obstacles of the application of traditional responsibility rules to international financial

${ }^{3}$ See ex multis P. Sands, Principles of International Environmental Law, $1^{\text {st }}$ edn. (Manchester and New York: Manchester University Press, 1995) 357-360. See also M. Bothe, "The Evaluation of Enforcement Mechanisms in International Environmental Law", in R. Wolfrum (ed.), Enforcing Environmental Standards: Economic Mechanisms as a Viable Means? (Berlin, Heidelberg, New York: Springer Verlag, 1996), 13-19; B.J. Richardson, "Environmental Regulation through Financial Organisations: Comparative Perspectives on the Industrialised Nations", Non-State Actors \& Int'l L., 2003, $327 \mathrm{ff}$.

${ }^{4}$ On the World Bank Inspection Panel see, inter alia, F. Seatzu, Il Panel di ispezione della Banca Mondiale: contributo allo studio della funzione di controllo nelle banche internazionali di sviluppo (Torino: Giappichelli, 2008); S. Schlemmer-Schulte, "The World Bank Inspection Panel: A Model for other International Organizations?", in Schermers and Blokker (eds.), supra n. 2, 483-548; I.F.I. Shihata, The World Bank Inspection Panel: In Practice, (Oxford: Oxford University Press, 2000).

5 This is unsurprising if you consider that "transparency is an important means of enhancing the performance and public accountability of international financial institutions". See G-22, Report of the Working Group on Transparency and Accountability, October 1998 (under the heading "Preface"), as quoted by the A. Gowlland Gualtieri, "Environmental Accountability of the World Bank to Non State Actors: Insights from the Inspection Panel”, British YB Int'l L., 72(2002) 213-253, at 222, note 66. 
organizations, particularly when regional development banks are involved. ${ }^{6}$ But the IRM is certainly not a court of law where the responsibility of the European Bank for Reconstruction and Development can be invoked. ${ }^{7}$ The mechanism improved the accountability of the Bank Management and staff for the observance of its procedures and policies to enhance quality control in project design, appraisal and implementation. ${ }^{8}$ The Resolution establishing the IRM addresses the situation when inspection is requested by any group of two or more individuals with a common interest which is, or is likely to be, directly or adversely affected by a Bank financed project, or an appointed agent of such group. In addition, the IRM also includes a problem solving function to be used where complaints can also, or alternatively, benefit from problem solving techniques to assist in trying to resolve the underlying issues. Those techniques encompass independent mediation, fact-finding, conciliation, investigation and reporting. ${ }^{9}$

The purpose of the present article is to explore the question of the environmental accountability of the international financial institutions to third party non-State actors by focusing on the experience of the IRM of the EBRD. The approval by the international community of sustainable development objectives has resulted in broadening the mandate of the Bank, that now includes consideration of environmental factors in its operations. It has also fostered calls for greater legitimisation of international decision-making processes, inclusive of accountability. A relevant trend in the development of the accountability of international development banks has been its extension to third party non-State actors, such as non-governmental organizations, individuals and communities concerned by the acts of or omissions of the Banks, thereby belying the notion that international financial institutions are solely accountable to their Member States. As illustrative of these developments the IRM provides a forum for nonState subjects to hold the EBRD accountable for the way in which it conducts its lending activities with regard to environmental protection.

The first part examines the applicable law governing the lending activities of the EBRD with respect to environmental conservation, that represents the indispensable prerequisite for the mise en oeuvre of accountability by means of the IRM. The second part is devoted to the general functioning of the IRM mechanism, the IRM's mandate, and its advantages and disadvantages. The following part describes the IRM's procedure, and discusses special issues and developments regarding the assessment of the eligibility of a request for inspection. It will also deal with the IRM's legal nature in general. Furthermore, it will address the limits of the IRM's mandate,

${ }^{6}$ On these issues see ex multis J. Fox and L. Brown (eds.), The Struggle for Accountability: The World Bank, NGOs and Grassroots Movements (Cambridge, Massachusetts: MIT Press, 1998); D. Clark, J. Fox and K. Treakle (eds.), Demanding Accountability (Lanham, Boulder, New York, Oxford: Rowman \& Littlefield Publishers, Inc., 2003).

7 See C. Wold and D. Zaelke, "Establishing an Independent Review Board at the European Bank for Reconstruction and Development: A Model for Improving MDB Decision-making”, Duke Envt'l Pol'y \& L. Forum, 2 (1992), 59-78.

${ }^{8}$ See E. Christensen, Green Appeal: A Proposal for an Independent Commission Inquiry at the World Bank, (Washington, DC: Natural Resources Defense Council, 1992).

${ }^{9}$ See EBRD, Independent Recourse Mechanism: The Guide to Making a Complaint about an EBRD Financed Project (2004). 
particularly with regard to the interpretation, application, and enforcement of EBRD procedures and policies. Part IV considers the consequences of IRM's investigations and recommendations. A concluding part assesses the IRM's desirability.

\section{The Environmental Policies and Procedures as the Applicable Law To EBRD LOAN DEvElopment ACTIVITIES}

The EBRD's constitution expressly requires environmental considerations to be taken into account in the institution's operations, unlike the World Bank's Articles of Agreement. The EBRD's constituent instrument stipulates that: "the Bank (...) will promote in the full range of activities environmentally sound and sustainable development." ${ }^{\prime 10}$ The inclusion of this mandate to consider the environmental consequences of loan projects represents recognition of environmental considerations in development project design. ${ }^{11}$ Furthermore, the reference to the "full range" of the EBRD activities clearly suggests that it also represents recognition of environmental considerations in any technical assistance and Special Fund operations. ${ }^{12}$

The Bank's mandate thus has to be considered perfectly in line with the concept of sustainable development, which is commonly understood as "development that meets the need of the present without compromising the ability of future generations to meet their own needs", and is endorsed in several non-binding acts, as well as in major environmental agreements. ${ }^{13}$ Clearly enough the endorsement of an "integrated"

10 ILM, 12 (1990), $1077 \mathrm{ff}$

11 See, e.g., J. Linarelli, "The European Bank for Reconstruction and Development: Legal and Policy Issues”, Boston College Int'l \& Comp. L. Rev., 16 (1995), 361-400; G. Maresca, "La Banca Europea di Ricostruzione e Sviluppo", Com. Int., 45 (1990) 538-548; F. Bestagno, "Banca europea per la ricostruzione e lo sviluppo (BERS)”, Digesto delle Discipline pubblicistiche-Aggiornamento (Torino, UTET, 2000) 74-85; C. Rosano, "La Banca Europea per la Ricostruzione e lo Sviluppo", in A. Giardina and G.L. Tosato, Diritto del commercio internazionale (Milano: Giuffré, 1996), 337; E. Lee Smith, "The European Bank for Reconstruction and Development", Butterworths Journal of International Banking and Financial Law, 6 (1991), 109; I.F.I. Shihata, The European Bank for Reconstruction and Development. A Comparative Analysis of the Constituent Agreement (Amsterdam/Dordrecht/Boston: Graham \& Trotman, 1991); J.R. Strand, "Power Relations in an Embedded Institution: the European Bank for Reconstruction and Development", Journal of European Integration, 25 (2003) 115-129.

12 See S.C. Guyett, "Environment and Lending: Lessons of the World Bank, Hope for the European Bank for Reconstruction and Development", NYU J. Int'l L. \& Pol., 33 (1992), 889-919; M.A. Civic, "Prospects for the Respect and Promotion of Internationally Recognized Sustainable Development Practices: A Case Study of the World Bank Environmental Guidelines and Procedures", Fordham Envt'l L. J., 13 (1998) 231-260

13 See United Nations, Brochure on Johannesburg Summit 2002: World Summit on sustainable development (26 August-2 Sept. 2002), available at <http://www.johannesburgsummit.org/html/brochure/brochure12.pdf $>$ (visited 1 February 2008). See also the Rio Declaration, adopted by the 1992 Conference on Environment and Development which, at its Principle 3, provides that: "The right to development must be fulfilled so as to equitably meet developmental and environmental needs of present and future generations". See generally A. Gillespie, The Illusion of Progress. Sustainable Development in International Law and Policy (London: Earthscan, 2001), at 12; P. Sands, "International Law in the Field of Sustainable Development", British YB Int'l L., 65 (1994), 303-381; V. Lowe, "Sustainable Development and Unsustainable Arguments", in A. Boyle and D. Freestone (eds.), International Law and Sustainable Development (Oxford: Oxford University Press, 1999) 19-37. 
conception of development has led to evolving expectations on the part of the international community of the role of the EBRD. Since its institution the latter has been called upon both to contribute to the funding of sustainable development and environmental conservation, and to integrate related considerations in their operations.

Following mounting concern over the adverse impact of its lending activities on the environmental conditions in borrowing States, the EBRD has explicitly adopted a sustainable mandate. ${ }^{14}$ Hence the EBRD's Articles of Agreement have provided a good framework for the expansion of the Bank's mandate to encompass broad objectives relating, inter alia, to environmental issues. It follows that the contours of this mandate have been shaped in part by the development of the subsequent practice of the institution through the adoption of environmental related operational procedures and policies.

Within the constitutional framework of its charter, the EBRD has undertaken a noteworthy programme of environmental reform. The pursuance of environmental goals by the Bank comprises on the one hand the integration of non-economic considerations in the Bank's overall loan development activities, and on the other the funding of projects which have as their main objective the protection of the environment.

The process of integration of environmental, social and political considerations in the Bank's loan development activities has been realised mainly through the enactment of internal environmental procedures, which have undergone processing in many sectors, but particularly in public consultation. ${ }^{15}$ The format of these acts has varied since their inception. Shortly after the EBRD's constituent instrument was signed, the Board of Directors produced a statement on the natural environment. The purpose of this was to broaden the meaning of Article 2 of the EBRD's Article of Agreements and provide guidance for the creation of loan procedures. Apart from its plan to encourage environmental procedures and provisions, the EBRD also adopted "environmentally sound operational procedures". These procedures, at least in abstract terms, integrated environmental decisions into the fundamental phases of the loan review process. The procedures demand a full environmental assessment for specific types of operations. The borrower should bear responsibility for supplying sufficient information on the environmental impact of its proposed project to the Bank's project leader. Though the information comes from the borrower, the project leader at the Bank should examine it and ascertain the environmental implications. Indeed all the projects undergo a rigorous environmental due diligence process versus the

${ }^{14}$ See, e.g., A. Rigo Sureda, "The Law Applicable to the Activities of International Development Banks", RdC, 308 (2004), 9-251, at 91-92; W. Hurlock, "New Approaches to Economic Development: The World Bank, the EBRD and the Negative Pledge Clause", Harvard Int'l L. J., 35 (1994) 345-386.

15 As is evidenced by the fact that the Bank incorporated public consultation requirements in its first environmental policy approved in 1991 and procedures approved in 1992 which included requirements for disclosure and public consultation on draft environmental impact assessments (EIAs), prior to finalisation. For further references see An evolution of public consultation requirements within the environmental impact assessment process at the European Bank for Reconstruction and Development, available at $<$ siteresources.worldbank.org/INTRANETENVIRONMENT/1705772177181681657/21209013/EBDRpubliconsultation.pdf $>$ (visited 31 January 2007). See also L. Clark, Strategic Guide: Strategic Tips for Filing Complaints with International Financial Institutions (Oxford: Friends of the Earth International and International Accountability Project, 2004) 
applicable national environmental, safety and health regulations, World Bank group guidelines, EU standards, international labour standards, best international environmental, health and safety practices. Environmental Action Plans are developed as a result of the environmental due diligence process in order to bring the clients into compliance with these standards. ${ }^{16}$ The EBRD also pledges to "ensure that project sponsors provide adequate information to local governments and populations", thereby assuring that interested third parties will receive significant information on its loans. Again, the EBRD has enacted an Environmental Policy which aims to ensure, through a detailed environmental appraisal process, that the projects it finances are environmentally sound and are designed to operate in compliance with applicable regulatory requirements. ${ }^{17}$

It is worth mentioning that all these internal documents aim to provide standards for the Bank's staff to deal with environmental issues raised during the project cycle of Bank financed projects. Moreover, all these procedures and policies of the Bank are to be considered in a wider context than the internal legal order of the EBRD. As an institution with international legal personality, the EBRD operates within the frame of the law of the international community. It has consequently entrusted itself to pursue its tasks in compliance with international environmental agreements.

Therefore the EBRD commences its mandate in compliance with any international environmental agreement to which the borrower is a Party, as well as other international environmental rules. While the EBRD, like the other international development banks, is not a Party to multilateral environmental treaties, and is thus not bound by them, international environmental standards constitute essential milestones in the interpretation and application of internal procedures and policies.

\section{The IRM's Mandate AND ITs General Functioning}

\subsection{IRM Independence and Membership}

The accountability of the EBRD for its compliance with the environmental related principles and provisions briefly illustrated in the above part of this chapter can be raised before an internal recourse mechanism. The IRM, a permanent body set up in 2003, is not a novel mechanism in the law of international financial institutions as it has been preceded by the Inspection Panel of the World Bank, as well as the quasi-judicial mechanisms of the Inter American Development Bank and the Asian

${ }^{16}$ For a fuller account of these issues see A. Schin, European Bank for Reconstruction and Development: Corporate Approaches to Sustainability, available at $<$ http://www.spri.cam.ac.uk/events/russianoil/presentations/schin.pdf> (visited 30 January 2007). See also S. Darcy, Collective Responsibility and Accountability under International Law (New York: Transnational, 2007); M. Hirsch, The Responsibility of International Organizations toward Third Parties: Some Basic Principles (Dordrecht: Nijhoff, 1995); P. Klein, La responsabilité des organisations internationales (Paris: Pedone, 1998).

${ }_{17}$ See the European Bank for Reconstruction \& Development, Environmental Policy (2003), available at $<$ http://www.ebrd.com/about/policies/enviro/policy/policy.pdf> (visited 30 January 2007). 
Development Bank. ${ }^{18}$ As already stated above, the IRM allows private entities to hold the Bank directly accountable for its non-compliance with internal procedures and rules. However, it cannot address the issue of the non-compliance of borrowing States with environmental provisions. ${ }^{19}$ The mandate and the IRM's basic operating principles are laid down in the Resolution that founded this mechanism.

As required by the Resolution, the IRM is composed of the following bodies and officers: a) the Board of Directors, which has decision-making power in the case of complaints concerning the projects which have received Board approval; $b$ ) the President of the EBRD, who has decision-making authority in the case concerning projects which have not yet received Board approval and any problem solving initiative; c) a Roster of three to ten experts who are appointed by the Board of Directors upon recommendation by the EBRD's President; d) The Chief Compliance Officer, who has assumed additional duties as the coordinator of the IRM and who is appointed by the Board of Directors from among the three members of the Roster. It is important to stress here that the above-mentioned experts are retained in accordance with the EBRD's procurement provisions applicable to the IRM and also minimum qualifications relating to the expertise of the experts are stipulated in the Resolution. Thus far, the members of the EBRD Roster are paid a retainer for which they are demanded to spend five days each year at the EBRD learning about the environmental procedures and policies of the Bank. ${ }^{20}$

In order to be credible, the IRM should be sufficiently independent from the institution which created it. This is unsurprising: since the institution of the IRM, the Board of Directors has frequently asserted the relevance of the IRM's independence. Its interest in this regard is well expressed in the Resolution that contains various requirements to ensure the independence of the EBRD Rosters. The Resolution provides, first of all, that an expert shall not have worked for the EBRD (either as a staff member, Bank official, Director, Alternative Director, Director's Assistant or consultant) for at least two years prior to being appointed to the Roster. Secondly, EBRD Rosters shall serve on a single non-renewable five year term. Thirdly, EBRD Rosters, after their term of office expires, will be ineligible for employment with the Bank. And fourthly, experts may only be removed from office by a decision of the Board of Directors for cause. ${ }^{21}$ It should be emphasised from the very outset, however, that unlike international tribunals, the IRM is not a really independent body despite these safeguards for independence. The IRM's independence is mainly counterbalanced by the circumstances that it only has advisory functions. As will be illustrated below, the IRM has only the power to make a recommendation to the Board of Directors as to

\footnotetext{
18 See G. Handl, Multilateral Development Banking: Environmental Principles and Concepts Reflecting General International Law and Public Policy, (The Hague: Kluwer Law International, 2001), at 7; T.L. Gutner, Banking on the Environment Multilateral Development Banks and Their Environmental Performance in Central and Eastern Europe (Massachussets: MIT Press, 2002).

19 On this issue see M. Fitzmaurice and C. Redgwell, "Environmental Non-Compliance Procedures and International Law", Netherlands YB Int'l L., 31 (2001) 35-65.

${ }^{20}$ See Bank Information Center, Accountability at the EBRD, available at <www.bicusa.org/en/Issue. 18 . aspx $-34 \mathrm{k}>$ (visited 3 February 2006).

${ }^{21}$ See EBRD, Independent Recourse Mechanism Rules of Procedure, supra n. 1, par. 6.
} 
whether the issue of request must be investigated. It cannot start an investigation of the request without prior approval by the Board of the Directors. ${ }^{22}$

IRM proceedings provide additional insights in terms of independence. That the IRM is a mechanism of last recourse suggests a strong presumption towards the resolution of disputes within the Bank's managerial structure rather than by means of an IRM investigation. As mentioned above, this presumption is evidenced by the Board of Directors' competence to authorize an investigation into the merits of a complaint. A balance should thus be sought between the preservation of sufficient independence for EBRD Rosters and the EBRD's will to maintain a certain level of control over the procedure. Rigorous requirements in terms of the participation of the complainants and transparency ensure a tenable and effective process.

\subsection{Some General Remarks on the Functioning of the IRM}

The IRM's activity lays the ground for greater compliance with the EBRD's procedures and policies through both positive measures and hindrance. ${ }^{23}$ The IRM's supervisory power is clearly defined in the Resolution pursuant to which the IRM can only investigate complaints that the Bank has failed to follow its own procedures and policies in its operational work. Accordingly, the substantive standards against which the IRM reviews Bank performance are above all internal provisions. ${ }^{24}$ Like the World Bank Inspection Panel, the IRM does not apply domestic or general international law. This is so even though it would be truly desirable for the IRM to review an EBRD project not solely against internal but also against international law standards. The investigation process is to be performed in two separate phases. In the first phase, the IRM determines the eligibility of the complaint and the registered request for investigation after the Board of Directors has responded to the concerns expressed in the complaint. If the Chief Compliance Officer decides the complaint is meritorious (i.e., non-"manifestly ineligible"), this phase concludes with the appointment of an independent expert from the Roster, the Eligibility Assessment Expert, to assist in assessing its eligibility. The Eligibility Assessors, comprised of the Chief Compliance Officer and the Eligibility Assessment Expert, should make an Eligibility Assessment of the registered complaint within thirty business days of the receipt of the complaint. It is worth noting that the Resolution does not explicitly provide for provisional measures pending the outcome of the investigation, even though such measures might be necessary to prevent an alleged irreparable damage resulting from the execution of the project. If the Eligibility Assessor recommends that the complaint is ineligible, notice shall be given within fifteen business days of receipt of the complaint. If the

\footnotetext{
22 Ibidem, para. 19 ss.

${ }^{23}$ For similar remarks with regard to the World Bank Inspection Panel see E. Nurmukhametova, "Problems in Connection with the Efficiency of the World Bank Inspection Panel", Max Planck YB UN L., 10 (2006) 397-421, at 401.

${ }^{24}$ But see Rigo Sureda, supra n. 14, at 92, who correctly states that "[t]he policy of the EBRD deals explicitly with the application of "good international practice". This includes applicable national law and EU standards, and if they do not exist or are not applicable, the EBRD identifies "other sources of good international practice, including relevant World Bank Group guidelines, the approach of other IFIs (....) and donors, and good industry practice"."
} 
complaint is found ineligible, the Assessors should make a reasoned recommendation to dismiss the complaint. This recommendation will be sent to the complainant, the project sponsor and the relevant Bank department. The complainant will be entitled to comment on this recommendation.

After the Chief Compliance Officer and the independent expert have completed their review, the second phase begins. In this phase, the Chief Compliance Officer and the independent expert submit a report and recommendation either to put an end to the process or to conduct a compliance review. The report is submitted either to the President of the Bank or to the Board of Directors, depending on whether the project has received Board approval or not. If the competent decision-maker is the President of the EBRD, the report will be transmitted to the Board of Directors for informational purposes. The appropriate decision-maker then decides whether or not to accept the recommendation. If the recommendation is to dismiss the complaint, the appropriate decision-maker may accept the recommendation or may remit it back to the Chief Compliance Officer for supplementary investigation or for reconsideration by a different expert. If the recommendation is to conduct a compliance review, an expert will be nominated as soon as the appropriate decision-maker approves the recommendation. It should be observed that if the Chief Compliance Officer or the expert is of the idea that serious or irreparable harm will be caused by the implementation of the project, they may recommend that the President of the EBRD suspend work on the project or disbursement of the loan. This phase ends with the submission of a Report to the Bank's President, who finally transmits the Report to the Board of Directors. The Report includes the experts' findings on whether the Bank has complied with the relevant Bank procedures and policies, as well as all relevant facts. The findings of the experts should be restricted to establishing whether or not there has been a material policy violation. But the experts can suggest systematic internal changes within the Bank to guarantee future compliance with EBRD's procedures and policies as well as changes in the scope or implementation of the project.

The Resolution provides for certain requirements in terms of public participation during the IRM process. But provisions in the Resolution granting participatory rights to complainants during the IRM procedure are limited. ${ }^{25}$ Requesters are notified of the IRM reports and Board decisions at the same time that these documents are revealed to the public. Moreover, the Resolution does not explicitly refer to any rights of requesters to acquire and reply to information exchanged between the IRM experts and other involved parties, nor to participate in the IRM proceedings after the submission of the complaint. While it mandates the experts to consult with the President of

${ }^{25}$ On the significance of participatory rights in the context of the international development banks' operational policies and procedures see L. Boisson de Chazournes, "The World Bank Inspection Panel: About Public Participation and Dispute Settlement", in T. Treves et al. (eds.), Civil Society, International Courts and Compliance Bodies (The Hague: TMC Asser Press, 2005), 187-203, at 191, who stressed that "[t]his principle [public participation], that blossomed at the end of the 1980s, has become a key concept in efforts to ensure the effective application of projects and that they produce the expected results". See also L. Boisson de Chazournes, "La mise en oeuvre du droit international dans le domaine de la protection de l'environnement: enjeux et défis", Rev. Gén. Dr. Int. Pub., 99 (1995) 37-76; C. Cullen and W. Morrow, "International Civil Society in International Law: The Growth of NGO Participation", Non-State Actors \& Int'l L., 1 (2001) 7-39. 
the Bank before they issue their recommendation on the investigation, and during the investigation itself, the Resolution makes no reference to consultation with the complainant. It is worth noting that the Resolution does not mention the existence of participatory rights for third parties to the procedure. Thus this act does not enable any external observer to submit amicus curiae briefs during the processing of complaints, if they demonstrate that they have an interest in the findings of the investigation.

With regard to information communication, first, the EBRD should make publicly accessible certain types of documents emerging during the IRM process. These records comprise demands for investigation, IRM reports and recommendations on investigations, and Board of Directors' decisions thereon. IRM related documents are, however, kept secret until after they have been examined by the Board.

As the Complaint Process has been described in detail elsewhere, only some aspects of the IRM's assessment of the eligibility of a complaint will be analyzed in the following paragraph.

\section{THE IRM PROCEDURE}

\subsection{The Jurisdiction of the IRM}

The "jurisdiction" of the IRM extends to an affected Party that should consist of at least of two persons in the territory of the borrower country. Like in the constituent resolution of the World Bank Inspection Panel this community of persons should moreover represent a "commonality of interests", which is that the persons should share the same "common interests or concerns". ${ }^{26}$ The community of interest cannot precede the events which lead to the request for investigation, but may result from the sharing in the alleged harm that causes affected parties to act together. Moreover, requesters should be located in the territory of the borrower. This means that such groups must have a true territorial presence that, in the case of incorporated entities, implies that they should have substantive activities in the territory. Furthermore, requesters should be parties whose interests or rights have been or are likely to be directly affected by an action or omission of the Bank that has or threatens to have a material adverse effect. The wording of the constituent resolution of the IRM suggests that for evaluating the material adverse effect, the "without project" situation must be used as the base case for comparison, taking into account what baseline information can be available. It is worth noting that, unlike in the resolution of the World Bank Inspection Panel, requests for inspections cannot be submitted by any individual Managing Director of the Bank, or by the Managing Directors acting as a Board.

${ }^{26}$ In contrast, the IFC/MIGA CAO's jurisdiction extends to claims by single individuals who are damaged, as well as by free aggregations of individuals that do not automatically have a "commonality of interests". The text of the "Office of the Compliance Advisor/Ombudsman" (CAO) is available at <www.ifc. org/cao/index.html $>$ (visited 3 February 2008). For a commentary see A. Murphy and A.H. Chayes, Beyond Compliance? An External Review Team Report on the Compliance Advisor/Ombudsman Office of IFC and MIGA (24 July 2003). 
The requesters should allege that they have been adversely affected by a project financed by the EBRD in which this failed to comply with its operational procedures and policies. For public sector projects, the allegations may relate to any of the Bank's operational procedures and policies. But in the case of private sector projects, the allegations should relate only to the Bank's environmental and social safeguard policies, that include its policies dealing with education, good governance, health, environment, etc. The requests can be brought before the commission of environmental harm, even at an earlier stage, namely during the preparation and appraisal phases of the project cycle.

The jurisdiction of the IRM is assessed during the first phase of its functions, that is, when determining on a prima facie basis the eligibility of submitted complaints. This determination enables the IRM to make a recommendation to the Board of Directors on whether or not the issue should be investigated. The IRM's jurisdiction is tested with regard to considerations of standing, time, and applicable law.

The IRM's jurisdiction ratione materiarum is, according to the Resolution, restricted to scrutinizing Bank compliance with internal Bank provisions and standards. This brings up two considerations - on the one hand, the position of international environmental rules in the interpretation and application of safeguard procedures and policies and, on the other, the normative significance of the environmental polices and procedures of the Bank from an internal point of view.

With respect to the first issue, the EBRD has affirmed that it aims to lead its operations in accordance with multilaterally agreed environmental rules and standards. But do such rules and standards intrude to any length in IRM proceedings? While the Resolution expressly determines that a complaint before the IRM experts might not assert Bank non-compliance with international legal rules, it does not make clear that the IRM cannot take into consideration communication other than that embodied in demands. In view of the EBRD's environmental commitments, internal procedures and policies should be regarded as aiming to endorse standards included in at least some international environmental instruments. Moreover, certain procedures and policies scatter general rules and principles of international environmental law, inclusive of, for example, the precautionary and preventive principles, and the prohibition of environmental harm beyond national jurisdiction. It may be maintained that the IRM, like the requester, should use environmental rules and standards found in general principles of international law, and non-binding instruments to fill inherent lacunas in EBRD procedures and policies and to interpret the rights and responsibilities arising out of these acts. This reflects the circumstance that, while lasting within the boundaries of the Resolution, the interpretation of environmental policies and procedures can take place within the normative frame in which the EBRD operates on the international level.

The IRM's jurisdiction is subject to three limitations in terms of time. Like the World Bank Inspection Panel the IRM constitutes a mechanism of last recourse. It has jurisdiction only after the requester has exhausted other avenues within the Bank, i.e., has submitted the complaint to the Bank's Board of Directors, which has omitted to provide the IRM, within a very short period, with evidence that it has complied, or intends to comply, with the applicable provisions. Secondly, the IRM is not competent to receive complaints related to a particular issue or issues over which it has 
already made its recommendation upon having received a prior request, unless justified by new circumstances or evidence not known at the time of the prior request. Thirdly, solely complaints involving the allegation of environmental harm that has occurred or is likely to occur as a consequence of projects can be brought before the IRM.

\subsection{The Consequences of IRM's Investigations and Recommendations}

The consequences of an inspection commenced by the IRM relate to the kinds of redress and remedies which are potentially available to those negatively affected by the omissions and acts of the EBRD, as well as to the capacity for modifications in the Bank's development operations in terms of environmental protection. As already stated above, the IRM cannot take recommendations or decisions on additional action stemming from investigation reports. This can represent an improvement to project and policy implementation. Nevertheless, IRM reports correspond to a non-insignificant impediment on the Board of Directors in the event of findings of Bank infringements of environmental procedures and policies.

The consequences of the IRM process may be singled out at two different stages. On the one hand, the direct outcome of the specific project which is the core of the complaint may be affected by means of different types of remedial measures.

On the other hand, a second category of consequences may be seen as wider in scope and less project oriented. IRM recommendations and reports may influence the development of the applicable law, by providing relevant guidelines on the interpretation and implementation of and compliance with EBRD environmental procedures and policies. Furthermore, the establishment of the IRM has promoted transparency in Bank operations, as in order for the mechanisms to operate parties external to the Organization should be informed of, and have unfettered access to, the most significant Bank acts. In terms of democratic participation in Bank operations, the IRM encourages external input by non-governmental entities, private individuals, and local communities. Beyond the internal stage, IRM recommendations and reports may encourage normative evolutions in environmental, institutional and human rights law.

This appraisal of the potential outcomes of the IRM operation reveals a relevant feature of the mechanism, that is, its emphasis on deterrence. The IRM system responds to the assumption of prevention in two different means. In a general viewpoint, the IRM operation can further hindrance of future harm by laying the ground for broader compliance by the EBRD with environmental procedures and policies in loan operations through both hindrance and positive actions. In project specific terms it concedes that complaints be brought prior to the committing of environmental damage, as they may regard projects in the preparation and appraisal steps of the project cycle. Complainants may therefore request possible expenses. 


\section{Assessment AND Final Remarks}

\subsection{An Assessment of the IRM}

As the EBRD does not enter into contractual relationships with the entities which are potentially concerned by bank financed projects, the Bank's procedures and policies do not provide for enforceable rights against the Bank. Individuals can only rely on domestic remedies which are usually not available for the asserted violations. Any attempt to find a foreign State willing to promote the victims' cause will likely to be vain: Member States usually refrain from bringing complaints of environmental and human rights violations by another State under any international procedure.

These circumstances have not changed with the establishment of the IRM. With the creation of the IRM, the EBRD has set a relevant precedent for offering non-State entities the chance of triggering a compliance monitoring system that may, in the end, result in the correction of failures resulting from non-compliance with its own environmental project requirements. The IRM does not, however, represent a legal remedy system through which positions indicated in the EBRD's rights or policies referred to in the Resolution might be enforced against the Bank. The Resolution grants individuals standing before an independent accountability mechanism. It does not accord them the remedy of a legal action in a court.

As already said above, the institution of the IRM was the EBRD's response to a growing international movement demanding greater accountability, transparency and citizen participation at international development banks such as the World Bank, the Asian Development Bank, the Inter American Development Bank and the European Bank for Reconstruction and Development, that are accused of making decisions that affect the existences of private persons all over the world, especially the lives of the defenceless and poor, without a system of accountability. The IRM demonstrates the EBRD's willingness to increase its transparency and accountability. According to the IRM members themselves, the mere existence of the IRM has already enhanced Bank staff awareness that they are accountable for the Bank's compliance with its own procedures and policies.

The creation of the IRM could be regarded as an attempt by the EBRD to create a solution to a serious dilemma which development banks that provide advice and funding for development projects are confronted with. The dilemma is caused by two prima facie conflicting tasks, to help developing Member States use their resources to maximise public welfare, and to ensure that the majority does not advance at the expense of the environment.

Though the IRM has not invoked international law rules and standards other than Bank procedures and policies, it is a significant means of holding an international bank accountable for compliance with its own procedures and policies, and for the adverse effects that their actions and decisions can have on the natural environment. 


\subsection{Some Modest Proposals for Reform}

Ten years after the foundation of the World Bank Inspection Panel the EBRD established the IRM in response to a growing public debate over the environmental and social effects of Bank lending. The IRM's activity should lead not only to environmental and human rights protection during preparation, appraisal and implementation of the projects financed by the Bank, but also to transparency in Bank operations in general terms. Recognizing sustainable development principles, the Bank must fulfil the related duties and obligations.

Under the Resolution, the IRM is required to determine whether or not Management has been in compliance with some of the Bank's most relevant procedures and policies and has to make recommendations on whether to proceed or not with the investigation of a request. But it is not empowered to provide recommendations on the subject itself. This is certainly one of the major obstacle. Analyzing this or that case for a long time, the IRM could give some useful recommendations concerning the case at hand. Therefore problematic issues that have been examined have only short-term results as a consequence of the added attention brought by filing an IRM claim but this attention does not necessarily translate into long-term sustainable results. Far too often the IRM's recommendations and the subsequent Board of Directors decision provide only for a brief period of change. The main reason for this is the IRM's mandate, according to which the IRM's remedies are very restricted. This explains also why the IRM does little, at present, to redress project affected communities. ${ }^{27}$

In connection with the mandate the following must also be noted. The IRM's should be broadened. In this respect it is necessary to underline a possible problem relating to the Management's ad hoc remedial plans. In presenting its remedial action plans to the IRM and the Board of Directors just prior to the meetings, or at the same meeting at which the Board addresses the IRM's recommendations for investigation, Management has made it impossible for the IRM and the Board to determine whether the plans do, in fact, address the concerns of the requesters and the findings of the IRM inspectors. Besides, given the speed with which these plans are elaborated and developed, consultation appears almost to be precluded. If Management chooses to present a remedial action plan, the IRM's role should be to assess the consistency of plans with Bank policies, including participation by affected people and adequate consultation and to evaluate Management's supervision of remedial action plans.

Again, at least the most relevant steps in the investigation process should have a time frame associated with them. Moreover, the requesters should be informed of the status of the request throughout the process. ${ }^{28}$

27 Drawing, in fact, on eleven cases submitted to the IRM since its foundation, a study by Bankwatch CEE revealed that procedural constraints make the mechanism practically toothless; and that the constraints contravene the principles of the international Aarhus Convention, which EBRD recognises. For a fuller account of these issues see, Bank Information Center, supra n. 20.

${ }^{28}$ But the President of the EBRD notifies the affected group in writing as to whether the compliance review or a problem-solving initiative is accepted or rejected. 
Furthermore, the IRM must also have a function allowing it to analyze projects which are likely to develop problems during implementation. That environmental damage must be prevented rather than compensated constitutes a leitmotif of international environmental law, as such prejudice is often irreversible and rather hard to assess in terms of economic compensation. In such cases, the President of the EBRD could send projects that are experiencing difficulties or posing particular risks to the IRM for its further scrutiny.

Finally, a request may at present be brought only by a physical or juridical person affected by the Bank financing project and not by external non-governmental organizations acting on their own behalf. But there is very little doubt about the existence of public interests which should be protected when environmental protection is at stake. This is especially true when there is no specific Party directly affected by the Bank project, but rather the project's implementation which leads to general environmental harm. ${ }^{29}$ NGOs must be entitled to protect public interests, particularly in the framework of international financial institutions.

The suggested widening of the IRM's task would lead to a mechanism operating more efficiently. It must be stressed that effective compliance with the Bank's procedures and policies demands a supplementary problem-solving unit within the Bank is no solution. It is suggested by the experience of the IRM that this unit should be responsible for remedying the environmental policy violations ascertained by the IRM and help to guarantee that affected communities are properly compensated to improve their standards of living. But such a unit can often cause new difficulties. The IRM in fact has to communicate not only with the Board of Directors but also with this unit. Instead, it would be surely more effective to broaden the IRM's mandate and to provide it the powers indispensable to pursue these tasks itself.

Clearly, the successful solution of all these issues depends almost entirely on the EBRD's willingness. If the IRM's mandate is not modified, the work of this recourse mechanism will continue to be rather disputable.

\section{FINAL REMARKS}

This article has attempted to analyse both substantive and procedural issues of the IRM, in order to investigate some of the movements that are taking place in the direction of a greater accountability of the EBRD. The creation of the IRM may be regarded as an answer to the impediments to the application of traditional liability and responsibility concepts to international financial institutions, particularly when development banks are involved. As already stated above, the IRM is not a court of law where the liability or responsibility of the EBRD may be invoked. It does not have binding decision-making powers and does not reach an enforceable judgment. The IRM fits into a more elastic concept of compliance, that aims at surveying and increasing compliance with certain environmental rules and principles, while instituting a soft frame to address cases of non-compliance.

29 Accordingly Nurmukhametova, supra n. 23. 
As a consequence of its informal character, however, the IRM is a mechanism lacking effectiveness, mainly because of its relative lack of independence and jurisdiction to enhance remedial action. Competing ideas of the scope of its functions have been advanced in turn by the text of the Resolution and the decisions of the Board of Directors. The IRM may be considered as a body with either restricted investigatory competence, undertaken by means of flexible procedures, or as having functions of a quasi judicial nature completed through a formalized process. In this sense, the IRM reminds one of the World Bank Inspection Panel that is a conciliatory mechanism aimed mainly at securing a friendly arrangement between parties in dispute.

On the other hand, the Resolution grants the IRM quasi-judicial powers during the eligibility and investigation steps, such as to establish its jurisdiction, analyse the merits of a complaint by applying legal rules to circumstances and arrive at a determination on the issue of non-compliance after an investigation conducted in accordance with juridical rules and on the basis of principles of equity and fairness. The adoption of a problem-solving initiative has marked a trend towards accentuating the quasijudicial aspects of the IRM with respect to the body's competence to decide on the commencement of investigations. While the IRM must remain a flexible dispute resolution mechanism, emphasizing its quasi-judicial functions has the ability to give the system greater effectiveness. From the perspective of environmental protection, longterm movements in the development loan process pursued by international development institutions such as the EBRD may indeed be furthered by the institution of more formal supervisory processes, permitting an independent body such as the IRM to intervene between the Bank and the requester, with the aim of ascertaining the applicable law and assessing compliance with existing duties. The mechanism's impact in this respect may be reinforced by the Board of Directors continuing to allow investigations when suggested by the IRM, the IRM benefiting from wider room to manoeuvre in the conduct of inspections, all parties in the procedure being attributed equal procedural rights, and by the Bank's significant implementation of remedial measures on the basis of the IRM findings.

In conclusion, the development of accountability mechanisms such as the IRM suggests that States can no longer circumvent certain fundamental rules of public policy behind the "veil" of international development institutions because the latter's collective decisions can be subjected to accountability standards. That the EBRD, amongst other institutions, has committed itself to pursue its tasks in accordance with environmental principles and provisions proves the "externalization" of the operations of international development banks. In an integrated international legal order, international banks have become the addressees of policy and legal standards and provisions arising from sustainable development. Participatory requirements also suggest that non-private parties should be legally preserved against the negative effects that may originate from the loan development operations of banks. The IRM, like the World Bank Inspection Panel, constitutes an important step towards securing objectivity and transparency in the operation of international banks, bold in its involvement of local communities and non-governmental entities in the process. ${ }^{30}$

${ }^{30}$ For analogous remarks with regard the World Bank Inspection Panel see J.C. Collier and P. Lowe, The Settlement of Disputes in International Law (Oxford: Clarendon Press, 1999), at $121 \mathrm{ff}$. 
Section III

Institutional and Procedural Aspects 
1 


\title{
Chapter Twenty \\ Structural and Institutional Aspects of Non-Compliance Mechanisms
}

\author{
Alessandro Fodella
}

\section{INTRODUCTION}

Non-compliance mechanisms of multilateral environmental agreements (MEAs) rely, for their functioning, on an articulated quasi-institutional framework made of ad-hoc so-called "compliance bodies" and other treaty bodies, as well as on participation in the compliance review process by other subjects and "actors", whether States or non-State entities, or international institutions. While there may be some common basic features among all the mechanisms as far as the above structural elements are concerned, these are outnumbered by the differences that in many cases can be quite significant, making each non-compliance mechanism a "tailor-made" one for each treaty. ${ }^{1}$

It would be an overly ambitious task to illustrate and analyze in detail all the structural aspects of all non-compliance mechanisms on this occasion. Therefore, taking as reference the mechanisms that have been analyzed during the present research project, ${ }^{2}$ this chapter will address some of those structural aspects that may be relevant and interesting from the point of view of the effectiveness of non-compliance mechanisms, in particular the legal basis for the non-compliance mechanisms, the nature, role and institutional characteristics of the compliance bodies, the participation by other treaty bodies, States Parties and civil society to the mechanisms, and inter-institutional coordination issues.

${ }^{1}$ P. Széll, "The Development of Multilateral Mechanisms for Monitoring Compliance", in W. Lang (ed.), Sustainable Development and International Law (London: Graham \& Trotman/Martinus Nijhoff, 1995) 97-109, at 108.

2 See the studies on individual non-compliance procedures (NCPs) collected in this book supra $11-274$

T. Treves et al., eds., Non-Compliance Procedures and Mechanisms and the Effectiveness of International Environmental Agreements

(C) 2009, T.M.C. ASSER PRESS, The Hague, The Netherlands, and the Authors 


\section{The Legal Basis for the Creation of Non-Compliance Mechanisms: Structures Built on "Unstable Foundations"?}

As with any structure, the analysis should start from the foundations of the same, that is, in the present case, the legal basis and source for the creation of such noncompliance mechanisms. Unlike other compliance review mechanisms in other sectors of international law (such as in the international protection of human rights, for example), the non-compliance mechanisms of the MEAs considered herein have not been established directly by the relevant treaties, but by decisions of the "governing bodies" of the latter. ${ }^{3}$ This may raise some issues as to the legal value and functioning of the mechanisms themselves from more than one point of view.

Non-compliance mechanisms have been established with such COP decisions relying essentially on two different bases: firstly, with reference to so-called "enabling clauses" in the treaties, i.e., clauses that explicitly provide for the power or the duty of the COP to establish such mechanisms, whether or not containing indications as to the nature and functioning of the future mechanism; ${ }^{4}$ secondly, and more implicitly, on the competence of the COP in the field of compliance review or treaty implementation and on its power to establish subsidiary bodies. ${ }^{5}$ Despite possible doubts (especially as far as the second implicit solution mentioned above is concerned), it is fair to say that in both cases these norms seem to provide for enough ground to establish the mandate and competence for the COPs to create the mechanisms. ${ }^{6}$

However, the use of COP decisions for the creation of non-compliance mechanisms may raise the issue of the functioning and nature of the latter. In fact, it is debatable whether COP decisions as such may be binding upon the Parties to the treaty (unless, obviously, the treaty is explicit on the matter). ${ }^{7}$ Therefore, there may be

3 These are the bodies representing the Parties to the treaty, whether they may be called "Conference of the Parties", "Meeting of the Parties" or otherwise. We shall refer to these bodies generally as "governing bodies" or "COPs".

${ }^{4}$ A list of treaties with full references is provided supra at XXXVII. See, for example, Montreal Protocol, Art. 8; Kyoto Protocol, Art. 18; Cartagena Protocol, Art. 34; Aarhus Convention, Art. 15; Protocol on Water and Health, Art. 15; Rotterdam PIC Convention, Art. 17; Stockholm POPs Convention, Art. 17.

5 See, for example, Basel Convention, Art. 15.5; LRTAP Convention, Art. 10.2; Alpine Convention, Arts. 5, 6 and 8 (L. Pineschi, "The Compliance Mechanism of the 1991 Convention on the Protection of the Alps and its Protocols", supra 205-220). A particular case is that of the Espoo Convention: the establishment of the NCP is based on a provision of the Convention assigning to the COP the competence in implementation review matters (Art. 11.2), but an additional ad hoc provision regarding the establishment of the NCP was nonetheless introduced with an amendment that has not entered into force yet (see E. Fasoli, "Procedures and Mechanisms for Review of Compliance under the 1991 Espoo Convention on Environmental Impact Assessment in a Transboundary Context and its 2003 Protocol on Strategic Environmental Assessment", supra 181-203, at 184).

${ }^{6}$ The Decision establishing the Montreal Protocol NCP explicitly recognizes such function to itself (F. Romanin Jacur, "The Non-Compliance Procedure of the 1987 Montreal Protocol to the 1985 Vienna Convention on Substances that Deplete the Ozone Layer", supra 11-32, at 13).

7 On this issue in general see, among others, U. Beyerlin, "State Community Interests and InstitutionBuilding in International Environmental Law", ZaöRV, 56 (1996) 602-627, at 614 ff.; J. Sommer, "Environmental Law-Making by International Organizations", ibid., 628-667, at 634 ff.; V. Röben, "Institutional Developments under Modern International Environmental Agreements", Max Planck YB UN L., 4 (2000) 363-443, at 371 ff.; J. Brunnée, "COPing with Consent: Law-Making Under Multilateral Environmental 
doubts about whether a COP decision could create a procedure or mechanism that the Parties would be obliged to follow or respect, and that may be capable of producing binding consequences for them.

One may argue that, in the absence of clearer indications, the binding effect of COP decisions may be implicit in the very powers given by the treaty to the COP in implementation or compliance review matters, ${ }^{8}$ or in the mandate to establish the noncompliance mechanism itself. Others may disagree, as any conclusion over the implicit binding effects of the COPs' decisions should not be lightly presumed, in order to safeguard the respect for States' sovereignty and consent. ${ }^{9}$ A compromise between these two opposite views may be possible: it would be reasonable to say that if the treaty contains an enabling clause for the establishment of a non-compliance mechanism, and/or it gives the powers to the COP in compliance review matters, the existence of a duty for Parties to follow the compliance procedure established thereof could be hardly rebutted, if the mechanism is what we may call a "soft" one (i.e., one that is characterized by the non-binding nature of its outcomes). Such a duty would derive from the obligation to cooperate with the other Parties and to respect the treaty in good faith and it could be considered the minimum implicit in the treaty itself.

The question is going to be more critical for "harder" mechanisms, whose envisaged outcome would be a binding one, i.e., those that are intended to produce obligations for Parties beyond the treaty itself (such as, for example, sanctions or suspension of rights). ${ }^{10}$ The issue has clearly arisen, for example, in the context of the non-compliance mechanism of the Kyoto Protocol. ${ }^{11}$ In fact the negotiators seemed aware of the problem, as they specified in Article 18 of the Protocol, after giving mandate to the COP to establish the mechanism, that "[a]ny procedures and mechanisms under this article entailing binding consequences shall be adopted by means of an amendment to this Protocol." The mechanism has been adopted provisionally by a COP

Agreements", Leiden J. Int'l L., 15 (2002) 1-52 at $4 \mathrm{ff}$. On the value of COP Decisions in the specific context of NCPs see the comprehensive chapter by M. Fitzmaurice, "Non-Compliance Procedures and the Law of Treaties", infra 453-482, at $460 \mathrm{ff}$.

${ }^{8}$ See, for example, E. Milano, "Procedures and Mechanisms for Review of Compliance under the 1979 Long-Range Transboundary Air Pollution Convention and its Protocols", supra 169-180, at 176-177.

9 An answer in the negative is given, for example, by Fitzmaurice (M. Fitzmaurice, "International Protection of the Environment", $R d C, 293$ (2001) 1-488, at 360, and M. Fitzmaurice and C. Redgwell, "Environmental Non-Compliance Procedures and International Law", Netherlands YB Int'l L., 31 (2000) 35-65, at 48-49). See also Pineschi, who confirms, albeit indirectly, an interpretation on the non-binding character of COP decisions, see Pineschi, supra n. 5, at 215-216.

${ }^{10}$ For a thorough analysis of the value of NCPs' outcomes and, in particular, of the very meaning of their binding or non-binding effects see E. Milano, "The Outcomes of the Procedure and their Legal Effects", infra $407-418$, at $411 \mathrm{ff}$.

11 But other mechanisms as well entail potentially binding consequences for the Parties, such as sanctions or the suspension of rights arising out of the treaty. See Report of the Fourth Meeting of the Parties, Annex V, doc. UNEP/OzL.Pro.4/15 (25 November 1992); Decision I/7 on Review of Compliance, doc. ECE/ MP.PP/2/Add.8 (2001, late issued on 2 April 2004) (Aarhus Convention NCP), para. 37; Decision I/2 on Review of Compliance, doc. ECE/MP.WH/2/Add.3 - EUR/06/5069385/1/Add.3 (3 July 2007) (Protocol on Water and Health NCP), paras. 34, 35; and the Decision SC-3/20 on Non-Compliance, doc. UNEP/POPS/ COP.3/30 (4 May 2007), Annex, (Stockholm POPs Convention Draft NCP) at 57. 
decision, ${ }^{12}$ but the issue is still under consideration by the governing body of the Protocol. ${ }^{13}$ From another point of view, similar concerns have been also addressed indirectly under the Alpine Convention, when it was decided that the procedure would have entailed only "soft" results and that stronger outcomes would be avoided because this would have required an amendment to the Convention. ${ }^{14}$ These cases show that COP decisions may not have binding effects in the sense of creating new obligations or amending existing ones for the Parties and, therefore, that the same decisions may hardly be used as a proper legal basis for non-compliance mechanisms with a potential truly binding outcome.

The matter of the legal value of the instruments establishing the non-compliance mechanisms is thus still unresolved in a clear-cut and definitive way. It is a part of a wider debate on the value of COP decisions and it touches upon other issues, such as the value of the outcome of non-compliance procedures and of the relationship between non-compliance mechanisms and the law of treaties, which are comprehensively addressed elsewhere in this book. ${ }^{15}$ The fact remains that relying almost entirely on the theoretical basis of implied powers is probably not a very certain solution for non-compliance mechanisms, especially for those that could be envisaged to be "hard" ones. One may say that, from the structural point of view, these mechanisms are still based on rather "unstable foundations".

It is clear that COP decisions are more flexible and faster solutions than amendments to the treaty or new binding instruments (such as, for example, separate ad hoc protocols on non-compliance), and this may bring few advantages indeed. It is also probably true that the COP decision solution, adopted for the first non-compliance mechanisms, has been followed by the others as a model. ${ }^{16}$ However, one should establish its structure on very solid ground, such as on a treaty provision, if a strong mechanism is what one is looking for.

The time may have come to think again about the efficacy of such solutions and to look for possible improvements. Perhaps a compromise solution that could be "imported" into other mechanisms, especially in those designed to be strong, is the one envisaged within the Kyoto Protocol, namely to adopt a Decision on a provisional basis, with the view of adopting a subsequent treaty amendment afterwards, if necessary.

12 Decision 27/CMP.1 on Procedures and Mechanisms Relating to Compliance under the Kyoto Protocol, doc. FCCC/KP/CMP/2005/8/Add.3 (30 March 2006), at 92 (Kyoto Protocol NCP).

13 S. Urbinati, "Procedures and Mechanisms Relating to Compliance under the 1997 Kyoto Protocol to the 1992 United Nations Framework Convention on Climate Change", supra 63-84.

14 Pineschi, supra n. 5, at 215.

15 On these issues see, respectively, the already mentioned chapters by Milano, supra n. 10 and Fitzmaurice, supra n. 7.

${ }^{16}$ Széll was right in arguing, over ten years ago, that the solution of the COP decision, adopted "by chance" for the NCP of the Montreal Protocol, would have been replicated by other mechanisms, see Széll, supra $\mathrm{n} .1$, at 107. 


\section{The Nature and Role of "Compliance Bodies"}

\subsection{Independence vs. Political Control?}

Moving on from the foundations to the structure itself, every non-compliance mechanism entails the creation of an ad hoc body dedicated to compliance (that may be called generally a "compliance body"17) which is the "core" of the structure. Such "organ" of the quasi-institutional framework of the treaty may have different functions, ranging from the analysis of the Parties' reports on their implementation of the treaty, to the consideration of individual cases or general issues of non-compliance. It may thereafter be entrusted with the capacity to take actions directly in relation to the Parties, mainly of a facilitative and assistance-oriented nature (such as giving advice, recommendations or information, or providing assistance), but also, in more rare cases, of a sanction-oriented one (such as "issuing cautions" or deciding over suspension of rights). It may, more frequently, make appropriate recommendations to the governing body of the treaty, which would then decide on the kinds of actions, mentioned above, to be taken vis-à-vis the non-compliant party. One of the key factors to assess the functioning and effectiveness of the mechanisms, from the structural point of view, is the nature of such compliance bodies, particularly in terms of their independence from the Parties, and their relationship with the governing body of the treaty.

Most compliance bodies will be explicitly defined as "subsidiary bodies" of the COP. ${ }^{18}$ This element does not seem to be a decisive one as far as the independence of the compliance body is concerned. Such definition may indicate a general power of the COP to decide over the compliance bodies' existence and functions, and to oversee their work in broad terms, ${ }^{19}$ but nothing suggests that, for this very definition, the compliance bodies will act under the detailed instructions of the COP on single matters or cases (unless this is explicitly provided in the treaty). ${ }^{20}$ Practice seems to confirm this conclusion, since compliance bodies which may be considered subsidiary

17 This expression will be used for a treaty body that may be defined differently ("compliance committee", "implementation committee", "reviewing committee" or similar) depending on the relevant NCP.

${ }^{18}$ This is the case, for example, of the Montreal Protocol NCP (Decision IV/5 on Non-Compliance Procedure, doc. UNEP/OzL.Pro.4/15 (25 November 1992), at 13 and Annex IV at 44, subsequently amended by Decision X/10 on Review of the Non-Compliance Procedure, doc. UNEP/OzL.Pro.10/9 (3 December 1998), at 23 and consolidated text in Annex II, at 47); the Basel Convention NCP (Decision VI/12 on Establishment of a Mechanism for Promoting Implementation and Compliance, doc. UNEP/CHW.6/40 (10 February 2003), at 45), the Espoo Convention NCP (Decision III/2 on Review of Compliance, doc. ECE/MP.EIA/6 (13 September 2004), Annex II), the Alpine Convention NCP (Decision VII/4 Mécanisme de verification du respect de la Convention alpine et de ses protocols d'application (2002), reprinted in Envt'l Po'y \& L., (2003) 179), or the Stockholm POPs Convention Draft NCP.

${ }_{19}$ This may entail, for example, the duty for the compliance body to report to the COP on its work at regular intervals (see, for example, such duty in the Kyoto Protocol mechanism - Urbinati, supra n. 13, at 71).

${ }^{20}$ This may happen in the case of compliance bodies' competence to examine "general issues of compliance", since such competence is usually exercised under the specific guidance of the COP (infra n. 50). 
bodies of the COP (according to the criteria identified above) clearly act de facto as independent entities. ${ }^{21}$

In this regard, the critical factor seems to be the status of the members of compliance bodies. As far as this issue is concerned, there are essentially two possible models: a body that is made up of representatives of a restricted number of the Parties to the treaty, and another one that is composed of independent experts, in both cases elected by the governing body of the treaty. Examples of the first kind include the mechanisms of the Montreal Protocol, the LRTAP Convention, or the Espoo Convention, with a special case being that of the Alpine Convention whose Reviewing Committee is composed of two members for each Party. Examples of the second one would be the mechanisms of the Kyoto Protocol, the Aarhus Convention, or the Protocol on Water and Health. In other cases the status of members would not be entirely certain. $^{22}$

A compliance body made up of States' representatives is a political entity, functional to compromise and negotiation, which some would define quite simply a diplomatic conference of States. ${ }^{23}$ This would not necessarily mean that the mechanism would be ineffective; on the contrary, States may be more willing to rely upon this kind of entity ${ }^{24}$ However, a mechanism based on this type of compliance body would certainly not be objective and, more importantly, it would also be based on the assumption that compliance is a "negotiable" matter. ${ }^{25}$ Considering that the political governing body of the treaty would still retain the crucial decision-making role in the process (by taking action on the basis of recommendations by the compliance body), ${ }^{26}$ the compliance body may nearly "duplicate" the political and diplomatic functions of the COP. As a consequence, the non-compliance mechanism may end up being nothing more than a way of managing more efficiently the political compliance review competence of the governing body of the treaty in a decentralized manner. ${ }^{27}$ The choice of this structural model clearly underlies the intention of the Parties to maintain full control over the process, and it may be suitable for the facilitative and assistance-oriented functions of non-compliance mechanisms. ${ }^{28}$ Such choice was adopted

${ }^{21}$ See, for example, the Aarhus Convention NCP (C. Pitea, "Procedures and Mechanisms for Review of Compliance under the 1998 Aarhus Convention on Access to Information, Public Participation and Access to Justice in Environmental Matters", supra 221-250, at 227).

${ }^{22}$ See infra nn. 34 and 35.

${ }_{23}$ P. Birnie and A. Boyle, International Law and the Environment (Oxford: Oxford University Press, 2002), 202.

${ }^{24}$ The mechanisms of the Montreal Protocol, of the LRTAP Convention (Decision 2006/2 on Implementation Committee, its Structure and Functions and Procedures for Review, doc. ECE/EB.AIR/89/Add.1 (5 February 2007), at 4) and of the Espoo Convention have been triggered few times and are fully operational.

${ }^{25}$ G. Handl, "Compliance Control Mechanisms and International Environmental Obligations”, Tul. J. Int'l \& Comp. L., 9 (1997) 29-49, at 37.

${ }^{26}$ See, for example, the NCPs of the Montreal Protocol, the LRTAP Convention, the Espoo Convention or the Alpine Convention.

${ }^{27}$ Such "duplication" is particularly evident as far as the Alpine Convention is concerned, since all parties are represented within the compliance body.

28 This may be confirmed also by practice, considering the many self-referrals by potential non-complying States under this kind of NCPs. See, for example, the mechanisms of the Montreal Protocol (Romanin Jacur, supra n. 6, at 30) and the LRTAP Convention (Milano, supra n. 8, at 179-180). 
mainly in the earlier mechanisms, starting from that of the Montreal Protocol, when States were still very reluctant to delegate to a third party any compliance review function over their obligations. This attitude was progressively softened, and the model of compliance bodies made up of independent experts progressively gained support, being endorsed in several non-compliance mechanisms, particularly in more recent ones.

In fact the choice of an independent body of experts entrusted with compliance review duties seems a preferable solution. It would certainly be a more suitable option for entities that in most cases are devoted to reviewing technical matters, and it should guarantee impartiality and objectivity ${ }^{29}$ in the mechanism (at least in certain phases of the same). An element of independent evaluation should be an indispensable feature of any reliable mechanism and it seems to give more strength to the mechanisms themselves.

In some non-compliance mechanisms characterized by an independent compliance body, the latter may review compliance by the Parties and adopt "soft" measures of a facilitative nature (such as assistance or recommendations) directly vis-à-vis the Parties concerned, and/or recommend more appropriate and incisive action to the COP. ${ }^{30}$ In this way, the competence would be fairly distributed between the compliance body and the Parties, with the latter keeping the main control over the process in terms of decision-making power on more relevant specific - whether "soft" or "hard" - measures to be taken to react to non-compliance. In such cases the independent, objective review of the compliance body would bring a truly additional value to the political dimension of COP decision-making, striking a fair balance between diplomacy and independent assessment, or at least ensuring that diplomacy and decision-making are based on an independent and objective assessment.

In other cases, independent compliance bodies may have such powers and such a relevant role within the mechanism that there may be a shift away from the diplomatic character of the system, towards a "quasi-adjudicative" one. This may be the case of the mechanism of the Aarhus Convention, whereby the compliance body (which is capable of adopting "soft" measures directly vis-à-vis the non-complying party or to recommend further measures to the COP) may receive submissions from the public and it may draft its assessment of States' compliance in quasi-judicial terms, in such a way that it may resemble quasi-judicial mechanisms of human rights treaties. $^{31}$ The non-compliance mechanism of the Protocol on Water and Health (largely inspired by that of the Aarhus Convention) goes even further, as the independent compliance body may even adopt measures of a sanction-oriented nature

\footnotetext{
${ }^{29}$ Subject to what will be addressed immediately infra regarding the ways to ensure independence.

${ }^{30} \mathrm{See}$, for example, the NCPs of the Basel Convention or of the Cartagena Protocol (Decision BS-I/7 on Establishment of Procedures and Mechanisms on Compliance under the Cartagena Protocol on Biosafety, doc. UNEP/CBD/BS/COP-MOP/1/15 (27 February 2004), Annex I, at 98), as well as the draft mechanisms of the Rotterdam PIC Convention (Decision RC-3/4 on Draft text of the Procedures and Mechanisms on Compliance with the Rotterdam Convention, doc. UNEP/FAO/RC/COP.3/26 (10 November 2006), Annex, at 27) and of the Stockholm POPs Convention.

31 Pitea, supra n. 21, at 249.
} 
(such as "issuing cautions") directly with reference to the Parties. ${ }^{32}$ Finally, such a shift may be particularly evident in the non-compliance mechanism of the Kyoto Protocol, whereby the Enforcement Branch of the Compliance Committee may assess compliance and decide directly (without the intermediation of the COP) on the consequences that may be suffered by the non-compliant Party. ${ }^{33}$

Such "strong" and innovative solutions, which are often coupled with extensive triggering capacities by different actors, may be particularly suitable and effective for treaties like the Aarhus Convention or the Protocol on Water and Health, which aim at protecting the interests of the public in addition to environmental values as such. They should be welcome, however, also for other treaties (like the Kyoto Protocol), since they seem to combine an "adversarial" or quasi-judicial nuance with the purely non-confrontational spirit of non-compliance mechanisms. The above-mentioned examples may indicate that States could be ready to accept this model, which could become the real compromise between traditional dispute settlement and political cooperation, being more flexible and accessible than the former and more incisive than the latter.

\subsection{Other Issues of Efficient Institutional Design}

The effective functioning of the non-compliance mechanisms may depend, inter alia, upon the proper institutional design of the compliance bodies, especially as far as a few relevant aspects are concerned: the independence of their members, expertise requirements, access to information and the scope of their competence.

The effectiveness of the solution of an independent compliance body depends upon whether and how the system is able to define and ensure the independence of the members, both formally and in substance. In this regard, the mechanisms provide for quite different solutions. From the formal point of view some would specify that the members "will serve objectively and in the best interest of the Convention". ${ }^{4}$ Although this formula suggests the choice in favour of independence, it is still rather ambiguous, and it could be adopted precisely as a compromise. ${ }^{35} \mathrm{~A}$ much clearer and thus more satisfactory solution in favour of independence is that of adding that

32 C. Pitea, "Procedures and Mechanisms for Review of Compliance under the 1999 Protocol on Water and Health to the 1992 Convention on the Protection and Use of Transboundary Watercourses and International Lakes", supra 251-262, at 272.

33 Urbinati, supra $\mathrm{n} .13$, at $72,79-80$.

34 See, for example, the Basel Convention NCP and the Rotterdam PIC Convention Draft NCP.

35 As far as the mechanism of the Basel Convention is concerned, the first report of the Implementation and compliance committee highlighted that "the language of the text of the mechanism is a compromise. It was underlined that members should serve their function as objectively as possible" (see A. Fodella, "Mechanism for Promoting Implementation and Compliance with the 1989 Basel Convention on the Transboundary Movements of Hazardous Wastes and Their Disposal", supra 33-48, at 37). On the Rotterdam PIC Convention draft NCP see S. Brugnatelli, "Draft Procedures and Mechanisms on Compliance with the 1998 Rotterdam Convention on the Prior Informed Consent Procedure for Certain Hazardous Chemicals and Pesticides in International Trade", supra 85-100, at 90. 
members should not receive instructions from their governments, ${ }^{36}$ or to define the members as serving in their individual capacity. ${ }^{37}$

Despite the clarity of such definitions from a normative perspective, this may be not enough to ensure independence from the substantial point of view. Therefore, such formal recognition should be accompanied by other rules to secure this result. In several non-compliance mechanisms these may include the duty for members to express a solemn oath or declaration of impartiality, ${ }^{38}$ the exclusion from deliberations of members in conflict of interests ${ }^{39}$ (although the rule may be weakened by the fact that a definition of such conflict is often missing $),{ }^{40}$ and the possibility to revoke membership for those violating impartiality requirements. ${ }^{41}$ One of the most effective solutions, however, is the one developed by practice under the Aarhus Convention's non-compliance mechanism, which goes as far as excluding civil servants from membership in the compliance body altogether: ${ }^{42}$ this should avoid conflicts of interests from the outset, and it should prevent delegates sitting in other treaty bodies from being elected in the compliance body as well, something that could indirectly hamper their independence.

Moreover, considering the functions of compliance bodies, rules on expertise requirements for the members should not be underestimated, since they would have a great impact on the efficient functioning of such bodies. Most mechanisms would simply require that members should be experts in the fields relating to the treaty. ${ }^{43}$

${ }^{36}$ This is an interesting proposal which has been put forward as far as the future compliance procedure of the London Dumping Protocol 1996 is concerned, whereby members should serve "objectively and in the best interests of the Protocol, and not under instructions from their government" (emphasis added) (Compliance Procedures and Mechanisms Pursuant to Article 11 of the 1996 Protocol to the London Convention 1992, doc. LC 29/17 (14 December 2007), Annex 7 (London Dumping Protocol 1996 NCP). See S. Trevisanut, "The Compliance Procedures and Mechanism of the 1996 Protocol to the 1972 London Convention on the Prevention of Marine Pollution by Dumping of Wastes and other Matter", supra 49-62, at 54).

37 See, for example, the mechanisms of the Aarhus Convention, of the Protocol on Water and Health, and of the Kyoto Protocol (which specifies that members shall serve in an independent and impartial manner and avoid real or apparent conflicts of interest - see Urbinati, supra n. 13, at 68).

${ }^{38}$ See, for example, the Kyoto Protocol NCP and the Aarhus Convention NCP.

${ }^{39}$ See, for example, the NCPs of the Aarhus Convention, of the Cartagena Protocol, of the Kyoto Protocol, as well as the draft mechanism of the Stockholm POPs Convention (which requires a member of the committee who is a citizen of a Party under consideration not to participate in the procedure - G. Bigi, "Draft Non-Compliance Procedure under the 2001 Stockholm Convention on Persistent Organic Pollutants", supra 121-136, at 126). Basic requirements to avoid a conflict of interests are established also for compliance bodies made up of States representatives: in some cases members representing the State whose compliance is under consideration may be excluded from the procedure (for example, the NCP of the Espoo Convention).

${ }^{40}$ See for example C. Ragni, "Procedures and Mechanisms on Compliance under the 2000 Cartagena Protocol on Biosafety to the 1992 Convention on Biological Diversity", supra 101-120, at 112; Pitea, supra n. 21 , at 236

41 The Kyoto Protocol's NCP provides for detailed rules on the exclusion, by the COP, of members that are not impartial or that do not act independently (see Urbinati, supra n. 13, at 68).

${ }^{42}$ Pitea, supra n. 21, at 225-226 and V. Koester, "The Compliance Mechanisms of the Aarhus Convention and the Cartagena Protocol on Biosafety: A Comparative Analysis of the Negotiation Histories and their Outcomes", supra 277-302, at 284.

${ }^{43}$ For example the NCPs of the Montreal Protocol, of the Cartagena Protocol or of the Basel Convention. See also the draft mechanisms of the Rotterdam PIC Convention and the Stockholm POPs Convention. 
However, the issue is that expertise requirements have a meaning if they lead to diversity of expertise, in particular if they ensure a proper balance between technical and legal experts, both of which are necessary. Rules in this regard are not very satisfactory, since at best diversity of expertise is simply "encouraged", ${ }^{44}$ and requirements of specific legal expertise are extremely rare. ${ }^{45}$

Alternatively, the mechanisms should ensure the possibility for compliance bodies to rely upon the expertise of other treaty bodies ${ }^{46}$ or upon a purely external one. ${ }^{47}$

Along the same lines, the structural design of the mechanisms should focus on ensuring that compliance bodies have enough access to information regarding matters under their consideration. From this point of view it is important that compliance bodies have sufficient capacity to investigate, including through on-site inspections (with the consent of the party concerned), and to seek information beyond that provided by the parties with their reports. ${ }^{48}$ For this purpose, the non-compliance mechanisms may also be coordinated with activities of relevant international organizations. ${ }^{49}$

Furthermore, as far as the functions of compliance bodies are concerned, they may consider specific situations regarding individual States, but they may also address "general issues" of non-compliance, often under the direction of the COP. ${ }^{50}$ The latter has to be regarded as an essential element of any effective non-compliance mechanism. Given the mainly supportive objective of non-compliance mechanisms, one of their most useful functions should be that of clarifying the scope of the treaties' obligations, since the lack of clarity over the latter may often be one of the obstacles against compliance. Such a role would also enhance the preventive nature of the

${ }^{44}$ For example the NCPs of the Aarhus Convention and of the Protocol on Water and Health.

45 See the case of the Kyoto Protocol compliance body (at least as far as the enforcement branch is concerned) (Urbinati, supra n. 13, at 68).

46 See infra paragraph 4.1 .

47 The compliance body of the Basel Convention's mechanism, for example, may rely on the Secretariat for consultation or it may draw upon outside expertise with the consent of the Party concerned or as directed by the Conference of the Parties. Outside expertise may be relied upon also within the Aarhus Convention's NCP (Pitea, supra n. 21, at 237).

${ }^{48}$ Extensive information gathering powers are given to the compliance bodies of the NCPs of the Kyoto Protocol (Urbinati, supra n. 13, at 77), of the Espoo Convention (Fasoli, supra n. 5, at 196), of the Basel Convention (Fodella, supra n. 35, at 32-33), $\mathbf{\square}$ of the Alpine Convention (which includes the possibility to gather information from observers) (Pineschi, supra n. 5, at 214), of the Montreal Protocol (although in this case the information may be obtained through the Secretariat) (Romanin Jacur, supra n. 6, at 23-24) and of the draft mechanism of the Stockholm POPs Convention (Bigi, supra n. 39, at 131). The mechanisms of the Protocol on Water and Health and of the Aarhus Convention are particularly effective in this regard: both provide for the possibility to gather information from NGOs and the public and the latter also to consider that received from the scientific community and obtained from "on-the-spot" missions (Pitea, supra n. 21, at 237-238; Id., supra n. 32, at 259).

49 Infra paragraph 5.

${ }^{50}$ See, for example, the NCPs of the Basel Convention, of the Cartagena Protocol, of the Aarhus Convention, of the Protocol on Water and Health, of the Espoo Convention or of the draft Rotterdam PIC Convention and draft Stockholm POPs Convention. It is unclear whether this option is available for other mechanisms, such as the Montreal Protocol's (Romanin Jacur, supra n. 6, at 19) and whether it will be available for other future mechanisms still in a draft form, such as the one relating to the International Treaty on Plant and Genetic Resources for Food and Agriculture (ITPGRFA) (L. Crema, "Draft Procedures and Operational Mechanisms to Promote Compliance and to Address Issues of Non-Compliance under the 2001 International Treaty on Plant and Genetic Resources for Food and Agriculture", supra 137-152, at 146-147). 
mechanism. This may be an important added value with respect to traditional dispute settlement, a value that may not be easily ensured through consideration of individual cases alone.

Finally, compliance bodies should always have the mandate to consider compliance with all the substantive obligations of the treaties, and should not be limited to the analysis of the respect of procedural ones. Needless to say, this second option would be too restrictive for the effectiveness of any non-compliance mechanism.

\section{EFFECTIVENESS OF NON-COMPLIANCE MECHANISMS AND PARTICIPATION BY OTHER “ACTORS” IN THE SYSTEM}

Apart from the roles of the compliance body and of the governing body of the treaty, one of the most relevant structural aspects for the effectiveness of non-compliance mechanisms is the participation (the term being used in the widest possible sense) in the compliance review process by other treaty bodies, by States Parties and by other non-State actors.

\subsection{Participation by Treaty Bodies}

As to the first issue, the role played by the Secretariat of the MEA to which the noncompliance mechanism relates is a fundamental one. Apart from its administrative function (for example providing administrative support to the meetings of the compliance bodies), the Secretariat is often a crucial focal point for information gathering and exchange regarding non-compliance, due to its role within the treaty as such; ${ }^{51}$ in certain cases, it may establish a preliminary constructive dialogue with the Party concerned, at the beginning of the non-compliance procedure, ${ }^{52}$ within some noncompliance mechanisms, it may even trigger the mechanism itself. ${ }^{53}$ The Secretariat is an actor of the process in a privileged position because of its direct access to information, and for this reason it should be entrusted with a prominent role within any noncompliance mechanism. In particular, its triggering prerogative should be extended to all non-compliance mechanisms, or at least to those of a facilitative nature, ${ }^{54}$ also considering that practice suggests that this option may be used, in some cases, more than Party-to-Party triggering. ${ }^{55}$ From the point of view of the Secretariat's role, the

${ }^{51}$ The Secretariat usually receives the reports from the Parties regarding their implementation of, and compliance with, the treaty and it is, more generally, the focal point of all information sharing regarding the treaty between the Parties and the institutional framework of the treaty itself. It may also receive information from civil society when there is no possibility to address the compliance body directly (for example in the Montreal Protocol's NCP - Romanin Jacur, supra n. 6, at 16).

${ }^{52}$ For example under the Montreal Protocol's NCP.

53 See, for example, the NCPs of the Montreal Protocol, the Basel Convention, the LRTAP Convention or the Protocol on Water and Health.

${ }^{54}$ A triggering capacity related to a more confrontational kind of NCP could attract more criticism, as it may be seen as incompatible with the neutral role of the Secretariat.

${ }_{55}$ See, for example, the Montreal Protocol NCP (Romanin Jacur, supra n. 6, at 20) and the LRTAP Convention NCP (Milano, supra n. 8, at 179). 
fact that the treaty to which the non-compliance mechanism relates has been adopted within the framework of an international organization (for example UNECE or UNEP, as in the case of many non-compliance mechanisms considered herein) may be a crucial factor: this often means that the Secretariat will be managed by the same organization, ${ }^{56}$ and such an element may have a great impact on the effectiveness of the non-compliance mechanisms, at least in terms of technical expertise, availability of resources and inter-institutional networking. ${ }^{57}$

The compliance bodies may also interact with other specialized treaty bodies, such as those with financial competence ${ }^{58}$ or, more importantly, technical ones, which the compliance body may use to draw information or expertise from. ${ }^{59}$

\subsection{Participation by States Parties}

As to the second issue, participation by all States Parties in the MEA should be ensured, from the point of view of both triggering capacity and involvement in the procedure.

Triggering possibilities for all Parties to the treaty are provided for by some mechanisms, such as those of the Montreal Protocol, the Kyoto Protocol, or the LRTAP Convention. The ratio for such solution may be that these treaties protect collective environmental interests of the community of the Parties (such as the protection of the atmosphere, the ozone layer, or climate stability). A similar solution has been adopted also within the Aarhus Convention or the Protocol on Water and Health: in this second instance there are no collective environmental interests at stake, but the Parties recognize certain rights to subjects under their jurisdiction, and obligations are established mainly in the interest of groups or individuals. In both cases, the extensive triggering capacity seems to reflect an erga omnes partes nature of treaty obligations. In most of these mechanisms, such a triggering system will also be accompanied by extensive possibilities to participate in the procedure for submitting and concerned parties. ${ }^{60}$

On the contrary, other non-compliance mechanisms are very limitative of participation by States in the compliance review process, not only in terms of triggering

56 The Secretariats of the Montreal Protocol, the Basel Convention or the Stockholm POPs Convention, for example, are provided for by UNEP; the Secretariat for the LRTAP Convention or the Espoo Convention by UNECE. Other organizations may be involved as well: the Secretariat of the Protocol on Water and Health is performed jointly by UNECE and WHO, that of the Rotterdam PIC Convention jointly by UNEP and FAO, that of the 1996 Protocol to the 1972 London Dumping Convention by IMO.

57 See also infra paragraph 5.

58 See, for example, the Executive Committee of the Multilateral Fund in the Montreal Protocol's NCP, which deals with financial issues and technology transfer that are relevant for the compliance procedure (Romanin Jacur, supra n. 6, at 12).

59 See, for example, the "expert review team" of the Kyoto Protocol (Urbinati, supra n. 13, at 70), the "Biosafety Clearing House Mechanism" of the Cartagena Protocol (Ragni, supra n. 40, at 107-108), the Cooperative Programme for Monitoring and Evaluation of the Long-Range Transmission of Air Pollutants in Europe (EMEP) of the LRTAP Convention (Milano, supra n. 8, at 170,175) or the Global Ozone Observing System of the Montreal Protocol (Romanin Jacur, supra n. 6, at 24).

${ }^{60}$ See, for example, the NCPs of the Aarhus Convention (Pitea, supra n. 21, at $228 \mathrm{ff}$ ) or of the Protocol on Water and Health (Pitea, supra n. 32 at $253 \mathrm{ff}$ ). 
rights, but also as far as more general participation is concerned. In some mechanisms, such as those of the Basel Convention, the Espoo Convention or the Cartagena Protocol, only "affected" States may trigger the mechanism (apart from the self-triggering option) and only the State whose compliance is under consideration may participate more generally in the process. This may be justified, in theory, by the nature of the treaties under consideration, which mainly create a web of bilateral obligations between the Parties. Participation by other States should nevertheless be allowed. In fact, even in treaties that are mainly "bilateralized" in nature there may be some collective interests to be addressed. ${ }^{61}$ Moreover, even bilateral relationships may affect other Parties at least from the economic point of view. ${ }^{62}$ Lastly, this solution goes against one of the most useful functions of non-compliance mechanisms, which is that of clarifying the scope of the treaties' obligations, something that every State would be interested in, regardless of the existence of a more specific bilateral relationship with another Party. Indeed one of the great advantages of non-compliance mechanisms is that they provide for mainly soft mechanisms of a supportive nature to address the protection of the environment, which is intrinsically a collective interest; for this reason, they should precisely overcome the frequent difficulties of triggering traditional dispute settlement mechanisms. The involvement of States Parties should thus not be narrowly interpreted.

Looking at the issue of States' participation from another point of view, the success of a non-compliance mechanism will depend also upon its capacity to reflect, within its structure, the balance of interests of all groups of States, especially developed and developing countries, but also countries with economies in transition, as well as the different sub-interests within each group. These considerations, which are embodied more frequently in global instruments but are not neglected in regional ones (such as those of the UNECE system), may be enunciated in principle in the relevant legal texts ${ }^{63}$ but may also be reflected in the structure of the mechanism itself. In this second sense, they may be implemented through rules which generally require an equitable geographical representation in the compliance bodies, ${ }^{64}$ which address

61 The Basel Convention, for example, prohibits the movements of hazardous wastes to Antarctica (Art. 4.6), or it prohibits the trade of hazardous wastes with non-Parties (Art. 4.5). In both cases there is not a single particularly "affected State" involved.

62 As Handl would say "[...] as the economic cost of compliance with such environmental regulations rises, states have an increased interest in making sure that other states, subject to the same international regulations, live up to their obligations, thereby ensuring competition on a level playing field" (Handl, supra n. 25 , at 31 ).

63 The Decision establishing the Cartagena Protocol's NCP, for example, specifically states the necessity to address the needs of developing countries and countries with economies in transition, and such principle is reflected in the procedure more in general (Ragni, supra n. 40, at 105, 111, 114, 117-118). Along the same lines are also the draft mechanism of the Stockholm POPs Convention (Bigi, supra n. 39, at 123, 125, 127), or Art. 21 of the ITPGRFA (which embodies the principles of the future compliance mechanism). See also the Kyoto Protocol mechanism, whereby the Facilitative Branch must take into consideration the principle of common but differentiated responsibilities

${ }^{64}$ Some mechanisms may provide for rules requiring equitable geographical representation based on the regional groups of the United Nations (e.g., the NCPs of the Montreal Protocol, of the Basel Convention and of the Cartagena Protocol). Others may provide more generally that consideration should be given to 
more specifically the balance between developed and developing countries ${ }^{65}$ or more articulated interests (as in the case of the Kyoto Protocol's mechanism ${ }^{66}$ ), and which may or may not be accompanied by special voting procedures to this end. ${ }^{67}$ These balancing requirements should be prima facie more important, for obvious reasons, for committees made up of representatives of States Parties, but they may also enhance the credibility of mechanisms that are based on independent bodies. However, as with many other rules of this kind, they may remain on paper without proper financial resources. From this point of view, an interesting solution seems to be the one adopted within the LRTAP Convention mechanism, whereby a Trust Fund has been established to cover part of the costs of meetings, in order to encourage participation by representatives of countries with economies in transition. ${ }^{68}$

Finally, the issue of equal participation by different kinds and groups of countries may also be indirectly linked to the triggering system of each non-compliance mechanism. Those mechanisms where the procedure can be triggered by any State may suggest also the possibility of "collective actions" of groups of States, or of a State on behalf of a group, as in the case of the Kyoto Protocol's mechanism whereby South Africa presented 15 submissions "as chairman of the Group of 77 and China". ${ }^{69}$ Specific procedural rules for such kinds of actions still need to be developed, inter alia, in order to avoid using the non-compliance mechanism as a forum for the management of political conflicts between different groups of States.

\subsection{Participation by Civil Society}

As to the third issue, participation by civil society at different levels would clearly be an essential element of any non-compliance mechanism. Firstly, it should bring into the mechanism a degree of increased control over compliance, as it introduces one more "controller" into the system. Secondly, it should enhance the independence of the system, as NGOs should not follow States' agendas. Thirdly, it may supplement the resources of the official institutionalized system in terms of expertise and information gathering. The ways NGOs may be involved in the system are different and reflect these functions: they may participate as observers in the process ${ }^{70}$ and

the geographical distribution of membership (e.g., the NCPs of the Aarhus Convention and of the Protocol on Water and Health).

${ }^{65}$ This is one of the proposals for the draft mechanism of the Stockholm POPs Convention (Bigi, supra n. 39 , at 127).

${ }^{66}$ Each branch of the Committee of the Kyoto Protocol mechanism is composed of one member from each of the five regional groups of the United Nations and one member from the small island developing States, as well as two members from Parties included in Annex I and two members from Parties not included in Annex I "taking into account the interest groups" as reflected in the practice of the institutional framework of the treaty.

${ }^{67}$ Some decisions of the compliance committee of the Kyoto Protocol mechanism are adopted with a double majority of Annex I and non-Annex I Parties (see Urbinati, supra n. 13, at 78).

68 Milano, supra n. 8, at 179.

${ }^{69}$ Urbinati, supra n. 13 , at 83.

${ }^{70}$ For example in the NCPs of the Alpine Convention, of the Montreal Protocol and LRTAP Convention (in the last two cases NGOs may participate before the governing body rather than the compliance body) or 
they may provide information (officially or informally) to different treaty bodies ${ }^{71}$ or to the parties. ${ }^{72}$ In the most advanced systems, they may even trigger the procedure ${ }^{73}$ and their participation may even become "institutionalized", as happens in the Aarhus Convention mechanism, whereby NGOs may present their candidates in the implementation committee ${ }^{74}$ and to a lesser extent in the non-compliance mechanism of the Protocol on Water and Health. ${ }^{75}$

However, there may be drawbacks in this role. Their input into the system would be positive only if NGOs are truly objective and if they pursue the interests of the collectivity: should they be subject to other actors' interests and agendas, their participation may be damaging to the mechanism. The difficult issue is how to assess and ensure their independence. An important (though not essential) parameter in this regard could be their financial resources: if NGOs are financed by States, this may raise some doubts about their capacity to handle compliance issues with the necessary independent approach. ${ }^{76}$

Some systems would also provide for triggering capacity and participatory rights for the public at large. Although such a solution has been adopted mainly in "rightsoriented" mechanisms, like those of the Aarhus Convention or the Protocol on Water and Health, it may be extended to other mechanisms as well. This option is very likely to require a significant increase in the resources allocated to compliance mechanisms, ${ }^{77}$ but it is probably worth being expanded, in view of the inherent collective interests to the environmental protection at stake, and of the general principle of public participation in environmental matters which should be endorsed in the crucial compliance review phase as well.

Finally, a question should be raised on the definition of what "civil society" is, as participation by the private sector and so-called "business NGOs" increases. Some mechanisms, like the one of the LRTAP Convention, already allow for participation by such actors ${ }^{78}$ and discussions are ongoing about extending this solution to other mechanisms. ${ }^{79}$ This approach may be suggested prima facie by the nature of the

that of the Espoo Convention (where the compliance body has accepted NGOs on a provisional basis - see Fasoli, supra n. 5, at 173).

${ }^{71}$ NGOs can submit information to the Secretariat in the NCPs of the Montreal Protocol or the Aarhus Convention

72 See, for example, the NCP of the Basel Convention.

73 As in the cases of the NCPs of the Aarhus Convention or of the Protocol on Water and Health.

74 Pitea, supra n. 21, at 225.

75 In this case candidatures are presented by Parties but "taking into account" proposals made by NGOs (Pitea, supra n. 32, at 254).

${ }^{76}$ CIPRA International, for example, an NGO which is extremely active within the Alpine Convention framework, is financed substantially by Liechtenstein (see CIPRA International, 2006 Annual Report, available at <http://www.cipra.org/en/CIPRA/cipra-international/ueber-uns/annual-report>, at 15).

77 See Pitea, supra n. 21, at 249 in this regard.

${ }^{78}$ NGOs representing industrial interests can participate as observers before the COP of the LRTAP Convention (Milano, supra n. 8, at 179).

${ }^{79}$ In the NCP of the Protocol on Pollutant Release and Transfer Registers the possibility of seeing business NGOs nominating their representatives in the compliance body has been envisaged (C. Pitea, "Procedures and Mechanisms for Review of Compliance under the 2003 Protocol on Pollutant Release and Transfer Registers to the 1998 Aarhus Convention", supra 221-250, at 267) and more general participation of the 
treaties considered herein, which may affect economic and industrial interests of the private sector. However, for the very same reason the involvement of these entities at the compliance review level, through the means of civil society participation, seems a rather dangerous solution which does not seem to be entirely justified: considering that these actors would most probably pursue their own private interests, which will also probably collide with the environmental objective of the treaty, this option would appear incoherent with the function of non-State actors' participation in non-compliance mechanisms as explained above.

\section{INTER-INSTITUTIONAL COORDINATION}

Lastly, from the structural point of view, one element that should not be underestimated is the importance of inter-institutional cooperation between different institutions or quasi-institutions involved in the compliance review process, in particular between different non-compliance mechanisms, between the latter and other institutions of other MEAs, or other international institutions in general.

It is common understanding that coordination must be ensured between the many overlapping treaties that now exist in international environmental law, in order for this sector of international law to be truly effective. This coordination between different legal regimes at the substantial level should be reflected at the compliance review level as well. This should not be seen solely from the point of view of overlapping or conflicting quasi-jurisdictions. Considering the facilitative, cooperative and assistance-oriented nature of most non-compliance mechanisms, such coordination within the compliance review process would certainly be an effective way of enhancing coherence and synergies between legal regimes from the substantial point of view as well. ${ }^{80}$

An example of this approach is contained in the non-compliance mechanism of the Aarhus Convention, whereby communications between the compliance committee and other compliance bodies (not only of $\mathrm{MEAs}^{81}$ ) is encouraged, and in that of the Protocol on Water and Health, whereby the committee may communicate with other compliance bodies, or invite members of other committees as observers. ${ }^{82}$ Some rules in this regard are envisaged also by the draft Stockholm POPs Convention mechanism. ${ }^{83}$

Cooperation should not be emphasized only between compliance mechanisms, but it should be ensured also with all relevant international institutions. Some mechanisms

same actors in the procedure is being discussed as far as the ITPGRFA's mechanism is concerned (Crema, supra n. 50, at 209).

${ }^{80}$ Potential interlinkages between different compliance monitoring and review mechanisms are highlighted in UNEP, Comparative Analysis of Compliance Mechanisms Under Selected Multilateral Environmental Agreements (Nairobi: UNEP, 2005), $108 \mathrm{ff}$.

81 See Pitea, supra n. 21, at 242.

82 Pitea, supra n. 32 at 260.

83 According to such mechanism, the Committee may "ask information from compliance committees dealing with hazardous substances and wastes under other MEAs and then report on these activities to the COP" (Bigi, supra n. 39, at 134). 
already provide for this solution: the non-compliance mechanism of the Protocol on Water and Health encourages communication by the compliance committee with secretariats of other MEAs; $;^{84}$ according to the non-compliance mechanism of the Montreal Protocol, the implementation committee may invite UNDP, UNEP, UNIDO and the World Bank as Implementing Agencies of its Multilateral Fund; ${ }^{85}$ according to the draft compliance procedure of the 1996 Protocol to the 1972 London Dumping Convention, the compliance body should refer to the International Atomic Energy Agency (IAEA) on compliance matters involving radioactive wastes ${ }^{86}$ according to the noncompliance mechanism of the Aarhus Convention, the compliance body may carry out investigations in cooperation with relevant international organizations (such as OSCE or UNDP). ${ }^{87}$

Moreover, some international institutions, like the GEF, may have a role in more than one compliance mechanism ${ }^{88}$ and the coordination of its activities within all these processes may be a decisive factor in order to ensure the efficiency and coherence of the overall system.

From all these inter-institutional points of view, a crucial factor for the effective functioning of a non-compliance mechanism may be the international organization under whose umbrella the treaty and the mechanism have been adopted, especially if such organization plays a role in the institutional structure of the mechanism itself. As already said, the majority of the mechanisms belong to what we may call the "family" of either UNEP or UNECE, and it is not uncommon for these organizations to act as the Secretariat of the relevant convention to which the non-compliance mechanism refers. The strength and effectiveness of a non-compliance mechanism from the structural point of view may also depend upon the contribution that such an "umbrella organization" could bring into the process. For example, the organization may foster, favour and enhance the coordination between the different non-compliance mechanisms belonging to its own "family" already referred to above. Some Secretariats of a few MEAs have already organized a stable cooperation among themselves, in order to ensure coherence between their respective treaties, ${ }^{89}$ and this could happen also at the compliance review level as well. This may solve the problem of the inefficacy of a provision on inter-institutional coordination that is included in only one of the mechanisms that need to be coordinated. There may be also advantages from the economic point of view, since, through a Secretariat that is established within an international organization, part of the financial burden of the non-compliance mechanism could be taken away from the parties. ${ }^{90}$ Of all the treaties considered herein, only the Alpine Convention is "self-sufficient" from this point of view, since for political reasons

\footnotetext{
${ }^{84}$ Pitea, supra $\mathrm{n} .32$ at 260

85 Romanin Jacur, supra n. 6, at 12 .

86 Trevisanut, supra n. 37, at 55.

87 Pitea, supra n. 21, at 237.

${ }^{88}$ See, for example, the NCPs of the Montreal Protocol, of the Cartagena Protocol and the draft one of the Stockholm POPs Convention.

${ }^{89}$ For examples of synergies and coordination between MEAs Secretariats see UNEP, Manual on Compliance with and Enforcement of Multilateral Environmental Agreements (Nairobi: UNEP, 2006), $269 \mathrm{ff}$.

${ }_{90}$ The UN budget covers the Secretariat functioning, for example, of the Aarhus Convention and the Protocol on Water and Health (see Pitea, supra n. 21, at 247; Pitea, supra n. 32, at 262).
} 
everything is managed by the parties to the treaty and no other organizations have a role to play. This may ensure a higher degree of independence, but it also makes the Alpine Convention's non-compliance mechanism a much more isolated one, which will be out of reach of the potential coordination process referred to above.

\section{CONCLUSIONS}

Every non-compliance mechanism entails the creation of a structure which is based on few elements, all of which contribute to the stability, efficacy and good functioning of the system. Although in general these systems can be regarded as effective, there are some issues that should be addressed with a view to their improvement.

As to the foundations of non-compliance mechanisms, the issue of the legal basis of their creation will have to be addressed sooner or later, especially if the law of noncompliance develops in the direction of stronger mechanisms, which need a stronger legal basis in order to work properly.

Future mechanisms will have to design the core of the structure (the compliance body) taking into account the necessity of an independent and objective review. This means creating a compliance body of independent experts and ensuring such independence and expertise with proper legal solutions, both in theory and in practice. Moving from the assumption that non-compliance mechanisms should be established for the protection of the collective interest in the protection of the environment, compliance bodies should focus on individual cases but also on general issues of noncompliance, which is a crucial added value of non-compliance mechanisms with respect to traditional dispute settlement systems.

No mechanism will be effective without the representation or participation by all the key actors in the process: non-compliance mechanisms should be open to all States Parties, in terms of triggering powers and more general participation, and to civil society, including the public at large.

Finally, non-compliance mechanisms should not be seen in isolation, but as a part of a more comprehensive structural framework in international environmental law, so that they may become, from this point of view, the privileged forum in which a coherent international environmental legal framework could be eventually built, or, at least, pursued. 


\title{
Chapter Twenty-One \\ Triggering Non-Compliance Procedures
}

\author{
Francesca Romanin Jacur
}

\section{INTRODUCTION}

Although non-compliance procedures are conceived as facilitative means to help States facing compliance difficulties in respecting their obligations under MEAs, the way they are set in motion is perceived as a politically sensitive matter by the States involved. In fact, in the course of the procedure, there may be a disclosure of sensitive information, which may become known to other States or attract the attention of public opinion and States generally prefer to avoid this situation. This is one of the main reasons why the triggering of non-compliance procedures is a delicate issue that is highly debated during the negotiations of these mechanisms. ${ }^{1}$

Under some MEAs the mandate of compliance bodies, in broad terms, includes various functions such as, inter alia, the provision of advice to non-Parties wishing to become Parties, ${ }^{2}$ the consideration of general problems of implementation which have not yet emerged as specific cases of non-compliance, and the adoption of recommendations on possible solutions to cases of persistent non-compliance.

Consideration of these matters by compliance bodies is generally demanded by COPs or is undertaken proprio motu by compliance committees. ${ }^{3}$

1 A. Shibata, "The Basel Compliance Mechanism", 12 RECIEL (2003) 183-198, at 185. This is confirmed by the recurring square brackets on triggering related matters in many non-compliance procedures currently under negotiation.

2 Under the London Convention NCP (Compliance Procedures and Mechanisms Pursuant to Article 11 of the 1996 Protocol to the London Convention 1992, doc. LC 29/17(14 December 2007), Annex 7), para. 2.2.8 the Committee may "upon request of a non-Party, provide advice and guidance to facilitate its becoming a Party to the Protocol".

${ }^{3}$ See, for example, Basel Convention NCP (Decision VI/12 on Establishment of a Mechanism for Promoting Implementation and Compliance, Appendix, doc. UNEP/CHW.6/40 (10 February 2003), at 45), para. 21: "The Committee shall, as directed by the Conference of the Parties, review general issues of compliance and implementation under the Convention relating to, inter alia: (a) Ensuring environmentally sound management and disposal of hazardous wastes;" and Stockholm POPs Convention Draft NCP (Decision SC-3/20 on Non-Compliance, doc. UNEP/POPS/COP.3/30 (4 May 2007), Annex, at 57), para. 32: "The Committee may examine systemic issues of general compliance and implementation of interest to all Parties when: (a) The Conference of the Parties so requests; (b) The Secretariat, while acting pursuant to its functions under the Convention, obtains information from Parties on the basis of which the Committee decides

T. Treves et al., eds., Non-Compliance Procedures and Mechanisms and the Effectiveness of International Environmental Agreements

(C) 2009, T.M.C. ASSER PRESS, The Hague, The Netherlands, and the Authors 
These issues, however, present a set of radically different aspects compared to the procedures dealing with specific cases of non-compliance and are beyond the scope of the present analysis which will focus, firstly, on the different subjects entitled to set in motion the procedures with regard to specific situations of non-compliance; secondly, on some procedural aspects of the triggering phase; and, finally, on requirements that need to be fulfilled for submissions to be admissible.

\section{Subjects Entitled to Set in Motion Non-Compliance Procedures}

Among the different subjects that may trigger the procedure, usually there are the Parties which can trigger it with regard to themselves and with regard to other Parties, and the Secretariat; in some exceptional cases, procedures may be triggered also by other organs of the MEA, observers or members of the public.

\section{$2.1 \quad$ Self Trigger}

The rationale of non-compliance procedures being facilitative and preventive means is the main reason why all these procedures recognize the right of Parties to bring a case regarding their own implementation problems to the attention of the competent bodies. $^{4}$

This way of triggering the procedure has frequently been used in practice, especially under MEAs whose compliance mechanisms have adopted a facilitative approach and therefore encourage Parties to go to compliance bodies confident that they will receive technical and financial assistance. Another way to encourage the self trigger is to assure the confidentiality of information contained in self-submissions of Parties, as provided in the Aarhus Convention non-compliance procedure. ${ }^{5}$

that there is a need for an issue of general non-compliance to be examined and for a report thereon to be made to the Conference of the Parties; (c) The Secretariat draws the attention of the Committee to relevant information it has obtained through reports by Parties under the Convention and other sources."

${ }^{4}$ Aarhus Convention NCP (Decision I/7 on Review of Compliance, doc. ECE/MP.PP/2/Add.8 (2002, subsequently issued on 2 April 2004)), para. 16; Alpine Convention NCP (Decision VII/4 Mécanisme de verification du respect de la Convention alpine et de ses protocols d'application (Seventh Alpine Conference, 2002), reprinted in 33 Envt'l Po'y \& L. (2003) 179), para. 2.2; Basel Convention NCP, para. 9(a); Cartagena Protocol NCP (Decision BS-I/7 on Establishment of Procedures and Mechanisms on Compliance under the Cartagena Protocol on Biosafety, doc. UNEP/CBD/BS/COP-MOP/1/15 (27 February 2004), Annex I, at 98), section IV.1(a); Espoo Convention NCP (Decision II/4 on Review of Compliance, doc. ECE/MP.EIA/4 (7 August 2001), Annex IV, at 72 revised by Decision III/2 on Review of Compliance, doc. ECE/MP.EIA/6 (13 September 2004), Annex II (consolidated text)), para. 4(b); Kyoto Protocol NCP (Decision 27/CMP.1 on Procedures and Mechanisms Relating to Compliance under the Kyoto Protocol, doc. FCCC/KP/CMP/2005/8/Add.3 (30 March 2006), at 92), section VI.1(a); Montreal Protocol NCP (Decision IV/5 on Non-Compliance Procedure, doc. UNEP/OzL.Pro.4/15 (25 November 1992), at 13, subsequently amended by Decision X/10 on Review of the Non-Compliance Procedure, doc. UNEP/OzL.Pro.10/9 (3 December 1998), at 23 and consolidated text in Annex II, at 47), para. 4; Rotterdam PIC Convention Draft NCP (Decision RC-3/4 Draft text of the Procedures and Mechanisms on Compliance with the Rotterdam Convention, doc. UNEP/FAO/RC/COP.3/26 (10 November 2006), Annex, at 27), para. 12(a); Stockholm POP Convention Draft NCP, para. 17(a).

5 Aarhus Convention NCP, para. 28. 
The practice, however, has shown that the good will of Parties confessing their difficulties to compliance bodies is not always rewarded as expected. This is what happened to the Russian Federation under the Montreal Protocol. Notwithstanding the positive and collaborative approach, at least on a formal level, of the non-complying State, ${ }^{6}$ the MOP, upon recommendation of the Implementation Committee, while deciding financial assistance, also adopted punitive measures consisting of the prohibition to trade ozone depleting substances with countries not Parties of the Commonwealth of Independent States.

\subsection{Party-to-Party Trigger}

The power of a Party to start the procedure against another Party is foreseen by all non-compliance procedures ${ }^{7}$ but it is not frequently used because of its "adversarial" nature, which does not fit well within the amicable nature of non-compliance mechanisms. Moreover, it is often difficult for Parties to become aware of the level of compliance in other States unless, as we will see, the lack or incorrect implementation of the MEA directly affects the State willing to trigger the procedure.

This way of triggering the non-compliance procedure is envisaged with different characteristics depending on the type of MEA and on the nature of the obligations assumed by the Parties.

Treaties addressing global environmental problems, such as ozone layer depletion or climate change, have a universal dimension: they aim at protecting the human community from a threat whose solution depends on a joint and collective response on behalf of the international community. Obligations arising from these MEAs entail a shared responsibility of Member States and, on the other side, they constitute obligations erga omnes partes, i.e., which are owed to all Parties and therefore, in the case of treaty violation or non-compliance, there is no single injured State since all States Parties to the MEA are concerned.

The triggering system of non-compliance procedures under these MEAs reflects the structure of their obligations: the triggering Party does not need to demonstrate that it has a specific interest which is, or may be, hampered by lack of compliance by another Party. ${ }^{8}$

A different structure may be envisaged with regard to MEAs which, although addressing matters having a global environmental dimension, contain obligations of a bilateral nature. This is the case of MEAs whose implementation involves

\footnotetext{
${ }^{6}$ See J. Werksman, "Compliance and Transition: Russia's Non-Compliance Tests the Ozone Regime”, ZaöRV, 56 (1996) 750-773 and reference therein, at 758, noting that: "[a]t no point since its difficulties became manifest has Russia forsworn the objectives and principles of the Ozone regime."

${ }^{7}$ See, for example, Basel Convention NCP, para. 9(b); Kyoto Protocol NCP, section VI.1(b); Montreal Protocol NCP, para. 1; Cartagena Protocol NCP, section IV.1(b).

8 This is reflected in the relevant provisions, stating merely that the Party that has "reservations regarding another Party's implementation of its obligations" may address those "concerns" to the Secretariat. See Montreal Protocol NCP, para. 1 and Kyoto Protocol, section VI.1(b): "The Committee shall receive, through the Secretariat, [...] questions of implementation submitted by [a]ny Party with respect to another Party, supported by corroborating information."
} 
transboundary relations both of an intentional - for example commercial - and of an accidental nature. ${ }^{9}$

Under these MEAs a Party willing to initiate the procedure against another Party is required to demonstrate that it has an individual interest affected by the failure to comply and, in certain cases, that there is a direct relation between itself and the other Party involved. ${ }^{10}$

Other issues relate to whether only a single Party is entitled to start the procedure and only with regard to another one, or if also more Parties, for example grouped together, may be legitimated to refer a matter concerning more States considered in alleged non-compliance.

While some non-compliance mechanisms expressly state that "one or more Parties" may bring a submission to the compliance bodies, ${ }^{11}$ others do not contain clear provisions on this issue.

This situation was addressed by the Facilitative Branch of the Kyoto Protocol when a submission was brought to it by South Africa, on behalf of the Group of 77 and China, against various Parties for failure to communicate national reports. The Branch was unable to take a decision on whether to proceed or not to proceed with the matter for several reasons. ${ }^{12}$

9 A first example may be provided by CITES, which aims at protecting biodiversity by limiting the exploitation of endangered species through the control of trade in products deriving from them; other examples of treaties whose implementation is highly dependent on bilateral inter-state relations are the Basel and the Rotterdam PIC Conventions. Among MEAs concerned with the accidental movement across borders of dangerous substances there is the Stockholm POPs Convention and with regard to genetically modified organisms, the Cartagena Protocol.

${ }^{10}$ Basel Convention NCP, para. 9(b): "A Party that has concerns or is affected by a failure to comply with and/or implement the Convention's obligations by another Party with whom it is directly involved under the Convention." See A. Fodella, "Mechanism for Promoting Implementation and Compliance with the 1989 Basel Convention on the Transboundary Movements of Hazardous Wastes and Their Disposal", supra 33-48, at 39; Cartagena Protocol NCP, section IV.1 (b): "The Committee shall receive, through the Secretariat, any submissions relating to compliance from: [...] (b) Any Party, which is affected or likely to be affected, with respect to another Party."; Rotterdam PIC Convention Draft NCP, para. 12: "Submissions may be made in writing, through the secretariat [...] by: [(b) A Party that has concerns or is affected by a failure to comply with the Convention's obligations by another Party [with which it is directly involved under the Convention]"; Stockholm POP Convention Draft NCP, para. 17: "Submissions to the Committee may be made by: [...][(b) A Party that is affected or may be affected by another Party's difficulties in complying with the Convention's obligations]". Shibata notes that the use of the terms "failure to comply" in the Basel and in the PIC Convention non-compliance procedures may entail a higher threshold for the triggering of the procedure by the Party affected compared to other texts referring to "difficulties in complying". See Shibata, supra $\mathrm{n}$. 1, at 190.

${ }_{11}$ See, for example, the Espoo Convention NCP, para. 5(a); Aarhus Convention NCP, section IV.15; Water and Health Protocol NCP, section IV.14; PRTR Protocol NCP (Draft Decision on Review of Compliance, doc. ECE/MP.PP/AC.1/2007/L.10 (18 July 2007)), section IV.15; LRTAP Convention NCP (Decision 1997/2 Concerning the Implementation Committee, its Structure and Functions and Procedures for Review of Compliance, doc. ECE/EB.AIR/53 (7 January 1998), Annex III, at 28, subsequently amended. Consolidated text in Decision 2006/2 on Implementation Committee, its Structure and Functions and Procedures for Review, doc. ECE/EB.AIR/89/Add.1 (5 February 2007), at 4), para. 4(a); Montreal Protocol NCP, para. 1.

12 See R. Lefeber, "The Practice of the Compliance Committee under the Kyoto Protocol to the United Nations Framework Convention on Climate Change (2006-2007)", supra 303-317, at 311. 
As regards the proponents of the triggering, it is interesting to note that the admissibility of the submission was denied also because, in the view of the Facilitative Branch

"The communication was not submitted by a Party on its own behalf through a representative duly authorized for this purpose. The procedures and mechanisms do not provide for the possibility of groups of Parties making submissions by proxy nor give the facilitative branch a mandate to consider any question of implementation that has not been duly submitted in accordance with section VI.1 of the annex to decision 27/CMP.1."13

On the side of the Parties in respect of which the submission is made the Facilitative Branch considered, in the same decision, that

"The submission does not clearly and individually name the Parties with respect to which it purports to raise a question of implementation."

The approach adopted by the Facilitative Branch on these specific points seems too formalistic, considering that non-compliance mechanisms do not regulate in detail the various steps and procedural requirements of the triggering phase and are generally inspired by flexibility in the interpretation of the rules governing their procedures.

Moreover, the identification of the alleged non-complying Parties could be easily made by looking at what national communications the Secretariat did not receive. In fact, the Secretariat itself, as mentioned by the same decision, had already identified the Parties concerned. ${ }^{14}$

The Branch concludes its decision not to proceed by making clear that:

"This decision not to proceed is without prejudice to the right of any Party to submit a question of implementation with respect to the same matter through its duly authorized representatives." 15

\subsection{Trigger by organs of the MEA}

\section{a) Secretariat}

The Secretariat collects, analyzes and files relevant data, information and documentation received from the Parties and, in so doing, it may become aware of situations of non-compliance.

This is why a Secretariat trigger has been accepted in many MEAs, although exceptions exist of non-compliance procedures that may be initiated only by Parties

${ }^{13}$ Report of the Compliance Committee on the Deliberations in the Facilitative Branch Relating to the Submission Entitled "Compliance with Article 3.1 of the Kyoto Protocol" (CC-2006-1/FB to CC-2006-15) $F B$ ), doc. CC-2006-15-2/FB, para. 4(a).

14 The decision sounds somehow contradictory in that, on the one hand it says that the submission lacks precision because it fails to name the Parties in alleged non-compliance but, on the other, it demands the Secretariat to notify the decision to Austria, Bulgaria, Canada, France, Germany, Ireland, Italy, Latvia, Liechtenstein, Luxembourg, Poland, Portugal, Russia, Slovenia and Ukraine.

15 Ibid., para. 4(c). 
and where the Secretariat has nevertheless an important role because it provides useful information to COPs or compliance committees.

Under the Cartagena Protocol, for example, a triggering power of the Secretariat, although taken into consideration during the negotiation of the non-compliance mechanism, has not been included in the final text. ${ }^{16}$

A compromise solution consists of limiting its triggering function with regard to compliance only with certain obligations, namely the reporting ones, and in identifying the sources of information the Secretariat may rely on and may use when triggering the procedure.

With regard to the first matter, while some non-compliance procedures do not specify with respect to what kind of obligations the Secretariat may trigger the procedure and therefore a broad scope of the triggering power should be recognized, ${ }^{17}$ others stipulate that only compliance with reporting obligations may be the subject of the Secretariat's trigger. ${ }^{18}$

As regards the second issue, there are procedures requiring the Secretariat to use only information contained in documents provided by the Parties or acquired while preparing its reports, ${ }^{19}$ while others say that the Secretariat may become aware of situations of non-compliance, inter alia, through examination of the Parties' reports, ${ }^{20}$ but

${ }^{16}$ See C. Ragni, "Procedures and Mechanisms on Compliance under the 2000 Cartagena Protocol on Biosafety to the 1992 Convention on Biological Diversity", supra 101-120, and reference therein to Compliance (Article 34), Synthesis of Views Regarding Elements and Options for a Compliance Regime, Note by the Executive Secretary, doc. UNEP/CBD/ICCP/2/13 Add.1 (17 July 2001), para. 23. Also the Kyoto Protocol NCP may only be triggered by Parties.

${ }^{17}$ Montreal Protocol NCP, para. 3: "Where the Secretariat [...] becomes aware of possible non-compliance by any Party with its obligation under the Protocol, [...]". Similar provisions are LRTAP Convention NCP, para. 5; Aarhus Convention NCP, para. 17.

${ }_{18}$ Basel Convention NCP, para. 9(c): "The secretariat, if, while acting pursuant to its functions under articles 13 and 16, it becomes aware of possible difficulties of any Party in complying with its reporting obligations under article 13, paragraph 3 of the Convention [...]". An analogous limited trigger, if accepted in the final text, could characterize also the Rotterdam PIC Convention Draft NCP, para. 12: "[(c) The secretariat, if, while acting pursuant to its functions under [articles 4, 5, and 10 of] the Convention, it becomes aware of possible difficulties for any Party in complying with its obligations under [articles 4, 5, and 10 of] the Convention [...]."

19 Barcelona Convention NCP (Decision IG 17/2 on Procedures and Mechanisms on Compliance under the Barcelona Convention and its Protocols, doc. UNEP(DEC)/MED IG. 17/10 (18 January 2008) (the Almeria Report), Annex 5, at 21), para. 23: "If the Secretariat becomes aware from the periodic reports referred to in Article 26 of the Convention and any other reports submitted by the Parties that a Party is facing difficulties in complying with its obligations under the Convention and its Protocols [...]"(emphasis added); Montreal Protocol NCP, para. 3: "Where the Secretariat, during the course of preparing its report, becomes aware of possible non-compliance by any Party with its obligation under the Protocol, [...]"(emphasis added). Similar provisions are found in the Water and Health Protocol NCP, section V.15; Basel Convention NCP, para. 9(c); Stockholm POPs Convention Draft NCP, para. 17(c); Rotterdam PIC Convention Draft NCP, para. 12(c). Shibata, supra n. 1, at 191 notes that: "The purpose of this restriction is to limit the authority of the Secretariat so that it will not actively investigate and search for possible compliance difficulties faced by parties."

${ }^{20}$ A standard provision in this sense is the Aarhus Convention NCP, para. 17: "Where the secretariat, in particular upon considering the reports submitted in accordance with the Convention's reporting requirements, becomes aware of possible noncompliance by a Party with its obligations under the Convention [...]" (emphasis added). See also LRTAP Convention NCP, para. 5, PRTR Protocol NCP, para. 17. 
do not exclude that other sources, such as data from other organs of the Convention, competent international organizations or NGOs or even autonomous investigations, may be used.

While earlier non-compliance procedures have been cautious in opening the procedure to external information, the more recent ones seem to acknowledge the growing importance of coordinating their action with the expertise of other international organizations, also of a non-governmental nature. The Rotterdam PIC Convention Draft non-compliance procedure envisages the possibility - albeit in square brackets, indicating that agreement has not yet been reached on this matter - for the Secretariat to receive "submissions from individuals or organizations having reservations about a Party's compliance with its obligations under the Convention."21

\section{b) The Committee}

Initiative by the compliance body is rarely foreseen by non-compliance procedures because of the negative impact this trigger has on the impartiality of the procedure. ${ }^{22}$

At present only the Espoo and the Aarhus Conventions non-compliance procedures provide for such a triggering function of the compliance committee, ${ }^{23}$ and it might be accepted under the Stockholm POPs Convention Draft non-compliance procedure. ${ }^{24}$

c)

\section{The COP}

The COP is entitled to directly trigger the procedure under the ITPRGFA and the London Dumping Convention. ${ }^{25}$

\section{d) Other Subsidiary Organs}

Compliance procedures may in rare cases be triggered by other organs established under the treaty regime.

Some MEAs, such as the Montreal Protocol, considered this option but finally preferred to limit the role of subsidiary and technical organs to providing complementary information to the Secretariat while drafting its triggering report. ${ }^{26}$

\footnotetext{
${ }^{21}$ Rotterdam PIC Convention Draft NCP, para.12(c).

${ }^{22}$ M. Goote and R. Lefeber, "Compliance Building under the International Treaty on Plant Genetic Resources for Food and Agriculture", Background Study Paper 20 (UNEP), at 11: "Such right would create a situation where the compliance body would become a 'judge' in its own case and the compliance body may therefore not be perceived as an impartial body in such a case."

${ }^{23}$ Espoo Convention NCP, para. 6; Aarhus Convention NCP, para. 14.

${ }^{24}$ Stockholm POPs Convention Draft NCP, para. 17(c alt).

${ }^{25}$ ITPRGFA Draft NCP (Draft Procedures and Operational Mechanisms to Promote Compliance and to Address Issues of Non-Compliance, doc. IT/GB-2/07/14 (2 November 2007)), section.V.1(c); London Dumping Convention NCP, para. 4.1.1.

${ }^{26}$ During the review of the non-compliance procedure there was a proposal to allow the Secretariat of the Multilateral Fund, the Implementing Agencies and other actors, who are in a strategic position to achieve relevant information, to bring non-compliance cases to the Implementation Committee. See Report of the Ad Hoc Working Group of Legal and Technical Experts on Non-Compliance with the Montreal Protocol, doc. UNEP/OzL.Pro/WG.4/1/3 (18 November 1998), para. 3 and F. Romanin Jacur, "The Non-Compliance
} 
The Kyoto Protocol system introduces an innovative element in this regard, because here

"The Committee shall receive, through the secretariat, questions of implementation indicated in reports of expert review teams under Article 8 of the Protocol, together with any written comments by the Party which is subject to the report [...]." ${ }^{27}$

Expert review teams are groups of independent experts, which may be representatives of the Parties but also of international and non-governmental organizations, selected by the Secretariat. ${ }^{28}$ Their mandate is to conduct a "thorough and comprehensive technical assessment" of the reports of States engaged in reducing their greenhouse gases emissions and submit the outcomes of their analysis to the compliance committee. ${ }^{29}$

The fact that expert review teams submit their assessments to the committee represents a very important element which can contribute to the success of the Kyoto Protocol compliance system. ${ }^{30}$

Recently the first question of implementation was identified by an expert review team with regard to Greece. ${ }^{31}$

\section{$2.4 \quad$ Trigger by Non-State Actors}

The right to initiate the procedure could also be attributed to international and nongovernmental organizations competent in the subject dealt with by the treaty.

With regard to this kind of trigger, different approaches have been adopted at the global level and at the regional level, mainly in the framework of UNECE treaties. In fact, while the issue of allowing NGOs the possibility of starting the procedure was considered also during the negotiations of non-compliance mechanisms under MEAs of a global relevance, to date only treaties with a regional application, or with a particular vocation, ${ }^{32}$ have agreed to open the procedure to non-State actors, such as NGOs, observers and, in some cases, even individuals.

Procedure of the 1987 Montreal Protocol to the 1985 Vienna Convention on Substances that Deplete the Ozone Layer", supra 11-32, at 21.

${ }^{27}$ Kyoto Protocol NCP, section VI.1.

${ }^{28}$ On expert review teams, see G. Ulfstein and J. Werksman, "The Kyoto Compliance System: Towards Hard Enforcement", in O. Stokke, J. Hovi and G. Ulfstein (eds.), Implementing the Climate Regime: International Compliance (London [etc]: Earthscan, 2005) 39-62, at 43.

${ }^{29}$ Kyoto Protocol, Art. 8.2. On the negotiating history related to the role of expert review teams, see $\mathrm{X}$. Wang and G. Wiser, "The Implementation and Compliance Regimes under the Climate Change Convention and its Kyoto Protocol", 11 RECIEL (2002) 181-198, at 194.

${ }^{30}$ Ulfstein and Werksman, supra n. 28, at 43 consider that: "[...] most questions of implementation presented to the Compliance Committee will be contained in the reports of the expert review teams. Ensuring that the expert review teams operate in an effective and unbiased manner will therefore be essential to the system's integrity."

31 See Lefeber, supra n. 12, at 315; S. Urbinati, "Procedures and Mechanisms Relating to Compliance under the 1997 Kyoto Protocol to the 1992 United Nations Framework Convention on Climate Change", supra 63-84, at 83 and M. Fitzmaurice, "Non-Compliance Procedures and the Law of Treaties", infra $453-481$, at 479 .

32 The Aarhus Convention, for example, aims at the protection of rights of individuals related to the environment. 
For example, while under the Basel and the Cartagena systems Parties rejected the trigger by NGOs, under the Alpine Convention ${ }^{33}$ and most of the UNECE treaties, such as the Aarhus Convention and its related PRTR Protocol and Water and Health Protocol, NGOs and observers are empowered to submit communications regarding potential non-compliance situations to the compliance bodies. ${ }^{34}$

Some of these latter systems envisage an original and progressive solution: the public trigger. ${ }^{35}$

According to the relevant provisions adopted by the COP of the Aarhus Convention, members of the public are natural and legal persons, not necessarily nationals of a Party to the Convention, and they can submit communications concerning a general failure to implement appropriate legislative measures, as well as specific actions or omissions by State authorities of State Parties which have not opted out. ${ }^{36}$

As already noted above, although the trigger by non-State actors has not been adopted in MEAs with a global scope, here, however, NGOs are entitled to participate at the COPs' meetings and on these occasions they may submit information relating to cases of non-compliance to the COP. Such information may constitute an "indirect trigger" of the non-compliance procedure when the COP considers that the matter is worthy of being forwarded to the competent compliance bodies.

\section{Procedural Aspects Related to the Triggering Phase}

Non-compliance procedures are not conceived as formal and strict procedures mandated at declaring breaches of environmental obligations and corresponding responsibilities of violating States but rather as flexible and amicable means. It follows that generally a flexible approach to the matters under consideration is adopted and therefore procedural aspects, in particular in earlier mechanisms, are not regulated in detail.

However, the need for procedural rules has emerged from the practice and in more recent non-compliance systems greater attention is given to procedural requirements that shall be met, in particular, when the procedure is triggered. ${ }^{37}$

\footnotetext{
33 See Alpine Convention NCP, para. 2: "Il Gruppo di verifica esercita le seguenti funzioni: [...]3. tratta le domande di verifica relative al presunto non rispetto della Convenzione e dei suoi Protocolli che gli vengono sottoposte dalle Parti contraenti e dagli osservatori."

${ }^{34}$ See Alpine Convention NCP, para. 2.3; Aarhus Convention NCP, para. 18; PRTR Protocol NCP, para. 18; Water and Health Protocol NCP, para. 16. Under the Espoo Convention, the public trigger was considered but finally not endorsed, see J. Jendrośka, "Practice and Relevant Cases that Emerged in the Context of the Espoo Convention Implementation Committee", supra 319-335, at 323.

${ }^{35}$ See, for example, Aarhus Convention NCP, para. 18: "On the expiry of twelve months from either the date of adoption of this decision or from the date of the entry into force of the Convention with respect to a Party, whichever is the later, communications may be brought before the Committee by one or more members of the public concerning that Party's compliance with the Convention, unless that Party has notified the Depositary in writing by the end of the applicable period that it is unable to accept, for a period of not more than four years, the consideration of such communications by the Committee."

${ }^{36}$ See Modus Operandi of the Compliance Committee (Modus Operandi), available at $<$ www.unece.org/ env/pp/compliance.htm> (visited 15 July 2008), at 31.

${ }^{37}$ On procedural guarantees see M. Montini, "Procedural Guarantees in Non-Compliance Mechanisms", infra 389-405.
} 
A case of irregular trigger is the way the Russian Federation's compliance was treated under the Montreal Protocol non-compliance procedure. The Russian Federation manifested its compliance difficulties to the COP/MOP, in the first place, and subsequently to the Open-ended Working Group but it did not address its submission to the Secretariat, as requested by paragraph 4 of the procedure. Although neither the COP nor the Working Group are entitled to trigger the procedure, the Implementation Committee was unofficially informed of the non-compliance situation and considered the case as a self-trigger. ${ }^{38}$

The Russian Federation, which was present at subsequent meetings of the COP/ MOP and of the committee, presented many arguments in defense of its non-compliance situation but never challenged the legal basis of the competence of the Implementation Committee to consider its "unintentional submission". Such behavior seems to indicate that the Russian Federation has accepted this trigger of the procedure by acquiescence.

Starting with the preliminary phase of the trigger, there are actions which States and organs intending to initiate the procedure shall go through before formally triggering the procedure.

These are mainly the duty of prior consultation among the Parties and organs involved and the duty to notify the submission to the Party in alleged noncompliance. ${ }^{39}$

It is a common feature of international dispute settlement procedures that before their initiation the Parties concerned should proceed to consultations among them in order to seek to solve the matter in an amicable way. ${ }^{40}$

Compliance procedures also generally envisage a similar duty of prior consultation between the Parties involved, in the case of a Party-to-Party trigger, and between the Party in alleged non-compliance and the Secretariat, in the case of Secretariat trigger, in order to seek a solution before submitting the matter to the compliance bodies.

The prior consultation is usually without a precise time limit when it relates to the Party-to-Party trigger, ${ }^{41}$ while in case of the Secretariat trigger this can only take place after consultations have been carried out for a period of generally three months. ${ }^{42}$

Coming to the strictu sensu triggering phase, a procedural issue to be considered is whether the Secretariat, when informed of a potential case of non-compliance, has a discretionary power to go further with the procedure.

${ }^{38}$ Werksman, supra n. 6, at 764, refers to the Implementation Committee's action as a "bold step".

${ }^{39}$ See, for example, Barcelona Convention NCP, para. 20: "The Secretariat shall, within two weeks of receiving a submission in accordance with paragraph 18(b) [Party-to-Party trigger], send a copy of that submission to the Party concerned"; Kyoto Protocol NCP, section VI.2: "The secretariat shall forthwith make available to the Party in respect of which the question of implementation is raised [...] any question of implementation submitted under paragraph 1 above."

${ }^{40}$ See, for example, Law of the Sea Convention, Art. 283.1: "When a dispute arises between States Parties concerning the interpretation or application of this Convention, the parties to the dispute shall proceed expeditiously to an exchange of views regarding its settlement by negotiation or other peaceful means."

${ }^{41}$ See, for example, Basel Convention NCP, para. 9(b); Stockholm POPs Draft NCP, para. 17(b); Rotterdam PIC Convention Draft NCP, para. 12(b); London Convention NCP, para. 4.1.3. An exception is found in the Barcelona Convention NCP where consultations may not last more than six months (para.18 (b)).

${ }^{42}$ See, for example, Basel Convention NCP, para. 9(c); Stockholm POPs Draft NCP, para. 17(c); Rotterdam PIC Convention Draft NCP, para. 12(c); Barcelona Convention NCP, para. 23. 
In this respect a distinction may be drawn between, the role the Secretariat plays in cases of Party-to-Party and self trigger on the one hand, and in the case of the Secretariat trigger on the other.

While in the former the Secretariat merely has an administrative function consisting of transmitting the submission to the committee and has no discretion in evaluating the compliance matter, ${ }^{43}$ in the latter it has been argued that its triggering power may not be considered as a strict obligation to report to the compliance committee. According to this view, the first step the Secretariat should ("may") undertake to activate the procedure is the request of information from the Party in alleged non-compliance and only after this step has been gone through does a duty to continue the process and bring the matter to the compliance body arise..$^{44}$

However, an overview of the different procedures suggests that a more plausible interpretation would be that in some cases the Secretariat has discretionary power in asking the Party for information before triggering the procedure, but this does not constitute a necessary precondition to the triggering of the procedure. In this view, there may be discretion with regard to the duty of the Secretariat to ask the Parties for information as appropriate but, on the other hand, there is an autonomous legal obligation for the Secretariat to forward the matter to the committee. ${ }^{45}$

\section{AdMISSIBILITY CRITERIA}

Beside the procedural steps there are other requirements that should be met in order to effectively trigger the procedure. Also with regard to these matters there has been increasing attention to substantive and formal criteria that should characterize the submissions presented to compliance bodies.

${ }^{43}$ See, for example, Basel Convention NCP, para. 11: "Where a submission is made under paragraph 9 (a) [self-submission], the secretariat shall forward the submission, within two weeks of its receiving the submission, to the Committee for consideration at its next meeting."

${ }^{44}$ D.G. Victor, "The Early Operation and Effectiveness of the Montreal Protocol's Non-Compliance Procedure", IIASA Paper ER-96-2 (1996), at 5, with regard to the Montreal Protocol, notes that "The Secretariat has an ambiguous obligation to inform the Implementation Committee if it becomes aware of possible non-compliance."

${ }^{45}$ Compare, for example, the provisions of the LRTAP Convention NCP, para. 5: "Where the secretariat, $[. .$.$] becomes aware of possible non-compliance by a Party with its obligations, it may request the$ Party concerned to furnish necessary information about the matter. If there is no response or the matter is not resolved within three months or such longer period as the circumstances of the matter may require, the secretariat shall bring the matter to the attention of the Committee" with the relevant provisions under the Barcelona Convention NCP, para. 23: "If the Secretariat becomes aware [...] that a Party is facing difficulties in complying with its obligations under the Convention and its Protocols, the Secretariat shall notify the Party concerned and discuss with it ways of overcoming the difficulties. If the difficulties cannot be overcome within a maximum period of three months, the Party concerned shall make a submission on the matter to the Compliance Committee in accordance with paragraph 18 (a). In the absence of such a submission within six months of the date of the above mentioned notification, the Secretariat shall refer the matter to the Committee." (emphasis added) 


\subsection{Formal requirements}

Under all non-compliance mechanisms, as a minimum common requirement, submissions shall be made in writing to the Secretariat.

Some of the more recent compliance systems, such as the ones under the Aarhus Convention and the Kyoto Protocol, prescribe detailed rules specifying the content of the submissions.

The Aarhus Convention procedure makes it clear that

"[t]he Committee will not consider any communication that it determines to be: (a) Anonymous; (b) An abuse of right to make such a communication; (c) Manifestly unreasonable; (d) Incompatible with the decision on review of compliance (decision I/7) or with the Convention; (e) Concerning a State which is not a Party to the Convention; (f) Concerning a Party which has opted out." ${ }^{46}$

On the other hand, under the Kyoto Protocol necessary requirements are: the indication of the triggering Party and of the Party concerned, a statement identifying the question of implementation, the reference to the relevant provisions of the Protocol or of COP/MOP decisions, which constitute the legal basis for the submission and, in the case of a Party-to-Party trigger, corroborating information supporting the question of implementation. ${ }^{47}$ Furthermore, submissions "shall be signed by the agent of the Party and be delivered to the secretariat in hard copy and by electronic means" and "any relevant documents in support of the submission or comment shall be annexed to it." ${ }^{\prime 48}$

A formal requisite that may limit the capacity of triggering the procedure is the language in which submissions shall be drafted. Indeed, requiring a specific language places the burden of the translation on the submitting Party. ${ }^{49}$

46 These indications are listed in the Modus Operandi of the Aarhus Convention NCP.

47 See Decision 4/CMP.2 on Rules of Procedure of the Compliance Committee of the Kyoto Protocol, doc. FCCC/KP/CMP/2006/10/Add.1 (2 March 2007), Annex, rules 14 and 15. According to rule 14.2, other elements a self-submission should contain are: “(a) Any provisions of the decisions of the Conference of the Parties serving as the meeting of the Parties to the Kyoto Protocol and the reports of the subsidiary bodies that are applicable to the question of implementation; (b) The information that is material to the question of implementation; (c) The branch from which action is sought; (d) The action requested from the branch; (e) A list of all documents annexed to the submission."

48 Ibid., rule 18.

${ }^{49}$ Under the Espoo Convention NCP, according to rule 21 of the Draft Operating Rules. The draft Operating Rules of the Implementation Committee are set out in Draft Decision IV/2 on the Review of Compliance, doc. ECE/MP.EIA/2008/4 (21 February 2008), Annex, submitted to the fourth MOP. On this issue see also Jendrośka, supra n. 34, at 325. A different approach is adopted by the Aarhus Convention NCP, where the Modus Operandi provides that communications from the public may be submitted in any of the official languages of the Convention (English, French or Russian) and where this is not possible, the Secretariat will arrange the translation into English. This could slow the process but it does not place the burden of translation on the triggering subject. 


\subsection{Substantive requirements}

In as much as the submissions of Parties with regard to themselves are concerned, according to the rules of many non-compliance mechanisms States shall demonstrate that they did their best in order to avoid the situation of non-compliance and explain the causes of their non-compliance. ${ }^{50}$ Some more advanced procedures require also that submissions should indicate the specific obligations and corresponding treaty provisions concerned and, in some cases, also possible solutions considered appropriate to solve the compliance matter.

Furthermore, there are mechanisms that expressly provide for a list of information that shall support the self trigger and the submissions by other Parties or, when admitted, communications from the public, while others more generically refer to "corroborating information". ${ }^{51}$

Compliance committees may consider inadmissible submissions that are manifestly ill-founded ${ }^{52}$ or de minimis. ${ }^{53}$

Another matter that is considered under certain non-compliance procedures in determining the admissibility of the submission is the existence of parallel proceedings under other jurisdictions, i.e., whether the same issue is being considered under a dispute settlement or inquiry procedure..$^{54}$

Under the Aarhus Convention, for example, a communication submitted by an English citizen was declared not admissible because "the matter was subject to an ongoing inquiry", ${ }^{55}$

Moreover, a further requirement is provided by certain UNECE Conventions' noncompliance procedures, according to which the prior exhaustion of local remedies shall be verified:

"The Committee should at all relevant stages take into account any available domestic remedy unless the application of the remedy is unreasonably prolonged or obviously does not provide an effective and sufficient means of redress." ${ }^{56}$

As a final remark, the admissibility of a submission is determined also with regard to the existence of a jurisdiction ratione temporis of the relevant compliance mechanism. In effect, compliance procedures may address situations which have already occurred,

${ }^{50}$ Montreal Protocol NCP, para. 4

1 Ibid., para. 1.

${ }^{52}$ London Convention NCP, para. 4.2.

53 Stockholm POPs Convention Draft NCP, para. 25; Rotterdam PIC Convention Draft NCP, para. 17; Basel Convention NCP, para. 18;

${ }^{54}$ See Espoo Convention NCP, paras. 14, 15. The London Convention NCP, para. 4.6 provides that: "Where a submission raises compliance matters involving radioactive wastes and other radioactive matter, the Secretariat, on behalf of the Compliance Group, shall refer the matter to the IAEA for technical evaluation and review."

${ }_{55}$ See the Letter (Re: Communication ACCC/C/2007/19 (UK) of Mr. Jeremy Wates, (Secretary of the Convention) to $\mathrm{Mr}$. Hall and the Datasheet with the same reference number, available at $<\mathrm{http}: / / \mathrm{www}$.unece. org/env/pp/compliance/C2007-19/toCommunicant2007.12.19.pdf $>$ (visited 15 July 2008).

${ }_{56}$ Aarhus Convention NCP, para. 21. Identical provisions are PRTR Protocol NCP, para. 21 and Water and Health Protocol NCP, para. 19. 
but they may also be called upon to consider possible or future cases of compliance. Usually the Party-to-Party trigger relates to actual compliance problems, ${ }^{57}$ while self submissions or Secretariat/Committee initiatives may concern also future difficulties. ${ }^{58}$

Under the practice of the Espoo Convention with regard to a case between Romania and Ukraine, the committee analyzed whether the assessment of the Bystroe Canal project could be considered to fall within the mandate of the committee. In fact the canal already existed before the two States ratified the Convention, and therefore could not be considered as a "new activity", according to Article 1(v) of the Convention. However, the committee considered that the project falls within the scope of the Convention as it represents a "major change" to a "proposed activity", according to Article 2.3 of the Convention. The committee ends up by stating that:

"In such a situation, the requirements of the Convention do apply to the project and the opinion of the Committee is that Romania should be considered as the 'affected Party'."

\section{CONCLUSION}

The way non-compliance procedures are set in motion is a sensitive issue that finds different solutions, depending on each MEA and its specific features.

The delicate nature of the "trigger issue" is also reflected in the parallel recognition of procedural guarantees and other safeguards in non-compliance mechanisms recognizing a broad trigger. This is the case, for example, of the Aarhus Convention and other UNECE treaties which entitle members of the public to trigger the procedure, but also allow the State Parties to temporarily delay the operation in their respect of this triggering by making a notification that they are unable to accept compliance issues raised by the public. ${ }^{60}$

Another example is provided by the negotiation of the Stockholm POPs Convention procedure, where the Chair of the Working Group, at its session in May 2007, proposed linking the Secretariat trigger to the higher guarantee of consensus voting in

\footnotetext{
${ }^{57}$ See, for example, Espoo Convention NCP, para. 5(a): "A submission may be brought before the Committee by one or more Parties to the Convention that have concerns about another Party's compliance [...]"; Similarly, Barcelona Convention NCP, para. 18(b); Water and Health Protocol NCP, para. 14; Rotterdam PIC Convention Draft NCP, para. 12(b); LRTAP Convention NCP, para. 4(b); PRTR Protocol NCP, para. 15. An exception is found in the Stockholm POPs Convention Draft NCP, para. 17(b).

${ }^{58}$ See, for example, Espoo Convention NCP, paras. 5(b): "A submission may be brought before the Committee by a Party that concludes that, despite its best endeavours, it is or will be unable to comply [...]" and 6: "Where the Committee becomes aware of possible non compliance [...]" (emphasis added); Similarly, Barcelona Convention NCP, paras. 18(a) and 23; Stockholm POPs Convention Draft NCP, para. 17(a) and (c); Water and Health Protocol NCP, para. 13 and 15; Rotterdam PIC Convention Draft NCP, paras. 12(a) and (c); LRTAP Convention NCP, para. 4(a) and 5; PRTR Protocol NCP, paras. 16 and 17.

${ }^{59}$ Review of the Work Done by the Working Group on Environmental Impact Assessment and Adoption of Decisions, doc. ECE/MP.EIA/2008/6 (27 February 2008), para. 37.

${ }^{60}$ Aarhus Convention NCP, section VI.18.
} 
the Committee, replacing majority voting and deleting the more severe measures that may be adopted by the Committee. ${ }^{61}$

Some common features are present in all non-compliance procedures, such as the self-trigger and the Party-to-Party trigger, or the central role of the Secretariat which serves as the intermediary between Parties and compliance bodies by providing the necessary information and communication.

As regards the procedural aspects of the triggering phase, non-compliance procedures, particularly the more recent ones, usually specify the time limits and deadlines to be respected both by the Parties to submit responses and information and for the Secretariat and the Committee to consider the case and take appropriate action.

Another common aspect is the duty to proceed to consultations with the concerned Party before setting in motion the procedure in order to verify whether the case can be solved "informally".

On the other hand there are issues that have been addressed in a different way. These include the sources of information that can be used when triggering the noncompliance procedure, or the other subjects, such as NGOs, observers or other organs of the treaty, that may be entitled to initiate the procedure.

Lacunae have been highlighted by the practice, for example, of the Kyoto Protocol, where the Facilitative Branch was unable to decide on the admissibility of a submission and has shown the uncertainty of the rules governing the triggering phase and the inadequacy of the decision-making methods of the compliance procedure.

Under the Espoo Convention interesting considerations were advanced by the committee on legal aspects of the triggering with regard to the legal basis of the jurisdiction ratione temporis in the Bistroe Canal case.

An overview of existing non-compliance procedures focused on the triggering phase shows that we are still in an early phase of development of these procedures, where relevant rules are subject to evolving interpretation by the compliance bodies and by the Parties involved.

${ }^{61}$ See Report of the Conference of the Parties of the Stockholm Convention on Persistent Organic Pollutants on the Work of its Third Meeting, (Appendix to Decision SC-3/20, Chair's Proposal), doc. UNEP/ POPS/COP.3/30 (4 May 2007), at 63. 
1 


\title{
Chapter Twenty-Two \\ Procedural Guarantees in Non-Compliance Mechanisms
}

\author{
Massimiliano Montini*
}

\section{INTRODUCTION}

In the context of the compliance regimes which have been established under the most relevant MEAs, the issue of the procedural guarantees provided on the basis of such regimes is becoming an important topic which, however, has not yet attracted the attention of many scholars. The difficulty in addressing such a topic lies primarily in the fact that the compliance regimes in question, apart from sharing a common dispute avoidance rather than a dispute settlement approach and from having essentially a facilitative rather than sanctioning nature, do not necessarily have very much in common. Indeed, the compliance regimes which have been developed so far do not derive from or refer to a common model to prevent and address disputes and they are not based on a common list of indicative principles, reference procedures or administrative regulations.

Therefore, the aim of the present contribution lies in the attempt firstly to determine whether some common principles may be said to exist within the compliance regimes elaborated under the most relevant MEAs, ${ }^{1}$ secondly whether some procedural rules and guarantees may be identified and thirdly whether there are common specific features regarding how decisions rendered in the framework of the said compliance regimes are taken.

Before the analysis starts, however, it should be underlined that while all recent multilateral environmental agreements envisage the establishment of specific compliance regimes, MEAs' relevant provisions normally deal only in very brief and broad

\footnotetext{
* The author wishes to thank Dr Francesca Romanin Jacur and Dr Francesca Volpe for their support in drafting the present contribution.

1 The present contribution will be based on the analysis of the provisions of the non-compliance mechanisms of the following MEAs: the Kyoto Protocol, the Montreal Protocol, the Cartagena Protocol, the Basel Convention, the Stockholm Convention on Persistent Organic Pollutants (POPs), the Rotterdam Convention on the Prior Informed Consent Procedure for Certain Hazardous Chemicals and Pesticides in International Trade (PIC), the Aarhus Convention. A list of treaties with full references is provided supra at XXXVII.
}

T. Treves et al., eds., Non-Compliance Procedures and Mechanisms and the Effectiveness of International Environmental Agreements

(C) 2009, T.M.C. Asser PRESS, The Hague, The Netherlands, and the Authors 
terms with the matter and generally mandate the adoption of the procedure to a subsequent decision to be adopted by the COP. ${ }^{2}$

Specific rules governing the compliance regimes are in fact to be found primarily in the Conference of the Parties' decision establishing the procedure. While the COP's decision in question normally regulates the overall functioning of the compliance procedure, more detailed aspects relating to the compliance committee organization and to its work are often contained in the Rules of Procedure, either those of the COP which are applicable mutatis mutandis to its subsidiary bodies (including compliance bodies) or the specific Rules adopted directly by compliance committees.

\section{The Principles of the Non-Compliance Procedure}

In most cases, the COP's decision establishing the compliance regime under the relevant MEA contains a specific reference to the basic principles upon which the procedure is based.

In this sense, a paramount principle which informs all compliance procedures is the general principle of cooperation, in accordance to which Parties and treaty bodies in charge of controlling compliance should act in a facilitative and supportive way in order to help Parties to overcome the non-compliance situation. This principle is often contained in the preamble or in the first paragraphs of all compliance mechanisms, in order to clearly identify the nature of these procedures. Reference is often made also to the basic objectives of the compliance procedures which are to facilitate and promote the implementation and compliance with the treaty's obligations, rather than to sanction the non-compliant Parties.

Building upon the general principle of cooperation, compliance procedures normally contain a list of indicative basic principles upon which the procedure ought to be based. The compliance procedures, therefore, are generally characterized by a series of recurrent constitutive features, variously named as follows: non-confrontational, non-adversarial, cooperative, non-judicial, consultative, transparent, fair, predictable and effective, flexible, simple, facilitative.

An example in this sense is represented by the compliance regime established for the Cartagena Protocol, which is based upon the following main goals: "promote compliance" of the Parties with the provisions of the Protocol as well as "provide advice or assistance, where appropriate". To this effect, the mechanism is meant to be "simple, facilitative, non-adversarial and cooperative in nature". Moreover, "the operation of the compliance procedures and mechanisms shall be guided by the principles of transparency, fairness, expedition and predictability." A specific reference is made also to the duty to take into account "the special needs of developing country Parties, in particular the least developed and small island developing States among them, and Parties with economies in transition.”3

${ }^{2}$ See A. Fodella, "Structural and Institutional Aspects of Non-Compliance Mechanisms", supra 355372 , at 356 .

${ }^{3}$ See Decision BS-I/7 on Establishment of Procedures and Mechanisms on Compliance under the Cartagena Protocol on Biosafety, doc. UNEP/CBD/BS/COP-MOP/1/15 (27 February 2004), Annex I, at 98 
The compliance regime of the Montreal Protocol is also clearly based on the principle of cooperation, although the term "cooperation" is not explicitly stated in the text of the Protocol, which however states as follows:

"The Implementation Committee shall consider the submissions, information and observations referred to in paragraph 7 with a view to securing an amicable solution of the matter on the basis of respect for the provisions of the Protocol". ${ }^{4}$

The reference to the "amicable solution" as the preferred outcome of the procedure, in fact, makes it clear that the procedure is based on a cooperative and facilitative approach.

A further reference to the principle of cooperation is the one contained in the draft compliance regime elaborated for the Stockholm POPs Convention, which is meant to be based, inter alia, upon the principles of cooperation, as stated in the relevant constitutive instrument:

"The procedures shall be administered in a manner that is simple, effective, non-confrontational, non-adversarial, forward-looking, flexible, transparent, fair, predictable and cooperative." 5

In the framework of the Aarhus Convention, in Article 15 there is clearly established a duty placed upon the MOP to establish a compliance procedure based on the following principles and criteria: "be non-confrontational, non-judicial and consultative" for reviewing compliance with the provisions of the Convention. ${ }^{6}$

The compliance procedure established for the Kyoto Protocol is based on the assumption that the "procedures and mechanisms are to facilitate, promote and enforce compliance". In the text of the compliance regime, the usual reference to the most common basic principles which represent the reference criteria for the compliance regimes within the MEAs is absent, but some other, more specific, principles are enunciated for each branch of the compliance committee. For instance, Section IV.4 of the Kyoto non-compliance procedure states that the Facilitative Branch

"shall be responsible for providing advice and facilitation to Parties in implementing the Protocol, and for promoting compliance by Parties with their commitments under the Protocol, taking into account the principle of common but differentiated responsibilities and respective capabilities."

On the other hand, Section V.6 states that measures adopted by the Enforcement Branch

(Cartagena Protocol NCP), section I.3. See C. Ragni, "Procedures and Mechanisms on Compliance under the 2000 Cartagena Protocol on Biosafety to the 1992 Convention on Biological Diversity", supra 101-120, at 105 .

${ }^{4}$ See Art. 8 of the Montreal Protocol.

${ }^{5}$ See Decision SC-3/20 on Non-Compliance, doc. UNEP/POPS/COP.3/30 (4 May 2007), Annex, at 57 (Stockholm POPs Convention Draft NCP) para. 2. See also G. Bigi, "Draft Non-Compliance Procedure under the 2001 Stockholm Convention on Persistent Organic Pollutants", supra 121-135, at 125.

${ }^{6}$ See Art. 15 of the Aarhus Convention. 
"shall be aimed at the restoration of compliance to ensure environmental integrity, and shall provide an incentive to comply." 7

In the Basel Convention, the compliance mechanism is meant to be non-confrontational, transparent, simple and flexible, but here there is a reference also to the features of cost-effective, preventive and non-binding nature as constitutive elements of the procedure, together with the indication that the whole procedure shall be "oriented in the direction of helping parties to implement the provisions of the Basel Convention." 8

All the basic principles just examined, which inform the compliance regimes of the most relevant MEAs, may be finally said to represent the concrete expression of the underpinning dispute avoidance or facilitative nature of the compliance mechanisms, as compared to the dispute settlement or sanctioning nature of the traditional means for the settlement of disputes normally available under international law. ${ }^{9}$ In this sense, they may be considered nothing but specific tools to give a more concrete shape to the facilitative nature of the compliance regimes.

\section{The Procedural Guarantees}

\subsection{Procedural Guarantees under MEAs}

Compliance procedures are typically organised along two different phases. The first one is of a facilitative nature, and in such a context the compliance committee collects and analyses information on the non-compliance situation at stake and finds out the facts and the causes of the matter of concern. The compliance committee may decide, after consultation with the Party concerned, to adopt facilitative measures. The second part of the procedure takes place when, despite the facilitative measures adopted, the compliance case has not been resolved. The compliance committee at this stage may consider recommending to the COP the adoption of further measures, some of them being of a sanctioning nature, to be addressed to the Party whose compliance is at stake.

7 See Decision 27/CMP.1 on Procedures and Mechanisms Relating to Compliance under the Kyoto Protocol, doc. FCCC/KP/CMP/2005/8/Add.3 (30 March 2006), at 92 (Kyoto Protocol NCP), Sections IV.4 and V.6. See S. Urbinati, "Procedures and Mechanisms Relating to Compliance under the 1997 Kyoto Protocol to the 1992 United Nations Framework Convention on Climate Change", supra 63-84.

${ }^{8}$ See Decision VI/12 on Establishment of a Mechanism for Promoting Implementation and Compliance, Appendix, doc. UNEP/CHW.6/40 (10 February 2003), at 45 (Basel Convention NCP), para. 2. See also, A. Fodella, "Mechanism for Promoting Implementation and Compliance with the 1989 Basel Convention on the Transboundary Movements of Hazardous Wastes and Their Disposal", supra 33-48, at 36.

9 See Art. 33 of the UN Charter, which lists the traditional instruments to settle disputes under international law: "The Parties to any dispute, the continuance of which is likely to endanger the maintenance of international peace and security, shall, first of all, seek a solution by negotiation, enquiry, mediation, conciliation, arbitration, judicial settlement, resort to regional agencies and arrangements, or other peaceful means of their own choice". On the relation between non-compliance mechanisms and traditional dispute settlement, see T. Treves, "The Settlement of Disputes and Non-Compliance Procedures", infra 499-518. 
It must be noted that the facilitative stage has to be gone through before action by the COP may be recommended by the compliance committee. The prior exhaustion of the facilitative phase makes it possible for the Party in alleged non-compliance to remedy and return to compliance with the assistance provided by the committee and the secretariat, before having to face a more serious reaction by the compliance committee and the COP. ${ }^{10}$

For instance, notwithstanding the general support for the principle of the prior exhaustion of the facilitative phase, under the practice of the Montreal non-compliance mechanism, the Russian Federation that was found to be in non-compliance with reporting and substantial obligations arising from the Protocol, contested the approach adopted by the Implementation Committee in this respect. In fact, although the committee did go through a consultation phase, where it sought an agreed solution to the matter with the non-complying State, it finally adopted more severe measures without respecting the order to be followed according to the List of Measures that the COP is entitled to adopt in cases of non-compliance, pursuant the Montreal non-compliance procedure. ${ }^{11}$

As to their legal nature, the compliance regimes elaborated under the MEAs do not have the characteristics of judicial proceedings. As evidenced in the legal literature, in fact, this is indicated by several factors:

"[t]he general lack of procedural safeguards for the Parties involved in the process; the minimal consideration of burden of proof issues; and the fact that the outcomes of the compliance process are principally recommendations to the COP." 12

In fact, such regimes rather represent a sort of administrative procedures established by the COPs and managed by the compliance committees. However, this does not mean that they do not include some procedural guarantees, albeit of a different nature and degree than those normally available in judicial proceedings.

Quite on the contrary, the analysis of the most relevant compliance mechanisms elaborated under the MEAs seems to show that some procedural guarantees to be

${ }^{10}$ With regard to the prior exhaustion of the facilitative phase, under the Basel Convention NCP, para. 20, it is provided that: "If, after undertaking the facilitation procedure in paragraph 19 above and taking into account the cause, type, degree and frequency of compliance difficulties, as well as the capacity of the Party whose compliance is in question, the Committee considers it necessary in the light of paragraphs 1 and 2 to pursue further measures to address a Party's compliance difficulties, it may recommend to the Conference of the Parties." Analogous provisions are found in the Stockholm POPs Convention Draft NCP, para. 27 and in the Rotterdam PIC Convention Draft NCP, para. 19 (Decision RC-3/4 Draft text of the Procedures and Mechanisms on Compliance with the Rotterdam Convention, doc. UNEP/FAO/RC/COP.3/26 (10 November 2006), Annex, at 27), see S. Brugnatelli, "Draft Procedures and Mechanisms on Compliance with the 1998 Rotterdam Convention on the Prior Informed Consent Procedure for Certain Hazardous Chemicals and Pesticides in International Trade", supra 85-100, at 94.

11 See Decision VII/18 of the Seventh Meeting of the Parties on Compliance with the Montreal Protocol by the Russian Federation, doc. UNEP/OzL.Pro.7/12 (27 December 1995), para. 8 and F. Romanin Jacur, "The Non-Compliance Procedure of the 1987 Montreal Protocol to the 1985 Vienna Convention on Substances that Deplete the Ozone Layer", supra at 11-32 .

${ }^{12}$ See in H. Adsett, A. Daniel, M. Husain and T.L. McDorman, "Compliance Committees and Recent Multilateral Environmental Agreements: The Canadian Experience with Their Negotiation and Operation", Canadian YB Int'l L., 42 (2004) 91-142, at 103 
applied throughout the various stages of the procedure, so as to duly take into account and protect all legitimate interests of the Parties involved, do exist. Furthermore, they can be seen as the concrete transposition of the general principles underpinning the procedures mentioned in the previous paragraph.

In earlier compliance mechanisms, such as the one of the Montreal Protocol, these procedural guarantees were rare and stated in vague terms, but their relevance has been increasingly rising since then and they have now become an issue of fundamental importance when framing the more recent compliance mechanisms.

In fact, procedural guarantees relating to such administrative procedures are not static features, but they rather constitute a set of elements which may be periodically reviewed, and possibly amended and updated, by the COP in order to take into account the emerging issues and the peculiar needs of the Parties related to the correct implementation of the MEAs.

An example in this sense is represented once again by the Montreal non-compliance mechanism, which was amended in 1998 in order to clarify some vague expressions, specify the deadlines to make sure that Parties involved have sufficient time to respond and furthermore introduce the obligation for the Secretariat to send a reminder in cases when the non-compliant Party has not replied to the first notification. ${ }^{13}$ Moreover, specific provisions recalling the amendments introduced by way of practice under the Montreal Protocol have recently been adopted in the more recent non-compliance procedures, some of which are currently under negotiation. ${ }^{14}$

The following analysis of the procedural guarantees of the compliance mechanisms of the MEAs will be grouping them along three main headings, related, respectively, to: (i) the due process; (ii) the most relevant characteristics of the compliance committee, including composition, impartiality and equitable geographical representation, and to (iii) the main features of the outcomes of the procedures.

\subsection{Due Process}

The presence of adequate procedural guarantees and safeguards within the framework of compliance regimes is essential in order to satisfy the basic requirements of a "due process" characterised by "fairness" for the Parties involved, which - although normally not explicitly mentioned either in the decisions establishing the procedures or in the Rules of Procedure - ought to be considered inherent to each of the compliance mechanisms established under the MEAs which are the subject of the present analysis. $^{15}$

${ }^{13}$ See Decision IV/5 on Non-Compliance Procedure, doc. UNEP/OzL.Pro.4/15 (25 November 1992), at 13 and Annex IV at 44, subsequently amended by Decision X/10 on Review of the Non-Compliance Procedure, doc. UNEP/OzL.Pro.10/9 (3 December 1998), at 23 and consolidated text in Annex II, at 47 (Montreal Protocol NCP), and Romanin Jacur, supra n. 11, at 14.

${ }^{14}$ See, for example, the Stockholm POPs and Rotterdam PIC Conventions Draft NCPs. For an overview of specific deadlines established in order to assure a fair, time and cost effective procedures, see infra, the following paragraph

${ }^{15}$ For a general analysis of the due process requirement within "administrative" procedures, see D.J. Galligan, Due Process and Fair Procedures (Oxford: Clarendon Press, 1996), at 96. 
Under the due process heading, various procedural issues may be considered, ranging for instance from the right to participate in the procedure, to the timeliness of the submissions and the related languages which may be used by the Parties, to the rights of confidentiality and transparency within the procedures.

Participation at the non-compliance procedure is a crucial issue for the Party in alleged non-compliance. Moreover, the participation issue may arise also with respect to the triggering Party, in the case that the procedure has been prompted by another Party to the MEA.

Participation of both the Party that triggered the procedure and the Party concerned is ensured in several compliance procedures in different ways.

Participation at the procedure may take place through different means. In the first place, Parties should be entitled to make written and oral submissions to the committee during the various stages of the procedure. Secondly, their physical presence at meetings constitutes a procedural guarantee that has to be ensured unless there are legitimate reasons to the contrary.

With regard to the first aspect, in earlier compliance procedures the right for the Party, whose compliance is at stake, to submit statements is implied by the fact that the Party is entitled to participate at the meetings of the committee where its submission is going to be considered. ${ }^{16}$

A different approach may be adopted with regard to the participation of the triggering Party at the compliance committee's meetings. While some compliance procedures are favourable to it, others are not. This is due to the fact that in balancing the legitimate interest of the triggering Party with the non-confrontational nature of the compliance mechanism such procedures prefer to give a priority to the latter. This is the case, for instance, of the Basel non-compliance mechanism where the participation of the triggering Party is subject to the prior and favourable decision of the committee and of the Party concerned. ${ }^{17}$

An opposite solution has been adopted in the framework of the Cartagena noncompliance mechanism where an explicit reference is made to the right of the triggering Party to participate at the deliberations of the committee. ${ }^{18}$

A radically different approach has been chosen in all compliance procedures with regard to the participation of both Parties involved (non-compliant Party and triggering Party) in the meetings where the compliance committee adopts the report. In order to assure impartiality, these sessions are closed to the Parties and also when a member of the committee is a representative of a Party involved she/he shall abstain from participating in the decision. ${ }^{19}$

\footnotetext{
${ }^{16}$ See Montreal Protocol NCP, para. 10; Cartagena Protocol NCP, Section IV.4; Basel Convention NCP, para. 15; Kyoto Protocol NCP, Section VIII.8.

17 See Basel Convention NCP, para. 16: "Meetings dealing with specific submissions relating to the compliance of an individual Party shall not be open to other Parties or the public, unless the Committee and the Party whose compliance is in question agree otherwise."

${ }_{18}$ See the Cartagena Protocol NCP, Section IV.4: "A Party, in respect of which a submission is made or which makes a submission, is entitled to participate in the deliberations of the Committee. This Party shall not participate in the elaboration and adoption of a recommendation of the Committee."

19 See Montreal Protocol NCP, para. 11; Basel Convention NCP, para. 15; Kyoto Protocol NCP, Section VIII.2; Decision I/7 on Review of Compliance, doc. ECE/MP.PP/2/Add.8 (2002, subsequently issued on
} 
Finally, as far as the participation in the final phase of the procedure is concerned, an innovative provision is found in the Aarhus Convention non-compliance procedure where it is stated that:

"The Committee shall send a copy of its draft findings, draft measures and any draft recommendations to the Parties concerned and the member of the public who submitted the communication if applicable, and shall take into account any comments made by them in the finalization of those findings, measures and recommendations." ${ }^{20}$

In order to make effective the participation of less developed countries and Parties with special circumstances, several MEAs take into account the specific needs of some categories of Parties. In MEAs addressing biodiversity and climate change, special categories of States are taken into consideration, such as particularly vulnerable small islands developing countries, States with economies in transition, least developed countries.

For instance, the Basel non-compliance procedure provides that particular attention must be paid to the special needs of developing countries and countries with economies in transition, and cooperation between all Parties is to be promoted. The mechanism should complement the work performed by other Convention bodies and by the Basel Convention Regional Centres. ${ }^{21}$

Similarly, the Stockholm POPs Convention Draft non-compliance procedure provides that:

"[t]he non-compliance procedure shall take into account [all principles of the Convention and the] special needs of developing country Parties and Parties with economies in transition and the specific characteristics of the Convention, such as Articles 12, 13 and 7]." 22

The provision of specific deadlines for the submission of statements by the Parties ${ }^{23}$ and by the Secretariat ${ }^{24}$ and of time limits for decisions to be taken by the compliance committee $^{25}$ is a fundamental feature for ensuring a fair and efficient, cost-effective procedure. Some evidence of this feature can be found in almost every MEA at stake: for instance in the Aarhus non-compliance mechanism it is said that each report of the committee shall be finalized not later than twelve weeks in advance of the meeting of

2 April 2004), as amended by Decision II/5 on General Issues of Compliance, doc. ECE/MP.PP/2005/2/Add.6 (13 June 2005), para. 12, (Aarhus Convention NCP), paras. 32-33, see also C. Pitea, "Procedures and Mechanisms for Review of Compliance under the 1998 Aarhus Convention on Access to Information, Public Participation and Access to Justice in Environmental Matters", supra 221-249, at 233.

20 See Aarhus Convention NCP, para. 34. A similar wording can be found in the Stockholm POPs Convention Draft NCP, para. 24.

${ }^{21}$ See Basel Convention NCP, para. 2.

22 See Stockholm POPs Convention Draft NCP, para. 4.

${ }_{23}$ See Basel Convention NCP, para. 13; Kyoto Protocol NCP, Section VI.2; Montreal Protocol NCP, para. 2; Aarhus Convention NCP, para. 15.

${ }^{24}$ See Basel Convention NCP, para. 14; Kyoto Protocol NCP, Section IX.1; Montreal Protocol NCP, para. 2; Aarhus Convention NCP, para. 15.

${ }_{25}$ See Kyoto Protocol NCP, Sections VII.3 and IX.4, 8. 
the Parties at which it is to be considered ${ }^{26}$ and stricter time frames for the procedure, compared to those fixed in the decision establishing the mechanism, have been set by the committee; according to the Cartagena Protocol non-compliance procedure

"the Secretariat shall, within fifteen days of receipt of submission under paragraph 1 (b) above, make the submission available to the Party concerned, and once it has received a response and information from the concerned Party, it shall transmit the submission, the response and information to the Committee."27

In the Kyoto non-compliance mechanism the Party concerned is given ten weeks to make a written submission to the Enforcement Branch and time frames are fixed for the whole subsequent process; similar guarantees are provided by the Montreal non-compliance mechanism as well, where it is established that the Secretariat shall, within two weeks of its receiving a submission, send a copy of that submission to the Party concerned and that any reply is to be submitted to the Secretariat and to the Parties involved within three months from the date of the dispatch or in a longer period as the circumstances of any particular case may require. The Secretariat shall, as soon as the reply and information from the Party are available, but not later than six months after receiving the submission, transmit the submission, the reply and the information, if any, provided by the Parties to the Implementation Committee referred to in paragraph 5, which shall consider the matter as soon as practicable.

According to the Rotterdam PIC Convention Draft non-compliance procedure, the Parties may present responses or comments at every step of the proceedings, while three months are provided for the forwarding to the Secretariat of any additional information.

Moreover, in order to enable an effective participation of the Parties in the compliance procedure, compliance committees may allow the use of various languages for submissions, communications as well as other relevant documents to be filed by the Parties, although the normal working language of all non-compliance mechanisms is nowadays English.

For instance, the Aarhus Convention allows Parties to submit documents in each of the three official languages of the Convention, namely English, French and Russian. Moreover, all provisional documents of the committee, such as draft findings, recommendations or measures are normally issued only in English (although translation into the two other official languages may be arranged upon request), whereas all official documents, including findings, measures and recommendations are issued in the three languages, in accordance with the general UNECE rules.

According to the Stockholm POPs Convention Draft non-compliance procedure, the official languages of the COP, ${ }^{28}$ namely Arabic, Chinese, English, French, Russian and Spanish, shall be considered also as official working languages of the compliance committee. The Rules of Procedure of the COP provide that any statement

\footnotetext{
${ }^{26}$ Aarhus Convention NCP, para. 35

${ }^{27}$ Cartagena Protocol NCP, Section IV.2.

${ }^{28}$ See Decision SC-1/1 on Rules of Procedure, doc. UNEP/POPS/COP.1/SC-1/1 (6 May 2005), at 14, Rule 55.
} 
made in an official language shall be interpreted into the other ones; the same shall also happen as far as official documents of the meetings are concerned.

The compliance committees must base their decisions on the relevant information sources as determined by the decision establishing the mechanism or by the Rules of Procedure. An example in this sense is represented by the provisions of the Kyoto Protocol non-compliance mechanism which foresees that each branch shall base its deliberations on any relevant information provided by:

“(a) Reports of the expert review teams under Article 8 of the Protocol; (b) The Party concerned; (c) The Party that has submitted a question of implementation with respect to another Party; (d) Reports of the Conference of the Parties, the Conference of the Parties serving as the meeting of the Parties to the Protocol, and the subsidiary bodies under the Convention and the Protocol; and (e) The other branch." ${ }^{29}$

Another procedural safeguard that contributes to the fairness and efficiency of the procedure is provided by the minimum content of the submissions in the case that another Party to the MEA triggers the procedure. In relation to this aspect recent MEAs provide in detail what the submissions should contain. ${ }^{30}$

Moreover, the interests of the Parties may need to be safeguarded in the case of discrepancies between the data contained in their reports and data provided, for example, by other sources. Such a case has been addressed by the Montreal non-compliance mechanism and it was decided that the Secretariat may ask for further clarifications by the Party but has no right to reject the submitted data and in the case that the data remain inconsistent, the data provided by the Party to the Secretariat should be used. ${ }^{31}$

A different approach has been adopted by the Kyoto Protocol non-compliance mechanism, where the Enforcement Branch in case of disagreement between an Expert Review Team and a Party involved has the power to decide

29 See Kyoto Protocol NCP, Section VIII.3.

${ }^{30}$ Extremely detailed provisions are contained in the Rules of Procedure of the Compliance Committee of the Kyoto Protocol, Decision 4/CMP.2 on Compliance Committee, doc. FCCC/KP/CMP/2006/10/ Add.1 (2 March 2007), at 17, Rule 15: "1. A submission by any Party raising a question of implementation with respect to another Party shall set out: (a) The name of the Party making the submission; (b) A statement identifying the question of implementation; (c) The name of the Party concerned; (d) A reference to the provisions of the Kyoto Protocol and decision 27/CMP.1 that form the basis for raising the question of implementation; (e) Corroborating information supporting the question of implementation. 2. The submission should also set out: (a) Any provisions of the decisions of the Conference of the Parties serving as the meeting of the Parties to the Kyoto Protocol and the reports of the subsidiary bodies that are applicable to the question of implementation; (b) The branch from which action is sought; (c) A list of all documents annexed to the submission." On the same issue see also the Basel Convention NCP, para. 10.

31 See Report of the Seventh Meeting of the Parties, doc. UNEP/Ozl.Pro.7/12 (27 December 1995), para. 38, stating that: "Regarding potential discrepancies between data submitted by a Party and data available elsewhere, as was the case concerning the population figures for Lebanon, the Committee had agreed that the best available data should be used whenever possible and supported consultations by the Secretariat to that end. The Committee had also agreed, as the matter concerned sovereign States, that data submitted and supported by an individual country might be respected." 
"adjustments to inventories under Article 5, paragraph 2 of the Protocol [...] and correction to the compilation and accounting database for the accounting of assigned amounts under Article 7, paragraph $4[\ldots] .{ }^{\prime 32}$

Moreover, Parties whose compliance is under scrutiny, should be given the possibility to comment and respond to information provided by other Parties and/or third parties, such as for instance some amici curiae, which in certain non-compliance mechanisms are given the possibility to submit pertinent observation and documents. ${ }^{33}$

Finally, the concerned Parties should be given the possibility to analyse and comment the draft recommendations prepared by the compliance committee for the COP, before they are finally adopted and issued.

For instance, in the Cartagena Protocol non-compliance mechanism it is provided that a Party, in respect of which a submission is made or which makes a submission, is entitled to take part in the deliberations of the committee, except for those regarding the adoption of recommendations. However, in the latter case the Party concerned shall be given an opportunity to present in writing its comments on such recommendations that shall be forwarded to the COP/MOP, together with the compliance committee's report and proposed decision.

What we have just mentioned, in fact, may be said to represent the practical expression of the right to due process (principe du contradictoire), which ought to be respected also in such administrative procedures as the ones established under the compliance mechanisms examined here. ${ }^{34}$

The right to due process (principe du contradictoire) is also related to the principles of transparency and confidentiality. In fact, all compliance procedures address the treatment of confidential information. A typical provision in this sense may be found in the Rotterdam PIC Convention Draft non-compliance procedure:

"Subject to Article 14 of the Convention, the Committee, any Party and any person involved in the deliberations of the Committee shall protect the confidentiality of information received in confidence." ${ }^{35}$

Article 14 of the Rotterdam PIC Convention specifies in detail the categories of information that shall not be considered as confidential, ${ }^{36}$ and in so doing, it gives clear guidelines to the compliance committee and to the Parties involved in the procedure on what information may be treated as confidential. Neither the committee nor the Parties will then have any discretionary power in determining what information is to be kept confidential.

32 See the Kyoto Protocol NCP, Section V.5.

${ }^{33}$ See Kyoto Protocol NCP, Section VIII.4. On this issue see also L. Boisson de Chazournes and M.M. Mbengue, "A propos du caractère juridictionnel de la procédure de non-respect du Protocole de Kyoto", in S. Maljean-Dubois (ed.), Changements climatiques, les enjeux du contrôle international (La Documentation Française: Paris, 2007) 73-109, at 94

${ }^{34}$ See Boisson de Chazournes and Mbengue, supra n. 33, at 95.

${ }_{35}$ Rotterdam PIC Convention Draft NCP, para. 23.

${ }^{36}$ See Rotterdam PIC Convention, Art. 14.3. 
A similar provision is found in the Draft non-compliance procedure of the Stockholm POPs Convention, where the confidentiality of sensitive information is a matter that is taken into account. However, in such a case there are some limitations to the discretionality the Parties have in assessing the confidential nature of issues at stake. ${ }^{37}$ In fact, this provision recalls Article 9.5 of the Convention, which states that:

"For the purpose of this Convention, information on health and safety of humans and the environment shall not be regarded as confidential. Parties that exchange other information pursuant to this Convention shall protect any confidential information as mutually agreed."

Confidentiality may also be in relation with whether the meetings of the committee shall be open or closed. Some compliance procedures directly regulate the matter. An example in this sense is represented by the Kyoto Protocol non-compliance mechanism, where it is established that the Party under scrutiny for alleged non-compliance has the right to be heard by the Enforcement Branch and that

"[s]uch a hearing shall be held in public, unless the enforcement branch decides, of its own accord or at the request of the Party concerned, that part or all of the hearing shall take place in private. ${ }^{\prime 38}$

Several other MEAs do not explicitly regulate the issue of confidentiality in relation to the meetings of the compliance committee. The issue is sometimes addressed by Rules of Procedure of the meetings of the committee, but more often it is decided on a case-by-case basis by the Chair of the committee depending on the matters that will be discussed in the following meeting. ${ }^{39}$

Moreover, with regard to some MEAs, an important transparency provision provides that when the compliance committee adopts the final report by majority voting, the report shall reflect the view of all members of the committee. ${ }^{40}$

\subsection{The Compliance Committee: Composition, Impartiality and Equitable Geographical Representation}

As regards the status of members of compliance committees, different solutions have been adopted under MEAs. In earlier non-compliance mechanisms, such as the Montreal Protocol, members are representatives of State Parties. ${ }^{41}$ More recently,

37 See Stockholm POPs Convention Draft NCP, para. 31.

38 See Kyoto Protocol NCP, Section IX.2.

39 This issue, for instance, has been addressed by the Cartagena Protocol compliance committee, see Report of the Second Meeting of the Compliance Committee under the Cartagena Protocol, Annotations to the Provisional Agenda, doc. UNEP/CBD/BS/CC/2/1/Add.1 (18 November 2005), item. 3, para. 14.

${ }^{40}$ See Decision BS-II/1 on Rules of Procedure for Meetings of the Compliance Committee, Annex, doc. $\mathrm{UNEP} / \mathrm{CBD} / \mathrm{BS} / \mathrm{COP}-\mathrm{MOP} / 2 / 15$ (6 June 2005), at 29, Rule 18.1: "The Committee shall make every effort to reach agreement on all matters of substance by consensus. If all efforts to reach consensus have been exhausted and no agreement has been reached, any decision shall, as a last resort, be taken by a two-thirds majority of the members present and voting or by eight members, whichever is the greater. Where consensus is not possible, the report shall reflect the views of all members of the Committee."

41 See Montreal Protocol NCP, para. 5. 
while in the Aarhus Convention, the Cartagena and Kyoto Protocols non-compliance mechanisms the members serve in their personal capacity, ${ }^{42}$ under the Basel, Rotterdam PIC and Stockholm POPs Conventions they are representatives of State Parties with the specific duty to act "[o]bjectively and in the best interest" of the treaty. In fact, in these latter cases, departing from the more traditional approach, a compromise solution was found to compose the views of some States which suggested that members should be experts serving in their personal capacities only, with those of other States which were not keen to empower independent experts with an external scrutiny on the implementation of their obligations. ${ }^{43}$

In most MEAs it is established that the members of the compliance committee are required to have a specific legal or technical background in order to ensure that the requirements for a "due process" are respected, in particular in terms of recognised competence and impartiality.

The impartiality requirement also includes a specific duty for the members of compliance committees to make sure that any possible "conflict of interest" during the discharge of their duties is avoided. ${ }^{44}$ In this view, there are non-compliance procedures that provide for specific rules and criteria to be followed by the members of the committee who find themselves in a conflict of interest. ${ }^{45}$

Beside the issues related to the composition rules and the impartiality requirements, another interesting feature which is common to most compliance regimes is the rule of the "equitable representation" of the five regional groups of the United Nations, which ought to be respected in the selection process for the choice of the members for the compliance committees.

Some pertinent examples in this sense may be found in the compliance regimes established for instance by the Kyoto Protocol, the Basel Convention or the Rotterdam PIC Convention. In the Kyoto procedure it is established that each of the two branches which compose the compliance committee must consist of

"[o]ne member from each of the five regional groups of the United Nations and one member from the small island developing States, two members from Parties included in Annex I and two members from Parties not included in Annex I." ${ }^{46}$

In similar terms, the fifteen members of the Basel Convention non-compliance mechanism must be nominated by the Parties and elected by the COP on the basis of

${ }^{42}$ See Aarhus Convention NCP, para. 2; Cartagena Protocol NCP, Section II.3; Kyoto Protocol NCP, Section II.6.

${ }^{43}$ See Basel Convention NCP, para. 5; Rotterdam PIC Convention Draft NCP, para. 3; Stockholm POPs Convention Draft NCP, para. 7.

${ }^{44}$ For instance in the Kyoto Protocol NCP, it is established that the Plenary of the Compliance Committee may adopt rules, inter alia, on the conflict of interests: see Kyoto Protocol NCP, Section III.2(d).

${ }^{45}$ See, for instance, the Stockholm POPs Convention Draft NCP, para. 16: "Each member of the Committee shall, with respect to any matter that is under consideration by the Committee, avoid direct or indirect conflicts of interest. When a member finds himself or herself faced with a direct or indirect conflict of interest, or is a citizen of a Party whose compliance is in question, that member shall bring the issue to the attention of the Committee before consideration of the matter. The concerned member shall not participate in the elaboration and adoption of a recommendation of the Committee in relation to that matter."

46 See Kyoto Protocol NCP, Sections IV.1 and V.1. 
the "equitable geographical representation of the five regional groups of the United Nations." Moreover, an almost identical provision is contained in the Rotterdam PIC Convention Draft non-compliance procedure, according to which in "electing members [of the Compliance Committee], due consideration shall be given to the principle of equitable geographical representation of the regional groups of the United Nations." ${ }^{47}$

\section{The Outcomes of the Procedures}

The issue of the main features of the outcomes of the procedures is somehow related to the principles upon which the compliance procedures and the procedural guarantees examined in the previous paragraphs are based. However, it seems more appropriate to deal with it in a separate paragraph.

The main features which will be presented and briefly discussed here refer to the motivation of the decisions recommended by the compliance committees and normally adopted by the COPs of the several MEAs, to the voting procedure, which is normally based on consensus at least as the normal means, to the boundaries of the discretionary power of the compliance committees in choosing and proposing measures and sanctions against non-compliant Parties as well as to the possibility to foresee a right of appeal against the decisions taken by the COP upon recommendations by the compliance committee, which to date is foreseen just by the compliance regime elaborated for the Kyoto Protocol.

As far as the motivation of the decisions recommended by the compliance committees is concerned, it should be noted that in all compliance regimes it is normally explicitly stated that decisions taken against non-compliant Parties must include "conclusions and reasons", so as to enable the Party to understand the precise and concrete reasons upon which the measures proposed are based. For instance, the Kyoto Protocol non-compliance mechanism requires that "[d] ecisions shall include conclusions and reasons" and that they must be notified in writing to the Party concerned, which must be given the possibility to comment in writing on any decision of the relevant branch. ${ }^{48}$

With regard to the voting procedure adopted for the decisions of the compliance committees, it can be said that in all the compliance regimes examined, decisions by the compliance committees are normally taken by consensus. However, in some cases, should it prove impossible to reach a decision by consensus in a specific circumstance, a majority vote system is foreseen.

This is the case, for instance, of the Kyoto Protocol which prescribes that:

" $[t]$ he Committee shall make every effort to reach agreement on any decisions by consensus. If all efforts at reaching consensus have been exhausted, the decisions shall as a last resort be adopted by a majority of at least three fourths of the members present and voting."

\footnotetext{
${ }^{47}$ See Rotterdam PIC Convention Draft NCP, para. 2.
}

${ }^{48}$ See Kyoto Protocol NCP, Section VIII.7, 8. 
In addition, in the case of decisions adopted by the Enforcement Branch, their adoption shall require a majority of members from Parties included in Annex I present and voting, as well as a majority of members from Parties not included in Annex I present and voting, whereas "members present and voting means members present and casting an affirmative or a negative vote." 49

Similarly, under the provisions of the Aarhus Convention non-compliance mechanism,

"Every effort shall be made to adopt the report by consensus. Where this is not possible, the report shall reflect the views of all the Committee members." 50

Similar, but more sophisticated, approaches have been proposed for the Rotterdam PIC Convention Draft non-compliance procedure, according to which:

"The Committee shall make every effort to reach agreement on all matters of substance by consensus. [Where this is not possible, the report shall reflect the views of all the Committee members. If all efforts to reach consensus have been exhausted and no agreement has been reached, any decision shall, as a last resort be taken by a two-thirds majority of the members present and voting or by 8 members, whichever is greater]." ${ }^{51}$

In most cases, compliance committees have a broad discretionary power in choosing sanctions, despite the existence in some non-compliance mechanisms of an "indicative list" of consequences for non-compliance by Parties. ${ }^{52}$ The only exception to that is represented by the case of the Kyoto Protocol non-compliance mechanism with respect to the Enforcement Branch, which may issue against the non-compliant Party only those "measures" explicitly foreseen by the Decision establishing the compliance regime. ${ }^{53}$

An unresolved issue in this sense relates to whether it is better in terms of guarantees for the non-compliant Party that the compliance committees established under MEAs have a greater or more limited discretionary power in choosing sanctions. In fact, in general terms, a greater flexibility related to a broader discretionary power may be better suited in the context of facilitative mechanisms such as those foreseen by the MEAs compliance regimes. On the other side, in the case where the compliance committee is empowered to adopt measures against the non-compliant Parties which amount to real sanctions, the said Parties are probably better guaranteed if there is a more limited discretionary power in choosing the type of sanctions which may be issued.

In addition to that, another open question relates to whether it is possible to argue for the implicit existence of a duty to prior recourse to facilitative measures in the

\footnotetext{
${ }^{49}$ Ibid., Section II.8, 9 .

${ }^{50}$ See Aarhus Convention NCP, para. 35

${ }^{51}$ See Rotterdam PIC Convention Draft NCP, paras. 10, 11.

${ }^{52}$ The List of measures is contained in the Report of the Fourth Meeting of the Parties, Annex V, doc. UNEP/OzL.Pro.4/5 (25 November 1992).

${ }^{53}$ See Kyoto Protocol NCP, Section XV. On this issue see also M. Montini, "The Compliance Regime of the Kyoto Protocol", in W.T. Douma, M. Massai and M. Montini (eds.), The Kyoto Protocol and Beyond (The Hague: TMC Asser Press, 2007) 95-109, at 103.
} 
framework of the compliance mechanisms of the most relevant MEAs. The issue is quite sensitive with regard to earlier compliance procedures which do not distinguish between a facilitative and an enforcement phase, such as the Montreal Protocol noncompliance mechanism, whereas the solution seems to be easier in more recent compliance procedures, such as the one of the Kyoto Protocol, which foresees a double track system, encompassing a Facilitative and an Enforcement Branch, which ought to apply a different set of consequences against a non-compliant Party.

Finally, it should be underlined that so far only the Kyoto Protocol compliance regime envisages the possibility of an appeal to the COP against a final decision of the Enforcement Branch, in the case that a Party considers that it was denied a due process. ${ }^{54}$ In such a circumstance, the COP may decide to override the appealed decision by three-quarters majority and refer the matter back to the Enforcement Branch.

The possibility to introduce a right of appeal was also discussed by the COP of the Montreal Protocol but no decision in this sense was ever taken. ${ }^{55}$

\section{CONCLUSION}

The attention devoted to procedural guarantees or safeguards with regard to compliance procedures relating to MEAs is a specific feature of a broader issue concerning the legitimacy of international environmental governance and dispute resolution or avoidance. ${ }^{56}$ It is indeed very important to build confidence and trust in the compliance regimes just seen above and the existence of procedural guarantees or safeguards may significantly contribute to increase the perception of the dispute avoidance or compliance procedures as legitimate and effective tools to address and resolve cases of non-compliance. ${ }^{57}$ This issue is particularly important for compliance procedures entailing more severe measures, such as in the case of the Kyoto Protocol non-compliance mechanism, where, as highlighted above, some of the consequences which may be adopted by the compliance committee against a non-compliant Party may

\footnotetext{
54 See Kyoto Protocol NCP, Sections VII.3 and IX.4, 8.

55 See Romanin Jacur, supra n. 11, at 22.

${ }^{56}$ On this issue, see D. Bodansky, "The Legitimacy of International Governance: A Coming Challenge for International Environmental Law?", Am. J. Int'l L., 93 (1999) 596-627; D. Bodansky, "Legitimacy”, in D. Bodansky, J. Brunnée and E. Hey (eds.), Oxford Handbook of International Environmental Law (Oxford: Oxford University Press, 2007) 704-723; J. Brunnée, "Between Sovereignty, Efficiency, and Legitimacy: Lawmaking under Multilateral Environmental Agreements", in O.C. Okafor and O. Aginam (eds.), Humanizing Our Global Order: Essays in Honour of Ivan Head (Toronto: University of Toronto Press, 2003) 62-79; R. Wolfrum, "Legitimacy in International Law", A. Reinisch and U. Kriebaum (eds.), The Law of International Relations: Liber Amicorum Hanspeter Neuhold (Utrecht: Eleven International Publishing, 2007) 471-482.

57 See E. Hey, "International Institutions", in Bodansky, Brunnée and Hey (eds.), supra n. 56, 749-769, at 767: "Formalization of compliance procedures again, I suggest, is a factor that will contribute to securing the legitimacy of ensuing decisions. Given the interest at stake in compliance procedures, such procedures should be transparent, result in reasoned decisions that are proportional, and be subject to scrutiny through, for example, an appeals procedure. Compliance procedures, however, have not attained this degree of formalization."
} 
amount to real "sanctions". However, it is outside the scope of the present chapter to deal extensively with such a broad issue.

A final comment may relate to whether some sort of coordination among the principles upon which the compliance procedures are based and the related procedural guarantees and features may be needed. Provided that no coordination exists at the moment, but considering the fact that many countries, particularly less developed Parties, are progressively becoming overloaded with all the administrative work required by all the MEAs to which they are Parties, the possibility to adopt some sort of common principles, as well as some common procedural guarantees and features for most MEAs, should be seriously explored, particularly in all those cases where differences are not required by the specific nature or context of the specific MEA at stake.

In this sense, an interesting starting point for exploring such a possibility could be represented by the work undertaken in the recent past by the UNEP on the issue of the implementation and enforcement of international environmental agreements, which has led to the adoption of the "Guidelines on Compliance with and Enforcement of Multilateral Environmental Agreements" (2002) and the related "Manual on Compliance with and Enforcement of Multilateral Environmental Agreements" (2006). ${ }^{58}$

The Guidelines in particular, although being advisory only, purport to define some common principles which may help Parties and COPs in the management of compliance issues related to MEAs. So far, the Guidelines contain just a very brief reference to the opportunity to promote the adoption of specific compliance mechanisms for all MEAs, which ought to include procedural safeguards for the Parties involved. ${ }^{59}$

A further way to progress in the work already done by UNEP could consist in developing common procedural guarantees or safeguards to be used in various MEAs as reference characteristics and features for the functioning of their specific compliance procedures.

${ }^{58}$ See the UNEP Guidelines, Draft Guidelines on Compliance with and Enforcement of Multilateral Environmental Agreements, doc. UNEP/GCSS.VII/4/Add.2 (23 November 2001), Annex, adopted by the UNEP Governing Council with Decision SS.VII/4 on Compliance with and Enforcement of Multilateral Environmental Agreements, doc. UNEP/GCSS.VII/6 (5 March 2002), Annex I, at 43, and the Manual in $<$ http://www.unep.org/dec/onlinemanual/> (visited 15 July 2008)

${ }^{59}$ See Art. 14(d)(iii) of the UNEP Guidelines. 
1 


\title{
Chapter Twenty-Three
}

\section{The Outcomes of the Procedure and their Legal Effects}

\author{
Enrico Milano
}

\section{INTRODUCTION}

The outcomes and effects of non-compliance procedures under multilateral environmental agreements (MEAs) are related to the very legal nature of these procedures and the objectives they seek to achieve. MEAs are for the most part based on the commitment of State Parties to put in place short- and long-run national strategies and policies to reach reduction targets set at the international level as a result of the transnational nature of many environmental concerns. Classical means of law-assessment and law-enforcement at the inter-State level such as those under the law of State responsibility exist in theory, yet practice shows that the nature of environmental obligations under MEAs does not easily lend itself to adjudication or arbitration, nor to the adoption of countermeasures and requests for reparation. The only, but nonetheless significant, tools in the hands of international bodies established under those conventions to monitor and induce compliance is to remind States of their commitments, monitor their level of compliance through a thorough and comprehensive reporting system and offer technical advice and financial support for those Parties encountering difficulties with compliance. In other words, the non-compliance procedures are primarily non-confrontational and supportive. Thus, the outcomes and effects related thereto normally tend to induce compliance by States Parties through soft and facilitative measures, such as advice, recommendations, technical and financial assistance; as we shall see, stronger measures such as condemnations and the suspension of treaty rights and privileges and sanctions play a residual, yet not absent, role.

The present chapter aims to examine the outcomes of non-compliance procedures under MEAs and their legal effects on non-complying Parties through a comparative analysis of the phenomenon. It seeks to provide an overall mapping and evaluation, yet it is by no means exhaustive of all the kinds of measures and outcomes which may greatly vary from treaty to treaty. We shall first consider the decision-making process leading to the adoption of measures related to non-compliance, with particular regard to the institutional setting involved in the negotiation and determination of outcomes and effects for the non-complying Party. We shall then look at the different types of measures and their legal effects, with special emphasis on the question of possible additional legal obligations created for the non-complying Party.

T. Treves et al., eds., Non-Compliance Procedures and Mechanisms and the Effectiveness of International Environmental Agreements

(C) 2009, T.M.C. ASSER PRESS, The Hague, The Netherlands, and the Authors 
It should be pointed out at the very outset that, while the question of the effectiveness of institutional mechanisms overseeing compliance is at the core of a description and assessment of any of the many interesting issues involving non-compliance procedures under MEAs examined in the present volume, the impact that such mechanisms actually produce in practice on State Parties' compliance is beyond the scope of the present analysis. Suffice it to state that practice under these non-compliance procedures is so far rather scanty and that in order for one to make sense he/she should wait until most of these procedures become operational. Moreover, the overall question of the effectiveness of MEAs and their non-compliance procedures will have to result from cross-cutting, comparative assessments by lawyers, economists, scientists and international relations theorists. ${ }^{1}$

\section{DeCISION-MAKING AND TyPes OF Measures}

While compliance bodies play a central role in determining the outcomes and effects of their own procedures, their decision-making function is often exercised in conjunction with Conferences of the Parties or Meetings of the Parties (COP/MOP), these latter being the main political body within environmental regimes. In that respect one can be drawn to differentiate outcomes and effects which are produced by the action of the compliance committee alone, on the one hand, and outcomes and effects which are the result of communication and joint procedures involving both the compliance committee and the conference or meeting of the Parties, on the other. This differentiation is important because decision-making in a conference or meeting of the Parties by the very nature of this organ is much more political, while compliance bodies, despite often being composed of State Parties' representatives tend to be much more focussed on the technicalities of compliance.

As far as the 'exclusive' competence of the compliance bodies per se is concerned, it is important to note their central role in the determination of non-compliance, which normally precedes, or is a pre-condition for, any action taken with regard to a State Party. While such a determination is at the core of the non-compliance procedure, it should not be confused with a judicial or quasi-judicial function where a third party simply assesses the conformity of State conduct with its legal obligations. First of all, a non-compliance situation may be submitted by the non-complying Party itself, which makes the compliance body the recipient of a preliminary self-assessment (which is far from an adversarial claim). Secondly, the non-compliance procedure may be triggered also in order to prevent violations of treaty obligations, rather than to react to a violation of the treaty that has already occurred. Thirdly, a committee may interpret its role of non-compliance determination in a broad manner, which involves initiating a non-compliance procedure also with regard to situations where

\footnotetext{
${ }^{1}$ For interesting insights on compliance under MEAs from the point of view of international relations theory see R. Mitchell, "Compliance Theory: Compliance, Effectiveness and Behavioural Change in International Environmental Law", in D. Bodansky, J. Brunnée and H. Hey (eds.), The Oxford Handbook of International Environmental Law (Oxford: Oxford University Press, 2007) 893-920.
} 
the Party, albeit not infringing upon any provision of the treaty, acts contrary to the spirit of the treaty itself and to general principles of international law. ${ }^{2}$

Still as to the exercise of the competence by the compliance bodies, we may mention the compliance regimes under the Basel Convention and under the Aarhus Convention. ${ }^{3}$ In this context, the committee may provide the Party encountering difficulties with compliance with information, advice and non-binding recommendations.

Such assistance may concentrate, inter alia, on: establishing or strengthening the Party's regulatory regimes; facilitating assistance, especially for developing countries and countries with economies in transition, on access to financial and technical support; elaborating voluntary compliance action plans and reviewing their implementation; establishing follow-up arrangements for progress reporting to the committee. As far as the Basel Convention is concerned, the outcome should be provided "after coordination" with the Party concerned. ${ }^{4}$ The list is not exhaustive and the Implementation Committee may also adopt other kinds of measures, yet such measures should be taken "in agreement" with the Party concerned. ${ }^{5}$ As underlined by Alessandro Fodella, the wording suggests that in the latter case the Party has a stronger role than in the former. ${ }^{6}$ Another difference, according to that author, may be that the Implementation Committee has the power to adopt measures of the first kind and that the "coordination" refers to the implementation only; whereas for the second kind of measures the adoption must be in agreement with the Party concerned.

The requirement of consent by the non-complying Party is also provided under the Aahrus Convention with regard to recommendations issued by the Compliance Committee. Such a requirement has been bypassed by re-formulating the recommendation in the form of advice, which only requires "consultation with the Party concerned". In any case, the Compliance Committee has maintained that it will not take such an action if an MOP is to take place within a few months; in such case it would only report to the MOP. ${ }^{9}$

It appears that the regime where the Compliance Committee plays the most independent and important role in enhancing compliance by State Parties is that of the

\footnotetext{
2 See the case of Hungary before the Aarhus Committee, mentioned in C. Pitea, "Procedures and Mechanisms for Review of Compliance under the 1998 Aarhus Convention on Access to Information, Public Participation and Access to Justice in Environmental Matters", supra 221-250.

3 A list of treaties with full references is provided supra at XXXVII. For the non-compliance mechanisms under the two conventions see, respectively: Decision VI/12 on Establishment of a Mechanism for Promoting Implementation and Compliance, doc. UNEP/CHW.6/40 (10 February 2003), at 45 (Basel Convention NCP), see A. Fodella, "Mechanism for Promoting Implementation and Compliance with the 1989 Basel Convention on the Transboundary Movements of Hazardous Wastes and Their Disposal", supra 33-48; and Decision I/7 on Review of Compliance, doc. ECE/MP.PP/2/Add.8 (2001, late issued on 2 April 2004), as amended by Decision II/5 on General Issues of Compliance, doc. ECE/MP.PP/2005/2/Add.6 (13 June 2005), para. 12 (Aarhus Convention NCP), see Pitea, supra n. 2.

${ }^{4}$ Basel Convention NCP, para. 19.

5 Ibid.

${ }^{6}$ See Fodella, supra n. 3

7 Ibid., at 44

${ }^{8}$ Pitea, supra n. 2, at 241.

${ }^{9}$ Ibid.
} 
Kyoto Protocol. ${ }^{10}$ According to Section XIV, the Facilitative Branch of the Compliance Committee is responsible for the "provision of advice and facilitation of assistance to individual Parties regarding the implementation of the Protocol", as well as the "facilitation of financial and technical assistance [...], including technology transfer and capacity building from sources other than those established under the Convention and the Protocol for the developing countries."

The Enforcement Branch under the same Kyoto Protocol non-compliance procedure does not have a general mandate, but it is responsible for overseeing compliance by Annex I Parties. Section XV describes a number of different measures to be taken according to the type of non-compliance. ${ }^{12}$ In the event of non-compliance by an Annex I Party with the requirements provided by Articles 5.1 and 5.2 to the effect that a national system should be established or that related to the updating of the annual inventory as provided by Article 7.1 and 7.4, the Enforcement Branch shall apply the following consequences: a) a declaration of non-compliance; b) the development of a plan in accordance with the following procedure: the Party found not in compliance shall, within three months after the determination of non-compliance, or such longer period that the Enforcement Branch deems appropriate, submit a plan that includes: (a) an analysis of the causes of non-compliance of the Party; (b) measures that the Party intends to implement in order to remedy the non-compliance; (c) a timetable for implementing such measures within a time frame not exceeding twelve months which enables the assessment of progress reports on the implementation of the plan on a regular basis. ${ }^{13}$

Where the Enforcement Branch has determined that a Party is not in compliance with the obligation to reduce emission of greenhouse gases as provided for in Article 3.1 of the Protocol, it may apply the following consequences: "a) deduction from the Party's assigned amount for the second commitment period of a number of tonnes equal to 1.3 times the amount in tonnes of excess emissions; b) development of a compliance action plan in accordance with paragraph 6 and 7 below; and c) suspension of the eligibility to make transfers under Article 17 of the Protocol until the Party is reinstated in accordance with section X, paras. 3 or $4 .{ }^{\prime 14}$

Where a non-compliance situation is found as a result of a Party's unwillingness to act, the procedure provides for the application of consequences in the form of a suspension of the rights, benefits and privileges granted under the Convention. Under the non-compliance procedure in point there are two cases in which privileges and benefits may be suspended. The first is where an Annex I Party fails to meet one or more eligibility requirements to accede to the flexibility mechanism. The second is the case

${ }^{10}$ Decision 27/CMP.1 on Procedures and Mechanisms Relating to Compliance under the Kyoto Protocol, doc. FCCC/KP/CMP/2005/8/Add.3 (30 March 2006), at 92 (Kyoto Protocol NCP), see S. Urbinati, "Procedures and Mechanisms Relating to Compliance under the 1997 Kyoto Protocol to the 1992 United Nations Framework Convention on Climate Change", supra 63-84, and the literature mentioned therein for further references.

11 Ibid., at 79

12 Ibid.

13 Ibid.

14 Ibid. 
of non-compliance with commitments under Article 3.1 of the Protocol, to which we referred earlier. ${ }^{15}$

The Kyoto Protocol non-compliance mechanism shows an unprecedented complexity both in terms of institutional setting and in terms of measures that can be adopted to redress situations of non-compliance. It is too early to say whether such complexity is matched by its overall effectiveness, the first steps have shown more political division than a common resolve aimed at enhancing compliance. ${ }^{16}$

More commonly and more generally, the compliance body and the conference or meeting of the parties interact with each other in the adoption of measures. The compliance body recommends to the COP the kind of measures to be adopted: such measures are normally decided by the COP by consensus. In this respect, a much cited case of practice concerns the Russian Federation under the non-compliance procedure of the Montreal Protocol. In that case, the seventh COP decided to take trade measures against the Russian Federation, imposing a ban on trade in ozone depleting substances with States outside the Commonwealth of Independent States. The COP did not refer to the List of Measures and was accused by the Russian representatives of abusing its powers under the non-compliance procedure. The seventh COP adopted the draft decision by "consensus minus one", quite an uncommon technical device used to bypass the Russian "veto". The Secretariat made clear that "the practice followed in the Meeting of the Parties to the Montreal Protocol was that, when only one Party objected to a draft decision, that decision would be carried by consensus and the position of the dissenting Party would be clearly reflected in the report of the Meeting." ${ }^{17}$ Some doubts should be raised over the appropriateness of such a decision-making procedure, especially where procedural rules on majority-voting are lacking. The technical device of "consensus minus one" is likely to alienate State Parties which find themselves at the receiving end of the procedure, hence undermining the very nature and aims of non-compliance procedures.

\section{Outcomes And Legal EfFects}

More importantly, we should look at the effects of the measures that may be taken under many of the environmental regimes examined. With the only exception of the Kyoto Protocol and the issuing of cautions by the Committee under the Protocol on Water and Health, ${ }^{18}$ such measures are ultimately taken by the COP/MOP, while compliance committees may recommend to the COP/MOP the adoption of such measures

\footnotetext{
15 Ibid.

16 R. Lefeber, "The Practice of the Compliance Committee under the Kyoto Protocol to the United Nations Framework Convention on Climate Change (2006 2007)”, supra 303-318.

${ }^{17}$ F. Romanin Jacur, "The Non-Compliance Procedure of the 1987 Montreal Protocol to the 1985 Vienna Convention on Substances that Deplete the Ozone Layer", supra 11-32, at 31-32.

18 Decision I/2 on Review of Compliance, Annex, doc. ECE/MP.WH/2/Add.3 - EUR/06/5069385/1/ Add.3 (3 July 2007), (Protocol on Water and Health NCP), para. 34(d). See C. Pitea, "Procedures and Mechanisms for Review of Compliance under the 1999 Protocol on Water and Health to the 1992 Convention on the Protection and Use of Transboundary Watercourses and International Lakes", supra 251-262, at 259-260; and, generally, on the UN Convention on the Law of Non-navigational Uses of International
} 
only. The main recurrent question is whether the measures and decisions taken by the COP/MOP are legally binding. Little guidance is given in the relevant treaties in question, which provide no specific indication concerning the legal effects that such measures may produce. Again, we must differentiate measures according to their nature and take into account the objectives and purposes of the non-compliance procedure which is by its very nature non-confrontational and facilitative.

Needless to say, recommendations and provision of advice are by their very nature not legally binding. As a matter of fact, we have seen above that despite this characteristic, some of the compliance regimes provide the consent requirement even for recommendations as a form of safeguard for the Party concerned. ${ }^{19}$ We cannot fail to mention the practice of non-compliance measures adopted within the Convention on International Trade in Endangered Species (CITES), which presents some peculiar features. Under that system, both the Standing Committee and the COP have been endowed with the power to recommend to CITES Parties to suspend trade in a single species or all CITES-listed species from one or more countries. ${ }^{20}$ What we see here is a mix of stronger measures involving a sanction towards the non-complying Party and the lack of binding effect produced by the recommendation adopted by the COP or the Standing Committee. That has resulted in the adoption of non-mandatory trade embargos, where participation in the sanctioning process by the most important importing countries has constituted a strong economic deterrent towards continuing

Watercourses, see A. Tanzi and M. Arcari, The United Nations Convention on the Law of International Watercourses (London, The Hague, Boston: Kluwer Law International, 2001).

19 Supra paragraph 2.

${ }^{20}$ In 2007 the COP endorsed the "Guide to CITES Compliance Procedure" elaborated by a special working-group set up by the Standing Committee. The Guide will regulate the activity of COP and the Standing Committee on compliance issues. It is interesting to report the part of that Guide related to measures, which also includes trade suspensions. " $C$. Measures to achieve compliance. 29. If a compliance matter has not been resolved, the Standing Committee decides to take one or more of the following measures: a) provide advice, information and appropriate facilitation of assistance and other capacity-building support to the Party concerned; b) request special reporting from the Party concerned; c) issue a written caution, requesting a response and offering assistance; d) recommend specific capacity-building actions to be undertaken by the Party concerned; e) provide in-country assistance, technical assessment and a verification mission, upon the invitation of the Party concerned; f) send a public notification of a compliance matter through the Secretariat to all Parties advising that compliance matters have been brought to the attention of a Party and that, up to that time, there has been no satisfactory response or action; g) issue a warning to the Party concerned that it is in non-compliance, e.g. in relation to national reporting and/or the National Legislation Project; and h) request a compliance action plan to be submitted to the Standing Committee by the Party concerned identifying appropriate steps, a timetable for when those steps should be completed and means to assess satisfactory completion. 30. In certain cases, the Standing Committee decides to recommend the suspension of commercial or all trade in specimens of one or more CITES-listed species, consistent with the Convention. Such a recommendation may be made in cases where a Party's compliance matter is unresolved and persistent and the Party is showing no intention to achieve compliance or a State not a Party is not issuing the documentation referred to in Article X of the Convention. Such a recommendation is always specifically and explicitly based on the Convention and on any applicable Resolutions and Decisions of the Conference of the Parties (emphasis added). 31. The list of measures above is not necessarily an exhaustive list of measures applied to date." See CITES doc. Res. 14/3-5, (June 2007), available at <http://www.cites.org/eng/res/all/14/E14-03. pdf $>$ (visited 8 July 2008). For an overview of the CITES compliance regime see S. Biniaz, "Remarks about the CITES Compliance Regime", in U. Beyerlin, P.T. Stoll and R. Wolfrum (eds.), Ensuring Compliance with Multilateral Environmental Agreeements (Leiden/Boston: Martinus Nijhoff, 2006) 89-96. 
a policy of non-compliance. ${ }^{21}$ The system designed in recent decisions on the CITES non-compliance procedure appears to be in conformity with the law of countermeasures laid down in Articles 48 to 54 of the 2001 Articles on State Responsibility, ${ }^{22}$ especially because it is based on an assessment of proportionality made by the COP or Standing Committee and because it is aimed at inducing a return to compliance, rather than "punishing" the non-complying Party. ${ }^{23}$ Moreover, the question of compatibility of trade measures with WTO rules has not arisen in practice and according to one commentator remains "largely hypothetical". ${ }^{24}$

Declarations of non-compliance are not, strictly speaking, "outcomes" of the noncompliance procedure, but they appear very significant in terms of the effects that they produce. As far as declarations of non-compliance by the COP/MOPs or compliance bodies are concerned, one could arguably state that this function is not to be confused with a judicial and quasi-judicial function: non-compliance procedures do provide a valuable alternative to classic means of dispute settlement, insofar as they promote compliance without assigning the blame for violations of treaty provisions. Moreover, the determination by the COP/MOP is not binding upon the Parties, if by "binding" we refer to the fact that the determination involves a finding of international responsibility, entailing a number of consequences under general international law. ${ }^{25}$ It does not entail the application of the principles of res judicata or lis pendens. ${ }^{26}$ Yet at least one mechanism, that under the Aarhus Convention, shows peculiar features that have led Cesare Pitea to talk about "existing seeds of judicialisation" in view of the fact that the compliance body under that mechanism is not a subsidiary body of the MOP and is made up of independent experts, its procedure is highly formalised and that procedural rights are guaranteed to all parties involved, including individual communicants. ${ }^{27}$ Albeit presenting features more typical of "standard" compliance bodies, the same trend towards a quasi-judicial mechanism has been suggested by Jerzy Jendrośka with regard to the practice of the Espoo Implementation Committee. ${ }^{28}$ Jan Klabbers has recently maintained that the Kyoto Protocol non-compliance procedure "looks, in part, like a judicial procedure, complete with conditions relating to the admissibility of complaints (Article VII), procedural guarantees

\footnotetext{
${ }^{21}$ P.H. Sand, "Sanction in Case of Non-Compliance and State Responsibility: Pacta Sunt Servanda - Or Else?", in Beyerlin, Stoll and Wolfrum (eds.), supra n. 20, 259-272, at 263.

${ }^{22}$ Draft Articles on the Responsibility of States for Internationally Wrongful Acts, Report of the ILC on the Work of its Fifty-third Session, UN GAOR, 56 ${ }^{\text {th }}$ Sess, Supp No. 10, at 43, doc A/56/10 (2001), Arts. 48 and 54, reprinted in J. Crawford (ed.), The International Law Commission's Articles on State Responsibility: Introduction, Text and Commentaries (Cambridge: Cambridge University Press, 2002), at 281-305.

${ }_{23}$ Sand, supra $\mathrm{n} .21$, at 267-271.

${ }^{24}$ Ibid., at 267.

${ }^{25}$ T. Treves, "The Settlement of Disputes and Non-Compliance Procedures", infra 499-518; P. Sands, "Non-Compliance and Dispute Settlement", in Beyerlin, Stoll and Wolfrum (eds.), supra n. 20, 353-358, at $356-357$.

${ }^{26}$ Pitea, supra n. 2, at 466

27 Ibid.

${ }^{28}$ J. Jendrośka, "Practice and Relevant Cases Emerged in the Context of the Espoo Convention Implementation Committee", supra 319-336.
} 
(Article VIII), the possibility of appeal (Article XI), and possible consequences attached to a finding of non-compliance (Article XV)." ${ }^{29}$

More generally, one cannot overlook the fact that the function of law-determination under international law is hardly centralised and that important effects are produced regardless of the obligations and rights established by a legally binding decision, such as a determination reached by an arbitral tribunal or a finding of noncompliance by the International Court of Justice in a contentious case. What are these effects? The first one is that there is an authoritative, institutional finding of non-compliance, hence the Party found in non-compliance will inevitably have to bear the brunt of bad publicity both at the international and at the national level. The so-called "social sanction" will characterise the "gentle pressure" exercised on the non-complying Party and it is, after all, at the core of the non-compliance procedures. Secondly, the collective and institutional determination of non-compliance will strengthen the effectiveness of the obligations breached, by producing a pattern of "institutionalised" protest against non-compliance. ${ }^{30}$ The collective effort behind the non-compliance procedure is fundamental to the effective commitment of each Party to the achieving of the environmental targets it has subscribed to. Last but not least, the finding of non-compliance may precede stronger measures such as cautions or the suspension of treaty rights and privileges. In such cases, the law-determination function exercised in the non-compliance procedure, albeit non-judicial, and the effects thereof should not be underestimated.

As for the outcomes stricto sensu, it is important to note the strong wording used in one of the mechanisms, that under the 1979 Long-Range Transboundary Air Pollution Convention (LRTAP Convention), showing more institutional practice. ${ }^{31}$ In that context, the Executive Body has used expressions directed at the non-complying party, such as "requests", "urges", "strongly urges", "calls on". ${ }^{32}$ The nature and purpose of the non-compliance procedure and the lack of an empowering provision under the LRTAP Convention seem to indicate that despite the strong emphasis such decisions do not purport to create additional legal obligations on State Parties. On the other hand, one should bear in mind that under the LRTAP Convention's system the Executive Body is the leading political organ and it is composed of representatives of all State Parties acting by consensus; when dealing with compliance it acts in fulfilment of its implementation function under Article 2.a of the Convention. Its display of political and legal authority in the compliance procedure seems to be based on its implied powers under the Convention itself. The rate of compliance with its decisions

29 J. Klabbers, "Compliance Procedures”, in Bodansky, Brunée and Hey (eds.), supra n. 1, 995-1009, at 999.

${ }^{30}$ With regard to protest as an instrument reducing the weakening effect of violations upon norms see A. Tanzi, Introduzione al diritto internazionale contemporaneo, $2^{\text {nd }}$ edn. (Padua: CEDAM, 2006), at 417.

${ }^{31}$ Generally, on the LRTAP Convention's non-compliance regime and for further references see E. Milano, "Procedures and Mechanisms for Review of Compliance under the 1979 Long-Range Transboundary Air Pollution Convention and its Protocols", supra 169-180.

32 E.g., Decision 2007/5 on Compliance by Spain with its Obligations under the 1991 Protocol Concerning the Control of Emission of Volatile Organic Compounds and their Transboundary Fluxes, doc. ECE/ EB.AIR/91/Add.1 (27 February 2008), para. 6; Decision 2007/6, Compliance by Denmark with its Obligations under the 1998 Protocol on Persistent Organic Pollutants, ibid., para. 5. 
is indeed very high. A possible conclusion on the legal nature of those decisions entailing a stronger wording for the non-complying Party is that they do create obligations of due diligence upon Parties, with a view to enhancing compliance with the targets set out by the relevant protocol to the convention. These obligations would reinforce those obligations of result deriving directly from the reduction targets provided for in the protocols.

It is also interesting to recall the different kinds of measures that may be adopted within the non-compliance procedure of the Kyoto Protocol. Article 18 of the Kyoto Protocol is somewhat peculiar and deserves special attention. It states as follows:

"The Conference of the Parties serving as the meeting of the Parties to this Protocol shall, at its first session, approve appropriate and effective procedures and mechanisms to determine and to address cases of non-compliance with the provisions of the Protocol, including through the development of an indicative list of consequences, taking into account the cause, type, degree and frequency of non-compliance. Any procedures and mechanisms under this article entailing binding consequences shall be adopted by means of an amendment to this Protocol."

The "indicative list of consequences" was laid down in decision 27/CMP.1, in sections XIV and $\mathrm{XV} .{ }^{33}$ As already mentioned, under that decision non-compliance measures are not taken by the COP, but by the Compliance Committee itself, whose institutional complexity and powers have no equal in other environmental regimes.

The precise meaning of the last sentence in Article 18, i.e., that "[a]ny procedures and mechanisms under this article entailing binding consequences shall be adopted by means of an amendment to this Protocol" has given rise to some controversy. Saudi Arabia, by asking that the decision by the COP/MOP establishing the compliance mechanism would be incorporated in the Kyoto Protocol as an amendment, implicitly supported a broad interpretation of that sentence. ${ }^{34}$ However, the prevailing view was that the reference to "binding consequences" should be read as relating to the outcome of the non-compliance procedure. This results in a distinction to be made between those measures such as recommendations and advice which are "soft" in nature, hence are not binding, and those measures, such as the deduction of emission rights, which are binding in nature. These latter kinds of measures may thus require an amendment to the Protocol empowering the competent organs to bind the Parties. ${ }^{35}$ Such an amendment has not been on the agenda as yet and there have not been attempts to use stronger measures against non-complying Parties. That shows that State Parties and institutional bodies dealing with compliance are not very keen to stretch the powers provided under the treaty and under relevant decisions establishing the non-compliance procedure and that an assumption of implied powers allowing the

\footnotetext{
${ }^{33}$ Report of the Conference of the Parties serving as the meeting of the Parties to the Kyoto Protocol on its first session, doc. FCCC/KP/CMP/2005/8/Add.3 (30 March 2006).

${ }^{34}$ Kyoto Protocol NCP, Section II.

${ }^{35}$ See, generally, R. Lefeber, "From the Hague to Bonn to Marrakesh: a Negotiating History of the Compliance Regime under the Kyoto Protocol”, Hague YB Int'l L., 14 (2001) 25-54.
} 
adoption of stronger, legally-binding measures is most of the time ruled out. Practice under other regimes confirms this trend. ${ }^{36}$

Sections XIV and XV of decision 27/CMP.1 indeed provide for two types of consequences in terms of outcome of the non-compliance procedure: on the one hand, those measures of facilitation that support the country in question in reaching the targets set out by the Protocol; on the other hand, some consequences of the compliance procedure entail a sanction against the non-complying State. That results from the text of Article 18 which provides that the cause, type, degree and frequency of the non-compliance pattern shall be taken into account. Thus, as highlighted in the contribution on the Kyoto Protocol deriving from the present research project, if non-compliance is due to a lack of structural or financial resources, facilitative and supportive measures are the most appropriate measures in order to induce compliance. Yet, if a State has deliberately breached the obligations set by the Protocol or shown gross negligence with respect to compliance, then the consequences may take the form of sanctions. ${ }^{37}$

As far as the suspension of treaty rights and privileges (perhaps the most severe measures that may be taken) are concerned, one may notice that the applicable instruments may provide for the adoption of such measures in conformity with customary international law, as codified under Article 60 of the Vienna Convention on the Law of the Treaties. ${ }^{38}$ In that sense, it is correct to argue that such provisions do not empower States with further rights and prerogatives that they do not normally possess under general international law, as such further rights would require an amendment of the treaty in question: suspension of treaty rights by the COP/MOP or compliance body where applicable should only relate to such collective responses to material breaches of the treaty in accordance with Article 60 . We shall not dwell extensively on this question which is the subject of Malgosia Fitzmaurice's contribution, ${ }^{39}$ suffice it to say at this stage that a decision of suspension of treaty rights, whether taken unilaterally or through a competent multilateral body, does not as such aim at creating new obligations for the non-complying State; it is only aimed at preventing the application of treaty rights by the concerned Party vis-à-vis those States taking the decision to suspend such treaty rights. Be that as it may, one should rather question the bindingness of these decisions for the Parties, i.e., whether a State Party allowing the exercise of treaty rights by the non-complying Party in their bilateral relation would breach international law, because of the obligations created by the decision of the COP/MOP. It is submitted that such bindingness may be derived from general international law as codified at Article 60, without the need to elaborate a normative theory on the nature of institutional acts taken by such bodies. In this latter respect, one should then make the useful distinction between treaty rights and special rights and

${ }^{36}$ See the practice of the non-compliance procedure under the Convention on the Protection of the Alps (Salzburg, 7 November 1991) in L. Pineschi, "The Compliance Mechanism of the 1991 Convention on the Protection of the Alps and its Protocols", supra 205-220, at 217-218; and T. Enderlin, "A Different Compliance Mechanism", Envt'l Pol'y \& L., 33 (2003) 155-162.

37 Urbinati, supra n. 10, at 79.

38 E.g., Aarhus Convention NCP, supra n. 3, para. 37(g); Protocol on Water and Health NCP, supra n. 18 , para. $35(f)$.

39 M. Fitzmaurice, "Non-Compliance Procedures and the Law of Treaties", infra 453-482. 
privileges established under COP/MOP decisions, as such not subject to Article 60 requirements, which may be suspended regardless of the type of breach if a consensus in that sense is reached in the COP/MOP or compliance body. ${ }^{40}$

Finally, one should not be confused by the reference to the verb "decide upon" in some of the legal instruments establishing the non-compliance procedures and their outcomes, such as in the case of those under the Protocol on Water and Health and of the draft decision on the establishment of a compliance procedure under the Protocol on Pollutant Release and Transfer Register (PRTRs Protocol). ${ }^{41}$ The bindingness of the measures should be assessed mainly with reference to their very nature and the use of the verb "decide" only relates to the act that leads to the adoption of the measure, namely a decision by consensus. As a matter of fact, stronger measures such as trade suspensions have been finalized through mere "recommendations", such as in the case of CITES analysed above. No parallels should be drawn with other institutional mechanisms, whose nature, purpose and objectives are profoundly different and may justify the adoption of binding measures without the amendment of the constitutive instrument. As stated at the very outset, the non-compliance mechanisms are by nature non-confrontational and cooperative. Any legal effect of stronger measures that may be adopted by the compliance committee or the COP/MOP is only the result of the continuing obligation for States to fulfil their treaty duties in good faith.

\section{CONCLUding Remarks}

As noted by Klabbers, any obligatory nature of the non-compliance procedure relates more to the duty of Parties to participate in the procedure than to the legally-binding effects produced by its results and outcomes. ${ }^{42}$ As the author suggests, the procedure works at its best as long as its results are seen as voluntary: if they come to be seen as binding, the non-complying Party will most likely decide to opt for traditional means of dispute settlement, which would normally offer better procedural guarantees, such as the appointing of an ad hoc judge or the participation in the selection of the arbitration panel..$^{43}$ That points to the fact that more stringent and adversarial measures, such as the issuing of cautions and, especially, the suspension of rights and privileges will

40 Pitea, supra n. 2, at 240-241. See, for example, the draft non-compliance procedure under the Convention on the Prior Informed Consent Procedure for Certain Hazardous Chemicals and Pesticides in International Trade (Rotterdam PIC Convention), which provides, as a form of sanction, for the ineligibility to serve as the President of the COP or as a member of the Bureau until the non-complying Party has fulfilled its obligations, see Decision RC-3/4 on Draft Text of the Procedures and Mechanisms on Compliance with the Rotterdam Convention, doc. UNEP/FAO/RC/COP.3/26 (10 November 2006), Annex, para. 19, lett. f), (Rotterdam PIC Convention NCP) and S. Brugnatelli, "Draft Procedures and Mechanisms on Compliance with the 1998 Rotterdam Convention on the Prior Informed Consent Procedure for Certain Hazardous Chemicals and Pesticides in International Trade", supra 85-100, at 98.

${ }^{41}$ See, respectively, Protocol on Water and Health NCP, para. 34 (Pitea, supra n. 18, at 260) and Draft Decision on Review of Compliance, doc. ECE/MP.PP/AC.1/2007/L.10 (18 July 2007), para. 37 (PRTRs Protocol NCP), see Pitea, "Procedures and Mechanisms for Review of Compliance under the 2003 Protocol on Pollutant Release and Transfer Registers to the 1998 Aarhus Convention”, supra 263-274, at 272.

${ }^{42}$ Klabbers, supra n. 29, at 999.

43 Ibid., at 1006 . 
most likely remain residual in the overall picture, not so much due to the lack of willingness by the Parties to adopt more effective measures against non-compliance, but precisely because the general trust of States depends on the cooperative and facilitative nature of these mechanisms.

In conclusion, the non-compliance procedures under international environmental law generally aim at a soft, non-confrontational approach to compliance, with a view to avoid alienating the non-complying Party. The objective is that of strengthening the effectiveness of primary obligations deriving from the treaties in question and of reminding States of powers that they already have under general international law, such as those laid down in Article 60 of the Vienna Convention on the Law of the Treaties and under the law of State responsibility. In this latter respect, the instruments of response to a violation of a multilateral treaty are coordinated and targeted to the specific situation of non-compliance in accordance with different factors, in order to make such response more effective. One would point out that non-compliance procedures should be assessed by their effectiveness, beyond their normative legal effects. 


\title{
Chapter Twenty-Four
}

\section{Controlling and Assisting Compliance: Financial Aspects}

\author{
Francesca Romanin Jacur
}

\section{INTRODUCTION}

Practitioners and academics have repeatedly noted that an effective response to environmental degradation calls for an improvement of the implementation of existing MEAs, rather than on the conclusion of new conventions. ${ }^{1}$ The establishment of procedures and bodies whose mandate is to monitor and verify compliance with commitments deriving from MEAs is an answer to this "implementation deficit".

Once set in place, however, these mechanisms require an adequate level of funding in order to function effectively.

This contribution deals, firstly, with the sources of funding of these mechanisms, which are often unpredictable and not sufficiently stable, and with the ensuing problems which have emerged.

A second set of issues concerns the interplay of compliance bodies with financial mechanisms and economic instruments created under MEAs in order to facilitate, respectively, developing and industrialized States in the achievement of their targets.

These are, on one side, the funds created under MEAs or other financial institutions that facilitate the compliance of developing countries by providing them with financial assistance. While some of these funds are built on voluntary contributions, others may no longer be conceived as a form of "liberality" of developed countries towards poorer ones and a legal obligation to contribute to them may be foreseen.

On the other side, in order to reduce the costs that industrialized countries bear to cut greenhouse gases emissions, flexibility mechanisms have been established by the Kyoto Protocol. These innovative financial instruments create an unforeseen implementation scenario, characterized by partnerships between developed and developing States and the establishment of a market, where a new environmental commodity is traded. In this complex picture, the non-compliance mechanism of the Protocol represents a key element for the sound functioning of the whole system.

1 See, e.g., P. Sand, "The evolution of international environmental law", in D. Bodansky, J. Brunnée and E. Hey (eds.), Oxford Handbook of International Environmental Law (Oxford: Oxford University Press, 2007) 30-43, at 40: "[i]nternational environmental law [...] suffered a severe loss of credibility [...]. Hence, the focus of attention shifted to the 'effectiveness' of the existing international legal structure, its empirical verification, and procedural/institutional anchorage."

T. Treves et al., eds., Non-Compliance Procedures and Mechanisms and the Effectiveness of International Environmental Agreements

(C) 2009, T.M.C. ASSER PRESS, The Hague, The Netherlands, and the Authors 
Finally, an assessment is made of the role of non-compliance mechanisms with regard to the control of the above-mentioned financial matters and whether it would be desirable to entrust non-compliance mechanisms with the competence to monitor compliance of Member States with their financial obligations.

\section{Financing Non-Compliance Mechanisms}

A survey of the practice under operating non-compliance mechanisms shows that lack of an adequate budget causes a reduction in the number of the committees' meetings and in some of their activities, such as on-site information gathering and expert advice so that, as a result, Parties may be unable to address compliance matters in a timely and efficient manner. ${ }^{2}$

The disbursement of special funding is also essential to assure an effective participation of representatives of developing countries willing and entitled to participate in meetings of the treaty bodies, in general, and of compliance bodies, in particular. ${ }^{3}$

Even members of compliance committees may not always be able to count on financial support to participate in the meetings. ${ }^{4}$ This entails a dangerous weakening of procedural guarantees, especially when they participate as representatives of Parties deemed to be in non-compliance or that have triggered the procedure because, by taking part in the deliberations of the committee, they provide relevant information with regard to the cases under scrutiny.

These issues were expressly taken into account under the non-compliance mechanisms of the Cartagena Protocol and of the Basel Convention, where the respective compliance committees expressed concern with regard to the lack of financial

\footnotetext{
${ }^{2}$ For example, the President of the Compliance Committee of the Kyoto Protocol invited Parties to increase their contributions to a Fund that supports the Committee and explained that: "While the Committee had made all efforts to use resources allocated to it by the Conference of the Parties as efficiently as possible, its remaining funds would not be sufficient to support the expected intensifying workload of the Committee. That was in large part due to a shortfall in the contributions received so far." (Report of the Conference of the Parties serving as the meeting of the Parties to the Kyoto Protocol on its second session, doc. FCCC/KP/ $\mathrm{CMP} / 2006 / 10$ (26 January 2007), at 15). Under the Basel Convention on-site information gathering was limited by the fact that the COP did not allocate financial resources for this purpose. (See A. Shibata, "The Basel Compliance Mechanism", RECIEL, 12 (2003) 183-198, at 195 and reference therein to Decision VI/41 on Financial Matters, doc. UNEP/CHW.6/40 (10 February 2003), Appendix II, at 176.)

3 The need to ensure an effective participation of developing countries in international law-making is recognized in Agenda 21, Chapter 39, para. 9: "The effective participation of all countries, in particular developing countries, should be ensured through provision of technical assistance and/or financial assistance." (United Nations Conference on Environment and Development, Earth Summit. Agenda 21 (New York: United Nations Publication, 1993). See also J. Brunnée, "COPing with consent: Law-Making under Multilateral Environmental Agreements", Leiden J. Int'l L., 15 (2002) 1-52, at 48: "To the extent possible, parties must also be enabled to participate on a level playing field. For example, in the case of some developing countries, genuine participation may be contingent upon financial and legal capacity."

${ }^{4}$ Members of the Basel Convention Compliance Committee, for example, may not count on financial support to participate in meetings of the Committee.
} 
arrangements to provide support for these purposes and recommended the COP to take appropriate action. ${ }^{5}$

Another drawback, due to lack of funding, is that committee meetings are conducted only in English, without the translation of relevant documents and information from local languages into English and vice versa. This weakens the right for the Parties involved to participate on equal standing in the procedure.

This overview of the non-compliance mechanisms actually in place shows that lack of appropriate funding for these procedures leads to their ineffective functioning and to impoverished procedural safeguards with a consequent weakening of their legitimacy. ${ }^{6}$

\subsection{The General Budget as the Source of Financing for Compliance Committees under MEAs}

Financial resources for compliance committees derive mainly from the regular budget adopted by the COP, although a part of the resources for funding may also derive from voluntary funds usually devoted to facilitating the participation of developing countries. ${ }^{7}$ While binding contributions are more predictable and generally stable, the voluntary ones are far less reliable.

The legal basis of the competence of COPs to determine the financial obligations of State Parties and consequently their duty to contribute to the regular budget is generally found in a treaty provision. ${ }^{8}$ Here the duty to contribute (an) is expressed in general terms and the precise content of the obligation, i.e., the exact amount of the contributions (quantum), is periodically decided by the COP.

With the decision on financial matters the COP forecasts the future expenses necessary for an effective functioning of the overall institutional structure for a certain period and consequently determines, usually by consensus, the contributions due by

${ }^{5}$ See Report of the Second Meeting of the Compliance Committee under the Cartagena Protocol on Biosafety, doc. UNEP/CBD/BS/COP-MOP/3/2 (8 February 2006), at 4; and Decision VIII/32 on Mechanism for promoting implementation and compliance: work programme for 2007-2008, doc. UNEP/CHW.8/16 (5 January 2007), at 55.

${ }^{6}$ See E. Hey, "International Institutions", in Bodansky, Brunnée and Hey (eds.), supra n. 1, 749-769, at 767 .

7 Special Trust Funds are established under the Desertification Convention, the UNFCCC and the Stockholm POPs Convention and are dedicated to paying for the costs of participation to meetings of COPs and subsidiary bodies for representatives of specific categories of developing countries, such as the leastdeveloped countries particularly affected by desertification, small island developing States, or States with economies in transition.

${ }^{8}$ Art. 6.3 of the Vienna Ozone Convention constitutes an example of the standard provision found in MEAs and it provides that: "The conference of the Parties shall by consensus agree upon and adopt rules of procedure and financial rules for itself and for any subsidiary bodies it may establish, as well as financial provisions governing the functioning of the secretariat." Similar statements are found, among others, in Art. 7.2(k) of the UNFCCC; Art. 11.3(b, i) of the Montreal Protocol; Art. 23.3 of the Convention on Biodiversity; Art. 22.2(e, g) of the Desertification Convention; Art. 18.4 of the Rotterdam PIC Convention; Art. 19.4 of the Stockholm POPs Convention; Art. 15.3 of the Basel Convention. A list of treaties with full references is provided supra at XXXVII. 
each Member State on the basis of the United Nations General Assembly's scale of assessment, with the necessary amendments due to the different participation, although other criteria may also be chosen.

This competence of the COPs pertains to their internal powers and is established in order to enable them to provide the necessary means to ensure an effective functioning of the treaty structure.

Although the disbursement of funds to MEAs involves political considerations, it is useful to make some remarks relating to the obligation that State Members to MEAs have to provide the necessary resources to ensure an efficient functioning of the structure.

When a compliance mechanism is established, the Parties generally provide for a specific budget line for its financing ${ }^{9}$ but, despite this express provision, resources are often inadequate either because of an undersized assessment or because Parties fail to pay their contributions. These matters are often addressed by compliance committees and COPs frequently manifest concern over the frequent delays in the payment of the agreed contributions by Parties. ${ }^{10}$

The lack of sufficient resources to finance bodies in charge of controlling compliance under MEAs reflects a general financial problem that has constantly arisen with regard to international organizations due to the inevitable costs that they involve. ${ }^{11}$

The United Nations experienced a serious financial crisis due to shortages of funds and not only States representatives and legal scholars tried to clarify the nature and the extent of the obligation to contribute to the UN budget but also the General Assembly sought an advisory opinion from the International Court of Justice on these matters.

\footnotetext{
${ }^{9}$ For example, with regard to the Cartagena Protocol, see Decision BS-IV/7 on Programme budget for the costs of the secretariat services for and the biosafety work programme of the Cartagena Protocol on Biosafety for the biennium 2009-2010, doc. UNEP/CBD/BS/COP-MOP/4/18 (25 June 2008), at 69.

${ }_{10}$ At the nineteenth MOP to the Montreal Protocol concern was formally expressed "over delays in payment of agreed contributions by Parties, contrary to the provisions in paragraphs 3 and 4 of the terms of reference for the administration of the Trust Fund for the Montreal Protocol." See Decision XIX/5 on Financial matters: financial reports and budgets, doc. UNEP/OzL.Pro.19/7 (21 September 2007), at 32.

11 On these matters, see J.G. Stoessinger, Financing the United Nations System (Washington D.C: The Brookings Institution, 1964); G. Tesauro, Il finanziamento delle organizzazioni internazionali (Napoli: Casa Editrice Jovene, 1969); P. Paone, "Il problema del finanziamento delle organizzazioni internazionali a carattere universale", Com. Int., 25 (1970) 559-591; A. Pellet, "Budgets et programmes aux Nations Unies. Quelques tendances récentes", Ann. Français Dr. Int., 22 (1976) 242-282; M. Bertrand, "Planification, programmation, budgétisation et évaluation à l'ONU", Ann. Français Dr. Int., 32 (1986) 401-425; C.A. Colliard, "Quelques aspects des problemes de financement des organisations internationales", Société Française pour le Droit International (ed.), Les organisations internationales contemporaines. Crise, mutation, développement (Paris: Pedone, 1988) 63-91; J.E. Alvarez, "Financial Responsibility", in C. Joyner (ed.), The United Nations and International Law, (Cambridge: American Society of International Law, 1997) 409-431; C.F. Amerasinghe, "Financing", in R.J. Dupuy (ed.), Manuel sur les organisations internationals, (Dordrecht: Nijhoff, $2^{\text {nd }}$ edn., 1998) 313-337; V. Della Fina, Il bilancio nel diritto delle Nazioni Unite (Milano: Giuffrè, 2004).
} 
As recognized by most scholars ${ }^{12}$ and by the International Court of Justice, ${ }^{13}$ Article 17 of the UN Charter ${ }^{14}$ is the legal basis for the competence of the General Assembly to apportion binding contributions among Member States.

Notwithstanding the difficulties encountered in assuring the respect of these obligations because States have continued to be in arrears with their disbursements and on some occasions they have even claimed the right to withdraw their contributions, it is now generally recognized that Members of an organization have a legal obligation to contribute to its financing, in accordance with the apportionment decided by the plenary organ of the latter. ${ }^{15}$

An analogous conclusion may be reached with regard to the competence of COPs.

Without giving a definitive statement on the general issue of whether institutional structures established by MEAs should be considered as international organizations, we admit here that, in as much as their internal administration and, in particular, financial matters are concerned, COPs competences share the same ratio of traditional

${ }^{12}$ See, e.g., G. Bastid-Burdeau, “Article 17, paragraphe 1 et 2", in J.P. Cot, A. Pellet, M. Forteau (eds.), La Charte des Nations Unies, Commentaire article par article, 3 edn. (Paris: Economica, 2005) 775-789, at 785; W. Koschorreck, "Contributions, System of", in R. Wolfrum (ed.), United Nations: Law, Policies and Practice, (Dordrecht: Martinus Nijhoff Publishers, 1995) 356-365; F. Francioni, "Multilateralism à la Carte: The Limits to Unilateral Withholdings of Assessed Contributions to the UN Budget", Eur. J. Int'l L., $11(2000) 43-59$

${ }^{13}$ See Certain Expenses of the United Nations (Article 17, paragraph 2 of the Charter), Advisory Opinion of 20 July 1962, ICJ Reports (1962), 151. The request of the General Assembly was on whether the expenses of the UN, within the meaning of Art. 17, para. 2, covered not only the regular "administrative" budget but also the costs of operative actions, such as, in the specific case, peace-keeping activities in Congo and in the Middle East. The Court answered in the affirmative: it recognized that these activities had been undertaken in order to attain an objective of the organization and stated that therefore their costs were included in the expenses of the organization. Although the Court did not address directly the issue of the legal nature of the obligation to contribute to the budget, which was considered a preliminary issue, the opinion clearly recognizes that such a legal obligation exists. See Certain Expenses case, at 164: "By Article 17, paragraph 1, the General Assembly is given the power not only to 'consider' the budget of the Organization, but also to 'approve' it. The decision to 'approve' the budget has a close connection with paragraph 2 of Article 17, since thereunder the General Assembly is also given the power to apportion the expenses among the Members and the exercise of the power of apportionment creates the obligation, specifically stated in Article 17, paragraph 2, of each Member to bear that part of the expenses which is apportioned to it by the General Assembly." For a comment to the Advisory Opinion, see R. Monaco, "Gli obblighi finanziari degli Stati membri delle Nazioni Unite nel parere della Corte internazionale di giustizia", Riv. Dir. Int., 45 (1962) 605-615, at 612; Y. Beigbeder, "La crise financière de l'Organisation des Nations Unies et le Groupe des 18 Perspectives de réforme?”, Ann. Français Dr. Int., 32 (1986) 426-438.

${ }^{14}$ The text of Art. 17 reads: "1. The General Assembly shall consider and approve the budget of the Organization. 2. The expenses of the Organization shall be borne by the Members as apportioned by the General Assembly."

${ }^{15}$ On this matter see P. Cahier, "L'ordre juridique interne des organisations internationales", in Dupuy (ed.), supra n. 11,377-397, at 392: “[...] les Etats devront se soumettre, même s'ils se sont exprimés par un vote contraire, aux règles financiers promulguées par l'organisation et accepter le barème des quota-parts pour la répartition des dépenses, tel qu'il est approuvé par l'organe compétent. Cette attitude est constante dans la pratique et dans la doctrine, y compris chez des auteurs qui estiment que les recommandations ne sont pas obligatoires mais qui font sur ce point une exception." 
international organizations and therefore they determine, in a binding way, the contributions owed by the Parties. ${ }^{16}$

These institutions, indeed, need financial support to achieve their goals in the same way as other organizations and when States become Parties to a MEA they accept the burden of its financing. This commitment is then periodically renewed, as already noted, in occasion of the meetings of the COPs where States, by participating and voting, consent to be bound by the decision containing the budget.

An indication that Member States consider as legally binding the contributions assessed by the COP may be found in a declaration made by representatives of developing countries under the Rotterdam PIC and the Stockholm POPs Conventions. These representatives manifested regret with regard to the adoption of the financial rules of the Convention on the basis of the UN scale of assessment, as adjusted in consideration of the different participation in the two treaties, because they considered that the rules did not respect the "capacity to pay" criteria.

Although consensus on the decision was finally reached, they stated that

"the Conference of the Parties was a sovereign body, which could establish its own scale of assessment, and that use of current scale would deter other developing countries from joining the Convention, while those that already had would be forced to sacrifice implementation projects in order to meet assessed contributions." 17

The words and the behavior of these Parties show that, notwithstanding their criticisms of the decision, States consider that contributions as determined by the COP constitute for them a legal obligation. ${ }^{18}$

The conclusion in favor of the binding nature of the duty to contribute to the budget of MEAs is also based on the interpretation of the texts of the relevant treaty

${ }^{16}$ G. Ulfstein, "Treaty Bodies", in Bodansky, Brunnée and Hey (eds.), supra n. 1, 877-889, at 881: "As with IGOs, internal decisions, such as guidance by the COP to subsidiary bodies and the Secretariat, should be considered binding unless the MEA or the relevant decision itself specifically indicates that a certain type of decision was intended to be non-binding." Sands, according to whom COPs are international organizations, considers: "Where the act is an internal act of the organization (adopting the budget or procedural rules, or establishing a subsidiary organ), the resolution may bind all members of the organization as a matter of the internal law of the organization." (P. Sands, Principles of International Environmental Law, $2^{\text {nd }}$ edn. (Cambridge: Cambridge University Press, 2003), 136).

${ }^{17}$ Letter from the President of the Conference of the Parties to the Rotterdam PIC Convention to the President of the sixtieth session of the United Nations General Assembly, reproduced in Communications of the Secretariat, doc. UNEP/FAO/RC/COP.3/INF/7 (11 July 2006), Annex I. The same issue is addressed in a letter of the President of the Conference of the Parties to the Stockholm POPs Convention to the President of the fifty-ninth session of the United Nations General Assembly. (Concerns About the Scale of Contributions, doc. UNEP/POPS/COP.3/INF/18 (5 March 2007), Annex A).

${ }^{18}$ With regard to the same decision, the representative of Argentina stated that: "Argentina, although a developing country, contributed more to the Convention's budget than some developed countries." He also said that "[...] his Government reserved the right to seek a revision to the indicative scale of assessment adopted by the Conference of the Parties at its current meeting and a reduction of the percentage assigned in the scale of Argentina." (Ibid., at 2) 
provisions ${ }^{19}$ and of COPs' decisions ${ }^{20}$ where obligations that States intended as discretionary are clearly differentiated from the ones that are considered as binding.

Also the decision-making procedures through which contributions are assessed speak in favour of a binding commitment since they generally require consensus or, as a last resort in some MEAs, a double majority vote. Consensus and double majority voting are decision-making procedures that are used under MEAs for the adoption of the most delicate issues, entailing substantial commitments on Member States. In fact they both ensure a high degree of control for States on the decisions to be adopted, and in the case of financial matters they allow greater financial accountability and the possibility to block their adoption, if contributors consider that the burden is too high or if they do not agree with the objective for which certain expenses have been decided.

As a final consideration, it should be recalled that the duty to contribute to the budget of international organizations has been considered as "a matter of inherent necessity" 21 and, in this view, even when this competence of the plenary organ was not expressly stated in the treaty, it may be considered as an implied power finding its roots in customary international law..$^{22}$ Consequently, it may be argued that even in the absence of an express provision, a power to assess the contributions of Member States to the budget on the basis of implied powers may exist also for COPs.

\subsection{Responses to the Lack of Adequate Funding}

In order to overcome problems related to budget constraints, some COPs have conferred a certain degree of flexibility to Secretariats in the management of the budget and allow them to allocate budget resources to cover unexpected costs deriving, for example, from the intensified workload of compliance committees.

19 Art. 13.1 of the Montreal Protocol provides an example: "The funds for the operation of this Protocol, including those for the functioning of the Secretariat related to this Protocol, shall be charged exclusively against contributions from the Parties."

${ }^{20}$ The following decision adopted by the COP/MOP of the Cartagena Protocol may serve as example: "The Conference of the Parties serving as the meeting of the Parties to the Cartagena Protocol on Biosafety [...] Adopts the scale of assessments for the apportionment of the costs under the Protocol for 2007 and 2008 set out in table 5 below [...] Takes note of the funding estimates for activities under the Protocol to be financed from: (a) The Special Voluntary Trust Fund [...] and urges Parties to make contributions to these funds; Invites all Parties to the Protocol to note that contributions to the core programme budget (BG) are due on 1 January of the year in which these contributions have been budgeted for, and to pay them promptly." (Decision BS-III/7 on Programme budget for the costs of the Secretariat services for and the biosafety work programme of the Cartagena Protocol on Biosafety for the biennium 2007-2008, doc. UNEP/CBD/BS/ COP-MOP/3/15 (8 May 2006), at 48).

${ }^{21}$ Certain Expenses case, supra n. 13, Separate opinion of Judge Fitzmaurice, at 208.

22 This view is maintained by Amerasinghe, supra n. 11, at 321: "There is a strong case for suggesting that even in the absence of provision for apportionment in the constitution of an organization, as in the case of the OAU Charter, for instance, the principal organ of the organization may apportion expenses with binding effect, which is what happens in that organization. This would be an implied power of the organization vis-à-vis member States, because it is essential for the efficient performance of the organization's functions." See also Alvarez, supra n. 11, at 1099: "[...] a legal duty to pay for at least the administrative expenses of the organization would have arisen, even in the absence of Article 17, based on customary international law." 
To meet costs and to allow representatives of developing countries to participate, meetings of the committees may take place in conjunction with other subsidiary organs for which funds are available. This solution may work for committees whose members are included in national delegations but has strong drawbacks because it cannot be adopted when members participate in their personal capacity.

Moreover, holding committee meetings in conjunction with COP meetings, as is the case under the Montreal Protocol, may cause difficulties in terms of lack of sufficient time for the committee to prepare its report and for the COP to consider it and consult with concerned Parties before its final adoption. ${ }^{23}$

Another useful initiative in the view of reducing costs is the harmonization of the different reports required under the various MEAs. This would create synergies and avoid overlaps and duplication of work that cause heavy burdens for compliance bodies and for States, especially developing countries. ${ }^{24}$ This approach has recently been adopted in the field of chemicals and wastes by the Secretariats of the Basel, Rotterdam PIC and Stockholm POPs Conventions which have established an ad hoc joint working group on cooperation and coordination between their respective conventions. $^{25}$

23 The negative aspects of this practice have been noted by V. Koester, "Compliance Committees within MEAs and the desirability and feasibility of establishing special compliance bodies under CITES", Document SC54 Inf.3 (20 May 2004), para. 33. However, in the Primer of the Implementation Committee (Implementation Committee under the Non-compliance Procedure of the Montreal Protocol on Substances that deplete the Ozone Layer, Primer for Members, October 2007 (Implementation Committee Primer) available at $<$ http://ozone.unep.org/Publications $>$ ), the view is expressed that this practice has positive effects on the functioning of the procedure because it allows States more time to submit their comments, see F. Romanin Jacur, "The Non-Compliance Procedure of the 1987 Montreal Protocol to the 1985 Vienna Convention on Substances that Deplete the Ozone Layer", supra 11-32. Other positive effects are indicated by the Executive Secretary of the Convention on Biodiversity: "There is a pattern of pairing meetings under the CBD. The organization of thematically related back-to-back meetings has allowed the SCBD (Secretary of the Convention on Biological Diversity) to streamline our organizational and logistics process and achieve important savings estimated approximately US \$100.000-US \$150.000." (Information provided by the Secretariat of the Convention on Biological Diversity on its experience in organizing back-to-back meetings requested by the second meeting of the ad hoc joint working group on cooperation and coordination between Basel, Rotterdam and Stockholm Conventions, doc. UNEP/FAO/CHW/RC/POPS/JWG.3/INF/4 (29 February 2008)).

${ }^{24}$ E. Maruma Mrema, "Cross-cutting Issues Related to Ensuring Compliance with MEAs", in U. Beyerlin, P.-T. Stoll and R. Wolfrum (eds.), Ensuring Compliance with Multilateral Environmental Agreements: a Dialogue between Practitioners and Academia (Leiden/Boston: Martinus Nijhoff Publishers, 2006) 201-227, at 204 notes that: "Parties [...] are overwhelmed by the burden imposed on them to take the necessary and appropriate measures, especially at the national level, to implement MEA provisions. [...] For many countries, such tasks are a challenge given their inadequate financial and human resources." On the creation of links among MEAs, see S. Oberthür, "Clustering of Multilateral Environmental Agreements: Potential and Limitations", Int'l Envt'l Agreements, 2 (2002) 317-340.

25 The study commissioned by the second COP to the Rotterdam PIC Convention on how coordinated administrative arrangements might save financial resources shows that significant savings, in the range of US $\$ 315.000$ to US $\$ 765.000$, depending on the different options envisaged, may be obtained. The study suggests that "by parallel COP decisions the liberated financial resources could be used for the implementation of the three conventions and for capacity building and support for developing countries and countries with economies in transition."(See Swiss paper on how coordinated administrative arrangements might liberate financial resources for the implementation of the three conventions, doc. UNEP/FAO/CHW/RC/POPS/ JWG.3/INF/8 (17 March 2008)). 
Recently this joint working group has recommended to the three COPs the consideration of innovative possibilities to enhance coordination among non-compliance mechanisms. It is particularly worth mentioning the proposal of holding meetings of the respective committees back-to-back and, even more far-reaching and groundbreaking, the one envisaging the establishment of a single body to administer jointly the three mechanisms. ${ }^{26}$

\section{Financial Means to Assist Countries in Complying with Their OBLigations}

A cooperative and supportive approach is a central element of the theory of compliance according to which States often fail to respect their obligations not because of lack of will but because of lack of capacity. ${ }^{27}$

Financial resources constitute instruments of "active management" of the compliance process: on the one hand they build and reinforce the capacities of developing countries committed to implementing MEAs and, on the other, they may be used to reduce the compliance costs of developed States Parties by giving them a sort of "incentive" to comply. ${ }^{28}$

\subsection{Funds for Developing Countries}

Although almost all recently negotiated MEAs contain provisions on financial assistance, it is difficult to identify a unique structure.

In fact each treaty envisages different forms through which financial resources are to be transferred to countries in need and these forms involve differentiated commitments, some of them achieving the status of binding obligations to provide financial resources while others constitute less stringent commitments and others are of a pure voluntary nature.

Earlier funds existing under environmental agreements are often of a voluntary nature and had, and in many cases still have, relatively limited capabilities. These

\footnotetext{
${ }^{26}$ See Draft recommendations to the Conferences of the Parties to the Basel, Rotterdam and Stockholm Conventions prepared by the Co-chairs of the ad hoc joint working group, doc. UNEP/FAO/CHW/RC/ POPS/JWG.3/2 (29 February 2008), at 7.

${ }^{27}$ See A. Chayes and A. Handler Chayes, The New Sovereignty. Compliance with International Regulatory Agreements (Cambridge, Massachusetts: Harvard University Press, 1995) at 9; A. Chayes, A. Handler Chayes and R. Mitchell, "Managing Compliance: A Comparative Perspective", in E. Brown Weiss and H. Jacobson (eds.), Engaging Countries. Strengthening Compliance with International Environmental Accords (Cambridge, London: MIT Press, 1998) 39-62.

${ }^{28}$ Chayes and Handler Chayes, The New Sovereignty, supra n. 27, at 227: "[...] Compliance activity for the most part involves assisting and organizing the efforts of willing, or at least nonrecalcitrant, parties to move toward increasingly complete fulfillment of their obligation. Technical assistance, research, information and education, and capacity building are the primary instruments. [...] The treaty and the regime in which it is embedded are best seen not as a set of prohibitory norms, but as institutions for the management of an issue area over time."
} 
funds are generally devoted to financing the protection of specific environmental resources and are inspired by a "donor-beneficiary" approach. ${ }^{29}$

This traditional approach is gradually being superseded by the development of new trends brought by the evolution of international environmental law and the increasing influence of the principle of common but differentiated responsibilities. ${ }^{30}$

According to these developments financial resources, in more recently negotiated MEAs, are devoted to the broad purpose of enhancing sustainable development and have an essential role because they make the implementation of substantial commitments by developing countries possible. In this view, financial assistance is seen as a concrete application of the principle of common but differentiated responsibilities and consequently it entails a strengthened form of responsibility for developed countries to provide for adequate funding to developing ones. ${ }^{31}$

The main funds of this type are the Multilateral Fund of the Montreal Protocol and the Global Environmental Facility (GEF) but other smaller funds exist under almost every MEA. ${ }^{32}$

The Multilateral Fund and the GEF have similar objectives because they both intend to meet all agreed incremental costs ${ }^{33}$ of projects and activities undertaken by developing countries or countries with economies in transition to implement their commitments deriving from MEAs.

${ }^{29}$ See L. Boisson de Chazournes, "Technical and Financial Assistance”, in Bodansky, Brunnée and Hey (eds.), supra n. 1, 947-973, at 962: "[...] the provision of technical and financial assistance from developed to developing countries is perceived as a relation between donor and recipient countries, and is not considered to benefit the international community as a whole."

${ }^{30}$ Rio Declaration on Environment and Development (doc. A/CONF.151/26 (Vol. I) (12 August 1992), Annex I), Principle 7: "States shall cooperate in a spirit of global partnership to conserve, protect and restore the health and integrity of the Earth's ecosystem. In view of the different contributions to global environmental degradation, States have common but differentiated responsibilities. The developed countries acknowledge the responsibility that they bear in the international pursuit to sustainable development in view of the pressures their societies place on the global environment and of the technologies and financial resources they command."

31 Among the many scholars that share this opinion, see R. Wolfrum and J. Friedrich, "The Framework Convention on Climate Change and the Kyoto Protocol", in Beyerlin, Stoll and Wolfrum (eds.), supra n. 24, 53-68, at 56. L. Boisson de Chazournes, "Technical and Financial Assistance and Compliance: the Interplay", in Beyerlin, Stoll and Wolfrum (eds.), ibid., 273-300, at 279 considers the funds established by the World Heritage Convention and the Ramsar Convention and underlines that: "In international practice, and in particular within a treaty framework, the legal nature of the assistance often evolves: as States grow to rely on voluntary contributions, those contributions may take on the character of legal obligations. States relying on the contribution develop a legal entitlement to them and contributing States must then provide assistance due to the obligation of cooperation." See also L. Rajamani, Differential Treatment in International Environmental Law (Oxford: Oxford University Press, 2006), 117.

32 Under the Climate Change regime, besides the GEF, other funds are: the Special Climate Change Fund, the Least Developed Countries Fund and the Adaptation Fund. The Convention on Biodiversity and the Cartagena Protocol also established a Trust Fund. Similar Trust Funds exist under the CITES, the World Heritage Convention, and the Ramsar Convention.

33 There is no common agreement on the definition of incremental costs. In simplified terms they may be considered as the costs that would not exist if the State was not a Party to the MEA. Under the Montreal Protocol, the COP/MOP has adopted an "Indicative list of categories of incremental costs" (Report of the Fourth Meeting of the Parties, doc. UNEP/OzL.Pro.4/15 (25 November 1992), Annex VIII, at 49). 
The Multilateral Fund was established through an amendment to the Montreal Protocol to provide funding to developing countries to phase out ozone depleting substances and functions directly under the authority of the COP/MOP. ${ }^{34}$

A recent example of the fundamental role played by this fund is evident in the decision adopted by the nineteenth Meeting of the Parties to the Montreal Protocol to accelerate the phase-out of production and consumption of hydro chlorofluorocarbons (HCFCs). In adopting such a decision, Parties agreed that

"funding available through the Multilateral Fund for the implementation of the Montreal Protocol in the upcoming replenishment shall be stable and sufficient to meet all the agreed incremental costs to enable article 5 Parties to comply with the accelerated phase-out schedule both for production and consumption sectors [...]." ${ }^{35}$

During the negotiations of this decision, adequate funding by the Multilateral Fund was considered as a necessary precondition for approval of the new commitments.

The GEF, on the other side, is a multipurpose fund managed by the World Bank and implemented by agencies of the United Nations. It finances projects in the areas of biodiversity, climate change, ozone depletion, persistent organic pollutants, and land degradation following the guidelines provided by the COPs of each convention. ${ }^{36}$

\section{a) The Legal Nature of the Obligation to Contribute to Funds}

To what extent may obligations to contribute to these funds be considered binding? In occasion of the Rio Conference, developed States were reluctant to accept a general commitment to provide financial resources for the protection of the environment, ${ }^{37}$ and still at present a binding nature of these obligations might not be recognized in general. However, under specific environmental agreements and with respect to precise categories of costs, a legal obligation in this sense may be envisaged.

Environmental agreements contain reference to the need to transfer financial resources in their preambles, in articles of the treaty and in decisions adopted by the COPs that implement the previous norms. As seen before with regard to contributions to the regular budget, also the legal basis of the duty to contribute to funds devoted to the implementation of MEAs is generally contained in the treaty, while the precise assessment of the quotas is left to the COP.

\footnotetext{
${ }^{34}$ For a detailed overview of the establishment of the Multilateral Fund, see G. Bankobeza, Ozone Protection: The International Legal Regime (Utrecht: Eleven International Publishing, 2005), 191.

${ }^{35}$ Decision XIX/6 on Adjustments to the Montreal Protocol with regard to Annex C, Group I, substances (hydro chlorofluorocarbons), doc. UNEP/OzL.Pro.19/7 (21 September 2007), para. 5.

${ }^{36}$ On the GEF, see L. Boisson de Chazournes, "The Global Environment Facility (GEF). A Unique and Crucial Institution", RECIEL, 14 (2005) 193-201; E. Hey, "Exercising Delegated Public Powers. MEAs and Multilateral funds", in R. Wolfrum and V. Röben (eds.), Developments of International Law in Treaty Making (Berlin: Springer, 2005) 437-461.

${ }^{37}$ See R. Wolfrum, "Means of Ensuring Compliance With and Enforcement of International Environmental Law", $R d C$, 272 (1999) 9-154, at 123.
} 
In the case of the Montreal Protocol, these obligations are beyond reasonable doubt legally binding ${ }^{38}$ and Parties indeed cautioned that such a far-reaching financial mechanism should be without prejudice to future ones to be adopted in other environmental treaties. ${ }^{39}$

Also with regard to the climate change regime ${ }^{40}$ and more recently the Stockholm POPs Convention, ${ }^{41}$ there are strong elements for their qualification as binding obligations. Different solutions, however, may be reached for other treaties, such as in the case of the Desertification Convention. ${ }^{42}$

Under the Convention on Biodiversity the legal nature of the obligation to provide financial assistance was a controversial issue during its negotiation. The text of the relevant provisions, Articles 20 and 21, reflects a compromise and it leaves to subsequent COP's decisions the task to clarify their meaning. ${ }^{43}$ It is therefore unsurprising that the ultimate meaning of these provisions remains open to differing interpretations.

On one side, several industrialized States made declarations stating that:

"Nothing in article 20 and 21 authorises the COP to take decisions concerning the amount, nature, frequency or size of the contributions of the Parties under the Convention." ${ }^{44}$

${ }^{38}$ Montreal Protocol, Art. 10.6: "The Multilateral Fund shall be financed by contributions from Parties not operating under paragraph 1 of Article 5 [...] on the basis of the United Nations scale of assessment. Contributions by other Parties shall be encouraged." In this view, see L. Gündling, "Compliance Assistance in International Environmental Law: Capacity-Building through Financial and Technology Transfer", ZaöRV, 56 (1996) 796-809, at 805.

39 Montreal Protocol, Art. 10.10: "The financial mechanism set out in this Article is without prejudice to any future arrangements that may be developed with respect to other environmental issues."

${ }^{40}$ UNFCCC, Art. 4.3: "The developed country Parties and other developed Parties [...] shall provide new and additional financial resources to meet the agreed full costs incurred by developing country Parties [...]". Kyoto Protocol, Art. 11 recalls and repeats the content of this provision. For an accurate analysis of these provisions see Rajamani, supra n. 31, at 206 noting that: "The contributions under the FCCC were made binding. The level of funding, however, was left unspecified, and each industrial country can determine for itself the size of its financial contribution."

${ }^{41}$ Stockholm POPs Convention, Art. 13.2: "The developed country Parties shall provide new and additional financial resources to enable developing country Parties and Parties with economies in transition to meet the agreed full incremental costs of implementing measures which fulfil their obligations under this Convention $[\ldots] . "$

${ }^{42}$ Desertification Convention, Art. 20, while acknowledging the "central importance of financing to the achievement of the objective of the Convention", uses weak expressions to define the commitments of Parties that "taking into account their capabilities, shall make every effort to ensure that adequate financial resources are available", "shall seek full use and continued qualitative improvement of all national, bilateral and multilateral funding sources and mechanisms."

${ }^{43}$ L. Glowka, F. Burhenne-Guilmin and H. Synge, A Guide to the Convention on Biological Diversity (Cambridge: IUCN, The World Conservation Union, 1994), at 100.

44 Declaration of the United Kingdom upon ratification of the Convention. Similar declarations were made by Switzerland: "With regard to financial cooperation, Switzerland interprets the provisions of articles 20 and 21 as follows: the resources to be committed and the management system will have regard, in an equitable manner, to the needs and interests of the developing countries and to the possibilities and interests of the developed countries." And by Italy: "The Italian Government [...] declares its understanding that the decision to be taken by the Conference of the Parties under article 21.1 of the Convention refers to the 'amount of resources needed' by the financial mechanism, not to the extent or nature and form of the contributions of the Contracting Parties." 
However, in support of the opposite thesis, it may be assumed that, according to an interpretation of the text of Articles 20 and 21 in the light of the principle of common but differentiated responsibilities, these obligations to provide financial resources to developing countries constitute indeed a legal commitment for industrialized States. ${ }^{45}$

The evolution towards strengthened obligations to contribute is reflected also in the participation on an equal basis of developed and developing countries in the governing bodies of these funds. ${ }^{46}$ The voting rules of the Executive Committee of the Multilateral Fund and of the GEF Council require consensus or, when agreement cannot be reached, double qualified majorities representing the majority of the countries present and voting as well as the majority of contributors for the adoption of decisions on their replenishment and on disbursement of resources. ${ }^{47}$ In so doing, developed and developing countries participate "as equal partners in financial decisionmaking". 48

It may be noted that these voting procedures require the same conditions as the ones related to the binding contributions to the regular budget.

\section{b) The Relationship between Lack of Transfer of Financial Resources and Non-Compliance by Developing Countries}

Another relevant matter, linked to the one just analyzed, is whether developing countries shall achieve their compliance commitments even in the case that financial assistance is not transferred.

Also with regard to this matter, different situations exist under the various conventions.

The practice under the Montreal Protocol, for instance, shows that in the case of the non-compliance of a developing country due to the lack of financial resources the Implementation Committee generally adopts a tolerant approach toward the

45 The language of Arts 20 and 21 differentiates clearly between binding commitments, for which it uses terms as "shall" such as, for instance: "The developed country Parties shall provide new and additional financial resources to enable developing country Parties to meet the agreed full incremental costs" from voluntary obligations, for which it adopts a softer terminology: "Other Parties [...] may voluntarily assume the obligation of developed countries", "Contributions from other countries and sources on a voluntary basis would also be encouraged". (emphasis added)

46 The Executive Committee is composed of fourteen members, seven representatives of developing countries and seven of industrialized ones, see Terms of reference of the Executive Committee of the Multilateral Fund, para. 2, (Report of the Ninth Meeting of the Parties, doc. UNEP/OzL.Pro.9/12 (25 September 1997), Annex V, at 59 as modified by the Sixteenth Meeting of the Parties in Decision XVI/38 on Need to ensure equitable geographical representation in the Executive Committee of the Multilateral Fund, doc. UNEP/OzL.Pro.16/17 (16 December 2004) at 68). The GEF Council is composed of 32 members: 18 representatives of recipient countries, 14 of donor countries. (Instrument for the Establishment of the Restructured Global Environment Facility (available at <http://www.gefweb.org/uploadedFiles/GEF_Instrument March08.pdf>, visited 20 July 2008), para. 16).

47 See Terms of reference of the Executive Committee of the Multilateral Fund (supra n. 46), Arts. 10.4 and 10.9; the GEF Council requires a double majority of $60 \%$ (Instrument for the Establishment of the Restructured Global Environment Facility, supra n. 46, para. 25(c, i).

${ }^{48}$ In this view, see Wolfrum, supra n. 37, at 127 noting that: "The Fund is not an institution of development assistance, but reflects the common but differentiated responsibilities of States parties concerning the protection of the ozone layer." 
non-complying State and urges the Party and the financing agencies to cooperate without delay in order to resolve the situation. ${ }^{49}$

Moreover, the Montreal Protocol provides for a procedure that developing countries, unable to respect their obligations due to the inadequate transfer of financial assistance, may trigger in order to defend themselves from a claim of non-compliance. In fact they can notify the matter to the Secretariat, which in turn informs the COP/MOP. Furthermore, pending the decision of the COP/MOP on the matter, the non-compliance procedure cannot be triggered against the notifying Party. ${ }^{50}$ This provision establishes a sort of sui generis non-compliance procedure that operates without the involvement of the Implementation Committee. ${ }^{51}$

It is interesting to note that this procedure was included in the Montreal Protocol with the same amendment that established the Multilateral Fund and thus it indicates the close connection existing between financial assistance and the compliance of developing countries. ${ }^{52}$

Non-compliance by developing countries due to the lack of technical and financial assistance is also considered in the draft texts of the non-compliance procedures of the Stockholm POPs and Rotterdam PIC Conventions. Here, if these cases occur, the respective compliance committees can adopt only facilitative measures and not the more stringent ones, such as issuing a statement of concern or a declaration of noncompliance, issuing a caution or publishing the case on the website of the convention. ${ }^{53}$

All these provisions recognize that there is indeed a legal connection between the duty to provide financial assistance by industrialized countries and the obligation to comply of developing countries. ${ }^{54}$ However, as it has correctly been remarked, the

49 See the case of Botswana which did not comply because it was waiting for assistance from an implementing agency. The Implementation Committee "agreed [...] to request Botswana to continue to work with relevant implementing agencies, as a matter of urgency." Report of the Implementation Committee under the Non-compliance Procedure for the Montreal Protocol on the work of its thirty-sixth meeting, doc. UNEP/ OzL.Pro/ImpCom/36/7 (10 July 2006), 11.

${ }_{50}$ Montreal Protocol, Art. 5.7.

${ }^{51}$ Boisson de Chazournes, supra n. 31, at 282 notes that: "Developing States are thus given the power to put pressure on developed States to ensure that they have the necessary means to meet their commitments."

${ }_{52}$ See Rajamani, supra n. 31, at 110: "The creation of the Multilateral Fund had a dramatic impact on developing country participation. Until then Mexico was the only developing country producer of ozone depleting substances to have signed the Protocol. Shortly after the creation of the Multilateral Fund, China joined, followed by India and eventually by almost all developing countries."

53 See Decision SC-3/20 on Non-Compliance, doc. UNEP/POPS/COP.3/30 (4 May 2007), Annex, at 57 (Stockholm POPs Convention Draft NCP), para. 28: "[In case a developing country is found to be noncompliant because of lack of technical and financial assistance, sub-paragraphs 27 (c)-(f) shall not be applicable]". In an earlier draft of the Rotterdam PIC Convention NCP an analogous provision was found, but has been deleted in the more recent version. (See the Report of the Open-ended Ad Hoc Working Group on Non-Compliance on the work of its first session, doc. UNEP/FAO/RC/OEWG.1/3 (28 September 2005), Annex, para. 20: "It is understood that, as far as developing countries and countries with economies in transition are concerned, additional measures referred to in paragraph 19 should not be undertaken towards these countries, if the reasons for non-compliance are lack of technical assistance [financial resources] or inadequate capacity to fulfill their obligations]") and the Decision RC-3/4 Draft text of the Procedures and Mechanisms on Compliance with the Rotterdam Convention, doc. UNEP/FAO/RC/COP.3/26 (10 November 2006), Annex, at 27 (Rotterdam PIC Convention Draft NCP), where para. 20 is missing.

${ }^{54}$ In this view, see Wolfrum, supra n. 37, at 133 noting that: "[...] a legal interrelation between the conservation obligations of developing countries and the obligations of developed countries, to provide the 
fact that the compliance of developing countries depends on the prior implementation of financial obligations by industrialized States does not a priori absolve developing countries from acting in a supportive manner, at national and international level, towards fulfilling their obligations..$^{55}$

\subsection{Flexibility Mechanisms for Industrialized Countries}

A new type of financial instrument was adopted under the Kyoto Protocol with the aim of allowing industrialized States to achieve compliance with their obligations to reduce greenhouse gases emissions in an effective and economically efficient manner. These so-called flexibility mechanisms are the Clean Development Mechanism $(\mathrm{CDM}){ }^{56}{ }^{5}$ oint Implementation (JI) ${ }^{57}$ and International Emission Trading (IET) ${ }^{58}$

The first two mechanisms rely on the assumption that reductions of greenhouse gases emissions are beneficial for the global climate wherever they are achieved. Therefore, industrialized countries are encouraged to invest in projects located in developing countries or in countries with economies in transition which demonstrably reduce these emissions and contribute to the sustainable development of the host country. ${ }^{59}$ When the projects respect all the requirements set by the Kyoto Protocol and by the relevant COP/MOP's decisions, industrialized countries can offset an equivalent quantity of the reduced emissions from the targets assigned to them by the Protocol. ${ }^{60}$

Beside these two project-based mechanisms, the Kyoto Protocol establishes a market-based mechanism, according to which industrialized countries may exchange and trade their entitlements to emit greenhouse gases.

These mechanisms introduce innovative elements such as flexibility and the involvement of private subjects and the combination of these two elements attracts new means and sources of funding, as can be seen by the great development that the carbon market has experienced in recent years.

former with new and additional resources, is established" and Boisson de Chazournes, supra n. 31, at 275: "The Montreal Protocol, the Convention on Biological Diversity and the Convention on Climate Change have shaped this commitment as a 'compliance requirement': it is explicitly recognized that the extent to which developing country Parties will effectively implement their treaty obligations depends on the effective implementation by developed Parties of their commitments to provide financial resources and technology."

${ }^{55}$ Rajamani, supra n. 31, at 212 (referring to Art. 4.7 of the UNFCCC): "It does not absolve developing countries of responsibility if financial assistance and technology transfer are not forthcoming. To construct this provision otherwise would be to deny the 'common concern' element of the endeavour, and the customary international legal obligation to respect the environment of other states and common areas, as qualified by the duty of diligence."

56 Kyoto Protocol, Art. 12

57 Ibid., Art. 6.

${ }_{58}$ Ibid., Art. 17. For a detailed study of the legal implication connected to the functioning of the flexibility mechanisms, see D. Freestone and C. Streck (eds.), Legal Aspects of Implementing the Kyoto Mechanisms: Making Kyoto Work (Oxford: Oxford University Press, 2005).

59 Kyoto Protocol, Art. 12.2.

${ }^{60}$ On the CDM, see J. Werksman, "The Clean Development Mechanism: unwrapping the 'Kyoto surprise'”, RECIEL, 7 (1998) 147-158; H. Wilkins, "What's new in the CDM?", RECIEL, 11 (2002) 144-158; C. Streck and J. Lin, "Making Markets Work: A Review of CDM Performance and the Need for Reform", Eur. J. Int'l L., 19 (2008) 409-442. On Joint Implementation, see C. Streck, “Joint Implementation: History, Requirements, and Challenges", in Freestone and Streck (eds.), supra n. 58, 107-126. 
The partnerships between developing and industrialized countries and the creation of a new market entail new challenges for international environmental law, in general, and for the Kyoto Protocol institutions and for its compliance committee, in particular.

There is, indeed, a close relationship between these mechanisms and the non-compliance procedure of the Kyoto Protocol, as the latter is called upon to ensure the correct and efficient functioning of the overall implementation system. There are, in fact, many specific requirements that must be met and conditions to be respected by the subsidiary bodies, international organizations and States involved in the procedures for the approval of projects and the creation of emission reductions units.

The compliance mechanism of the Kyoto Protocol will face far more complex situations than other non-compliance systems; one may think, for instance, of the mandate of the Enforcement Branch to determine compliance with eligibility requirements to participate in the flexibility mechanisms and the corresponding measures the Branch may take in the cases where these requirements are not met. ${ }^{61}$

Moreover, the success of the carbon market will depend on the capacity of the Kyoto non-compliance mechanism to work effectively and to guarantee an adequate control of the good functioning of the market. ${ }^{62}$

While some problems have already emerged, due to the recent start of the first commitment period, major challenges for the compliance bodies will most likely appear in the coming years and in 2012, when the commitment period will expire and industrialized countries will have to demonstrate that they are in compliance with their emission reduction targets.

\section{The Control Exercised by Non-Compliance Mechanisms on Financial MATTERS}

While financial assistance is an issue that is frequently addressed by compliance bodies, especially when the difficulties of developing countries in implementing their obligations are at stake, other issues, such as the control of the disbursement of contributions owed by State Parties, both to the general budget and to financial institutions, have never been undertaken under compliance systems.

With regard to the first point, under the Montreal Protocol the MOP made it clear that "the disbursement of the international assistance should be contingent on the settlement of those problems with the Implementation Committee." This means that

${ }^{61}$ See Decision 27/CMP.1 on Procedures and Mechanisms Relating to Compliance under the Kyoto Protocol, doc. FCCC/KP/CMP/2005/8/Add.3 (30 March 2006), at 92 (Kyoto Protocol NCP), section XV.4. The eligibility requirements include: calculation and communication of the initial cap for each industrialized country, submission of emissions inventories, establishment of National registries. See E. Meijer and J. Werksman, "Keeping in Clean - Safeguarding the Environmental Integrity of the Clean Development Mechanism", in Freestone and Streck (eds.), supra n. 58, 191- 211, at 204.

${ }^{62}$ At the second meeting of the Compliance Committee, the President recalled that " $\left.\mathrm{t}\right]$ he compliance mechanism under the Kyoto Protocol was designed to strengthen the environmental integrity of the Protocol and the credibility of the carbon market. A strong and effective compliance mechanism was therefore key to the successful implementation of the Protocol." 
actions undertaken by the Executive Committee of the Multilateral Fund should be subject to the prior approval of the compliance committee. ${ }^{63}$

The practice of proceeding to the exchange of information and consultation with financial institutions operating under the treaty regime, which originally appeared under the Montreal Protocol, has subsequently been incorporated in the text of the more recently negotiated non-compliance mechanisms, whose preambles state that compliance bodies "shall complement the work performed by other Convention bodies and the financial mechanism". ${ }^{64}$

Notwithstanding this trend recognizing the link between compliance and financial matters, non-compliance mechanisms generally do not have the power to decide directly on the disbursement of financial assistance, except with regard to limited and minor facilitative activities, such as the provision of advice and facilitation of financial assistance. ${ }^{65}$

In fact under most compliance systems the compliance bodies, after considering the submission and eventually consulting with the relevant financial bodies, recommend appropriate action to the COP which provides instructions to the financial entities. $^{66}$

As regards the second matter, non-compliance mechanisms have never engaged in assessing the compliance of Parties with their obligations to disburse financial resources.

This matter is part of a broader issue that relates to the definition of what constitutes a situation of non-compliance.

The matter was addressed in the elaboration of the Montreal Protocol non-compliance procedure, where the following possible situations of non-compliance were identified: failure to meet substantial obligations, failure to report data, non-payment of contributions to the Multilateral Fund and non-respect of COP/MOP decisions. While there were States that argued that non-payment resulted in non-compliance and therefore should fall under the competence of the compliance mechanism, others

${ }^{63}$ See Decision VII/18 on Compliance with the Montreal Protocol by the Russian Federation, doc. UNEP/OzL.Pro.7/12 (27 December 1995), at 33-35, para. 9(e) and the contribution by Romanin Jacur, supra $\mathrm{n} .23$, at 30 .

${ }^{64}$ Stockholm POPs Convention Draft NCP, para. 3 which is further specified by para. 30(c): "In carrying out its functions, the Committee may: [...] Exchange information with the Council of the Global Environment Facility, in particular for the purpose of drawing up its recommendations, related to the provision of financial assistance under Articles 12 and 13 of the Convention". A similar provision is also found in the Basel Convention NCP (Decision VI/12 on Establishment of a Mechanism for Promoting Implementation and Compliance, doc. UNEP/CHW.6/40 (10 February 2003), at 45), para. 2. See also in more general terms, the Rotterdam PIC Convention Draft NCP, para. 27.

${ }^{65}$ See, for example, the Stockholm POPs Convention Draft NCP, para. 26(c) stating that the Committee may "[f]ollowing consideration of the need for technical and financial assistance, facilitate technical and financial assistance, including by providing advice on sources and modalities of technology transfer, training and other capacity-building measures." Similarly, Basel Convention NCP, para. 19(b), Cartagena Protocol NCP (Decision BS-I/7 on Establishment of Procedures and Mechanisms on Compliance under the Cartagena Protocol on Biosafety, doc. UNEP/CBD/BS/COP-MOP/1/15 (27 February 2004), Annex I, at 98), section III.1 (c), Kyoto Protocol NCP, Section XIV.

${ }^{66}$ See, for example, Cartagena Protocol NCP, Section VI.1(b); Stockholm POPs Convention Draft NCP, para. 27(a); Rotterdam PIC Convention Draft NCP, para. 19(a). 
considered that contributions should be considered voluntary. The proposal to include this commitment failed because no agreement on the matter could be reached. ${ }^{67}$

This subject has never been discussed again under the Montreal Protocol and, even though countries with economies in transition indicated their inability to pay and never paid their contributions to the Multilateral Fund, other Parties never formally complained about non-payment. ${ }^{68}$

The mandate of more recently established non-compliance mechanisms is generally stated in broad terms by providing that they are responsible for dealing with compliance with all the commitments under the MEA. ${ }^{69}$ The way these provisions are framed, therefore, in theory includes also obligations to provide contributions to financial mechanisms, when, as noted previously, they are to be considered binding. However, when considering the practice of these mechanisms, it emerges that none of them has ever taken into consideration compliance with these commitments.

Scholars are aware of what might be considered a loophole in the functioning of compliance procedures ${ }^{70}$ but, perhaps because of its political implications, they generally avoid considering deeply the matter of whether it would be desirable to extend the competence of non-compliance mechanisms also to other substantive obligations arising from multilateral environmental agreements. ${ }^{71}$

\section{Conclusions}

COPs have repeatedly addressed issues concerning the inadequate level of financial resources with regard to the regular budget. When these cases arise, COPs generally recommend consultations with States and remind them that payments are due by specific dates, or request them to agree on payment plans.

${ }^{67}$ The Report of the Third Meeting of the ad hoc working group of legal experts on non-compliance with the Montreal Protocol, doc. (UNEP/OzL.Pro/WG.3/3/3 (9 November 1991), para. 38 reproduces the highly controversial atmosphere in which the debate took place: "Because of lack of time and the apparent political implications of the question concerned, it was decided not to pursue the discussion [...]. A number of delegations expressed surprise at and serious concern with the view that Article 10 did not contain an obligation to contribute to the financial mechanism. One delegation expressed surprise at that expression of surprise and concern."

${ }^{68}$ These cases represent a borderline situation as these countries, although they have an obligation to contribute to the Multilateral Fund, are eligible for funding by the GEF and therefore it would be unreasonable to require them to disburse financial resources for implementation. K. Madhava Sarma, Compliance with the Montreal Protocol, Paper presented to the $7^{\text {th }}$ International Conference on Environmental Compliance and Enforcement, Marrakech, Morocco, 9-15 April 2005, notes that: "Perhaps all of the Parties realized, without formally recognizing it, that these Parties were unable to pay. The dues from these Parties are still in the books of the MF as arrears to be collected."

${ }^{69}$ See Kyoto NCP, Section I: Rotterdam PIC Convention Draft NCP, Preamble; Stockholm POPs Convention Draft NCP, para. 4; Cartagena Protocol NCP, Section I.1; Basel Convention NCP, para. 1.

${ }^{70}$ Wolfrum, supra n. 37, at 119: "Since both obligations, the one to reduce and eliminate the production of and the trade with controller substances and the financial ones, are of a reciprocal nature, the noncompliance procedure should cover both."

${ }^{71}$ M. Koskenniemi, "Breach of Treaty or Non-Compliance?: Reflections on the Enforcement of the Montreal Protocol”, YB Int'l Envt'l L., 3 (1992) 123-162, at 133. 
A similar "soft" approach to failure to pay on time reflects the strategy adopted by the General Assembly which, although Article 19 of the UN Charter provides for the suspension of the right to vote for States failing to pay their contributions for two years, has never taken this action against States unwilling to pay.

Control by compliance bodies on obligations to contribute both to the general budget of MEAs and to their financial mechanisms could be a positive development because it would put pressure on States in order to guarantee a more timely payment and consequently a more stable and predictable level of funding.

In consideration of the already existing connections between financial and compliance bodies, the latter may easily obtain the relevant information and, in so doing, their competence to consider compliance with these commitments, which is foreseen in theory by almost all texts governing the procedures, may become a reality.

In this view, COPs would have a clearer picture when addressing non-compliance with financial obligations and could adopt facilitative measures or even more severe ones, such as "naming and shaming", suspension of voting rights or other privileges, as recommended by their respective compliance committees.

The recognition of this competence and consequent measures entails delicate political considerations; however, it would not be new to international law as it shares the same ratio of Article 19 of the UN Charter.

A more efficient functioning of compliance mechanisms may also be assured by introducing new ways of financing them, for example through the withdrawal of a fee from the financial mechanisms' resources.

In this view, for example, a percentage of the financial resources allocated by funds to finance the implementation of the substantial commitments under MEAs could be used for financing non-compliance mechanisms which, at the end of the day, are also part of the implementation scheme of these treaties.

This system would have the positive effect of a sort of self-financing of compliance bodies which would allow them to be independent from the often irregular and unpredictable funding approved by the COP. ${ }^{72}$

72 This model of financing international bodies recalls somewhat the financing system under the European Coal and Steel Community (ECSC) where fees were witheld from the activity of companies producing steel and coal within the European area. See Tesauro, supra n. 11, at 8. A similar model has been recently adopted under the Kyoto Protocol to cover the administrative costs of treaty bodies established to manage the flexibility mechanisms. Here the Executive Board of the CDM, which is the body in charge of certifying projects reducing greenhouse gases emissions, is financed by a fee levied on the projects approved. Kyoto Protocol, Art. 12.8: "The Conference of the Parties serving as the Meeting of the Parties to this Protocol shall ensure that a share of the proceeds from certified projects activities is used to cover administrative expenses [...]." This way of financing has its drawbacks in that it shifts the administrative costs of treaty bodies onto private participants in the CDM process, i.e., project developers 
1 


\title{
Chapter Twenty-Five \\ Multiplication and Overlap of Non-Compliance Procedures and Mechanisms: Towards Better Coordination?
}

\author{
Cesare Pitea
}

\section{Overlap of Multiple Non-Compliance Procedures: Examples, REASONS AND RISKS}

International environmental law has developed mainly through the setting up of separate treaty regimes, with a consequent normative and institutional fragmentation. As the first part of this book clearly shows, non-compliance mechanisms established under multilateral environmental agreements (MEAs) do not escape this trend. They are invariably designed as regime-specific institutions and procedures: with some exceptions, ${ }^{1}$ each treaty establishes its own compliance mechanism. Therefore, their number has increased dramatically in recent years. The present book covers fifteen existing or perspective mechanisms, but the list might have been longer if broader criteria had been used for the purpose of defining the scope of the research.

This situation raises different issues. One may in fact wonder whether it is rational and cost-effective to maintain such a large number of separate compliance bodies. Indeed, the setting up of a non-compliance mechanism entails time and resource consuming activities by States, which are to provide the necessary financial means directly (when the relevant body is composed of States representatives) or by financing the activities of the various MEAs (when a body of experts sitting in their personal

\footnotetext{
${ }^{1}$ The Espoo Convention NCP (Decision II/4 on Review of Compliance, doc. ECE/MP.EIA/4 (7 August 2001), Annex IV, at 72 revised by Decision III/2 on Review of Compliance, doc. ECE/MP.EIA/6 (13 September 2004), Annex II (consolidated text)) will apply also to the SEA Protocol, which despite its name is a fully self-standing instrument, once this enters into force, see E. Fasoli, "Procedures and Mechanisms for Review of Compliance under the 1991 Espoo Convention on Environmental Impact Assessment in a Transboundary Context and its 2003 Protocol on Strategic Environmental Assessment", supra 181-203. In other cases the different instruments to which an NCP apply appear to be parts of a single regime as happens with the LRTAP Convention NCP (Decision 2006/2 on Implementation Committee, its Structure and Functions and Procedures for Review, doc. ECE/EB.AIR/89/Add.1 (5 February 2007), at 4) which applies also to the Convention's protocols, see E. Milano, "Procedures and Mechanisms for Review of Compliance under the 1979 Long-Range Transboundary Air Pollution Convention and its Protocols", supra 169-180, and the Alpine Convention NCP (Decision VII/4 Mécanisme de verification du respect de la Convention alpine et de ses protocols d'application (2002), reprinted in Envt'l Po'y \& L., 33 (2003) 179) which applies also to the Convention's Protocols, see L. Pineschi, "The Compliance Mechanism of the 1991 Convention on the Protection of the Alps and its Protocols", supra 205-219.
}

T. Treves et al., eds., Non-Compliance Procedures and Mechanisms and the Effectiveness of International Environmental Agreements

(C) 2009, T.M.C. ASSER PRESS, The Hague, The Netherlands, and the Authors 
capacity is in place). ${ }^{2}$ One may wonder whether arrangements may and should be envisaged to rationalise the system, by avoiding the duplication of efforts and thus saving precious resources.

Further concerns are connected with the possibility that the very same facts may trigger compliance issues under different treaties and that different compliance procedures may come into play. In certain cases, even the obligations whose compliance is challenged in different procedures may be similar, given that an overlap of substantive norms of different MEAs may occur.

One recent case perfectly illustrates the potential for overlap and multiplication of procedures. In 2003 Ukrainian authorities decided to authorize the construction of a canal for navigation connecting the Black Sea and the Bystroe arm of the Danube river delta. The Danube delta is internationally recognised as an area of a peculiar environmental importance. A large part of it was designated as a Wetland of International Importance under the Ramsar Convention in $1991,{ }^{3}$ it was inscribed by Romania in the UNESCO World Heritage List in $1991^{4}$ and was recognised as a transboundary Biosphere Reserve under UNESCO's Man and the Biosphere Programme in $1998 .{ }^{5}$ It is also the habitat of species protected under the Bern Convention on the Conservation of European Wildlife and Natural Habitats. ${ }^{6}$

Environmental groups and the Romanian Government claimed that Ukraine failed to comply with various protection standards required by the special international status of the area, and with obligations to cooperate with Romania, in particular for not having conducted a proper transboundary environmental impact assessment, as required under the Espoo Convention, and with the obligation to inform and involve the public in the decision-making process, as required by the Aarhus Convention. Control procedures set up under a plethora of different treaties have therefore been set in motion to assess whether Ukraine had indeed failed to respect its international commitments and to induce it to do so.

A second case offers a further variation on the theme. The case concerns the alleged failure by the Albanian authorities to properly inform the public and allow public participation in the planning and realisation of an industrial and energy park near the city of Vlore, in an area of environmental interest protected under national law. International financial institutions (IFIs), including the World Bank, the

\footnotetext{
${ }^{2}$ See F. Romanin-Jacur, "Controlling and Assisting Compliance: Financial Aspects”, supra 419-437.

3 According to the Secretariat of the Ramsar Convention "[t]wo adjacent Ramsar Sites cover the main part of the Danube Delta: $\mathrm{N}^{\circ} 113$ Kyliiske Mouth in Ukraine and $\mathrm{N}^{\circ} 521$ Danube Delta in Romania. Four additional Ramsar Sites are linked with the Delta, situated along the Danube in ascending order: $\mathrm{N}^{\circ} 760$ Kugurlui Lake and $N^{\circ} 761$ Kartal Lake in Ukraine, $N^{\circ} 1029$ Lower Prut Lakes in the Republic of Moldova, and $N^{\circ} 1074$ Small Island of Braila in Romania. Further Ramsar Site designations are in preparation", see Follow Up to Ramsar Advisory Mission 53, Danube Delta / Kyliiske Mouth Ramsar Site, Ucraine, Mission of 26-29 April 2005 by Tobias Salathé, Ramsar Secretariat, available at <http://www.ramsar.org/ram/ ram_rpt_53e_update.pdf $>$ (visited 15 March 2008), note 1. A full list of Ramsar Sites is available at $<$ http:// www.ramsar.org/sitelist_order.pdf $>$ (visited 15 March 2008).

${ }^{4}$ See information available at $<$ http://whc.unesco.org/en/list/588> (visited 15 March 2008). 2008)

5 See information available at $<$ http://www.unesco.org/mab/BRs/TBRs.shtml $>$ (visited $15 \mathrm{March}$

${ }^{6}$ A list of treaties with full references is provided supra at XXXVII.
} 
European Bank for Reconstruction and Development (EBRD) and the European Investment Bank, concurred in the financing of the project, after having subjected it to their internal rules relating to environmental assessment, which include public participation requirements. An Albanian NGO, the Civic Alliance for the Protection of the Vlore Bay, after submitting the case to the Compliance Committee of the Aarhus Convention, requested and obtained an inspection by the Panel of the World Bank, ${ }^{7}$ as well as a compliance review under the Independent Recourse Mechanism of the EBRD ${ }^{8}$ In the meantime, the Aarhus Convention Compliance Committee produced its own report, finding that Albania had not complied with certain obligations under Articles 6 and 7 of the Aarhus Convention. ${ }^{9}$ Therefore the same facts have been submitted to review to three different international mechanisms in order to assess compliance with largely overlapping international standards.

Faced with this kind of situation, the need to prevent the duplication of efforts and diverging evaluations suggests that arrangements should be established with a view to reducing duplications in fact finding and information gathering activities, avoiding conflicting findings as to compliance with overlapping obligations, and promoting common approaches in tackling non-compliance in specific cases.

\section{A Single Non-Compliance Mechanism? An Unrealistic and Unsuitable Perspective}

The need to rationalise the functioning of this disordered bunch of international institutions and procedures to deal with non-compliance with environmental treaties should not be misinterpreted as a case for the setting up of a unified "universal" system of compliance review. A number of obstacles oppose its realisation.

From a normative point of view, amendments of the various treaties would probably be necessary, although some could argue that, given the wide discretion given to the relevant COP/MOPs by treaty clauses enabling the establishment of compliance arrangements or on the basis of the doctrine of implied powers, the Parties are not strictly prevented from entrusting compliance functions to a body which is not a subsidiary one, internal to the institutional structure created under the relevant treaty. Practical issues would also emerge, due to the heterogeneous participation of States in the various treaties and to the specific expertise that technical aspects of certain

\footnotetext{
7 See Report and Recommendation on "Albania: Power Sector Generation and Restructuring Project (IDA Credit No. 3872-ALB)”, Report No. 40213-AL (2 July 2007), available at $<$ http://siteresources.worldbank.org/EXTINSPECTIONPANEL/Resources/Request_for_Inspection.pdf> (visited 2 March 2008).

${ }^{8}$ Independent Recourse Mechanism (IRM), Eligibility Assessment Report on complaint "Vlore Thermal Power Generation Project” (27 September 2007), approved by the EBRD Board on 12 October 2007, documents and information available at $<$ http://www.ebrd.com/about/integrity/irm/register.htm $>$ (visited 2 March 2007). On the IRM see, in this book, F. Seatzu, "In Search of New Ways to Ensure Effective Compliance with Environmental Procedures and Policies: The Experience of the European Bank for Reconstruction and Development with its Internal Recourse Mechanism”, supra 337-352.

${ }^{9}$ Findings and Recommendations with Regard to Compliance by Albania (Communication ACCC/C/2005/12) from the Civic Alliance for the Protection of the Vlore Bay (Albania)), adopted 15 June 2007, doc. ECE/MP.PP/C.1/2007/4/Add.1 (31 July 2007).
} 
treaties require. Also in this case arrangements could be envisaged, but they would probably overcomplicate the functioning of the mechanism..$^{10}$

The main obstacle to an arrangement of this kind seems to be of a political nature. Indeed the political constituencies of the various treaties may vary considerably according to their subject-matter and territorial scope and States have consistently expressed the view that non-compliance mechanisms should be regime-specific. Guidance documents on compliance issues adopted in intergovernmental fora, including the UNEP Guidelines, consistently stress "the importance of tailoring compliance provisions and mechanisms to the agreement's specific obligations." ${ }^{11}$ This makes it possible to take fully into account the technical, political and legal dimension of each regime and facilitates a more flexible handling of cases.

Apart from practical issues, also a more theoretical reflection suggests that a unification of non-compliance procedures would not to be welcomed. In fact, institutional fragmentation shall not necessarily be seen as a weakness of international environmental law. ${ }^{12}$ Rather, it is a factor enhancing development and innovation. States may be ready to accept and establish some innovative or forward looking arrangements in a certain context, while they might not be willing or able to do so in other contexts. If a certain innovative solution were to be applied in a cross-regime institutional framework, resistance would invariably prevail and progress in cooperation would be slowed down. Conversely, the existence of a plurality of fora allows innovative solutions to be experimented in certain contexts and, subsequently, spill over to other contexts, positively influencing their development.

\section{Information-Sharing Clauses in Existing and Perspective Non-Compliance Mechanisms}

Even though the establishment of a single institutional framework to deal with noncompliance with MEAs is largely undesirable and unfeasible, the need to establish other effective means to coordinate the activities of the various compliance bodies and to enhance synergies between them cannot be overlooked. Such arrangements should consist of more or less institutionalised forms of cooperation and dialogue between compliance bodies. Indeed, this necessity is recognised in most recent

${ }^{10}$ For example by dividing the composition of the compliance body between permanent and variable members. The permanent members could be elected on the basis of a legal expertise by States Parties to any of the covered agreements expressing a vote for each agreement they are a party to. Variable members would be elected only by the States Parties to the agreement concerned on the basis of technical expertise relevant in the field of the instrument concerned, and would sit only for cases in which compliance with that instrument is at stake.

${ }^{11}$ Draft Guidelines on Compliance with and Enforcement of Multilateral Environmental Agreements, doc. UNEP/GCSS.VII/4/Add.2 (23 November 2001), Annex, adopted by the UNEP Governing Council with Decision SS.VII/4 on Compliance with and Enforcement of Multilateral Environmental Agreements, doc. UNEP/GCSS.VII/6 (5 March 2002), Annex I, at 43.

${ }^{12}$ T. Gehring, "Treaty-making and Treaty Evolution", in D. Bodansky, J. Brunnée and E. Hey (eds.), The Oxford Handbook of International Environmental Law (Oxford: Oxford University Press, 2007) 467-497, at 475 . 
non-compliance mechanisms. The mechanism established under the Aarhus Convention has played a pioneering role in this respect, being the first to include a clause on "enhancement of synergies", providing that

"[i]n order to enhance synergies between this compliance procedure and compliance procedures under other agreements, the Meeting of the Parties may request the Compliance Committee to communicate as appropriate with the relevant bodies of those agreements and report back to it, including with recommendations as appropriate. The Compliance Committee may also submit a report to the Meeting of the Parties on relevant developments between the sessions of the Meeting of the Parties."13

This provision has been reproduced verbatim in other arrangements in the framework of UNECE that have taken inspiration from the precedent set by the Aarhus Convention. These include the non-compliance mechanism of the Protocol on Water and Health ${ }^{14}$ and the one adopted, but not yet operational, under the PRTRs Protocol. ${ }^{15}$ At the global level similar clauses (although different in wording) have been proposed during the negotiation of the non-compliance procedure for the London Dumping Protocol 1996 amending the Convention on dumping at sea ${ }^{16}$ and are under consideration in the process of establishing non-compliance mechanisms under the Rotterdam PIC Convention ${ }^{17}$ and the Stockholm POPs Convention. ${ }^{18}$ The non-compliance

13 Decision I/7 on Review of Compliance, doc. ECE/MP.PP/2/Add.8 (2001, late issued on 2 April 2004) (Aarhus Convention NCP), para. 39, see C. Pitea, "Procedures and Mechanisms for Review of Compliance under the 1998 Aarhus Convention on Access to Information, Public Participation and Access to Justice in Environmental Matters", supra 221-249, at 242-244.

${ }^{14}$ Decision I/2 on Review of Compliance, doc. ECE/MP.WH/2/Add.3 - EUR/06/5069385/1/Add.3 (3 July 2007) (Protocol on Water and Health NCP), para. 37, see C. Pitea, "Procedures and Mechanisms for Review of Compliance under the 1999 Protocol on Water and Health to the 1992 Convention on the Protection and Use of Transboundary Watercourses and International Lakes", supra 251-262, at 260.

${ }^{15}$ Draft Decision on Review of Compliance, doc. ECE/MP.PP/AC.1/2007/L.10 (18 July 2007) (PRTRs Protocol NCP). See C. Pitea, "Procedures and Mechanisms for Review of Compliance under the 2003 Protocol on Pollutant Release and Transfer Registers to the 1998 Aarhus Convention", supra 263-274, at 272.

16 See Report of the Twenty-sixth Consultative Meeting, doc LC 26/15 (17 December 2004). Appendix, para. 33. See S. Trevisanut, "The Compliance Procedure and Mechanism of the 1996 Protocol to the 1972 London Convention on the Prevention of Marine Pollution by Dumping of Wastes and Other Matter", supra 49-61, at 59.

17 Decision RC-3/4 Draft text of the Procedures and Mechanisms on Compliance with the Rotterdam Convention, doc. UNEP/FAO/RC/COP.3/26 (10 November 2006), Annex, at 27 (Rotterdam PIC Convention Draft NCP). See S. Brugnatelli, "Draft Procedures and Mechanisms on Compliance with the 1998 Rotterdam Convention on the Prior Informed Consent Procedure for Certain Hazardous Chemicals and Pesticides in International Trade", supra 85-100, at 99. The agreed text of para. 28 of the draft, under the heading "Information sharing with other relevant multilateral environmental agreements" provides that "[w]here relevant, the Committee may solicit specific information, upon request by the Conference of the Parties, or directly, from compliance committees dealing with hazardous substances and wastes under the auspices of other relevant multilateral environmental agreements and report on these activities to the Conference of the Parties."

18 Decision SC-3/20 on Non-Compliance, doc. UNEP/POPS/COP.3/30 (4 May 2007), Annex, at 57 (Stockholm POPs Convention Draft NCP), see G. Bigi, "Draft Non-Compliance Procedure under the 2001 Stockholm Convention on Persistent Organic Pollutants", supra 121-135, at 134. Under the heading "Other multilateral environmental agreements", para. 38 of the draft text provides that "[w]here relevant, the Committee may solicit information, upon request by the Conference of the Parties [or directly,] from compliance 
mechanism of the Protocol on Water and Health is, so far, the only one containing some further provisions that will be addressed later.

One may wonder what may be the meaning and purpose of a clause with the standard drafting. Apparently, its introduction in recent texts indicates that States do recognise the need for subsidiary bodies dealing with compliance to exchange information and experiences, but it also stresses their conviction that these activities can take place only if and when duly authorised by the relevant COP/MOP. States have shown their will to maintain a strict control over the relations between compliance bodies, since exchange of information can take place only following a specific request of the $\mathrm{COP} / \mathrm{MOP}$ and with an obligation to report back on it.

This normative choice evidently frustrates the usefulness of the provisions on enhancement of synergies. Since COP/MOPs may take place once a year or even, depending on the treaty concerned, at longer intervals of two or three years, the procedure envisaged in the clauses appears excessively burdensome and time-consuming, in contrast with the need of a prompt response that is normally expected from noncompliance procedures. States seem to have become aware that coordination clauses as currently drafted establish a complex process of limited use and the texts under negotiation for the establishment of non-compliance mechanisms for the two global conventions on chemicals may finally provide that the compliance body may solicit information "directly" (e.g., without a prior authorisation of the COP/MOP) from other compliance committees dealing with hazardous substances and wastes. ${ }^{19}$

\section{The Practice of Synergy Enhancement}

\subsection{Institutional Synergies: The Role of Secretariats}

Given that clauses introduced in texts establishing non-compliance mechanisms are formulated in a way that they are of little (if any) use, other less formal solutions have developed through practice and further ones may be envisaged.

Synergies and information sharing may be realised by allowing members of a compliance body to participate in meetings of other compliance bodies. Occasionally this may happen because some individuals may sit in more committees, as it is actually the case in some instances. The non-compliance procedure of the Protocol on Water and Health explicitly provides that " $[\mathrm{t}]$ he Committee may invite members of other compliance committees dealing with issues related to those before it for consultation." 20 The normative function of this provision seems to be rather limited. Indeed, it does not add to powers that the Committee, like almost any other compliance body, already enjoys. Nothing seems to prevent compliance bodies from inviting persons sitting in other compliance committees, in the framework of the broad powers they normally have to gather information, including through inviting

committees dealing with hazardous substances and wastes under the auspices of other relevant multilateral environmental agreements and report on these activities to the Conference of the Parties."

19 See supra, nn. 17 and 18.

${ }^{20}$ Protocol on Water and Health NCP, para. 38. 
experts. However, an explicit normative statement may be seen as having the policy objective of encouraging the use of this tool to enhance synergies between compliance bodies.

In practice, however, the exchange of experience seems to take place mainly through other channels, although practice is still scarce. The Aarhus Committee, while considering the case relating to the Bystroe project, did consider it necessary to receive information on the ongoing parallel process under the Espoo Convention, but it decided to invite to one of its meetings the Secretary of the Convention rather than a member of the Implementation Committee. Similarly, in the Vlore industrial park case, the same Committee informed the IFIs involved in the financing of the projects of the ongoing procedure and invited them to comment on the issue at stake, including on draft findings and recommendations. More recently, Secretaries of other UNECE conventions having a compliance mechanism have been invited to the first meeting of the Compliance Committee of the Protocol on Water and Health to present their experience and in particular their internal procedures.

These examples bring us to the major trend emerging from practice, which is precisely to leave to Secretariats the task of keeping contacts with other compliance bodies, as a part of their institutional mandate. An example of this trend is given by the ongoing dialogue, triggered by the above-mentioned case of the Vlore industrial park in Albania, between the Secretariat of the Aarhus Convention and IFIs, in particular with the EBRD, on action to be taken to ensure better coordination of the internal rules and compliance procedures of the latter with those of the Aarhus Convention.

The Bystroe case offers another example. After it arose, a fact-finding mission to Ukraine was set up, which was led by the European Union and included the Secretariats of the MEAs involved. Quite interestingly, this cooperation took place outside the formal procedures of compliance review. For instance, the Aarhus Convention Compliance Committee did not consider it as on-the-spot information gathering under Decision I/7. This notwithstanding the report of this mission was produced by the communicant and its content was used by the Committee as evidence. ${ }^{21}$

A similar status may in the future be recognised to findings of fact contained in reports of other compliance bodies, when they are publicly available even if they are not submitted by parties to the procedure.

\subsection{Procedural Synergies: Taking into Account Procedures under other Compliance Mechanisms and Ensuring Harmonious Jurisprudential Developments}

The analysis of how a cross-system exchange of experience and information may take place leaves unprejudiced a central issue: what are the effects for a given procedure relating to a specific case of non-compliance of the existence of a previous or parallel

${ }^{21}$ See Finding and Recommendations with Regard to Compliance by Ukraine with the Obligations under the Aarhus Convention in the Case of Bystroe Deep-Water Navigation Canal Construction (submission ACCC/S/2004/01 by Romania and communication ACCC/C/2004/03 by Ecopravo-Lviv (Ukraine)), adopted 18 February 2005, doc. ECE/MP.PP/C.1/2005/2/Add.3 (14 March 2005). 
non-compliance procedure elsewhere on the same or a similar matter? In particular, what is the status in the former of legal findings made in the latter?

A quick glance at texts establishing non-compliance procedures confirms that the approach to be taken in this context is very different from that adopted in the context of human rights treaty bodies of a judicial and quasi-judicial nature. According to their own rules on the admissibility of petitions, these bodies are precluded, temporarily or finally, from considering any matter that has been decided by, or is pending before, another international procedure of investigation or settlement. ${ }^{22}$ This approach is based on the application of classical concepts such as lis pendens and res iudicata. None of the compliance procedures concluded so far includes a clause of this kind. Indeed, in the non-compliance procedure under the Aarhus Convention, which shares some similarities with human rights control mechanisms, the inclusion of a similar provision was rejected during negotiations. ${ }^{23}$

This may be explained by the fact that the concepts of lis pendens and res judicata seem to have a very little role to play, if any, in non-compliance procedures, given their non-judicial character ${ }^{24}$ Needless to say, it is precisely the flexible and resultoriented nature of these procedures that allows compliance bodies, possibly upon the request of the Party concerned, to give a broad relevance to procedures taken

22. See, for example, Art. 5.2(a) of the Optional Protocol to the ICCPR and Art. 35.2(b) of the European Convention on Human Rights. It should be noted that consideration of a situation by an environmental noncompliance body may never constitute a bar to the admissibility of individual petitions or communications before human rights treaty bodies under the above-mentioned clauses. The issue could be raised with respect of the non-compliance procedure under the Aarhus Convention, given that it provides for communications from individuals and that, allegedly, in certain specific cases a claim of violation of rights under the Aarhus Convention may be "substantially the same" as a claim under a human rights treaty (for a reflection on the links between the Aarhus Convention and existing rights under human rights instruments, see J. Ebbesson, “The Notion of Public Participation in International Environmental Law", YB Int'l Envt'l L., 8 (1997) 51-97, at 69-75 and P. Quillacq, "Is Legal Symbiosis Possible? The Coming Synergy between the Aarhus Convention and the European Court of Human Rights", in The Future of Environmental Law: International and European Perspectives, EUI Working Group On Environmental Law Collected Reports 2004-2005 (2006), 72-76, available at <http://cadmus.iue.it/dspace/bitstream/1814/4083/1/WPLAWNo.20061ELWG. pdf $>$ (visited 2 March 2008). However, the procedure before the Compliance Committee of the Aarhus Convention lacks one of the fundamental characters required from the competing procedures referred to in relevant admissibility clauses before human rights judicial and quasi-judicial bodies. These bodies have elaborated a notion of "equivalence" that presupposes the judicial or quasi-judicial nature of the concurring procedure. A fundamental test to pass for this purpose is that the concurring procedure should be one aimed at redressing individual violations. The Compliance Committee of the Aarhus Convention has underlined that Decision I/7 does not provide for a "redress procedure" in the case of the violation of rights guaranteed by the Convention, in that it does not aim at providing relief to individual victims: see Report on the Third Meeting, doc. MP.PP/C.1/2004/2 (2 March 2004), paras. 5 and 17.

${ }_{23}$ In an initial draft it was proposed that "The Committee shall not consider any such communication unless it has ascertained that (a) The same matter is not being examined under another procedure of international investigation or settlement", see Report of the First Meeting of the Task Force on Compliance Mechanisms, doc. CEP/WG.5/2000/4 (17 April 2000), Annex VI, para. 7(a).

${ }^{24}$ Indeed, even if those concepts were considered to be applicable, their practical relevance would be quite limited by the fact that the operation of these rules is limited to cases in which the competing procedures have the same parties and the same object, including the identity of the claim and applicable law, see generally Y. Shany, The Competing Jurisdictions of International Courts and Tribunals (Oxford: Oxford University Press, 2003). 
elsewhere to review compliance with overlapping obligations. Practice in this respect is almost lacking and derives exclusively from cases of non-compliance with the Aarhus Convention.

In the Bystroe case the Compliance Committee of the Aarhus Convention was called to rule upon the general issue of lack of public involvement in the process of authorising the construction of the canal. Since the "public concerned" to be consulted under the Aarhus Convention is not limited to a national public, this issue may overlap with the obligation under the Espoo Convention to provide information and participation to the public in affected States ${ }^{25}$ that was subject to review by the Implementation Committee of the Espoo Convention. This situation raised no concern in the Compliance Committee of the Aarhus Convention when the latter discussed and decided the case. Quite interestingly, the attitude of the Committee was radically different when, in the very same case, it had to deal with a more specific claim of noncompliance with Article 6.2(e) of the Aarhus Convention, under which national authorities are obliged to inform the public concerned of " $[t]$ he fact that the activity is subject to a [...] transboundary environmental impact assessment procedure." In one of the possible readings of this provision ${ }^{26}$ its violation was dependent on the actual applicability of the Espoo Convention, e.g., by the existence or likelihood of "significant transboundary harm". This issue was, at the time, pending before an Inquiry Commission that had the power to determine it, although without binding effects. ${ }^{27}$ The Aarhus Compliance Committee decided to defer the consideration of this specific issue "in the light of the findings of the inquiry procedure being undertaken under the Espoo Convention." ${ }^{28}$ After the Inquiry Commission delivered its report, and significant transboundary harm had been ascertained, the Committee took the very practical view that the issue would be monitored in the framework of the follow-up process on the implementation of the recommendation adopted by the first MOP. ${ }^{29}$

Different elements may have contributed towards the different position taken by the Committee with respect to the two procedures, both of which were initiated after the relevant communication was submitted to the Aarhus Committee. One may attach weight to the nature of the concurring procedure: the one before the Inquiry

${ }^{25}$ On the obligation for Parties to the Espoo Convention to provide information and participation to the public in affected States, see Fasoli, supra n. 1, at 132. It is important to stress that the threshold for obligations under the Espoo Convention to be applicable, namely the existence of a significant transboundary harm, is higher than the threshold for the operation of the obligation under the Aarhus Convention which requires the involvement of "the public to be affected or likely to be affected by, or having an interest in, the environmental decision-making" (Art. 2.5).

${ }^{26}$ In fact the Committee raised the issue of whether the obligation was triggered by the mere existence of a legal (international) obligation to carry out a transboundary impact assessment procedure or by the actual conduction of such a procedure, see Report on the Thirteenth Meeting, doc. ECE/MP.PP/C.1/2006/6 (16 November 2006), para. 13

27 See Art. 3.7 of the Espoo Convention.

${ }^{28}$ See Finding and Recommendations with Regard to Compliance by Ukraine with the Obligations under the Aarhus Convention in the Case of Bystroe Deep-Water Navigation Canal Construction (submission ACCC/S/2004/01 by Romania and communication ACCC/C/2004/03 by Ecopravo-Lviv (Ukraine)), adopted 18 February 2005, doc. ECE/MP.PP/C.1/2005/2/Add.3 (14 March 2005), para. 8. See also Report on the Fifth Meeting, doc. MP.PP/C.1/2004/6 (26 November 2004), para. 12.

${ }^{29}$ Report on the Thirteenth Meeting, doc. ECE/MP.PP/C.1/2006/6 (16 November 2006), paras. 11-14. 
Commission is a compulsory dispute settlement procedure, although not legally binding on the parties to the dispute, while the procedure before the Implementation Committee lacks this character. Another element may be that, compared to the Espoo Implementation Committee, the Inquiry Commission was expected to deliver its report in a relatively short time, although in the end it took over two years. Finally, and this seems to be the prevalent rationale, the Committee may have been implicitly guided by a principle of speciality. It considered that its competence to deal with the issue of whether the public - nationally and abroad - had been properly involved was not affected by a pending (but posterior) procedure before the Espoo Implementation Committee. At the same time, as a matter of opportunity, it deferred to the ongoing decision of a competent Inquiry Commission of the Espoo Convention the issue of whether the latter was indeed applicable.

The report prepared by the Espoo Implementation Committee on the Bystroe Canal case, ${ }^{30}$ after recalling in very general terms that the Aarhus Compliance Committee had found that the Ukrainian regulatory framework for public participation was insufficiently clear, ${ }^{31}$ contains findings that are substantially in line with the latter, ${ }^{32}$ but it does not emphasise any reliance on them.

In the case concerning the Vlore Industrial Park in Albania, the Compliance Committee of the Aarhus Convention noted that the issues of public participation in certain decision-making processes might also be considered in the course of inspection proceedings carried out by the Panels established by the World Bank and the European Bank for Reconstruction and development. The Committee, recognising "the need to avoid duplication of effort and enhance synergies, (...) agreed to inform these institutions that it was considering a communication on the matter and to inquire about their involvement in the proposed projects and about whether their respective inspection panels were addressing the issue. ${ }^{\prime 33}$ This position further demonstrates a willingness by the Compliance Committee of the Aarhus Convention to ensure the harmonious development of international law and practice in the field it is concerned with. However, given the fact that the internal review procedures of the two banks were at a very early stage, the Committee completed its decision-making process autonomously, thus showing that the enhancement of synergies must be balanced with other considerations, such as the need not to cause undue delay in the compliance review procedure.

${ }^{30}$ Findings and Recommendations further to a Submission by Romania Regarding Ukraine (EIA/ IC/S/1), doc. ECE/MP.EIA/2008/6 (27 February 2008).

${ }^{31}$ Ibid., para. 32.

${ }^{32}$ See, in particular, para. 43 ("Ukraine did not follow the requirements of the Convention in relation to assuring the proper involvement of the (...) public in the respective EIA procedures. In particular, Ukraine (...) (f) Did not enter into consultations with Romania concerning the potential transboundary impact and measures to reduce or eliminate such impact, as required under Article 5, and did not take steps to agree with Romania on a time frame for such consultations, as also required under Article 5") and para. 60 ("Ukraine has established a domestic EIA system, but that Ukraine does not comply fully with Article 2, paragraph 2, of the Convention because it does not provide sufficiently clearly in its regulatory framework the information referred to in paragraph 59").

${ }^{33}$ See Report on the Eleventh Meeting, doc. ECE/MP.PP/C.1/2006/2 (10 May 2006), para. 17. 
On their part, concurring internal procedures of compliance review carried out by the two banks have not yet been completed. In its recourses and arguments, the complainant has heavily relied on the findings of the Aarhus Convention Compliance Committee and it will be interesting to see if and how the final reports of the Inspection Panel of the World Bank and of the compliance review of the IRC will reflect or consider such findings relevant, thus continuing this trend of openness and crossfertilisation.

From the legal texts it clearly emerges that compliance bodies are not precluded from considering an issue because it is similar to one already considered, or under consideration, by another compliance body. Nor is there a duty to defer to decisions already made by the latter. However, there is a discretionary power to do so and the scarce practice existing is not conclusive as to the willingness and modalities to use these possibilities. The first elements show a positive attitude towards coordination and highlight that compliance bodies can be ready to pay attention to relevant decision previously made by other bodies. As to pending procedures, it seems that discretionary suspension of proceedings to wait for findings by another body may be decided upon on the basis of speciality, that is the peculiar competence recognised to another body to decide upon the matter or a specific aspect of it, rather than priority, which is the traditional criterion of lis pendens.

\section{THE WAY FORWARD}

The issue of coordination and cooperation between compliance bodies and procedures is already on the table, but attempts to formalise it have so far failed. Informal ways of exchanging experiences have proved more effective, especially by emphasising the role of Secretariats and by enhancing jurisprudential dialogue between different bodies. However, some lessons have been learned and new ideas may be put forward.

Having excluded from the outset the feasibility and opportunity of creating a universal non-compliance mechanism, one may still wonder whether in certain cases enhanced institutional synergies could be realised. It seems natural for new coordination arrangements to be experimented among non-compliance mechanisms under agreements sharing basic features as to their subject-matter and/or sharing the services of the same organization, such as UNEP or UNECE. ${ }^{34}$

The issue is actually under consideration for the three UNEP conventions on hazardous substances (Basel, Rotterdam PIC and Stockholm POPs Conventions). Through converging decisions of the respective governing bodies an Ad hoc Joint Working Group has been established to prepare and send back joint recommendations on enhanced cooperation and coordination among the three conventions. ${ }^{35}$ The Draft

\footnotetext{
${ }^{34}$ See also A. Fodella, "Structural and Institutional Aspects of Non-Compliance Mechanisms", supra $355-372$, at 371 .

35 See Decision SC-2/15 on Synergies, doc. UNEP/POPS/COP.2/30 (15 May 2006) at 54; Decision $R C-3 / 8$ on Cooperation and Coordination between the Rotterdam, Basel and Stockholm Conventions, doc. UNEP/FAO/RC/COP.3/26 (10 November 2006), at 41 and Decision VIII/8 on Cooperation and Coordination between the Basel, Rotterdam and Stockholm Conventions, doc. UNEP/CHW.8/16 (5 January 2007), at 34.
} 
recommendations adopted by the Joint Working Group address also the non-compliance mechanisms in various ways. On the first level, they request the three Secretariats to exchange information on progress made on the operation or establishment of the non-compliance mechanisms under the three conventions. Furthermore, the three COPs are recommended to explore the possibilities for enhancing coordination among the compliance mechanisms, after the processes of their adoption is completed. The Joint Working Group has suggested that this could include convening back-to-back meetings of the three compliance bodies, encouraging the appointment of members to the body or bodies to administer the mechanisms of those who have experience with other compliance mechanisms and even the establishment of a single body to administer the three mechanisms. ${ }^{36}$

The initiative taken in the context of the conventions on hazardous substances is definitely to be welcomed and might provide inspiration for better coordination of existing non-compliance mechanisms, especially those operating under the auspices of the UNECE. However, the proposals made in that context are not to be considered exhaustive. For example, one may imagine that a more institutionalised consultation between compliance bodies could be put in place by building on the model provided by the Inter-Committee Meeting and the Meeting of the Chairpersons of the UN Human Rights Treaty Bodies.

A further suggestion may add a different flavour to the issue. It builds on the existing provision of the non-compliance mechanism of the Protocol on Water and Health, which enables the Committee to "transmit information to the secretariats of other international environmental agreements for consideration in accordance with their applicable procedures on compliance." ${ }^{37}$ The idea behind this provision is self-explanatory. However, its effectiveness depends on a number of factors. In particular, the clause seems to be suited for Committees composed of individuals: States representatives may be reluctant to extend the scope of international scrutiny into another State's behaviour. Moreover, the rules of the non-compliance mechanism notified shall allow the Secretariat to trigger the mechanism beyond issues arising out of States reports, or the Committee to act proprio motu.

These are only some of the many, and probably better, proposals that may be formulated. However, they well represent a direction that coordination techniques should take: they should aim at creating a culture of cooperation leading the various compliance bodies to regard themselves not as isolated bodies but rather as elements of a global effort to protect the environment for the benefit of present and future generations.

${ }^{36}$ Draft Recommendations to the Conferences of the Parties to the Basel, Rotterdam and Stockholm Conventions prepared by the Co-chairs of the Ad Hoc Joint Working Group, doc. UNEP/FAO/CHW/RC/ POPS/JWG.3/2 (29 February 2008), paras. 15 and 16.

${ }^{37}$ Protocol on Water and Health NCP, para. 38. 


\section{Section IV}

Non-Compliance Mechanisms and

INTERNATIONAL LAW 
1 


\title{
Chapter Twenty-Six \\ Non-Compliance Procedures and the Law of Treaties
}

\author{
Malgosia Fitzmaurice
}

\section{INTRODUCTION}

\section{$1.1 \quad$ The Scope of the Chapter}

Non-compliance procedures have become a feature of modern treaty regimes, most notably under conventions for the protection of the environment, which are commonly referred to as MEAs. Issues of the law of treaties arise in relation both to MEAs and to the non-compliance procedures within them, in a number of ways, of which, in broad terms, four are the subject of the present chapter.

(i) It has become commonplace, most notably in those MEAs which have adopted the so-called "umbrella" or "framework" form, for the initial convention to leave substantial issues to be decided by the Parties in the future; and to set up formal structures within which these decisions can be taken. This involves a continuing process of law-making, or at least rule-making, between the Parties within the overall structure of the initiating convention. To carry out this process, MEAs create a number of organs, according them certain decision-making powers. This gives rise to a general issue of the extent and legal nature of those powers and, in particular, whether their decisions can have binding force on the Parties. These issues, broadly, are the subject of paragraph 2 of the chapter.

(ii) There are also similar, though in some respects distinct, issues concerning the legal nature and force of "measures" or (as they are called in some non-compliance procedures) "consequences" which organs of non-compliance procedures may decide to impose on non-complying States. This issue is covered mainly in paragraph 3.4 of the chapter.

(iii) Some of these "measures" appear to overlap with certain remedies available under the 1969 Vienna Convention on the Law of Treaties (Vienna Convention) ${ }^{1}$ as well as with the law relating to counter measures and issues that arise concerning the interrelationship of all of these. This issue is covered in paragraph 3.2.

(iv) The general issues referred to above have arisen in particular in practice in relation to the non-compliance procedures set up, respectively, under the Montreal

\footnotetext{
${ }^{1}$ A list of treaties with full references is provided supra at XXXVII.
} 
Protocol ${ }^{2}$ and the Kyoto Protocol. ${ }^{3}$ As well as the more general issues which are covered in paragraphs 2 and 3 of the chapter, some issues have arisen which relate to practice under, or to very particular treaty provisions relating to, one or other of these two non-compliance procedures; and these issues are covered in paragraph 4 of the chapter.

\subsection{New Treaty Structures and Treaty Regimes}

The most important of the structures set up within MEAs consists of regular formal gatherings of all the Parties to the convention which are generally called "Conferences" or "Meetings" of the Parties. ${ }^{4}$ Among other things, these organs are regularly charged with the task of developing or refining the commitments of the Parties under the convention, including, in some cases, the defining of core obligations of the Parties, as well as with the development of technical standards and of yet further forms of organ necessary to further objectives of the convention.

By comparison with the traditional form of treaty in which more or less all that was to be agreed by the Parties was decided before adoption of the convention documentation, and then encapsulated in it, this new treaty structure immediately raises issues as to the procedures to be adopted in the organs concerned, and the legal nature of the decisions that they arrive at. Obviously, the important issues here will be, in procedural terms, whether decisions have to be arrived at by consensus (unanimously), or may be reached by some form of majority decision; and in substantive terms, whether they are intended to, and whether they actually do, have binding force on the Parties, and in particular whether, where decisions affecting the obligations' of the Parties are taken by majority vote, they can (whether intended to or not) actually be binding on the minority which objected to, or at least did not actively support, them.

These issues have arisen in particular in relation to the amendment/adjustment provisions of the Vienna Ozone Convention, as well as in some other conventions; and in relation to the enabling provisions of the Kyoto Protocol.

\footnotetext{
2 The Montreal Protocol on Substances which Deplete the Ozone Layer, 1987, which is the protocol to the Vienna Convention for the Protection of the Ozone Layer, 1985 (Vienna Ozone Convention). For full texts of the Convention and the Protocol (including amendments and ancillary documentation), see, respectively, the Handbook for the Vienna Convention for the Protection of the Ozone Layer ( $7^{\text {th }}$ edn., 2006) available at <http://ozone.unep.org/Publications/VC_Handbook/index.shtml>; and the Handbook for the Montreal Protocol on Substances that Deplete the Ozone Layer ( $7^{\text {th }}$ edn., 2006) available at $<\mathrm{http} / / /$ ozone. unep.org/Publications/MP_Handbook/index.shtml> (both sites last visited February 2008).

${ }^{3}$ The Kyoto Protocol to the United Nations Framework Convention on Climate Change, signed 1997, came into force 2005 (text available at $<\mathrm{http}: / / \mathrm{unfccc}$.int/resource/docs/convkp/kpeng.pdf $>$ ), which is the protocol to the United Nations Framework Convention on Climate Change, 1992 (UNFCCC), text available at $<$ http://unfccc.int/resource/docs/convkp/conveng.pdf $>$ ) (both sites last visited February 2008).

${ }^{4}$ Under the UNFCCC and Kyoto Protocol the device was adopted of having the Conference of the Parties of the Convention "serve as the Meeting of the Parties" of the Protocol. What would otherwise be referred to as the MOP of the Kyoto Protocol has thus become known as the COP/MOP, and will be so referred to in this chapter. There are no relevant legal implications deriving from this device.
} 


\subsection{The Setting up of Non-Compliance Procedures}

One of the tasks which Conferences of the Parties (COPs) or Meeting of the Parties (MOPs) have been charged with (in particular under both the Montreal and the Kyoto Protocols) has been the design and setting up of non-compliance procedures. Noncompliance procedures generally involve a further structural layer within the regime, consisting of various forms of panel or committee. Generally, these make only recommendations directed to the COP or MOP, which itself then makes the relevant decisions based on them. But, as will be seen in paragraph 3 below, in the non-compliance procedure of the Kyoto Protocol decisions are made by the compliance bodies themselves, giving rise to a kind of double delegation of decision-making power, first by the Protocol to the COP/MOP, and then, by the COP/MOP to the compliance bodies.

\subsection{Novelty, Innovation and the Law of Treaties}

There is no doubt that the novelty of the nature, structure and objectives of modern MEAs, coupled with a sense of urgency to achieve effective regimes with "strong", and if possible binding, rule-making within them, in particular in relation to the major threats to the global environment, has been seen as warranting novel solutions to the legal problems to which they give rise. But the fact that this may involve the development of new practices which are not expressly covered by the particular rules of treaty law that evolved on the basis of earlier practices, and have been codified in the Vienna Convention, does not mean that the law of treaties cannot accommodate them. There appears to be a tendency to forget that international law applies the principle pact sunt servanda with great freedom and permissiveness, both in procedural and substantive terms, so that, for instance (and as to this see further below in paragraph 2.2(b)), while the law of treaties does indeed require that Parties to a treaty should have expressed their intention to be bound by the agreement contained in it, it does not require that the means of that expression be in one of the particular forms enumerated in the Vienna Convention.

Within this freedom as to how States express their intention to be bound by an agreement, and freedom, indeed, as to the content of that agreement, lies, however, the major problem which emerges in the survey below, namely, that States do, if their objectives are to be supported by the law of treaties, have to be willing to be bound, and have to manifest that willingness in some ascertainable way. We will see, however, that it is exactly that willingness which is lacking, or with respect to which, at least, there is ambivalence, among States in relation to the objectives of MEAs.

\section{The Issue in Relation to Modification of Treaty Obligations}

\section{$2.1 \quad$ Introduction}

This first issue with which we are concerned, of the power of the organs within a treaty regime to make binding modifications to the obligations of the Parties to the treaty, has arisen in relation to a number of provisions in MEAs. The most important 
of these involves the powers of treaty organs to amend or supplement the terms of the treaties themselves.

There are in practice two forms that this capacity has taken. The first is the power of treaty organs to make amendments or adjustments (in one way or another) to modify existing obligations of the Parties; the second is the ability of treaty organs to flesh out, or extend the range of, treaty provisions, through the use of so-called "enabling clauses".

\subsection{Amendment or Adjustment Procedures}

\section{a) Traditional means combined with COP/MOP Decisions}

Initially, the powers of COP/MOPs in relation to the amendment of conventions and their protocols was limited by their mandate under the convention in question to proposing amendments and initiating the traditional procedures of ratification, approval or accession by States Parties to a treaty themselves. ${ }^{5}$ The procedure adopted involved the proposal of amendments by the Parties and communication of the proposal to other Parties and signatories at some specified period prior to an ordinary meeting of COP/MOP. The proposed amendments would then be discussed at that meeting and every effort be made to achieve consensus. If, despite all efforts, consensus could not be achieved, the amendments could, as a last resort, be adopted by the three-fourths majority of the Parties present and voting. However, the amendments so adopted would still only bind those Parties which gave formal subsequent validation by explicitly expressing their consent to be bound through one of the means set out in Article 11 of the Vienna Convention, ${ }^{6}$ by virtue of which a treaty - or amendment - becomes binding on a State, or acquires the characteristics of a "juridical act"7 and which comprise signature, exchange of instruments constituting a treaty, ratification, acceptance, approval or accession.

This procedure is uncontroversial. Controversy arises only when the traditional means of expression of consent to be bound are abandoned. This happens when modifications to the convention itself are intended to be brought about directly by the adoption of the modification by the COP or MOP, without further act of validation by the Parties, or where, also without such further act, other decisions of treaty bodies are intended give rise directly to binding obligations on the Parties. However, this fact in itself does not take the matter outside the law of treaties, for Article 11 of the Vienna Convention, having recited the formal means of expression of consent to be

\footnotetext{
5 R. Churchill and G. Ulfstein, “Autonomous Institutional Arrangements in Multilateral Environmental Agreements: A Little Known Phenomenon in International Law?”, Am. J. Int'l L., 94 (2000) 623-659, at 638-639; G. Loibl, "Conference of the Parties and Modification of Treaty Obligations", in M. Craven and M. Fitzmaurice (eds.), Interrogating the Treaty. Essays in the Contemporary Law of Treaties (Nijmegen: Wolf Legal Publishers, 2006) 103-119, at 105-109.

${ }^{6}$ Art. 11 of the Vienna Convention provides: "The consent of a State to be bound by a treaty may be expressed by signature, exchange of instruments constituting a treaty, ratification, acceptance, approval or accession, or by any other means if so agreed."

7 A. Bolintineau, "Expression of Consent to be Bound by a Treaty in the Light of the 1969 Vienna Convention", Am. J. Int'l L., 68 (1974) 672-696.
} 
bound enumerated above, adds the words "or by any other means if so agreed". No limits are placed by international law on what those means might be, so that, it is submitted, quite radical new decision-making processes can be accommodated within treaty law.

\section{b) Need for New Methods}

The classical means of consent to be bound were based on a strict concept of sovereignty, intended to constitute a traditional safeguard for the individual interests of States. Generally, however, as has been noted by Judge Simma, this classical approach and its variations can be seen as "standing in the way of multilateral conventions being capable of accommodating community interests in a truly satisfactory manner." ${ }^{\prime}$ A multilateral approach to States' relations is particularly useful, if not, indeed, indispensable, for the purposes of protection of the global environment, which requires, to be effective, common action, in the interests of all. Thus, the argument runs, there is a need for a common approach, for a true multilateralism; and this has lead to the emergence of some alternative means of law-making which may take place not just in the course of diplomatic conferences through the classical process of creation of treaty obligations, but also, subsequently, in the organs and forums created under the provisions of MEAs, in particular the COPs or MOPs. Such "new" ways of multilateral law-making, which may bypass the specific classical methods of expression of consent to be bound enumerated in Article 11 of the Vienna Convention, have raised questions as to their legitimacy within the general law relating to treaties, and have been the subject of many divergent opinions - despite which their legal character is still not fully resolved or understood. ${ }^{9}$

\footnotetext{
${ }^{8}$ B. Simma, "From Bilateralism to Community of Interests", $R d C$, 221 (1994) 217-384, at 325.

${ }^{9}$ See for example the following publications: R. Churchill and G. Ulfstein, supra n. 5; J. Brunnée, "COPing with Consent: Law-making Under Multilateral Environmental Agreements", Leiden J. Int'l L., 15 (2002) 1-52; Id., "The Kyoto Protocol: Testing Ground for Compliance Theories?", ZaöRV 63 (2003) 255-280; Id., "A Fine Balance: Facilitation and Enforcement In the Design of a Compliance Regime for the Kyoto Protocol", Tul. Envt'l L. J., 13 (2000) 223-270; Id., "Reweaving the Fabric of International Law? Patterns of Consent in Environmental Framework Agreements" in R. Wolfrum and V. Röben (eds.), Developments in International Law-Making (Berlin, Heidelberg, New York: Springer, 2005) 101-127; G. Handl, "International 'Law Making' by Conference of the Parties and Other Politically Mandated Bodies", in Wolfrum and Röben (eds.), supra in this note, 127-145; G. Ulfstein, "Reweaving the Fabric of International Law? Patterns of Consent in Environmental Framework Agreements (Comments)", in Wolfrum and Röben (eds.), supra in this note, 145-155; R. Lefeber, "Creative Legal Engineering", Leiden J. Int'l L., 13 (2000) 1-19, at 13; N. Lavranos, "Multilateral Environmental Agreements: Who Makes the Binding Decisions?", Eur. Envt'l L. Rev., 11 (2002) 44-50; G. Loibl, supra n. 5; M. Fitzmaurice, "Consent to be Bound-Anything new Under the Sun?", Nordic J. Int'l L., 74 (2005) 483-508; Id., "Expression of Consent to be Bound by a Treaty as Developed in Certain Environmental Treaties", in J. Klabbers and R. Lefeber (eds.), Essays in the Law Treaties. A Collection of Treaties in Honour of Bert Vierdag (The Hague: Martinus Nijhoff Publishers, 1998) 59-80; A. Halvorssen and J. Hovi, "The Nature, Origin and Impact of Legally Binding Consequences: The case of the Climate Change Regime", Int'l Envt'l Agreements, 6 (2006) 157-171; X. Wang and G. Wiser, "The Implementation and Compliance Regime Under the Climate Change Convention and its Kyoto Protocol", RECIEL, 11 (2002) 181-191; G. Wiser, "Report to CAN on Compliance Section of Marrakesh Accords to the Kyoto Protocol", 7 December 2001, available at $<$ http://www. climatenetwork.org/climate-change-basics/by-meeting/cop-7 docs/gwcompliancefinal.pdf $>$ (visited20 June);
} 
Also giving rise to varying views is the nature of the convention organs or bodies concerned in making the decisions. On one view, they can be seen as free standing entities, involving institutional arrangements, or structures, which are independent from the Parties, and having, at least to a certain extent, an autonomous character in the sense of having their own law-making or rule-making power, or at least power to generate, or alter, the obligations, as between themselves, of the Parties; and to formulate, or operate, mechanisms such as compliance procedures, within the treaty regime which may have effects which are binding on the Parties. ${ }^{10}$ Churchill and Ulfstein call such institutions, "autonomous institutional arrangements" (AIAs). ${ }^{11}$ On the other hand, some of the organs of MEAs, in particular the COPs or MOPs, can be seen as no more than a form of diplomatic conference providing a continuous, or at least regular, context within which decisions can more readily be made than through the calling of ad hoc diplomatic conferences. In fact, it is submitted, COPs and MOPs may partake of the character of either, depending on both the substantive nature of what they are discussing, and on whether or not decisions on it will require subsequent validation to become binding on the Parties.

Their institutional character became more prominent when, as is the case now with several AIAs, they began to introduce new ways of amending the scope of treaty obligations, usually in relation to technical or administrative matters, in such a way as to have direct binding effect for the Parties, including those which had not expressed their consent to the proposed amendment (at least in any traditional sense) and without resorting to a formal amendment of the Convention according to classical procedures as outlined above. ${ }^{12}$

\section{c) Montreal Protocol}

A principal example of a MEA which did this is the Montreal Protocol. It provides not only for an amendment procedure in more or less the traditional sense (i.e., using the procedure outlined in paragraph 2(a) above), but also for an "adjustment procedure", which is innovative.

This "adjustment" procedure, which is set up under Article 2.9 of the Montreal Protocol, provides that adjustments may be adopted on the basis of periodic scientific and technological assessments (Article 6 of the Montreal Protocol), and concerns modifications in the scope of Parties' duties under the Protocol such as a tightening of control measures, by bringing forward the phasing out of certain substances. Decisions adopting an adjustment are as rule to be adopted by consensus. However, in case of a failure of all efforts to reach consensus, such decision can be adopted by a two-thirds majority vote of Parties present and voting and representing a majority of both developing and developed countries. The decision has to be communicated to

G. Ulfstein and J. Werksman, "The Kyoto Compliance System: Towards hard Enforcement", in J. Hovi, O.S. Stokke and G. Ulfstein, (eds.), International Compliance: Implementing Climate Change (London, Sterling, VA: Earthscan, 2005) 39- 65.

${ }_{10}$ Churchill and Ulfstein, supra n. 5, at 1.

11 Ibid., at 1.

${ }^{12}$ Loibl, supra n. 5, at 106. 
the Parties, and then enters into force for all Parties, including those which opposed its adoption, six months from the date of circulation of the communication. While this procedure has been used on a number of occasions, in practice agreement on adjustments has always been arrived at by consensus.

\section{d) IMO Treaties}

Another important, though surprisingly little known, example of modification of treaty obligations by majority vote arises in relation to the International Maritime Organization (IMO). The IMO has very extensive regulatory powers in relation to shipping and the protection of the marine environment. ${ }^{13}$ In order to discharge its powers, the IMO elaborates drafts and manages agreements, makes recommendations and convenes conferences and drafts "soft" law, non-binding codes. ${ }^{14}$ These "soft" law codes are often incorporated into conventions through their amendment procedure. This procedure is simplified and also binds the minority. For example, on 27 May 1999, the voluntary 1993 International Code for Safe Carriage of Packaged Irradiated Nuclear Fuel, Plutonium and High-Level Radioactive Waste on Board Ships (the INF Code),${ }^{15}$ was adopted at the $71^{\text {st }}$ session of the Maritime Safety Committee (the MSC) on the basis of Resolution 88(71). At the same session, in order to give effect to this code, Chapter VII (Carriage of Dangerous Goods) of the 1974 International Convention on the Safety of Life at Sea (the SOLAS Convention) was amended. ${ }^{16}$ This amendment was adopted in accordance with Article VIII(b) of the SOLAS Convention. ${ }^{17}$ The procedure under this Article merits attention. First of all, it is the IMO's MSC, not the Parties to the SOLAS Convention, which suggests the amendments to the SOLAS. Secondly, and most importantly, amendments may be approved by majority vote in the MSC and are adopted if objections are raised only by a minority of less than a third of the Contracting Parties to the SOLAS Convention, representing less than $50 \%$ of gross tonnage of the world's merchant fleet. It is thus possible that an amendment based on the decision of a majority on the MSC, and approved by only a majority of SOLAS Contracting Parties, may be binding on the minority of Parties which had objected to it. It is significant that this amendment imposed a considerable burden on States. As of 1 January 2001, the Code introduced by it applied to all ships, regardless of size, engaged in the carriage of packaged

\footnotetext{
13 Information is available at $<$ http://www.imo.org/> (visited 20 June 2008).

14 P. Birnie, "The Status of Environmental 'Soft Law': Trends and Examples with Special Focus on IMO Norms", in H. Ringbom (ed.), Competing Norms in the Law of Marine Environmental Protection (The Hague: Kluwer Law International, 1997) 31-57, at 42.

151993 International Code for Safe Carriage of Packaged Irradiated Nuclear Fuel, Plutonium and HighLevel Radioactive Waste on Board Ships, full text available at <www.admiraltylawguide.com/conven/ infcode1999.html $>$ (visited 20 June 2008).

${ }^{16}$ Resolution SC.87 (71) on Adoption of Amendments to the International Convention for the Safety of Life at Sea, 1974, as amended, (27 May 1999), Annex 3, doc. MSC 71/23/Add.1, available at <http://www. navcen.uscg.gov/marcomms/imo/msc_resolutions/MSC71-23a1-3.pdf> (visited 20 June 2008).

17 Art. VIII(b) reads as follows: "Amendments shall be deemed to have been accepted on a particular date, unless more than one third of the Contracting Governments to the SOLAS, or Contracting Governments the combined merchant fleets of which constitute not less than 50 percent of the gross tonnage of the world's merchant fleet, have notified their objections to the amendment."
} 
irradiated nuclear fuel, plutonium and high-level radioactive wastes. By virtue of these Regulations, ships are required to hold a valid International Certificate of Fitness, which certifies that a ship was constructed according to certain standards, including such matters as strength, stability, fire protection, cargo securement and temperature control and integrity of power supplies. Despite this, the minority of States Parties who objected are obliged to comply with this burdensome amendment adopted by the majority of States Parties. ${ }^{18}$

\subsection{Analysis of the Legal Nature of the Adjustment Procedure}

It is apparent that this process, whereby States opposing an adjustment nevertheless become bound by it on the basis of a majority decision of a MOP (or, in the case of the IMO, a Committee), does not, at least at the time the decision is taken, involve any of the traditional means of expression of consent to be bound, giving it the appearance of having a legislative character. This has been described as "remarkable in that it allows for formally binding lawmaking by the Meeting of the Parties in relation to alterations of the treaty's substance, indeed, of its central commitments." ${ }^{\prime 19}$ The subjection of the minority to the majority decision has thus given rise to the view that the adjustment procedure of the Montreal Protocol "constitutes an embryonic legislative mechanism, rather than merely a contractual mechanism by which States voluntarily assume obligations." ${ }^{20}$

If this were the case (but see further below) it could be seen as constituting a further stage of development of processes relating in particular to such things as standard setting by international organizations, such as the International Civil Aviation Organisation (ICAO), the IMO and the fisheries commissions, to mention a $\mathrm{few}^{21}$ which have quite a long history. These standards are usually adopted by a majority (such as two-thirds) and become binding on all members who have not positively and formally indicated unwillingness to be bound by them, ${ }^{22}$ a process now known as the "opting out" system or "tacit approval". ${ }^{23}$ The intention of the system is to combine the principle of sovereignty (the right of a State to lodge an objection) whilst making it politically unattractive, encouraging the creation of a uniform system for all States which are Parties to a convention. Considerations concerning the legal character of this early stage of, as it is alleged, development of an international legislative process put forward similar arguments to those now propounded in relation to contemporary powers of AIAs. Opinions differed whether the acts of international organizations operating under the opting out procedure had an independent law-making character,

${ }^{18}$ Fitzmaurice, “Consent to be Bound...”, supra n. 9, at 502.

19 Brunnée, "Reweaving...", supra n. 9, at 110.

${ }^{20}$ D. Bodansky, "The Legitimacy of International Governance: A Coming Challenge For International Environmental Law?”, Am. J. Int'l L., 93 (1999) 596-624, at 608.

${ }^{21}$ C. Brölmann, "Limits of Treaty Paradigm", in Craven and Fitzmaurice (eds.), supra n. 5, at 36-38.

${ }^{22}$ Generally, under this system, if (notwithstanding the original majority vote in favour of the amendment), a majority in the event "opt out", then the provisions adopted are dropped for all Parties.

${ }^{23}$ See on this subject K. Skubiszewski, "A New Source of the Law of Nations-Resolutions of International Organisations”, in P. Guggenheim (ed.), Receuil des Études de Droit International en Hommage à Paul Guggenheim (Geneva: Faculté de Droit de L’Université de Genève, 1969) 508-520. 
or constituted, in effect, an agreement analogous to an amendment to a treaty between the Parties concerned. ${ }^{24}$ This process has been seen as "going far beyond traditional sources of international law", which are subject to "orthodox ratification". ${ }^{25}$ It is a process which is seen as responding to the dwindling ability of governments to address domestic environmental issues (referred to by Bodansky as the "decisionmaking deficit", ${ }^{26}$ which, it is said, requires a gradual strengthening of the role of international institutions; something that, in its turn, highlights the question of how to legitimise such processes. It has even been considered (a matter which goes beyond the scope of the present chapter) whether the rule-making of COPs or MOPs is evolving into what may be called the "equivalent of global legislation". ${ }^{27}$

However, the opting out system in fact remains firmly based on the treaty provisions. At most, the decisions of organizations under it might be referred to as creating "derivative treaty obligations", i.e., although the organization is the immediate "legislator" or, perhaps more properly, rule-maker, its legal power to act in this way is ultimately founded on specific provisions of the treaty establishing the organization. ${ }^{28}$

The Montreal Protocol certainly constitutes a significant development over this earlier system as it allows no "opting out" by non-assenting Parties. Even so, Bodansky asserts that the basis for this quasi legislative authority lies in the Montreal Protocol itself, which embodies the authority of the Parties for an ongoing system of governance which allows a qualified majority of Parties to adopt the adjustments regarding the controls on regulated substances. ${ }^{29}$ This, it is submitted, leaves the process firmly within the realm of treaty law, involving a binding present - i.e., upon signature and ratification of the Montreal Protocol - agreement, to which the Parties indicate their consent to be bound by traditional means, and by which they delegate the authority to make the decisions on adjustments to a majority of the MOP. Were a precedent needed in the form of a well established similar construction which lies within the realm of treaty law, it is, it is submitted, to be found in the authority under the Charter of the UN by virtue, and by virtue alone, of which the Security Council is empowered to make decisions - also by majority vote - which are binding on Member States. ${ }^{30}$

${ }^{24}$ R. Ago, "Die Internationalen Organisationen und Ihre Funkionen im inneren Tätigeitsgebiet", Rechsfragen der Internationalen Organisation 27, (1955) 20-38.

${ }^{25}$ F. Kirgis, "Specialised Law-Making Processes", in O. Schater and C. Joyner (eds.), The United National Legal Order (Cambridge: Cambridge University Press, 1995) 65-97, at 70-77.

${ }^{26}$ Bodansky, supra n. 20, at 623.

${ }^{27}$ See in depth, Brunnée, "COPing...", supra n. 9, at 7-15. The same author suggests that one way of dealing with such a concern would be the departure from the formal concept of international law and the recourse to so-called "interactional law", ibid., at 33-50; Id., "Reweaving...", supra n. 9, at 117-123. See also on compliance theories: J. Brunnée and S.J. Toope, "Persuasion and Enforcement: Explaining Compliance with International Law”, Finnish YB Int'l L., 13 (2002) 273-295.

${ }^{28}$ P. Szasz, "International Norm-Making", in E. Brown-Weiss (ed.), Environmental Challenge and International Law (Tokyo: United Nations University Press, 1992) 41-70, at 65.

${ }^{29}$ Ibid., at 604.

${ }^{30}$ For a recent discussion of the legal basis of Security Council resolutions which asserts the "treaty" nature of the Council's resolutions, see Sir Michael Wood, 2006 Sir Hersch Lauterpacht Memorial Lectures given at the Lauterpacht Centre for International Law, Faculty of Law, University of Cambridge, text available at $<$ http://www.lcil.cam.ac.uk/lectures/2006 sir_michael wood.php $>$ (last visited 17 February 2008). 
In summary, essentially, these examples of COP/MOP decision-making are examples of delegated authority which fall within existing paths of treaty law being either (in the case of the Montreal Protocol type amendment procedures) subject to subsequent validation by traditional means of amendment of a treaty under the Vienna Convention; or (in the case of the Montreal Protocol adjustments or IMO treaty amendments) the subject of prior mandate or delegation of power by the originating convention or protocol.

\section{$2.4 \quad$ Enabling Clauses}

a) Nature of the Problem

The second type of new method of modification of States' obligations under the convention is derived from so called "enabling clauses" in conventions (or protocols), which charge COPs or MOPs the elaboration of rules in some particular area without expressly providing for actual amendment of the convention (though they may well result in modifications of the Parties' obligations). The essential distinguishing characteristic of the enabling clauses, and the decisions made under them, from what has gone before, is that they do not provide a detailed procedure for the making of the decision by the COP or MOP and do not, in particular, make any express provision (like Article 2.9(d) of the Montreal Protocol) for the decisions made under them to be binding (whether made by consensus or by majority). Despite this, matters decided by COPs or MOPs on the basis of enabling clauses are often claimed to be binding on the Parties; or, at least, it is often claimed that they ought to be. But these claims are by no means undisputed. They thereby raise, in a much more challenging way, issues concerning the legal character of the COP/MOP decisions than was the case with amendment or adjustment procedures.

\section{b) General Examples of Enabling Clauses}

One example of the use of enabling clauses has been the establishment of non-compliance procedures. For example, the non-compliance procedure under the Montreal Protocol was adopted by virtue of Article 8, which states as follows:

"The Parties, at their first meeting, shall consider and approve procedures and international mechanisms for determining non-compliance with provisions of this Protocol and for the treatment of Parties found to be in non-compliance."

The Cartagena Protocol, is another example of a treaty containing enabling clauses. For example, Article 7.4 states that COP/MOP may adopt a decision identifying those living modified organisms (LMOs) to which the advanced informed agreement procedure will not apply - as not being likely to have adverse effects on the conservation and sustainable use of biological diversity - taking into account risks to human health. Similarly, Article 18.2(a) provides that COP/MOP shall take a decision within two years after the entry into force of the Cartagena Protocol on the detailed 
requirements for labeling of LMOs that are intended for direct use as food or feed or for processing. ${ }^{31}$

The most extensive use made of enabling clauses is in the Kyoto Protocol, to the structure of which they are central. A series of key provisions to the climate change regime, elements which were also highly controversial, were left to be decided at meetings of the COP/MOP under enabling clauses.

The most striking are the three Articles (Articles 6, 12 and 17) which authorize the COP/MOP to elaborate guidelines, and set up machinery to regulate, the so-called "flexible mechanisms", and Article 18, which charges the COP/MOP with elaborating and instituting the non-compliance procedure. Of these, it is with Articles 17 and 18, which are by far the most controversial, that we will be mostly concerned.

The provisions of Article 17, which charges the COP with the task of defining "the relevant principles, modalities, rules and guidelines, in particular for verification, reporting and accountability for emissions trading", are among the most pivotal of the whole Protocol. Trading in emissions was one of the most contentious issues during the negotiations of the Protocol; and the regime for emissions trading is a central factor for its success. Equally contentious in its negotiation was the form of the noncompliance procedure pursuant to Article 18 of the Kyoto Protocol, which differs significantly from that of other non-compliance procedures which had been created before it. ${ }^{32}$

As a result of this, the Kyoto Protocol may be seen as something of a special case in relation both to the legal character of decisions taken under its enabling clauses, and in relation to the legal character of decisions of its non-compliance procedure, and both these aspects will be the subject separate treatment in paragraph 5 below, though, in a general way, the considerations relating to the legal character of COP/ MOP decisions set out in the next section do apply to the Kyoto Protocol as well as other to conventions.

\subsection{Theories as to the Legal Character of COP/MOP Decisions}

\section{a) Further Definition of the Issue}

Looking at the issue generally, what we are here considering is the situation in which the COP or MOP is charged with making decisions which purport to modify or extend the obligations of the Parties or which set up procedures or consequences relating to non-compliance; but where the treaty provisions so charging them do not either set out a clear procedure for their adoption, and/or do not specify their legal nature (whether Parties are to be legally bound by them)..$^{33}$

\footnotetext{
31 Loibl, supra n. 5, at 109-111.

32 See R. Lefeber, "From the Hague to Bonn to Marrakesh and Beyond: A Negotiating History of the Compliance System under the Kyoto Protocol”, Hague YB Int'l L., 14 (2001) 25-54.

${ }_{33}$ There is an additional possible situation related to this, namely, where a COP or MOP makes a decision which purports to modify or extend the obligations of the Parties, but without the existence of any treaty
} 
A number of theories concerning the legal nature of decisions of this kind have been suggested. But in looking at them, it is always necessary to bear in mind that, in practice, the problems encountered generally derive as much, or indeed more, from problems of ascertaining the intention of the Parties, as from problems of legal theory. Generally, it can be said that if the Parties make their intention as to the legal status to be accorded to any decisions to be made by a COP, MOP or other body under a treaty provision absolutely clear in the enabling or other relevant clauses, there are no legal principles which stand in the way of that intention being effective. The problem is that the Parties very often do not make their intention clear. ${ }^{34}$ In fact, Parties' ambiguity in this respect is often in effect intentional; and this constitutes a major problem in relation to analysis of the legal effect of their decisions. Indeed, in a number of instances it simply is not possible, as things stand at present, to say with certainty what the legal character of certain decisions, or types of decision, or legal status of certain organs, are. We will see particular illustrations of this problem in paragraph 3 below in relation to the ambiguity of certain provisions of the non-compliance procedure of the Montreal Protocol (and consequent uncertainty as to the nature of the decisions of the MOP under that procedure relating to the non-compliance of Russia); and in relation to the ambiguity of Article 18 of the Kyoto Protocol, combined with the way the COP/MOP took the decision setting up the non-compliance procedure pursuant to it (paragraph 5 below).

The theories which have been put forward broadly fall into three categories:

(i) Theories which, on one basis or another, accord binding force to the COP or MOP decisions as deriving from the intention of the Parties - i.e., in its broadest sense, they are treaty based. There are several varieties of these theories;

(ii) Theories which, assuming that the decisions do not have formally binding legal effect, nevertheless attempt to find some intermediate (or as might be said "soft" or "de facto") status for them; and

(iii) Theories which, also assuming that the decisions do not have formally binding force on the basis of the intention of the Parties, seek to substitute an alternative basis, from outside the law of treaties (even in its widest sense) for their binding character.

\section{b) Theories Based on Intention of the Parties}

These theories have looked at two possibilities. Firstly, emphasis has been placed on the wording of the enabling or other treaty clause mandating the decision of the COP or MOP, for instance wording of the enabling clauses of the Kyoto Protocol, in particular of Article 17 and its use of the word "rules" (COP "shall define the relevant

provision charging it with the task of doing so, but, as it were, entirely of its own motion. For an excellent discussion concerning this, see Handl, supra n. 9. Attempts at making such decisions appear more or less to have been rejected, in practice, by Parties, and we will not consider the matter in detail further here (but see some general comment in Part 5, Conclusions).

${ }^{34}$ As one very experienced authority said, in relation to the drafting of Security Council resolutions: "[T]here may be cases where it is politically convenient not to be clear whether the provisions of a Security Council resolutions are legally binding or not, if only to achieve a consensus. Ambiguity is often the price of agreement, with Security Council resolutions as with treaties", see Sir Michael Wood, Lauterpacht Lectures, supra $\mathrm{n} .30$. 
principles, modalities, rules and guidelines" - emphasis added), though it has been doubted if that in itself would be sufficient to cause the decision of the COP/MOP to be binding. ${ }^{35}$

An alternative approach looks rather at the COP or MOP decision than at the enabling clause of the convention as the expression of the Parties' intention that the decisions should be binding. In effect, this theory treats COPs/MOPs decisions, if taken by consensus, as agreements in a simplified form, which are binding on the Parties. ${ }^{36}$ In this case, wording of the decision is important. For instance, Brunnée pointed out that many of these decisions employ language ("shall") normally used for legally binding commitment. ${ }^{37}$ An instance of this may be seen in the creation of the noncompliance procedure under the Basel Convention which was effected by a decision of the COP, made of its own motion in the absence of any enabling clause, but, apparently without subsequent objection from any of the Parties.

In fact, the process of construing the Parties intention will almost always have to take into account not only all the written sources which may be said to comprise the agreement - e.g., both the enabling clause and the actual decision of the COP or MOP - but also all the surrounding circumstances, including both prior and subsequent conduct of the Parties, in accordance with the provisions concerning interpretation of treaties of the Vienna Convention.

Whatever the particular factors to be taken into account in interpreting the intention of the Parties, it is submitted that from a theoretical point of view, either of the above bases would be capable of creating binding obligations on the Parties arising from COP or MOP decisions. The effectiveness of the first basis (involving a clear mandate to the COP or MOP) has been referred to above. With regard to the second, though it may appear contradictory, on the face of it, that an informal decision of the COP could in effect cause modification of the provisions of the formal convention or protocol in a manner not provided for in it, the great flexibility and permissiveness of the law of treaties (which was emphasised above) is such as, it is submitted, to make it possible. Such an agreement would not, of course, actually amend the terms of the convention or protocol; but it could provide that the Parties would not enforce certain of its provisions, or would interpret it in a particular way or, while not amending it, provided that the terms of the subsequent informal agreement would take priority if in conflict with it. ${ }^{38}$

The Theories of "Soft" or "De Facto" Effect

Considering in particular the Kyoto Protocol MOP decisions in relation to the flexible mechanisms of the Kyoto Protocol, it has been postulated that, even if they do not have binding effect in the full sense, nevertheless they may affect Parties' rights and obligations in that failure to comply with them may have consequences as regards

\footnotetext{
35 Brunnée, "Reweaving...", supra n. 9, at 112.

${ }^{36}$ Churchill and Ulfstein, supra n. 5, at 640.

37 Brunnée, "Reweaving...", supra n. 9, at 111.

${ }^{38}$ In accordance with the provisions of Art. 30.3 of the Vienna Convention.
} 
compliance $^{39}$ and this has been described as "de facto law-making". ${ }^{40}$ This term is arguably subject to the same criticism as the term "soft law", in terms of its attempt to blur what should (at least in the sphere of legal thought, as opposed to that of international relations) be a clear distinction, between what is legally binding and what is not; nevertheless, it does describe a real situation which is important in terms of international relations, in terms of the effectiveness and functioning of treaty regimes, and in terms of its influence on the formation of legally binding rules. It is a concept that has also has been applied in relation to the operation of the suspension power of the Implementation Committee of the Montreal Protocol non-compliance procedure and will be referred to further in paragraph 3 of the chapter.

\section{d) Theories Based Outside the Law of Treaties}

Finally, it has been suggested that international institutional law may be applicable to COPs/MOPs (or in general to AIAs). The consequence of such an approach would be applicability of the concept of "implied powers", which would constitute another possible basis for holding the decisions of COPs/MOPs to be legally binding decisions. ${ }^{41}$

A full consideration of the applicability of this line of reasoning to the organs of MEAs is beyond the scope of the present chapter. But certain thoughts may be briefly introduced:

Firstly, as the structures under MEAs do not technically constitute international organizations (proponents of this theory do not claim otherwise), it applies, by way of analogy, to the concept of implied powers of international organizations; and these are ultimately based (in distinction to the concept of "inherent" powers) on the more teleological approach generally considered to be applicable to constituent treaties setting up international organizations. In other words, the theory does not take one actually out of the realm of the law of treaties at all. What, it is submitted, may well be arguable is that, in the case of multilateral treaties of the type of MEAs, where the Parties have a particular common goal, and where so much is left to future decision by the various structures set up, this same more teleological approach to interpretation of the treaty documents may also be appropriate. On that basis, it may well be that the organs of MEAs could be found to have certain implied powers. But they would have them not on some principle of analogy to international organizations, but by way of proper interpretation of the constituent agreements relating to the MEA organs themselves.

Secondly, it has never been alleged that the principle of implied powers applies to any but "internal" decisions of the organizations concerned. Without attempting at all to define positively what does constitute an "internal" decision, which may be a matter of some difficulty, it seems clear that decisions which have a direct effect on the substantive obligations of the Parties under the conventions do not fall into this category. This, it is submitted, would rule out the possibility of application of the principle the important decisions of COPs and MOPs which are substantially

\footnotetext{
39 Brunnée, "Reweaving...", supra n. 9, at 111.

40 Ibid.

${ }^{41}$ Churchill and Ulfstein, supra n. 5, at 633-634.
} 
concerned with, to put it in general terms, modifying or developing the substantive obligations of the Parties under the relative conventions. It would also rule out its application to the decisions of non-compliance procedures (or of COPs or MOPs under non-compliance procedures) in so far as they directly affect individual Parties' obligations.

\subsection{Interim Conclusions}

The above consideration of the theories relating both to the amendment and adjustment type procedures, and to decisions made pursuant to enabling clauses, indicates that there is really no single theory that can account for the multiplicity of situations which arise in relation to the decision-making of MEA organs (or AIAs). It is submitted that, rather than attempting to take the short cut of postulating a single "one fits all" theory, the more useful approach involves, rather, the often longer route of attempting to construe in each case, in the light of all the circumstances, the intention of the Parties - a process which can only by carried out to a limited extent on a theoretical basis in advance of particular issues having arisen in practice.

3. The Relationship of the Actions under Non-Compliance Procedures in Response to Non-Compliance with Provisions of Article 60 of the VIENNA CONVENTION

\subsection{The Nature of the Problem}

It is apparent that the existence of an internal system for dealing with non-compliance with treaty provisions, providing its own distinct forms of response to these, is likely to give rise to issues concerning the relationship of the system, and the measures it may adopt, with the remedies provided under general international law, which may be aimed at responding to the same act of non-compliance as the internal system. This issue has been highlighted in relation to certain provisions of the non-compliance procedure under the 1987 Montreal Protocol ${ }^{42}$ and was further emphasised after the establishment of the Non-Compliance Mechanism under the 1997 Kyoto Protocol. ${ }^{43}$

${ }^{42}$ M. Koskenniemi, "Breach of Treaty or Non-Compliance? Reflections on the Enforcement of the Montreal Protocol", YB Int'l Envt'l L., 3 (1992) 123-161.

${ }^{43}$ See Lefeber, supra n. 32; M. Fitzmaurice and C. Redgwell, "Environmental Non-Compliance Procedures and International Law, Netherlands YB Int'l L., XXXI (2000) 35-65; M. Fitzmaurice, “The Kyoto Protocol Compliance Regime and Treaty Law", Singapore YB Int'l L., 8 (2004) 23-40; G. Ulfstein, "Dispute Resolution, Compliance Control and Enforcement in International Law", in G. Ulfstein, T. Marauhn and A. Zimmermann (eds.), Making Treaties Work, Human Rights, Environment and Arms Control (Cambridge: Cambridge University Press, 2007) 115-134. See also Hovi, Stokke and Ulfstein (eds.), supra n. 9; M. Vespa, "Climate Change 2001: Kyoto at Bonn and Marrakesh”, Ecol. L. Q., 29 (2002) 395-420. 


\subsection{Provisions as to Suspension of Treaty Rights under Non-Compliance Procedures}

The Montreal Protocol non-compliance procedure, which was adopted by the fourth MOP in 1992, provided that, after considering the report of the Implementation Committee concerning an alleged case of non-compliance, the Parties (at a meeting of the MOP) might:

"taking into consideration the circumstances of the matter, decide upon and call for steps to bring about full compliance with the Protocol, including measures to assist the Parties' compliance with the Protocol, and to further the Protocol's objectives."

At the same MOP, the Parties adopted an "Indicative List of Measures that might be taken by a Meeting of the Parties in respect of non-compliance with the Protocol", which included, under heading " $\mathrm{C}$ ":

"suspension, in accordance with the applicable rules of international law concerning suspension of the operation of a treaty, of specific rights and privileges under the Protocol, whether or not subject to time limits, including those concerned with industrial rationalisation, production, consumption, trade, transfer technology, financial mechanisms and institutional arrangements." ${ }^{44}$

A number of other non-compliance procedures have similar provisions. For instance, the non-compliance procedure under the 1998 Aarhus Convention ${ }^{45}$ provides that one of the measures which may be taken by the MOP is to "suspend, in accordance with the applicable rules of international law concerning the suspension of the operation of a treaty, the special rights and privileges accorded to the Party concerned under the Convention." ${ }^{36}$ Another non-compliance procedure that provides for suspension of treaty rights is that set up under the CITES ${ }^{47}$ the Guidelines to which state that one of the measures to achieve compliance decided by the Standing Committee is to " $[\mathrm{r}]$ ecommend the suspension of commercial or all trade in specimens of one or more CITES-listed species." ${ }^{\prime 48}$ In this case, it may be noted (and see further below), reference to rules of international law is omitted. Other non-compliance procedures, on the

\footnotetext{
${ }^{44}$ Report of the Fourth Meeting of the Parties, Annex V, doc. UNEP/OzL.Pro.4/5 (25 November 1992).

${ }_{45}$ Decision I/7 on Review of Compliance, doc. ECE/MP.PP/2/Add.8 (2002, late issued on 2 April 2004), as amended by Decision II/5 on General Issues of Compliance, doc. ECE/MP.PP/2005/2/Add.6 (13 June 2005).

${ }^{46}$ Ibid., Section XII.37(g).

47 Decision 14.3 of the Fourteenth Conference of the Parties, doc. Resolution Conf. 14.3, (2007), Annex, available at $<$ http://www.cites.org/eng/disc/text.shtml $>$ (visited 15 July 2008). This Decision consolidates in one instrument the previously exsisting piecemeal approach to non-compliance by the Parties to CITES.

${ }^{48}$ Ibid., para. 30. A distinguishing feature of compliance control under the CITES is that it does not have any specific treaty article mandating the establishment of such a procedure, neither has a special body to deal with non-compliance been set up. This role is fulfilled by the Standing Committee of the CITES. R. Reeve, "The Convention on International Trade in Endangered Species of Wild Fauna and Flora (CITES)", in Ulfstein, Marauhn and Zimmermann (eds.), supra n. 43, 134-161, at 136. For a full description of compliance control under the CITES, see ibid., at 136-148.
} 
other hand, make no provision for suspension - e.g., the Mechanisms for Promotion of Implementation and Compliance under the Basel Convention ${ }^{49}$ and the Procedures for Review of Compliance under the Espoo Convention. ${ }^{50}$ The Kyoto Protocol noncompliance procedure does not contain a general provision concerning suspension of rights; but it does contain provisions relating to the suspension of non-complying Parties from participation in the flexible mechanisms. Being so specific in their application, they do not give rise to quite the same problem in terms of their relationship with other fields of international law, though they give rise to problems in relation to their "bindingness" or legality.

\subsection{Relationship with Article 60 of the Vienna Convention}

It is in particular the words "in accordance with the applicable rules of international law concerning the suspension of the operation of a treaty" (used in relation to the Montreal Protocol and Aarhus Convention non-compliance procedures that emphasize certain problems of interpretation. The first problem is what rules are actually being referred to. The rules of the law of treaties expressly referring to suspension of treaty rights are those of Article 60 of the Vienna Convention, which, however, do not really relate to the situations which would generally come before a non-compliance procedure. The second problem is how, if in fact a situation were to arise to which both the non-compliance procedure and those of Article 60 apply, they would relate to each other.

Article 60 of the Vienna Convention ${ }^{51}$ provides for a gradation of the available measures, depending on the position of Parties in relation to the breach:

(1) a specially affected Party is entitled to invoke a breach of a treaty as a ground for suspending the operation of the treaty in whole or in part in the relationship between itself and the defaulting State;

(2) The other Parties, with the exclusion of the defaulting State, by unanimous agreement, are entitled to suspend the treaty or to terminate it either in their relations with the defaulting State or as between all Parties;

(3) Any Party, other than the defaulting Party, may invoke the breach as grounds for the partial or total suspension of the treaty between it and the defaulting Party if the breach is such as to radically change the position of every Party with respect to the further performance of its obligations under the treaty.

If these are the rules referred to in the non-compliance procedures mentioned above, the issue would arise as to their relevance within the context of a suspension under the non-compliance procedure rules, and here the relevant effect might be to require the non-compliance procedure (or $\mathrm{COP}$ acting on its recommendation) to incorporate

49 Decision VI/12 on Establishment of a Mechanism for Promoting Implementation and Compliance, doc. UNEP/CHW.6/40 (10 February 2003), at 45.

${ }^{50}$ Decision II/4 on Review of Compliance, doc. ECE/MP.EIA/4 (7 August 2001), Annex IV, at 72 revised by Decision III/2 on Review of Compliance, doc. ECE/MP.EIA/6 (13 September 2004), Annex II (consolidated text)

${ }^{51}$ For detailed discussion see Fitzmaurice and Redgwell, supra n. 43, 59-62. 
into its decisions the several safeguards which are contained in Articles 65-66 of the Vienna Convention, ${ }^{52}$ but which are absent from non-compliance procedure provisions.

However, the more fundamental question is whether the two sets of rules, noncompliance procedures and Article 60 are intended, or at least are at all likely in practice, to cover the same types of situation. The critical factor is that Article 60 applies only to material breaches - i.e., which involve "a repudiation of a treaty not sanctioned by the present Convention; or [...] violation of a provision essential to the accomplishment of the object and purpose of the treaty. ${ } 53$

Bearing in mind the objective of non-compliance procedures, which is to bring Parties back into compliance, and to use basically persuasive and non-confrontational means to do so, it would seem that a complete repudiation of the treaty by a Party would fall outside the forms of non-compliance with which it is intended to deal. It seems also inherently unlikely that a situation of non-compliance sufficient to constitute a material breach within the meaning of Article 60's second test, would come within the purview of a non-compliance procedure.

There are a number of other differences between suspension under a non-compliance procedure and the rules relating to material breach under the Vienna Convention. In particular, Article 60 grants more extensive rights to Parties of a treaty than the non-compliance mechanisms, as it provides that in cases of a unanimous decision, not only the suspension but also termination of the operation of the treaty in part or in whole may be adopted, a measure which is not permitted under the non-compliance procedures. ${ }^{54}$ On the other hand, the Vienna Convention provides a number of safeguards in relation to suspension or termination which are not present in the rules relating to non-compliance procedure's suspension.

\subsection{Some General Comments}

(i) It should be borne in mind always that the provisions of Article 60 of the Vienna Convention (as in effect is the case with all provisions of the Vienna Convention, other than those relating to peremptory norms in Article 53) are not mandatory on Parties to a treaty or convention. In fact this is expressly provided in Article 60, para. 4 which says that "the foregoing paragraphs are without prejudice to any provision in the treaty applicable in the event of a breach." Thus, in the absence of anything to the contrary, it could be said that, to the extent at least that they cover any particular situation of breach, the provisions of a non-compliance procedure relating to the consequences of non-compliance, including any suspension involved, would

52 Suspension or termination of a treaty requires a prior notification to the other Parties, including the defaulting State. No measure can be taken until three months after the notification. If a Party objects, then in order to seek a solution, the procedure enumerated in art. 33 of the United Nations Charter shall be employed.

${ }^{53}$ Art. 60.3 of the Vienna Convention.

${ }_{54}$ Art. 60(a) provides as follows: "the other Parties by unanimous agreement to suspend the operation of the treaty in whole or in part or to terminate it either: (i) in relations between themselves and the defaulting State; or (ii) as between the Parties." 
supersede the provisions of Article $60 .{ }^{55}$ It would be a fine point of interpretation, resolution of which is beyond the scope of the present chapter, to decide if the provisions of, e.g., the Montreal Protocol non-compliance procedure referring to the "applicable rules of international law concerning the suspension of the operation of a treaty" were intended to have the effect of overriding Article 60.4 and making the provisions of Article 60 as a whole applicable, or were intended to have the effect of giving Article 60 some kind of residual effect to cover issues not expressly covered by the noncompliance procedure rules, or, indeed, by a slightly more attenuated interpretation, to exclude Article 60, paras. 1 to 3 altogether by referring actually to Article 60.4 .

(ii) The conclusion to be drawn from this, it is submitted, is similar to that drawn in relation to the issues covered in paragraph 1 of the chapter, namely, that rather than seeking a single theoretical solution, the process to be followed remains always one of ascertaining the meaning of the treaty or agreement and/or intention of the Parties in each particular case.

(iii) Material breach of a treaty, as codified in Article 60, is rooted in the general principle of reciprocity in international law. This is reflected in the construction of the right of suspension or termination of treaty relations in case of material breach. Material breach under multilateral treaties constitutes, for a Party specifically affected, a ground for invoking the suspension of the treaty; in other words, such suspension essentially depends on the exercise of a right of election by the specifically affected State to invoke the breach and its consequences, rather than the material breach itself giving rise to termination or suspension of the treaty.

The nearest that Article 60 comes to confronting this problem is in para. 2(c). ${ }^{56}$ Other Parties may seek recourse to the remedy of suspension or termination only when the material breach in question radically changes the position of every Party with respect to further performance of their obligations. The International Law Commission (ILC) cited the example of disarmament conventions, in which there is little point in any Party reducing its numbers of particular types of weapons unless all of the others do the same. ${ }^{57}$ These obligations correspond to what Fitzmaurice termed "interdependent obligations" - i.e., obligations, which by reason of the character of the treaty, are necessarily dependent on a corresponding performance by all other Parties. ${ }^{158}$ In the modern world one may cite environmental agreements as typically containing provisions of this kind - because to achieve a particular regional or global environmental effect, it is often, if not indeed almost always, necessary for all States

\footnotetext{
${ }^{55}$ For instance, the provisions providing for suspension of trade under the CITES NCP do not refer to any general principles of international law, but rely only on "the Convention and (...) any applicable Resolutions and Decisions of the Conference of the Parties". It may be presumed therefore that operation of Art. 60 of the Vienna Convention is excluded.

${ }^{56}$ Art. 60.2(c) reads: "any Party other than the defaulting State to invoke the breach as a ground for suspending the operation of the treaty in whole or in part with respect to itself if the treaty is of such a character that a material breach of its provisions by one Party radically changes the position of every Party with respect to the further performance of its obligations under the treaty."

57 Commentary to Art. 19, para. 91. Sir Gerald Fitzmaurice, "Third Report”, Vol. II, YB Int'l L. Comm. (1958), at 44.

58 Ibid.
} 
in the region, or for international community as a whole, to act in accordance with some standard, or to impose upon itself some restraint. ${ }^{59}$

However, the ethos of Article 60, even in the case of invocation under para. 2(c), remains one of dealing with a situation essentially of reaction to a breakdown of treaty relations which contrasts with the ethos of non-compliance procedures which operate to maintain treaty relations with a view to accomplishing compliance. ${ }^{60}$

4. The Issue of Suspension of Rights (OR Imposition of Trade

Restrictions) by the Montreal Protocol Non-Compliance

Procedure in Relation to the Non-Compliance of Certain Former

SOVIET Block STATES

\subsection{How the Issue Arose}

The only significant and documented instance to date in which the issue of the relationship between the non-compliance procedure's measures and rules of Article 60 of the Vienna Convention might have arisen was when Russia, along with a number of other former communist block countries including Ukraine and Belarus, following the collapse of the Soviet Union, announced that they would be in breach of their commitments under the Montreal Protocol, so that the matter was referred to the Implementation Committee under the provisions of the Non-Compliance Procedure. ${ }^{61}$

In response, the Implementation Committee recommended, inter alia, restrictions on the trade of these countries in ozone depleting substances (ODS) with developed country Parties other than Member States of the Commonwealth of Independent States (CIS) ${ }^{62}$ It appears to have been assumed that this "measure", with respect to which the Implementation Committee attempted to get the agreement of the countries concerned, was being imposed under item $\mathrm{C}$ of the Indicative List of Measures (see above paragraph 3.2). It is questionable whether this was the case, the "measure"

${ }^{59}$ M. Fitzmaurice and O. Elias, Contemporary Issues in the Law of Treaties (Utrecht: Eleven International Publishing, 2005), at 327.

${ }^{60}$ Concerns in this respect were voiced by Professor Wolfrum, who doubted the general appropriateness of Art. 60 in relation to treaty provisions serving the community of States as a whole. He is of the view that the normative function of such treaties "should render the validity and the applicability of international agreements immune against actions in reaction to their breach (R. Wolfrum, "Means of Ensuring Compliance with and Enforcement of International Environmental Law", RdC, 272 (1998) 9-154, at 152.

${ }^{61}$ See J. Werksman, "Compliance and Transition: Russia's Non-Compliance Tests Ozone Regime", ZaöRV, 56 (1996) 750-773; A. Gillespie, "Implementation and Compliance Concerns in International Environmental Law: The State of the Art within Three International Regimes", New Zealand J. Envt'l L., 7 (2003) 53-84

${ }_{62}$ The Implementation Committee's draft decision, which was the same in respect of all three countries, proposed a decision of the MOP, inter alia, "8. to note that [Belarus/Russia/Ukraine] has agreed not to export any virgin, recycled or recovered substance controlled under the Montreal Protocol to any Party operating under Art. 2 of the Protocol not member of the Commonwealth of Independent States and that such Parties shall not import such controlled substances from [Belarus/Russia/Ukraine]", Report of the Implementation Committee under the Non-Compliance Procedure for the Montreal Protocol on the Work of its Thirteenth Meeting, doc. UNEP/OzL.Pro.13/3/ (28 March 1996), Annex II, para. 13. 
being in fact the imposition of a new restriction on the countries' right to trade with other Parties which they enjoyed quite independently of the Protocol, not the suspension of a right conferred by the Protocol. Certainly, Russia saw it as the imposition of an unwarranted sanction. In any case, what is notable in relation to the issues related to Article 60 of the Vienna Convention is that neither the Implementation Committee, nor the MOP, nor any of the countries concerned in their various statements and submissions appear to have given any thought to Article 60 , or indeed to the relationship of the proposed measures with the law of treaties at all; nor were any of the procedures or safeguards imposed by Article 60 followed.

In the case of the Ukraine and Belarus, which had agreed to the proposals of the Implementation Committee, the MOP adopted the form of decision proposed by the Implementation Committee, but in the case of Russia, which did not agree to the proposed decision, it removed express mention of the trade restriction, apparently intending it to be implied, in effect, from surrounding circumstances and the positive "allowance" of trade with CIS Parties (to which Russia was anyway fully entitled under the Protocol).

Thirdly, the MOP added a new provision into the Decision enjoining the three countries, respectively, to take steps to restrain re-export of ODSs by the CIS countries to which they might export it themselves. This provision could not be regarded as within the Indicative List of measures, and indeed it would seem difficult to bring it within the terms of the wider authority of the non-compliance procedure itself. ${ }^{63}$

\subsection{Subsequent Position of the Parties}

Finally, however, in the event and despite its original protests as to the illegality and negative effect of the Decision, Russia appears in fact to have ultimately agreed to comply with it $;{ }^{64}$ and the MOP adopted a softer form of Decision which appeared to go some way to meeting the objections of Russia to the original Decision.

\subsection{Conclusions}

In the light of this history, it is submitted, firstly, that it is simply not possible to reach a meaningful conclusion as to the legal nature of what the non-compliance procedure was actually doing. In fact, even though in the case of the Montreal Protocol noncompliance procedure it is highly arguable that the MOP had the authority to issue a binding decision, in the light of the absence of any apparent consideration of the legal aspects of the decisions they actually took in this case, and apparent disregard even for what was the strict authority under which they took them, one has to conclude

${ }^{63}$ It appears to have been introduced at the request of developing countries as a measure of protection for their own nascent production industries, see Werksman, supra n. 61 .

${ }^{64}$ At the Ninth MOP, in September 1997, it was noted at para. 5 that "the Russian Federation had started implementation of its exports control of ozone-depleting substances from July 1996 by not exporting any ODS including used, new, recycled or reclaimed substances, to any Party with the exception of Parties operating under Art. 5 and of Parties that are members of the Commonwealth of Independent States, including Belarus and Ukraine, as per decision VII/18". Report of the Ninth Meeting of the Parties, doc. UNEP/OzL. Pro.9/12 (25 September 1997), at 40. 
that, despite the mandatory language (at least in the case of Russia), the process was regarded as more recommendatory than legally binding, ${ }^{65}$ and that the intention was rather to rely on the cooperation of the Parties, an intention which we have noted above was in the event fulfilled. ${ }^{66}$

\section{The Special Problems Relating to the Kyoto Protocol}

\section{$5.1 \quad$ Introduction}

\section{a) Subject of this Part}

It was indicated in paragraph 2.4(c) that there were factors which distinguish the enabling clauses of the Kyoto Protocol and its non-compliance procedure from the enabling clauses, and non-compliance procedures, of other MEAs. These relate in particular to Articles 6, 12 and 17 (which concern the flexible mechanisms) and Article 18 which concerns the non-compliance procedure. Not only are these clauses by far the most important of the enabling clauses in the Kyoto Protocol, but also they are, due to the potential effect of decisions under the non-compliance procedure on eligibility of Annex I Parties to participate in the mechanisms, and the legal issues concerning those decisions, closely bound up together.

\section{b) The Distinctions between the Kyoto Protocol Enabling Clauses}

It is necessary, nevertheless, to distinguish between Articles 6, 12 and 17, on the one hand and Article 18, on the other.

Article 18 is a pure enabling clause. Its fundamental active element is the mandate to the $\mathrm{COP} / \mathrm{MOP}$ to define and establish the non-compliance procedure. Articles 6, 12 and 17, on the other hand, are not only enabling clauses. Their primary provisions are those which grant to Annex I Parties a right to use the results of their participation in the flexible mechanisms to assist in meeting their Article 3 emissions reduction targets, and, particularly in the case of Articles 6 and 12, to establish certain definitions of the mechanisms themselves. The enabling aspect of each of these Articles, which is to delegate to the COP/MOP the task of "fleshing out" the rules and structures of the mechanisms, is really secondary to this. We shall start by looking at the legal status of the flexible mechanisms under the first of these groups, going on to look at Article 18 and the non-compliance procedure as an initially separate issue. However, it will be necessary to revert to the issue of the legal character of the flexible mechanisms and of Articles 6, 12 and 17, in the light of the provisions of Article 18 concerning the adoption of the non-compliance procedure by amendment, firstly, in relation to any effect these provisions may have by implication in terms of the Parties' intentions under Articles 6, 12 and 17; and secondly because, in the light of the decision of the Parties to adopt the non-compliance procedure by simple decision of

\footnotetext{
${ }^{65}$ Ulfstein, supra n. 43, at 130
}

${ }^{66}$ Ibid. 
the COP/MOP, it may ultimately be the position under these Articles which defines the measures available to the Parties in relation to non-compliance, at least with respect to the flexible mechanisms themselves.

\subsection{The Legal Character of the COP/MOP Decisions under the Kyoto Enabling Clauses}

a)

Articles 6, 12 and 17 (the Flexible Mechanisms)

As stated above, the right of Annex I Parties to use the flexible mechanisms to help meet their Article 3 emissions reduction targets arises under the Protocol itself, not on the basis of any enabling element. That they would have such a right was, in fact, an essential element in the Annex I Parties' willingness to sign the Protocol. But, it is submitted, the structure and wording of the three Articles indicate a clear intention that this right was not intended to be absolutely free and unrestricted, but was to be subject to rules or modalities which in the first place were set out in the three Articles themselves (more elaborately in Articles 6 and 12 than in Article 17), and which were to be elaborated by the COP/MOP. It is suggested that one possible interpretation of these Articles is that the "right" set up in the three Articles was from the outset defined and limited by all these rules, with the effect that it would never come into operation for a Party that failed to meet any requirements under the rules.

This analysis of the intention manifested in the Protocol itself is supported by the course of the negotiations which took place at the seventh COP, when the actual elaboration of the rules was under consideration. The view was then generally evolved that Parties wishing to make use of the mechanisms had to abide by them as a precondition; and in this sense, it has been argued by Loibl, the conclusion may be drawn that "rules" have binding effect, which is an alternative, but in its effect similar, way of analysing the rules and conditions set out in the Articles and evolved by the COP/ MOP as that suggested above. The same author further argues that although the legal status of "rules" was not fully clarified during the negotiations, they were treated as having legally binding force on the Parties. And, as Loibl further points out, Annex I Parties only ratified the Protocol after the "rules" on the mechanisms were agreed upon, which, in his view, would strengthen the argument that the "enabling clauses" for the mechanisms authorise the COP/MOP to adopt "rules" having binding legal effect on the Parties. ${ }^{67}$

It should be mentioned that it has been suggested that it might be implied from Article 18, which explicitly subjects the non-compliance procedures and mechanisms "entailing binding consequences" to an amendment procedure (see further below), that the Parties did not envisage COP/MOP decisions under other provisions of the Protocol as having binding effect. ${ }^{68}$ But is submitted that the nature and subject-matter

\footnotetext{
${ }^{67}$ Loibl, supra n. 5, at 116. See also Churchill and Ulfstein, supra n. 5, at 639. Brunnée, contrasts this argument with the adjustment procedure under the Montreal Protocol and argues that that the Kyoto Protocol, "carries no necessary authority for binding lawmaking. 'Rules' can be binding, but need not to be." See Brunnée, "Reweaving...", supra n. 9, at 112. See also, Brunnée, “COPing...”, supra n. 9, at 23-25.

${ }^{68}$ Brunnée, "Reweaving...", supra n. 9, at 112.
} 
of Articles 6,12 and 17 are sufficiently distinct from those of Article 18 to prevent such an implication arising.

\subsection{The Legal Character of the Consequences Applicable under the Kyoto Protocol Non-Compliance Procedure}

The Kyoto Protocol's non-compliance procedure was the product of long and contentious negotiations. There was a strong movement among the Parties for an overtly "strong" procedure for the climate change regime, ${ }^{69}$ and as a result of this the Kyoto Protocol non-compliance procedure differs from other non-compliance procedures in existence at the time of its formulation ${ }^{70}$ in a number of important respects..$^{71}$ In particular:

(i) The Kyoto Protocol non-compliance procedure has two "branches", the Facilitative Branch and the Enforcement Branch, the members of which are elected by the COP/MOP in their own capacity, on the basis of personal expertise, not as representatives of the Parties. This reflects the wording of Section I, Objectives, of the noncompliance procedure, which reads: "The objective of these procedures and mechanisms is to facilitate, promote and enforce compliance with the commitments under the Protocol" (author's emphasis).

(ii) It is on the face of it the two Branches that make decisions (or, as to which see below, findings). In other non-compliance procedures the compliance or implementation committee make only recommendations, decisions being made by the COP or MOP.

(iii) The nature of the "consequences" of non-compliance provided in the Kyoto Protocol non-compliance procedure are more specific in their nature (and more specifically related to particular obligations or rights under the Kyoto Protocol) than is the case with "measures" available under earlier non-compliance procedures. Furthermore, some of them are arguably punitive (or at least deterrent) in both their intention and their potential effect.

Notable in this respect are the provisions for suspension of the eligibility of Parties to participate in the flexible mechanisms, ${ }^{72}$ and the imposition on Annex I Parties who fail to meet their emission reduction targets for the first commitment period of

\footnotetext{
${ }^{69}$ See Lefeber, supra n. 32.

${ }^{70}$ Though some of its features have now been adopted in, or are under discussion in relation to, a number of other NCPs.

${ }^{71}$ For the text establishing the NCP, see Decision 27/CMP.1 on Procedures and Mechanisms Relating to Compliance under the Kyoto Protocol, doc. FCCC/KP/CMP/2005/8/Add.3 (30 March 2006), at 92.

72 Section XV.4 of the Kyoto Protocol NCP provides: "Where the enforcement branch has determined that a Party included in Annex I does not meet one or more of the eligibility requirements under art. 6, 12 and 17 of the Protocol, it shall suspend the eligibility of that Party in accordance with relevant provisions under those articles."
} 
a deduction in their "assigned amount" for the second period equal to 1.3 times the amount of their first period excess. ${ }^{73}$

\section{b) Analysis of the Nature of the Decision-Making Capacity of the Enforcement Branch}

The Parties in the Protocol delegated more or less entirely the design, setting up and operation of the non-compliance procedure to the COP/MOP, which, in turn, delegated certain decision-making aspects of the non-compliance procedure to an independent Enforcement Branch, including findings in relation to non-compliance as well as the imposition of certain consequences. It is submitted that, in accordance with principles discussed earlier in this chapter, international law would have enabled them to do this had they had, and expressed, a clear intention to do so. It is also arguable that, taken in their context, the provisions of the first sentence of Article 18, coupled with the wording of subsequent documents, in particular of the seventh COP and of the first COP/MOP Decisions relating to the setting up of the non-compliance procedure might have been sufficient to do this. But the situation fundamentally changed by the inclusion of the second sentence of Article 18.

\section{c) The Amendment Requirement of Article 18 of the Kyoto Protocol}

The second sentence of Article 18 of the Kyoto Protocol provided that: "Any procedures and mechanisms under this Article entailing binding consequences shall be adopted by means of an amendment to this Protocol." 74

The presence of this provision in the Kyoto Protocol placed the Parties when they were negotiating the terms of the non-compliance procedure in a dilemma. It was feared that if the non-compliance procedure was adopted by Amendment, with the subsequent necessity of ratification by a minimum number of Parties before it came into force, there would be substantial, perhaps years of delay before it came into force. Furthermore, even when it did, it would do so only with respect to those Parties that had ratified it. As it was anticipated that a number of States would not ratify it, there would have arisen the kind of two tier system, one tier consisting of States which did not ratify the amendment and therefore remain bound only by the original Kyoto Protocol (according to the principle pacta tertii nec nocent nec prosunt) and the second tier consisting of States which would be bound by the amendment to the

\footnotetext{
${ }^{73}$ Section XV.5 of the Kyoto Protocol NCP provides: "Where the enforcement branch has determined that the emissions of a Party have exceeded its assigned amount [...] it shall declare that that Party is not in compliance with its commitments under art. 3.1, of the Protocol, and shall apply the following consequences: (a) Deduction from the Party's assigned amount for the second commitment period of a number of tonnes equal to 1.3 times the amount in tonnes of excess emissions."

${ }^{74}$ In full, art. 18 reads as follows: "The Conference of the Parties serving as the meeting of the Parties to this Protocol shall, at its first session, approve appropriate and effective procedures and mechanisms to determine and to address cases of non-compliance with the provisions of this Protocol, including through the development of an indicative list of consequences, taking into account the cause, type, degree and frequency of non-compliance. Any procedures and mechanisms under this Article entailing binding consequences shall be adopted by means of an amendment to this Protocol."
} 
Protocol..$^{75}$ This would have had the result that the strong measures of the non-compliance procedure would apply to some only of the Parties.

To avoid this, the Kyoto Protocol non-compliance procedure was in the end adopted by simple (consensus) decision of the COP/MOP. ${ }^{76}$ But this has, on the face of it, been at the expense of achieving the desired "strong" non-compliance procedure with legally binding consequences.

\section{d) The Effect of the Adoption of the Non-Compliance Procedure by Decision, in view of the Article 18 Amendment Requirement}

Notwithstanding certain ambiguities that it contains, and arguments which attempt in one way or another to by-pass its effects, ${ }^{77}$ it is submitted that it is difficult to deny that Article 18 effectively prevents the "consequences" set out in Section XV of the non-compliance procedure which result from a finding of non-compliance by the Enforcement Branch having, in themselves, any binding effect on the Parties. They are the product of a procedure or mechanism under Article 18, as, indeed, is the whole non-compliance procedure. Thus, if the Parties intended that they should have binding effect they had to adopt them by means of an amendment if their intention was to be put into effect.

This would mean that consequences based solely on the provisions of the noncompliance procedure would not be enforceable, but have only such de facto, or, as it is sometimes referred to, "political" force as the circumstances give rise to (which, see above in relation to Russian non-compliance under the Montreal Protocol, may not be inconsiderable). Out of the important consequences referred to above, this would apply in particular to the $1.3 \%$ reduction in the assigned amount as a consequence of failure to meet Article 3 commitments, ${ }^{78}$ which is a consequence having no basis outside the non-compliance procedure itself.

It is submitted, however, that this is not necessarily the case with the consequences set out in Section XV.4 of the non-compliance procedure relating to suspension of eligibility in the flexible mechanisms. A full analysis of this issue is beyond the scope of the present chapter. But, briefly, it is suggested that it is at least highly arguable, on the basis of the analysis above of the structure of Articles 6, 12 and 17 of the Kyoto Protocol that, if a Party fails to meet any of the eligibility requirements or other rules or conditions pertaining to one or other of the flexible mechanisms, it is not necessary that any particular decision, or action, is taken to bring about that Party's suspension from use of the mechanism. The situation is, rather, that the Party's right to use the

75 See Halvorssen and Hovi, supra n. 9, at 164.

76 The issue of adoption of the NCP by an amendment to the Kyoto Protocol was in fact left on the table for future decision. But at the third MOP in Bali in December 2007 the matter was still not resolved; and it is widely anticipated that it never will be.

77 Ulfstein and Werksman, supra n. 9, at 58. Lefeber, supra n. 32, at 51, explains that a decision of COP/ MOP on the NCP mechanisms under the Kyoto Protocol "can only be classified as internal rules. As these procedures "do not impose any obligations on Parties (...) other than procedural obligations relating to the effective functioning of the Kyoto Protocol. Thus, the procedures and mechanisms on compliance are binding on Parties (...) even if adopted by means of a decision."

${ }^{78}$ Kyoto Protocol NCP, Section XV.5. 
mechanism to assist in meeting its Article 3 targets simply does not arise in the first place (or automatically ceases under the terms of the Protocol itself). The Parties' emissions reductions under Article 3 would then be calculated on the basis of the Party's own domestic reductions alone; and if these fell short of the Party's targets, that Party would be in breach of Article 3 .

Such a construction would go some way towards mitigating the effects of lack of binding force in the non-compliance procedure's decisions; but would still leave it much weakened in relation to other "consequences" which it is empowered to apply in relation to other forms of non-compliance.

The recent decision of the Enforcement Branch regarding the issue of non-compliance by Greece did little to clarify the legal problems analysed above. ${ }^{79}$ This was the first time that a State Party has been officially found in non-compliance with any Kyoto Protocol obligation. On 16-17 April the Enforcement Branch held its fourth meeting. During this meeting the main question was the confirmation of its preliminary finding of non-compliance with respect to Greece (adopted at its third meeting on 4-6 March). Greece was found to be in non-compliance with national system requirements for countries with 2012 targets (Annex B Parties)..$^{80}$

The consequences applied by the branch, with immediate effect, were that Greece was: a. Declared to be in non-compliance; $b$. Required to submit a plan to address its non-compliance within three months; c. Not eligible to participate in the market mechanisms (Article 17, Emissions Trading; Article 12, Clean Development Mechanism; and Article 6, Joint Implementation). The consequences of this are following: (i) Greece cannot sell and transfer credits (unless they are verified under a special track II Joint Implementation procedure), and cannot acquire any credits except those forwarded by a host developing country; (ii) The preliminary finding, and by extension the final decision, note that the branch received expert advice that identified the need for an in-country review on the basis of an annual inventory report generated by the new national system in order for the enforcement branch to assess compliance; (iii) Greece submitted an annual inventory report in April 2008. No in-country review by an expert review team has yet been scheduled.

In drafting this decision, the Enforcement Branch followed closely the text of the Marrakech Accords relating to possible consequences applicable by the Enforcement Branch following a finding of non-compliance. It may be noted that, in relation to the issue of non-eligibility to participate in the mechanisms, the Enforcement Branch limits itself to a simple statement that Greece was "not eligible to participate", which appears, if anything, to support the construction set out above according to which Greece's non-eligibility would derive from the terms of the Protocol itself (i.e., from their failure to comply with provisions of the Protocol relating to the formulation of a National Plan), rather than directly from the decision of the Enforcement Branch.

79 See the website of the Kyoto Protocol <http://unfccc.int/files/kyoto_protocol/compliance/background/ application/pdf/informal information note on recent and current cases_.pdf $>$ (visited 20 June 2008). See also S. Urbinati, "Procedures and Mechanisms Relating to Compliance under the 1997 Kyoto Protocol to the 1992 United Nations Framework Convention on Climate Change", supra 63-84, at 83-84.

${ }^{80}$ The national system is required for a Party to account for its emissions and demonstrate compliance. This is not directly related to whether Greece is in compliance with its 2012 emissions target. 
Notwithstanding the apparent support thus lent to the above construction, however, it cannot be regarded as being on its own conclusive of this, so that alternative views on the nature of decisions of the Enforcement Branch probably remain still open.

\section{CONCLUSIONS}

It may be observed from the above study of the legal relationship of non-compliance procedures - and the decision-making processes within MEA upon which they are based - with the law of treaties, that there are many aspects of this subject which remain obscure, and the objectives of those who seek "strong" regimes and, in particular, non-compliance procedures, in terms of their ability to make binding decisions remain in uncertain of achievement.

A number of legal theories have been put forward as offering a route out of the apparent impasse. Many of these amount not so much to development of new principles as, simply, to the application of the existing underlying principles of the law to treaties - within which, as has been argued above - the basis of legal structures to achieve these objectives could be found. However, use of this route is thwarted by the one necessity that the law of treaties does impose, which is a sufficient degree of certainty as to the intention of States to be bound by an agreement, and to the content of what they have agreed; and it is exactly these certainties that, in a number of cases reviewed above, have been lacking.

It is inevitable that proponents of strong regimes will then look to find legal principles that have their basis outside the law of treaties and thus may give rise to binding effects not because of States intentions, but despite them. It has been suggested above that none of these theories - at least as things stand at present - offers solutions in more than very limited circumstances.

Study of how such rules might develop in the future is beyond the scope of this chapter. But however this might come about, the practice of States in support of some kind of independent rule-making capacity for treaty organs is likely to be essential; and in this respect, the present situation is not promising.

Firstly, the phenomenon of binding decision-making within treaty regimes, even on the basis of clear agreement or mandate, is not as wide-spread as is often asserted by authors. In fact there are very few examples of the kind of new law-making and indirect consent to be bound by States that was looked at in paragraph 2 of the chapter; indeed, the example there considered of the adjustment procedure of the Montreal Protocol is the only real instance of this.

In fact, such practice as there is tends to emphasise the concerns of States in relation to any expansion of the powers of treaty organs. For instance, the Basel Convention contains no provisions authorising the COP to further develop its provisions. Nevertheless, the second COP adopted by consensus a decision banning all movement of hazardous wastes from OECD to non-OECD countries. Even so, a number of States questioned the COP's authority to increase the scope of the legal obligations of the Parties to the Convention; and because the Decision was not incorporated in the text of the Convention itself, the question as to whether it was legally binding or not 
arose ${ }^{81}$ The conflict was only resolved when, at the third COP in 1995, it was decided that the ban be formally incorporated into the Basel Convention as an amendment. ${ }^{82}$

Another example of such concerns arose during the negotiation of the non-compliance procedure under the Aarhus Convention, when the decision to establish the noncompliance procedure was adopted by consensus by the MOP. However, the United States (neither a Party, nor a signatory to the Convention) expressed concerns that this decision was taken in the absence of express authority in the Convention. In particular, the United States objected to the possibility of the adoption of one of the indicative measures in cases of non-compliance - i.e., suspension in accordance with the applicable rules of international law, of the special rights and privileges under the Convention in relation to a non-complying State, as there was no basis for such a measure in the Convention itself. ${ }^{83}$

${ }^{81}$ As described above (paragraph 2.5(b)), per contra, no objections were raised to the adoption of the NCP under the Basel Convention by the COP with similar lack of express authority from the Convention itself.

${ }^{82}$ Decision III/1on Amendment to the Basel Convention, doc. UNEP/CHW.3/35 (28 November 1995).

${ }^{83}$ Handl, supra n. 9, at 135-136. 
1 


\title{
Chapter Twenty-Seven \\ Non-Compliance Procedures and the Law of State Responsibility
}

\author{
Laura Pineschi
}

\section{INTRODUCTION}

According to Article 55 of the Draft Articles on Responsibility of States for Internationally Wrongful Acts adopted by the International Law Commission on second reading in 2001 (hereinafter: ILC Draft Articles), ${ }^{1}$ these provisions do not apply

"where and to the extent that the conditions of an internationally wrongful act or the content or implementation of the international responsibility of a State are governed by special rules of international law."

As the Commission points out in its commentary, the purpose of Article 55, briefly summarized under the heading "Lex specialis", is to apply secondary rules on State responsibility without prejudice to the operation of special regimes of State responsibility. ${ }^{2}$ In other words, Article 55 is a saving clause, based on the assumption that general rules on State responsibility are not exhaustive. This rule, therefore, allows for the co-existence, with the general regime codified by the ILC, of obligations

${ }^{1}$ Report of the International Law Commission, Fifty-Third Session (23 April-1 June and 2 July-10 August 2001), doc. A/56/10 (2001), 58.

${ }^{2}$ Ibid., at 356. The Special Rapporteur, Roberto Ago, had already avowed that "In the text of a particular treaty concluded between them, some States may well provide for a special régime of responsibility for the breach of obligations for which the treaty makes specific provision; obviously if such a breach occurred, the perpetrator would be subject to the special régime established by the treaty in question"; R. Ago, "Fifth Report on State Responsibility", YB Int'l L. Comm., 2, Part One, (1976), para. 14. However, the issue was not further developed, as it was not considered relevant with regard to the problem that the Special Rapporteur was dealing with. As a matter of fact, it was necessary to decide whether the customary or conventional nature of the infringed rule was relevant for the codification of the general rules on State responsibility. Also the Special Rapporteur, Willem Riphagen, sketched the problem in his third report: "[...] a treaty may create a subsystem of international law with its own, express or implied, secondary rules, tailored to its primary rules. This does not necessarily mean that the existence of the subsystem excludes permanently the application of any general rules of customary international law relating to the legal consequences of wrongful acts [...] the subsystem as a whole may fail, in which case a fall-back on another subsystem may be unavoidable." W. Riphagen, Third Report on the content, forms and degrees of international responsibility (part 2 of the draft articles), YB Int'l L. Comm. (1982), 2, Part One, para. 54

T. Treves et al., eds., Non-Compliance Procedures and Mechanisms and the Effectiveness of International Environmental Agreements

(C) 2009, T.M.C. ASSER PRESS, The Hague, The Netherlands, and the Authors 
belonging to certain "closed legal circuits"3 (the so-called "self-contained regimes"), ${ }^{4}$ where substantial obligations are accompanied by special rules governing the consequences of a breach of an obligation within those regimes. ${ }^{5}$ According to the principle of speciality, these secondary rules prevail over the secondary rules envisaged by the general regime on State responsibility.

As the Special Rapporteur, Gaetano Arangio-Ruiz, explained in his fourth report to the ILC, the aim of special regimes can be either to achieve, by means of an ad hoc machinery, the organisation of a more effective monitoring system on violations and responses thereto, or to prevent a reaction to a violation from precluding the achievement of the aim of the breached rule. ${ }^{6}$ However, since these rules derogate from the general rules in question, special regimes are admissible to the extent that they are consistent with the fundamental principles envisaged by the general regime on State responsibility:

"In particular, no treaty-based provisions would be admissible that would involve derogation from (a) the prohibition of the use of force; (b) the rule of respect for fundamental rights; (c) the basic exigencies of diplomatic relations; (d) other peremptory rules of general international law; (e) the duty to respect the right of 'third' States; (f) the principle of proportionality; or $(\mathrm{g})$ the rule under which the lawfulness of any unilateral measure must be assessed in the light of its ultimate legal function."”

In any case, clearly expressing his perplexity about the notion itself of "self-contained regimes" both in treaty ${ }^{8}$ and customary law, ${ }^{9}$ the Special Rapporteur concluded his

$31731^{\text {st }}$ Meeting of the ILC, YB Int'l L. Comm. (1982), 1, 202, para. 16.

4 The Permanent Court of International Justice and the International Court of Justice employed this expression in its judgment in S.S. Wimbledon (France, Great Britain, Japan and Italy v. Germany, Poland intervening), Judgment of 17 August 1923, PCIJ Reports (1923), Series A, No. 1, 6, at 23-24: “[...] the Kiel Canal is open to the war vessels and transit traffic of all nations at peace with Germany, whereas free access to the other German navigable waterways referred to the Allied and Associated Powers alone [...]. The provisions relating to the Kiel Canal in the Treaty of Versailles are therefore self-contained" and in the United States Diplomatic and Consular Staff in Tehran (United States v. Iran), Judgment of 24 May 1980, ICJ Reports (1980), 3, para. 86: "The rules of diplomatic law, in short, constitute a self-contained régime which, on the one hand, lays down the receiving State's obligations regarding the facilities, privileges and immunities to be accorded to diplomatic missions and, on the other, foresees their possible abuse by members of the mission and specifies the means at the disposal of the receiving State to counter any such abuse". On the notion of "self-contained regime" see the report of the Working Group established by the ILC chaired by Martti Koskenniemi, Fragmentation of International Law: Difficulties Arising from the Diversification and Expansion of International Law, doc. A/CN.4/L.682 (13 April 2006), $65 \mathrm{ff}$. and, in the literature, the contributions by B. Simma, "Self-Contained Regimes", Netherlands YB Int'l L., 16 (1985) 111-136 and B. Simma and D. Pulkowski, "Of Planets and the Universe: Self-contained Regimes in International Law", Eur. J. Int'l L., 17 (2006) 483-589.

${ }^{5}$ G. Arangio-Ruiz, "Fourth Report on State Responsibility", YB Int'l L. Comm. (1992), 2, Part One, para. 97.

6 Ibid., para. 112.

7 Ibid.

${ }^{8}$ See also Simma, supra n. 4, at 123 ss. and Simma and Pulkowski, supra n. 4, at $516 \mathrm{ff}$.

${ }_{9}$ M. Spinedi, "Les conséquences juridiques d'un fait internationalement illicite causant un dommage à l'environnement", in F. Francioni and T. Scovazzi (eds.), International Responsibility for Environmental Harm (London, Dordrecht, Boston: Graham \& Trotman, 1991) 75-124. 
analysis by raising some objections to the relevant draft article proposed by the previous Special Rapporteur, Willem Riphagen: ${ }^{10}$

"[...] when States introduce into a treaty special rules governing the consequences of its violation, their aim is not to exclude, in their mutual relations, the rights, obligations and facultés - in short, the guarantees - which each derives, vis-à-vis each of the other parties, from the normal operation of the general rules on State responsibility. On the contrary, the aim pursued is to strengthen the normal, unstructured and sometimes unsatisfactory guarantees of general law, by making them more dependable and effective, either by means of institutional devices or, failing that, by means of more precise stipulations. In no case does that mean renouncing the possibility of "falling back" on less developed, "natural" guarantees $[\ldots] . " 11$

The new Special Rapporteur on responsibility of States for internationally wrongful acts, James Crawford, did not go back on these remarks in his third report. He simply took note that member States of the Sixth Commission of the General Assembly had generally accepted this principle. A number of States merely disputed the location of the draft article. Considering the general character of this provision, which is relevant for all articles of the project, draft Article 37 should have been moved to the general part of the draft. ${ }^{12}$ Therefore, in the end, the derogation headed "lex specialis" was included in Article 55 of the ILC draft articles.

The commentary to the ILC Draft Articles essentially stresses the residual character of the provision under Article 55, as well as the important role of the interpreter to ascertain whether the special consequences that follow from a breach of certain rules exclude the application of the consequences envisaged by general international law:

"For the lex specialis principle to apply it is not enough that the same subject matter is dealt with by two provisions; there must be some actual inconsistency between them, or else a discernible intention that one provision is to exclude the other. Thus the question is essentially one of interpretation." 13

Under this premise, it can be useful to investigate the specific relationship existing between the non-compliance procedures established by certain multilateral environmental treaties and the ILC Draft Articles on State responsibility. In particular, the purpose of this chapter is to try to answer two basic questions. First of all: can the non-compliance procedures established by multilateral environmental treaties be considered special systems of responsibility according to Article 55 of the ILC draft articles? Second: can a State Party to a multilateral environmental treaty invoke the responsibility of another State Party under the general regime on State responsibility despite the establishment of a non-compliance mechanism under that treaty?

${ }^{10}$ See draft Art. 2 of the Second part of the ILC Draft Articles in YB Int'l L. Comm. (1991), 2, Part Two, 126 , note 359

${ }^{11}$ Arangio-Ruiz, supra n. 5, para. 124

${ }^{12}$ J. Crawford, Third Report on State Responsibility, Addendum, doc. A/CN.4/507/Add.4 (4 August 2000), $25 \mathrm{ff}$.

${ }^{13}$ Report of the International Law Commission, Fifty-Third Session, supra n. 1, at 358. 


\section{The Non-Compliance Procedures: Special Regimes of State RESPONSIBILITY?}

In the opinion of the Special Rapporteur Arangio-Ruiz, for a true derogation from the general rules on State responsibility it should be necessary, at least, for the Parties to a treaty establishing a special regime to expressly indicate that by entering this instrument they exclude the application of some or all of the general rules of international law on the consequences of internationally wrongful acts. ${ }^{14}$ Conversely, the commentary to Article 55 of the ILC draft articles emphasises the role of the interpreter to ascertain whether the consequences that follow from certain particular breaches exclude the application of the remedies envisaged by the general regime of State responsibility. ${ }^{15}$ Therefore, the willingness of the Parties to derogate from the general regime could be also implicitly inferred from the wording of a specific instrument.

From the analysis of different non-compliance procedures it is evident that neither the multilateral environmental treaties providing for the adoption of such mechanisms nor the instruments specifically regulating these procedures contain a provision expressly aimed at excluding the application of the rules of general international law on State responsibility.

In principle, the resolutions that the Parties to an environmental treaty adopt to establish and regulate non-compliance mechanisms contain a saving clause whose purpose, however, is that these mechanisms apply without prejudice to the operation of the settlement of disputes procedures laid down in the same environmental treaty. This is the case, for instance, of the chapeau of Decision IV/5 of 1992, governing the non-compliance procedure of the Montreal Protocol on substances that deplete the ozone layer: ${ }^{16}$

"The following procedure has been formulated pursuant to Article 8 of the Montreal Protocol. It shall apply without prejudice to the operation of the settlement of disputes procedure laid down in Article 11 of the Vienna [Ozone] Convention." 17

\footnotetext{
${ }^{14}$ Arangio-Ruiz, supra n. 5, para. 125(b).

${ }_{15}^{15}$ See supra paragraph 1.

${ }^{16}$ A list of treaties with full references is provided supra at XXXVII.

${ }_{17}$ Decision IV/5 on Non-Compliance Procedure, doc. UNEP/OzL.Pro.4/15 (25 November 1992), at 13 and Annex IV at 44 (emphasis added). See also the mechanisms adopted under the Basel Convention (Decision VI/12 on Establishment of a Mechanism for Promoting Implementation and Compliance, doc. UNEP/CHW.6/40 (10 February 2003), at 45 (Basel Convention NCP)), para. 27; the Kyoto Protocol (Decision 27/CMP.1 on Procedures and Mechanisms Relating to Compliance under the Kyoto Protocol, doc. FCCC/KP/CMP/2005/8/Add.3 (30 March 2006), at 92 (Kyoto Protocol NCP)); the Cartagena Protocol (Decision BS-I/7 on Establishment of Procedures and Mechanisms on Compliance under the Cartagena Protocol on Biosafety, doc. UNEP/CBD/BS/COP-MOP/1/15 (27 February 2004), Annex I, at 98 (Cartagena Protocol NCP)), Preamble; the LRTAP Convention (Decision 1997/2 Concerning the Implementation Committee, its Structure and Functions and Procedures for Review of Compliance, doc. ECE/EB.AIR/53 (7 January 1998), Annex III, at 28, subsequently amended. Consolidated text in Decision 2006/2 on Implementation Committee, its Structure and Functions and Procedures for Review, doc. ECE/EB.AIR/89/Add.1 (5 February 2007), at 4) (LRATP Convention NCP), para. 12; the Espoo Convention (Decision II/4 on Review of Compliance, doc. ECE/MP.EIA/4 (7 August 2001), Annex IV, at 72 revised by Decision III/2 on Review of Compliance, doc. ECE/MP.EIA/6 (13 September 2004), Annex II (consolidated text) (Espoo Convention NCP), paras. 12 and 13; the Alpine Convention (Decision VII/4 Mécanisme de verification du respect de la Convention
} 
From the reading of the travaux préparatoires which preceded the adoption of the Montreal Protocol's mechanism it is evident that the negotiators were concerned, above all, with the relationship between the non-compliance procedure, to be established according to Article 8 of the Montreal Protocol, and the dispute settlement procedure envisaged by Article 11 of the 1985 Vienna Convention for the protection of the ozone layer (Vienna Ozone Convention), and adopted in 1989, during the first COP to this Convention. ${ }^{18}$ From the beginning it was the clear intention of the Parties to avoid a duplication of efforts, ${ }^{19}$ as well as any conflict between the two procedures. ${ }^{20}$ In the end, the idea prevailed that these mechanisms would both work, independently:

"Many experts were of the view that the judicial and arbitral settlement of disputes provided for in Article 11 of the Vienna Convention and the Non-Compliance Procedure referred to in Article 8 of the Montreal Protocol were two distinct and separate procedures which could well exist in parallel. It was also stated that the Parties should have the right to exercise either option in any given situation." 21

During the negotiations, the Spanish delegation raised the problem of the relationship between non-compliance procedures and other procedures which are envisaged by other international instruments of a general nature, such as Article 33 of the United Nations Charter and, above all, Article 60 of the Vienna Convention on the Law of Treaties. However, the same delegation concluded that the latter procedures

"[...] would, because of their general nature and because they pre-date the Convention and Protocol by such a long time, be hard to apply, but their provisions, where compatible, could serve as a guide." ${ }^{22}$

Only the Basel Convention on the transboundary movements of hazardous wastes contains a provision expressly mentioning the general regime on State responsibility:

alpine et de ses protocols d'application (Seventh Alpine Conference, 2002) (Alpine Convention NCP), para. 4.4; and the Aarhus Convention (Decision I/7 on Review of Compliance, doc. ECE/MP.PP/2/Add.8 (2001, late issued on 2 April 2004), as amended by Decision II/5 on General Issues of Compliance, doc. ECE/MP.PP/2005/2/Add.6 (13 June 2005), para. 12 (Aarhus Convention NCP), para. 38.

${ }_{18}$ Report of the First Meeting of the Conference of the Parties to the Vienna Convention, Annex II, doc. UNEP/OzL.Conv.1/5 (28 April 1989).

19 "[I]t was important to avoid drawing up an unnecessarily complex and duplicative system", Report of the First Meeting of the Ad Hoc Working Group of Legal Experts on Non-Compliance with the Montreal Protocol, doc. UNEP/OzL.Pro.LG.1/3 (14 July 1989), para. 9.

20 " $[\mathrm{T}]$ he procedure proposed should not alter or weaken in any way article 11 of the Vienna Convention", ibid., para. 9(d).

${ }^{21}$ Report of the Second Meeting of the Ad Hoc Working Group of Legal Experts on Non-Compliance with the Montreal Protocol, doc. UNEP/OzL.Pro/WG-3/2/3 (11 April 1991), para. 18. On the settlement of international disputes procedures, see the contribution by T. Treves, "The Settlement of Disputes and NonCompliance Procedures", infra 499-518.

${ }^{22}$ Note from the Delegation of Spain on the procedure for the settlement of disputes under the Montreal Protocol, doc. UNEP/OzL.Pro.LG.1/Inf.1 (10 July 1989), at 2. 
"[...] States are responsible for the fulfilment of their international obligations concerning the protection of human health and protection and preservation of the environment, and are liable in accordance with international law." 23

Furthermore,

"[...] in the case of a material breach of the provisions of this Convention or any protocol thereto the relevant international law of treaties shall apply." 24

Finally, the Basel Convention non-compliance mechanism expressly lays down that the Committee, when considering allegations of non-compliance,

"shall take into account any specific procedures provided for under the Convention concerning failures to meet Convention obligations." ${ }^{25}$

This is, however, a distinctive feature of the Basel Convention, where unlike other multilateral environmental treaties providing for non-compliance procedures, the hypothesis of a bilateral conflict prevails over multilateral conflicts. ${ }^{26}$

Looking beyond the wording of the single provisions, further considerations can be developed in a more general perspective. The ratio and the purposes of non-compliance procedures, as well as their implementing instruments, are very different from those that are envisaged by the general regime on State responsibility. It cannot be overlooked, for instance, that the mechanisms adopted so far have a prominent political nature, both because they operate on the basis of more pragmatic than legal considerations ${ }^{27}$ and because certain solutions, which could be unacceptable for a judicial mechanism (it suffices here to mention the modest guarantees from which the State

23 Basel Convention NCP, Preamble, para. 15 (emphasis added).

${ }^{24}$ Ibid., para. 16. However, it does not seem relevant that a Protocol on liability and compensation for damage resulting from transboundary movements of hazardous wastes and their disposal (Basel, 10 December 1999) has been adopted under Art. 12 of the Basel Convention. The Protocol has not entered into force yet (information updated at 18 April 2008). The Protocol particularly addresses the problem of the compensation of damage caused by single operators, without affecting "[T] $]$ he rights and obligations of the Contracting Parties under the rules of general international law with respect to State responsibility" (Art. 16 of the Protocol). On the Protocol see A. Fodella, Il movimento transfrontaliero di rifiuti pericolosi nel diritto internazionale (Torino: Giappichelli, 2004), at $319 \mathrm{ff}$. and the ample bibliography mentioned therein.

${ }^{25}$ Ibid., para. 28.

26 "Because of the legal structure [of the Convention] [...], many of the non-compliance cases under the Basel Convention would in fact result in disputes between importing, exporting and/or transit states as to the application and interpretation of the Convention [...]. Thus, [...] compliance with the Basel Convention could be ensured through the traditional, bilateral means of ensuring compliance with international law, namely the system of state responsibility and dispute settlement", A. Shibata, "Ensuring Compliance with the Basel Convention - Its Unique Features", in U. Beyerlin, P.-T. Stoll and R. Wolfrum (eds.), Ensuring Compliance with Multilateral Environmental Agreements. A Dialogue between Practitioners and Academia (Leiden and Boston: Martinus Nijhoff, 2006) 69-87, at 86.

${ }^{27}$ For further considerations with specific reference to the non-compliance mechanism adopted under the Basel Convention, see Shibata, supra n. 26, at 85. 
under scrutiny can in principle benefit under a non-compliance procedure) can only be justified by the non-confrontational nature of these mechanisms. ${ }^{28}$

There are certain fundamental differences from the general rules on State responsibility, ${ }^{29}$ which have their raison d'etre in the ratio and the purposes of the non-compliance procedures. For instance, the main function of these mechanisms, consisting of the full observance of the obligations laid down by a certain international instrument, is worth mentioning. The mechanisms adopted so far do not contain provisions preventing a non-complying State from the right to be heard, to propose compromise solutions different from strict compliance with the obligations undertaken and to see that these proposals are taken into consideration. This process becomes illusory if other Parties insist on strict adherence to the obligations undertaken by the non-complying State and they are not prepared to consider any other alternative solution. However, a systematic interpretation of the instruments regulating non-compliance procedures in the light of their object and purpose shows that "justifications" which can be invoked under the general regime on State responsibility as grounds for precluding wrongfulness do not make sense under these mechanisms. It is not the purpose of non-compliance procedures to entail the international responsibility of a State, but to facilitate or ensure the effective observance of certain environmental obligations. In other words, under a non-compliance procedure it is not relevant to know whether the breach (or the risk of a breach) of a treaty obligation is voluntary or unintentional. The main interest of all the Contracting Parties is that the environmental purposes of a certain treaty are effectively fulfilled. ${ }^{30}$

This interpretation is confirmed by States practice. Obviously, the non-complying Parties are inclined to provide arguments, which are sometimes very broad and detailed, on the reasons why they are prevented from carrying out their obligations. Furthermore, one of the main purposes of non-compliance procedures is to try to

${ }^{28}$ For a broader discussion on this issue, see in particular H. Adsett, A. Daniel, M. Husain and T. McDorman, "Compliance Committees and Recent Multilateral Environmental Agreements: The Canadian Experience with Their Negotiation and Operation”, Canadian YB Int'l L., 42 (2004) 91-142, at 106 and $110 \mathrm{ff}$. and M. Montini, "Procedural Guarantees in Non-Compliance Mechanisms", supra 389-415.

${ }^{29}$ For a general survey on the role of State responsibility in the protection of the environment, see in particular: F. Francioni and T. Scovazzi (eds.), supra n. 9; T. Scovazzi, "State Responsibility for Environmental Harm", YB Int'l Envt'l L., 12 (2001) 43-67; M.J. Bowman and A.E. Boyle (eds.), Environmental Damage in International and Comparative Law - Problems of Definition and Valuation (Oxford: Oxford University Press, 2002); P. Sands, Principles of International Environmental Law (Cambridge: Cambridge University Press, $2^{\text {nd }}$ edn., 2003) 869-939; M. Fitzmaurice, "International Responsibility and Liability", in D. Bodansky, J. Brunnée and E. Hey (eds.), The Oxford Handbook of International Environmental Law (Oxford: Oxford University Press, 2007) 1010-1035.

${ }^{30}$ Also under the regime of State responsibility the principal aim of certain secondary rules is to safeguard the duty of States to comply with primary rules of international law. In particular, Art. 29 of the ILC Draft Articles ("Continued Duty of Performance") and Art. 30 ("Cessation and Non-Repetition") exercise the function to protect the interests of the injured State and the international community as a whole that the rule of law is preserved both requiring the responsible State to put an end to a violation of international law and reminding it of its continued duty to perform the obligation breached. However, while secondary rules on State responsibility come into play ex post facto, i.e., when a wrongful action or omission has been fulfilled, the non-compliance procedures operate mainly on the preventive level. For further considerations on this issue, see M. Fitzmaurice and C. Redgwell, "Environmental Non-Compliance Procedures and International Law", Netherlands YB Int'l L., 31 (2000) 35-65, at $52 \mathrm{ff}$. 
understand the origins of certain impediments or the impossibility of observing certain obligations and to suggest the most appropriate remedies to ensure (or to restore) their observance as soon as possible. However, the defensive strategy adopted by the Russian Federation when it was found to be in non-compliance with the obligations of the Montreal Protocol by the seventh Conference of the Parties in 1995 was unusual and remained an isolated case if one considers subsequent practice. On that occasion the Russian Government produced arguments that went beyond the explanation of simple facts: the non-fulfilment of certain obligations was not caused by the inefficacy of the measures adopted, but by economic troubles; since the Russian Federation was a successor State, it could not be considered responsible for the non-fulfilment of its obligations; the Soviet Union's collapse could be considered a force majeure or a "fundamental change of circumstances". ${ }^{31}$

In conclusion, the mechanisms under discussion cannot be linked to those of State responsibility because they are different, separate and independent from them. However, they integrate them, in so far as they do not preclude a priori, neither explicitly nor implicitly, the application of general rules on State responsibility. Therefore, to seek recourse to general international law mechanisms could be possible in exceptional cases.

The same conclusion could be achieved if the multilateral environmental treaties providing for non-compliance procedures were considered special regimes on State responsibility. As the Special Rapporteur Arangio-Ruiz already pointed out in his fourth report to the ILC, States bound to the treaties establishing these systems are not deprived of the right to turn to the general rules on international wrongful acts:

31 See J. Werksman, "Compliance and Transition: Russia's Non-Compliance Tests the Ozone Regime", ZaöRV, 56 (1996) 750-773, at 760-762. However, the same author suggests that the case of the Russian Federation should be considered in its true light: "Neither Russia nor the Non-Compliance Procedure addressed in any detail arguments with regard to succession and 'fundamental change in circumstances' and it can be concluded that they were invoked, at this stage, not to withdraw or terminate operation of the Protocol, but instead to elicit sympathy and unease from fellow Parties", ibidem, at 762. Within other systems, the Parties have not challenged the non-compliance allegation; they simply explained the reasons and facts that led to the non-compliance situation (see, for instance: T. Kuokkanen, "Practice of the Implementation Committee under the Convention on Long-Range Transboundary Air Pollution", in Beyerlin, Stoll and Wolfrum (eds.), supra n. 26, 39-51, at 43 and 47). A final consideration of a mere theoretical nature could also be added. While basic rules of international law concerning the responsibility of States for their internationally wrongful acts are generally qualified as secondary rules on State responsibility (i.e., rules aimed at defining the general conditions under international law for a State to be considered responsible for a wrongful act and the legal consequences which result from the infringement of international obligations laid down in primary rules) it can be wondered whether also the measures adopted under a non-compliance procedure can be qualified in the same manner. Indeed it could be said that since these measures are conceived neither as a consequence of an internationally wrongful act (it is not necessary, for instance, for an obligation to have already been breached), nor as reparation for an injury suffered by one or more States, they are a "corollary" of the "primary" obligations binding upon each Contracting Party. As a matter of fact, the non-compliance procedures achieve a dual function: to ensure the effective attainment of the objectives of the multilateral environmental treaty under which they have been established by means of strengthening the obligations of prevention and cooperation that have a customary nature and concern all the international environmental law sector, as well as reinforcing and better clarifying the scope of the non-fulfilled obligation. If the rules laid down in non-compliance procedures cannot be considered as secondary rules, they have a different nature from the ILC Draft Articles and fall outside the situations of conflict that are envisaged by Art. 55 of the ILC Draft Articles. 
"[...] it seems reasonable to assume, in particular, that a State joining a so-called selfcontained regime does not thereby restrict, by some kind of self-contained regime, its rights or facultés of unilateral action under general international law to such an extent that there is no possibility of any derogation from or integration of that 'regime'. Of course, any State accepting the 'regime' shall be bound, when confronted with a breach by another State party of an obligation deriving from that 'regime', first of all to react - if it so wishes - in conformity with the provisions of the relevant 'regime'. This does not exclude, however, a certain latitude for general law measures, the extent of such latitude depending on the degree of availability and effectiveness of the remedies envisaged by the treaty-based 'regime'." 32

Furthermore, as the Report of the Working Group on the fragmentation of international law rightly points out, "no regime is self-contained", ${ }^{33}$ because no legal regime is hermetically isolated from general international law. ${ }^{34}$ As for the terminology, the expression itself "self-contained regime" would not be appropriate ("the term "selfcontained regime' is a misnomer"). ${ }^{35}$

If we accept these assumptions, it remains to explore under which circumstances and on which conditions State responsibility can be entailed despite the existence of a non-compliance procedure.

\section{Coordination with General Rules on State Responsibility}

In their analysis of special regimes on State responsibility, academic writers have singled out various hypotheses, according to which a State could be entitled to invoke rules under the general regime on State responsibility, despite the existence of a special regime. All these hypotheses are based on the same assumption: the failure of the latter system. In principle, however, these scholars do not indicate general criteria in order to establish what exactly "failure" means, but only examples of possible scenarios. For instance, in his fourth report to the ILC, the Special Rapporteur ArangioRuiz illustrates two possible situations in which the possibility of a "fall-back" should remain open:

“(a) In the first hypothesis, the State injured by a violation of the 'system' resorts to that system's institutions, secures a decision in its favour, but fails to obtain, through the system's procedures, the reparation to which it is entitled under that decision. Clearly, as long as the wrongdoing State does not comply in full with its obligations, the injured State may lawfully resort to measures which, although not covered by the 'system' are available to it (with the relevant limitations) under general international law.

${ }^{32}$ Arangio-Ruiz, supra n. 5, para. 114.

${ }^{33}$ Fragmentation of International Law, supra n. 4, para. 192. See also para. 185: "[...] international law regimes are always partial in the sense that they regulate only some aspects of State behaviour while presuming the presence of a large number of other rules in order to function at all"; "It is in the nature of "general law to apply generally" - namely inasmuch as it has not been specifically excluded."

34 Ibid., para. 193.

35 Ibid., para. 179. 
(b) In the second hypothesis, the internationally wrongful act consists of an ongoing violation of the 'regime'. In this case too, except of course where the injured State would be entitled to act in self-defence, there is an obligation to seek recourse in the first place through the procedures agreed in the instrument concerned. However, if the unlawful conduct persists while these procedures are in progress - and in spite of any interim measures for which provision is made therein - the injured State may lawfully resort simultaneously to any 'external' unilateral measures which may be appropriate to protect its primary or secondary rights, without endangering the 'just' solution of the conflict which could be afforded by the 'system'." 36

Two scholars, Bruno Simma and Dirk Pulkowski, add a third hypothesis, actually a rather vague one, consisting of a unilateral action with a "defensive" purpose:

"[...] a fallback on state responsibility - and particularly on the regime of countermeasures - is conceivable in three scenarios: in the case of continuous violation of an obligation under a special system, despite a decision to the contrary by the system's competent dispute settlement body; in the case of an injured state's failure to obtain reparation, despite a respective decision by the system's competent dispute settlement body; if unilateral action is necessary as a defensive measure." ${ }^{37}$

Only the report of the Working Group on the fragmentation of international law suggests a general approach, envisaging two alternative failures of a self-contained regime authorising the residual application of general rules on State responsibility: a substantial failure, that should take place when the special regime completely fails to achieve the purpose for which it was established ${ }^{38}$ and a procedural failure, consisting of the inability of the institutions operating within the special system to function in the way they should. ${ }^{39}$ The same report, however, emphasises the fact that any attempt to give the subject a general framing still leaves open some important doubts. ${ }^{40}$

Therefore, the issue under discussion is very complex and it is not easier to deal with it if the inquiry is circumscribed in multilateral environmental treaties providing for the establishment of non-compliance procedures. The distinction between a substantial and a procedural failure, suggested by the Working Group on the fragmentation of international law, can be a useful starting point in the elaboration of a possible hypothesis, taking into account the nature and the specific character of the non-compliance systems. However, as we shall see further on, this framing does not encompass all possible scenarios.

Let us start with the hypothesis of a substantial failure. As a matter of fact it seems reasonable to maintain that non-compliance mechanisms exhaust their effects and the ordinary rules on State responsibility apply (and this includes countermeasures,

\footnotetext{
${ }^{36}$ Arangio-Ruiz, supra n. 5, para. 115.

37 Simma and Pulkowski, supra n. 4, at 509 (emphasis added).

38 The Working Group mentions, by way of example, the case where the "[...] pollution of a watercourse continues unabated despite pledges by riparian States Parties to a local environmental treaty", Fragmentation of International Law, supra n. 4, para. 188.

39 Ibid., para. 189

${ }^{40}$ Ibid., para. 190.
} 
provided that they are strictly limited to the conditions, limitations and procedural safeguards imposed by the general regime on State responsibility ${ }^{41}$ and that they do not impair the performance of environmental obligations ${ }^{42}$ ) when the non-compliance system does not achieve the purpose for which it has been established, since all the available remedies provided for by this procedure have not attained their purpose. By way of example, let us imagine the situation where a State persistently violates its obligations under a multilateral environmental treaty and it does not give effect to the measures that a compliance committee or a Conference of the Parties have adopted in order to facilitate or restore the compliance of this State with its treaty obligations.

In principle, if we bear in mind that the limited effectiveness of the traditional instruments on State responsibility in environmental matters has been one of the principal reasons that led to the adoption of non-compliance mechanisms, it may be wondered whether the traditional instruments on State responsibility can be successful where non-compliance procedures failed. However, it is worth noting that, under the non-compliance procedures, the supervising bodies have an ample but not unlimited choice of measures that they can adopt in order to induce a State to comply with its obligations. For instance, certain rights and privileges envisaged by a multilateral environmental treaty providing for a non-compliance procedure may be suspended, but rights and privileges deriving from other international treaties may not. ${ }^{43}$ This limit does not work if States Parties to an environmental treaty invoke general rules on State responsibility. Indeed, nothing prevents a Party to a multilateral environmental treaty, when complaining about the persistent violation of an environmental agreement by another Party, from taking a counter-measure involving the breach of an obligation laid down, for instance, in a commercial treaty to which the two States are

${ }^{41}$ See ILC Draft Articles 49-54.

${ }^{42}$ Since countermeasures are limited by the requirements of necessity and proportionality and they cannot be directed against States other than the State which has committed an internationally wrongful act (see commentary by the ILC, supra n. 1, $327 \mathrm{ff}$.), it is highly unlikely that a lawful countermeasure can consist of the infringement of an environmental obligation. The unpredictability of the environmental consequences of certain acts or, at least, the difficulty to contain their effects are incontrovertible matters of fact. In this sense, see for instance P. Okowa, State Responsibility for Transboundary Air Pollution in International Law (Oxford: Oxford University Press, 2000), at 251: “A State is [...] not permitted to suspend its obligations for instance under the 1979 ECE Treaty on transboundary air pollution or under the 1963 Nuclear Test Treaty, even where it has been prejudicially affected by the prior beach of another State Party. Its only choice is to suspend the performance of obligations in another field, where suspension would not affect the collective interests of third states." See also W. Riphagen, "Fourth Report on State Responsibility", YB Int'l L. Comm., 2, Part One (1983), para. 86 (injured States cannot take countermeasures consisting of the violation of an international obligation essential for the protection of interests common to a group of States, "[...] to the extent that a breach of such obligation cannot but adversely affect such common interest and, thereby, cannot be limited to the single member of the group which has committed an internationally wrongful act"); Arangio-Ruiz, supra n. 5, para. $89 \mathrm{ff}$. (countermeasures consisting of the violation of erga omnes obligations are not permitted); J. Crawford, Third Report on State Responsibility, doc. A/CN.4/507/Add.3 (18 July 2000), para. 347-348. For similar reasons, even the adoption of severe responses for every instance of non-compliance is considered unfeasible by certain academic writers. See, e.g., T. Yang, "International Treaty Enforcement as a Public Good: Institutional Deterrent Sanctions in International Environmental Agreements”, Michigan J. Int'l L., 27 (2005-2006) 1131-1184 at 1169.

${ }^{43}$ See M. Koskenniemi, "Breach of Treaty or Non-Compliance? Reflections on the Enforcement of the Montreal Protocol”, YB Int'l Envt'l L., 3 (1992) 123-162, at 154. 
bound. Taking for granted the injured State's observance of the principle of proportionality and of other restrictions imposed by general international law, direct pressure applied to economic interests can be particularly effective in accelerating a return to compliance with environmental obligations by the State which is responsible for an internationally wrongful act.

As far as procedural failure is concerned, the issue is very simple. It could be assumed, for instance, that the supervising bodies are inefficient or paralyzed (in other words, their members do not regularly meet or do not achieve an agreement on the measures to be adopted), despite the submission of non-compliance or possible noncompliance situations by States Parties.

However, it could be wondered whether recourse to the mechanisms of State responsibility would be possible beyond the two aforementioned hypotheses, namely in situations different from the strict "failure" of a non-compliance mechanism. The doubt can arise if one considers the situation where a State Party to a multilateral environmental treaty under which a non-compliance procedure has been established is affected by detrimental consequences that follow from the breach of certain treaty obligations by another Contracting Party. For instance, the State found in non-compliance or at risk of non-compliance with its obligations under a certain multilateral environmental agreement has already implemented the measures adopted by the supervising bodies operating under the non-compliance procedure. Therefore, if the measures of these bodies were effective, that State has probably filled the gaps that hampered the prompt compliance with certain environmental obligations or it has reestablished the situation which existed before the situation of non-compliance. It will be recalled, however, that non-compliance procedures do not provide for reparation (for instance, monetary compensation). Therefore, a Party which is particularly affected by the detrimental consequences arising from the conduct of the State found in non-compliance (and that Party is able to give evidence of this particular prejudice) should retain the right to seek compensation for any damage suffered under the general regime of State responsibility. In other words, if the injured State is able to prove the existence of a particular and direct prejudice, it is reasonable to assume that the bilateral relationship can be managed according to the traditional schemes of State responsibility. ${ }^{44}$

It seems, however, possible to discern between two different situations. If the noncompliance situation derives from the violation of an obligation erga omnes partes, it would be preferable for a single State not to invoke the responsibility of another State as long as the measures adopted within a non-compliance procedure have not produced any effect. First of all, a unilateral measure could impair the interests of other States Parties, as well as the attainment of the object and purpose of a multilateral environmental treaty or its protocol. Secondly, the fact that the Parties to this instrument agreed to establish a non-compliance procedure presumes their conviction that possible acts or omissions with their treaty obligations could be better dealt with by means of non-confrontational instruments to which, therefore, priority should be

${ }^{44}$ See Art. 42(b)( $i$ ) of the ILC Draft Articles: "A State is entitled as an injured State to invoke the responsibility of another State if the obligation breached is owed to: (b) a group of States including the State, or the international community as a whole, and the breach of the obligation: (i) specially affects that State." 
given. In other words, the provision under Article 42(b)(i) of the ILC Draft Articles should be combined with the general obligation pacta sunt servanda which implies, according to the wording of Article 26 of the Vienna Convention on the Law of Treaties, the performance of treaty obligations in a spirit of cooperation and good faith with other Parties. ${ }^{45}$

Conversely, if the infringed obligation is only relevant at the level of bilateral relations between two particular Contracting Parties of a multilateral treaty, it can be assumed that the State whose individual right has been denied or impaired is entitled to require the responsible State to comply with the legal consequences of an internationally wrongful act envisaged by the secondary rules of State responsibility. By way of example, mention may be made here of the case of 530 tons of toxic waste which were unloaded from a ship and abandoned in at least 15 sites around Abidjan (Côte d'Ivoire) in September 2006. In the following days, thousands of people sought medical help complaining of ill health (their symptoms included nosebleeds, nausea and vomiting, headaches, skin and eye irritation and respiratory problems). ${ }^{46}$ The ad hoc technical commission established by the Basel Convention Secretariat to assist Côte d'Ivoire in the assessment of the damage to human health and the environment

${ }^{45}$ In this sense see also Arangio-Ruiz, supra n. 5, para. 115(b), reproduced supra at 492. It is also worth remembering that according to Art. 50.2(a) of the ILC Draft Articles, "A State taking countermeasures is not relieved from fulfilling its obligations: (a) under any dispute settlement procedure applicable between it and the responsible State." Furthermore, pursuant to Art. 52.3 of the same project: "Countermeasures may not be taken, and if already taken must be suspended without undue delay if: [...] the dispute is pending before a court or tribunal which has the authority to make decisions binding on the parties." But can these provisions be invoked with reference to non-compliance procedures? As the ILC says in its comment to Art. 52.3: "The reference to 'a court or tribunal' is intended to refer to any third party dispute settlement procedure, whatever its designation. It does not, however, refer to political organs such as the Security Council”, Draft Articles on Responsibility of States for International Wrongful Acts, YB Int'l L. Comm., 2, Part Two, (2001), 137. Thus, it would be necessary to ascertain whether non-compliance procedures can be linked to "third party dispute settlement procedures" or whether they are not covered by this draft article, because their operation is not governed by judicial organs. In the opinion of certain academic writers, to liken non-compliance mechanisms to dispute settlement procedures is not possible ("non-compliance mechanisms [...] may appear to be a specific kind of dispute avoidance rather than dispute settlement", U. Beyerlin, P.-T. Stoll and R. Wolfrum, "Conclusions Drawn from the Conference on Ensuring Compliance with MEAs", in Beyerlin, Stoll and Wolfrum (eds.), supra n. 26, at 369). Furthermore, even though we could demonstrate that the activities of the bodies governing the operation of non-compliance procedures can be compared to those of judicial bodies, we should also demonstrate that the measures of non-compliance bodies are binding (draft Art. 52.3 expressly mentions "decisions binding on the parties"). It is well-known, however, that "decisions taken under compliance control mechanisms generally do not possess any legally binding force", Beyerlin, Stoll and Wolfrum, supra n. 26, at 369). In any case, it is possible to agree with the view according to which: "[...] the findings made in the non-compliance procedure should play an important role in any subsequent dispute settlement proceedings, although they do not possess any binding force. Due to the expertise involved and the Compliance Control Committee's legitimacy, any measure recommended or taken in a non-compliance procedure is likely to have so much weight and persuasiveness that it will have to be respected in any subsequent dispute settlement proceeding. Something like a shifting of the burden of proof should take place in the sense that the findings made under the compliance control mechanism can only be overruled in a subsequent dispute settlement proceeding if they have been rebutted by clear and convincing evidence", ibid. For further considerations, see also Treves, supra n. 21, at 507-509.

${ }^{46}$ UN News Centre, Deadly Toxic Waste Dumping in Côte d'Ivoire Clearly a Crime - UN Environmental Agency, 29 September 2006, available at <http://www.un.org/apps/news/story.asp?NewsID=20083\&Cr $=$ ivoire $\& C r 1=>($ visited 21 April 2008) 
resulting from the transfer of these toxic wastes was not able to establish whether the discharging of waste constituted illegal transboundary movement of hazardous waste under the 1989 Basel Convention. ${ }^{47}$ However, if the dumping had resulted in a violation of the obligations the States of export have under Article 6 of this Convention (for instance, if the transboundary movement of waste had not been previously notified and the State of import had not given its consent), the Côte d'Ivoire could certainly expect from the State of export the re-importation of the toxic waste (as also envisaged by Articles 8 and 9 of the Convention), as well as the rehabilitation of the polluted sites and compensation for damage to the environment and the health of the individuals who have suffered possible injuries (on the basis of general rules of international law). However, nothing could prevent the Côte d'Ivoire from turning directly to the mechanisms of State responsibility, without starting the non-compliance procedure. In particular, as mentioned before, ${ }^{48}$ it is not possible to infer from the text of the Basel Convention that this instrument excludes the application of general international rules on State responsibility. The Secretariat cannot provide assistance to the Parties motu proprio in their identification of cases of illegal trafficking, but only upon request of the Parties (Article 16.1(i) of the Basel Convention). Furthermore, according to the non-compliance procedure adopted under the Basel Convention, a bilateral solution of the matter is clearly preferred. Pursuant to Decision VI/12 which regulates the non-compliance procedure under the Basel Convention, when a failure to comply is submitted by a State, the burden of finding a solution to the matter explicitly falls upon the two interested Parties, through consultations. ${ }^{49}$

Obviously, such situations can easily develop where bilateral conflicts (and this is the case of the Basel Convention) are more likely to occur. It is also true, however, that if we consider other multilateral environmental instruments which have established non-compliance procedures, only the 1979 Convention on Long-Range Transboundary Air Pollution, the Montreal Protocol to the Ozone Convention and the Kyoto Protocol to the United Nations Framework Convention on Climate Change lay down obligations where the identification of an injured Party "particularly affected", or a causal link between the obligation infringed and the detrimental consequences arising from it are very difficult to establish. But it would be inaccurate to exclude $a$ priori the development of bilateral conflicts within other multilateral treaties. Similar situations could be envisaged, for instance, in the case of the violation of certain obligations under the 1991 Espoo Convention on environmental impact assessment (see, e.g., Article 3, concerning notification; Article 4, on the preparation of the environmental impact assessment documentation; and Article 5, regulating consultations) or non-compliance with provisions under the 2000 Cartagena Protocol on Biosafety, governing procedural obligations in the exportation of living organisms.

${ }^{47}$ Report of the Basel Convention Secretariat's Technical Assistance Mission to Côte d'Ivoire (20 November 2006-1 December 2006) in the Context of Decision V/32, doc. UNEP/CHW/OEWG/6/2 (12 July 2007), Annex to Decision VIII/1 on Côte d'Ivoire, para. 3(d).

${ }^{48}$ See supra paragraph 3.

49 Basel Convention NCP, para. 9(b). 


\section{CONCLUding Remarks}

In principle, a good functioning of non-compliance mechanisms excludes the resort to general rules on State responsibility, in so far as the "pathological" phase of States relations, where the traditional rules on the breach of international obligations offer inadequate means, can be avoided. If these mechanisms achieve their purpose, the conduct of a State cannot be characterised as an internationally wrongful act and possible problems in the interpretation of environmental obligations, instead of being dealt with at a bilateral level or by a third independent party, are discussed at a multilateral level, within the supervising bodies specifically established, with the participation of all States Parties to the relevant multilateral treaty or Protocol.

It is also quite clear that certain non-compliance procedures are complementary to general rules on State responsibility. In this case, the ad hoc mechanisms adopted within environmental treaties or protocols are to be added to the instruments of classic international law. As a result, States can avail themselves of a greater number of remedies to overcome the structural limits of the international society and its legal order. At any rate, it would be highly desirable for the monitoring bodies operating under certain environmental agreements, and in particular the Conference of the Parties, to play a special active role when the risk of a possible fall-back onto the general regime on State responsibility begins to take shape. A further strengthening of cooperation among Contracting Parties is preferable to any unilateral action, albeit lawful under general international law, both for the dangerous and unpredictable consequences of certain unilateral measures and for the necessity to preserve as far as possible the rationale for which specific non-compliance mechanisms have been adopted under certain environmental agreements.

Given this premise, any attempt to foresee all the possible situations in which a State Party to a multilateral environmental treaty or protocol is entitled to invoke the rules of general international law on State responsibility, despite the existence of noncompliance mechanisms, is a very complicated effort. A fall-back on general international law after the "failure" of these special mechanisms is the most plausible hypothesis, but there are also cases which do not arise from this hypothesis. In any case, each situation should be assessed on a case-by-case basis, taking into account the wording of the relevant treaty, its object and purpose, the general rules on the interpretation of international treaties and the rules governing a specific non-compliance procedure. In other words, an assessment on a case-by-case basis is necessary, in view of the variety of interests pursued by different environmental instruments and the situation of the particular case. In the end, considering the determining role of the willingness to cooperate of the States Parties to a multilateral environmental treaty, as the practice of non-compliance mechanisms - which are not perfect, but very flexible and pragmatic instruments - well shows, coordination between non-compliance mechanisms and general rules on State responsibility is a problem which is unlikely to be properly dealt with and solved in a satisfactory manner at an abstract level. 
1 


\title{
Chapter Twenty-Eight
}

\section{The Settlement of Disputes and Non-Compliance Procedures}

\author{
Tullio Treves
}

\section{INTRODUCTION}

Specific provisions for the settlement of disputes are set out for all the multilateral environmental agreements to which a non-compliance procedure is applicable. It seems interesting to examine these provisions in order to determine whether they can be of some use, and if so, in which circumstances. The very coexistence of these provisions with the non-compliance procedures indicates that there is a difference between the two. This raises a number of questions: do they work alternatively or cumulatively? Do the dispute-settlement mechanisms have a real role in the light of the obligations set out in multilateral environmental agreements? May other disputesettlement procedures apply? Are these procedures more or less helpful than those set out in the specific provisions of the environmental agreements?

\section{Dispute-Settlement Provisions of Environmental Agreements Providing For Non-Compliance Mechanisms}

\subsection{The Model Followed and the Variants Set Out in the Different Agreements}

The dispute-settlement provisions of the environmental agreements here considered are not identical. Most of them seem, nonetheless, to be based on the same model consisting of a relatively complex clause of which some agreements adopt all and others only some elements. The provisions adopting the complete model contain, with some variations in detail, the following elements: a) a paragraph providing that, in the event of a dispute between two or more Parties concerning the interpretation or the application of the relevant agreement, the Parties concerned shall seek a settlement of the dispute through negotiations or any other peaceful means of their choice; b) one or more paragraphs providing that each Party, when ratifying, accepting, approving or acceding to the relevant agreement, or at any time thereafter, may declare that, in relation to any Party accepting the same obligation, it recognizes, as a means for the compulsory settlement of disputes concerning the interpretation or application of the

T. Treves et al., eds., Non-Compliance Procedures and Mechanisms and the Effectiveness of International Environmental Agreements

(C) 2009, T.M.C. ASSER PRESS, The Hague, The Netherlands, and the Authors 
agreement, the submission of the dispute to the International Court of Justice, or to arbitration, or to both; c) one or more paragraphs providing that, when the Parties to the dispute have not accepted the same means of settlement as mentioned above, the dispute may be submitted, at the request of any of them, to conciliation.

This model has been adopted in full in a first group of environmental agreements, ${ }^{1}$ while a second group adopts the first two of the three elements mentioned above, omitting the third, compulsory conciliation. ${ }^{2}$ The agreements of the third group adopt only the first element, namely the commitment to seek solutions through negotiation and other means chosen by the Parties. ${ }^{3}$

A fundamental aspect common to all these provisions is that none of them provides for compulsory settlement by arbitration or by a permanent international tribunal. In other words, none of them provides that in all cases such arbitral or judicial settlement mechanism may be seized of a case at the initiative of one of the Parties to the dispute.

A different pattern is followed, nevertheless, in three agreements which provide that the dispute may be submitted to an arbitral tribunal at the initiative of one Party. The first is the London Dumping Protocol 1996 amending the 1972 Convention. While the first element set out in Article 16 corresponds to that of the other agreements mentioned, the basic rule here is compulsory arbitration, which can be derogated by agreement of the Parties in favor of the dispute-settlement provisions of the Law of the Sea Convention (which, as is well-known, also include the possibility of settlement by permanent judicial bodies, see Article 287). Compulsory settlement may, however, be unilaterally excluded by a declaration. The second is the OSPAR Convention which provides that in the case that disputes cannot be settled "otherwise" by the Parties, "for instance by means of inquiry or conciliation", they can be submitted at the request of one Party to arbitration (Article 32). The third is the Protocol concerning the Settlement of Disputes to the Alpine Convention. Under this protocol, when consultations do not lead to a settlement within six months, one Party can submit the dispute to an arbitral tribunal.

\section{2 "Negotiation" and other Peaceful Means of the Parties' Choice}

A good example of the clause constituting the first element of the above-mentioned model, and that, with a few variations, is present in all the agreements here examined, is Article 14.1 of the UNFCCC. It provides that the Parties to a dispute "shall seek

\footnotetext{
1 This group includes the Vienna Ozone Convention, Art. 11 (applicable also to the Montreal Protocol), the Convention on Biological Diversity, Art. 27 (applicable also to the Cartagena Protocol); the UNFCCC, Art. 14 (applicable also to the Kyoto Protocol); four of the Protocols to the LRATP Convention (the Second Sulphur LRATP Protocol, Art. 9; the Heavy Metals LRTAP Protocol, Art. 11; the VOC Protocol, Art. 12; the Acidification Protocol, Art. 11); the Rotterdam PIC Convention, Art. 20; the Stockholm POPs Convention, Art. 18; and the ITPGRFA, Art. 22. A list of treaties with full references is provided supra at XXXVII.

2 This group includes the Basel Convention, Art. 20; the Espoo Convention, Art. 15; the Barcelona Convention, Art. 22; the Aarhus Convention, Art. 16; and the Protocol on Water and Health, Art. 20.

3 This group includes the LRTAP Convention, Art. 13 and four of its early Protocols (the EPER LRTAP Protocol, Art. 7; the First Sulphur LRTAP Protocol, Art. 8; the NOx LRTAP Protocol, Art. 13; the VOC LRTAP Protocol, Art. 12).
} 
a settlement of the dispute through negotiation or any other peaceful means of their own choice."

This provision, and the others mentioned above that are similarly couched, echoes Article 33.1 of the UN Charter as well as a number of provisions in other conventions, such as Articles 279-280 of the Law of the Sea Convention. It gives priority to negotiation, the "diplomatic" method of seeking settlement most used in practice. It does not mention other diplomatic methods such as good offices or mediation by a third Party which, for instance, the Vienna Ozone Convention and the Convention on Biological Diversity indicate as a possibility open to the Parties, if negotiation is unsuccessful. ${ }^{4}$ This does not mean, however, that these methods are excluded. The Parties may always agree to utilize them. These procedures are in any case included in the notion of "any other means of their own choice", as well as in the notion, put forward in some conventions, of "other methods of dispute-settlement acceptable to the parties to the dispute". ${ }^{5}$

The last mentioned "other" means are not only "diplomatic" methods of settlement, namely methods whose aim is to facilitate settlement by agreement between the Parties. They include also "judicial" or "arbitral" settlement, in other words, settlement by a permanent court or tribunal or by an arbitral tribunal set up for the purpose of the particular dispute. In this case the settlement is reached through a judgment or award. Consequently, a binding settlement is a possibility under this clause only on the basis of agreement of the Parties to the dispute, and not as a result of a procedure which can be triggered unilaterally by one Party.

\subsection{Optional Compulsory Adjudication: ICJ and Arbitration}

Settlement by a judge or arbitrator whose decision is binding as the result of a procedure that can be triggered by one Party to the dispute is provided in the second element of the model considered. This element, as mentioned, is set out in the vast majority of the agreements considered. Nevertheless, compulsory adjudication or arbitration is made dependent on specific optional declarations that Parties may submit in writing to the depositary. The mechanism bears some similarity to those set out in Article 36.2 of the Statute of the ICJ and in Article 287 of the Law of the Sea Convention, although it is far less complete and strict.

According - for instance - to Article 14.2 UNFCCC, a Party may state in a declaration that:

"in respect to any dispute concerning the interpretation and application of the Convention, it recognizes as compulsory ipso facto and without special agreement, in relation to any Party accepting the same obligation:

(a) Submission of the dispute to the International Court of Justice and/or

(b) Arbitration in accordance with procedures to be adopted by the Conference of the Parties as soon as practicable, in an annex on arbitration."

\footnotetext{
${ }^{4}$ Vienna Ozone Convention, Art. 11; Convention on Biological Diversity, Art. 27.2.

${ }^{5}$ For instance, LRTAP Convention, Art. 13; Aarhus Convention, Art. 16.1; Espoo Convention
} Art. 15.1. 
This provision, in making the jurisdiction of the ICJ or of an arbitral tribunal compulsory ipso facto for disputes between Parties that accept, through their declarations, the same obligation, follows the pattern of the "optional clause" of Article 36.2 of the ICJ Statute. In allowing a choice between the ICJ and arbitration, it adopts a mechanism initiated (in a more elaborate way) in Article 287 of the Law of the Sea Convention and found also in other conventions. In the UNFCCC and in some other conventions, as in the Law of the Sea Convention, the option for the ICJ is not open to "regional economic integration organizations" (in practice: the European Community), ${ }^{6}$ because under the ICJ Statute the Court is open only to States (Article 34).

The effectiveness of this clause is far from certain. First of all, its applicability depends on the fact that all Parties to a dispute have "accepted the same obligation". This means that they have made the "optional" declaration, and secondly, that they have recognized the jurisdiction of the same court, in other words, that all Parties to the dispute have indicated at least as one of their choices (as there is the possibility to indicate both) either the ICJ or arbitration. Some agreements, such as the Espoo and Aarhus Conventions, specify that when the Parties to the dispute have chosen both arbitration and the ICJ, "the dispute may be submitted only to the International Court of Justice, unless the Parties agree otherwise." Secondly, there is no indication as to the consequences of the fact that two Parties to the dispute have not made the same choice. It would seem that, when one Party has indicated the ICJ and the other arbitration, they have not accepted "the same obligation", so that there is no compulsory adjudication, even though both Parties have made clear their preference for a compulsory means of settlement. The only possibility to obtain a result which would correspond to such common preference of the Parties would seem to be that a claimant Party would start the dispute before the adjudicating body chosen by the defendant, and that the defendant (that, because of its choice, may be deemed to favour adjudication at the request of one Party) does not object to the lack of jurisdiction, so that jurisdiction can be established through the mechanism of forum prorogatum.?

These difficulties may explain why States Parties have not rushed to take advantage of the right to make the declarations. In fact the declarations made under the relevant clauses of the environmental agreements here examined are extremely few. To quote just some examples, the UNFCCC has attracted only five declarations (the European Community, Finland, the Netherlands, Norway and Sweden), and so have the Basel and the Stockholm POPs Conventions (Albania, Cuba, Norway, Poland and St. Kitts and Nevis, and Austria, Bahrain, Liechtenstein, Moldova and Micronesia

\footnotetext{
${ }^{6}$ See the definition in Art. 1.6 UNFCCC, and compare with Art. 1 of Annex IX of the Law of the Sea Convention.

7 Admittedly, this mechanism would seem less likely to succeed than the similar one that could be envisaged, in the framework of the Law of the Sea Convention, in the case that the Parties to a dispute have declared, under Art. 287, their preference for two different means of compulsory settlement. In such a case divergent choices do not exclude compulsory adjudication. As compulsory arbitration is provided as a "default solution" (Art. 287, paras. 3 and 5), in the case of different choices, submitting the dispute to the preferred means of settlement of the defendant entails a strong possibility of forum prorogatum. In the case of the here examined clauses in environmental agreements, non-acceptance by the defendant of submission of the dispute to its preferred adjudicating body entails that there is no adjudicating body competent to hear the case, which may well be the outcome the defendant wishes.
} 
respectively); of the four protocols to the LRTAP Convention that provide for these declarations two have attracted two declarations, one three and one none. ${ }^{8}$

\subsection{Compulsory Conciliation}

A good example of the provisions setting out the third of the elements mentioned above is Article 14.5 UNFCCC. It states that:

"if, after three months following notification by one party to another that a dispute exists between them, the Parties concerned have not been able to settle their dispute through the means mentioned in paragraph 1 above, the dispute shall be submitted, at the request of any of the parties to the dispute, to conciliation."

In other words, failing negotiation or other diplomatic means on which the Parties could agree (it is less likely that agreed judicial or arbitral settlement would fail), a Party is entitled to submit the dispute to conciliation. This is a case of what is often called "compulsory conciliation": as is normal in conciliation, the report of the conciliator remains non-binding for the Parties, but once a Party triggers the procedure, all Parties are submitted to it. This method is used in a number of conventions for the codification and progressive development of international law, including the Law of the Sea Convention. ${ }^{9}$

The version of this method set out in Article 14.5 UNFCCC is particularly strict, as the three-months time-limit (not found in other conventions) starting from notification of the existence of the dispute is very short. The possibility that the Party making such notification starts a conciliation procedure within such a short time may serve as a powerful incentive for inducing the other Party or Parties to negotiate in good faith or to seek, in good faith also, to agree on other methods for settling the dispute.

Conciliation is not, of course, a method that unavoidably brings the dispute to a settlement, as Parties are always entitled not to accept the solution suggested by the conciliation commission in its report. Because of the pressure exercised on Parties by the prospect of being brought before a conciliation commission one should, nevertheless, not underestimate its importance for bringing the Parties to settlement, either through acceptance of the report of the conciliation commission, or through agreement reached otherwise. Such pressure depends on what a conciliation procedure may entail for the Parties to it an effort comparable to what they would have to produce for a case before an international judge or arbitrator. The legal and factual arguments may have to be fully presented, evidence may have to be gathered, legal and

\footnotetext{
${ }^{8}$ The declarations of Cuba under the Basel and under the Climate Change conventions state that any dispute "shall be settled through negotiation through the diplomatic channel". It may be questioned whether such declaration (in the light of the prohibition of reservations in both conventions) can exclude recourse to "compulsory" conciliation, once three months have elapsed without success of the negotiations, see infra paragraph 2.4).

${ }^{9}$ See T. Treves, Le controversie internazionali, Nuove tendenze, nuovi tribunali (Milano: Giuffré,1999), at 27-30 and 171-193; Id., "'Compulsory' Conciliation in the U.N. Law of the Sea Convention", in V. Goetz, P. Selmer and R. Wolfrum (eds.), Liber Amicorum Guenther Jaenicke Zum 85. Geburtstag (Berlin: Springer, 1998) 611-629.
} 
diplomatic talent may have to be utilized. "Compulsory" conciliation procedures provided in some recent treaties are very similar to arbitration procedures, including the fact that they provide for consideration of the legal aspects of the dispute by the conciliation commission. ${ }^{10}$ The remaining, and essential, difference with arbitration is the non-binding character of the end result. As stated in the last sentence of Article 14.6 UNFCCC, "[t]he [conciliation] commission shall render a recommendatory award, which the parties shall consider in good faith."11

Certainly, this non-binding character makes conciliation a weaker, less frightening method for settlement than arbitration or submission to a permanent international court. At least in certain circumstances, it may, nevertheless, entail political drawbacks making it less attractive than adjudication. Especially when conciliation is not secret, and international and domestic public opinion is aware of the suggested terms of settlement, the choice whether to accept the report of the conciliator or to reject it may be even harder than the decision to submit the dispute to arbitral or judicial settlement. From this angle, compulsory conciliation as provided in Article 14.5 UNFCCC may weigh heavily as a deterrent against attempts to prolong negotiations and to avoid reaching a settlement. It is worth mentioning, in this context, that "compulsory conciliation" has never been resorted to in practice, be it on the basis of provisions of environmental agreements or of other agreements.

The agreements here envisaged generally give some indications about the composition of the conciliation commission. For instance, Article 14.6 UNFCCC (following Article 11.11 of the Vienna Ozone Convention) states:

"A conciliation commission shall be created upon the request of one of the parties to the dispute. The commission shall be composed of an equal number of members appointed by each party concerned and a chairman chosen jointly by the members appointed by each party."

Only rarely do the agreements provide for an appointing authority in case one side does not designate its conciliator or conciliators or the designated conciliators do not agree on the president of the commission. The Secretary-General of the UN is entrusted with this function in Article 3 of Annex II on conciliation to the Convention on Biological Diversity. The lack of appropriate provisions on this subject may create difficulties in the practical functioning of this mechanism. Further practical difficulties may be eliminated by specific annexes on conciliation that the COPs may adopt.

${ }^{10}$ Law of the Sea Convention, Annex V, especially Art. 7.1. OSCE Convention on Conciliation and Arbitration, Art. 24

${ }^{11}$ See also, with identical wording: Vienna Ozone Convention, Art. 11.5. The four Protocols to the LRTAP Convention that provide for compulsory conciliation (see supra $\mathrm{n}$. 3) add to the above quoted sentence that "the Parties to the dispute shall consider in good faith" the recommendatory award (see, for instance, Acidification LRTAP Protocol, Art. 11.6). Art. 18.6 of the Stockholm POPs Convention and Art. 20.6 of the Rotterdam PIC Convention similarly provide that: "The conciliation commission shall render a report with recommendations". 
3. The Relationship between Dispute-Settlement and Non-Compliance Procedures under EnVIRONMENTAl AgreEments

\subsection{The "Without Prejudice" Clauses}

While the environmental agreements contain provisions for the settlement of disputes and for the establishment of a non-compliance mechanism, they do not envisage the question of the relationship between the two. This question was raised in the negotiations for the establishment of the non-compliance procedures concerning the Montreal Protocol to the Ozone Layer Convention. The result of the discussions is a clause to be found in the provisions setting up all the non-compliance mechanisms envisaged. In the Montreal Protocol non-compliance procedure it is as follows:

"[t]he following procedure [...] shall apply without prejudice to the operation of the settlement of disputes procedure laid down in Article 11 of the Vienna Convention." 12

The only further elaboration in legal texts concerning the "without prejudice" clauses is in the Montreal and in the Espoo non-compliance mechanisms. In the Montreal mechanism we may quote two provisions. Paragraph 12 states that:

"The Parties involved in a matter referred to in paragraphs 1, 3 or 4 shall inform, through the Secretariat, the Meeting of the Parties of the results of proceedings taken under Article

${ }^{12}$ Introductory "chapeau" to Decision IV/5 on Non-Compliance Procedure, doc. UNEP/OzL.Pro.4/15 (25 November 1992), at 13 and Annex IV at 44, subsequently amended by Decision X/10 on Review of the Non-Compliance Procedure, doc. UNEP/OzL.Pro.10/9 (3 December 1998), at 23 and consolidated text in Annex II (Montreal Protocol NCP), at 47. See also para. 27 of the Basel Convention NCP (Decision VI/12 on Establishment of a Mechanism for Promoting Implementation and Compliance, Appendix doc. UNEP/ CHW.6/40 (10 February 2003), at 45); section XVI of the Kyoto Protocol NCP (Decision 27/CMP.1 on Procedures and Mechanisms Relating to Compliance under the Kyoto Protocol, doc. FCCC/KP/CMP/2005/8/ Add.3 (30 March 2006), at 92); preamble to the Cartagena Protocol NCP (Decision BS-I/7 on Establishment of Procedures and Mechanisms on Compliance under the Cartagena Protocol on Biosafety, doc. UNEP/CBD/BS/COP-MOP/1/15 (27 February 2004), Annex I, at 98); para. 12 of the LRTAP Convention NCP (Decision 1997/2 Concerning the Implementation Committee, its Structure and Functions and Procedures for Review of Compliance, doc. ECE/EB.AIR/53 (7 January 1998), Annex III, at 28, subsequently amended. Consolidated text in Decision 2006/2 on Implementation Committee, its Structure and Functions and Procedures for Review, doc. ECE/EB.AIR/89/Add.1 (5 February 2007), at 4); para. 14 of the Espoo Convention NCP (Decision II/4 on Review of Compliance, doc. ECE/MP.EIA/4 (7 August 2001), Annex IV, at 72 revised by Decision III/2 on Review of Compliance, doc. ECE/MP.EIA/6 (13 September 2004), Annex II (consolidated text); para. 39 of the Aarhus Convention NCP (Decision I/7 on Review of Compliance, doc. ECE/MP.PP/2/Add.8 (2001, subsequently issued on 2 April 2004); section 4.4 of the Alpine Convention NCP (Decision VII/4 Mécanisme de verification du respect de la Convention alpine et de ses protocols d'application (2002), reprinted in Envt'l Po' $y$ \& L. (2003) 179), with a slightly different formulation, mentioning the "independent" character of the non-compliance procedure as regards the dispute-settlement procedure and that it has no prejudicial effects on such procedure; para. 36 of the Barcelona Convention NCP (Decision IG 17/2 on Procedures and Mechanisms on Compliance under the Barcelona Convention and its Protocols, doc. UNEP(DEC)/MED IG. 17/10 (18 January 2008), Annex 5, at 21). The "without prejudice" clause is also set out in the Draft NCPs of the Rotterdam PIC Convention (Decision RC-3/4 Draft text of the Procedures and Mechanisms on Compliance with the Rotterdam Convention, doc. UNEP/FAO/RC/ COP.3/26 (10 November 2006), Annex, at 27, para. 30) and of the Stockholm POPs Convention (Decision SC-3/20 on Non-Compliance, doc. UNEP/POPS/COP.3/30 (4 May 2007), Annex, at 57, para. 37). 
11 of the Convention regarding possible non-compliance, about implementation of those results and about implementation of any decision of the Parties pursuant to paragraph 9."

This provision requires that Parties involved in a pending non-compliance procedure ensure publicity in the forum of the meeting of States Parties of the result of disputesettlement procedures "regarding possible non-compliance". This sentence seems to imply that the results of traditional dispute-settlement procedures may concern noncompliance and that the COP/MOP may take decisions regarding the impact of the "result" of the dispute-settlement procedure on the pending non-compliance procedure.

As regards the converse case of a pending dispute-settlement procedure, paragraph 13 of the Montreal Protocol procedure provides that "[t]he Meeting of the Parties may, pending completion of proceedings initiated under Article 11 of the Convention, issue an interim call and/or recommendations." It may be wondered whether the interim call or recommendations should serve to ensure that the non-compliance procedure is not prejudiced, or that the compliance procedure does not prejudice the results of the dispute-settlement procedure.

Paragraph 15 of the Espoo Convention non-compliance procedure, which follows the usual "without prejudice" clause in paragraph 14, states that "[w] here a matter is being considered under an inquiry procedure under Article 3, paragraph 7, of the Convention, that matter may not be the subject of a submission under this decision." This provision concerns a situation in which the environmental impact mechanism provided for in the Convention is blocked by a disagreement as to whether one Party is affected by the significant transboundary impact of a proposed activity. It states that when such a disagreement is brought to a commission of inquiry - whose decision seems conclusive within the system of the Convention - the non-compliance system cannot be activated.

Independently of the special clauses just mentioned, the "without prejudice clauses", while providing that non-compliance procedures shall not prejudice disputesettlement procedures, do not mention the converse situation. As these clauses are set out in COP/MOP decisions and not in the agreements, it could not be otherwise. Their main function is to make sure that a procedure established by a decision of the COP/ MOP does not entail negative effects on procedures set out in the basic agreement. To state in a COP/MOP decision that the dispute-settlement procedures shall be without prejudice to the non-compliance procedures would be an attempt to change the agreement. It seems nevertheless fair to raise the question whether a pending non-compliance procedure may have an impact on a dispute-settlement procedure and whether the results of a concluded non-compliance procedure may have an impact on a pending dispute-settlement procedure.

The answers to these questions must be sought from the point of view of the dispute-settlement procedure based on the main agreement. The answers to the corresponding questions based on the "without prejudice" clauses must be sought from the point of view of the relevant agreement and of its non-compliance mechanism. 


\subsection{The Relationship between Dispute-Settlement and Non-Compliance Procedures from the Point of View of the Dispute-Settlement Bodies}

Let us take first the question whether and how a dispute-settlement body to which a dispute has been submitted under a multilateral environmental agreement has to take into account the fact that a non-compliance procedure is pending as regards one of the Parties to the dispute. It may be wondered whether lis pendens or a similar concept can be invoked in order to suspend or interrupt the dispute-settlement procedure. It would seem that a negative answer is in order. In a number of cases, the non-compliance procedure may not be based on a dispute between the same Parties, as it may have been self-triggered, or triggered by a Secretariat or by other subjects. Secondly, its object may not be identical to that submitted to the dispute-settlement body (for instance, "potential non-compliance" can sometimes be submitted to non-compliance mechanisms, while this is not the case for dispute-settlement mechanisms). Even in cases in which the non-compliance mechanism has been triggered by the same Party that has started the dispute, and even when the subject-matter appears to be the same - the non-compliance or breach of the main agreement, assuming that the two notions coincide - the petitum is likely to be different as breach of a treaty provision involves responsibility and its consequences, while the request for a decision of noncompliance aims at obtaining different results, in general more cooperative than confrontational, and not necessarily to be kept within the scope of what is requested. A dispute-settlement procedure aiming at obtaining a declaratory judgment stating that a State has breached (or not complied with) an obligation under the agreement might seem the closest approximation. It would, nonetheless, be different as the applicable standards for State responsibility under general international law (attribution, circumstances precluding wrongfulness, etc.) may not be the same as the standards applicable in the non-compliance procedure. ${ }^{13}$

In conclusion, there would be no legal reason for the dispute-settlement body to suspend or interrupt the proceedings. Nevertheless, it cannot be excluded that, in the exercise of its judicial discretion, for reasons of opportunity, and in the light of what will be said below concerning concluded non-compliance procedures, the dispute-settlement body may decide to postpone its decision awaiting the conclusion of the noncompliance body. It seems unlikely, however, that this decision would be made without obtaining the agreement of the Parties or, at least, without consulting them.

The second question concerns the relevance, from the point of view of the disputesettlement body, of a concluded non-compliance procedure involving a Party to the dispute. In particular, will a statement by the non-compliance body that a Party to the dispute has not complied with an obligation set out in a provision of the relevant agreement have an effect on the procedure for the settlement of a dispute concerning the breach of that provision? It must be stated, at the outset, that a conclusion adopted

\footnotetext{
13 Consequently I do not find persuasive the argument put forward by M. Koskienniemi, "Breach of Treaty or Non-Compliance? Reflections on the Enforcement of the Montreal Protocol", YB Int'l Envt'l L., 3 (1992) 123-161, at 158, according to which the Party that has promoted the non-compliance procedure would be estopped from invoking dispute-settlement procedures as in this situation there would be "lis pendens in the strict sense" assuming that the subject-matter would be the same in the two cases.
} 
by a non-compliance body that a certain State Party has not complied with a provision of the agreement cannot be considered as res judicata from the point of view of a dispute-settlement body, even when the non-compliance procedure has been triggered by the plaintiff in the dispute-settlement procedure against the defendant. Independently of the view one takes on whether the notion of res judicata applies as between decisions of different adjudicating bodies, this depends on the lack of judicial character of the non-compliance procedure, and on the different criteria for establishing noncompliance.

It would, nonetheless, be absurd that the work of the non-compliance body and its conclusions were to be wholly irrelevant for the dispute-settlement body. Existing rules of international law permit this result to be avoided. A dispute-settlement body has to base its decision on the applicable law within the scope of its jurisdiction. These two parameters are basically covered by the fact that the disputes that may be submitted to the dispute-settlement bodies under an environmental agreement must concern "the interpretation or application" of that agreement. General rules of international law are, however, to be considered as applicable as well (for instance those on the law of treaties or on State responsibility); moreover, in the interpretation of the agreements, under Article 31.3(c) of the Vienna Convention on the Law of Treaties "there shall be taken into account $[. .$.$] any relevant rules of international law applica-$ ble in the relations between the parties."

In my view, the dispute-settlement body can take into account the decisions of the compliance body of the treaty as relevant rules of international law applicable in the relations between the Parties. Admittedly, it may be questioned whether the decisions of the non-compliance bodies are "rules". That their binding effect is questionable and questioned, at least in a number of non-compliance procedures, should not always be seen as a serious objection, as the rules mentioned in Article 31.3(c) of the Vienna Convention may, at least in my view considering the interpretative function of the rule, be of a "soft law" character, as far as it can be determined that the Parties to the treaty have accepted their contents. ${ }^{14}$ The flexibility inherent in the fact that the dispute-settlement body has to "take into account" and not to "apply" these "rules", and that this is to be done in order to interpret the substantive rules to be applied and not as an addition to their application, makes it possible to consider the results of the noncompliance procedure as normative materials that may have an effect on the decision of the dispute-settlement body. It seems fair to add that the dispute-settlement body, in "taking into account" the non-compliance decision of the compliance body, should not stop at the mere notion of non-compliance and yield to the temptation to consider it automatically equivalent to a determination of breach. It should consider it in its context, including the criteria followed by the compliance body to ascertain non-compliance, the procedural guarantees and the purposes of the procedure. This would not be an intrusion by one body in the purview of another. It would be a necessary check in order to ascertain the effective content of normative material from which the

${ }^{14}$ See the dissenting opinion of Gavan Griffith QC, Award of 2 July 2003 of the Arbitration Tribunal concerning access to information under Art. 9 of the OSPAR Convention, Ireland v. United Kingdom, in $42 \operatorname{ILM}$ (2003), 1118 at 1161-1165. The Award (para. 103) seems to exclude "material that has not become law". 
dispute-settlement body may determine whether and within which limits it would take it into account. This would also have as a consequence that the differences between the various non-compliance mechanisms would be taken into account: the more similar to a judicial proceeding these mechanisms are, as is the case of the Kyoto Protocol mechanism as regards its Enforcement Branch, ${ }^{15}$ the more relevance the findings reached within them will have as international law in force between the Parties.

In cases - such as that of the Aarhus Convention - in which the determinations of the compliance body are submitted for adoption to the COP/MOP, these determinations may also be seen by the dispute-settlement body as "subsequent practice in the application of the treaty which establishes the agreement of the Parties regarding its interpretation" under Article 31.3(b) of the Vienna Convention on the Law of Treaties. The decision of the COP/MOP may be seen as a form of agreement of the Parties. Provided its contents impinge on the interpretation of the agreement, the dispute-settlement body may take it into account in order to develop its own interpretation of the agreement.

\subsection{The Relationship between the Dispute-Settlement and the Non-Compliance Procedures from the Point of View of the Non-Compliance Bodies}

From the viewpoint of the compliance body, does the fact that a dispute is pending before a dispute-settlement body have any consequences? In light of the lack of effect that a pending non-compliance procedure has on a dispute-settlement procedure, the non-compliance procedure can continue without any risk of prejudicing the disputesettlement procedure. The above-mentioned paragraph 11 of the Montreal Protocol non-compliance mechanism does not seem to be necessary in order to protect the dispute-settlement procedure. It seems significant that it has not been repeated in other non-compliance mechanisms. Would there, nonetheless, be reason to suspend the non-compliance procedure in order to await the results of the dispute-settlement procedure?

In principle, there would seem to be no legal reason to preclude the non-compliance body from exercising its discretion and waiting for the decision of the

${ }^{15}$ See L. Boisson de Chazournes and M.M. Mbengue, "A propos du caractère juridictionnel de la procédure de non-respect du Protocole de Kyoto”, in S. Maljean-Dubois (ed.), Changements climatiques, les enjeux du contrôle international (Paris: La Documentation Française, 2007) 73-109, for arguments showing that the Kyoto Protocol NCP (especially as regards the Enforcement Branch) meets most of the requirements needed to pass a "test de la juridictionnalité". While practically all these arguments seem well founded in pointing at similarities between the Kyoto Enforcement Branch and judicial or arbitral proceedings, it seems to the present writer that some main differences remain. In particular the possibility of self-trigger (which sets in motion a proceeding that is not different from those that can be triggered otherwise) seems very relevant in showing that, if one wishes to say that what is brought before the Enforcement Branch is a "dispute", it is very different from the dispute that brings cases to international judges and arbitrators. Another relevant difference is the kind of decision that may be taken by the Enforcement Branch, different from those a judge or arbitrator usually takes, or is entitled to take, as mentioned further on in the text. Thirdly, there is the fact, mentioned also by Boisson de Chazournes and Mbengue (at 85), that the Kyoto Protocol NCP (like other non-compliance mechanisms) may remain blocked by a failure to reach the required qualified majority derogating from the trend to avoid non liquet that is common to all judicial and arbitral procedures. 
dispute-settlement body. ${ }^{16}$ There may be practical reasons for its doing so. These reasons are connected to the relevance of the decision taken by the dispute-settlement body for the compliance procedure.

On the one hand, there would be no legal reason to consider that a decision on a dispute that one of the Parties to it has breached a provision in the agreement is automatically conclusive as to the "non-compliance" with such provision: the multilateral character of the non-compliance mechanism, even when triggered by one State Party as regards the alleged non-compliance of another, justifies this view. On the other hand, it would be absurd for the compliance body to fail to take into account the decision of the dispute-settlement body. The legal and factual determinations of the dispute-settlement body may be helpful materials for its decisions.

The decision of the compliance body will remain, nevertheless, a separate independent one. This seems particularly necessary in light of the fact that the consequences of the breach ascertained by the dispute-settlement body are unlikely to overlap with those the compliance body (or the COP/MOP) may recommend as consequences of non-compliance. The latter consequences are different from those a judge or arbitrator could decide. They are of a cooperative nature and, usually, cannot be assimilated to reparation or to satisfaction. When they consist of sanctions within the system of the agreement, they go beyond what a judge or arbitrator is entitled to prescribe as a consequence of the breach. A significant example are the decisions that may be taken by the Enforcement Branch of the Kyoto Protocol Compliance Committee, even though the procedure before such branch may be seen, among the noncompliance procedures, as the most similar to a judicial or arbitral one. The effects of a decision of non-compliance by the Enforcement Branch may consist of the suspension of the eligibility of the Party under Articles 6,12 and 17 of the Protocol, and of the further "consequences applied by the Enforcement Branch". These consequences include the adoption of a plan stating the measures to remedy non-compliance and the timetable for their implementation, and the "compliance action plan" concerning noncompliance with emissions obligations to be submitted by the non-complying Party mentioned in section XV of the Non-Compliance Procedure.

Exceptions to the separate character of the dispute-settlement and of the non-compliance procedure can be introduced through provisions of the non-compliance mechanism. These may give priority to a dispute-settlement procedure and relevance to its results. This seems to be the case of the above quoted paragraph 15 of the Espoo Convention's non-compliance mechanism. Under this provision no resort to the non-compliance procedure is allowed pending the settlement of a dispute of a bilateral nature, through an inquiry procedure set out in the same Convention, ${ }^{17}$ on a question whose solution could be a necessary premise for a decision of the non-compliance body. It must be underscored that, while the Espoo Convention non-compliance mechanism

${ }^{16}$ In the view of Koskienniemi, supra n. 13, 159, if the case has been submitted to binding arbitration or to the International Court of Justice "it would seem to be inappropriate to allow the continuation of proceedings within the Implementation Committee to the stage that a de facto determination of a Party's compliance or non-compliance is being made."

${ }_{17}$ The bilateral character of the dispute submitted to the Inquiry Procedure emerges clearly in Art. 3.6, and in Annex IV (setting out rules on the Inquiry procedure) of the Espoo Convention. 
provides, in addition to self-triggering, triggering by "one or more Parties to the Convention that have concerns about another Party's compliance with its obligations under that instrument" (paragraph 5(a)), the structure of the obligations in the convention is basically bilateral as such obligations oppose an "affected Party" to a "Party of origin". ${ }^{18}$ It is noteworthy that in the only case in which an inquiry procedure has been held under the Espoo Convention ${ }^{19}$ its effect went beyond precluding the noncompliance procedure under that convention. The Aarhus Convention's Compliance Committee decided to wait for its results before continuing a procedure concerning the same project that was pending before it. ${ }^{20}$

Another exception seems to be that set forth in Article 9(b) of the Basel Convention's non-compliance instrument. According to this provision, a submission may be made by

"[a] Party that has concerns or is affected by a failure to comply with and/or implement the Convention's obligations by another Party with whom it is directly involved under the Convention. A Party intending to make a submission under this subparagraph shall inform the Party whose compliance is in question, and both Parties should then try to resolve the matter through consultations."

In this other case in which the obligations can be seen as bilateral, a bilateral disputesettlement method (consultations) is given priority over the non-compliance procedure.

\subsection{Diplomatic and Binding Dispute-Settlement Procedures and Non-Compliance Procedures}

In referring to a "pending procedure" and to a "decision" of the dispute-settlement body we have assumed that this is a procedure aimed at reaching a binding decision of a judge or arbitrator. We know, however, that under the clauses for the settlement of disputes of the agreements here considered, the possibility of obtaining such a binding decision depends on the agreement of the Parties, or on a very unlikely combination of unilateral declarations. It follows that what will be at hand, in most cases, are "diplomatic" procedures aimed at helping the Parties to reach agreement for the settlement of the dispute, the most formal of which is conciliation. In these cases,

\footnotetext{
${ }^{18}$ As defined in Art. 1(iii) and (ii) of the Espoo Convention.

${ }^{19}$ See Espoo Enquiry Commission, Report on the likely significant adverse transboundary impacts of the Danube-Black Sea Navigation Route at the Border of Romania and the Ukraine, July 2007 in <www. unece.org/env/eia/documents/inquiry/Final\%Report\%2010\%20July\%202006.pdf> (visited 15 July 2008), and the UNECE Press release of 10 July 2006, <www.unece.org/press/pr2006/06env p05e.htm> (visited 15 July 2008)

${ }^{20}$ See Report on the Seventh Meeting, doc. ECE/MP.PP/C.1/2005/2/Add. 3 (14 March 2005), para. 8; and Report on the Third Meeting, doc. ECE/MP.PP/C.1/2006/6 (16 November 2006), para. 11, as well as Decision II5b on Compliance by Ukraine with its obligations under the Aarhus Convention, doc. ECE/ MP.PP/2005/2/Add.8 (13 June 2005). More details in T. Treves, "Fragmentation of International Law: The Judicial Perspective", in Comunicazioni e Studi, 23 (2007) 821-875, at 867-868; C. Pitea, "Procedures and Mechanisms for Review of Compliance under the 1998 Aarhus Convention on Access to Information, Public Participation and Access to Justice in Environmental Matters", supra 221-249.
} 
while there is a procedure, there is no decision. There may be, as a consequence of the procedure, an agreement settling the dispute. The arguments developed above as regards a pending dispute may apply to pending diplomatic procedures; those concerning the "decision" of the dispute-settlement body may apply to the agreement settling the dispute following negotiation, good offices, mediation, conciliation, etc.

It has been argued that, for a Party concerned, compliance with conflicting results of the non-compliance procedure and of the dispute-settlement procedure "may be burdensome", even though it may not involve a legal conflict. ${ }^{21}$ This may be true when the result of the dispute-settlement procedure is a binding judgment or award. When it is an agreement ensuing from a diplomatic procedure, including a conciliation procedure, this seems unlikely. It is reasonable to suppose that the Parties will control the timing and content of their agreement in order to avoid such a "burdensome" situation.

\section{4. "Disputes" under the Environmental Agreements}

\subsection{The Relevance of the Notion of Dispute}

The presence of provisions concerning the settlement of disputes in the environmental agreements envisaged, as well as the presence of the "without prejudice" clauses in the instruments establishing the non-compliance mechanisms, indicate clearly that the Contracting Parties assume that there is a possibility that disputes concerning the interpretation or application of the relevant agreement arise. Yet, in the light of the notion of dispute and of the nature of the obligations set out in the agreements, there seems to be reason to question whether such assumption is correct in all cases.

According to a well-known definition given by the Permanent Court of International Justice in 1924, a dispute is "a disagreement on a point of law or fact, a conflict of legal views or of interest between the parties." ${ }^{22}$ This definition is constantly repeated by the International Court of Justice, although with some further elements, such as that the claim of one Party has to be "positively opposed by the other", ${ }^{23}$ and that the attitudes of a Party may be inferred by its behaviour.

The "disagreement" or the "conflict" mentioned by the Court are not about abstract questions of principle. The point of law or of fact must, if determined in one way, give an advantage to one Party and, if determined otherwise, give an advantage to the other Party. There must - in other words - exist an interest in obtaining the settlement of the dispute.

${ }^{21}$ M.A. Fitzmaurice and C. Redgwell, "Environmental Non-Compliance Procedures and International Law", Netherlands YB Int'l L., 31 (2000) 35-65, at 50.

${ }^{22}$ Mavrommatis Palestine Concessions (Greece v. United Kingdom) Judgment of 30 August 1924 (Jurisdiction), PCIJ Reports (1923), Series A, No. 2, at 11.

${ }^{23}$ South-West Africa (Ethiopia v. South Africa, Liberia v. South Africa), Judgment of 31 December 1962 (preliminary objections), ICJ Reports (1962), at 328. 


\subsection{Different Kinds of Obligations and Possible Disputes}

If we examine the agreements under consideration, it is easy to see that they entail different kinds of obligations for the Parties. Some agreements establish, among others, obligations that apply to couples of States Parties or to a limited number of them. So, as already mentioned, the Basel Convention provides for obligations between the "State of export" and the "State of import", such as the duty of re-import that is incumbent upon the State of export following a notification by the State of import under Article 8. Similarly, according to the Espoo Convention, the obligation of notification applies as between the "State of origin" and the "affected State"; the Cartagena Protocol establishes (especially in Articles 8 and 9 on notification) obligations between the "State of export" and the "State of import", and so does Article 11 of the Rotterdam PIC Convention. These are obligations owed "individually" to one particular State, as the multilateral treaty gives rise to "a bundle of bilateral relations", to borrow the terminology of the Articles on State Responsibility adopted by the International Law Commission and commended to the attention of Governments by the UN General Assembly in 2001. ${ }^{24}$

All agreements, however, establish obligations of each State Party towards the other Parties taken collectively in such a way that these obligations cannot be separated into a bundle of bilateral relationships. These are so-called erga omnes partes obligations. Conventions concerning global risks, especially the Vienna Ozone Convention and its Montreal Protocol, as well as the UNFCCC and its Kyoto Protocol, establish only or especially such obligations. This depends on the fact that the activities considered by each State Party participate in creating by accumulation a risk for all States, making it very difficult to determine a situation in which the activity of one Party has specific consequences as regards another Party or a determined number of other Parties.

Disputes concerning obligations of the first category mentioned involving two or a limited number of Parties are easily conceivable as the alleged non-compliance by one Party is prejudicial to the specific interest of the other. Whether to have recourse to dispute-settlement mechanisms or to non-compliance mechanisms, or to both and whether at the same time or successively, will depend on an assessment of the interested Party.

In case of erga omnes partes obligations, a "dispute" between two Parties or among a limited number of Parties is more difficult to imagine. It is true that a breach of this kind of obligations is an internationally wrongful act that involves responsibility towards all other Parties. This emerges clearly from the Articles on State responsibility adopted by the International Law Commission. These Articles distinguish three cases: a) the invocation of international responsibility by the injured State specifically affected by the breach (Article 42(a)(i)); b) the invocation by the injured State in the case in which the breach of the obligation owed to it "is of such a character as

${ }^{24}$ Published in Annex to UNGA Res. A/56/83 of 12 December 2001, Art. 42(a) and para. 8 of the Commentary to Art. 42. The text and commentary are published, with a detailed introduction, in J. Crawford, The International Law Commission's Articles on State Responsibility (Cambridge: Cambridge University Press, 2002). 
radically to change the position of all the other States to which the obligation is owed with respect to the further performance of the obligation" (Article 42(a)(ii), the case of "integral" or "interdependent" obligations); c) and the invocation by a State "other than the injured State" when "the obligation breached is owed to a group of States including that State, and is established for the protection of a collective interest of the group" (Article 48.1(a)). The States of the third group, in other words, are not specifically affected. It is debatable whether the narrow definition of "injured State" adopted by the International Law Commission is helpful ${ }^{25}$ as the main differences between the invocation of responsibility in the first two cases and in the third are limited to the fact that, in the third, the possibility of countermeasures is not mentioned (even though not explicitly excluded) and that reparation can be claimed only in the interest of the injured State or of the beneficiaries of the obligation breached (Article 48.2(b)).

For our purposes it seems clear, nevertheless, that all States Parties to an agreement establishing erga omnes partes obligations can invoke State responsibility in the case of breach and that some of these States may be "specifically affected". The latter case could arise when, for instance, the breach of obligations under the Kyoto Protocol by a specific number of important Contracting Parties could be seen as the main cause of ocean level rise submerging a specific small island State. ${ }^{26}$ It may be discussed whether some of the breached obligations belong to the category of "integral obligations". This would seem to be arguable in cases in which the obligations aim at preventing a risk arising from accumulation of activities even though the test of the "radical change" of the position with respect to the further performance of the obligation is rather severe.

The notion of "specifically affected States" and, possibly, of a State injured by the breach of an "integral obligation" (whose importance, from the point of view of distinguishing the case of obligations owed to the non-injured State is limited, as mentioned, as regards the claims that can be made while invoking State responsibility) may be important from the point of view of the interest required in order to establish a dispute in the legal meaning of the term and to have an actionable claim.

Recent scholarly opinion argues that, provided a jurisdictional link exists, all Parties to a treaty establishing erga omnes partes obligations, independently of their being specially affected, may institute proceedings before the relevant international court or tribunal. In particular, the Institut de droit international, in its resolution on Obligations erga omnes in international law adopted at the Krakow session in 2005, states that:

"In the event of there being a jurisdictional link between a State alleged to have committed a breach of an obligation erga omnes and a State to which the obligation is owed, the latter

${ }_{25}$ See T. Treves, Diritto internazionale, problemi fondamentali (Milano: Giuffré, 2005), 560.

${ }^{26}$ Developments in J. Gupta, "Legal Steps Outside the Climate Change Convention: Litigation as a Tool to Address Climate Change", RECIEL, 16 (2007) 76-86, at 78; and R. Verheyen, Climate Change Damage and International Law, Prevention Duties and State Responsibility (Leiden/Boston: Kluwer, 2005) 279-322. 
State has standing to bring a claim to the International Court of Justice or other international judicial institution in relation to the dispute concerning compliance with that obligation."27

The Institut, in rejecting the originally proposed restriction to the notion of erga omnes rights consisting of the requirement that the State to whom the obligation is owed must be "specially affected", ${ }^{28}$ seems to presume that all States Parties to the treaty have a "juridical" interest in the compliance with these obligations by each of the other States Parties and that this interest overlaps with their standing to bring a claim to the competent international court or tribunal. ${ }^{29}$

Independently of whether we consider the non-specially affected State an "injured" State or, with the International Law Commission, a "non-injured" State, the question is whether such "juridical" interest is sufficient - as the Institut and recent doctrinal opinion state - in order to establish a dispute before an international court or tribunal.

In my view this interest is not automatically sufficient. The sum of the two requirements consisting in the existence of the jurisdictional link and of that a Party is owed, without being specially affected, an obligation erga omnes, would not seem such as to justify in all cases the move from substantial to procedural law, ${ }^{30}$ in other words to support jus standi in all cases. It will be for the court seized of the dispute to decide whether the importance of the obligation for the international community ${ }^{31}$ (as well as for the State introducing the claim) is such as to make the juridical interest relevant enough to justify the existence of a right to trigger proceedings before an international court or tribunal. To adopt the broader view would open the way to claims whose sole

27 Art. 3 of the Resolution, in IDI Annuaire (Annuaire de l'institut de droit international), 71(II) (2005) 287. See also the Plenary debates ibid., at $81-137$. The reports by Mr. Gaja and comments by Members can be found in IDI Annuaire, 71(I) (2005) 117-212. A detailed scholarly study, reaching conclusions similar to those of the Institut, is that of C. Tams, Enforcing Obligations Erga Omnes in International Law (Cambridge: Cambridge University Press, 2005), 158-197.

${ }^{28}$ Such requirement had been included in Art. B of the Draft Resolution submitted to the Kracow session (Annuaire, 71, (II) at 83); the corresponding Art. 2 of the Resolution adopted specifies, to the contrary, that all the States to which the obligation is owed are entitled to make claims to the responsible State "even if they are not specially affected by the breach" (ibid., at 287)

${ }^{29}$ See the intervention by Mr. Torres-Bernardez, IDI Annuaire, ibid., at $109 \mathrm{f}$. and the observations by C. Dominicé, "A la recherche des droits erga omnes", Droit du pouvoir, pouvoir du droit, Mélanges offerts à Jean Salmon (Bruxelles: Bruylants, 2007) 357-371, especially 366-367. He calls the position of the Institut on jus standi "une avancée spectaculaire" which has some precedents in conventional regimes (such as the Genocide Convention), while "la situation en droit international général n'est pas encore claire" (at 367).

${ }^{30}$ This concern seems present in the interventions made during the discussion at the Institut in Krakow by T. Franck, (IDI Annuaire, 71(II) 2005, at 91), R. Higgins (ibid., at 94 and 124), G. Bastid-Burdeau (ibid., at $95 \mathrm{ff}$.).

${ }^{31}$ According to the view that seems to be prevailing, the notion of erga omnes obligations is not limited to a structural requirement. It contains also the requirement that these obligations protect particularly important values: in the words of the Preamble of the above quoted Kracow resolution of the Institut, "the fundamental values of the international community"; according to the terminology of Tams, they require a "threshold of importance", they "protect values of heightened importance" (Tams, supra n. 27, at 156 and 310). The relevance of the assessment of the importance of the values protected by the obligations seems particularly relevant (and open to different solutions) in the case of obligations set out in multilateral treaties (erga omnes partes obligations). In the view of the former rapporteur on International responsibility of the ILC, G. Arangio-Ruiz, the characteristics that distinguish erga omnes obligations are only structural, see G. Arangio-Ruiz, "Fourth Report on State Responsibility", YB Int'l L. Comm., 2, Part One (1992), para. 92. 
purpose would be to make points of principle, while the Party which submits them would incur no real risk. Non-compliance procedures, which are available in environmental treaties, would seem to constitute a preferable alternative especially as obtaining effective compliance is seen as more important than attribution of the blame for wrong-doing. The latter case would include situations in which the importance of the questions involved for the international community as a whole could justify that the question is brought to a court or tribunal

\subsection{The Limited Availability of Dispute-Settlement Mechanisms in the Environmental Agreements}

The discussions considered above concerning the relationship between non-compliance and dispute-settlement mechanisms and about situations in which disputes under environmental agreements setting out non-compliance systems may arise, while theoretically extremely interesting, in practical terms are of limited importance. It seems clear that the Contracting Parties to the environmental agreements consider that noncompliance mechanisms, because of their often more political than legal character, of their non-confrontational nature and of the remedies offered which concentrate on re-establishing compliance more than on assigning blame for non-compliance, are more important for the good functioning of the agreements than dispute-settlement procedures. While, after the conclusion of the agreements, they have in a relatively short time established the non-compliance mechanisms, they have not hurried to establish detailed rules on arbitration or on conciliation as sometimes provided for in the agreements.

More importantly, as it emerges from the analysis set out in the first part of this paper, in adopting the agreements, with very few exceptions, the Parties have avoided introducing dispute-settlement mechanisms that can be triggered unilaterally by one Party and that entail a binding result. The possibility of resorting to such mechanisms has been made dependent upon parallel declarations by the Parties involved. Making such declarations does not seem attractive, as it emerges from their extremely limited number. It seems fair to say that the relevant provisions have no real impact. The only mechanism that, in a relatively high number of agreements, can be triggered unilaterally, independently of a declaration, is conciliation. The practical effect of the provisions concerning conciliation seems, nevertheless, very limited also, possibly because of the already mentioned relatively onerous character of this method as compared to its non-binding results.

That none of the dispute-settlement mechanisms provided for in the here examined agreements has ever been set in motion confirms these observations. The limited possibility of such disputes arising and the short time elapsed since the entry into force of most agreements may be an explanation. In fact the only exception, to my knowledge, is the inquiry mechanism set out in the Espoo Convention, which, as mentioned, has been utilized once in the Bystroe channel case at the request of Romania against the Ukraine. This mechanism, however, has particular characteristics. First, it can be triggered unilaterally by one Party; second, it concerns a bilateral situation; third, its purpose is to determine the existence of a prerequisite necessary to resort unilaterally to the non-compliance mechanism. 
The very limited applicability of the provisions concerning the settlement of disputes in the agreements here considered entails that most cases in which an international court or tribunal can be seized in matters concerning compliance with a multilateral environmental agreement are those in which compulsory and binding dispute-settlement clauses set out in applicable treaties outside the agreement can be utilized. Such case may arise if both Parties have accepted the compulsory jurisdiction of the ICJ under Article 36.2 of the Statute, if they are bound by a bilateral or regional mechanism entailing compulsory jurisdiction of a court of general competence (for instance the Pact of Bogotá or the European Convention for the settlement of disputes) or if the dispute falls within the scope of a convention setting out a compulsory system for the settlement of a particular category of disputes, such as the UN Law of the Sea Convention or the WTO Dispute-Settlement Understanding.

While the compulsory jurisdiction of the ICJ established on the basis of the optional clause, or of the participation of the Parties to the dispute in the above-mentioned regional agreements, would allow one Party to set in motion a procedure before the Court concerning a dispute on the application and the interpretation of provisions of one of the here considered environmental agreements, in the case of a compulsory mechanism for the settling of disputes set out in a specific international instrument (such as the Law of the Sea Convention or the WTO Dispute-Settlement Understanding $)^{32}$ the situation is different. The subject-matter of the dispute within the framework of these instruments must be the application or the interpretation of these very instruments and not that of environmental agreements. However, the environmental agreements may be seen as relevant international law binding for the Parties for the purpose of interpretation of the instruments on the basis of Article 31.3(c), of the Vienna Convention on the Law of Treaties. Moreover, conduct of the Parties that can be seen as compliance or as non-compliance with environmental agreements may also sometimes be seen as facts relevant to assess conformity with the instruments whose provisions are in dispute. ${ }^{33}$

\section{CONCLUding Remarks}

A number of conclusions may be drawn from the observations made. First, the distinction between dispute-settlement and non-compliance proceedings in the multilateral environmental agreements is reflected in the independence, in these agreements, of these two kinds of proceedings, neither of which excludes the other. Second, notwithstanding such independence, some relationships are possible, as some impact of dispute-settlement procedures on non-compliance proceedings, and vice versa, is unavoidable and explainable in the light of international law. Third, the disputesettlement procedures set out in the multilateral environmental agreements are very inefficient as they are mostly based on the agreement of the Parties and do not include

\footnotetext{
32 See A. González-Calatayud and G. Marceau, "The Relationship between the Dispute-Settlement Mechanisms of MEAs and those of the WTO", RECIEL, 11 (2002) 275-286.

${ }_{33}$ See ITLOS, Southern Bluefin Tuna case (New Zealand v. Japan, Australia v. Japan), Order of 27 August 1999, ITLOS Reports (1999), 280, para. 50.
} 
compulsory mechanisms, even though in some cases compulsory mechanisms may be available under applicable agreements different from the relevant multilateral environmental one. Fourth (even leaving aside jurisdictional problems) not all situations of alleged non-compliance with obligations set out in multilateral environmental agreements give rise to disputes that can be submitted to an international judge or arbitrator. In particular, it can be questioned whether not directly affected Parties to allegedly violated erga omnes partes obligations have the necessary jus standi. Fifth, non-compliance proceedings are in most cases the only practicable avenue open when non-compliance is alleged.

It is in light of the last conclusion mentioned that, notwithstanding the reasons that in some cases might make it preferable to follow the avenue of the traditional disputesettlement procedures, it seems important that non-compliance systems offer, as much as possible, the guarantees usually associated with judicial or arbitral proceedings. It is not (or, perhaps, not only!) a conservative reaction to new institutions that brings international lawyers instinctively to prefer what they know best and to consider the non-compliance mechanisms that are more similar to judicial or arbitral mechanisms as the best ones. It is the need, when determinations of fact and of law are made, to ensure that the best guarantees be made available to all those involved. The specificities of non-compliance systems, in particular the priority to be given to the general interest to a return to compliance of the non-complying Party, must not be put aside; but neither must the legacy of the centuries-old tradition of due process. 
Section V

Non-Compliance Mechanisms and

EUROPEAN UNION LAW 
1 


\title{
Chapter Twenty-Nine
}

\section{Non-Compliance Procedures in Multilateral Environmental Agreements: The Interaction between International Law and European Union Law}

\author{
Antonino Ali
}

\section{Introduction: Multilateral Environmental Agreements as Mixed AGREEMENTS}

International agreements to which both the Communities and one or more Member States are parties, better known as "mixed agreements", ${ }_{1}^{1}$ are a consolidated and well accepted phenomenon in the practice of the external action of the European Union (EU). ${ }^{2}$ The European Community (EC) has been concluding mixed bilateral and multilateral treaties since the early nineteen sixties. One of the fields in which the activism of the $\mathrm{EC}$ has been more evident on the international level is the protection of the environment. This action has been furthered by the explicit recognition to the EC of competences in the environmental field by the European Single Act (Articles $130 \mathrm{R}, 130 \mathrm{~S}, 130 \mathrm{~T})$ and the Maastricht Treaty.

The EC has been a party, with all or some of its Member States, to many ${ }^{3}$ multilateral environmental agreements (MEAs) ${ }^{4}$ which have been concluded as mixed agreements since the mid seventies. ${ }^{5}$

\footnotetext{
${ }^{1}$ A. Rosas, "Mixed Union - Mixed Agreements", in M. Koskenniemi (ed.), International Law Aspects of the European Union (The Hague, London, Boston: Kluwer Law International, 1998) 125-148.

${ }^{2}$ For a chronological list of the mixed agreements between 1958-2000, see J. Heliskoski, Mixed Agreements as a Technique for Organizing the International Relations of the European Community and its Member States (The Hague, London, New York: Kluwer Law International, 2001), 249-280. For a general overview of the external relations of the EC see P. Eeckhout, External Relations of the European Union. Legal and Constitutional Foundations (Oxford: Oxford University Press, 2004).

${ }^{3}$ For an updated list of Multilateral Environmental Agreements to which the EC is a Party see $<\mathrm{http}: / /$ ec.europa.eu/environment/international_issues/pdf/agreements_en.pdf $>$ (visited 15 July 2008).

${ }^{4}$ See E. Hey, "The European Community's Courts and International Environmental Agreements", RECIEL, 7 (1998) 4-10; A. Nollkaemper, "The European Community and International Environmental Cooperation: Legal Aspects of External Community Powers", Legal Issues of European Integration, 2 (1987) 55-91.

${ }^{5}$ L. Granvik, "Incomplete Mixed Environmental Agreements of the Community and the Principle of Bindingness", in Koskenniemi (ed.), supra n. 1, 256-272, at 256-257.
}

T. Treves et al., eds., Non-Compliance Procedures and Mechanisms and the Effectiveness of International Environmental Agreements

(C) 2009, T.M.C. ASSER PRESS, The Hague, The Netherlands, and the Authors 
Although the international legal personality of the European Community is widely recognised, the Community does not have an unlimited competence as it is based on the principle of attributed competences. Its external power is, as a matter of fact, narrower than that of its Member States. As it has been observed, this situation is different, if not opposite, from the one observed in federal States, in which the treaty-making power of the federal government is usually wider than its internal legislative jurisdiction. ${ }^{6}$

\section{The Reasons for Concluding Mixed Agreements}

When the subject-matter of a given treaty concluded by the Community falls entirely within the exclusive competence of the EC, there is no need for Member States to join the Community in becoming parties to that treaty. ${ }^{7}$ However, in many cases Community competences either do not cover all of the aspects of a treaty or they have a nonexclusive nature. In these cases the need arises to have recourse to mixed agreements. In other words, the field covered by those (mixed) agreements falls partially within the exclusive (or shared) competence of the EC and partially within the exclusive (or shared) competence of Member States. In those cases neither the organisation, nor the Member States, have full competence for the implementation of the agreement. ${ }^{8}$ This is particularly the case of the external environmental policy of the $\mathrm{EC}$, as the competences in the field of environmental protection are generally shared between the Community and its Member States (see Article 174.4 TEC).

Another reason, of a political nature, for a treaty to be mixed lies in the current division of competences in the EC Treaty. This is the result of a composite mix of objectives, substantive competences and functional competences. Thus rules on competence distribution are defined not only on the basis of the subject-matter and the field of action, but also in finalistic terms, taking into consideration the purpose to be achieved through regulation. ${ }^{9}$ The reluctance of Member States to leave the EC free

${ }^{6}$ T. Hartley, European Union Law in a Global Context. Text, Cases and Materials (Cambridge: Cambridge University Press, 2004), at 227-228. The author adds "There are matters with regard to which the treaty gives internal legislative power to the Community but with regard to which the Member States enjoy external competence". See also A. Tizzano, "The Foreign Relations Law of the EU between Supranationality and Intergovernmental Model”, in E. Cannizzaro (ed.), The European Union as an Actor in International Relations (The Hague, London, Boston: Kluwer Law International, 2002) 135-147.

${ }^{7}$ However, considering the nebulous way competences are divided between the Community and the Member States it is not rare that the a mixed agreement is concluded also in those cases in which most or all the competence is of the Community. In those cases the need for mixity comes from the third parties asking for Member State participation as a way to reassure the responsibility in the execution of the agreement or even for budgetary causes (see K. Lenaerts, P. Van Nuffel and R. Bray, Constitutional law of the European Union (London: Sweet \& Maxwell, 2005), 831-832 and 892-894. See also E. Cannizzaro, "Sull'utilizzazione delle riserve come strumento per assicurare la compatibilità fra convenzioni multilaterali e diritto comunitario", Riv. Dir. Int., 85 (2002) 372-375.

${ }^{8}$ H.G. Schermers, “A Typology of Mixed Agreements", in D. O'Keeffe and H.G. Schermers (eds.), Mixed Agreements (Deventer: Kluwer, 1983), 23-33, at 25-26.

9 A. Tizzano, "Lo sviluppo delle competenze materiali delle Comunità europee", Rivista di diritto europeo, 1981, 139-210, at 148 . 
to conclude autonomously those agreements depends on the resulting complexity and lack of clarity in the division of competences. At the same time, however, a clear delimitation of competences could also be counterproductive for the Community, since it would prevent the de facto and progressive enlargement of its competences through interpretation and practice. In fact the scope of Community activities has increased progressively and systematically since its creation. The recent jurisprudence of the European Court of Justice (ECJ) shows that the competences of the Community are still evolving and expanding ${ }^{10}$ and confirms the dynamic character of the external competences of the EC. ${ }^{11}$ In this sense, the role of the ECJ has been to widen the narrow (explicit) limits imposed by the strict wording of the treaties.

In this sense, it is possible to argue that the expanding use of mixed agreements have both a "static" reason (how the competences are disciplined in the founding Treaty) and a "dynamic" one (how those competences have been enlarged and interpreted extensively by the European Court of Justice).

\section{COMPETENCES AND RESPONSIBILITY}

The apparent lack of interest of both the EC and Member States in the exact delimitation of the respective competences nevertheless entails some significant consequences in relation to third parties. Delicate questions concerning the competence for negotiating, concluding ${ }^{12}$ and implementing such international instruments can be raised, with related issues of responsibility within the community legal system and on the international level. ${ }^{13}$

In very general terms, it has been correctly pointed out, as a direct application of the general rule pacta sunt servanda, that

"[i]f the EC becomes a party to a treaty it is bound by all the obligations under the treaty irrespective of whether or not it has competence for a certain matter under its internal rules [...] The same is true if both the EC and its member States become parties to a treaty. In the latter case, the obligations under the treaty are incumbent upon all of them."14

${ }^{10}$ On this topic see the G. Gaja, "First Report on Responsibility of International Organizations", doc. A/CN.4/532 (26 March 2003), citing Mr. A. El-Erian's first report on relations between States and intergovernmental organizations: "the continuous increase of the scope of activities of international organizations [was] likely to give new dimensions to the problem of responsibility of international organizations".

${ }^{11}$ See J. Heliskoski, supra $\mathrm{n} .2$ ("The scope of the Community's competence is not static but evolving"); L.S. Rossi, "Conclusione di accordi internazionali e coerenza del sistema: l'esclusività della competenza comunitaria", Riv. Dir. Int, 90 (2007) 1008-1027; E. Cannizzaro, "Le relazioni esterne della Comunità: verso un nuovo paradigma unitario?", Diritto dell'Unione europea, 12 (2007) 223-238.

${ }^{12}$ For a description of the EU decision-making procedures concerning mixed and exclusive agreements in the field of environment see T. Delreux, "The European Union in International Environmental Negotiations: A Legal Perspective on the Internal Decision-making Process", Int'l Envt'l Agreements, 6 (2006) 231-248.

${ }^{13}$ See M. Björklund, "Responsibility in the EC for Mixed Agreements - Should Non-Member Parties Care?", Nordic J. Int'l L., 70 (2001) 373-402.

${ }^{14}$ See S. Talmon, "Responsibility of International Organizations: Does the European Community require a Special Treatment?", in M. Ragazzi (ed.), International Responsibility Today (Leiden: Brill, 2005) $405-421$, at 416. 
The third States "are therefore entitled to expect that the Community will assume responsibility for monitoring the fulfilment of all of the obligations it has assumed." 15

This was also the position of Advocate-General Tesauro in his opinion ${ }^{16}$ delivered on 13 November 1997, with reference to WTO agreements, ${ }^{17}$ in which he underlined that

"while it is true that the approval of those agreements on behalf of the Community is restricted to 'matters within its competence', it is also true that the Final Act and the WTO Agreement contain no provisions on competence and the Community and its Member States are cited as original members of equal standing. In these circumstances, it should be recognised that the Member States and the Community constitute, vis-à-vis contracting non-member States, a single contracting party or at least contracting parties bearing equal responsibility in the event of failure to implement the agreement. This clearly means that, in that event, the division of competence is a purely internal matter."

In a similar vein, Advocate-General Jacobs in his opinion delivered on 10 November 1993 states that: "Under a mixed agreement the Community and the Member States are jointly liable unless the provisions of the agreement point to the opposite conclusion." 18

A different view is set out in the recent jurisprudence of the ECJ in which the Court's interest in the "internal rules of the organizations" emerges.

It is quite interesting to observe that in a judgment of 10 January 2006 the Court underlined the importance of the legal basis of Community action, not only for the reason usually produced, but also for the reason that:

"[...] by basing the decision approving the Convention on the dual legal basis of Article $133 \mathrm{EC}$ and Article 175(1) EC, the Community is also giving indications to the other parties to the Convention both with regard to the extent of Community competence in relation to that Convention which, as has been shown earlier, falls both within the scope of the common commercial policy and within that of the Community environmental policy, and with regard to the division of competences between the Community and its Member States, a division which must also be taken into account at the stage of implementation of the agreement at Community level" (emphasis added). ${ }^{19}$

${ }^{15}$ See the position of the European Commission in the Mox Plant case, Opinion of Advocate-General Misho (27 November 2001) in Commission v. Ireland (Mox), case C-13/00, para. 29.

${ }_{16}$ Hermès International, case C-53/96, ECR (1998) I-3603, para. 14.

17 To which both the Community and Member States are parties and are therefore Contracting Parties vis-à-vis Contracting non-Member States.

${ }^{18}$ In this specific case, it should be taken into account that the Convention analysed (The Fourth ACP-EEC Convention was concluded at Lomé on 15 December 1989) was concluded as a mixed agreement and had essentially a bilateral character.

${ }^{19}$ Commission v. Council, case C-94/03, ECR (2006) I-1, para. 55; see also the judgment delivered on the same day in Commission v. Parliament and Council, case C-178/03, ECR (2006) I-107. On these cases see the note of D. Schaffrin, "Dual Legal Bases in EC Environmental Law Revisited: Note on the Judgments of the European Court of Justice in the Cases C-94/03 (Commission of the European Communities v. Council of the European Union) and C-178/03 (Commission of the European Communities v. European Parliament and Council of the European Union)", RECIEL, 15 (2006) 339-343. The reference is to both a 
This position is in line with those who think that the very use of mixed agreements should alert third parties on the issue of the division of competences between the Community and its Member States. ${ }^{20}$

The European Commission has had the opportunity to express its position in the context of the work of the International Law Commission (ILC), led by the Special Rapporteur Giorgio Gaja, on the delicate topic of the responsibility of international organizations. ${ }^{21}$ The Commission drew the attention of the ILC to the peculiarities of the EC as an international organization. In the first place it recalled that the implementation of EC law, including that originating from international law, is carried out by Member States' authorities rather than by EC institutions. It therefore expressed the view that the attribution of responsibility for their conduct should be decided on the basis of the internal rules of the organizations and in particular having regard to the division of competence between the EC and its Member States. ${ }^{22}$

This is not the place to examine this position in detail, but it has been criticised as "Eurocentric" and incompatible with international law. However, the joint and several responsibility of the EC and the Member States from the perspective of international law does not prevent the respect, within the EC legal order, of the limitation of competences deriving from the EC Treaty.

\section{The Participation of the European Community in MEAs: the DeClarations of COMPETENCES}

One of the mechanisms used to solve these problems is the practice of attaching to mixed agreements a "declaration of competence". This mechanism entails that, at the moment of ratification or approval of a treaty, an international organization is required to declare its competence for entering into the agreement and for the implementation of the obligations resulting from it. ${ }^{23}$

It is quite evident that, as it has been correctly argued, a "discussion within the Community of the exact extent of the Community's powers" and the declaration of

Council Decision concerning the approval, on behalf of the European Community, of a Treaty and of a Regulation adopted to implement the rules of the same Treaty. The specific case concerned the Rotterdam PIC Convention, see, for further details, S. Brugnatelli, "Draft Procedures and Mechanisms on Compliance with the 1998 Rotterdam Convention on the Prior Informed Consent Procedure for Certain Hazardous Chemicals and Pesticides in International Trade", supra 85-100, at 99

${ }^{20}$ For a description of this position see Björklund, supra n. 13, at 400-402.

${ }^{21}$ At the time of writing the Special Rapporteur has released five reports, see $<$ http://untreaty.un.org/ilc/ guide/9_11.htm> (visited 15 July 2008).

22 See Responsibility of International Organizations. Comments and observations received from International organizations, International Law Commission, Fifty-sixth session, Geneva, 3 May-4 June and 5 July-6 August 2004, doc. A/CN.4/545 (25 June 2004), at 5, 13-14, 15 and 18-25.

23 The Law of the Sea Convention is described as one of the most effective examples of an agreement with a working declaration of competence (and parallel subordination clauses). See T. Treves, "The European Community and the Law of the Sea Convention: New Developments", in E. Cannizzaro (ed.), supra n. 6, 279-296; see also L. Granvik, supra n. 5, at 260-262, and M. Cremona, "External Relations of the EU and the Member States: Competence, Mixed Agreements, International Responsibility, and Effects of International Law", EUI Working Papers, Law No. 2006/22, European University Institute, Florence. 
competence, when needed at the time of becoming party to a convention, frustrates the "advantage of 'mixed' agreements". ${ }^{24}$

With some exceptions, ${ }^{25}$ MEAs provide for the formulation of such declarations. Their structure and content, although they may vary in some cases, are quite similar. They often start by recalling that, in accordance with the EC Treaty, the Community is competent for entering into international agreements, and for implementing the obligations resulting therefrom, which contribute to the pursuit of the objectives indicated in Article 175(1). They then usually mention that "the European Community is responsible for the performance of those obligations resulting from the [Treaty] which are covered by Community law in force" and that "the exercise of Community competence is, by its nature, subject to continuous development." Nearly all commentators have been fairly frank in underlining the ambiguity and vagueness of these sentences in a situation in which neither the Member States, nor the Community, are interested in stating the exact distribution of competence. ${ }^{26}$

Another group of MEAs does not contain any "subordination clause" requiring the "Regional economic integration organizations (REIO)" to give information on the division of competence between itself and the Member States. Consequently these treaties have not attracted declarations of competence by the EC. ${ }^{27}$

${ }^{24}$ See J.T. Lang, "The Ozone Layer Convention: A New Solution to the Question of Community Participation in 'Mixed' International Agreements”, Common Market L. Rev., 23 (1986) 157-176, at 160.

${ }_{25}$ See infra n. 27.

${ }^{26}$ This model of declaration of competences has been adopted for example in: the Cartagena Protocol (see the Annex B - "Declaration by the European Community in accordance with article 34.3 of the Convention on biological diversity"), see Council Decision of 25 June 2002 concerning the conclusion, on behalf of the European Community, of the Cartagena Protocol on Biosafety, OJ (2002) L201/48; the Rotterdam PIC Convention (see Annex B - "Declaration by the European Community in accordance with article 25 (paragraph 3) of the Rotterdam Convention), see Council Decision 2003/106/EC of 19 December 2002 concerning the approval, on behalf of the European Community, of the Rotterdam Convention on the Prior Informed Consent Procedure for certain hazardous chemicals and pesticides in international trade, OJ (2003) L 63/27; the Stockholm POPs Convention (see Annex - "Declaration by the Community in accordance with Article 25(3) of the Convention"), see Council Decision 2006/507/EC of 14 October 2004 Concerning the Conclusion, on Behalf of the European Community, of the Stockholm Convention on Persistent Organic Pollutants, OJ (2006) L 209/1; the PRTRs Protocol (see Annex B - "Declaration by the European Community in accordance with Article 26.4 of the UN-ECE Protocol on Pollutant Release and Transfer Registers"), see Council Decision 2006/61/EC of 2 December 2005 on the conclusion, on behalf of the European Community, of the UN-ECE Protocol on Pollutant Release and Transfer Registers, OJ (2006) L 32/54 and the Kyoto Protocol (Annex III - "Declaration by the European Community made in accordance with article 24(3) of the Kyoto Protocol"), see Council Decision 2002/358/EC of 25 April 2002 concerning the approval, on behalf of the European Community, of the Kyoto Protocol to the United Nations Framework Convention on Climate Change and the joint fulfilment of commitments thereunder, OJ (2002) L 130/1 (see also L. Massai, "Obligations of the European Community and its Member States under the Kyoto Protocol”, supra 545-565.

27 That is the case of the ITPGRFA, see Council Decision 2004/869/EC of 24 February 2004 Concerning the Conclusion, on behalf of the European Community, of the International Treaty on Plant Genetic Resources for Food and Agriculture, OJ (2004) L 378/1; the Basel Convention, see Council Decision 93/98/ EEC of 1 February 1993 on the conclusion, on behalf of the Community, of the Convention on the control of transboundary movements of hazardous wastes and their disposal (Basel Convention), OJ (1993) L 39/1. 


\section{MEAs and the European Community: the Case of the Aarhus CONVENTION}

The practice that has emerged in the context of non-compliance mechanisms in MEAs concerning the EC is not very wide and the relevant cases are few, apart from some interesting cases that are specifically analysed by some authors in this book. ${ }^{28}$ However, the Aarhus Convention, and in particular its compliance mechanism, shows some interesting indications in this field and it can be seen as a test for the review of compliance by the Community. ${ }^{29}$

The Aarhus Convention was signed by the $\mathrm{EC}^{30}$ and all Member States (except Ireland) as a mixed agreement. The Convention has the aim to improve environmental protection through raising public awareness and involvement in environmental matters. In particular, the Convention intervenes specifically in three areas: ensuring public access to environmental information held by public authorities; fostering public participation in decision-making which affects the environment; extending the conditions of access to justice in environmental matters.

The EC made the following declaration upon signature:

"... the European Community itself is being actively involved in the protection of the environment through a comprehensive and evolving set of legislation, it was felt important not only to sign up to the Convention at Community level but also to cover its own institutions, alongside national public authorities. Within the institutional and legal context of the Community and given also the provisions of the Treaty of Amsterdam with respect to future legislation on transparency, the Community also declares that the Community institutions will apply the Convention within the framework of their existing and future rules on access to documents and other relevant rules of Community law in the field covered by the Convention. The Community will consider whether any further declarations will be necessary when ratifying the Convention for the purpose of its application to Community institutions."

It has also adopted appropriate legislation to fully implement the Convention on a double level. ${ }^{31}$

${ }^{28}$ See Massai, supra n. 26; on the Kyoto Protocol, see also F. Jacquemont, "The Kyoto Compliance Regime, the European Bubble: Some Legal Consequences", in M. Bothe and E. Rehbinder (eds.), Climate Change Policy (Utrecht: Eleven International Publishing, 2005) 351-406, at 370

${ }^{29}$ See C. Pitea, "Procedures and Mechanisms for Review of Compliance under the 1998 Aarhus Convention on Access to Information, Public Participation and Access to Justice in Environmental Matters", supra 221-250, at 24 and S. Kravchenko, Strengthening Implementation of MEAs: the Innovative Aarhus Compliance Mechanism, Seventh International Conference on Environmental Compliance and Enforcement, 9-15 April 2005, Marrakech <http://www.inece.org/conference/7/vol2/58_Kravchenko.pdf> (visited 15 July 2008).

${ }^{30}$ See Council Decision 2005/370/EC of 17 February 2005 on the conclusion, on behalf of the European Community, of the Convention on access to information, public participation in decision-making and access to justice in environmental matters, OJ (2005) L 124/1.

31 According to G.S. Kremlis, "The Aarhus Convention and its implementation in the European Community" < http://www.inece.org/conference/7/vol1/> (visited 15 July 2008): "This is not required under recent European Court of Justice case law ('Étang de Berre' case law; case C-239/03 Commission of the European Communities v. French Republic of 7 October 2004) which states that the mere European Community accession would per se introduce the Aarhus obligations into the Community legal order as part of the 'acquis communautaire' thus making them binding both for the Member States and for the institutions 
At the first level, in 2003 the European Parliament and the Council adopted two directives concerning public access to environmental information (2003/4/EC) $)^{32}$ and providing for public participation in respect of the drawing up of certain plans and programmes relating to the environment $(2003 / 35 / \mathrm{EC})^{33}$ and also amending, with regard to public participation and access to justice, Council Directives 85/337/EEC and 96/61/EC. ${ }^{34}$ Member States therefore had to adopt the laws, regulations and administrative provisions necessary to comply with those directives.

The obligations descending from these directives require something more than merely to bring into force laws, regulations and administrative provisions.

"[E]nsuring compliance is not limited to a straightforward exercise of transposition, as might be the case in some areas, but it is necessary to ensure at a later stage, e.g. adoption of plans and programmes, designations or establishment of protected zones and areas etc. Some of the secondary obligations also imply establishment of infrastructure and major investments (urban wastewater treatment, drinking water, landfills etc.)."${ }^{35}$

With reference to the second level, it should be observed that in consideration of the fact that the obligations of the Aarhus Convention can be referred also to the "public authorities" 36 of the EC, the European Parliament and the Council adopted in 2006 a Regulation on the application of the provisions of the Aarhus Convention to Commu-

('monist approach')". On the European legal framework, see also J. Jendroska, "Aarhus Convention and Community Law: the Interplay”, J. Eur. Envt'l Plan. L., 2 (2005) 12-21.

${ }^{32}$ Directive 2003/4/EC of the European Parliament and of the Council of 28 January 2003 on public access to environmental information and repealing Council Directive 90/313/EEC, OJ (2003) L 41/26. See also the judgments of the ECJ of 9 November 2006 in Commission v. Ireland, case C-216/05, ECR (2006) I-10787 and of 12 June 2003, Eva Glawischnig, case C-316/01, ECR (2003) I-5995; it should be recalled that at the time of approval the EC deposited the following Declaration concerning certain specific provisions under directive 2003/4/EC: "In relation to Article 9 of the Aarhus Convention, the European Community invites Parties to the Convention to take note of Article 2(2) and Article 6 of Directive 2003/4/EC of the European Parliament and of the Council of 28 January 2003 on Public Access to Environmental Information. These provisions give Member States of the European Community the possibility, in exceptional cases and under strictly specified conditions, to exclude certain institutions and bodies from the rules on review procedures in relation to decisions on requests for information. Therefore the ratification by the European Community of the Aarhus Convention encompasses any reservation by a Member State of the European Community to the extent that such a reservation is compatible with Article 2 (2) and Article 6 of Directive 2003/4/EC."

33 Directive 2003/35/EC of the European Parliament and of the Council of 26 May 2003, OJ L 156, 25.6.2003, p. 17-25.

34 Other provisions for public participation in environmental decision-making are included in the Directive 2001/42/EC of the European Parliament and of the Council of 27 June 2001 on the assessment of the effects of certain plans and programmes on the environment (SEA Directive), OJ (2001) L197/30, and in Directive 2000/60/EC of the European Parliament and of the Council of 23 October 2000 establishing a framework for Community action in the field of water policy (Water Framework Directive), OJ (2000) L $327 / 1$.

${ }^{35}$ See G. Kremlis and J. Dusík, "The Challenge of the Implementation of Environmental Acquis Communautaire in the New Member States", Seventh International Conference on Environmental Compliance and Enforcement, 9-15 April 2005, Marrakech <http://www.inece.org/conference/7/vol2/59 Kremlis.pdf > (visited 15 July 2008).

${ }^{36}$ See Art. 2(2) of the Convention. 
nity institutions and bodies. ${ }^{37}$ The definition of "public authorities" in the Convention was quite broad, and the EC decided to specify that Community institution or body means "any public institution, body, office or agency established by, or on the basis of, the Treaty except when acting in a judicial or legislative capacity." 38

In the meantime the Council concluded the Convention on behalf of the EC. ${ }^{39}$ Upon approval, the EC deposited the following "declaration in accordance with Article 19":

"The European Community declares that, in accordance with the Treaty establishing the European Community, and in particular Article 175 (1) thereof, it is competent for entering into international agreements, and for implementing the obligations resulting there from, which contribute to the pursuit of the following objectives: preserving, protecting and improving the quality of the environment; protecting human health; prudent and rational utilisation of natural resources; promoting measures at international level to deal with regional or world-wide environmental problems. [...] Finally, the Community reiterates its declaration made upon signing the Convention that the Community institutions will apply the Convention within the framework of their existing and future rules on access to documents and other relevant rules of Community law in the field covered by the Convention. The European Community is responsible for the performance of those obligations resulting from the Convention which are covered by Community law in force. The exercise of Community competence is, by its nature, subject to continuous development."

To summarize, the description of this complex legal framework shows that Member States have some legal obligations descending directly: (a) from the Convention, as the States (all or some) are parties of an international treaty together with the EC; (b) from the secondary legislation adopted by the institutions of the EC (in particular the directives) $4^{40}$ (c) from the mixed agreement as part of the Community legal order, in

${ }^{37}$ Regulation (EC) 1367/2006 of 6 September 2006 on the application of the provisions of the Aarhus Convention on Access to Information, Public Participation in Decision-making and Access to Justice in Environmental Matters to Community institutions and bodies, OJ (2006) L 264/13; before the adoption of this regulation, Regulation (EC) 1049/2001 of the European Parliament and of the Council of 30 May 2001 regarding public access to European Parliament, Council and Commission documents, OJ (2001) L 145/43, already covered, although in a partial way, some obligations descending from the Aarhus Convention. Recently, two decisions have been adopted to implement the Regulation: Commission Decision 2008/50/EC of 13 December 2007 laying down detailed rules for the application of Regulation (EC) No. 1367/2006 of the European Parliament and of the Council on the Aarhus Convention as regards requests for the internal review of administrative acts, OJ (2008) L 13/24, and Commission Decision 2008/401/EC, Euratom of 30 April 2008, amending its Rules of Procedure as regards detailed rules for the application of Regulation (EC) No. 1367/2006 of the European Parliament and of the Council on the application of the provisions of the Aarhus Convention on Access to Information, Public Participation in Decision-making and Access to Justice in Environmental Matters to Community institution and bodies, OJ (2008) L 140/22. See also T. Crossen and V. Niessen, "NGO Standing in the European Court of Justice - Does the Aarhus Regulation Open the Door?", RECIEL, 16 (2007) 332-340; see the pending case Liga para a Protecção da Natureza v. Commission, case T-29/08, subsequent to an action brought on 18 January 2008.

${ }^{38}$ See supra n. 22 and V. Rodenhoff, “The Aarhus Convention and its Implications for the 'Institutions' of the European Community", RECIEL, 11 (2002) 343-357.

39 See supra n. 30

${ }^{40}$ See the observations of Rodenhoff, supra n. 38. 
so far as the provisions fall within the scope of Community competence; ${ }^{41}$ (d) from a general obligation in relation to the Community, which has assumed responsibility for the due performance of the agreement ${ }^{42}$ and finally, (e) form a general duty of cooperation $^{43}$ in a situation involving shared competences. ${ }^{44}$ In particular, in the fulfilment of the commitments entered into "the obligation of cooperation flows from the requirement of unity in the international representation of the Community." 45

\section{The Practice and the Relevant Cases Concerning the EC that Have Emerged in the ConteXt of the Non-Compliance Mechanism in MEAs}

The legal framework and the solutions that have been described in the previous paragraphs found a particular characterization in the context of the non-compliance mechanism of the Aarhus Convention. ${ }^{46}$ One of the cases submitted to the Aarhus Convention Compliance Committee begun with a communication alleging non-compliance by one Member State, immediately followed by another one concerning noncompliance by the EC. ${ }^{47}$

${ }^{41}$ See the judgments of 7 October 2004 in Commission v. French Republic, case C-239/03, ECR (2004) I-9325, paras. 25-26; and of 30 September 1987 in Demirel v. Stadt Schwäbisch Gmünd, case C-12/86, ECR (1987) 3719, paras. 9 and 11; and of 30 May 2006 in Commission v. Ireland (Mox), case C-13/00, ECR (2006) I-2943, paras. 14-15.

${ }^{42}$ See especially the judgment of the ECJ of 26 October 1982 in Kupferberg, case C-104/81, ECR (1982) 3641, para. 13: "In ensuring respect for commitments arising from an agreement concluded by the community institutions the member states fulfil an obligation not only in relation to the non-member country concerned but also and above all in relation to the community which has assumed responsibility for the due performance of the agreement. That is why the provisions of such an agreement, as the court has already stated in its judgment of 30 April 1974 in the case 181/73, Haegeman, European Court reports, 1974, 449 , form an integral part of the community legal system."

${ }^{43}$ Art. 10 of the TEC provides that "Member States shall take all appropriate measures, whether general or particular to ensure fulfilment of the obligations arising [out] of this Treaty or resulting from action taken by the institutions of the Community. They shall facilitate the achievement of the Community's tasks. They shall abstain from any measure which could jeopardise the attainment of the objectives of the Treaty."

${ }^{44}$ See M. Petite, "Current Legal Issues in the External Relations of the European Union", EUI Law Working Paper No. 2006/38 (December 2006).

${ }^{45}$ See the Opinion of the Court of 15 November 1994, Opinion 1/94 (Competence of the Community to conclude international agreements concerning services and the protection of intellectual property), ECR (1995) I-05267, para. 108; and also Opinion of the Court of 19 March 1993, Opinion $2 / 91$ (Convention $N^{o} .170$ of the International Labour Organization concerning safety in the use of chemicals at work), ECR (1993) I-01061, where the Court underlines that: "This duty of cooperation, to which attention was drawn in the context of the EAEC Treaty, must also apply in the context of the EEC Treaty since it results from the requirement of unity in the international representation of the Community."

${ }^{46}$ See, generally, Pitea, supra n. 29.

47 On the position of the EC on the compliance mechanism in MEAs see, in this volume, N. Notaro, "The Policy and Practice of the European Union on Compliance Mechanisms under Multilateral Environmental Agreements", supra 535-544, and the Commission staff working paper, "Compliance mechanism in Multilateral environmental agreements (MEAs)”, Brussels, 18 March 2005, SEC (2005) 405. 
The case originates with the authorisation of a landfill in the territory of Kazokiskes, a village in Lithuania. It has been the subject of two different communications ${ }^{48}$ by the Association Kazokiskes Community (an NGO from Lithuania) to the Compliance Committee. The Association in one case alleged non-compliance by Lithuania with its obligations under Article 6 and Article 9, para. 2, of the Convention (ACCC/C/2006/16) with respect to decision-making on the establishment of the landfill; in the other the Association alleged the non-compliance by the European Community with Article 6, para. 2 and 4, and Article 9, para. 2 (ACCC/C/2006/17) of the Convention. ${ }^{49}$ In the Community legal order, the financing of a landfill belonged to the project listed in Annex I to the EIA Directive and to the installations listed in Annex I to the IPPC (Integrated Pollution Prevention and Control) Directive. In consideration of the obligations deriving from the implementation of the public participation and access to justice of the Aarhus Convention both directives were amended.

In particular, the communicant alleged that the EC institutions failed to comply on the one hand with the provisions of Article 6 of the Convention regarding the decision-making process concerning co-financing of the establishment of the landfill, and on the other there was a general failure of implementation of the provisions of the Convention into the EC legislation (in particular through the provision of the IPPC directive).

In relation to the first issue concerning Article 6 of the Convention, the Compliance Committee decided not to consider the allegation made, in consideration of the fact that the decision to finance the project was taken before the EC had ratified the Convention and that the issue of funding is under consideration in another communication $(\mathrm{ACCC} / \mathrm{C} / 2007 / 21) .^{50}$

On the issue of the application of Article 6 of the Convention in relation to multiple authorisations for landfills, after a premise on the variety of approaches to regulatory control of activities in Annex I of the Convention, the Committee underlined the specificity of the EC legal order and found no failure by the EC to comply with the Convention when transposing it through the EIA and IPPC directives.

In fact, according to the Committee:

"Article 6 of the Convention obliges the Parties to meet the minimum requirements for public participation in decision-making related to all activities listed in annex I (and other activities determined by the Parties). While this applies to the Party concerned too, the structure of the European Community and its legislation differs from those of all other Parties to the Convention in the sense that while relevant Community legislation has been

${ }^{48}$ See Decision I/7 on Review of Compliance, doc. ECE/MP.PP/2/Add.8 (2001, late issued on 2 April 2004) (Aarhus Convention NCP), paras. 18-24.

${ }^{49}$ See $<$ http://www.unece.org/env/pp/pubcom.htm> (visited 15 July 2008).

${ }^{50}$ In this communication an NGO from Albania has emphasized that the European Community (through the European Investment Bank) has violated Art. 6 of the Convention because the procedure leading to the approval of the European Investment Bank loan from the selection of the site of the Thermo-Power Plant (TEPP) at Treport Beach (Albania) through the end of the permitting procedures were conducted without the public participation requirements set by the Aarhus Convention. At the moment of writing the case is still pending. 
adopted to ensure public participation in various cases of environmental decision-making, it is the duty of its Member States to implement Community directives. This is the case also with the EIA Directive and the IPPC Directive, both of which apply to the decision-making concerning landfills" ${ }^{51}$ (emphasis added).

On the other hand, even though some of the activities analysed took place before the Convention's entry into force for Lithuania and consequently the non-compliance of the Party was excluded ${ }^{52}$ in its conclusions the Compliance Committee found that the Lithuanian legal framework was not in compliance with Article 6 of the Convention and consequently recommended the Meeting of the Parties "to recommend to the Government of Lithuania to take the necessary legislative, regulatory, administrative and other measures" and invited "the Government of Lithuania to draw up an action plan for implementing the above recommendations with a view to submitting it to the Committee by 31 December 2008" and "to provide information to the Committee at the latest six months in advance of the fourth meeting of the Parties on the measures taken and the results achieved in implementation of the above recommendations."

This very first case concerning the European Community and one of its Member States has been an occasion for the Committee to clarify the different roles played by those Parties in the implementation of the Aarhus Convention (at least for the issues that were taken into consideration by the Compliance Committee).

What it is also remarkable from a strict legal perspective is that in its conclusions the Compliance committee followed an approach different from "the classic search for responsibility". Indeed the Committee was inspired by a pragmatic and cautious approach. In accordance with its mission to facilitate compliance with the Convention, rather than applying rules of attribution to identify who would have been responsible under international law the Committee sought to achieve compliance in practice, by identifying who was in the position to adopt that conduct that would finally result in compliance with the Convention.

It is of little consequence whether the fulfilment of the above-mentioned commitments under the Aarhus Convention might involve the responsibility of both the Member State and of the Community. In other words, if the position taken by the Aarhus Compliance Committee in this case were generalised, the non-compliance body should take into account the internal rules of the organization and, in particular, the apportionment of competences in order to identify who is accordingly to take the necessary steps that will lead to compliance with the international obligation. In this

${ }^{51}$ See Compliance by the European Community with its Obligations under the Convention, doc. ECE/MP.PP/2008/5/Add.10 (2 May 2008), para. 44.

52 See ibid., para. 85 where the Compliance Committee argued that: "Since the bulk of activities related to preparation of the waste management plans took place well before the Convention entered into force in relation to Lithuania, the Committee did not address the subject matter of the corresponding allegations. Nevertheless the Committee is of the opinion that pending the ratification process, the Party should strive to apply the Convention. In this regard, the Committee notes that at the first meeting of the Parties (Lucca, Italy, October 2002) Lithuania, like other Signatories, approved the declaration calling on all the Signatories to put in place the full set of implementing legislation as well as procedures and mechanisms for implementing the specific provisions of the Convention and, in the interim, to seek to apply the provisions of the Convention to the maximum extent possible (ECE/MP.PP/2/Add.1, para. 9)." 
framework it is of little importance whether this is also the subject that is to be held responsible under the law of international responsibility.

One could say that the argument used by the Compliance Committee is not very far from the position held by the European Commission in response to the reports of the Special Rapporteur mentioned above, where the sui generis character of the EC was invoked to justify special treatment in the field of responsibility.

\section{ON THE INTERACTION OF THE EUROPEAN COMMISSION AND THE Non-Compliance Mechanism in MEAs}

Finally, it should be remembered that, as a general result of its institutional position in the European legal order the Commission continues to play a significant and decisive role in the enforcement of EC environmental law. ${ }^{53}$ However, the commitment to ensure that the Convention is implemented and applied correctly by the $27 \mathrm{Mem}$ ber States appears to be too challenging a task ${ }^{54}$ the effectiveness of which can be debated. Although environmental cases account for a large number of infringement proceedings promoted under Article $226 \mathrm{EC}$, only a few of them have been the result of a supposed infraction in the implementation of MEAs and even fewer have reached the judicial stage..$^{55}$

Against this background it is arguable that the action of compliance bodies established under MEAs could become a useful means of enforcement not only at the international but also at the European level, in a field in which the intervention of the Commission is neither immediate nor frequent. Paradoxically, from the restricted view of compliance with EC law, non-compliance procedures appear to be a valuable tool for improving the implementation and application of Community laws of international origin in the legal system of the Member States and of the EC. The action by compliance committees could thus be regarded as a complement to the supervisory role of the European Commission.

In this connection, it is also noteworthy that the very nature of non-compliance procedures (at least when non-adversarial and facilitative) $)^{56}$ seems to exclude that consideration by the relevant bodies of non-compliance issues by EC Member States in fields covered by community competences could be considered a breach of the exclusive jurisdiction of the ECJ based on Article $292 \mathrm{TEC}^{57}$ in the light of the absence of a dispute concerning the interpretation or application of the EC

\footnotetext{
${ }^{53}$ See P. Wenneras, The Enforcement of EC Environmental Law (Oxford: Oxford University Press, 2007), at 251.

${ }^{54}$ See Seventh Annual Survey on the Implementation and Enforcement of Community Environmental Law, SEC(2006) $1143<\mathrm{http}: / /$ ec.europa.eu/environment/law/pdf/7th en.pdf $>$ (visited 15 July 2008).

${ }^{55}$ See Hey, supra n. 4, at 7-8.

${ }^{56}$ In some respects, the consequences of the non-compliance mechanism in the Kyoto Protocol when the State Party has deliberately not complied could take the shape of sanctions.

${ }^{57}$ Art. 292 of the EC Treaty states that "Member States undertake not to submit a dispute concerning the interpretation or application of this Treaty to any method of settlement other than those provided for therein."
} 
Treaty. ${ }^{58}$ Non-compliance mechanisms look more like a complement than an alternative to the infringement procedure provided by the Treaty (Article 226-228 TEC).

${ }^{58}$ See the ECJ judgments in Commission v. Ireland (Mox), supra n. 41. For comments see C. Romano, "Commission of the European Communities v. Ireland. Case C-459/03. Judgment", Am. J. Int'l L., 101 (2007) 171-179; F. Casolari, "La sentenza Mox: la Corte di giustizia delle Comunità europee torna ad occuparsi dei rapporti tra ordinamento comunitario ed ordinamento internazionale", Diritto dell'Unione Europea, 12 (2007) 327-367; N. Lavranos, "The Mox Plant Judgment of the ECJ: How Exclusive is the Jurisdiction of the ECJ?”, Eur. Envt'l L. Rev., 15 (2006) 291-296; see also L.S. Rossi, supra n. 11. 


\title{
Chapter Thirty \\ The Policy and Practice of the European Union on Compliance Mechanisms under Multilateral Environmental Agreements
}

\author{
Nicola Notaro*
}

\section{INTRODUCTION}

This chapter provides a brief explanation of the basis for EC international action in the environment field while casting some light on the notion of shared competence under Multilateral Environmental Agreements (MEAs). After that, the core of the chapter provides a detailed description of EU policy and practice on compliance under MEAs, its reception by other countries and the powers left to the EC in case of non-compliance with a MEA by one of its Member States.

\section{The International Dimension of European Community Environment} POLICY

The international dimension of EC environment policy has been present since its inception ${ }^{1}$ but the promotion of international action in the environmental field has been specified as a key objective in the EC Treaty (Article174) only since its Maastricht amendment in 1992. ${ }^{2}$

The action of the EC in environmental matters, as well as its participation in international negotiations, is based upon Title XIX of the EC Treaty containing Articles 174 to 176 .

Under Article 174, Community policy on the environment shall contribute to "promoting measures at international level to deal with regional or worldwide environmental problems." It is therefore one of the objectives of EC environment policy to

\footnotetext{
* The views expressed here are the author's only.

${ }^{1}$ For a quick overview of the origins of EC environment policy, see N. Notaro, "European Union Environmental Policy", in Gloeckler et al. (eds.), Guide to EU Policies (London: Blackstone, 1998).

2 For electronic access to the original Treaties and all their amendments see $<$ http://eur-lex.europa.eu/ en/treaties/index.htm> (visited 15 July 2008)
}

T. Treves et al., eds., Non-Compliance Procedures and Mechanisms and the Effectiveness of International Environmental Agreements

(C) 2009, T.M.C. ASSER PRESS, The Hague, The Netherlands, and the Authors 
address environmental problems that are of a transboundary nature. The same provision also clarifies how such environmental issues shall be addressed by stating:

"within their respective spheres of competence, the Community and the Member States shall cooperate with third countries and with the competent international organisations. The arrangements for Community cooperation may be the subject of agreements between the Community and the third parties concerned, which shall be negotiated and concluded in accordance with Article 300."

The above provision enshrines at the highest level in the EC hierarchy of norms, i.e., in the Treaty, EC support for multilateral solutions to environmental problems of a regional or worldwide nature. It also recognises that the environment is an area of shared competence where both the Member States and the Community can conclude international agreements with third countries, when these agreements are in accordance with the Treaty's procedures.

It is estimated that about $70 \%$ of EC legal acts in the field of the environment are linked to the implementation of international commitments. ${ }^{3}$ It is therefore not a surprise that the EC is a major player in the international environmental arena that it influences with its political weight and its advanced and progressive legislation. In turn, the EC is influenced in the further development of its policies and laws by developments occurring under international law.

The EC is currently a Contracting Party to about forty MEAs, including agreements with a global scope (e.g., on climate, biodiversity, hazardous waste, ozone layer, chemicals, biosafety, etc.) and regional and sub-regional agreements (e.g., on the Mediterranean, the Baltic Sea, and several UNECE and Council of Europe conventions). ${ }^{4}$

In order for the EC to become a Party to a MEA, a special clause allowing the participation of a Regional Economic Integration Organization (REIO) needs to be inserted in the MEA in question. ${ }^{5}$

After the Maastricht Treaty that marked the transition, or evolution, of the EEC into the EC, the reference to economic integration to define the EC might sound almost obsolete. However, the presence of REIO clauses at least allows the EC to exercise its external competence in environmental matters. The situation is more

\footnotetext{
${ }^{3}$ On the relationship between international and EC environmental law, see N.Notaro, "International and European Environmental Law - Mutual Supportiveness for Improving 'Green Governance'", in Demaret et al. (eds.), Thirty Years of European Legal Studies at the College of Europe, 2 (2005) 511-526.

${ }^{4}$ For a list of the MEAs to which the EC is a Party, see $<$ http://ec.europa.eu/environment/international_ issues/agreements_en.htm> (visited 15 July 2008).

5 A list of treaties with full references is provided supra at XXXVII. See, in particular, Arts. 3(j) and 36 of the Cartagena Protocol. Art. 3(j): "Regional economic integration organization means an organization constituted by sovereign States of a given region, to which its member States have transferred competence in respect of matters governed by this Protocol and which has been duly authorized, in accordance with its internal procedures, to sign, ratify, accept, approve or accede to it"; Art. 36: "This Protocol shall be open for signature at the United Nations Office at Nairobi by States and regional economic integration organizations $[\ldots] "$.
} 
difficult in relation to 'old Conventions' such as CITES 6 and Ramsar Convention' that were concluded in the 1970s when the EC was not yet a significant international player in environmental matters, and do not therefore contain REIO clauses. In these cases, the EC enjoys observer status only and its full participation is hampered.

\section{Shared Competence in MEAs}

The very notion of a REIO implies a transfer of competence from the Member States to the REIO. This transfer can cover a particular area completely, thereby creating an exclusive competence for a REIO; or might be partial only, determining a situation of shared/joint competence. In the fields of trade, agriculture and fisheries, the EC has exclusive competence on most subject-matters. The same is true for many issues related to the internal market. In the field of the environment, as mentioned above, Community competence can be generally characterized as either shared or joint.

The notion of shared competence explains why both the EC and its Member States become Parties to MEAs; but also creates tensions between the Member States and the Community as their respective readings of who does what in international negotiations may differ.

The competence of the Community, be it exclusive or shared, is always based on the EC Treaty. While it is clear that the Commission negotiates for the Community on matters under exclusive competence, for shared competence the "rule of thumb" is to refer to the extent of the acquis ${ }^{8}$ related to the subject-matter of the negotiations. The more extensive EC legislation is on a certain matter, the more justified it will be for the Community to negotiate on the same matter at the international level. Due to the extensive legislative action undertaken by the Community in the environmental field, Community competence here is often shared but predominant. In these cases, it is for the Commission to lead international negotiations rather than for whichever Member State is then holding the (rotating) Presidency of the EU.

In any event, independently of who is representing the EC and its Member States in international negotiations, the Community institutions and the Member States are bound by a duty of loyal cooperation enshrined in Article 10 of the EC Treaty. Member States and the Commission have to coordinate their positions, in respect of international meetings, in a specific Working Group of the EU Council of Ministers dealing with international environmental matters. Such coordination processes also take place during the international meetings themselves in order to ensure the unity of the external representation of the EU throughout the negotiations.

It is also worth noting that the ratification of a MEA by the EC binds the Member States on matters covered by EC competence, even when they have not themselves become Parties to the MEA in question.

\footnotetext{
See $<$ http://www.cites.org $>$ (visited 15 July 2008).

7 See $<$ http://www.ramsar.org $>$ (visited 15 July 2008).

8 This term, in Community jargon, encompasses the whole body of EC policy and legislative measures in place.
} 


\section{EU Position on Compliance: Where Is It AND What Is in It?}

The above-described institutional set up has a direct relevance for the development of an EU (EC and Member States) position on compliance negotiations under MEAs. Conscious of the horizontal character of compliance as it is relevant to all MEAs, several EU Presidencies and the European Commission have attempted to 'codify' the EU position on compliance and reflect it in one agreed paper at Council level. These attempts have produced limited, though useful, outputs.

There exists no single formal EU Council decision or equivalent document containing an agreed EU position applicable to all compliance negotiations under all MEAs. However, already during the Belgian Presidency of the EU in 2001, a "Belgian paper", discussed at Working Group level in the Council, collected elements for an EU position on compliance under MEAs. ${ }^{9}$ The Commission followed up this first attempt by adopting in 2005 a Commission staff working paper on this issue. ${ }^{10}$ As a reaction to this Commission initiative, the UK Presidency attempted a new synthesis in 2005 developing a "UK paper"11 which still represents the state of the art of the EU position on compliance under MEAs. None of these papers has been formally endorsed by the Council, essentially because some Member States, while agreeing generally with the substance of the papers, feared being linked once and for ever to a position that might need to be adjusted in relation to the particular negotiation at stake. While this approach is correct in theory, both the language and the content of the UK paper make it clear beyond any doubt that the EU believes that, for compliance mechanisms under MEAs, there cannot be a "one size fits all" approach: all MEAs are different, each negotiation is different and flexibility is needed. However, the paper also recognises that when the EU approaches the issue of compliance from a horizontal point of view it is possible to identify the main EU objectives and, as a consequence, the main features of a compliance mechanism that are necessary to achieve those objectives. Therefore, the above-mentioned fears are more the expression of an overly cautious approach of some EU Member States than a rational and justified national position.

Against this background the UK Presidency paper is to be seen as a resource paper that is systematically used by the EU as the basis to develop specific EU position papers for each compliance negotiation. The main elements of the UK paper are described in the following sections under sub-headings reflecting the typical features of compliance mechanisms.

\subsection{Enabling Clauses}

The EU pays particular attention in treaty negotiations to the presence and content of enabling clauses. ${ }^{12}$ Such clauses generally provide for the establishment of

\footnotetext{
${ }^{9}$ On file with the author, this is not a public document.

${ }_{10}$ Commission Staff Working Paper of 18 March 2005 on Compliance Mechanisms in Multilateral Environmental Agreements (MEAs), SEC(2005) 405.

${ }_{11}$ On file with the author, this is not a public document.

12 See, e.g., Montreal Protocol, Art. 8; and Cartagena Protocol, Art. 34.
} 
a compliance mechanism and, since the EU supports the latter as a useful tool to enhance the implementation of MEAs, it also argues for the inclusion of enabling clauses in the text of MEAs. While it is unrealistic to think of developing a compliance mechanism already when negotiating an international agreement, it is in that context that enabling clauses should be agreed as an element of the negotiation package. Otherwise, it is likely to prove more difficult to start negotiations on compliance at a later stage, on the basis of a decision of the COP to the treaty in question, when some Parties who wanted a treaty may have reasons not to support a compliance mechanism thereunder.

Generally, the EU supports the inclusion in the enabling clause of a specific time frame for the adoption of the compliance mechanism (e.g., at the first COP) in order to speed up the process. In cases where this type of deadline is absent, negotiations of compliance procedures have tended to drag on indefinitely. ${ }^{13}$ In order to be able to develop an effective compliance mechanism, the EU tends to support a broad scope for enabling clauses that may also refer to the nature of the mechanism in question (facilitative in the first place but also punitive when necessary) and to the preferred method of adoption, i.e., a COP decision or, in rare cases, a binding amendment to a treaty.

\subsection{Objectives-Size and Composition-Functions}

The objectives of a compliance mechanism are the element that determines to a great extent the other features of such mechanism; therefore they are particularly controversial to negotiate. ${ }^{14}$ The EU supports mechanisms that promote and secure compliance, thereby including both a facilitative element, particularly important for developing countries, and a punitive element for cases of wilful non-compliance. When holding this position, the EU is often isolated in compliance negotiations, maybe with the exception of Switzerland and Norway. This is because developing countries as well as other developed countries are afraid that the punitive element might be used against them one day. As a result, a compromise to try and reconcile these opposing standpoints is often necessary.

In relation to the size of compliance committees, the EU favors small standing bodies in order to ensure efficiency and for the sake of continuity. Also the EU has

${ }^{13}$ E.g., in the case of the Rotterdam PIC Convention, see the latest version of the Draft compliance mechanism (Decision RC-3/4 on Draft Text of the Procedures and Mechanisms on Compliance with the Rotterdam Convention, doc. UNEP/FAO/RC/COP.3/26 (10 November 2006), Annex, at 27). For a similar case, see para. 2 of the Stockholm POPs Convention Draft non-compliance procedure (Decision SC-3/20 on Non-Compliance, doc. UNEP/POPS/COP.3/30 (4 May 2007), Annex, at 57) (Stockholm POPs Convention Draft NCP).

${ }^{14}$ See, e.g., the Kyoto Protocol non-compliance procedure (Decision 27/CMP.1 on Procedures and Mechanisms Relating to Compliance under the Kyoto Protocol, doc. FCCC/KP/CMP/2005/8/Add.3 (30 March 2006), at 92) (Kyoto Protocol NCP). See in particular Section I therein. See also the Cartagena Protocol non-compliance procedure (Decision I/7 on Establishment of Procedures and Mechanisms on Compliance under the Cartagena Protocol on Biosafety, doc. UNEP/CBD/BS/COP-MOP/1/15 (27 February 2004), Annex I, at 98) (Cartagena Protocol NCP); in particular Section I.1. See as well the Basel Convention non-compliance procedure (Decision VI/12 on Establishment of a Mechanism for Promoting Implementation and Compliance, Appendix, doc. UNEP/CHW.6/40 (10 February 2003), at 45). 
been a strong defender of independent committees whose members act in a personal and individual capacity and hold a range of expertise from legal to technical as relevant for the MEA in question. ${ }^{15}$ The EU position often faces the opposition of developing countries which tend to support larger committees to increase their chances of being represented in them in line with the idea that members of these committees are government representatives rather than independent experts.

Concerning the functions of compliance committees, ${ }^{16}$ the EU, in line with its overall support for compliance mechanisms, supports wide-ranging functions that allow the committees to address specific compliance cases as well as general or systemic compliance problems, in particular by reviewing Parties' reports. Also, the EU supports a distinction between the role of the committee and that of the COP, with the latter generally being the body entitled to take decisions that have financial implications or a punitive character.

\subsection{Triggering}

The triggering is the mechanism through which compliance issues are brought to the attention of compliance committees. ${ }^{17}$ The EU generally supports a wide scope for triggering in order to maximise the usefulness of committees. Therefore, it argues in favor of : 1. self-triggering (a Party with respect to itself); 2. Party to Party triggering (a Party with respect to another Party); 3. triggering by the secretariat; 4. triggering by the compliance committee; 5 . triggering by the COP; and 6 . triggering by the public. While the first five triggering mechanisms are generally supported by the EU in all cases, there exist nuances among EU Member States in relation to the order of priority among them. Some Member States attach more importance to the Party to Party trigger while others have a strong preference for the secretariat trigger. However, the only triggering mechanism that has really proven somewhat controversial within the EU is the public trigger. Some Member States (e.g., the UK and Germany) are afraid that a completely open ended public trigger might result in compliance committees being overwhelmed with complaints. Other Member States (e.g., Denmark, the Netherlands and Sweden) argue that the benefits of openness would outweigh the potential disadvantages. In some instances, particularly in the framework of the Aarhus Convention, it has proven rather difficult to arrive at a common EU position on this issue.

${ }_{15}$ See, e.g., Kyoto Protocol NCP, Section II, in particular II.4 on composition and II.6 on individual capacity. See also Cartagena Protocol NCP, Section II.3 on serving objectively and in a personal capacity.

${ }_{16}$ See, e.g., Cartagena Protocol NCP, Section III.1, in particular (e) on taking measures.

17 See, e.g., Kyoto Protocol NCP, Section VI.1 on Party and Party-to-Party trigger. See also the Montreal Protocol non-compliance procedure (Decision IV/5 on Non-Compliance Procedure, doc. UNEP/OzL. Pro.4/15 (25 November 1992), at 13 and Annex IV at 44, subsequently amended by Decision X/10 on Review of the Non-Compliance Procedure, doc. UNEP/OzL.Pro.10/9 (3 December 1998), at 23 and consolidated text in Annex II, at 47) (Montreal Protocol NCP); in particular para. 1 on Party-to-Party trigger. 


\subsection{Transparency and Openness}

In relation to the openness to the public of the deliberations of compliance committees, ${ }^{18}$ the EU defends the principle of openness in a wide sense, including the possibility to attend and participate for the Party concerned by the compliance matter under discussion, for other Parties and for observers, even though with some procedural limitations for the latter. Also, the EU supports the faculty for compliance committees to access all sources of information they deem relevant and recognises that a committee should be able to decide to have closed sessions when specific circumstances so require, e.g., to protect confidential information.

\subsection{Procedural Safeguards}

An EU concern with regard to compliance procedures is that they be fair by providing for adequate procedural safeguards. To this end, it argues that compliance claims should be supported by corroborating information; that the Party concerned should be given a right to reply within a reasonable time limit and that manifestly ill founded or de minimis claims should be rejected.

\subsection{Compliance Measures and Decision-Making}

Concerning the measures that compliance committees may adopt, the EU generally supports an open list of measures or, at least, a comprehensive closed list. They may include: provision of advice, facilitation of technical or financial assistance, voluntary action plans, etc. The EU also supports the possibility for committees to apply stronger measures but, as a compromise in many compliance negotiations, it has accepted that the latter be the prerogative of the COP. Such stronger measures should again be part of an open list or a comprehensive closed list. They may include: a caution, the publication of non-compliance, a statement of concern, appearance before the COP for the Party concerned, a declaration of non-compliance, the suspension of rights and privileges, a recommendation to restore the damaged environment, etc. Considering the strong opposition faced by the EU from both developing and (most of the other) developed coutries, it has not been possible for the EU to secure a comprehensive list in many cases. ${ }^{19}$

Furthermore, the EU identifies a number of criteria to be taken into account when determining the compliance measures to be applied by a committee or by the COP. Attention should be paid to the cause, type, degree, duration and frequency of

${ }_{18}$ See for instance Aarhus Convention non-compliance procedure (Decision I/7 on Review of Compliance, doc. ECE/MP.PP/2/Add.8 (2002, late issued on 2 April 2004) (Aarhus Convention NCP); in particular, Section VIII. See also Cartagena Protocol NCP, Section V.4; and Montreal Protocol NCP, para. 16, on confidentiality.

19 For a comprehensive list, see under the Montreal Protocol, the "Indicative list of measures that might be taken by a meeting of the Parties in respect of non-compliance with the Protocol" contained in the Report of the Fourth Meeting of the Parties, Annex V, doc. UNEP/OzL.Pro.4/5 (25 November 1992). See also Cartagena Protocol NCP, Section VI.2(d); Kyoto Protocol NCP, Section XV; and Basel Convention NCP, paras. 19 and 20 . 
non-compliance. Through these criteria, the different levels of capacity of the Parties to a MEA can be taken into account, paying due attention to the principle of common but differentiated responsibility. ${ }^{20}$ Therefore, the EU has in most cases rejected the idea that this principle be applied when determining if a Party is in compliance or not. That is supposed to be, in the EU view, an objective assessment of the facts. Individual Parties' circumstances only come into play when the committees/COPs look at ways to address the non-compliance situation.

In order to foster the efficiency of compliance committees, the EU supports decision-making based on qualified majority. This is in fact the standard rule for compliance committees apart from one regrettable exception. ${ }^{21}$

\subsection{Capacity Building and Financial Mechanisms}

Non-compliance is often a matter of lack of capacity of the Party concerned but compliance committees can build capacity only to a limited extent as they generally do not have a role to play in the allocation of financial resources. ${ }^{22}$ However, they can facilitate the provision of financial and technical assistance, e.g., by identifying where compliance problems lie. In this respect, the EU supports, as mentioned above, a facilitative role for compliance committees, while it is conscious of the fact that financial/technical assistance as such can only be provided by the COP, either directly or, more frequently, through guidance to the Global Environment Facility (GEF) ${ }^{23}$ that acts as the financial mechanism for a number of MEAs.

Developing countries make ever more often the link between the design of a strong compliance mechanism and the provision of financial resources. For instance, the unfinished compliance negotiations under the Rotterdam PIC Convention ${ }^{24}$ - which does not have a financial mechanism - have shown that some developing countries (e.g., India) object to any strong measure aimed at securing compliance arguing that they do not have the resources to comply. This argument is flawed in two respects: first, that Convention does not really entail incremental costs and, second, stronger compliance measures would always have to differentiate Parties on the basis of their capacity and take into account the reasons for non-compliance.

\subsection{Compliance v. Dispute Settlement - Review Clauses}

It is important for the EU to keep a clear distinction between compliance mechanisms and dispute settlement and, to this end, it supports standard clauses stating that

20 See Principle 7 of the Rio Declaration on Environment and Development, doc. A/CONF.151/26 (Vol. I) (12 August 1992), Annex I, reprinted in ILM, 31 (1992) 876.

${ }^{21}$ Under the Cartagena Protocol NCP no agreement was reached on the compliance committee's Rule of Procedure 18.1 (See Decision II/1 on Rules of procedure for Meetings of the Compliance Committee, doc. $\mathrm{UNEP} / \mathrm{CBD} / \mathrm{BS} / \mathrm{COP}-\mathrm{MOP} / 2 / 15$ (6 June 2005), at 29) and the decisions of the committee have to be taken by consensus.

${ }^{22}$ See, e.g., Cartagena Protocol NCP, Section I.3 and VI.1; see also Basel Convention NCP, para. 2; and Kyoto Protocol NCP, Section XIV on consequences applied by the Facilitative Branch.

${ }^{23}$ For GEF coverage see <http://www.gefweb.org/> (visited 15 July 2008).

${ }^{24}$ See supra n. 13 
compliance procedures are without prejudice to MEAs' rules on dispute settlement. ${ }^{25}$ In fact, compliance procedures have a multilateral character and do not concern a dispute between two Parties. They address non-compliance issues which are the collective interest of all Parties as non-compliance can affect the achievement of the objectives of MEAs and prejudice the environment as a common good. Moreover, compliance procedures - in contrast with dispute settlement - are generally nonadversarial and forward looking, aiming to re-establish compliance. Aware of the need to tailor compliance mechanisms to the MEA to which they apply, the EU also supports review clauses allowing for the periodical review of the effectiveness of compliance procedures.

\section{EU Position ON COMPliance ANd Third Parties}

During the late 80's and the 90's, many of the MEAs' compliance mechanisms were adopted and the EU was the main international actor behind their development. When looking at what these mechanisms have achieved and at their relative strengths and weaknesses, the picture is mixed. If under CITES, the Montreal Protocol and the Kyoto Protocol, rather strong and effective mechanisms are in place, under the Basel Convention and the Cartagena Protocol no case has been brought to the committees for a number of years. Even worse, in some other cases negotiations have failed to develop new mechanisms as under the Stockholm POPs Convention and Rotterdam PIC Convention as well as under the ITPGRFA. One of the reasons for such failures is the above-mentioned lack of a financial mechanism or, even for MEAs covered by the GEF, the perceived inadequacy of the latter. Other obstacles in the way of strong compliance mechanisms are the lack of true multilateralism on the side of some industrialised countries (US, Australia and, to a lesser extent, Japan, Canada and New Zealand) and their resistance to supranational bodies that could check domestic implementation of MEAs.

Facing this situation, the German Presidency launched in 2007 a stock taking exercise and an internal EU reflection on the future of compliance mechanisms under MEAs. This is being carried forward by the EU under individual MEAs, e.g., under the Cartagena Protocol, where the EU is shifting emphasis in its internal discussions from its request for stronger measures to the opening up of a "facilitative trigger" that could allow the committee or the secretariat to trigger the compliance procedure without the possibility of applying to Parties stronger measures or any kind of penalty. This entirely facilitative procedure might be necessary to make the most of compliance committees that are not being used despite the fact that non-compliance is widespread.

\footnotetext{
${ }^{25}$ See, e.g., Cartagena Protocol, Art. 34.
} 


\section{Non-Compliance of Member States and Consequences for the EC}

The strong non-compliance stand of the EU in international negotiations could have a boomerang effect in the case that the EU - the EC and/or its Member States - were incapable of ensuring their own compliance with the obligations undertaken under MEAs. Clearly, this is a political risk that the EU has accepted to take and this is also a good incentive to ensure compliance within the EU. However, due to the highly complex EU institutional set up, one may wonder what would be the consequences for the EC as Party to a MEA in the case that one of its Member States were to be found in non-compliance. Such a case is not remote or abstract and could have important political and economic implications in MEAs such as the Montreal and Kyoto Protocols which have a strong trade component. The European Court of Justice (ECJ) has touched upon this question in the "Etangs de Berre" judgment ${ }^{26}$ where it sets out a few principles in this regard. The ECJ ruled that, in ensuring compliance with commitments arising from an agreement concluded by the Community institutions, the Member States fulfil an obligation in relation to the Community, which has assumed responsibility for the due performance of the agreement. The Community has an interest in Member States' compliance with MEAs, at least in areas largely covered by EC law. Therefore, the Commission may bring Member States before the ECJ for their non-compliance with MEAs obligations, even when there is no breach of EC secondary law. The Commission is therefore in a much better position than any compliance mechanism to ensure the fulfilment of EU Member States' obligations under MEAs.

\footnotetext{
${ }^{26}$ Commission v. France, case C-239/03, ECR (2004) I-9325.
} 


\title{
Chapter Thirty-One \\ Obligations of the European Community and its Member States under the Kyoto Protocol
}

\author{
Leonardo Massai
}

\section{INTRODUCTION}

Three major events have characterized the international and European climate change and energy debate in the years 2007 and 2008. At the beginning of 2007, the EU Member States as well as the European institutions engaged in clear and ambitious commitments for the reduction of greenhouse gas (GHG) emissions and the promotion of cleaner energy by 2020 . This was the result of two major decisions, namely the Energy Policy for Europe package adopted on 10 January 2007 by the European Commission and the Presidency Conclusions of the European Council adopted on 8-9 March 2007. ${ }^{1}$ In the latter, Member States agreed on binding targets for the reduction of GHG emissions and the increase of $20 \%$ in the share of renewable energy in the final consumption of energy by 2020 and for the reduction of energy consumption by $20 \%$ in comparison with the 2020 projections to be achieved through the increase of energy efficiency. Furthermore, in November 2007, the international community gathered in Bali, Indonesia, under the umbrella of the UN Framework Convention on Climate Change (UNFCCC) and the Kyoto Protocol and agreed on the "Bali Action Plan", a roadmap defining the future of the Kyoto Protocol regime after 2012. Finally, on 23 January 2008, the European Commission presented a package of legislative proposals on the integration of climate and energy policy in the EU which set the stage for the future European commitment in these fields.

Stemming from above, this paper looks retroactively by addressing the core of the European Community (EC) and the Member States commitments in the international climate regime with a clear emphasis on the nature and the legal consequences of the participation of the EC and the Member States in the UNFCCC and the Kyoto Protocol. In particular, the details of the EU Burden Sharing Agreement in the light of Article 4 of the Kyoto Protocol and the latest EU enlargements (2004 and 2007) are addressed. Furthermore, the differentiation between the nature and extent of the

\footnotetext{
${ }^{1}$ Communication of the European Commission to the European Council and the European Parliament of 10 January 2007 on An Energy Policy for Europe, COM(2007) 1, and Presidency Conclusions of the European Council of 8-9 March 2007, Brussels 20 May 2008, REV 1 7652/1/08.

T. Treves et al., eds., Non-Compliance Procedures and Mechanisms and the Effectiveness of International Environmental Agreements

(C) 2009, T.M.C. Asser Press, The Hague, The Netherlands, and the Authors
} 
obligations created by the Kyoto Protocol are considered, together with the details of the consequences for non-compliance to be applied to the EC and the Member States from the perspective of both international and European law. Finally, the issue of the EC and Member States responsibility under EC law is commented.

\section{The Participation of the EC and its Member States in the International Climate Regime}

The international climate regime is based on the UNFCCC and the Kyoto Protocol, at least until the end of 2012. The UNFCCC was signed in Rio de Janeiro in 1992 and entered into force in 1994 and sets a series of general objectives aimed at the stabilisation of GHG levels in 2000 at the 1990 level through the cooperation between developed and developing countries, respectively Annex I and non-Annex I Parties. ${ }^{2}$ The list of Annex I Parties included the main industrialized nations, namely OECD members with the exclusion of Mexico and Turkey. ${ }^{3}$

In 1997, within the framework of the UNFCCC negotiations, the Kyoto Protocol was adopted by the third COP as an international binding agreement related to the UNFCCC and establishing stronger and more ambitious targets in the fight of the developed countries against climate change. Among others, the Kyoto Protocol sets a target of a 5\% overall reduction of GHG emissions in the period 2008-2012 from 1990 levels for Annex B Parties (Annex I states with quantified emission limitation and reduction commitments (QELRC) within the Protocol). The Kyoto Protocol runs until 31 December 2012 and the discussion over the future of this system has already started in the international community. ${ }^{4}$ Three are the main and peculiar features which contribute towards considering the Kyoto Protocol as one of the most advanced Multilateral Environmental Agreements (MEAs) in the field of environmental protection.

At first, the Kyoto Protocol introduced the possibility for Annex I Parties to meet some of the obligations created by the Kyoto Protocol via the implementation of the so-called flexible mechanisms, which can be used by Annex I Parties to meet part of their GHG reduction obligations. International Emission Trading (IET) - Article 17 of the Kyoto Protocol - is one of the flexible mechanisms and it allows Annex B Parties to acquire units from other Annex I Parties. These units may be in the form of assigned amount units (AAUs), removal units (RMUs), emission reduction units (ERUs) and certified emission reductions (CERs). The other two flexible mechanisms are the project-based activities, namely Joint Implementation (JI) and Clean Development Mechanism (CDM) - respectively Articles 6 and 12 of the Kyoto Protocol allowing Annex I Parties to implement projects reducing GHG emissions, or

\footnotetext{
2 A list of treaties with full references is provided supra at XXXVII.

3 Annex I Parties to the UNFCCC are: Australia, Austria, Belarus, Belgium, Bulgaria, Canada, Croatia, Czech Republic, Denmark, European Community, Estonia, Finland, France, Germany, Greece, Hungary, Iceland, Ireland, Italy, Japan, Latvia, Liechtenstein, Lithuania, Luxembourg, Monaco, Netherlands, New Zealand, Norway, Poland, Portugal, Romania, Russian Federation, Slovakia, Slovenia, Spain, Sweden, Switzerland, Turkey, Ukraine, United Kingdom of Great Britain and Northern Ireland and the United States of America.

${ }^{4}$ Kyoto Protocol, Art. 3.9.
} 
removing carbon from the air, in other Annex I Parties and non-Annex I Parties respectively, in return for ERUs and CERs respectively.

Secondly, the Kyoto Protocol established a comprehensive ad hoc non-compliance regime based on a permanent Compliance Committee and two branches, the Facilitative and Enforcement Branch. While the former is a consultative body whose main task is to assist countries in the achievement of their obligations under the Kyoto Protocol, the latter is a quasi-judicial body which can decide on specific consequences for non-compliance to be applied to the Annex I Parties in question.

Finally, the Kyoto Protocol recognized the possibility for Annex I Parties to offset part of their GHG emissions through the utilization of national resources in the agricultural and forestry sectors in terms of land-use, land-use change and forestry (LULUCF) activities. ${ }^{5}$

Both the UNFCCC and the Kyoto Protocol are open to the ratification of regional economic integration organizations (REIO), ${ }^{6}$ respectively under Articles 1.6 and 24.2. Accordingly, the EC first ratified the UNFCCC with the adoption of Council Decision 94/69/EC ${ }^{7}$ followed by all EU Member States, and later ratified the Kyoto Protocol with Council Decision 2002/358/EC. ${ }^{8}$ Council Decision 2002/358/EC concerned the approval of the Kyoto Protocol by the EC and in particular the joint fulfilment of the obligations created by the Protocol by the EC and the EU Member States. Member States were required "to take the necessary steps with a view to depositing their instruments of ratification or approval [...] not later than 1 June 2002." All 27 Member States of the EU have ratified or accepted both the UNFCCC and the Kyoto Protocol. Among these, Malta and Cyprus are not included in the list of Annex I Parties since at the moment of the opening for signatures for the UNFCCC in 1992, those two countries were not able to meet the general criteria for inclusion in the group of developed countries. This implies that both Malta and Cyprus are considered by the international climate regime as part of the developing countries group eligible for financial and technical assistance provided by developed countries or by the Global Environmental Facility (GEF) to comply with some of the requirements established by the UNFCCC and the Protocol, as well as by the flexible instruments established by the Kyoto Protocol. In order to include Malta and Cyprus in the Annex I of the UNFCCC, an amendment of the Convention is required and this can be adopted either by consensus of all Parties or by a three-fourths majority vote of the Parties present and voting. Furthermore, the proposed amendment will enter into force only in the case that at least three-fourths of the Parties to the UNFCCC have accepted or ratified

\footnotetext{
5 Ibid., Art. 3.3 and 3.4.

${ }^{6}$ UNFCCC, Art. 1.6: "Regional economic integration organization means an organization constituted by sovereign States of a given region which has competence in respect of matters governed by this Convention or its protocols and has been duly authorized, in accordance with its internal procedures, to sign, ratify, accept, approve or accede to the instruments concerned."

7 Council Decision 94/69/EC of 15 December 1993 concerning the conclusion of the United Nations Framework Convention on Climate Change, OJ (1994) L 33/11.

8 Council Decision 2002/358/EC of 25 April 2002 concerning the approval, on behalf of the European Community, of the Kyoto Protocol to the United Nations Framework Convention on Climate Change and the joint fulfilment of commitments thereunder, OJ (2002) L 130/1.

9 Ibid., Art. 6.
} 
it. On the basis of this lengthy and complex procedure, it is reasonable to think that the proposal for the inclusion of Malta and Cyprus on the list of Annex I Parties, indispensable for the $\mathrm{EU}$ to negotiate as a whole a future agreement on the reduction of greenhouse gas emissions, will be included in the amendment covering the details of the post-2012 climate regime.

In the field of the protection of the environment, the EC Treaty gives the Community and the Member States, "within their respective spheres of competence" the power to cooperate with non-EU countries as well as international organizations and negotiate international agreements in this field. ${ }^{10}$ This has been defined by many scholars as explicit external competence of the EC. ${ }^{11}$ Furthermore, the EC enjoys an implicit external power competence in all cases where the Community has adopted common rules at the European level. This is the main message of the European Court of Justice (ECJ) in the ERTA case which recognized a connection and a parallel between the external power and all cases where internal competence has been exercised by the Community. ${ }^{12}$ In respect of the position of the Member States vis-à-vis the EC and its external competence, in practice, all the major MEAs have been concluded by the Community and its Member States in a coordinated way. The same applies to the international climate regime, whereas the EC and its Member States have negotiated and implemented together, as well as signed and ratified separately but in a coordinated way, both the UNFCCC and the Kyoto Protocol. These international agreements are usually referred to as mixed agreements, namely treaties where the competence between the EC and the Member States is shared. In the field of environmental protection, the Community and the Member States have a shared competence as confirmed by the EC Treaty. Article 175.1 confers to the EC a general competence to adopt all legislative measures which are necessary to meet the objectives indicated under Article 174.1. ${ }^{13}$ On the other hand, Member States are given by Article 176 of the EC Treaty the possibility to introduce "more stringent protective measures", provided that such measures must be compatible with the EC Treaty and must be notified to the Commission. The Kyoto Protocol has been ratified by the Community with the adoption of Council Decision 2002/358/EC and simultaneously by the Member States and it falls within the shared competence of the EC and its Member States.

${ }^{10}$ EC Treaty, Art. 174.4: "Within their respective spheres of competence, the Community and the Member States shall cooperate with third countries and with the competent international organizations. The arrangements for Community cooperation may be the subject of agreements between the Community and the third parties concerned, which shall be negotiated and concluded in accordance with article 300 . The previous subparagraph shall be without prejudice to Member States' competence to negotiate in international bodies and to conclude international agreements."

${ }^{11}$ See in general I. MacLeod, I.D. Hendry, and S. Hyett, The External Relations of the European Communities (Oxford: Clarendon Press, 1996) and J. Jans, European Environmental Law (Groningen: Europa Law Publishing, 2008).

12 On the theory of implied external competence, see Commission v. Council, case C-22/70, ECR (1971) 263; and Officier van Justitie v. Cornelius Kramer, cases 3, 4 \& 6/76 ECR (1976) 1279 and Opinion 1/76 on the Draft Agreement Establishing a Laying-up Fund for Inland Waterway Vessels, ECR (1977) 741.

13 EC Treaty, Art. 175.1: "The Council [...] shall decide what action is to be taken by the Community in order to achieve the objectives referred to in Article 174." 
The EC participates together with its Member States in the international negotiations for the implementation of both the Convention and the Kyoto Protocol with its own negotiating group. As already mentioned, both the EC and its Member States share an equal status in the international climate regime, as well as a unique right to vote which cannot be exercised simultaneously by the EC and its Member States. Although the ECJ has several times required unity and close cooperation between the Member States and the EC in the representation and conclusion of an international treaty, ${ }^{14}$ the role of the European Commission and its experts is of extreme relevance, since they have the adequate knowledge and capacity to negotiate on behalf of both the Community and the Member States at the international level on such complex topics. ${ }^{15}$ In practice, the EC and its Member States participate and negotiate at the international level, especially in bilateral meetings, through the so-called "troika system", namely with the direct involvement of representatives of the European Commission, as well as the ongoing and future EU Presidency. The ongoing EU Presidency speaks in the plenary, but as already mentioned the role of the Commission is fundamental especially in matters where the Community has fully or almost completely harmonized the internal legislation.

\subsection{Article 4 of the Kyoto Protocol}

On the issue of the joint commitment of the EC and its Member States in the fulfilment of the obligations created by the international climate regime, it is relevant to emphasize that the UNFCCC provides for this possibility under Article 4.1 and the EC and its Member States agreed to be jointly committed to limit anthropogenic $\mathrm{CO}_{2}$ emissions. ${ }^{16}$ Under the Kyoto Protocol, the EC and its Member States decided to fulfil jointly the obligations indicated in Article 3.1, namely the reduction of GHG emissions, in accordance with Article 4 of the Protocol. The details of the European joint agreement were included in the instrument of ratification of the Kyoto Protocol, Council Decision 2002/358/EC, ${ }^{17}$ submitted by the EC to the UNFCCC Secretariat in accordance with Article 4.2 of the Kyoto Protocol. ${ }^{18}$

14 Opinion of the Court of 15 November 1994, Competence of the Community to Conclude International Agreements Concerning Services and the Protection of Intellectual Property - Art. 228.6 of the EC Treaty, ECR (1994), I-5267 and Opinion of the Court of 19 March 1993, Opinion of the International Labour Organization concerning safety in the use of chemicals at work, ECR (1993) I-1061.

15 EC Treaty, At. 300.1: "The Commission shall conduct these negotiations in consultation with special committees appointed by the Council to assist it in this task and within the framework of such directives as the Council may issue to it."

${ }^{16}$ Kyoto Protocol, Art. 4.1: "Any Parties included in Annex I that have reached an agreement to fulfill their commitments under Article 3 jointly, shall be deemed to have met those commitments provided that their total combined aggregate anthropogenic carbon dioxide equivalent emissions of the greenhouse gases listed in Annex A do not exceed their assigned amounts calculated pursuant to their quantified emission limitation and reduction commitments inscribed in Annex B and in accordance with the provisions of Article 3. The respective emission level allocated to each of the Parties to the agreement shall be set out in that agreement."

17 Council Decision 2002/358/EC of 25 April 2002, supra n. 8.

${ }^{18}$ Kyoto Protocol, Art. 4.2: "The Parties to any such agreement shall notify the secretariat of the terms of the agreement on the date of deposit of their instruments of ratification, acceptance or approval of this 
Article 4 of the Kyoto Protocol not only provides for Annex I Parties to fulfil part of their commitments jointly, it sets also specific boundaries which need to be highlighted. First of all, it blocks the mentioned joint fulfilment from both the temporal and the territorial point of view. Article 4.3 does not allow any change in the agreement until the end of the first commitment period, therefore until 31 December 2012. ${ }^{19}$ Furthermore, Article 4.4 does not recognize "any alteration in the composition of the organization" which could affect the agreed commitments under the Kyoto Protocol. ${ }^{20}$ The reasons that explain the "blocking clauses" established by Article 4 of the Kyoto Protocol are to be found in the negotiating process which contributed to the finalization of the text of the Protocol. In particular, in respect of the possibility for Parties to agree on a joint agreement to achieve the GHG emission reduction targets, the international community aimed at ensuring that this agreement would have not created the possibility for Annex I Parties to meet their emission reduction obligations in a less stringent way, namely through the utilization of cheaper reduction credits available in the EU due to the latest enlargements of 2004 and 2007. This was partially due to the desire of the negotiators to safeguard the environmental integrity of the Kyoto Protocol obligations, but also to the necessity not to provide any advantage to Parties of the Kyoto Protocol who decided to opt for a joint commitment. In particular, strong pressure in this direction was brought to bear by the so-called "JUSSCANNZ group" during the UNFCCC negotiations on the text of the Kyoto Protocol, notably Australia, Japan and the US, which were opposed to accepting any change in the composition of REIOs within the first commitment period.

The final part of Article 4 deals with the issue of the responsibility of Annex I Parties for compliance with the commitments agreed under Article 4.1. In the case that the agreed combined level of emission reductions is not achieved, Article 4.5 refers to individual State responsibility and each Party to the joint agreement is considered responsible for the failure to comply with its own level of emissions. ${ }^{21}$ Furthermore, Article 4.6 even goes a bit further and refers to the individual and also joint responsibility of each Party to the REIO. In the event that the combined level of emission reductions is not achieved both the REIO and the Parties shall be held responsible for their level of emissions. ${ }^{22}$ While in terms of international law, it seems quite clear to

Protocol, or accession thereto. The secretariat shall in turn inform the Parties and signatories to the Convention of the terms of the agreement."

${ }^{19}$ Kyoto Protocol, Art. 4.3: "Any such agreement shall remain in operation for the duration of the commitment period specified in Article 3, paragraph 7."

${ }^{20}$ Kyoto Protocol, Art. 4.4: "If Parties acting jointly do so in the framework of, and together with, a regional economic integration organization, any alteration in the composition of the organization after adoption of this Protocol shall not affect existing commitments under this Protocol. Any alteration in the composition of the organization shall only apply for the purposes of those commitments under Article 3 that are adopted subsequent to that alteration."

${ }^{21}$ Kyoto Protocol, Art. 4.5: "In the event of failure by the Parties to such an agreement to achieve their total combined level of emission reductions, each Party to that agreement shall be responsible for its own level of emissions set out in the agreement."

${ }^{22}$ Kyoto Protocol, Art. 4.6: "If Parties acting jointly do so in the framework of, and together with, a regional economic integration organization which is itself a Party to this Protocol, each member State of that regional economic integration organization individually, and together with the regional economic integration organization acting in accordance with Article 24, shall, in the event of failure to achieve the total 
conclude that the compliance system established under the Kyoto Protocol will decide on the responsibility of both the REIO at stake and its Parties in the case that the joint commitment is not achieved, less clear is the issue of the division of responsibility among the REIO and its Member States at the internal level.

Finally, it is important to emphasize that Article 4 establishes the possibility of a joint agreement among Parties in reference to QELRC under the Kyoto Protocol while not mentioning any other commitments created by the Kyoto Protocol.

\section{$2.2 \quad$ EU Burden Sharing Agreement}

The EU Burden Sharing Agreement was negotiated and agreed by the Community and the 15 Member States (EU-15) in 1997 as a decision of the Council Environment of 19 June $1998 .^{23}$ In accordance with Article 4 of the Kyoto Protocol, the EU-15 agreed to share internally the common reduction goal of the EC $(-8 \%)$ and to distribute the burden among themselves. On 31 May 2002, with the adoption of Council Decision 2002/358/EC, the EU Burden Sharing Agreement was notified to the UNFCCC together with the instrument of ratification of the Kyoto Protocol by the EC. With Decision 2002/358/EC, the ratification of the Kyoto Protocol and the joint fulfilment of its commitments (EU Burden Sharing Agreement) were integrated into the EU acquis communautaire and therefore became part of the requirements all EU Member States are required to comply with by EC law. Under the Burden Sharing Agreement, the EU-15 agreed on the establishment of national GHG emission reduction targets and on the joint fulfilment of those national obligations under the Kyoto Protocol as well as the EC target. Under recital 10 of the preamble of Council Decision 2002/358/EC:

"in deciding to fulfill their commitments jointly in accordance with Article 4 of the Kyoto Protocol, the Community and the Member States are jointly responsible, under paragraph 6 of that article and in accordance with Article 24(2) of the Protocol, for the fulfilment by the Community of its quantified emission reduction commitment under Article 3(1) of the Protocol.".24

Council Decision 2002/358/EC has to be considered in a slightly different way from the definition of Article 249 of the EC Treaty, namely a measure "binding in its entirety upon those to whom it is addressed", insofar as it concerns the ratification of a mixed agreement by the EC and its Member States and the introduction of the obligations created by this treaty in the EC legal order. The importance of the legal

combined level of emission reductions, be responsible for its level of emissions as notified in accordance with this Article."

${ }^{23}$ Document 9702/98 of 19 June 1998 of the Council of the European Union reflecting the outcome of proceedings of the Environment Council of 16-17 June 1998, Annex I.

24 The internal EU Burden Sharing Agreement has been included in Annex II of Council Decision 2002/358/EC and it establishes the following reduction commitments: EC -8\%, Belgium -7.5\%, Denmark $-21 \%$, Germany $-21 \%$, Greece $+25 \%$, Spain $+15 \%$, France $0 \%$, Ireland $+13 \%$, Italy $-6.5 \%$, Luxembourg $-28 \%$, Netherlands $-6 \%$, Austria $-13 \%$, Portugal $+27 \%$, Finland $0 \%$, Sweden $+4 \%$ and United Kingdom $-12.5 \%$. 
effects of Council Decision 2002/358/EC to the Community and its Member States is confirmed by the bargaining among the EU institutions in respect of the choice of the correct legal basis. Originally, the legal basis considered for the adoption of Council Decision 2002/358/EC was Article 174.4 of the EC Treaty, as indicated in the legislative proposal $\operatorname{COM}(2001) 579$, but this changed following the ECJ opinion 2/00 which established Article 175.1 as the correct legal basis for the ratification of mixed agreements by the Community. ${ }^{25}$ The difference in the procedures for the exercise of the EC external competence included in, respectively, Articles 174.4 and 175.1 relies on the stronger involvement of the Council in the latter. Indeed, although Council Decision 2002/358/EC was finally adopted with the consensus of all Member States, during the EU decision-making procedure, there were even some Member States which would have preferred Council Decision 2002/358/EC to be adopted on the basis of Article 175.2 - unanimity - claiming the strong relationship between the GHG emission reduction targets and the Member States' national energy policies. ${ }^{26}$ The obligations included in Annex II to such a decision are therefore binding for the EU Member States in terms of Community law and independently from the developments on the international climate regime at the international level.

\section{$2.3 \quad$ EU Enlargement}

Both of the two decisions on the ratification of the UNFCCC and the Kyoto Protocol mentioned above were adopted by the European Council before the latest enlargements of the EU, namely the accession of the Czech Republic, Cyprus, Estonia, Hungary, Latvia, Lithuania, Malta, Poland, Slovakia and Slovenia on 1 May 2004 and of Bulgaria and Romania on 1 January 2007. ${ }^{27}$ The same applies to the adoption of the Kyoto Protocol by the international community in 1997 and also the adoption of a few key EC provisions aimed at the implementation of the Kyoto Protocol, among which Council Directive 2003/87/EC ${ }^{28}$ and Decision 280/2004/EC on the mechanism for monitoring Community GHG emissions and for the implementation of the Kyoto Protocol..$^{29}$ However, in the case of the adoption of EC secondary legislation before 1 May 2005, representatives of the governments of the new Member States were involved in the decision-making process as observers. Furthermore, the new Member

${ }^{25}$ Opinion 2/00 on the Cartagena Protocol on Biosafety, ECR (2001) I-09713.

${ }^{26}$ F. Jacquemont, "The Kyoto Compliance Regime, the European Bubble: Some Legal Consequences", in M. Bothe and E. Rehbinder (eds.), Climate Change Policy (Utrecht: Eleven Publishing, 2005) 351-406, at 377 .

${ }^{27}$ In the context of this article, new Member States refer to the 12 countries which joined the EU in 2004 and 2007. These countries, with the exception of Malta and Cyprus, are also defined within the UNFCCC as Economies in Transition, namely States that are in the process of making the transition to a market economy.

28 Directive 2003/87/EC of the European Parliament and of the Council of 13 October 2003 establishing a scheme for greenhouse gas emission allowance trading within the Community and amending Council Directive 96/61/EC, OJ (2003) L 275/32-46.

${ }^{29}$ Decision 280/2004/EC of the European Parliament and of the Council of 11 February 2004 concerning a mechanism for monitoring Community greenhouse gas emissions and for implementing the Kyoto Protocol, OJ of 19 February 2004 L 49/1-8. 
States obtained transitional and derogation periods for certain areas and regulations of EC environmental law, which differ significantly from one country to another.

As for the new Member States, Malta and Cyprus have different legal status compared to the rest of the new Member States. Both countries have ratified the UNFCCC and the Kyoto Protocol, but they are not included in Annex I to the UNFCCC since at the moment of the adoption of the Convention they were not able to meet specific criteria in terms of monitoring and reporting of GHG emissions. It is important to emphasize that the status of non-Annex I Parties has allowed Malta and Cyprus to be eligible for the funding of the GEF which has been used for the preparation of the national communications. As mentioned earlier, the status of Malta and Cyprus in the UNFCCC will probably be changed together with the amendments to the international climate regime for the period post-2012.

The Kyoto Protocol under Articles 4.3 and 4.4 explicitly refers to the joint commitment of the EC which embraces the 15 Member States that originally negotiated the Protocol, with no consideration of the EU enlargement that took place on 1 May 2004, nor of the accession of Bulgaria and Romania of 2007. Furthermore, since the enlargement occurred after the adoption of Council Decision 2002/358/EC, the ratification and implementation of the Kyoto Protocol are a compulsory obligation for the new Member States as included in the acquis communautaire. The integration of international agreements and all related obligations in the $\mathrm{EC}$ legal order is a principle which was stressed by the ECJ in the Haegeman decision in $1974 .{ }^{30}$

In terms of the participation of the EC and its Member States in mixed agreements, the new Member States are required under Article 6 of the Act of Accession ${ }^{31}$ to accede to the agreements or conventions to which the EC and the existing Member States are bound and to implement such treaties in accordance with the details and obligations negotiated by the EC and its existing Member States. Considering that the protection of the environment falls within the competence of the EC and taking into account the limits set under Article 4.4 of the Kyoto Protocol, there was no legal need and possibility for the $\mathrm{EC}$ in its new composition to negotiate any additional protocol or amendment to the Kyoto Protocol in respect of the EU enlargement. New Member States have negotiated and agreed their own specific targets under the international climate regime and they are therefore bound by the Kyoto Protocol on a single basis. However, the case of the participation of the $\mathrm{EC}$ in the international climate regime is quite unique in the sense that the EC not only participates in the Kyoto Protocol as a REIO, but it has also agreed to fulfil jointly with its Member States the GHG emission reduction obligations under the Kyoto Protocol.

\footnotetext{
${ }^{30}$ See Haegeman v. Belgian State, case 181/73, ECR (1974) 449

${ }^{31}$ Act concerning the conditions of accession of the Czech Republic, the Republic of Estonia, the Republic of Cyprus, the Republic of Latvia, the Republic of Lithuania, the Republic of Hungary, the Republic of Malta, the Republic of Poland, the Republic of Slovenia and the Slovak Republic and the adjustments to the Treaties on which the European Union is founded, OJ (2003) L 236/33.
} 


\section{EC and Member States Compliance with the Kyoto Protocol OBLIGATIONS}

On the basis of the principle of common but differentiated responsibilities, the UNFCCC and the Kyoto Protocol have created a wide range of differentiated commitments for both Annex I and non-Annex I Parties.

Essential commitments for all Parties are included in Article 4.1 of the UNFCCC, namely: national inventories of GHG emissions and removals and national programmes containing measures for climate change - such as mitigation by addressing GHG emission sources and sinks, adaptation, transfer of technologies, sustainable management, cooperation for adaptation, research, education - and communication of information in accordance with Article 12.

Differentiated commitments for Annex I and non-Annex I Parties are listed in Article 4.2 to 4.8 of the UNFCCC. These are: voluntary commitment to reduce GHG emissions "individually or jointly" to 1990 levels and adoption of policies and measures and information accordingly (Annex I Parties); ${ }^{32}$ financial and technical assistance to developing countries for mitigation and adaptation (Annex II Parties); ${ }^{33}$ information (national inventories and national communications) and specific entitlements of certain Parties (non-Annex I Parties). ${ }^{34}$

In this paper we focus on the following three main sets of commitments created by the Kyoto Protocol for Annex I Parties: methodological and reporting obligations, eligibility obligations and reduction obligations.

\subsection{Methodological and Reporting Obligations}

The UNFCCC and the Kyoto Protocol established a wide set of specific methodological and reporting requirements for Annex I and non-Annex I Parties which respond to two main functions: at first, these requirements oblige Parties to the international climate regime to establish an adequate and precise system for accounting for GHG emissions at the national level whose methodological approach and technical aspects can be used for the monitoring of other pollutants falling outside the scope of the climate change system. Secondly, a uniform and functioning accounting system is crucial to assess the compliance of Annex I Parties with the GHG emission reduction obligations and for their participation in the flexible mechanisms.

The Kyoto Protocol and the Marrakech Accords established several requirements for Annex I Parties which give shape to the Kyoto Protocol accounting system aimed at the estimation of GHG emissions and the tracking of assigned amounts by Annex I Parties at the national level. In particular, rules for emission monitoring, government reporting and review of information and an accounting system for transaction under the flexible mechanisms and the sinks activities are established. These requirements are the following: (i) preparation of a national system for the estimation of GHG emissions by sources and removals by sinks (national GHG inventory) no later than

\footnotetext{
${ }^{32}$ Kyoto Protocol, Art. 4.2.

33 Ibid., Arts. 4.3 and 4.5.

34 Ibid., Arts. 4.6 and 4.8.
} 
1 January $2007 ;^{35}$ (ii) establishment of a registry for the tracking of Kyoto Protocol units ${ }^{36}$ (iii) submission of annual GHG inventory; ${ }^{37}$ (iv) regular submission of the national communication. ${ }^{38}$

In accordance with Article 4.1 and 4.12 of the UNFCCC, the international climate regime established two periodic reporting requirements for Annex I Parties, namely the submission of an annual report and a periodic national communication. Article 12 of the UNFCCC and Article 7 of the Kyoto Protocol set the details of the information to be included in this documentation. The annual report shall contain information on the national GHG inventory as well as additional information on the implementation of the Kyoto Protocol by Annex I Parties and on the holdings of the Kyoto units, emissions and removals from LULUCF, etc. Annual reports shall be submitted in the period 2007-2014 and will be the main source of information for monitoring the compliance of Annex B Parties with the Kyoto Protocol obligations. ${ }^{39}$

The ninth $\mathrm{COP}^{40}$ decided also to request Annex I Parties, by 15 April each year since 1996, to provide annual national GHG inventories covering emissions and removals of GHG from six sectors (energy, industrial processes, solvents, agriculture, LULUCF, waste), and for all years from the base year or period up to the most recent year. $^{41}$

35 Ibid., Art. 5.1. The national system for the preparation of the GHG inventory, namely the adoption of all the institutional, legal and procedural steps necessary for the preparation of the national GHG inventory, as well as its reporting and archiving of inventory information was due for all Parties by 31 December 2006.

${ }^{36}$ Decision 13/CMP.1 on Modalities for the accounting of assigned amounts under Article 7, paragraph 4, of the Kyoto Protocol, Annex, doc. FCCC/KP/CMP/2005/8/Add.2 (30 March 2006), para. 17.

37 Kyoto Protocol, Art. 7.1.

38 Ibid., Art. 7.2.

39 The annual report due on 15 April 2010 includes the information on national inventories for the first year of the commitment period. See Decision 14/CMP.1 on Standard Electronic Format for Reporting Kyoto Protocol Units, doc. FCCC/KP/CMP/2005/8/Add.2 (30 March 2006), para. 1 and Decision 15/CMP.1 on Guidelines for the preparation of the information required under Article 7 of the Kyoto Protocol, ibid., Annex, Section I.

${ }^{40}$ See Decision 9/CP.2 on Communications from Parties included in Annex I to the Convention: guidelines, schedule and process for consideration, doc. FCCC/CP/1996/15/Add.1 (29 October 1996); Decision 3/CP.5 on Guidelines for the preparation of national communications by Parties included in Annex I to the Convention, Part I: UNFCCC reporting guidelines on annual inventories, doc. FCCC/CP/1996/6/Add.1 (2 February 2000) and Decision 18/CP.8 on Guidelines for the preparation of national communications by Parties included in Annex I to the Convention, part I: UNFCCC reporting guidelines on annual inventories, doc. FCCC/CP/2002/7/Add.2 (28 March 2003).

${ }^{41}$ When Annex I Parties have to prepare their national communications and GHG inventories, they are required to follow specific guidelines defined by the COP. These guidelines were revised at the second COP for the preparation of the second national communications and at the fifth COP for the preparation of the third round of communications, where a few specific reporting guidelines for annual inventories of greenhouse gases were also indicated, see Guidelines for the preparation of national communications by Parties included in Annex I to the Convention, Part I: UNFCCC reporting guidelines on annual inventories, doc. FCCC/CP/1999/7 (16 February 2000). In accordance with the UNFCCC reporting guidelines on annual inventories, information to be submitted annually by Annex I Parties shall be in the form of a national inventory report (NIR) and common reporting format (CRF) tables including data from the base year or period up to two years before the year of submission, i.e., period 1990-2005 for submissions in 2007. 
Information on GHG emissions and removals are collected by the Secretariat and are available on the UNFCCC website. ${ }^{42}$

The registry system designed under the Kyoto Protocol is composed of three different components: the national registry, the CDM registry and the International Transaction Log. The national registry is established for tracking the holdings and transactions of Kyoto units by a Party, namely ERUs, CERs, AAUs and RMUs in accordance with the modalities adopted under Article 7.4 of the Kyoto Protocol. ${ }^{43}$ Annex I Parties are required to put in place a national registry at least before 31 December 2006. The establishment of a national registry is fundamental for Annex I Parties to participate in the flexible mechanisms, since the registries will serve to track emissions transfers under different units representing GHG reductions and to record and account them. National registries record and assess the assigned amounts of Annex I Parties and any movements of Kyoto units due to transactions under IET. National registries are fundamental instruments for the assessment of compliance by Annex I Parties with the Kyoto Protocol requirements. ${ }^{44}$

The CDM registry is established and maintained by the Executive Board of the $\mathrm{CDM}$ and contains the CERs accounts for non-Annex I Parties participating in the CDM.

The International Transaction Log is established and maintained by the Secretariat in order to supplement the national registries and to provide the checking of compliance of Annex I Parties at the end of the first commitment period. The International Transaction Log will verify transactions of ERUs, CERs, AAUs and RMUs as they are proposed, including their issuance, transfer and acquisition between registries, cancellation and removal. Moreover the International Transaction Log will also check whether an Annex I Party is meeting the eligibility criteria. If any transaction is found not to be in order, the registry is required to stop such transaction. When the commitment period expires, the verification of whether Annex I Parties are in compliance with their reduction obligations is done through the comparison of Annex I Parties' emissions in the commitment period with their holdings of ERUs, CERs, AAUs and RMUs. These data are included in the national registries.

As already mentioned, Articles 4.1 and 4.12 of the UNFCCC require Parties to prepare and submit periodical national communications including information on the implementation of the Convention. Most Annex I Parties presented their first national communications in 1994 or 1995 while the second round was submitted by most Parties in 1997. Economies in Transition were arranged according to a longer timeframe

42 The eighth COP requested the secretariat to publish on its website the annual inventory submissions consisting of the national inventory report (NIR) containing detailed descriptive and numerical information and the common reporting format (CRF) containing information on all GHG emissions and removals, as well as sectoral background data tables for reporting the emission factors involved and the activity data of all Annex I Parties.

${ }^{43}$ Decision 12/CMP.1 on Guidance relating to registry systems under Article 7, paragraph 4, of the Kyoto Protocol, doc. FCCC/KP/CMP/2005/8/Add.2 (30 March 2006) and Decision 13/CMP.1.

44 They will include the total assigned amount in the first year, all the unit transactions and transfers, the units removed during the year, and the final total assigned amount in the national registry. While the guidelines provided within the UNFCCC framework for the preparation of national inventories have been defined by the Marrakech Accords in 2001, the rules concerning the flexible mechanisms have been adopted later. 
and the second national communications were presented by the majority of countries in 1998. The third national communication was requested by 30 November 2001. In accordance with Article 7.2 of the Kyoto Protocol the national communication should also include supplementary information for Annex I Parties to demonstrate their compliance with the obligations of the Protocol.

The information submitted in the GHG inventory and the national communications are reviewed by the Expert Review Teams (ERTs) in accordance with the review procedure under Article 8 of the Kyoto Protocol. The ERTs will report to the COP-MOP and the Secretariat. Furthermore, the Kyoto Protocol and the Marrakech Accords require Annex I Parties to observe additional procedures for accounting assigned amounts before the first commitment period in order to participate in the flexible mechanisms.

\subsection{Eligibility criteria and flexible mechanisms}

The Kyoto Protocol established the flexible mechanisms whose procedural and operational rules were mainly defined in Marrakech in 2001 at the seventh COP. In order to participate in the flexible mechanisms, Annex I Parties shall comply with the following eligibility requirements defined under the Marrakech Accords on the basis of Articles 5.1, 5.2, 7.1 and 7.4 of the Kyoto Protocol: ratification of the Kyoto Protocol; calculation of the initial assigned amount in terms of the $\mathrm{CO}_{2}$-equivalent necessary for the determination of Annex I Parties' level of AAUs; establishment of a national system for the estimation of GHG emissions and removals as required under Article 5.1 of the Kyoto Protocol; establishment of a national registry for the management of the Kyoto units as required under Article 7.4 of the Kyoto Protocol; submission of the GHG inventory for the most recent year as required under Article 7.1 of the Kyoto Protocol; submission of information on the assigned amount as required under Article 7.1 of the Kyoto Protocol.

In other words, to be eligible to participate in the flexible mechanisms, Annex I Parties must have ratified the Kyoto Protocol and be in compliance with the correspondent methodological and reporting commitments. Any question over an Annex I Party's eligibility is addressed by the Enforcement Branch of the Compliance Committee, through expedited procedure.

The list of Parties meeting the eligibility criteria under Articles 6, 12 and 17 is provided by the Enforcement Branch of the Compliance Committee. ${ }^{45}$

On 28 December 2007, the Secretariat received a question of implementation on the basis of the ERT report on the review of the initial report of Greece. Greece was the first EU Member State subject to a question of implementation for the failure to comply with the preparation of the guidelines for national systems under Article 5.1

${ }^{45}$ Decision 3/CMP.1 on Modalities and procedures for a clean development mechanism as defined in Article 12 of the Kyoto Protocol, Annex, para. 34(b), doc. FCCC/KP/CMP/2005/8/Add.1 (30 March 2006) and Decision 9/CMP.1 on Guidelines for the implementation of Article 6 of the Kyoto Protocol, Annex, para. 27, doc. FCCC/KP/CMP/2005/8/Add.2 (30 March 2006) and Decision 11/CMP.1 on Modalities, rules and guidelines for emissions trading under Article 17 of the Kyoto Protocol, Annex, para. 4, doc. FCCC/KP/ CMP/2005/8/Add.2 (30 March 2006). 
of the Kyoto Protocol ${ }^{46}$ and the guidelines for the preparation of the information required under Article 7 of the Kyoto Protocol. ${ }^{47}$ Since the question of implementation is related to the eligibility requirements, the expedited procedures apply in this case and the decision of the Enforcement Branch on this matter is therefore expected within three months after the opening of the procedure..$^{48}$

Once eligibility to participate in the flexibility mechanisms is established, Annex I Parties shall ensure that this is maintained during the first commitment period. To this aim, each Annex I Party is required to submit annually the report on the GHG emissions and removals and its national registry to the Secretariat. Eligibility must be satisfied when the Kyoto units are transferred among Annex I Parties. Eligibility remains unless the Enforcement Branch declares an Annex I Party is in non-compliance with one or more of the eligibility criteria recalled above. The Enforcement Branch is the only entity authorized to suspend a Party's eligibility. The question of implementation can be raised either by the ERT or by another Party.

In addition, Article 3.2 requires Annex I Parties to provide the Secretariat with the report on demonstrable progress under the Kyoto Protocol. ${ }^{49}$

\subsection{Reduction obligations}

Under Article 3.1 of the Kyoto Protocol, Annex I Parties are required to ensure that

"their aggregate anthropogenic carbon dioxide equivalent emissions of the greenhouse gases listed in Annex A do not exceed their assigned amounts, calculated pursuant to their quantified emission limitation and reduction commitments inscribed in Annex B."

These reduction obligations have been agreed in order to reduce Annex I Parties' overall GHG emissions "by at least 5 per cent below 1990 levels in the commitment period 2008 to 2012". During the international negotiations for the design of the Kyoto Protocol, two were the main positions on the adoption of the details for the QELRC. On the one hand there was the EU position in favour of a single target year (2010); on the other the position of JUSSCANNZ - an umbrella group including, among others, the US, Japan, Canada, New Zealand and Australia - which successfully managed to negotiate the target period of 2008-2012.

The determination of compliance by Annex I Parties with the reduction obligations under Article 3.1 of the Kyoto Protocol is based on the comparison between the total GHG emissions listed in Annex A of the Protocol and the available assigned amounts at the end of the first commitment period. The latter corresponds to the initial assigned

${ }^{46}$ Decision 19/CMP.1 on Guidelines for national systems under Article 5, paragraph 1 of the Kyoto Protocol, doc. FCCC/KP/CMP/2005/8/Add.3 (30 March 2006).

47 Decision 15/CMP.1.

48 See S. Urbinati, "Procedures and Mechanisms Relating to Compliance under the 1997 Kyoto Protocol to the 1992 United Nations Framework Convention on Climate Change", supra 63-84, at 83-84 and M. Fitzmaurice, "Non-Compliance Procedures and the Law of Treaties", supra 453-481, at 479-480.

49 This report contains information on national policies and measures adopted for the implementation of the Kyoto Protocol GHG emission reduction obligations, the future scenario of these emissions, as well as information on the activities undertaken in accordance with Arts. 10 and 11 of the Kyoto Protocol. 
amounts, namely the quantity of units calculated in accordance with Article 3.7 and 3.8 , together with any addition and subtraction from the assigned amount through LULUCF activities and the Kyoto Protocol flexible mechanisms. ${ }^{50}$

\section{Consequences for Non-Compliance with the Kyoto Protocol OBLIGATIONS}

The Facilitative Branch is responsible for addressing questions of implementation in two cases: 1) ensuring compliance by Annex I Parties with the principle of supplementarity in the use of flexible mechanisms; 2) the minimization of "adverse social, environmental and economic impacts on developing countries" by Annex I Parties in the implementation of the GHG reduction obligations under Article 3.1. ${ }^{51}$ Consequences for non-compliance applied by the Facilitative Branch only consist of provisions and recommendations whose aim is to facilitate financial and technical assistance for the Parties concerned. ${ }^{52}$ Additionally, the Facilitative Branch is called upon to provide "early-warnings" and recommendations for Parties which are in danger of failing to meet their GHG emission reduction obligations, as well as the methodological and reporting requirements. ${ }^{53}$

The Enforcement Branch is responsible for addressing the compliance of Annex I Parties with the main three obligations indicated above. Moreover, the Enforcement Branch is also responsible for deciding on "adjustments to inventories under Article 5.2 " in the case of a dispute between a Party and the ERT, as well as "a correction to the compilation and accounting database" for assigned amounts under Article 7.4 in the case of a dispute between a Party and the ERT in respect of the validity of a transaction. ${ }^{54}$ The latter two cases will be called adjustment and correction consequences.

The Enforcement Branch is responsible for deciding on the compliance of Annex I Parties with the mentioned requirements and for determining the consequences of non-compliance. ${ }^{55}$

\footnotetext{
${ }^{50}$ According to Decision 13/CMP.1, each Annex I Party with a commitment inscribed in Annex B to the Protocol is required to facilitate the calculation of its assigned amount pursuant to Arts. 3.7 and 3.8, for the first commitment period and demonstrate its capacity to account for its emissions and assigned amount. To this end, each Party is required to submit the initial report containing all information required for this purpose, as defined in the Annex to Decision 13/CMP.1, by 1 January 2007 or one year after the entry into force of the Kyoto Protocol for that Party.

${ }^{51}$ Kyoto Protocol, Art. 3.14 and Decision 27/CMP.1 on Procedures and Mechanisms Relating to Compliance under the Kyoto Protocol, doc. FCCC/KP/CMP/2005/8/Add.3 (30 March 2006), at 92 (Kyoto Protocol NCP), Section IV.5.

${ }_{52}$ Ibid., Section XIV.

${ }^{53}$ Ibid., Section IV.6.

${ }^{54}$ Ibid., Section V.5.

${ }^{55}$ Kyoto Protocol NCP, Section XV.1, 2, 3, 4, 5. See Urbinati, supra 63-84, at 79. In case of non-compliance with the eligibility obligations, the suspension from participating in a flexible mechanism depends on which of the specific eligibility requirements are not met and therefore there may well be a situation where a Party is allowed to participate in one but not all flexible mechanisms. Obviously, the suspension from participating in international emissions trading may affect JI and CDM, namely the exchange of ERUs and/or CERs. The expedited procedure to reinstate eligibility mentioned above was introduced into the Marrakech
} 
In the case of compliance with the reduction obligations and once the review and compliance procedures have been completed, namely once the ERTs have finished assessing the final annual emissions inventory of Annex I Parties, the so-called "trueup" period lasting 100 days begins. In this period, Annex I Parties are granted an additional opportunity to finalize the transactions of carbon units (AAUs, CERs, ERUs or RMUs) under IET in order to comply with the reduction obligations under Article 3.1. The date for the start of the "true-up" period has to be decided by the COP-MOP prior to 2014.

Parties under the Kyoto Protocol enjoy the right of appeal to the COP/MOP against a decision of the Enforcement Branch if they believe that due process has been denied. The COP/MOP can "override the decision of the Enforcement Branch" by a majority of three quarters of the voting Parties and "refer the appeal back to the enforcement branch". ${ }^{56}$

\section{EC and Member States Compliance with the Kyoto Protocol OBLIGATIONS}

On the basis of the monitoring obligations established by the Kyoto Protocol, the EC has adopted a harmonized system for the accounting and monitoring of GHG emissions and for national registries to track all the different emission reduction units created within the framework of the Kyoto Protocol and its flexible mechanisms, as well as the European Union Allowances traded under the EU Emissions Trading Scheme. This system originated with Council Decision 93/389/EEC followed by Council Decision 99/296/EC for a monitoring mechanism of Community $\mathrm{CO}_{2}$ and other GHG emissions ${ }^{57}$ which introduced the obligations for the Member States to submit national programmes for the limitation and/or reduction of their GHG emissions as well as to prepare and submit to the European Commission each year, not later than 31 December, data on the "anthropogenic $\mathrm{CO}_{2}$ emissions and $\mathrm{CO}_{2}$ removal by sinks for the previous calendar year" and "a national inventory of data on emissions by sources and removals by sinks of the other greenhouse gases for the previous year but one and provisional emission data (inventories) for the previous year."

The EU monitoring system is completely in conformity with the requirements of the UNFCCC and the Kyoto Protocol and the compliance by the Member States with the EC monitoring decision is the precondition for the compliance of the EC with the monitoring obligations. The EC monitoring systems have been amended and updated in line with the developments of the international climate regime with the adoption of Decision 280/2004/EC amending Decisions 99/296/EC and Commission Decision

Accords under the specific request of Japan and it consists of the Party's right to request, either through an ERT or directly to the Enforcement Branch, the restoration of eligibility in the case that the problem has been rectified and the relevant criteria are met.

56 Ibid., Section XI.1.

57 Council Decision 93/389/EEC of 24 June 1993 for a monitoring mechanism of Community $\mathrm{CO}_{2}$ and other greenhouse gas emissions, OJ (1993) L 167, at 31-33 and Council Decision 99/296/EC amending Council Decision 93/389/EEC for a Monitoring Mechanism of Community $\mathrm{CO}_{2}$ and other Greenhouse Gas Emissions. 
2005/166/EC identifying parameters for projecting future emissions as well as indicators for the measurement of progress towards GHG emission commitments. ${ }^{58}$ On 18 July 2007, the European Commission adopted new guidelines for the monitoring and reporting of GHG emissions by companies falling within the scope of Directive 2003/87/EC. ${ }^{59}$ The guidelines replaces a similar document adopted before the start of the EU Emissions Trading Scheme and will apply from January 2008 when the second phase of the Scheme starts. According to the Commission, the new guidelines will reduce the costs of compliance with the directive by increasing the level of costeffectiveness. The EU registry system necessary for the tracking of European Union Allowances and other Kyoto units is defined under Regulation 2216/2004/EC for a standardized and secure system of registries pursuant to Directive 2003/87/EC and Decision 280/2004/EC, as well as under Commission Regulation 916/2007/EC. ${ }^{60}$

The data on GHG emissions indicated in the national inventories submitted by each Member State to the Commission every year are used by the Commission with the support of the European Environment Agency (EEA) to prepare the annual report on the Community developments towards GHG reduction commitments, namely the report on GHG emissions trends and projections in the EU, as well as periodical reports on the European environment outlook. Furthermore, it is also the duty of the European institutions, in particular of the Commission, to provide periodical information on the levels of GHG emissions to the Parliament and the Council, as well as to the European citizens and the UNFCCC Secretariat. For instance it is under Article 5.3 of Decision 280/2004/EC concerning a mechanism for the monitoring of the Community GHG emissions and for the implementation of the Kyoto Protocol that the Commission is required to prepare a report on the EC progress towards the Kyoto Protocol targets achieved by 2005.

On 27 November 2007 the EEA released Report N. 5/2007 “Greenhouse gas emission trends and projections in Europe 2007" which shed light on the EU-15 road toward the Kyoto Protocol targets and which represents, at the moment of writing, the latest available inventory on the EU levels of GHG emissions. According to the EEA, the EU-15 is likely to meet the $-8 \%$ GHG emission reduction targets without the inclusion of flexible mechanisms and sinks, provided that existing and additional domestic policies and measures are correctly implemented in the Member States. ${ }^{61}$

${ }_{58}$ Decision 280/2004/EC of the European Parliament and of the Council of 11 February 2004 concerning a mechanism for monitoring Community greenhouse gas emissions and for implementing the Kyoto Protocol, OJ (2004) L 49, at 1-8 and Commission Decision 2005/166/EC laying down rules implementing Decision No. 280/2004/EC of the European Parliament and of the Council concerning a mechanism for monitoring Community greenhouse gas emissions and for implementing the Kyoto Protocol of 10 February 2005.

${ }^{59}$ Commission Decision 2007/589/EC establishing guidelines for the monitoring and reporting of greenhouse gas emissions pursuant to Directive 2003/87/EC of the European Parliament and of the Council of 18 July 2007, OJ (2007) L 229/1-85.

${ }^{60}$ Regulation 2216/2004/EC for a standardized and secured system of registries pursuant to Directive 2003/87/EC and Decision 280/2004/EC of 21 December 2004 of OJ of 29 December 2004 L 386/1 as well as under Commission Regulation 916/2007/EC of 31 July 2007, OJ (2007) L 200/5.

${ }^{61}$ The contribution of the EU-15 efforts to meet the GHG emission reduction obligations under the Kyoto Protocol can be divided into: existing domestic policies and measures, - 4\%; additional domestic policies and measures, $-3,9 \%$; Kyoto Protocol flexible mechanisms, $-2,5 \%$; carbon sinks, $-0,9 \%$. 
At the moment of writing this paper, in terms of compliance by the EC and its Member States with the eligibility requirements two cases have to be mentioned. First, the question of implementation in respect of Greece for the failure to comply with the requirements on the national system for accounting GHG emissions ${ }^{62}$ and, secondly, the adjustments on national inventories and the correction to the compilation and accounting database for the assigned amounts decided by the Enforcement Branch in the case of dispute between a Party and the ERT. This latter case has been applied so far to two EU Member States, namely Greece and Netherlands, with respectively six adjustments in the energy sector "for which base year emissions have been overestimated" and one adjustment in the LULUCF sector for the base year. ${ }^{63}$

While cases and consequences for non-compliance with the Kyoto Protocol obligations are decided at the international level by the Enforcement Branch of the Compliance Committee, still open is the issue of responsibility under Community law especially in reference to the implications for the EC as a whole (Annex I Party) as one or more EU Member States are in a situation of non-compliance. What happens to the EC eligibility to participate in the flexible mechanisms in the case that one or more EU Member States do not meet the eligibility criteria and what happens to the EC assigned amounts in the case of adjustments for one or more EU Member States is still question of debate. The following conclusion tries to contribute to this debate.

\section{CONCLUSIONS}

Once the compliance with the requirements of the international climate regime is addressed it is important to discuss the issue of the responsibility of the Community and its Member States with those obligations under both international and Community law. As already pointed out, these are methodological and reporting obligations, the eligibility requirements for participation in the flexible mechanisms and the agreed GHG emission reduction targets. In this respect, the text of the Kyoto Protocol, namely Article 4, is clear in determining the general rules addressing Annex I Parties who agreed to fulfill jointly part of the Kyoto Protocol obligations responsibility under international law. As stated above, the compliance committee will determine the situation and the consequences for non-compliance with the Kyoto Protocol obligations by Annex I Parties. Article 4.5 of the Kyoto Protocol addresses Annex I Parties as Parties to the joint agreement and clearly refers to their individual responsibility. Article 4.6 deals with the individual and joint responsibility of the REIO and Parties of the joint agreement "in the event of failure to achieve the total combined level of emission reductions". On the other hand, Article 4 is of less help as far as the

62 "In particular, the ERT concludes that the maintenance of the institutional and procedural arrangements; the arrangements for the technical competence of the staff; and the capacity for timely performance of Greece's national system is an unresolved problem, and therefore lists it as a question of implementation", see Report of the review of the initial report of Greece, doc. FCCC/IRR/2007/GRC (28 December 2007), 244.

${ }^{63}$ See ibid., at 244-246 and Report of the review of the initial report of the Netherlands, doc. FCCC/ IRR/2007/NLD (2 November 2007), 187-189. 
issue of the determination and distribution of responsibility between the EC and its Member States is concerned. From the perspective of Community law, even less satisfactory in this sense is the practice of the ECJ, which only in a few cases dealt with the issue of the joint fulfilment of international obligations by the EC and its Member States.

The compliance committee is called upon to decide on compliance with the Kyoto Protocol obligations by Annex I Parties. It is very unlikely, and moreover it does not fall within the sphere of competence of the compliance committee, that this body will address in its decision the issue of the division of responsibility among the EC and its Member States. This is a matter falling within the framework of EC law: since EC law regulates the relations between the EC and its Member States, the issue of responsibility for the consequences of non-compliance shall be decided at the EU level. To this end, it is necessary to look at the details included in the instrument adopted by the EC to ratify and accept the obligations of the Kyoto Protocol, namely Council Decision 2002/358/EC and in particular Annex III on the declaration of competences under the Kyoto Protocol. This declaration is usually issued by the EC when adopting a MEA, thus considering the fact that these treaties are usually to be considered mixed agreements. Annex III states that

"the EC declares that its QELRC under the Kyoto Protocol will be fulfilled through action by the Community and its Member States within the respective competence of each and that it has already adopted legal instruments, binding on its Member States, covering matters governed by the Protocol."

Furthermore, this thesis is confirmed by the Kyoto Protocol itself, namely Article 24.2 of the Kyoto Protocol which explicitly confers to the EC and its Member States the power to decide on their respective responsibilities. ${ }^{64}$ However, based on the considerations above, the membership to the EU implies that Member States are required to comply with the acquis communautaire, and the compliance with the obligations created by an international treaty to which the EC is bound is part of the acquis. In this sense, it is important to distinguish among the different obligations established by the Kyoto Protocol. In respect of the reduction obligations, the Community and the EU-15 are jointly liable on the basis of Article 4 of the Kyoto Protocol in the event of the failure by the EC to comply with its reduction obligation (-8\%). In this sense, although the Kyoto Protocol explicitly refers to the EC composed of $15 \mathrm{Mem}$ ber States, one could argue that under Community law it is the EU composed of 27 Member States together with the single 15 Member States which are liable under international law for the reduction obligations. In respect of the participation of the EC and its Member States in mixed agreements, the new Member States are required under Article 6 of the Act of Accession ${ }^{65}$ to accede to the agreements or conventions to which the EC and the existing Member States are bound and to implement such

${ }^{64}$ Kyoto Protocol, Art. 24.2: "In the case of such organizations, one or more of whose member States is a Party to this Protocol, the organization and its member States shall decide on their respective responsibilities for the performance of their obligations under this Protocol."

${ }^{65}$ Supra n. 31 
treaties in accordance with the details and obligations negotiated by the EC and its existing Member States. Affirming that the EU-12 share the same level of responsibility as that of the EU-15 in respect of the EC joint reduction commitment is probably too extreme since Annex II of Council Decision 2002/358/EC addressed only the EU15 and this is recalled also by Commission Decision of 14 December 2006 on the determination of emission levels of the EC and its Member States. ${ }^{66}$ What could be the subject of discussion is a kind of indirect responsibility of the EU-12, outside the EU Burden Sharing Agreement, in the case of the failure by the Community to meet its reduction obligation. In this respect one could claim a certain degree of responsibility of the Member States, old and new, to assist the Community in ensuring the fulfilment arising out of the obligations of the Kyoto Protocol as highlighted in Article 10 of the EC Treaty. ${ }^{67}$ Article 10 EC Treaty, namely the principle of loyal cooperation, is recalled by recital 10 and Article 2 of Council Decision 2002/358/EC. Furthermore, recital 12 of the preamble stresses once more the responsibility of the Member States towards the EC commitment, namely

"the Community and its Member States have an obligation to take measures in order to enable the Community to fulfill its obligation under the Protocol without prejudice to the responsibility of each Member State towards the Community and other Member States to fulfilling its own commitments".

In respect of the eligibility, as well as the monitoring and reporting obligations, under the Kyoto Protocol it is important to stress that once again the accession of 12 additional Member States after the ratification of the Kyoto Protocol by the Community in 2002 does not affect the Community's commitments under the Protocol.$^{68}$ On the other hand the information on monitoring and reporting of GHG emissions provided by the EC for the EU-27, including Malta and Cyprus, is clearly separated from that for the EU-15. In accordance with Community law, the GHG inventory information presented by the Community to the UNFCCC also includes information for the new Member States and the same applies, for instance, to the standardized system of registries. In this respect the responsibility of all $27 \mathrm{Member}$ States in the case of failure by the Community to comply with the eligibility as well as with the methodological and reporting obligations under the Kyoto Protocol is clear.

As for the consequences for Member States under Community law for failure by the EC to comply with the Kyoto Protocol obligations, the infringement procedure designed under Articles 226 and 228 of the EC Treaty applies. The distinction between the reduction obligations and all other obligations relies on the type of the

${ }^{66}$ Commission Decision of 14 December 2006 2006/944/EC determining the respective emission levels allocated to the Community and each of its Member States under the Kyoto Protocol pursuant to Council Decision 2002/358/EC, OJ (2006) L 358/87.

${ }^{67}$ EC Treaty, Art. 10: "Member States shall take all appropriate measures, whether general or particular, to ensure fulfilment of the obligations arising out of this Treaty or resulting from action taken by the institutions of the Community. They shall facilitate the achievement of the Community's tasks. They shall abstain from any measure which could jeopardise the attainment of the objectives of this Treaty."

${ }_{68}$ Report from the Commission $\operatorname{COM}(2006)$ 799, Assigned Amount Report of the European Union, Brussels 15 December 2006. 
potential breach of EC law by the Member States. The former would imply the breach of general principles of EC law, namely Article 10 of the EC Treaty, while the latter would be caused by the failure to implement existing and specific EC legislation.

The criticisms of the effectiveness of the infringement procedure under EC law, as introduced by the Treaty of Maastricht in 1993, namely the excessive lengthiness of the procedure, are in many aspects well-known. In this respect it is worth mentioning the changes to the infringement procedure proposed in the Treaty of Lisbon amending the Treaty on European Union and the Treaty establishing the European Community adopted by the European heads of State and government in December 2007. ${ }^{69}$ Indeed the Treaty of Lisbon amends substantially the infringement procedure designed by the Treaty of Maastricht and based on the principle that a Member State, in order to be compelled to pay a lump sum or penalty payment, shall first be sentenced by the ECJ in accordance with the procedure under Article 226 EC Treaty. The amended procedure included in Article 228.3 of the EC Treaty allows the European Commission, within the framework of a proceeding falling under Article 226 of the same Treaty and in the case that a Member State has failed to transpose a directive in the national legislation,

"to specify the amount of the lump sum or penalty payment to be paid by the Member State concerned which it considers appropriate in the circumstances."

With this procedure a Member States may be required to pay a lump sum or a penalty already within the procedure under Article 226. Although the amendments introduced by the Treaty of Lisbon only refer to the case of failure by Member States to transpose a directive, the introduction of such a change in the EC infringement procedure is certainly to be considered positively in terms of the enforcement and compliance mechanisms under EC law.

${ }^{69}$ See "Treaty of Lisbon amending the Treaty on European Union and the Treaty establishing the European Community" adopted by the Conference of the Representatives of the Governments of the Member States in Brussels on 3 December 2007. 
1 
Section VI

Conclusions 
1 


\title{
Chapter Thirty-Two \\ Non-Compliance Mechanisms: Lessons Learned and the Way Forward
}

\author{
Attila Tanzi and Cesare Pitea*
}

\section{INTRODUCTORY REMARKS}

In a short period of time non-compliance mechanisms have become a sort of a "must" within the institutional regimes established by multilateral environmental agreements (MEAs). This testifies to the fairly general consensus that has developed among negotiators on the need to establish similar procedures, with special regard to the particular standard-type studied in this book: namely, one in which specific cases of non-compliance are dealt with by a specialised standing treaty body. The appropriateness of such mechanisms is rarely questioned, while controversy only arises as to the way they should be designed, with special regard to a few discrete points. This has led to a number of variations on the theme. As highlighted throughout the present book, the main differences concern the composition of the relevant body, the subjects entitled to initiate the procedure and the relationship between the compliance body and the COP/MOP, with specific regard to their respective powers on the matter in hand.

This simple observation, however, does not preclude the possibility of making considerations of a more general nature. Firstly, there is widespread agreement on the fact that these mechanisms are to be non-judicial, non-confrontational and consultative. ${ }^{1}$ This means that States generally refuse to conceive these mechanisms as instruments for a third-party binding determination of whether the relevant obligations have been complied with or not. Secondly, there is a common perception that these mechanisms should primarily aim at facilitating compliance rather than stigmatising the concerned party. Thirdly, their effectiveness relies heavily on cooperation by the party experiencing difficulties in complying, in that it should itself bring the issue

\footnotetext{
* This chapter is the result of common reflections by the two authors - Paras. 1 and 2 were written by Attila Tanzi and para. 3 by Cesare Pitea.

${ }^{1}$ With the possible exception of the mechanism established under the Kyoto Protocol, whose Art. 18 requires the Parties to set up "appropriate and effective procedures and mechanisms to determine and to address cases of non-compliance with the provisions of this Protocol." Decision 27/CMP.1 indicates that the "[...] procedures and mechanisms are to facilitate, promote and enforce compliance [...]", see S. Urbinati, "Procedures and Mechanisms Relating to Compliance under the 1997 Kyoto Protocol to the 1992 United Nations Framework Convention on Climate Change", supra 63-94, at 67-68.
}

T. Treves et al., eds., Non-Compliance Procedures and Mechanisms and the Effectiveness of International Environmental Agreements

(C) 2009, T.M.C. ASSER PRESS, The Hague, The Netherlands, and the Authors 
before the relevant body or, at least, engage constructively in a process leading to the pinpointing of the reasons for and origins of non-compliance, as well as of the tools (and possibly resources) to remedy to the situation.

Although academia has never neglected the importance non-compliance mechanisms may have, scholars have mainly focused, through some seminal studies, on the theoretical basis for establishing such mechanisms and on how they relate with wellknown concepts of public international law. ${ }^{2}$ Another branch of scholarship has dwelled on the issue of their legal nature. ${ }^{3}$ However, due to their timing, these reflections have been highly theoretical in most cases, based on the observation of the mere textual element or, at most, of the narrow practice existing at the time of their writing. Less attention has been devoted to the more practical issue of how these mechanisms function in practice, in order to provide criteria for assessing their effectiveness and to identify whether this is influenced by certain features.

The research and discussion which have led to the present book have suggested a different approach. Also taking advantage of the latest developments of practice in this field, it is based on the assumption that trying to identify a common legal nature for non-compliance mechanisms simply by looking at their founding instruments is an impossible and far from useful exercise. It appears that, apart from the differences already noted between the various mechanisms, the overall phenomenon is still undergoing an evolutionary phase. COP/MOPs keep these mechanisms very much under observation and the flexibility of the instrument used to establish them - usually a COP/MOP decision - easily allows their amendment and modification. More importantly, given their innovative and to some extent unclear nature, in order to make a legal assessment of the phenomenon in point, what actually happens in practice is of crucial importance. Namely, it appears that the legal nature of each of these mechanisms is to a large extent being shaped by the way the women and men taking part in their functioning conceive their mandate.

However, a mere recognition of practice cannot be conclusive. Alongside a comparative analysis, a selective approach is suggested with a view to identifying formulae that best conform to the rationale underlying the very establishment of such mechanisms. Against such a rationale emerging from each given case, some minimum features of a general character for testing the effectiveness of a non-compliance mechanism will be suggested. This may allow for a fresh look at the long-debated issue of the legal nature of the mechanisms under review without forcing them into

\footnotetext{
${ }^{2}$ Especially relevant are the studies by M. Koskenniemi, "Breach of Treaty or Non-Compliance? Reflections on the Enforcement of the Montreal Protocol", YB Int'l Envt'l L., 3 (1992) 123-161 and by M. Fitzmaurice and C. Redgwell, "Environmental Non-Compliance Procedures and International Law, Netherlands YB Int'l L., XXXI (2000) 35-65.

${ }^{3}$ See, for example, J. Voïnov Kohler, Le mécanisme de contrôle du respect du Protocole de Kyoto sur les changements climatiques: entre diplomatie et droit (Zurich: Schulthess, 2006), especially at 110-124. See also C. Pitea, "The Non-Compliance Procedure of the Aarhus Convention: Between Environmental and Human Rights Control Mechanisms", Italian YB Int'l L., 16 (2006) 85-116, at 104-105; L. Boisson de Chazournes and M.M. Mbengue, "Nature. A propos du caractère juridictionnel de la procedure de nonrespect du Protocole de Kyoto", in S. Maljean-Dubois (ed.), Changements climatiques les enjeux du contrôle international (Paris: La Documentation Française, 2007) 73-109.
} 
the overemphasized dichotomy between the diplomatic and judicial means of dispute mechanisms. ${ }^{4}$

Needless to say, this approach is far from being neutral in terms of value judgment and the conclusions reached in the present chapter, inasmuch as they are the sole responsibility of its authors, owe much to the collective discussion which took place at the Milan Conference as reflected throughout the present book. ${ }^{5}$

\section{The Purpose of Non-Complance Mechanisms and the Factors ENHANCING THEIR EFFECTIVE FunCtioning}

\subsection{A Means to Enhance the Effectiveness of International Environmental Law}

The establishment of non-compliance mechanisms is firmly rooted in the need to foster the effectiveness of MEAs, upon consideration of the fact that traditional means for the enforcement of international law, including dispute settlement, have not proved fully appropriate in this particular field. ${ }^{6}$

Other reasons may induce States individually to propose and accept non-compliance mechanisms. This may include the need for Governments to appear as supporters of environmental protection before domestic and international public opinion or the prospects that such procedures may result in financial or technical support for the implementation of the relevant treaty obligations. ${ }^{7}$ Pessimists have made the case that the establishment of weak compliance mechanisms is aimed at providing a (costly) shield of good intentions behind which States may hide their unwillingness to have their obligations seriously scrutinized. ${ }^{8}$ Be that as it may, the general aim of the procedures under consideration is that of enhancing the effectiveness of their international obligations in the field, and practice has not provided evidence to the contrary.

Thus, the present chapter moves from the simple consideration that non-compliance mechanisms aim at ensuring and improving the compliance rate by the Parties to a given MEA on a non-selective and objective basis. For it appears that their

\footnotetext{
${ }^{4}$ On complementarity between judicial and diplomatic means of dispute settlement, see A. Tanzi, Introduzione al diritto internazionale contemporaneo (Padua: Cedam, 2006, $2^{\text {nd }}$ edn.), at 345-346.

${ }^{5}$ An account of the Conference is given by A. Broggiato, "Non-Compliance Mechanisms and International Environmental Law", Env. Pol'y \& L. 38 (2008) 70-73.

${ }^{6}$ Koskenniemi, supra n. 2, at 125-128; R. Wolfrum, "Means of Ensuring Compliance with and Enforcement of International Environmental Law", $R d C, 272$ (1999) 9-154, at 96-100; M. Ehrmann, "Procedures of Compliance Control in International Environmental Treaties", Colo. J. Envt'l L. \& Pol'y, 13 (2002) 377-443, at 435-436. For a more general analysis and further references, C. Romano, "International Dispute Settlement", in D. Bodansky, J. Brunée and E. Hey (eds.), Oxford Handbook of International Environmental Law (Oxford: Oxford University Press, 2007), 1037-1056.

7 See F. Romanin Jacur, "Controlling and Assisting Compliance: Financial Aspects", supra 419-437.

${ }^{8}$ A softer version of this position is taken by G. Ulfstein, T. Marahun, and A. Zimmermann, "Introduction", in G. Ulfstein, T. Marauhn, and A. Zimmermann (eds.), Making Treaties Work. Human Rights, Environment and Arms Control (Cambridge: Cambridge University Press, 2007) 3-12, at 3, who claim that a possible reason for the establishment of non-compliance procedures is that they allow more control by States over the process and its outcome than adjudication.
} 
legitimacy and effectiveness depend on their capacity to serve the common interest of the Parties as it is reflected in the treaty obligations they have undertaken.

To this end, compliance bodies must be such as to be able to consider the widest possible number of cases, regardless of the State or States concerned and of the political aspects involved. Also, if the rate of activity of a non-compliance mechanism is low, due to the lack of action by authorised subjects or to the frequent dismission of cases on procedural grounds by the compliance body, the usefulness of its very raison d'être comes into question. A further element enhancing effectiveness is the ability of this mechanism to engage the States concerned in the process of compliance review, since cooperation by them is co-essential for their functioning. However, the desire to engage States should not sacrifice the integrity of legal rules by legitimising deviations from the relevant obligations, otherwise the overall purpose of the mechanism would be frustrated altogether.

From these assumptions a number of preliminary elements have emerged as a key to assessing the effectiveness of compliance mechanisms and they are dealt with in the following subsections.

\subsection{Mandate. Between the Political and Legal Dimensions}

A major issue is how the mandate of a compliance body should be interpreted by the latter. The question may also depend on the relationship between compliance bodies and COP/MOPs. Some compliance bodies may regard themselves as political forums in which compliance issues are negotiated "on behalf" of the COP/MOP. Were this to be the case the workings of a compliance body would be tantamount to a preparatory stage of the decision-making process of the COP/MOP. This approach raises serious doubts as to the possibility for the compliance body to be up to an objective minimum standard of effectiveness. Indeed, according to this rather extreme position compliance mechanisms would be conceived as an especially "proceduralised" form of multilateral negotiation on the content and implementation of MEAs obligations, in which any evaluation would be of a political nature and there would be no place for legal assessment. ${ }^{9}$ It is difficult to subscribe to this approach on several counts, two of which deserve to be singled out. First, from a purely legal perspective, this would institutionalise the idea that treaty obligations may be subject to continuous renegotiation, through the political determinations of the COP/MOP or of a subsidiary body having the same political nature. According to this reasoning, treaty law would be turned into soft law. ${ }^{10}$ Although MEAs often provide for simplified and unconventional law-making processes, they never go so far as to question so radically

${ }^{9}$ This is sometimes expressed by those that emphasize the "diplomatic" nature of compliance procedures, see J. Klabbers, "Compliance Procedures", in D. Bodansky, J. Brunée and E. Hey (eds.), Oxford Handbook of International Environmental Law (Oxford: Oxford University Press, 2007) 995-1009, at 998.

${ }_{10}$ Jan Klabbers has gone further by indicating compliance procedures, and the terminology associated with them, as one of the elements of a more general move towards "turning international law into a commodity, to be used when desired, and to be disused when deemd unproductive", see J. Klabbers, "The Commodification of International Law", in H. Ruiz Fabri, E. Jouannet and V. Tomkiewicz (eds.), Select Proceedings of the European Society of International Law, Volume I, 2006 (Oxford and Portland: Hart, 2008) 341-358, at 343 and 349-350. 
the supremacy of treaty law over derived regulatory instruments. ${ }^{11}$ Second, from a broader policy perspective this approach would expose compliance to the differences in power among various parties. This would frustrate one of the basic reasons for establishing such mechanisms, which is precisely that of pursuing uniform implementation and safeguarding for all Parties the integrity of the common interest protected by the provisions of the treaty.

In order to avoid this risk, it is for each compliance body to interpret its mandate without losing sight of the core task of assessing, objectively and in accordance with legal criteria, whether the Parties' conduct conforms to the obligations they have freely assumed. ${ }^{12}$ This, of course, should not exclude flexibility and the balancing of interest considerations in the compliance-related decision-making process.

Once an assessment of compliance or non-compliance has been made objectively under international law, the compliance process leaves plenty of room for flexibility and political considerations. It does not require the automatic stigmatisation of noncompliance, nor the adoption of any negative consequence thereof for the non-complying State that accepts to be engaged in the process. Rather, the legal assessment is functional to the identification of the origins and the possible solutions of compliance problems through technical advice and, possibly, assistance. There is no denying that a fair degree of political discretion is the key feature of compliance review processes and that its exercise on a case-by-case basis may enhance their effectiveness. Indeed, States' reluctance to submit the review of their international commitments in the environmental field to traditional third party determination is - with special regard to judicial settlement - one of main reasons for the proliferation of the sui generis compliance procedures. Therefore, a non-confrontational attitude remains key to obtain the appropriate cooperation by States. However, the case is made that, from a general consideration of the mandates of the compliance bodies under review, such concerns may well be addressed without endangering the integrity of the legal rules against which compliance has to be assessed.

\subsection{Composition and the Issue of Independence}

The framing of compliance procedures as purely political processes is normally associated with compliance bodies composed of Parties and, often, with those operating with a high degree of confidentiality and with a strict control of triggering by States. As Alessandro Fodella has observed, ${ }^{13}$ there is a close relationship between the composition of a compliance body and the way in which it interprets and discharges its mandate. A body composed of State representatives is normally more inclined to negotiation and compromise than one composed of independent experts.

${ }^{11}$ See M. Fitzmaurice, "Non-Compliance Procedures and the Law of Treaties", supra 453-481, at $455-467$.

${ }^{12}$ As already noted elsewhere, the definition of non-compliance used by the Compliance Committee of the Aarhus Convention refutes the idea that the NCP is a political process leading to a political assessment and apart from the terminology used, makes it difficult any distinction with the notion of breach under the law of State responsibility, see also Pitea, supra n. 3, at 104-105.

${ }^{13}$ A. Fodella, "Structural and Institutional Aspects of Non-Compliance Mechanisms", supra 355-372, at 360 . 
Furthermore, this kind of composition hardly ensures continuity in membership, since the same government may designate a different representative for each meeting, and may result in argumentative inconsistency. In line with the observations made in the previous paragraph, compliance bodies appear to be able to best discharge their mandate objectively when composed of independent experts or, at least, of government representatives bound to serve continuously and objectively.

Nevertheless, practice shows that this assumption may not always prove to be true. For instance, Jerzy Jendrośka has observed that, so far, the political composition of the Espoo Convention Implementation Committee did not have an adverse effect on its objectivity. ${ }^{14}$ In certain cases, as underlined by Tullio Treves, a body composed of States may even authoritatively take politically bold stands that a body of experts could not take. ${ }^{15}$ Conversely, the case may be that even when the full independence of members is provided for by the relevant constitutive instrument, a compliance review process may remain highly politicised, as is the case with the non-compliance mechanism under the Kyoto Protocol, as one may infer from the report by René Lefeber. ${ }^{16}$

Another point concerning the composition of compliance bodies which may significantly bear on their functioning concerns the need for a balance between the technical experts in the field covered by the relevant convention and legal experts who are particularly knowledgeable in international law. The problem arises irrespective of whether the body concerned is composed of independent individuals or government representatives. It is self-evident that MEAs, as sources of international law, are to be interpreted in accordance with international law and in the context of general international law. This has recently emerged more fully during consideration of the Bystroe Project case by the Espoo Convention Implementation Committee in relation to the existence of an obligation for the Party concerned to suspend the related works, pending the assessment by an Inquiry Commission about the existence of a significant transboundary adverse effect ${ }^{17}$ and, consequently, the applicability of the Espoo Convention. As underlined by Jerzy Jendrośka in his chapter, the Committee did not find such an obligation in the Convention itself, but referred to general international law as its source. The decision establishing the Implementation Committee of the Espoo Convention does not require States to designate representatives with legal skills for the Committee's meetings and the presence of two members with a legal background may be considered to have occurred by accident. One may wonder whether the decision of the Committee on the case in point would have been the same otherwise.

${ }^{14}$ J. Jendrośka, "Practice and Relevant Cases that Emerged in the Context of the Espoo Convention Implementation Committee", supra 319-335, at 326.

15 See T. Treves, "Introduction", supra 1-8, at 5, commenting the decision of the Montreal Protocol Implementation Committee to qualify the request for a grace period submitted by the Russian Federation as a "submission" to the non-compliance procedure.

16 R. Lefeber, "The Practice of the Compliance Committee under the Kyoto Protocol to the United Nations Framework Convention on Climate Change (2006-2007)", supra 303-317.

${ }_{17}$ On the role of the inquiry commission within the Espoo Convention and on the Bystroe Project case, see E. Fasoli, "Procedures and Mechanisms for Review of Compliance under the 1991 Espoo Convention on Environmental Impact Assessment in a Transboundary Context and its 2003 Protocol on Strategic Environmental Assessment”, supra 181-203, at 198-199, and Jendrośka, supra n. 14, at 331-332. 


\section{$2.4 \quad$ The Relationship between Compliance Bodies and COP/MOPs}

Closely connected with the issue of the independence of compliance bodies is their relationship with COP/MOPs. Apart from the formal question whether compliance bodies are to be classified as "subsidiary bodies" of the COP/MOP, or otherwise, ${ }^{18}$ what appears to be of substantive relevance is what the actual division of powers between the two bodies is and the relationship between them. As Alessandro Fodella has observed, a compliance body composed of States representatives "may end up being nothing more than a way of managing more efficiently the political compliance review competence of the governing body of the treaty in a decentralized manner." 19 These words run counter to the assumption made above that the mandate of an effective compliance body should not be interpreted in such a way as to give it a strictly political connotation in order for it to adhere to the basic rationale of the compliance control function. Accordingly, the basic autonomy of compliance bodies from the political governing body of the relevant convention is a prerequisite for their minimum effectiveness.

As a matter of fact, this need appears to be met by practice: indeed, the governing bodies of MEAs have so far avoided interfering with the merits of a case before compliance bodies, consistently endorsing their findings and recommendations. For the purposes of optimal effectiveness, a compliance body should be able to assess without political interference whether a given situation amounts to non-compliance and indicate what type of action it deems appropriate. It should also be vested with the power to formulate its recommendations - at least on facilitative measures and/or on a provisional basis - directly to the Party concerned, in order to avoid delays due to the long intervals between COP/MOPs.

At the same time, the above consideration is not meant to downplay in any way the decision-making role of COP/MOPs. Indeed, leaving the formal decision-making on compliance issues with the political governing body may have several advantages. From a political point of view, it generates a feeling of ownership of the decision by the Parties as a whole, thus enhancing its legitimacy. From a strictly legal perspective, any decision of a compliance body backed by the COP/MOP through its adoption by consensus, especially when the provision at stake has been consistently interpreted in a certain way in different cases without objections by Parties, may amount to "subsequent practice in the application of the treaty" which, under Article 31.3(b) of the Vienna Convention, shall be taken into account when interpreting a treaty.

\footnotetext{
18 See the different points of view expressed, with reference to the Aarhus Convention Compliance Committee by V. Koester, "The Compliance Mechanisms of the Aarhus Convention and the Cartagena Protocol on Biosafety: A Comparative Analysis of the Negotiation Histories and their Outcomes", supra 277-302, at 298, and C. Pitea, "Procedures and Mechanisms for Review of Compliance under the 1998 Aarhus Convention on Access to Information, Public Participation and Access to Justice in Environmental Matters", supra 221-249, at 227.

19 Fodella, supra n. 13, at 360.
} 


\subsection{Transparency and the Role of non-State Actors}

As to the issue of transparency in compliance mechanisms, a general consensus has emerged in the opinions of the scholars and practitioners involved in the preparation of this book to the effect that it should be set out as a general rule of non-compliance mechanisms. However, this view is not fully reflected in the constituent decisions and actual practice of existing mechanisms. Apart from those established very recently, the view that confidentiality better ensures cooperation by States still prevails. Thus, in most cases, the meetings of compliance bodies take place in closed session when specific cases of non-compliance are considered and compliance related information may be held confidential. This reflects the traditional approach to diplomatic means of settlement, where confidentiality is considered as some kind of due deference to national sovereignty.

Nowadays, this approach seems to a large degree outdated. Following Principle 10 of the Rio Declaration, ${ }^{20}$ transparency emerges as a normative principle of international environmental governance and, as such, it should also apply to compliance review processes. ${ }^{21}$ One may also add that scrutiny of the work of compliance bodies by Parties and by the public may also help to ensure that the procedures in point are carried out on a fair and equitable basis. It appears, therefore, advisable that compliance procedures should adopt transparency (i.e., openness of meetings and publicity of information) as the rule. Confidentiality may be kept in well-defined cases (such those when it is necessary to protect international relations, national defence or public security or the secrecy of commercial and industrial information or to protect intellectual property rights), in the deliberation phase, as well as an incentive for States to make submissions on their own compliance. One could make the case that regulation on the matter applicable to the Aarhus Convention non-compliance procedure ${ }^{22}$ provides an advanced model from which inspiration may be drawn.

The issue of transparency often goes hand in hand with that of the participation of civil society. ${ }^{23}$ While participation by NGOs and the public in the mechanisms under consideration may play an important role in ensuring fairness in the proceedings, only exceptionally are NGOs vested with the power to trigger such mechanisms on

${ }^{20}$ Rio Declaration on Environment and Development, doc. A/CONF.151/26 (Vol. I) (12 August 1992), Annex I. According to Principle 10 of the Declaration, "[e]nvironmental issues are best handled with participation of all concerned citizens, at the relevant level. At the national level, each individual shall have appropriate access to information concerning the environment that is held by public authorities, including information on hazardous materials and activities in their communities, and the opportunity to participate in decision-making processes. States shall facilitate and encourage public awareness and participation by making information widely available. Effective access to judicial and administrative proceedings, including redress and remedy, shall be provided."

${ }^{21}$ On reluctance by States to fully accept NGOs as actors in the field of international environmental law, see A. Tanzi, "Controversial Developments in the Field of Public Participation in the International Environmental Law Process", in P.M. Dupuy and L. Vierucci (eds.), NGOs in International Law. Efficiency in Flexibility (London: EE, 2008) 135-152.

22 See C. Pitea, supra n. 18, at 235.

${ }^{23}$ For a more comprehensive view on the role of NGOs and civil society in compliance mechanisms, see C. Pitea, "The Legal Status of NGOs in Environmental Non-Compliance Procedures: An Assessment of Law and Practice", in Dupuy and Vierucci, supra n. 21, 181-203. 
individual cases of non-compliance. Such a possibility is generally regarded with hesitation, if not suspicion, by States. Less controversial is the possibility for a committee to use information coming from non-governmental sources, possibly taking advantage of an NGO's expertise, in proceedings already initiated by other subjects. Attempts to limit the role of NGOs as sources of information ${ }^{24}$ are reasons for particular concern to those who fear the undermining of the effectiveness of non-compliance procedures.

Particularly controversial is the question of the possible recognition to NGOs, or to the public, of the power to trigger non-compliance procedures. It is self-evident that allowing non-State actors to bring individual cases to the attention of a compliance body would enhance significantly the effectiveness of the mechanisms in point. It would help in identifying cases of non-compliance, and the causes thereof, through factual information and scientific and legal assessment. Such a contribution would be particularly desirable in view of the fact that NGOs are usually less - if at all - constrained than States by considerations of 'diplomatic appropriateness' in raising often delicate issues of non-compliance with environmental standards and rules. Regardless of the specific kind of civil society participation and notwithstanding the advantages in terms of fairness and effectiveness, this question is met with a fundamental objection by States, namely that it could undermine the non-confrontational and cooperative nature of the mechanism. The practical concern is also felt that, if the procedure may be triggered also by actors other then states, the Committees' agendas could become overloaded, with the consequent increase in the costs of the procedure.

Although progress in enhancing public participation has been made in some UNECE non-compliance procedures, it still generally appears to be difficult and even hardly negotiable to increase the role of NGOs in compliance mechanisms with regard to global treaties. In such a context, the reluctance of some relevant western States adds to the traditional opposition by developing countries. Practice shows that, when NGOs have been recognised a significant role in the procedures under consideration, they have discharged the responsibilities entrusted to them with diligence and efficiently, furthering the effectiveness of the compliance review action. One could say that recognition of a formal status for NGOs seems to enhance their transparency and accountability, at least within the area under consideration.

\section{Beyond Claims of State Responsibility through Inter-State Dispute Settlement: the Legal Nature of Non-Compliance Mechanisms}

The debate around the issue of the legal nature of compliance mechanisms and procedures is often constrained into the classical dichotomy between "diplomatic" and "judicial" procedures for the settlement of international disputes. As already observed, a compliance mechanism characterised by a body with a purely political mandate, composed of States representatives and deciding according to purely political criteria,

\footnotetext{
${ }^{24}$ See A. Fodella, "Mechanism for Promoting Implementation and Compliance with the 1989 Basel Convention on the Transboundary Movements of Hazardous Wastes and Their Disposal", supra 33-48, at 43 .
} 
can be classified as a sui generis diplomatic procedure for the settlement, and possibly for the prevention, of disputes.

We have also made the case that this kind of mechanism can hardly be effective and meet the objective of enhancing the effectiveness of treaty obligations within its competence. In most cases, tough, non-compliance procedures deviate from a purely diplomatic model. Therefore, a certain trend may be discerned among scholars in favour of qualifying those mechanisms, or at least some of them, as "quasi-judicial", ${ }^{25}$ thus underlining their proximity with mechanisms that are already known in other branches of public international law. Such a qualification, however, has little or no significance if it is not accompanied by substantive indications. Some authors have engaged in the exercise of measuring the degree of "judiciality" of non-compliance mechanisms by reference to certain criteria or features that belong to judicial bodies. ${ }^{26}$ To that end, reference has been made to independence and impartiality, existence of procedural guarantees for all the subjects involved, competence to ascertain the violation of a legal obligation and the binding force of such an assessment. If these criteria are applied, however, it is evident that almost all of the mechanisms concerned will fail to pass the test, with the possible exception of the mechanisms established under the Kyoto Protocol and the Aarhus Convention (and those modelled after the latter).

This approach, although methodologically rigorous, when applied to the generality of non-compliance procedures fails to grasp their reality and specificity, forcing them into categories of classical inter-State dispute settlement for classification purposes far removed from apparent practical use. Although it is not impossible for some of the non-compliance mechanisms to develop in the medium or long run into classical judicial or quasi-judicial dispute settlement procedures, one can make the case that, generally considered, they are a genus on their own, which can hardly be forced into the traditional categories of dispute settlement. At present, a different approach is suggested.

It may be recalled that, for a non-compliance procedure to be set in motion, the existence of a dispute is not necessary. The procedure may be triggered also by the very Party experiencing compliance problems and this is one of the few features common to all non-compliance mechanisms. Furthermore, it may be noted that, along the same lines, a situation in which the conduct of a Party is at variance with the obligations set forth in the relevant instrument - irrespective of the use of the terms "breach", "violation", or "non-compliance" to describe this situation - is not required for the compliance mechanism to be set in motion; nor is a finding to this effect necessary for the consequences flowing from the procedure to be deployed. Evidence shows that a potential or future violation may suffice for addressing recommendations to a Party concerned.

${ }^{25}$ See T. Marauhn, "Towards a Procedural Law of Compliance Control in International Environmental Relations", ZaöRV, 56 (1996) 696-731, at 731; V. Röben, "Institutional Developments under Modern International Environmental Agreements", Max Planck YB UN L., 4 (2000) 363-443, at 412; G. Handl, "Compliance Control Mechanisms and International Environmental Obligations", Tul. J. Int'l \& Comp. L., 5 (1997), 29-49, at 45; Voïnov Kohler, supra n. 3, at 115-116; V. Koester, "The Convention on Access to Information, Public Participation in Decision-Making and Access to Justice in Environmental Matters (Aarhus Convention)", in Ulfstein, Marauhn, and Zimmermann (eds.), supra n. 8, 179-217, at 204.

${ }^{26}$ Boisson de Chazournes and Mbengue, supra $\mathrm{n} .3$. 
Moreover, the procedure through which the possible existence of a situation of actual or potential non-compliance is determined is very different from the procedure before a court. Usually, only the Party concerned is entitled to take part in a compliance procedure as a guarantee of the fairness of the latter. In some cases similar participatory entitlements are recognised also to the Party (or possibly the non-State actor) that has initiated the procedure. ${ }^{27}$ The rationale for this, however, seems to be that of giving to the compliance body a more objective picture of the situation, enabling it to discharge more efficiently its tasks. In other words, the interest pursued by the recognition of participatory entitlements to the "complaining" Party or actor is considered to coincide with the general interest of having an efficient mechanism, rather than with the individual interests of the Party, or actor, involved.

This may be confirmed, by way of example, by observing the procedure before the Compliance Committee of the Aarhus Convention. In effect there is no direct confrontation between the parties involved, even when they present their arguments in front of the Committee. A further element relates to the flexibility of the procedure itself, as opposed to the rigid procedural rules of judicial proceedings. Such procedural flexibility is sometimes explicitly stated in the legal instruments instituting noncompliance mechanisms and may be confirmed by the prevailing practice. Again, the way in which the Compliance Committee of the Aarhus Convention works in practice sheds some light on the issue. To that end, one may refer to the examination of "admissibility requirements" for communications from the public, which is much less rigorous than the one under the procedure governing committees established under UN human rights treaties, not to mention that of the European Court of Human Rights. It is noteworthy that the same Committee has repeatedly stated that the scope of its review is not confined by that of the submission or communication at hand.

Finally, even when an actual situation has been determined to be one of non-compliance, it has been consistently held that the consequences of such finding are not those of State responsibility, with consequent remedial action, but those practically useful to engage in a process finally leading to full compliance.

These considerations emphasise how non-compliance procedures operate on a plan that is radically different from that of traditional inter-State claims of State responsibility, possibly through dispute settlement. The classical bilateral structure of the latter is lacking in the procedures under review. Furthermore, the expected outcomes of non-compliance mechanisms are considerably different from those of traditional disputes between States. A different dynamic seems to prevail in the context of noncompliance procedures, one in which a body representing a collective interest interacts with the subjects of regulatory measures. This dynamic concerns a State Party and a collective body acting in the common interest and takes place within the normative and institutional regime established by the relevant treaty. ${ }^{28}$ Its aim is to monitor, assess and facilitate compliance in a pragmatic and goal oriented manner. As

${ }^{27}$ See M. Montini, "Procedural Guarantees in Non-Compliance Mechanisms", supra 389-405, at 395-396.

${ }^{28}$ See G. Ulfstein, "Dispute Resolution, Compliance Control and Enforcement in International Environmental Law", in Ulfstein, Marauhn, and Zimmermann (eds.), supra n. 8, 115-133, at 132 ("non-compliance procedures of MEAs are in fact very different [from dispute settlement procedures] by releasing the disputing parties from pursuing violations of MEAs on their own and entrusting it to the MEA institutions"). 
it has been argued previously, this does not mean that non-compliance procedures are not "legal" procedures, nor that general international law has no role to play, as States sometimes hint. The procedure itself is not only created and regulated by legal rules of different sources, such as treaty law and COP/MOP decisions, plus in some cases the procedural regulatory powers of the compliance body itself: what is more important is that the core of the functioning, as well as the task of non-compliance procedures, is precisely objective factual and legal assessment. In its turn, such assessment can only be based on the interpretation of the rules of international law, an exercise governed by general international law and that cannot take place, to use the wellknown words of the WTO Appellate Body, in "clinical isolation" from other rules of international law. ${ }^{29}$ Moreover, non-compliance mechanisms not only provide for assistance and facilitative measures, but also for stronger measures aimed at sanctioning refusal to cooperate or wilful and continuous non-compliance.

All in all, non-compliance procedures may be considered to be "located within a wider category of non-confrontational avoidance procedures" ${ }^{\prime 30}$ and defined as administrative procedure ${ }^{31}$ within regimes created by MEAs.

${ }^{29}$ US-Gasoline, doc. WT/DS2/AB/R, at 17, DSR 1996:I, 3 at 16. This view was shared, as noted above, by the Espoo Convention Implementation Committee. A similar position was taken by the Aarhus Convention Compliance Committee, see Pitea, supra n. 18 at 239.

${ }^{30}$ M. Fitzmaurice, "International Protection of the Environment", in $R d C, 293$ (2001) 9-488, at 348. See also G. Hand1, "Controlling Implementation of and Compliance with International Environmental Commitments: The Rocky Road from Rio", Colo. J. Envt'l L. \& Pol'y, 5 (1994) 305-331, at 329 (stating that compliance procedures may be characterised as a system of multilateral assistance for dispute avoidance, at least when a real dispute cannot be singled out).

31 See K. Raustiala, "Compliance and Effectiveness in International Regulatory Cooperation", Case Western Reserve Journal of International Law, 32 (2000) 387-440, at 419. The use of this term does not imply total adhesions to recent theories on the emergence of "global administrative law" as a distinct international legal order from public international law. For the debate on this concept, see the special number on "The Emergence of Global Administrative Law", in Law and Contemporary Problems, 68 (2005), the Symposium in Eur. J. Int'l L., 17 (2006) 1-278. 


\section{Index}

Aarhus Convention,

general, 2, 4, 199, 221-224. 239, 243, 253, $263,500,502$

non-compliance mechanism, 4-7, 221-249,

255, 262, 277-302, 332, 350, 360, 374 $379,381,384,385,391,396,397,401$, 403, 409, 413, 440, 441, 443, 468, 481, $511,527,531,540,576,578,579$

Vlore Bay case (Albania), 440-441, 445

Bystroe Project case (Ukraine), see Bystroe Project case (Ukraine)

Protocol on PRTRs, see PRTRs Protocol

Acidification LRTAP Protocol, 171, 177, 500, 504

Alpine Convention

general, 205-208, 500

non-compliance mechanism, 5-6, 205-219, $358,360,371,381$

Amendment

of texts establishing non-compliance procedures, $14,15,22,35,172,176,224$,

of treaties, $3,4,13,33,50,66,87,102,156$, $184,207,209,223,321,357,415,416$, $429,441,456,478,539,547,570$

\section{B}

Barcelona Convention general, 5,6,60, 155-166 non-compliance mechanism, 155-168,

Basel Convention

Ad hoc Technical Commission on Côte d'Ivoire, 495

Ban amendment, 35, 480

general, 33, 122, 426, 480, 487, 495, 502, 513

non-compliance mechanism, 2, 6, 33-48, 296-300, 367, 381, 392, 395, 396, 401, 409, 420, 449, 465, 469, 488, 511, 543

Bern Convention, 440

Breach

of EC law, 544, 565, 578 of international obligations, 7, 45, 176, 240, $333,381,416,418,447,469,483,507$, $510,513,578$

Bystroe Project (or Canal) case, 198, 238, 243 , $331,386,440,445,447,448,511,516$

C

Cartagena Protocol

general, 101, 278, 462, 496, 513

non-compliance mechanism, 5, 101-120, 255, 277-302, 367, 378, 381, 390, 395, $397,399,401,420$

Charter of the UN, 227, 392, 423, 437, 461, 470,487

Common but differentiated responsibilities, 67, 71, 289, 290, 294, 304, 391, 428, 542,554

Common concern of humankind, 296

Commonwealth of Independent States (CIS), 472

Compliance Committees, see Non-compliance bodies

Conciliation, 98, 116, 134, 150, 339, 500, 503, 511,516

Conference of the Parties, see Governing bodies of MEAs (COP/MOPs)

Consent to be bound, 424, 456, 480

Convention on Biological Diversity, 101, 103, $108,137,140,501,504$

Convention on International Trade in Endangered Species (CITES), 115, 412, 417, 468, 537, 543

Convention on UN Privileges and Immunities 307

Countermeasures, 407, 413, 491, 514

Countries with economies in transition, 17, 21, $30,31,36,44,63,86,105,118,123$, $125,126,135,141,143,179,278,294$, $295,301,367,368,390,396,409,428$, $433,436,556$

Customary international law, 49, 87, 416, 425,483 
D

Desertification Convention, 430

Developing Countries, 12, 13, 15, 17, 18, 26 $30,34,39,44,64,69,71,79,86,88$, $105,107,111,118,119,123,125,127$, $133,135,141,143,165,278,292,294$, 295, 301, 304, 309, 349, 367, 368, 390, 396, 409, 419-434, 458, 479, 539-540, $541,542,546,547,554,577$

$\mathbf{E}$

Enabling clauses, 3, 12, 35, 51, 65, 88, 103 , $123,141,184,223,253,265,278,321$ $357,441,462,474,538$

Erga omnes obligations, 366, 375, 494, 513-515, 518

Espoo Convention

general, 181-183, 260, 502, 511, 513, 516, inquiry procedure, $182,198,334,447,506$, 510

non-compliance mechanism, 3, 6, 181-203, 243, 300, 319-335, 360, 367, 379, 387, 413, 440, 445, 447, 469, 496, 505-506, 574 ,

Bystroe Project case (Ukraine), see Bystroe Project case (Ukraine)

SEA Protocol, see Strategic Environmental Assessment (SEA) Protocol

European Bank for Reconstruction and Development (EBRD)

general, 445

Independent Recourse Mechanism (IRM), 337-352, 441, 448

European Community (EC)/European Union (EU)

general, 26, 345, 502

participation in MEAs, 29, 60, 81, 99, 116, 134, 150, 167, 177, 200, 216, 244, 261, $273,521,535,545$

Role in non-compliance procedures, see Non-compliance procedures - Role of the $\mathrm{EC} / \mathrm{EU}$

European Convention on Human Rights, 446 European Court of Justice (ECJ)

Commission v. Council, case C-22/70 (ERTA), 548
Commission v. Council, case C-94/03 (Rotterdam PIC Convention), 100, 524

Commission v. France, case C-239/03, 530

Commission v. France, case C-239/03 (Etangs de Berre), 544

Commission v. Ireland, case C-216/05, 528

Commission v. Ireland, case C-459/03 (Mox Plant), 247, 530

Commission v. Parliament and Council, case C-178/03 (Rotterdam PIC Convention), 100,524

Demirel v. Stadt Schwäbisch Gmünd, case $\mathrm{C}-12 / 86,530$

Eva Glawischnig, case C-316/01, 524

general, 29, 247, 523, 533, 563, 565

Haegeman v. Belgium, case 181/73, 553

Hermès International, case C-53/96, 524

Kupferberg, case C-104/81, 530

Officier van Justitie v. Cornelius Kramer, cases $3,4 \& 6 / 76,548$

Opinion 1/76 (Draft Agreement Establishing a Laying-up Fund for Inland Waterway Vessels), 548

Opinion 1/94 (International Agreements Concerning Services and the Protection of Intellectual Property), 530, 549

Opinion 2/00 (Cartagena Protocol on Biosafety), 273, 552

Opinion 2/91 (ILO Convention $N^{\circ} 170$ concerning safety in the use of chemicals at work), 530, 549

Exhaustion of domestic remedies, 229, 232, $247,257,270,385$

$\mathbf{F}$

First Sulphur LRTAP Protocol, 171

Forum prorogatum, 501

Fragmentation (of international law), 439, 442,491

G

Genetically modified organisms (GMOs), 222

Global Environment Facility (GEF), 17, 27, $30,31,109,110,117,123,135,371$, $428,431,542,543,547,553$

Governing bodies of MEAs (COP/MOPs), 
budget, 421

legal effect of decisions, 356, 411, 463, 508 ,

role in non-compliance mechanisms, see Non-compliance procedures - Role of governing bodies (COP/MOPs)

\section{$\mathbf{H}$}

Heavy Metals LRTAP Protocol, 171

Human Rights, 6, 239, 249, 251, 278, 338, $348,349,350,356,361,446,450,557$

I

Implementation Committees, see Non-compliance bodies

Implied powers, 177, 227, 310, 312, 313, 358, 414, 415, 425, 441, 466

International Atomic Energy Agency (IAEA), $55,91,371$

International Bank for Reconstruction and Development (IBRD), 338

International Civil Aviation Organisation (ICAO), 460

International Court of Justice (ICJ)

Applicability of the Convention on the Privileges and Immunities of the United $\mathrm{Na}$ tions (Advisory Opinion), 308

Certain Expenses (Advisory Opinion), 423

Gabcikovo-Nagymaros Project (Hungary/ Slovakia), 334

general, 45, 98, 134, 149, 177, 422, 500 $501,515,517$

Legality of the Threat or Use of Nuclear Weapons (Advisory Opinion), 334

Reparations for Injuries Suffered in the Service of the United Nations (Advisory Opinion), 310

South-West Africa (Ethiopia v. South Africa, Liberia v. South Africa), 512

United States Diplomatic and Consular Staff in Tehran (United States v. Iran), 484

International Law Commission (ILC), 246, 413, 471, 483-485, 486, 487, 490, 491, 493, 494, 495, 513-515, 525,

International Maritime Organization (IMO),
$50,52,55,61,366,459,460,462$

International Code for Safe Carriage of Packaged Irradiated Nuclear Fuel, Plutonium and High-Level Radioactive Waste on Board Ships (INF Code), 459

International responsibility

of International organizations, 245, 525

of States, 2, 198, 407, 413, 483-497, 513, 550,557

International Treaty for the Protection of Genetic Resources in Food and Agriculture (ITPGRFA)

general, 137-141

non-compliance mechanism, 137-152, 280, 543

International Tribunal for the Law of the Sea (ITLOS),

Southern Bluefin Tuna case (New Zealand v. Japan, Australia v. Japan), 517

K

Kyoto Protocol

Expert Review Team (ERT), 70, 72, 77, 83, 307, 310-317, 479, 557-562

Flexible mechanisms (Clean Development Mechanism, International Emission Trading, Joint Implementation), 64, 74, $80,83,307,309,312,410,419,433$, $463,465,475,479,546,557,560$

general, 4, 63-65, 433, 454, 463, 496, 513-514, 544, 558-559,

non-compliance mechanism, $4,5,7, \mathbf{6 3 - 8 4}$ 303-317, 357, 358, 360, 362, 366, 368, $376,380,384,387,391,397,410,415$, $419,434,455,463,469,474,509,510$, 543, 544, 559, 574, 578, case of non-compliance by 15 Annex I Parties, 83, 314, 368, 376 case of non-compliance by Greece, $83-84,315-316,380,479,557,562$

Participation of the EC, $81,544, \mathbf{5 4 5 - 5 6 5}$

$\mathbf{L}$

Law of the Sea Convention, 382, 500-504, 507,525 
Lis pendens, 413, 446, 449, 507

Living Modified Organisms (LMOs), 108, 109, 119, 462-463

London Dumping Convention and London Dumping Protocol 1996

general, 49-50

non-compliance mechanism, 49-61, 371, 379

LRTAP Convention

general, 169-171, 496, 500, 503,

non-compliance mechanism, 3, 7, 169-180, $282,296,299,300,360,366,368,369$, 414

\section{M}

Meeting of the Parties, see Governing bodies of MEAs (COP/MOPs)

Montreal Protocol

general, 3, 11-12, 71, 115, 428-434, 458-462, 496,500

non-compliance mechanism, $1,3,5,7$, 11-32, 171, 286, 297, 298, 299, 300, $358,360,361,366,371,375,379,382$, 391, 393, 394, 397, 398, 400, 404, 411, 426, 434, 467, 486, 505-506, 511, 513, 543

Case of non-compliance by the Russian Federation, 5, 31-32, 375, 382, 393, 411, 472-474, 490

$\mathbf{N}$

Non-compliance bodies

alternate members, $68,73,75,82,130,159$, 165,306

conflict of interest of members, 68, 111, $126,131,195,226,233,236,255,363$, 401

continuity of membership, 16, 326

decision-making, 24, 43, 78, 97, 113, 132, $149,165,176,196,214,238,259,271$, 298, 306, 316, 387, 408

election of members, 16, 36, 53, 68, 106, $126,144,159,173,188,225,254$, 267

geographical balance, 16, 36, 53, 69, 89, 90, $106,126,157,159,225,225,288,327$, 367,401 immunities of members, 307

independence of members, 37, 68, 90, 106, $126,144,160,173,225,254,267,284$, $307,360,362$

observer status, $5,15,17,22,30,38,40,54$, 56, 91, 107, 126, 160, 163, 173, 179, 196, 209-210, 214, 218, 225, 226, 235, $255,268,305,309,368,370,380-381$, 387,541

transparency, 22, 40, 57, 76, 95, 131, 158, $163,177,187,214,235,323,328$

Non-compliance procedures

admissibility requirements, $42,56,74,94$, $128,148,163,229,257,270,299,314$, $377,383-386,446,541,579$

appeal, 4, 22, 76, 404, 414, 560,

coordination among, 46, 59, 99, 134, 166, $242,260,272,366,370,427, \mathbf{4 3 9 - 4 5 0}$

due process guarantees, $4,6,15,21,40,57$, $65,70,76,95,11,130,158,163,174$, 195, 213, 234, 270, 286, 367, 394-400, $508,518,560$

financial aspects, 30, 46, 61, 82, 100, 117, $135,152,167,178,201,217,242,262$, 274, 419-437

legal basis, 3, 12, 34, 51, 65, 88, 103, 123, 141, 156, 171, 184, 208, 223, 253, $265,268,319,356$, see also enabling clauses

outcomes, 26, 44, 59, 78, 97, 113, 133, 149, $165,176,197,215,238,259,272,291$, 300, 361, 407-418, 463, 472, 510

suspension of rights and privileges, 7, 14, 66, 80, 117, 133, 240, 259, 272, 285, 290, 293, 301, 357, 359, 407, 410, 414, 416, 437, 468, 478, 510,541

relationship with dispute settlement procedures, $27,45,59,81,98,116,134$, $149,166,177,197,216,242,260,272$, 499-518

role of governing bodies (COP/MOPs), 18, $37,55,69,91,92-93,107,127,145$, $160,211,226,255,268,444$

role of secretariats, $16,37,55,70,91,107$, $126,145,160,173,187,211,226,255$, $268,377,382,444$

role of the EC/EU, 117, 147, 193-194, 197, 
208, 216, 237-238, 245-247, 248, 273, 274, 293, 295, 445, 527-534, 537-544, 554-565

sources of information, 23, 43, 58, 77, 96, $112,132,148,164,175,196,214,237$, $259,271,291,299,364,541,577$ trigger of, $6,20,39,56,72,92,110,127$ $147,161,174,192,212,228,256,268$, 296, 311, 314, 323, 329, 330, 349, 362, 365,368, 373-388, 395, 398, 450, 507, $511,540,576$

Non-Governmental Organizations (NGOs) general, 222-224 participation (including observer status), 5 , $8,18,41,54,91,159,160,173,189$, $195,209-210,225,226,254-255,286$, 287, 326, 368-370, 576

role in non-compliance mechanisms general, 8, 47, 215, 248, 249, 265, 576 sources of information, 23, 43, 57, 70, 77, $113,148,164,175,237,259,288$, 290, 291, 299, 348, 379, 576

Specific NGOs

Association Kazokiskes Community, 531

Basel Action Network (BAN), 47

Civic Alliance for the Protection of the Vlore Bay, 441

ECO Forum, 282

Ecopravo-Lviv, 243, 445, 447

UNISFERA, 189

trigger, 6, 8, 93, 110, 192-194, 212, 228, $248,257,267,269,288,297,329,330$, $339,351,379,380-381,387,441,577$

NOx LRATP Protocol, 178, 179, 500

\section{$\mathbf{O}$}

Observer status

in governing bodies of MEAs (COP/MOPs), $18,146,207,537$

in non-compliance mechanisms, see Noncompliance bodies - observer status

Optional Protocol to the ICCPR, 446

Organization for Security and Cooperation in Europe (OSCE), 237, 371

Convention on Conciliation and Arbitration, 504
OSPAR Convention, 500

$\mathbf{P}$

Pacta sunt servanda, 216, 495, 523

Permanent Court of International Justice (PCIJ)

Mavrommatis Palestine Concessions (Greece v. United Kingdom), 512

S.S. Wimbledon (France, Great Britain, Japan and Italy v. Germany), 484

POPs LRATP Protocol, 171

Precautionary principle or approach, 51, 102, $103,121,155,206,347$

Protocol on Water and Health

general, 6, 251-253, 500

non-compliance mechanism, 5,6, 251-262, $267,269,270,360,361-362,366,369$. 370-371, 381, 411, 443-444, 445, 450

PRTRs Protocol general, 263-265

non-compliance mechanism, 6, 263-274, 443

$\mathbf{R}$

Ramsar Convention, 440, 537

Reparation, 7, 407, 491, 494, 510, 514

Res judicata, 7, 413, 446, 508

Rio Declaration on Environment and Development, 85, 121, 221, 289, 290, 291, 291, 542, 576

Rotterdam PIC Convention general, 85-88, 426, 513,

non-compliance mechanism, 85-100, 124, $379,397,399,401-402,403,424,432$, $443,449,542,543$,

Sanctions, 7, 15, 18, 27, 47, 79, 80, 114, 117 $119,161,165,166,177,215,249,260$, $357,359,392,403,405,407,412,414$. $416,473,510$

Second Sulphur LRTAP Protocol, 171, 500

Security Council, 461, 495

Self-contained regimes, 25, 484, 491, SOLAS Convention, 459 
Stockholm POPs Convention general, 86, 121-124, 426, 500, 502, non-compliance mechanism, 121-135, 370, $379,386,396,397,400,401,424,430$, 432, 443, 449, 505,

Strategic Environmental Assessment (SEA) Protocol, 183-184

Subsidiary bodies, $3,12,25,34,36,50,53,66$, $69,72,77,88,90,93,100,102,112$, $126,132,139,144,149,152,168,173$, 183, 190, 194, 223, 227, 240, 253, 265, 291, 298, 356, 357, 379, 390, 398, 413, 426, 434, 441, 444, 572, 575.

Sustainable development principle, 101, 155, $184,205,338,340,350,352,428$, 433 ,

$\mathbf{U}$

United Nations Development Programme (UNDP), 12, 237, 371

United Nations Economic Commission for Europe (UNECE), 169-170, 176, 178, 199, 201, 221, 223, 237, 262, 264, 265, $273,278,287,293,295,297,324,332$, $366,371,380,381,385,386,397,443$, $445,449,450,536,577$

United Nations Educational, Scientific and Cultural Organization (UNESCO), 440

United Nations Environmental Programme
(UNEP), 11, 12, 63, 88, 101, 123, 156, $160,293,295,366,371,405,449$,

United Nations Framework Convention on Climate Change (UNFCCC), 63, 64, 70, 307-308, 500-504, 513, 545-556, $560,561,564$

United Nations Industrial Development Organization (UNIDO), 12, 371

\section{V}

Vienna Convention (on the law of treaties), 80, 100, 216, 240, 416, 318, 455-457, 462, 465, 467-472, 473, 487, 495, 508-509, 517,575 ,

Vienna Ozone Convention, 11, 27, 29, 54, 487, 500, 501, 504, 513

VOC LRTAP Protocol, 171, 178-179, 500

\section{W}

World Bank, 12, 243, 338, 340, 342, 344, 346, $349,350,371,429,440,448$

World Meteorological Organization (WMO), 63

World Trade Organization (WTO), 116, 122, 413, 517, 524

EC-Biotech Products, 116

US - Gasoline, 580 